\title{
PARTICIPAÇÃO DA MULHER NO MERCADO DE TRABALHO: SEGREGAÇÃO E DISCRIMINAÇÃO EM PERNAMBUCO E SÃO PAULO
}

\author{
ANA MARIA HOLLAND OMETTO \\ Economista Doméstica
}

Orientador: Prof. RODOLFO HOFFMANN

Tese apresentada à Escola Superior de Agricultura "Luiz de Queiroz", da Universidade de São Paulo, para obtenção do título de Doutor em Ciências, Área de Concentração: Economia Aplicada.

P IR A C I C A B A

Estado de São Paulo - Brasil

Maio - 1997 
Dados Internacionais de Catalogação na Publicação (CIP) DIVISÃO DE BIBLIOTECA E DOCUMENTAÇÃO - Campus "Luiz de Queiroz"/USP

Ometto, Ana Maria Holland

Participação da mulher no mercado de trabalho : segregação e discriminação em Pernambuco e São Paulo / Ana Maria Holland Ometto. - - Piracicaba, 1997. $294 \mathrm{p}$.

Tese (doutorado) - Escola Superior de Agricultura Luiz de Queiroz, 1997. Bibliografia.

1. Mercado de trabalho 2. Mulher 3. Pernambuco 4. Sảo Paulo I. Título

CDD 331.4 


\section{PARTICIPAÇÃO DA MULHER NO MERCADO DE \\ TRABALHO: SEGREGAÇÃO E DISCRIMINAÇÃO \\ EM PERNAMBUCO E SÃo PAULO}

ANA MARIA HOLLAND OMETTO

Aprovada em: 27/08/1997

Comissão Julgadora:

Prof. Dr. Rodolfo Hoffinann

ESALQ/USP

Prof. Dr. Carlos José Caetano Bacha

ESALQ/USP

Profa. Dra. Ana Lúcia Kassouf

ESALQ/USP

Profa. Dra. Angela A. Kageyama

IE/UNICAMP

Prof. Dr. Reynaldo Fernandes

FEA/USP

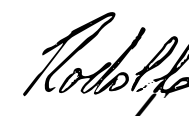

Prof. Rodolfo Houfmann

Orientador 
Dedico este trabalho

Aos meus pais, Luiz e Helena, pelas lutas que empreenderam.

Ao Marco, Thais e Alexandre, que souberam dividir a minha atenção, me apoiando e incentivando em todos os momentos. 


\section{AGRADECIMENTOS}

Agradeço, de forma especial, ao Prof. Dr. Rodolfo Hoffinann pelo estímulo constante, pela prontidão no atendimento e pela orientação segura e competente, que me proporcionou a tranqüilidade necessária para concluir este trabalho.

O incansável analista de sistemas do CIAQGRI/USP, Marcelo Corrêa Alves, merece, certamente, mais do que um muito obrigado pelo excelente trabalho de programação e manipulação dos dados.

Não poderia deixar de citar Joselene Rodrigues Monteiro, pela competência e profissionalismo e pelas noites e fins de semana que passou digitando este trabalho.

Registro meus agradecimentos à minha colega de doutorado e amiga de longa data Angela Maria C. J. Correa, cuja convivência em sala de aula e durante as horas em que discutimos os temas abordados no doutorado tornou o processo de aprendizado uma atividade mais fecunda e prazerosa.

Foi também importante o apoio e estímulo de algumas colegas de Departamento, em especial o de Cristina, Maria Angélica e Marina que, partilhando comigo as angústias e incertezas tão freqüentes ao longo do processo de doutorado, sempre tiveram uma palavra de confiança e de incentivo. 
Durante o desenvolvimento da pesquisa muitas pessoas me auxiliaram na obtenção de livros, artigos, etc. Lembro, em particular, das bibliotecárias do Departamento de Economia e Sociologia Rural, Maria Angélica e Luciane, pela atenção e paciência.

Gostaria de agradecer ainda a todos com os quais aprendi e convivi, incluindo meus professores, colegas de disciplinas e as secretárias do Departamento de Economia e Sociologia Rural e do Setor de Pós-Graduação da ESALQ.

Por fim, agradeço ao Setor de Processamento de Dados do Instituto de Economia da Universidade de Campinas (UNICAMP) pela cessão dos dados utilizados nesta pesquisa. 


\section{SUMÁRIO}

Página

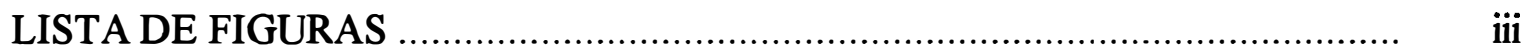

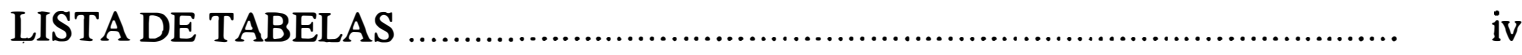

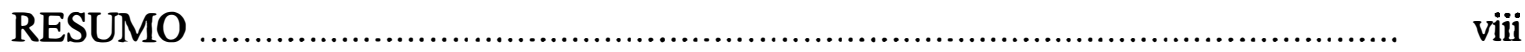

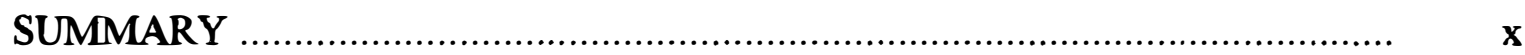

1 INTRODUÇÃO .............................................................................. 1

2 DISCRIMINAÇÃO CONTRA A MÃO-DE-OBRA FEMININA: INTERPRETAÇÕES ALTERNATIVAS ................................................... 10

2.1 A interpretação da teoria neoclássica: do modelo de Gary Becker à proposta do "Capital Humano" ............................................................... 12

2.2 A teoria da segmentação do mercado de trabalho ...................................... 25

3 ASPECTOS METODOLÓGICOS …........................................................ 32

3.1 Qualidade e li mitações dos dados utilizados ............................................... 32

3.2 A construção da amostra ...................................................................... 39

3.3 A medida de segregação ..................................................................... 42

3.3.1 A curva de segregação ........................................................................ 43

3.3.2 O Índice de Dissimilaridade de Duncan ................................................. 45

3.3.3 O efeito de alterações na estrutura ocupacional e composição por sexo das ocupações 
3.4 O cálculo da discriminação: o modelo estatístico …........................................ 49

3.4.1 A decomposição segundo os modelos tradicionais ................................... 52

3.4.2 A decomposição considerando os componentes intra e

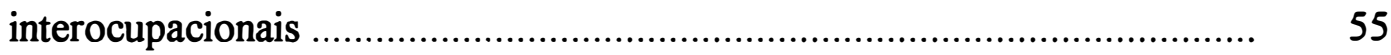

3.4.3 A agregação das ocupações e a seleção das variáveis ................................. 60

3.4.4 Algumas limitações da metodologia utilizada ........................................ 71

4 A EVOLUÇÃO DA SEGREGAÇÃO …..................................................... 74

4.1 Principais ocupações na absorção da mão-de-obra ........................................ 75

4.2 Inserção ocupacional diferenciada por gênero ……..................................... 80

4.3 A evolução da segregação ocupacional ....................................................... 82

4.4 A decomposição da segregação: efeito MIX e COMP ................................. 87

4.5 Diferenças de inserção ocupacional versus diferenças de rendimentos .......... 88

5 QUANTIFICANDO A DISCRIMINAÇÃO ............................................... 94

$5.1 \quad$ A estrutura ocupacional vigente …....................................................... 95

5.2 A estrutura ocupacional simulada .......................................................... 99

5.3 As equações de rendimento ............................................................. 102

$5.4 \quad$ As diferenças de qualificação ................................................................ 128

5.5 A decomposição das diferenças entre os rendimentos de homens e mulheres

5.6 Discriminação, desemprego e inflação .................................................. 153

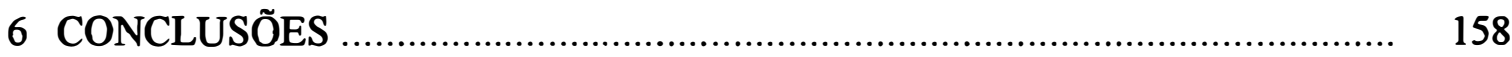

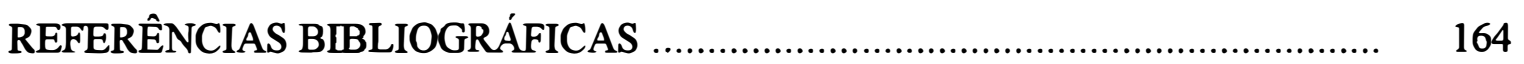

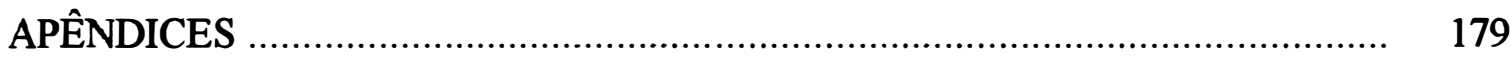




\section{LISTA DE FIGURAS}

1 Curva de Segregação ....................................................................... 44

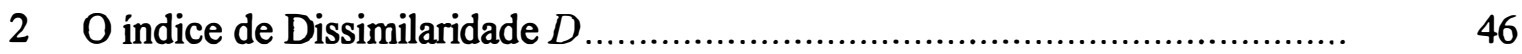

3 Evolução dos rendimentos relativos. São Paulo, 1981 a 1990 ..................... 90

4 Evolução dos rendimentos relativos. Pernambuco, 1981 a 1990 .................. 91

5 Relação entre os rendimentos por idade dos trabalhadores das classes extremas. São Paulo, 1984 _.......................................................... 117

6 Relação entre os rendimentos por idade dos trabalhadores das

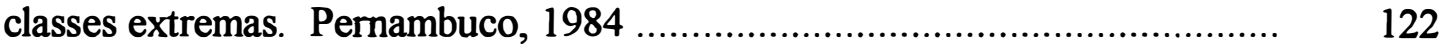

7 Evolução da distribuição percentual de homens e mulheres da PEA ocupada por níveis de escolaridade. São Paulo, 1981 a 1990

8 Evolução da distribuição percentual de homens e mulheres da PEA ocupada por níveis de escolaridade. Pernambuco, 1981 a 1990

9 Evolução da distribuição percentual de homens e mulheres da PEA ocupada segundo faixas etárias. São Paulo, 1981 a 1990

10 Evolução da distribuição percentual de homens e mulheres da PEA ocupada segundo faixas etárias. Pernambuco, 1981 a 1990

11 Evolução da distribuição percentual de homens e mulheres da PEA ocupada segundo a posição na ocupação. São Paulo, 1981 a 1990

12 Evolução da distribuição percentual de homens e mulheres da PEA ocupada segundo a posição na ocupação. Pernambuco, 1981 a 1990 


\section{LISTA DE TABELAS}

1 Indicadores de Condição de Atividade para as Pessoas de 10 anos ou mais de Idade - 1981 a 1990. Brasil

2 Rendimento médio mensal real, de todos os trabalhos das pessoas ocupadas, segundo o sexo. 1981 a 1990. Brasil ....

3 População com 10 anos ou mais e população economicamente ativa. São Paulo, 1981 a 1990

4 População com 10 anos ou mais e população economicamente ativa. Pernambuco, 1981 a 1990

5 Número de pessoas economicamente ativas ocupadas. São Paulo e Pernambuco, 1981 a 1990

6 Categorias ocupacionais segundo a composição por sexo das ocupações

7 Distribuição percentual da PEA feminina em algumas ocupações e composição por sexo das mesmas. São Paulo, 1981 e 1990

8 Distribuição percentual da PEA feminina em algumas ocupações e composição por sexo das mesmas. Pernambuco, 1981 e 1990

9 Distribuição percentual da PEA ocupada masculina em algumas ocupações e composição por sexo das mesmas. São Paulo, 1981 e 1990

10 Distribuição percentual da PEA ocupada masculina em algumas ocupações e composição por sexo das mesmas. Pernambuco, 1981 e 1990

11 Distribuição das ocupações segundo a composição por sexo. São Paulo e Pernambuco, 1981 a 1990

12 Distribuição percentual de homens e mulheres nas ocupações integradas, masculinas e femininas. São Paulo e Pernambuco, 1981 a 1990

13 Índice de segregação de Duncan. São Paulo e Pernambuco, 1981 a 1990 ....... 82

14 Taxa de desocupação da PEA. São Paulo e Pernambuco, 1981 a 1990 ........... $\quad 85$

15 Decomposição das alterações no índice de segregação entre 1981 e 1990. São Paulo e Pernambuco.

16 Evolução dos rendimentos relativos. São Paulo e Pernambuco, 1981 a 1990 (em \%) 
17 Distribuição percentual da PEA ocupada por classe de percentual de homens na ocupação. São Paulo, 1981 a 1990

18 Distribuição percentual da PEA ocupada por classe de percentual de homens na ocupação. Pernambuco, 1981 a 1990

19 Capacidade de previsão da distribuição da PEA masculina ocupada por classe nos modelos logitos multinomiais estimados. São Paulo e Pernambuco, 1981 a 1990 (\% de acertos)

20 Valores de LRT e número de observações $(N)$ nas equações de logitos multinomiais estimadas. São Paulo e Pernambuco, 1981 a 1989

21 Distribuição percentual estimada $\left(p_{l}^{f *}\right)$ da PEA feminina ocupada por classe ocupacional. São Paulo e Pernambuco, 1981 a 1990.

22 Valores de $R^{2}$ e $F$ para as equações de rendimento estimadas nas diferentes classes ocupacionais. São Paulo, 1981 a 1990.

23 Valores de $R^{2}$ e $F$ para as equações de rendimento estimadas nas diferentes classes ocupacionais. Pernambuco, 1981 a 1990.

24 Número de observações nas equações de rendimento estimadas por classe e sexo. São Paulo, 1981 a 1990

25 Número de observações nas equações de rendimento estimadas por classe e sexo. Pernambuco, 1981 a 1990

26 Valores de $F$ obtidos para o teste de Chow para diferença estrutural entre as equações de rendimento para homens e mulheres, dentro de cada classe ocupacional. São Paulo e Pernambuco, 1981 a 1990

27 Estimativa dos coeficientes das equações de rendimento ajustadas para a PEA ocupada, por sexo e classe ocupacional. São Paulo, 1984

28 Números-índices obtidos dos coeficientes das equações de rendimento ajustadas para a PEA ocupada, por sexo e classe ocupacional. São Paulo, 1984

29 Estimativa dos coeficientes das equações de rendimento ajustadas para a PEA ocupada, por sexo e classe ocupacional. Pernambuco, 1984

30 Números-índices obtidos dos coeficientes das equações de rendimento ajustadas para a PEA ocupada, por sexo e classe ocupacional. Pernambuco, 1984 
31 Principais ocupações da classe 5 quanto à absorção da mão-de-obra masculina. Pernambuco, 1984

32 Principais ocupações da classe 5 quanto à absorção da mão-de-obra feminina. Pernambuco, 1984

33 Principais ocupações da classe 5 quanto à absorção da mão-de-obra masculina. São Paulo, 1984

34 Principais ocupações da classe 5 quanto à absorção da mão-de-obra feminina. São Paulo, 1984

35 Distribuição percentual de homens e mulheres da PEA ocupada por níveis de escolaridade. São Paulo, 1981 a 1990.

36 Distribuição percentual de homens e mulheres da PEA ocupada por níveis de escolaridade. Pernambuco, 1981 a 1990

37 Distribuição percentual de homens e mulheres da PEA ocupada por faixas de idade. São Paulo, 1981 a 1990.

38 Distribuição percentual de homens e mulheres da PEA ocupada por faixas de idade. Pernambuco, 1981 a 1990.

39 Distribuição percentual de homens e mulheres da PEA ocupada que têm domicílio na área urbana.

40 Distribuição percentual de homens e mulheres da PEA ocupada segundo a posição na ocupação. São Paulo, 1981 a 1990.

41 Distribuição percentual de homens e mulheres da PEA ocupada segundo a posição na ocupação. Pernambuco, 1981 a 1990

42 Distribuição percentual deassalariados do sexo masculino e feminino com carteira de trabalho assinada. São Paulo e Pernambuco, 1981 a 1990.

43. Decomposição das diferenças entre a média dos logaritmos naturais dos rendimentos dos homens e mulheres na ocupação principal. São Paulo, 1981 a 1990

44 Decomposição da diferença relativa entre as médias geométricas dos rendimentos dos homens $\left(G^{m}\right)$ e mulheres $\left(G^{f}\right)$ na ocupação principal. Pernambuco, 1981 a 1990 
45 Decomposição percentual das diferenças entre a média dos logaritmos dos rendimentos dos homens e mulheres na ocupação principal. São Paulo, 1981 a 1990

46 Decomposição das diferenças entre a média dos logaritmos naturais dos rendimentos dos homens e mulheres na ocupação principal. Pernambuco, 1981 a 1990

47 Decomposição da diferença relativa entre as médias geométricas dos rendimentos dos homens $\left(G^{m}\right)$ e mulheres $\left(G^{f}\right)$ na ocupação principal. Pernambuco, 1981 a 1990

48 Decomposição percentual das diferenças entre a média dos logaritmos dos rendimentos dos homens e mulheres na ocupação principal. Pernambuco, 1981 a 1990

49 Taxas de Inflação. Brasil, 1981 a 1990 


\title{
PARTICIPAÇÃO DA MULHER NO MERCADO DE TRABALHO: SEGREGAÇÃO E DISCRIMINAÇÃO EM SÃO PAULO E PERNAMBUCO
}

\author{
Autor: Ana Maria Holland Ometto \\ Orientador: Prof. Rodolfo Hoffinann
}

\section{RESUMO}

O presente trabalho, utilizando dados individuais coletados através das Pesquisas Nacionais por Amostra de Domicílios (PNAD), analisa a evolução, ao longo do período compreendido entre 1981 e 1990, da segregação ocupacional por gênero e da discriminação que penaliza a mão-de-obra feminina nos estados de São Paulo e de Pernambuco.

o índice de segregação de Duncan, calculado considerando-se a classificação ocupacional em três dígitos do IBGE, revela a existência de considerável segregação ocupacional nos dois estados. Além disso, verifica-se que embora essa medida decresça, entre o início e o final do período, em São Paulo, se eleva substancialmente em Pernambuco. A análise de decomposição mostra que o impacto das alterações na composição por sexo das ocupações é mais importante do que 0 das modificações na estrutura ocupacional da mão-de-obra para explicar as transformações da segregação ocupacional no período.

Através do ajuste de logitos multinomiais, que objetivam estimar a distribuição ocupacional dos homens que compõem a amostra com base em um conjunto de 
características pessoais, e da substituição das caracteristicas das mulheres da amostra nos logitos multinomiais estimados, simula-se a distribuição ocupacional que mulheres teriam se os critérios de contratação fossem iguais para os dois sexos. Equações de rendimento estimadas por sexo e categoria ocupacional combinadas com a distribuição ocupacional simulada possibilitam identificar 0 impacto nas diferenças de rendimento por gênero das mulheres serem selecionadas ou remuneradas pelos critérios adotados para os homens.

Considerando-se que as variáveis explicativas dos rendimentos sejam os niveis de escolaridade, idade, situação do domicílio, posse de carteira de trabalho assinada e posição na ocupação, verifica-se que as diferenças por gênero medidas por meio dessas variáveis explicam uma parcela insignificante das diferenças entre os rendimentos de homens e mulheres no estado de São Paulo e contribuem para reduzi-las em Pernambuco.

o modelo utilizado permite concluir que as diferenças de remuneração entre os gêneros em São Paulo decorrem da existência das duas formas de discriminação - a intraocupacional e a ocupacional. Já em Pernambuco, decorrem, basicamente, da discriminação intraocupacional.

o ajuste de regressões nas quais as duas formas de discriminação são as variáveis dependentes e as explicativas são o tempo (em anos) e as taxas de inflação resulta estatisticamente significativo apenas em São Paulo, onde a discriminação intraocupacional apresenta tendência decrescente e está negativamente correlacionada com a inflação. 


\title{
WOMAN AT WORK: SEGREGATION AND DISCRIMINATION IN SÃO PAULO AND PERNAMBUCO
}

\author{
Author: ANA MARIA HOLLAND OMETTO \\ Adviser: PROF. RODOLFO HOFFMANN
}

\section{SUMMARY}

This study analyses the evolution of occupational segregation by gender and of female worker discrimination in the states of São Paulo and Pernambuco, for the period 1981-1990. The data set is provided by the National Household Sample Surveys (PNAD).

The index of segregation developed by Duncan \& Duncan (1955), estimated considering the three digits occupational classification detailed by IBGE, indicates the existence of a considerable occupational segregation by gender in both states. Moreover, it shows that even if this degree decreases among the initial and final period in São Paulo, it increases considerably in Pernambuco. A decomposition procedure shows that the impact of the changes in the gender composition within occupations is more important than the changes in the distribution of employment across occupations to explain the changes in the occupational segregation by gender during the period.

Earning equations estimated by gender and occupational class combined with the occupational distribution of the working women simulated through multinomial logit 
models allow the identification of the impact on the male-female earnings differentials of women being selected or paid using the same criteria adopted for men.

Considering that the explanatory variables of eamings are school apprenticeship, age, urban/rural sector, the possession of a signed work booklet and occupational position, it is notable that male-female differentials due to these variables explain an insignificant part of the eamings differentials by gender in São Paulo, and contribute to reduce them in Pernambuco.

The model used allows the conclusion that the male-female earnings difference in São Paulo is the result of two kinds of discrimination: the intra-occupational and the inter-occupational discrimination. Furthermore, the earnings differentials in Pernambuco result, mainly, from intra-occupational discrimination.

The estimated time series regressions in which discrimination is a dependent variable and the explanatory variables are the time (in years) and the rate of inflation were statiscally significant only in São Paulo, where the intra-occupational discrimination shows a decreasing tendency and is negatively correlated with inflation. 


\section{INTRODUÇÃO}

Nas últimas décadas, as transformações de ordem econômica, social e demográfica pelas quais passou a sociedade brasileira afetaram consideravelmente a composição da força de trabalho familiar.

As elevadas taxas de crescimento do Produto Interno Bruto per capita nos anos setenta, particularmente as taxas de crescimento dos setores secundário e terciário, geraram oportunidades de trabalho que levaram, pela primeira vez desde que as estatísticas oficiais de emprego se tornaram disponíveis, o crescimento da população economicamente ativa (PEA) a superar o da população.

Paralelamente, tomaram corpo mudanças consideráveis no âmbito da familia, tais como a generalização de um padrão característico do sudeste urbano, que é o formato aonde predomina a unidade biológica pai-mãe-filhos, e a sua contraface que é a diminuição das familias extensas; a diminuição do número de filhos, que se costuma associar à intensificação do processo de urbanização, e ao maior nível de escolaridade, bem como ao maior acesso aos meios anticoncepcionais; e o aumento das familias quebradas, especialmente das chefiadas por mulheres ${ }^{1}$.

1 Conforme OLIVEIRA (1987), COSTA, NOZOE \& PORTO (1987), OLIVEIRA, M. C. \& BERQUÓ (1990) e BERQUÓ, OLIVEIRA \& CAVENAGHI (1990), entre outros. 
A literatura especializada tem, reiteradamente, associado tais transformações ao crescimento, observado nas últimas décadas, da participação da mulher na força de trabalho.

A crise que se abateu sobre a economia brasileira no início dos anos oitenta não interrompe esse processo. Ao invés disso, contrariando as teses apoiadas no conceito marxista de "exército industrial de reserva", que levariam a prever que a discriminação histórico-estrutural da mulher iria se agudizar nas conjunturas recessivas, as estatisticas mostram que as taxas de atividade feminina se mantiveram ascendentes ao longo de toda a década de oitenta.

A Tabela 1, elaborada a partir de informações obtidas através das Pesquisas Nacionais por Amostra de Domicilios (PNAD), realizadas anualmente pelo Instituto Brasileiro de Geografia e Estatística (IBGE), permite verificar o crescimento substancial das taxas de atividade feminina no Brasil e o decorrente aumento da participação das mulheres na PEA, numa década em que a economia brasileira atravessa uma das mais graves crises de sua história.

É importante salientar, também, que o crescimento da participação feminina na PEA foi acompanhado por mudanças de composição, que podem impactar significativamente na evolução dos rendimentos dessa força de trabalho. Entre elas pode-se mencionar: a do perfil da participação etária, com acentuado crescimento de atividade nos grupos de idade intermediária; a setorial, decorrente do crescimento relativo de setores que usualmente são bons empregadores de mão-de-obra feminina e de um processo de feminilização a taxas diferenciadas por setor; a da posição 
na ocupação, que aponta principalmente para o processo de proletarização da mão-de-obra feminina na agricultura; a da educação, com o aumento dos níveis de escolaridade; a da estrutura ocupacional, com a mão-de-obra feminina se distribuindo em um elenco mais diversificado de ocupações; a da formalização das relações de trabalho, associada a oscilações do percentual de mulheres com carteira de trabalho assinada; e a regional, associada ao processo de urbanização ${ }^{2}$.

Tabela 1. Indicadores de condição de atividade para as pessoas de 10 anos ou mais de idade - 1981 a 1990. Brasil.

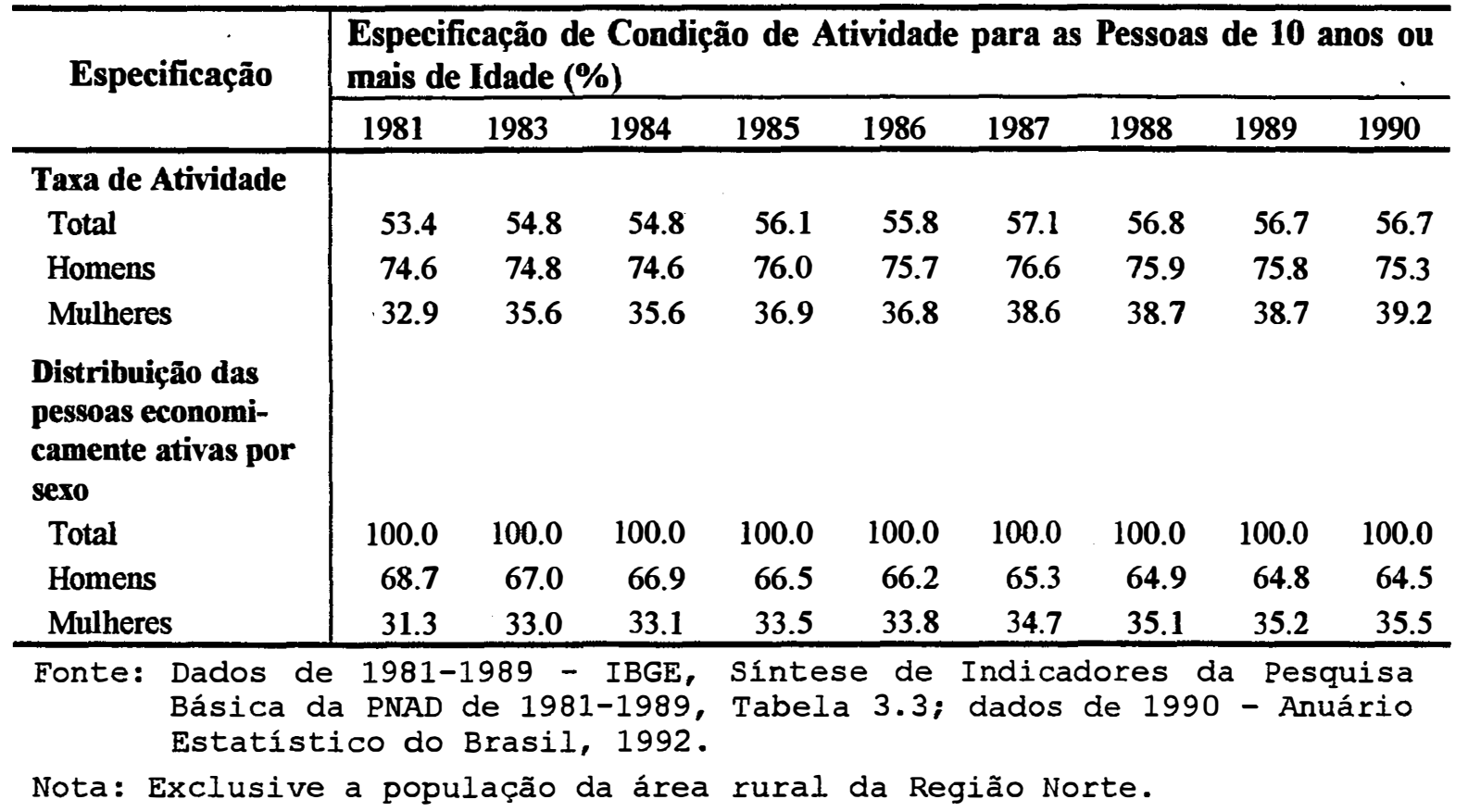

A despeito dessas transformações, o diferencial de rendimento entre os sexos, vigente na nossa sociedade, permanece elevado. A tabela 2 mostra a evolução dos rendimentos reais do trabalho de homens e mulheres ocupados

2 Conforme publicações das PNAD do período. 
na economia brasileira, no período compreendido entre 1981 e 1990. Nota-se que na primeira metade dessa década a remuneração das mulheres se mantém ao redor de 50\% da dos homens. A partir de então, o rendimento real feminino cresce proporcionalmente mais do que o masculino (1986) ou cai menos (1987, 1988 e 1990), de forma que, ao final do período, a remuneração das mulheres é 57,6\% da dos homens.

Tabela 2. Rendimento médio mensal real, de todos os trabalhos das pessoas ocupadas, segundo o sexo 1981 a 1990. Brasil.

\begin{tabular}{|c|c|c|c|c|c|c|c|c|c|}
\hline \multirow{2}{*}{ SEXO } & \multicolumn{9}{|c|}{$\begin{array}{l}\text { RENDIMENTO MÉDIO MENSAL REAL }{ }^{(1)} \text { DE TODOS OS } \\
\text { TRABALHOS DAS PESSOAS OCUPADAS }\end{array}$} \\
\hline & 1981 & 1983 & 1984 & $1985^{(2)}$ & 1986 & $198 x^{(2)}$ & $1988^{(2)}$ & 1989 & 1990 \\
\hline $\operatorname{Total}^{(3)}$ & 739 & 635 & 630 & 731 & 1.042 & 792 & 786 & 928 & 757 \\
\hline Homens $^{(3)}$ & 874 & 765 & 753 & 876 & 1.245 & 944 & 938 & 1.112 & 892 \\
\hline Mulheres ${ }^{(3)}$ & 443 & 372 & 381 & 441 & 642 & 504 & 502 & 591 & 514 \\
\hline Mulheres/Homens & 50,7 & 48,6 & 50,6 & 50,3 & 51,6 & 53,4 & 53,5 & 53,1 & 57,6 \\
\hline : IBG & Sint & & & res & & sa & isica & $P$ & $\mathrm{de}$ \\
\hline
\end{tabular}

Nota: Exclusive o rendimento da população da área rural da Região Norte.

(1) Inflacionado pelo INPC com base em setembro de 1989.

(2) Valores revistos.

(3) Valores em NCZ\$.

Em linhas gerais, a desigualdade de salários pode ser decorrente de dois fatores: 0 primeiro, ligado à heterogeneidade dos trabalhadores com respeito a seus atributos produtivos; o segundo, ao fato de trabalhadores com idêntica qualificação serem remunerados de forma distinta, seja porque são discriminados (ou, em outros termos, diferenciados com base em atributos não produtivos), seja porque o mercado de trabalho é segmentado 
(caso em que os postos de trabalho valorizam seus atributos de forma diferente) (Reis \& Barros, 1991).

Diz-se que as mulheres são discriminadas no mercado de trabalho quando, apesar de igualmente qualificadas, recebem salários menores porque têm acesso apenas às ocupações pior remuneradas e/ou recebem pagamento inferior no desempenho da mesma função. No primeiro caso, a discriminação é ocupacional, decorrente de uma segmentação do mercado de trabalho na qual o sexo se torna uma variável de triagem. O segundo compreende a discriminação salarial propriamente dita.

O debate sobre a segmentação no mercado de trabalho na economia brasileira evoluiu significativamente nos últimos anos, com a contribuição de uma série de trabalhos de natureza empírica que apontam para a existência de diferenciais apreciáveis de salários entre trabalhadores homogêneos quanto à qualificação, lotados em postos de trabalho distintos. Dentre as formas de segmentação detectadas encontram-se: a institucional ${ }^{3}$, a setorial ${ }^{4}$, a

3 KON (1989) e CACCIAMALI (1993) verificam que os trabalhadores com carteira assinada recebem, em média, salários mais elevados do que os demais. CACCIAMALI observa ainda que trabalhadores do setor nãoregulamentado possuem, em média, menor escolaridade e inserem-se entre os trabalhadores situados nas faixas etárias mais jovens e mais velhas, o que sugere que o diferencial de salários poderia decorrer da maior concentração de trabalhadores pouco qualificados no setor não-regulamentado. Entretanto, BARROS, RODRIGUES \& AIMEIDA REIS (1989) observaram que, quando os demais atributos da mão-deobra são controlados, persiste um diferencial salarial entre 15 e 208 a favor dos trabalhadores com carteira assinada.

4 GATICA, MIZALA \& ROMANGUERA (1990), utilizando dados da RAIS referentes à 1987, observam a existência de diferenciais apreciáveis de salário interindustriais para trabalhadores com caracteristicas semelhantes. MENEZES (1988) e RAMOS (1991), com base em informações da PNAD, também detectaram a existência de diferenças de rendimento para os trabalhadores lotados nos vários ramos industriais. 
decorrente da propriedade do capital da empresa ser pública ou privada ${ }^{5}$, ou ainda, a regional ${ }^{6}$.

Todavia, a produção intelectual voltada à análise da discriminação contra mulheres no mercado de trabalho no Brasil é surpreendentemente pequena, apesar das fortes evidências empiricas de tal discriminação.

Neste sentido, os dados fornecidos pela Relação Anual de Informações Sociais. (RAIS) para a década de oitenta mostram que nas empresas com mais de cinco empregados instaladas no Brasil, as mulheres auferem salários menores do que os homens em quase todos os setores nos quais estão inseridas, embora tenham, em média, maior tempo de serviço com o atual empregador e maior nível de escolaridade. Da mesma forma, as informações contidas nas PNAD desse período permitem verificar a prevalência de salários substancialmente menores para a mão-de-obra feminina, a despeito de sua maior escolaridade.

As pesquisas têm, usualmente, mencionado a vigência de barreiras ocupacionais no mercado, apontando para a segregação das mulheres nas ocupações de menor prestígio, para o menor acesso aos cargos de chefia e de supervisão e menor tradição sindical das atividades nas quais se concentram?

5 MACEDO (1985 e 1986), apoiado em dados da RAIS, verifica, após controlar o efeito de sexo, idade e educação, a persistência de diferenciais salariais que beneficiam os trabalhadores de empresas estatais.

6 SAVEDOFF (1990), tomando como base de dados as informações das PNAD de 1976 a 1987, computa diferenças persistentes e apreciáveis de salários entre as regiões metropolitanas. CORRÊA (1996), por sua vez, também através de informações das PNAD, detecta, no período de 1981 a 1990, diferenças significativas de rendimento do trabalho entre a mão-de-obra rural das cinco macro-regiões brasileiras. 
Entretanto, dado o cunho sociológico ou antropológico da maioria dos trabalhos preocupados com esse tema, as diferenças observadas na estrutura ocupacional e nos salários médios por ocupação têm sido encaradas como resultantes da discriminação, sem maiores preocupações com os aspectos quantitativos.

A rigor, são raras as pesquisas que se utilizam de ferramental econométrico para analisar de forma mais sistemática a discriminação salarial e ocupacional contra a mão-de-obra feminina vigente na economia brasileira ${ }^{8}$ E, além do mais, tais pesquisas têm um caráter pontual, não tendo como objetivo estabelecer a tendência da desigualdade de salário por gênero e sua relação com os movimentos cíclicos da economia.

Uma análise ao longo de vários anos permitiria não só conhecer a evolução e a tendência da discriminação no mercado de trabalho, como também definir se parte das suas flutuações tem caráter efêmero, podendo por isso ser desconsiderada nas discussões sobre a natureza estrutural do problema.

O presente trabalho pretende contribuir para a análise da desigualdade de renda na economia brasileira e subsidiar politicas voltadas à sua superação, centralizando a atenção na discriminação contra a mão-de-obra feminina,

8 Dentre as publicações relativamente recentes que se utilizam de dados brasileiros pode-se citar os trabalhos de CAMARGO \& SERRANO (1983) e o de BARROS, RAMOS \& SANTOS (1992). Na literatura internacional 0 interesse neste tema se ampliou a partir da década de setenta, gerando um volume considerável de trabalhos que tendem a interpretar as diferenças de salário entre os sexos segundo duas vertentes teóricas: a primeira, que enfatiza o papel desempenhado pelas caracteristicas pessoais (incluindo os trabalhos aficcionados à teoria do capital humanol e a segunda, que privilegia os fatores de ordem estrutural e institucional (os que enfatizam a segmentação do mercado). Uma tentativa de conciliar essas duas vertentes numa análise empírica foi realizada por BROWN, MOON \& ZOLOTH (1980). 
no período compreendido entre 1981 e 1990. Neste sentido, a pesquisa tem dois objetivos básicos:

(1) Analisar a evolução da estrutura ocupacional da mão-deobra masculina e feminina, quantificando as alterações nos indices de segregação ocupacional. Pretende, também, interpretar as transformações verificadas na segregação, investigando o impacto das alterações na composição por sexo das ocupações e o das modificações na estrutura ocupacional da mão-de-obra.

(2) Analisar a discriminação salarial e ocupacional contra a mão-de-obra feminina, observando a tendência dessas duas formas de discriminação e a relação entre suas flutuações e os índices de desemprego e de inflação que vigoraram na economia brasileira durante a década de oitenta.

Dadas as dificuldades envolvidas em uma análise que englobe a totalidade dos estados brasileiros, optou-se por restringíla às áreas urbanas e rurais dos estados de são Paulo e Pernambuco, escolhidos de molde a permitir uma comparação regional que tenha como sujeito estados com grande contingente populacional e bastante dispares em termos dos índices de distribuição de renda e dos níveis de desenvolvimento econômico vigentes. ${ }^{9}$

o trabalho está organizado em cinco capítulos.

o próximo análisa o embate teórico travado sobre o tema, apresentando uma síntese das interpretações relativas à discriminação no mercado de trabalho oferecidas pelas

9 HOFFMANN (1997), utilizando dados das PNAD de 1995, verificou que os rendimentos médio e mediano da PEA ocupada com rendimento em São Paulo são 2,25 e 2,43 vezes, respectivamente, os auferidos pela PEA ocupada com rendimento em Pernambuco. Os índices de Gini e de Theil em Pernambuco $(0,567$ e 0,729, respectivamente) são substancialmente maiores do que os que vigoram em São Paulo $(0,541$ e 0,631). 
abordagens de cunho neoclássico e pela teoria da segmentação do mercado de trabalho.

o capitulo 3 enfoca as principais questões metodológicas. Neste sentido, discute a qualidade e limitações da base de dados, o procedimento adotado na construção da amostra e os instrumentos metodológicos utilizados no desenvolvimento da pesquisa, quais sejam, a medida de segregação e sua decomposição e o modelo estatístico adotado para o cálculo da discriminação salarial e ocupacional.

O capítulo 4 relata a evolução da segregação ocupacional de homens e mulheres, investigando as razões que levam às alterações verificadas nessa segregação. A existência de tendência na evolução da segregação, e a relação entre a segregação e as taxas de crescimento do emprego são investigadas através do ajuste de regressões.

No capítulo 5 procede-se à decomposição das diferenças observadas entre os rendimentos de homens e mulheres da amostra, identificando as parcelas que podem ser explicadas ou não por diferenças intraocupacionais de qualificação e as que decorrem de diferenças (justificáveis ou não) da distribuição da mão-de-obra entre ocupações. A existência da tendência na évolução das formas de discriminação identificadas no período em questão, e a relação entre a discriminação e as taxas de crescimento do emprego e da inflação são também investigadas através do ajuste de regressões.

Finalizando, no último capítulo são apresentadas as principais conclusões da tese. 


\section{DISCRIMINAÇÃO CONTRA A MÃO-DE-OBRA FEMININA: INTERPRETAÇÕES ALTERNATIVAS}

As análises sobre discriminação contra mulheres no mercado de trabalho têm, basicamente, seguido dois caminhos: o primeiro deles abarca os estudos preocupados com a criação de modelos analíticos que, apoiados em diferentes pressuposições teóricas, descrevem as condições nas quais esse tipo de discriminação pode persistir; 0 segundo concentra um numeroso conjunto de pesquisas empíricas que procuram mensurá-la, quantificando o diferencial de pagamento entre homens e mulheres com produtividade equivalente.

As pesquisas deste segundo grupo podem, por sua vez, ser agrupadas em categorias que refletem 0 embate teórico centrado no tema. A primeira, claramente hegemônica em termos do número de publicações, abrange os trabalhos que enfocam a discriminação através do paradigma do capital humano. ${ }^{10}$ Como regra geral, os trabalhos deste grupo procuram, através do ajuste de equações de rendimento,

10 Segundo JENKINS(1994) existem virtualmente centenas de trabalhos empíricos embasados nesse referencial teórico. Dentre eles pode-se mencionar os de OAXACA (1973a, 1973b), BLINDER (1973), SAWHILL (1973), MINCER \& POLACHEK (1974), POLACHEK (1976 e 1979), CORCORAN \& DUNCAN (1979), WEISS \& GRONAU (1981), MINCER \& OFEK (1982), DOLTON \& MAKEPEACE (1987), CARLSON \& SWARTZ (1988) e WRIGHT\& ERMISCH (1991). 
decompor a diferença entre os salários médios de homens e mulheres na parcela que resulta de eventuais diferenças de seus atributos produtivos, sendo usualmente considerados como tais os níveis de escolaridade e experiência, e na que reflete a discriminação. A segunda categoria, vinculada aos modelos de segmentação do mercado de trabalho, privilegia a vigência de barreiras ocupacionais nesse mercado, enfatizando o papel das diferenças observadas na estrutura ocupacional masculina e feminina nos diferenciais de salário entre os sexos. ${ }^{11}$

De modo geral, pode-se dizer que as análises sobre a discriminação têm, como pano de fundo, uma questão central: o mercado de trabalho é unificado, ou existem impedimentos estruturais criando barreiras à mobilidade, que levam à constituição de mercados isolados, cada um dos quais com regras próprias de determinação de salários, promoções, etc.?

A partir de diferentes respostas a esta questão preliminar, a escola neoclássica, com sua vertente constituida pela teoria do capital humano, e a teoria do mercado de trabalho segmentado fornecem explicações particulares à remuneração persistentemente menor da mãode-obra feminina.

11 Nesta tradição encontram-se, entre outros, os trabalhos de SANBORN (1964), ZELNER (1972), WEISSKOFF (1972), BERGMANN (1974), STEVENSON (1975), BLAU (1977), BLAU \& HENDRICKS (1979), ENGLAND (1982), BELLER (1982, 1984 e 1985), CAMARGO \& SERRANO (1983), BIELBY \& BARON (1984) ALBELDA (1986), BLAU \& BELIER (1988), FIELDS \& WOLFF (1991) e GROSHEN (1991). 


\subsection{A interpretação da teoria neoclássica: do modelo de Gary Becker à proposta do "Capital Humano"}

Embora o primeiro neoclássico a abordar de forma relativamente sistemática a questão da discriminação tenha sido Edgeworth(1922, p. 431-57), o interesse no tema por parte dessa corrente da teoria econômica viria a se difundir apenas após a publicação do trabalho de Becker (1957).

Supondo um mercado de trabalho unificado, no qual existe perfeita informação dos agentes envolvidos e livre mobilidade, tanto dos trabalhadores em busca de melhores salários, como dos empregadores por mão-de-obra, a teoria neoclássica propõe que os salários e o emprego sejam determinados a partir dos processos de maximização do lucro das firmas e da utilidade dos indivíduos. Num mercado competitivo, as empresas maximizam seus lucros considerando a tecnologia e os preços dos fatores de produção como dados, contratando trabalhadores até o nível de emprego no qual os salários se igualam ao valor do produto marginal do trabalho. Neste processo se estabelece a demanda por trabalho. Os indivíduos, por sua vez, optam entre o trabalho (e subsequiente renda) e o lazer, e dadas as suas preferências e os salários (reais) com que se deparam, escolhem a combinação que maximiza a utilidade. Nesse processo se gera a oferta de trabalho. A interação entre a oferta e a demanda determina os níveis do emprego e do salário que vigorarão na economia. Em outros termos, a inexistência de entraves ao funcionamento desse mercado, tais como o estabelecimento de valor mínimo para os salários ou ainda limitações que impeçam sua flexibilidade, inibindo as oscilações salariais decorrentes de variações 
da oferta e da demanda por trabalho, garantirão o pleno emprego na economia.

Considerando um mercado de trabalho funcionando segundo esse modelo, Becker acrescenta as condições de que homens e mulheres sejam igualmente produtivos e de que exista a "preferência pela discriminação", motivo pelo qual "os indivíduos agem como se estivessem dispostos a pagar, diretamente ou na forma de renda reduzida, para se relacionar com algumas pessoas ao invés de outras" (Becker, 1957, p. 6). Esta preferência pode ter diversas origens, implicando, isolada ou conjuntamente, que os empresários estejam dispostos a contratar mulheres apenas por salário menor do que o que pagariam a homens igualmente produtivos, que os colegas de trabalho exijam um adicional de pagamento para compartilhar com elas o ambiente de trabalho, ou ainda, que os consumidores por elas atendidos adquiram as mercadorias apenas se lhes for oferecido um desconto.

A análise de Becker permite verificar que, sob tais hipóteses, as diferenças entre os rendimentos dos dois tipos de trabalhadores podem ocorrer apenas no curto prazo, numa situação de "desequilíbrio autocorrigível".

$\mathrm{Se}$ numa sociedade existem empregadores que discriminam mulheres, mas $\bigcirc$ volume de emprego oferecido pelos que não o fazem é suficiente para absorver a oferta de trabalho, homens e mulheres igualmente produtivos receberão salário equivalente, embora se configure uma situação de segregação, pois, em tais circunstâncias, as mulheres não encontrarão emprego nas firmas que as discriminam. Por outro lado, se 0 volume de emprego oferecido pelas empresas que não se pautam pelo preconceito é insuficiente para a absorção da oferta de trabalhadoras, os seus salários serão reduzidos (e o pleno 
emprego restaurado). Contudo, neste caso, a mão-de-obra contratada pelos empregadores sem preconceito será exclusivamente feminina, tornando tais firmas mais lucrativas, o que, pelas pressuposições do modelo, é insustentável no longo prazo ${ }^{12}$.

Se 0 preconceito se origina no consumidor, e estiver suficientemente difundido na economia, pode provocar a queda dos salários de mulheres em trabalhos que envolvam contato com consumidores (Becker, 1957, p. 56 e seguintes). Mas, neste caso, conforme alega stiglitz (1973), as trabalhadoras seriam encorajadas a procurar postos de trabalho que não exigissem tal contato, o que provocaria novamente segregação e não, necessariamente, diferencial salarial. Somente na hipótese pouco plausível da estrutura vigente do emprego impedir que as mulheres encontrem espaço em tais postos, é que o diferencial de salários se sustentaria.

Por fim, se colegas de trabalho preconceituosos exigissem um adicional de pagamento para trabalhar com mulheres igualmente capazes, novamente os custos maiores do emprego conjunto poderiam ser evitados através da segregação ocupacional (Becker, 1957, p 48). O diferencial de salários poderia persistir apenas quando $\circ$ número de trabalhadoras e trabalhadores sem preconceito fosse insuficiente para permitir $\circ$ funcionamento de firmas em escala economicamente viável que integrassem a mão-de-obra

12 Becker argumenta que a expansão das firmas sem preconceito somente poderia ser freada se os custos fossem crescentes à escala (p.36). E mesmo sob esta hipótese, a inexistência de barreiras à entrada que caracteriza o sistema de competição perfeita possibilitaria às firmas com lucros acima dos considerados "normais" a expansão da produção através da montagem de novas plantas e/ou compra das já existentes. 
de mulheres e homens sem preconceito ou nas quais se promovesse a segregação.

Assim, salvo em situações consideradas pouco prováveis, as diferenças salariais discriminatórias num mercado de trabalho competitivo seriam um fenômeno de curto-prazo, autocorrigível pelas próprias regras que norteiam o funcionamento do mercado.

Mesmo relaxando a pressuposição de competição perfeita, Becker encontra dificuldades em oferecer um modelo que explique de maneira convincente a persistência da discriminação.

Supondo novamente um mercado de trabalho que funcione com base em pressuposições neoclássicas, no qual os trabalhadores dos dois sexos sejam igualmente produtivos e exista a "preferência pela discriminação", a competição imperfeita pode ser introduzida através das seguintes hipóteses: (1) algumas firmas detêm monopólio no mercado de produtos; (2) um pequeno número de empregadores absorve fração expressiva da força de trabalho; e, (3) os trabalhadores estão organizados em sindicatos.

$\mathrm{Na}$ primeira situação é preciso ter em mente que embora o monopólio no mercado de produtos possa resultar em lucros acima dos considerados "normais" (o que viabilizaria perdas decorrentes de comportamento discriminatório), não implica poder no mercado de trabalho. Se a firma não puder afetar os salários, a sua situação de monopólio será irrelevante, pois não conseguirá contratar mulheres por salário inferior ao que vigora no mercado, e nem necessitará pagar aos homens, salário superior. Em decorrência, tal firma contratará apenas homens, configurando-se novamente a segregação, e não a discriminação da mão-de-obra. E mais, mesmo que a difusão 
dos monopólios na economia seja suficiente para que o comportamento do conjunto dessas empresas possa afetar 0 mercado de trabalho, ainda assim, se a posse for transferivel, a racionalidade dos agentes envolvidos levaria à que, no longo prazo, empresários menos preconceituosos assumissem o comando. Em outros termos, assim como a competição no mercado de produtos tende a eliminar a discriminação nas empresas competitivas, a competição no mercado de capitais deve reduzi-la nas empresas monopolistas (Becker, 1957, p. 38). Desta forma, conclui que a discriminação nas indústrias monopolistas poderia persistir apenas se a posse fosse intransferivel. E mesmo nesse caso a influência do monopólio como fonte primária de discriminação poderia ser questionada por razões de ordem prática. Conforme sugere Marshall (1974), monopolistas (ou oligopolistas) devem ter menor interesse em discriminar (dado que, nas grandes empresas, as relações estabelecidas entre a administração e os empregados são mais distantes) e maior facilidade em integrar a mão-deobra sem custos adicionais (visto que mesmo colegas de trabalho preconceituosos procuram evitar o sacrificio de boas posições no mercado de trabalho). Além do mais, as empresas monopolistas, pela sua proeminência pública, tendem a ser muito sensiveis à questão da imagem e, assim, às pressões organizadas de grupos minoritários, que podem prejudicá-las apelando ao público simpático aos interesses das minorias (Cain, 1986).

$\mathrm{Na}$ segunda situação, considerada como forma clássica de exploração da mão-de-obra, os trabalhadores estão cativos em um mercado no qual $\circ$ número de empregadores é suficientemente pequeno para que as ações de cada um deles, individualmente, afetem o nível de salários 
e a oferta de trabalhadores aos demais. Nestas circunstâncias, cada empregador se depara com uma oferta de trabalho ascendente, de forma que variações na sua demanda de trabalho afetam o nível de salários. $\mathrm{Na}$ busca de maximização dos lucros o monopolista empregará trabalhadores até que se atinja o ponto no qual a despesa marginal com a mão-de-obra iguale sua receita marginal o que, conforme descrito nos manuais de microeconomia neoclássica, leva a uma situação de equilíbrio na qual o volume de emprego e o salário são menores do que os que vigorariam num mercado competitivo. Pode-se demonstrar que, nesse modelo, o comportamento maximizador dos lucros resultará em salários menores para mulheres quando a oferta feminina de trabalho for menos elástica em relação aos salários do que a masculina (Madden, 1973).

Cain (1986) critica a viabilidade da persistência de diferenciais salariais por este motivo, argumentando que a prevalência de monopsônio no mercado de trabalho é muito limitada não apenas porque a maioria da população vive em grandes centros urbanos, mas também porque os meios de transporte modernos expandiram os limites geográficos desse mercado. Lembra, também, que as análises empíricas têm verificado que a elasticidade da oferta feminina de trabalho é usualmente maior do que a da masculina.

Por fim, quando trabalhadores preconceituosos formam um monopólio na venda da força de trabalho, podem, simultaneamente, elevar seus niveis salariais e restringir a entrada de mulheres na categoria (Becker, 1957, p. 54). E, embora a adoção de critério de contratação que exclua eventuais candidatos com base no sexo possa ser alvo de sanções, os sindicatos costumam negociar com os empregadores um conjunto de requisitos que afastam de fato 
as mulheres, tais como a experiência prévia no ramo, a disponibilidade para serviço noturno e horas extras, etc.

Ao contrário das situações de monopsônio, os sindicatos trabalhistas estão amplamente difundidos na sociedade. Além disso, uma série de pesquisas empíricas tem verificado efeito positivo da sindicalização na remuneração dos seus associados. Assim; a menor participação feminina em categorias cobertas por contratos coletivos de trabalho deveria resultar em salários médios menores do que os masculinos. Apesar disso, Ashenfelter (1973) verificou que, dado o baixo grau de sindicalização dos trabalhadores de ambos os sexos na economia norte-americana, o impacto da sindicalização no diferencial de pagamentos de homens e mulheres é insignificante (explicando apenas 1,9\% dele).

Portanto, a introdução de imperfeições no mercado de produto e/ou trabalho claramente não resolve os problemas encontrados pela teoria neoclássica para explicar as diferenças substanciais e persistentes entre o pagamento de homens e mulheres igualmente produtivos ${ }^{13}$.

As dificuldades enfrentadas por Becker na construção de uma "economia da discriminação" levaram Arrow (1972, p. 192) a concluir, corretamente, que "o modelo prevê a ausência do fenômeno que se propõe a explicar". Pelas mesmas razões, Welch (1975) denomina a teoria de Becker de "teoria da segregação" e não da discriminação.

13 Essas questões tem sido levantadas por críticos do modelo primitivo de Becker, tais como SOWELL (1971), STIGLITZ (1973), ARROW (1972, 1973), MARSALI (1974), WELCH (1975), DARITY (1975) e CAIN (1986). São, claramente, críticas internas à teoria, pois, embora procurem apontar as contradições internas do modelo de Becker, não colocam as pressuposições neoclássicas em xeque. CAIN (1986) e MADDEN (1988) apresentam revisão abrangente das idéias de Becker e das críticas subsequientes à publicação do seu trabalho. 
Arrow (1973), Phelps (1972) e Spence (1973), cientes dessas dificuldades, assim como do irrealismo da hipótese da "preferência pela discriminação" num modelo pautado pela racionalidade econômica dos agentes envolvidos ${ }^{14}$, buscaram justificar as diferenças salariais através do relaxamento da pressuposição de informação perfeita no mercado de trabalho.

No que se convencionou denominar "teoria estatística da discriminação", considera-se que os empregadores não pretendem discriminar as mulheres. Entretanto, embora estejam dispostos a pagar salários semelhantes para homens e mulheres igualmente produtivos, não dispõem de informações seguras sobre a produtividade real dos candidatos, necessitando avaliá-la com base em indicadores que não são plenamente confiáveis. Nesse mundo de informações imperfeitas, os empresários, baseados em suas percepções da realidade, constrõem estimativas da produtividade média de homens e mulheres com determinadas características (nível de escolaridade, experiência, etc.) e, considerando os custos envolvidos numa análise mais precisa, caso a caso, dos candidatos; optam por remunerar a mão-de-obra de acordo com as estimativas de que dispõem, ou seja, os individuos passam a ser julgados com base nas características médias dos grupos a que pertencem ${ }^{15}$.

14 Como justificar que trabalhadores e empresários, considerados agentes econômicos racionais que dispõem de perfeita informação, adotem um comportamento que pode excluilos do mercado ao solicitar, respectivamente, adicional de pagamento para compartilhar 0 ambiente de trabalho com mulheres igualmente produtivas, ou se dispor a pagar salários maiores a homens igualmente qualificados?

15 As normas preconizadas para o funcionamento do mercado de trabalho são as mesmas da teoria neoclássica convencional, com a diferença de que as empresas contratam trabalhadores até o nível de emprego no qual os salários se igualam não ao valor do produto marginal do trabalho, mas à estimativa da média desse valor. 
Neste contexto, os diferenciais de salários são explicados basicamente por dois argumentos. ${ }^{16}$

o primeiro propõe que, apesar de a mão-de-obra dos dois sexos ser, em média, igualmente produtiva, a variância da produtividade é maior para a mão-de-obra feminina. Nestas circunstâncias, a aversão ao risco do empresariado o levará a preferir contratar homens, deprimindo a demanda por mulheres no mercado de trabalho e, em conseqüência, os seus salários (Lundberg \& Startz, 1983).

No segundo, alega-se que, apesar de a produtividade média de homens e mulheres ser semelhante, os indicadores disponíveis são menos confiáveis para as mulheres. Novamente, a aversão ao risco do empresariado deprimirá a demanda pela mão-de-obra feminina e, consequentemente, o seu salário. ${ }^{17}$

Além de se poder questionar a razoabilidade das suposições de maior variância da produtividade e/ou da menor confiabilidade dos indicadores, também a argumentação não demonstra que o custo da procura de informações mais fidedignas é maior do que o dos erros de contratação que decorrem da ineficiência dos critérios. E, em quaisquer das hipóteses existem, dentro do referencial neoclássico no qual a teoria é construída, incentivos consideráveis para que trabalhadores e empresários encontrem indicadores mais eficazes da produtividade. Se é apenas a falta de informação que leva os trabalhadores a serem remunerados

${ }^{16}$ A formalização dos argumentos pode ser vista em PHELPS (1972).

17 SPENCE (1973) considera que, apesar de a educação formal não gerar aumentos de produtividade, os individuos naturalmente mais hábeis têm maior facilidade para alcançar níveis elevados de escolaridade. Assim, a escolaridade é encarada como uma credencial, que indica a produtividade inata do individuo. Entretanto, como é considerada um indicador menos confiável para as mulheres, a aversão ao risco do empresariado o leva a contratar mulheres apenas se os seus salários forem menores. 
pela estimativa da produtividade média do seu sexo, pode-se supor que os trabalhadores que se considerassem prejudicados pelos critérios adotados - não apenas as mulheres, mas todos os que acreditassem ter produtividade maior do que a média da sua categoria - provavelmente estariam dispostos a trabalhar por baixos salários durante um período de experiência, na expectativa dos salários maiores que vigorariam após tal período. Assim, diferenças salariais baseadas em percepções da realidade que a experiência demonstrasse ser equivocadas não deveriam persistir (Mccall, 1972).

Em suma, os obstáculos encontrados pela teoria neoclássica para justificar a existência de discriminação no mercado de trabalho aparentemente não puderam ser transpostos a contento, nem pelo abandono da pressuposição de competição perfeita e nem pelo da informação perfeita. o passo seguinte foi, então, considerar que as diferenças salariais são o resultado de diferenças - determinadas exogenamente ao mercado de trabalho - de qualificação da mão-de-obra. E esta tarefa foi empreendida pelos adeptos da teoria do capital humano.

A linha mestra dessa teoria é a hipótese de que grande parte dos gastos que os individuos têm consigo mesmos são realizados objetivando retornos futuros. Desta forma, a busca de maior escolaridade, informação, saúde, etc., implica em gastos que devem ser encarados, não como decisões de consumo, mas como decisões racionais de investimento.

Dada a fundamentação neoclássica da teoria, considera-se que o trabalhador seja pago pelo valor do seu produto marginal. Em decorrência, investimentos no "capital 
humano", sejam gerais (através do ensino formal) ou especificos (através do treinamento em atividades particulares da firma que emprega o trabalhador) levam a aumentos de produtividade que resultam em salários maiores. A racionalidade econômica dos indivíduos os leva a investir na sua formação com base em suas percepções dos custos das opções disponíveis e dos benefícios gerados por cada uma delas (Becker, 1975 e Mincer, 1962, 1974).

Sob tais hipóteses, a desigualdade de renda vigente numa sociedade em que prevalece a igualdade de oportunidades e 0 acesso a informações passa a ser 0 reflexo da distribuição de atributos pessoais natos, entre os quais o talento e o tino comercial, ou fruto de decisões individuais, tais como os investimentos na educação (que refletem, por sua vez, os padrões individuais de preferência temporal), e da experiência no mercado de trabalho.

Os diferenciais de rendimento entre os sexos vão decorrer, basicamente, do fato de homens e mulheres avaliarem suas opções considerando diferentes expectativas a respeito dos padrões de trabalho que esperam desenvolver ao longo de sua vida útil.

Tais expectativas resultam de uma divisão de trabalho na familia que, conforme Becker (1981, 1985), é favorecida por incentivos econômicos. Considerando que o consumo familiar envolve a aquisição de bens (o que, por sua vez, implica em rendimentos monetários, e, portanto, em trabalho remunerado) que devem ser transformados pelo trabalho doméstico, a subsistência familiar exige 0 desempenho de atividades no mercado de trabalho e no ambiente doméstico. Como tais atividades envolvem habilidades específicas, que podem ser aprimoradas através 
de investimentos sujeitos a retornos crescentes, a família como um todo ganha com a especialização dos seus membros. ${ }^{18}$

Consubstanciada essa divisão sexual do trabalho, as decisões de investimento em termos do "capital humano" dos membros da família são tomadas como base em expectativas a respeito dos padrões futuros de trabalho que diferem segundo 0 sexo.

Além do mais, assumindo-se que as responsabilidades domésticas resultem em um padrão de atividades remuneradas marcado pela descontinuidade, e que a interrupção da atividade seja "punida" pela depreciação dos salários que decorre da obsolescência das habilidades do trabalhador que se ausenta do mercado, a expectativa desse padrão ${ }^{19}$ leva as mulheres não apenas a menores investimentos na qualificação, mas também a buscar os empregos nos quais a descontinuidade receba menor penalidade (Polachek, 1976 e 1979). Como resultado, mesmo na ausência de discriminação, as escolhas racionais dos ofertantes do trabalho conduzem à segregação ocupacional: "Se o ciclo de participação no mercado de trabalho difere entre os indivíduos, e se os custos desses diferentes graus de intermitência variam entre as ocupações, então os indivíduos vão escolher as ocupações com menor penalidade para a participação que

18 Como percebe corretamente O'NEILL (1988), as pressuposições desse modelo resultam na especialização, mas não na divisão sistemática do trabalho segundo o gênero. Para tal seria necessária a vigência de outras condições: a mulher deveria apresentar vantagens comparativas na produção doméstica e/ou rendimentos potenciais menores no mercado de trabalho.

19 É preciso ter em mente que para a lógica da teoria não é necessário que $\circ$ padrão de descontinuidade se verifique, pois sua expectativa é condição suficiente para gerar os resultados preconizados. 
programam ter a longo de sua vida" (Polachek, 1979, p. 144). ${ }^{20}$

Ou seja, dado um padrão de divisão familiar do trabalho que confere maiores responsabilidades domésticas às mulheres, os diferenciais de rendimento entre os sexos e a segregação ocupacional se explicam por decisões racionais dos ofertantes do trabalho em termos dos investimentos diferenciados segundo o sexo na qualificação profissional e da escolha da carreira a seguir ${ }^{21}$.

A intermitência resulta ainda em menor experiência e como a experiência provoca aumento dos rendimentos em decorrência da produtividade gerada pelo treinamento que ocorre no trabalho (Mincer, 1962 e Becker, 1975), a teoria encontra uma justificativa adicional para os menores salários auferidos pelas mulheres.

Em suma, a abordagem do capital humano enfatiza a idéia de que o menor investimento, menor experiência e segregação ocupacional resultam de escolhas voluntárias da mão-de-obra feminina. Diferenças por gênero na estrutura da

20 ENGLAND (1982), através da análise das informações do National Longitudinal Survey (NLS), de 1967, não encontra suporte empírico para as idéias defendidas por Polachek. Verifica que os rendimentos das mulheres em ocupações predominantemente femininas não apresentam menor taxa de depreciação ou de valorização do que os das que estão inseridas em ocupações masculinas. Além disso, as mulheres que passam maior número de anos depois da escola fora do mercado de trabalho não se encontram em ocupações com maior predominância de mulheres do que as que têm atividade mais contínua.

Deve-se notar que essa explicação difere substancialmente da oferecida por BECKER (1957). Como vimos, para esse autor se houver preconceito contra mulheres por parte de empregadores, colegas de trabalho ou consumidores de certas empresas, no longo prazo, a mãode-obra feminina será realocada nas atividades onde os agentes envolvidos não se pautam pelo preconceito. Em outros termos, a análise de BECKER (1957) enfoca os determinantes da demanda de trabalho que levam à segregação das trabalhadoras em determinadas posições.. Contudo, é importante perceber que as duas abordagens não se constituem em interpretações opostas, mas sim complementares. 
demanda, por sua vez, desempenham papel passivo no modelo, à medida em que são consideradas como mero resultado da percepção correta dos empregadores acerca da menor produtividade das trabalhadoras.

\subsection{A teoria da segmentação do mercado de trabalho}

Rejeitando o universalismo a-histórico das análises neoclássicas, Doeringer \& Piore (1971) propõem ser a segmentação do mercado de trabalho uma consequiência do desenvolvimento da estrutura produtiva das economias capitalistas industrializadas.

o desenvolvimento desigual da indústria moderna acarreta o surgimento de setores oligopolizados, compostos por grandes empresas, tecnicamente dinâmicas, e setores menos concentrados, abrangendo firmas de menor porte e base técnica usualmente menos avançada.

A expansão do número de postos e funções que respondem à necessidade de normas de controle burocrático das grandes empresas do mundo contemporâneo, assim como às suas especificidades em relação à qualificação, tecnologia e processos de treinamento da mão-de-obra, faz com que 0 mercado de trabalho assuma natureza cada vez mais compartimentalizada. Assim, nas grandes empresas, as posições subalternas da hierarquia são preenchidas pelos trabalhadores que nelas ingressam. Contudo, uma vez admitidos, as promoções são decididas internamente, com base numa estrutura de cargos e salários que constituem carreiras específicas das firmas e visam, não apenas atender a normas de controle burocrático de estruturas agigantadas, mas também, e principalmente, diminuir os 
custos significativos da rotatividade de uma mão-de-obra que foi recrutada, selecionada e treinada para o desempenho de atividades específicas da empresa.

Deve-se considerar que a introdução de novas técnicas e o crescimento da produtividade da mão-de-obra registrado nessas empresas nas últimas décadas tornam os salários parcela cada vez menos importante do seus custos, permitindo-lhes conceder aumentos salariais sem comprometer a lucratividade. Entretanto, dada a oferta abundante de mão-de-obra para os postos de ingresso, tais aumentos não necessitam ser generalizados. Ao invés disso, abre-se a possibilidade de um amplo leque de salários que sanciona o estabelecimento do mercado interno de trabalho (Souza, 1980 p. 94).

A progressão do indivíduo na carreira à qual seu posto de ingresso dá acesso dependerá de sua adaptabilidade às normas estabelecidas, de sua identificação com os objetivos da empresa, dos treinamentos aos quais foi submetido, etc., ficando relegadas para segundo plano as dimensões avaliadas antes da incorporação do trabalhador.

Neste contexto, o processo de determinação dos salários difere significativamente do preconizado pela teoria neoclássica. A incorporação, na análise, dos custos fixos da força de trabalho (decorrentes do recrutamento, seleção, contratação e treinamento da mão-de-obra), que devem ser amortizados ao longo de uma permanência incerta do trabalhador na firma, dificulta sobremaneira a determinação dos salários pelo princípio da equivalência entre custos e produtividade marginal. Além disso, o salário, que não deve ser encarado como a remuneração do indivíduo, mas como a que pode ser recebida pela ocupação de determinado posto de trabalho, não está atado à 
produtividade individual, e sim a de grupos de trabalhadores na mesma função. Por fim, outro importante determinante neoclássico dos salários - a remuneração em oportunidades alternativas de emprego - também perde importância, pois os trabalhadores que abandonam a empresa têm acesso apenas a posições de ingresso (e, portanto, pior remuneradas) nas demais.

Logicamente, as grandes empresas não absorvem a totalidade da força de trabalho. No âmbito dos mercados internos de trabalho, cujo conjunto Doeringer e Piore denominam mercado primário, os salários se tornam relativamente elevados, as possibilidades de ascensão profissional amplas e os empregos estáveis. Contrapondo-se a ele encontra-se o mercado secundário de trabalho, que compreende os empregos que não se estruturam segundo niveis hierarquicamente estabelecidos (ou, em outros termos, aqueles para os quais não existe nenhum tipo de carreira), e os que, embora organizados segundo uma estrutura formal, tendem a ter muitos postos de ingresso e pouca mobilidade ou possibilidades de promoção. Neste mercado, que abrange principalmente os empregos localizados no setor doméstico e nas firmas de menor porte, além de alguns tipos de trabalho desenvolvidos em grandes empresas, a rotatividade não é percebida como um problema, pois a oferta de trabalhadores, pelas baixas exigências de qualificação e treinamento, é abundante, possibilitando que a reposição da mão-de-obra se faça praticamente sem custos. Em decorrência, no mercado secundário os cargos são menos estáveis, os salários mais baixos e a possibilidade de ascensão profissional menor. Nesta abordagem, a desigualdade de salários por gênero resulta de uma alocação da força de trabalho que 
seleciona as mulheres preferencialmente para as carreiras menos atrativas do mercado secundário.

A questão central que se coloca é o porque da segregação da mão-de-obra feminina em tais postos. E neste particular, a resposta da teoria do mercado segmentado é semelhante a dos adeptos da teoria estatistica da discriminação: o caráter intermitente do trabalho feminino favorece sua participação no mercado secundário, que encoraja a rotatividade da mão-de-obra através dos baixos salários e raras chances de promoção. A organização do mercado primário, por sua vez, pelos custos de treinamento da mão-de-obra e oportunidades de ascensão profissional, é mais adaptada à mão-de-obra masculina, encarada como mais estável e confiável. Se homens e mulheres diferem significativamente em termos da proporção que possue as caracteristicas desejadas (no caso, a estabilidade), num mundo onde não existe perfeita informação, a política mais eficiente de contratação pode ser, simplesmente, a exclusão dos candidatos do sexo feminino. Desta forma, o sexo torna-se uma variável chave de triagem e o diferencial de salários se explica por uma segregação ocupacional com predomínio de mulheres nos cargos pior remunerados (Doeringer \& Piore, 1971, cap. 8).

É claro que as práticas que restringem as mulheres às posições subalternas e lhes negam o acesso a treinamento devem provocar a elevação da rotatividade e do absenteísmo. Assim, pode-se criar um círculo vicioso através do qual as opiniões são reafirmadas sem que se ofereçam às mulheres oportunidades de responder a uma estrutura diferente de incentivos (Weisskoff, 1972, p. 164).

Os autores argumentam, ainda, que mesmo as trabalhadoras que estão incorporadas no mercado primário de 
trabalho podem ser pior remuneradas em decorrência de práticas discriminatórias nas regras que governam a determinação dos salários. Em primeiro lugar, a baixa remuneração que auferem no mercado secundário é transmitida para o primário através do rebaixamento dos níveis salariais iniciais das carreiras em que estão inseridas. Além disso, as carreiras com predominância de ocupação feminina podem também ser subvalorizadas pela aplicação de critérios desiguais de avaliação, que adotam como prática estabelecer salários semelhantes para mulheres lotadas em diferentes tipos de serviço, ao invés de procurar equiparálos pelo nível de qualificação exigido (Doeringer \& Piore, 1971, Cap. 7).

Em resumo, quando se busca verificar se a desigualdade por gênero observada na distribuição ocupacional e nos salários resulta de diferentes escolhas dadas as mesmas oportunidades, ou de oportunidades desiguais de realizar escolhas semelhantes, as correntes teóricas consideradas neste capitulo fornecem respostas diferentes.

Para os adeptos da abordagem do mercado de trabalho segmentado, a segregação das mulheres nos postos de trabalho pior remunerados é determinada pela demanda de trabalho. Entretanto, essa segregação não decorre, necessariamente, da discriminação por parte dos agentes econômicos, pois a expectativa do empresariado acerca da menor estabilidade do conjunto da mão-de-obra feminina, considerada uma característica chave para o setor oligopólico, é suficiente para excluir as mulheres dos empregos melhor remunerados. Desta forma, oportunidades desiguais que não são necessariamente provocadas pela discriminação levam tanto à segregação da mão-de-obra 
feminina num elenco restrito de ocupações, como à sua pior remuneração.

Os adeptos da teoria estatística da discriminação explicam os diferenciais de salário entre os sexos através da aversão ao risco do empresariado conjugada à sua percepção acerca da maior variância da produtividade da mão-de-obra feminina ou, ainda, da menor confiabilidade na capacidade dos indicadores disponíveis de avaliar corretamente a produtividade desse tipo de trabalhador. Assim, a menor remuneração das mulheres não é provocada pela discriminação, mas por características próprias de seu sexo, causadas por fatores exógenos ao mercado de trabalho, além da aversão ao risco do empresariado. A segregação das mulheres nas ocupações pior remuneradas não se constitui em objeto de análise dessa teoria.

Já para Becker (1957), a discriminação pode levar à segregação das trabalhadoras em postos de trabalho nos quais os agentes envolvidos não se pautam pelo preconceito. Entretanto, apenas em circunstâncias muito específicas tais postos podem ser persistentemente pior remunerados.

A abordagem do capital humano, por sua vez, enfatiza a idéia de que são as escolhas racionais das ofertantes de trabalho que levam à sua segregação nas ocupações menos penalizadas pela intermitência, as quais apresentam, correlatamente, reduzidas possibilidades de ascensão. Os diferenciais salariais explicam-se ainda pelos menores investimentos realizados pela mão-de-obra feminina no "capital humano" e pela sua menor experiência no mercado de trabalho.

Dadas as limitações envolvidas em uma análise realizada através de dados secundários, não é possível desenvolver um esforço sério no sentido de verificar qual 
proposta teórica é mais adequada à explicação das diferenças de rendimento e estrutura ocupacional de homens e mulheres na nossa economia. Contudo, é importante notar que a opção por cada uma dessas justificativas não conduz, necessariamente, a propostas politicas diferenciadas.

Se considerarmos que o padrão de divisão familiar do trabalho que confere às mulheres maiores responsabilidades domésticas pode ser provocado pelos seus rendimentos potenciais menores no mercado de trabalho, o tratamento igualitário nesse mercado elimina as razões para considerar as mulheres como donas-de-casa, em primeiro plano e trabalhadoras remuneradas, em segundo. Oportunidades iguais encorajarão as jovens a se preparar para a atividade profissional e, no longo prazo, a alegada inferioridade da mão-de-obra feminina em termos do seu "capital humano" tenderá a desaparecer.

Da mesma forma, uma estrutura de incentivos que ofereça às mulheres oportunidades de treinamento e o acesso a postos superiores na hierarquia, ou, em outros termos, o ingresso no mercado primário de trabalho, deve provocar a diminuição da sua rotatividade e taxas de absenteísmo, quebrando o círculo vicioso que as condena às posições pior remuneradas. 


\section{ASPECTOS METODOLÓGICOS}

\subsection{Qualidade e limitações dos dados utilizados}

Como base de dados, utilizaremos as informações referentes aos Estados de São Paulo e Pernambuco, coletadas nos levantamentos anuais realizados pelo Instituto Brasileiro de Geografia e Estatística (IBGE) através das Pesquisas Nacionais por Amostra de Domicílios (PNAD) de 1981 a 1990.

Embora essas informações sejam consideradas de excelente qualidade, no que concerne à cobertura regional e consistência intertemporal (Ramos, 1993), apresentam limitações que podem levar a erros na mensuração dos rendimentos, nas suas comparações regionais e intertemporais, e no cálculo da discriminação e da segregação.

No tocante ao primeiro aspecto, Hoffmann \& Kageyama (1986) consideram que a principal limitação desses dados diz respeito à subestimação da renda total, que é particularmente relevante por não afetar de maneira uniforme os diferentes estratos de renda. Nos estratos de menor poder aquisitivo, os rendimentos de pequenos produtores rurais podem estar subestimados por não serem coletadas informações sobre a produção para autoconsumo, que constitui parcela significativa da sua renda real. E, considerando a redução da produção para autoconsumo verificada ao longo do tempo, a sua exclusão afeta também a 
comparabilidade intertemporal dos rendimentos. Entretanto, o principal problema parece ser a subdeclaração das rendas altas, propiciada pela coleta de dados através de questionários. ${ }^{22}$ Embora, a rigor, haja possibilidade de subdeclaração nos diferentes estratos de renda, pesquisas comparando, em áreas ou estados brasileiros, o valor per capita do Produto Interno a custo de fatores com a renda per capita declarada no Censo Demográfico de 1970 (Lluch, 1982) e 1980 (Hoffmann, 1988) verificam que o grau de subdeclaração tende a crescer com o nível médio de renda da área ou estado, o que sugere ser a subdeclaração maior nos estratos de renda mais elevada. E, como as mulheres recebem, em média, remuneração significativamente menor do que os homens, a subdeclaração diferenciada por estrato de renda leva à subestimação dos diferenciais de rendimento entre os sexos e, portanto, das medidas de discriminação obtidas. ${ }^{23}$

Também o intenso ritmo inflacionário pode levar a erros, desta feita não intencionais, na declaração dos rendimentos fixos e/ou variáveis, acarretando dúvidas na interpretação da sua evolução nos períodos de inflação acelerada. Contudo, estes erros não estão associados ao sexo do respondente e, portanto, não devem provocar nenhum tipo de viés na medida da discriminação.

22 Trabalhos de GOLDSMITH (1950) e de BUDD \& RADNER (1969), mencionados por Hoffmann e Kageyama, comprovam que as declarações de rendimentos recebidos como salários são mais fidedignas do que as das rendas, juros e dividendos. Especula-se que também sejam pouco confiáveis as informações sobre os benefícios recebidos por executivos na forma de "mordomias" ou salário indireto.

23 COHEN (1971), analisando informações do Survey of Working Conditions de 1969, verifica que a inclusão de estimativa do valor de um conjunto de benefícios auferidos pelos trabalhadores amplia substancialmente $o$ diferencial de rendimentos entre os sexos. 
As PNAD apresentam ainda duas caracteristicas metodológicas problemáticas do ponto de vista da mensuração do emprego agrícola e do emprego feminino em geral: definem a PEA com base apenas na semana de referência e não mantêm essa semana fixa ao longo dos anos. ${ }^{24}$ Estas duas características problematizam a análise do emprego e da renda na agricultura devido à sazonalidade inerente a esta atividade (Kageyama, 1986). ${ }^{25} \mathrm{E}$, mais ainda, prejudicam a medição do trabalho feminino que com mais freqüência que o masculino é instável e sazonal.

Uma outra limitação liga-se à inexistência de dados longitudinais. O que se tem é uma série de dados tipo cross section que, embora contendo o mesmo conjunto de informações, não permitem que se acompanhe o mesmo grupo de indivíduos ao longo do tempo. Uma característica das análises baseadas em dados tipo cross section é que os perfis de rendimento por faixa etária estimados para homens e mulheres não se referem às coortes dos indivíduos. Ao invés disso, representam inferências delineadas de coortes "sintéticas". Embora este procedimento tenda a gerar estimativas de perfis mais "achatados" do que os reais (por

24 Embora na maioria dos anos considerados a semana de referência seja a última de setembro ou a primeira de outubro, em 1981 as informações sobre mão-de-obra referem-se ao período compreendido entre 8 e 14 de novembro.

25 LEONE (1994), referindo-se à semana de referência da PNAD de 1987, aponta para o fato dela corresponder "a um período de elevado emprego agrícola no Nordeste e baixo emprego agrícola nas demais regiões do país, salvo o Estado de São Paulo, em que o nível do emprego agrícola situa-se exatamente no nível médio anual do emprego. Conseqüentemente, as informações da PNAD conseguem representar melhor a situação ocupacional dos trabalhadores agrícolas neste Estado. No Nordeste provavelmente a PNAD superestima a proporção de empregados temporários e subestima a dos trabalhadores por conta-própria e não remunerados, ocorrendo o contrário nas demais regiões". Estas observações são pertinentes, aplicando-se aos demais anos estudados. 
não refletirem $\circ$ crescimento dos rendimentos associados a aumentos seculares de produtividade), não há razões para supor que seu impacto seja diferenciado por sexo (Gerhart, 1990). Mais problemática do ponto de vista metodológico é a ausência de informações sobre a atividade pregressa dos indivíduos, porque dificulta a obtenção de um indicador mais preciso de sua experiência no mercado de trabalho. Esta é uma falha particularmente relevante quando se procura analisar a discriminação das mulheres no mercado de trabalho, pois as alternativas usualmente utilizadas de adotar como proxy da experiência a "idade", ou ainda, "a idade menos escolaridade menos seis"26 não levam em conta a possibilidade de maior intermitência da atividade feminina:

As PNAD's também não indagam sobre 0 tempo de vinculação do indivíduo ao atual empregador. Conforme preconizado pela teoria da segmentação do mercado de trabalho, o acesso a posições hierarquicamente superiores de uma dada carreira depende, fundamentalmente, do "tempo de casa" do empregado. Desta forma, a duração de sua vinculação à empresa é crucial para explicar diferenças de salário, podendo ser, neste aspecto, inclusive mais importante do que a totalidade da experiência do indivíduo no mercado de trabalho.

Sabe-se, também, que as mulheres, além de estarem segregadas num elenco restrito de ocupações, ainda se

26 A utilização da "idade menos a escolaridade menos seis" como proxy da experiência é prática usual nas pesquisas sobre os determinantes dos rendimentos do trabalho realizadas em âmbito internacional. Pesquisadores brasileiros têm adotado a idade como proxy da experiência. Ambas as alternativas apresentam prós e contras, pois enquanto a utilização do primeiro indicador tende a subestimar a experiência das pessoas de classes inferiores de renda em relação à dás superiores, a adoção da segunda, ao pressupor que pobres e ricos comecem a trabalhar com a mesma idade, independentemente de sua permanência na escola, superestima mais a experiência dos indivíduos das classes superiores. 
concentram nos níveis hierarquicamente inferiores. ${ }^{27}$ Desta forma, podem receber salários menores do que os homens, não apenas porque são discriminadas e/ou alocadas nas ocupações pior remuneradas, mas também porque estão posicionadas nos níveis mais baixos da categoria ocupacional. Essa concentração de homens e mulheres em níveis diferentes das mesmas ocupações, conhecida como segregação vertical, não pode ser identificada pelos dados da PNAD.

Por fim, dada a inexistência de informações sobre os estabelecimentos que empregam os individuos relacionados nas PNAD, não é possível identificar a segregação ocupacional de homens e mulheres em diferentes firmas. Em decorrência, índices de segregação calculados através dessa fonte de dados devem estar subestimados também por esta razão ${ }^{28}$. Além disso, como os salários médios diferem substancialmente segundo o tamanho do estabelecimento, quaisquer que sejam os indicadores considerados (número de empregados, capital social, volume de vendas, etc.), o impacto de uma distribuição desigual dos sexos em empresas de diferentes tamanhos sobre os diferenciais salariais também não pode ser calculado.

Apesar dessas limitações, as PNAD constituem, atualmente, a principal fonte de dados para os interessados na análise da evolução da distribuição da renda no Brasil, por razões ligadas à periodicidade, ampla cobertura e

27 A este respeito conferir, por exemplo, BLAU \& FERBER (1988).

28 BLAU (1977), BIELBY \& BARON (1984) e GROSHEN (1991) verificam que homens e mulheres estão segregados não apenas em ocupações diferentes, mas também em estabelecimentos diferentes. Desta forma, mesmo as pessoas que escolhem ocupações consideradas integradas no tocante à sua composição por sexo, podem estar trabalhando, predominantemente, com pessoas do mesmo sexo. Este tipo de segregação tem impacto negativo na remuneração da mão-de-obra feminina, conforme comprovam MCNULTY (1967), BUCKLEY (1971), BLAU (1977) e GROSHEN (1991), entre outros. 
consistência intertemporal das informações. Por essas mesmas razões, constituem uma base de dados que pode fundamentar análises sobre a evolução da segregação e discriminação no mercado de trabalho brasileiro.

Este trabalho utiliza informações individuais do cadastro de pessoas e domicílios dos Estados de São Paulo e Pernambuco, de 1981 a 1990, exceto 1982 e $1986 .{ }^{29}$ Optou-se pela exclusão de 1982 por se considerar que a diferença do procedimento adotado na coleta dos dados (doze semanas de referência ao invés de uma, como nos demais anos) poderia prejudicar as comparações intertemporais dos resultados. 0 ano de 1986, por sua vez, foi excluído porque o número (expandido) de pessoas economicamente ativas não coincide com o publicado nos relatórios das PNAD/IBGE.

Por se tratar de pesquisa realizada através de amostragem, O IBGE fornece a ponderação ou fator de expansão para cada pessoa, família ou domicílio da amostra. Os cálculos foram realizados ponderando-se cada observação pelo respectivo peso ou fator de expansão.

As tabelas 3 e 4 apresentam, para são Paulo e Pernambuco respectivamente, a evolução da população economicamente ativa, masculina e feminina, obtida através da ponderação dos elementos da amostra pelos respectivos fatores de expansão.

29 As informações foram obtidas junto ao Setor de Processamento de Dados do Instituto de Economia da Universidade de Campinas (UNICAMP). 
Tabela 3. População com 10 anos ou mais e população economicamente ativa. São Paulo, 1981 a 1990

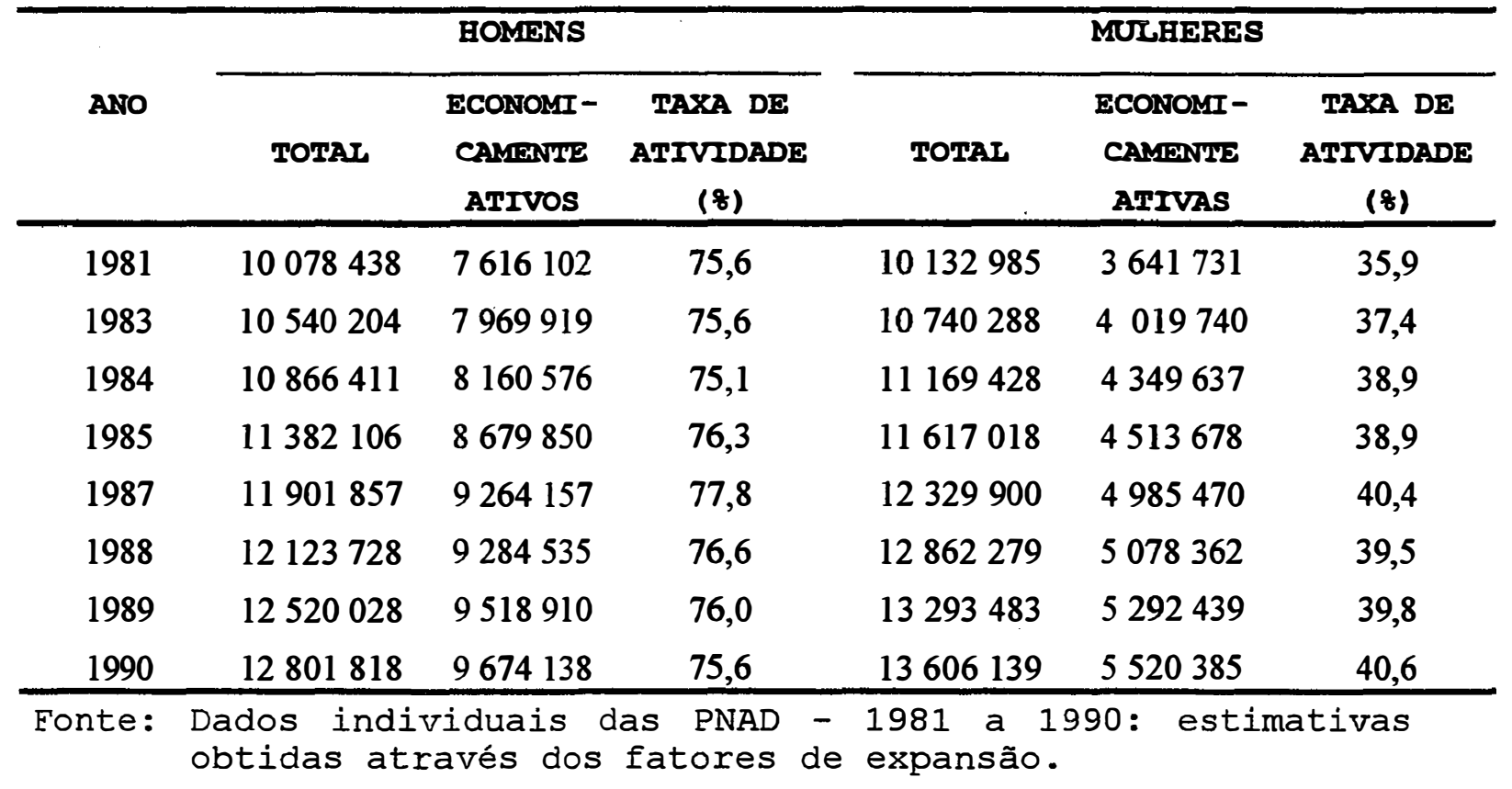

Tabela 4. População com 10 anos ou mais e população economicamente ativa. Pernambuco - 1981 a 1990

\begin{tabular}{|c|c|c|c|c|c|c|}
\hline \multirow[b]{2}{*}{ ANO } & \multicolumn{3}{|c|}{ HOMENS } & \multicolumn{3}{|c|}{ MULHERES } \\
\hline & TOTAL & $\begin{array}{l}\text { ECONOMI- } \\
\text { CAMFNIYL } \\
\text { ATIVOS }\end{array}$ & $\begin{array}{c}\text { TAYA DE } \\
\text { ATIVIDADE } \\
\text { (8) }\end{array}$ & TOTAI & $\begin{array}{l}\text { ECONOMI- } \\
\text { CAMINIY } \\
\text { ATIVAS }\end{array}$ & $\begin{array}{c}\text { TAXA DE } \\
\text { ATIVIDADE } \\
\text { (\%) }\end{array}$ \\
\hline 1981 & 2148254 & 1558525 & 72,5 & 2361425 & 702190 & 29,7 \\
\hline 1983 & 2195451 & 1595939 & 72,7 & 2418907 & 798377 & 33,0 \\
\hline 1984. & 2265848 & 1644902 & 72,6 & 2489432 & 789339 & 31,7 \\
\hline 1985 & 2327414 & 1715537 & 73,7 & 2574647 & 884682 & 34,4 \\
\hline 1987 & 2426478 & 1799415 & 74,2 & 2734998 & 946227 & 34,6 \\
\hline 1988 & 2514781 & 1819032 & 72,3 & 2776715 & 953528 & 34,3 \\
\hline 1989 & 2603540 & 1895910 & 72,8 & 2818210 & 961587 & 34,1 \\
\hline 1990 & 2646155 & 1917517 & 72,5 & 2920293 & 1013140 & 34,7 \\
\hline
\end{tabular}

Fonte: Dados individuais das PNAD - 1981 a 1990: estimativas obtidas através dos fatores de expansão. 
Esses dados evidenciam o crescimento da participação feminina no mercado de trabalho. Nota-se que, enquanto as taxas masculinas de atividade são exatamente iguais entre 0 início e 0 final do período, as taxas femininas crescem cerca de 13\% no estado de São Paulo e 17\% no de Pernambuco. Desta forma, embora a participação feminina seja menor em Pernambuco, as diferenças regionais, no tocante a esse aspecto, se reduzem no período em apreço. Desses dados básicos foram extraídos os utilizados no presente trabalho.

\subsection{A construção da amostra}

Quando se estuda a discriminação contra a mão-deobra feminina, a primeira decisão metodológica com que se depara o pesquisador é a escolha da unidade e da variável de análise. Neste trabalho a unidade de análise são as pessoas ocupadas, estratificadas segundo o sexo, cujas posições na ocupação compreendem as categorias dos assalariados, empregadores e autônomos. Os rendimentos por hora obtidos na ocupação principal e a estrutura ocupacional dos homens e mulheres selecionados constituem o objeto de análise.

A decisão de não restringir a amostra aos assalariados, mas considerar também os empregadores e autônomos, apoia-se na suposição de que embora as mulheres nessas duas últimas posições não possam ser discriminadas por empregadores, podem sê-lo por clientes e demais pessoas com as quais se relacionam no exercício de sua atividade profissional. Por outro lado, optou-se pela exclusão dos trabalhadores não-remunerados por se julgar que como grande parte deles são membros da familia do empregador, a não- 
remuneração desse tipo de trabalhador não deve estar associada à discriminação.

Considerando que a renda familiar é um determinante da escolha ocupacional, decidiu-se excluir, também, as pessoas cuja informação sobre esse tipo de rendimento é prejudicada. Assim, não fazem parte da amostra os empregados domésticos e seus parentes quando moram no emprego, e os agregados, pois a PNAD toma como renda familiar das pessoas nessas categorias a da família residente no mesmo domicílio (a família dos empregadores do empregado doméstico ou aquela com a qual o agregado divide o domicílio).

A restrição à análise da ocupação principal, por sua vez, decorre da falta de informações sobre as demais. ${ }^{30}$ E, como a jornada de trabalho remunerado da mão-de-obra feminina é, em média, substancialmente menor do que a masculina, optou-se pela análise dos rendimentos por hora trabalhada para evitar a obtenção de medidas tendenciosas de discriminação.

Além disso, somente foram consideradas as pessoas para as quais o rendimento por hora na ocupação principal e demais atributos de interesse estão claramente identificados. Tendo em vista $\circ$ elenco de informações contidas nessa base de dados, e, considerando-se que a desigualdade de rendimentos do trabalho decorre da desigualdade de atributos produtivos da mão-de-obra, da possibilidade do mercado de trabalho remunerar de forma diferente trabalhadores com a mesma qualificação (caso esse mercado seja segmentado), ou ainda, remunerar distintamente

30 Para as demais ocupações, os dados limitam-se a relatar o rendimento mensal e horas trabalhadas, sem especificar à qual, ou quais ocupações se referem. 
trabalhadores igualmente produtivos com base em atributos não produtivos (se houver discriminação), os atributos de interesse selecionados foram: a escolaridade, a idade, a situação do domicílio, a posição na ocupação, a posse de carteira de trabalho assinada e, logicamente, o sexo.

A tabela 5 apresenta a evolução do número de observações da amostra utilizada, para os estados de São Paulo e Pernambuco.

Tabela 5. Número de pessoas economicamente ativas ocupadas. São Paulo e Pernambuco - 1981 a $1990^{(1)}$

\begin{tabular}{|c|c|c|c|c|c|c|}
\hline \multirow{3}{*}{ ANO } & \multicolumn{6}{|c|}{ PEA OCUPADA } \\
\hline & \multicolumn{3}{|c|}{ SÃO PAULO } & \multicolumn{3}{|c|}{ PERNAMBUCO } \\
\hline & Homens & Mulheres & $\begin{array}{c}\% \text { de } \\
\text { mulheres na } \\
\text { PEA }^{(2)}\end{array}$ & Homens & Mulheres & $\begin{array}{c}\text { \% de } \\
\text { mulheres na } \\
\text { PEA }\end{array}$ \\
\hline 1981 & $\begin{array}{r}5895898 \\
(13542)\end{array}$ & $\begin{array}{r}2772250 \\
(6536)\end{array}$ & 31,98 & $\begin{array}{r}1134224 \\
(5794)\end{array}$ & $\begin{array}{r}468868 \\
(2801)\end{array}$ & 29,25 \\
\hline 1983 & $\begin{array}{r}6160862 \\
(14364)\end{array}$ & $\begin{array}{r}3146550 \\
(7462)\end{array}$ & 33,81 & $\begin{array}{r}1069907 \\
(5819)\end{array}$ & $\begin{array}{r}504059 \\
(3031)\end{array}$ & 32,02 \\
\hline 1984 & $\begin{array}{r}6419503 \\
(14977)\end{array}$ & $\begin{array}{r}3442256 \\
(8158)\end{array}$ & 34,91 & $\begin{array}{r}1205025 \\
(6060)\end{array}$ & $\begin{array}{r}544198 \\
(3098)\end{array}$ & 31,11 \\
\hline 1985 & $\begin{array}{r}6867686 \\
(15572)\end{array}$ & $\begin{array}{r}3607103 \\
(8415)\end{array}$ & 34,44 & $\begin{array}{r}1233866 \\
(6232)\end{array}$ & $\begin{array}{r}608631 \\
(3425)\end{array}$ & 33,03 \\
\hline 1987 & $\begin{array}{r}7274653 \\
(8401)\end{array}$ & $\begin{array}{r}3935677 \\
(4518)\end{array}$ & 35,11 & $\begin{array}{r}1315557 \\
(3443)\end{array}$ & $\begin{array}{r}672822 \\
(1961)\end{array}$ & 33,84 \\
\hline 1988 & $\begin{array}{r}7362633 \\
(8163)\end{array}$ & $\begin{array}{r}4036946 \\
(4448)\end{array}$ & 35,41 & $\begin{array}{r}1299443 \\
(3319)\end{array}$ & $\begin{array}{r}661485 \\
(1871)\end{array}$ & 33,73 \\
\hline 1989 & $\begin{array}{r}7514279 \\
(7951)\end{array}$ & $\begin{array}{r}4296868 \\
(4531)\end{array}$ & 36,38 & $\begin{array}{r}1360693 \\
(3570)\end{array}$ & $\begin{array}{r}692429 \\
(1977)\end{array}$ & 33,73 \\
\hline 1990 & $\begin{array}{r}7531089 \\
(8161)\end{array}$ & $\begin{array}{r}4344998 \\
(4686)\end{array}$ & 36,59 & $\begin{array}{r}1349455 \\
(3575)\end{array}$ & $\begin{array}{r}736469 \\
(2145)\end{array}$ & 35,31 \\
\hline
\end{tabular}

Fonte: : Dados individuais das PNAD - 1981 a 1990.

(1) Número de observações para as quais os atributos de interesse estão claramente identificados. Os números entre parênteses referem-se ao tamanho da amostra. Os demais valores à população estimada através dos fatores de expansão.

(2) Proporção da PEA ocupada constituída por mulheres. 
Nota-se que, a despeito das crises recorrentes que afetam a economia brasileira nesse período, as taxas de crescimento da PEA ocupada $(37,0 \%$ em São Paulo e 30,1\% em Pernambucol foram substancialmente maiores do que as do crescimento demográfico da população com 10 anos ou mais de idade $\left(30,7 \%\right.$ e $23,4 \%$, respectivamente).$^{31}$

Verifica-se também que, embora o número de homens e mulheres ocupados seja ascendente, o crescimento do número de mulheres é mais acentuado, de forma que a parcela feminina da PEA ocupada se eleva significativamente entre o início e o final do período.

\subsection{A Medida de Segregação}

Pode-se analisar a segregação ocupacional de homens e mulheres recorrendo-se a uma grande variedade de medidas conhecidas como índices de segregação. Embora nenhum desses índices possa ser considerado perfeito, ou mesmo melhor do que os demais, dado que sua avaliação envolve aspectos subjetivos, optou-se neste trabalho pela medida de segregação utilizada na grande maioria dos trabalhos internacionais desenvolvidos no tema, que é o indice $D$, de Dissimilaridade ou Deslocamento de Duncan \& Duncan (1955).

De modo geral, a obtenção desse índice, assim como a das demais medidas de segregação disponíveis na literatura, exige o conhecimento da proporção de mulheres (ou homens)

31 Deve-se ter em mente que esse crescimento está associado às taxas de crescimento da população estimadas pelo IBGE, que se refletem nos fatores de expansão da amostra fornecidos por esse Instituto. Apesar do Censo Demográfico de 1991 ter mostrado que o crescimento da população havia sido superestimado, a comparação é válida, dado que a superestimação dos fatores de ponderação independe da condição de atividade da pessoa. 
na força de trabalho e de um conjunto de informações que estão contidas na construção geométrica que Duncan \& Duncan (1955) denominam "Curva de Segregação".

\subsubsection{A Curva de Segregação}

Considerando que $F_{i}, M_{i}$ e $T_{i}$ são, respectivamente, o número de mulheres, de homens e o total de pessoas na ocupação $\boldsymbol{i}, \boldsymbol{n}$ ○ número de ocupações e $F, M$ e $T$ ○ total de mulheres, de homens e de pessoas na força de trabalho, a Curva de segregação pode ser obtida através de procedimento que envolve as seguintes etapas:

1a) inicialmente são calculadas as proporções $q_{i}$ de mulheres em cada ocupação, onde $q_{i}=\frac{F_{i}}{T_{i}}$, e as ocupações são ordenadas em ordem decrescente de magnitude dos $\boldsymbol{q}_{\boldsymbol{i}}{ }^{\prime} \mathbf{s}$, de maneira que $\frac{F_{1}}{T_{1}} \geq \frac{F_{2}}{T_{2}} \geq \ldots \geq \frac{F_{n}}{T_{n}}$.

2a) utilizando essa ordenação são computadas as proporções acumuladas de homens e mulheres nas ocupações, acumulando os valores de $\frac{M_{i}}{M}$ e $\frac{F_{i}}{F}$. A proporção acumulada de mulheres até a i-ésima categoria é

$$
\pi_{i}=\sum_{j=1}^{i} \frac{F_{j}}{F}=\frac{1}{F} \sum_{j=1}^{i} F_{j}
$$

e a correspondente proporção acumulada de homens é

$$
\Phi_{i}=\sum_{j=1}^{i} \frac{M_{j}}{M}=\frac{1}{M} \sum_{j=1}^{i} M_{j}
$$


$3^{\text {a })}$ os pares de valores assim obtidos definem pontos num sistema de eixos cartesianos ortogonais (no qual a proporção acumulada de mulheres é demarcada no eixo horizontal e a dos homens no vertical), pelos quais passa a curva de segregação, conforme ilustrado na figura 1 .

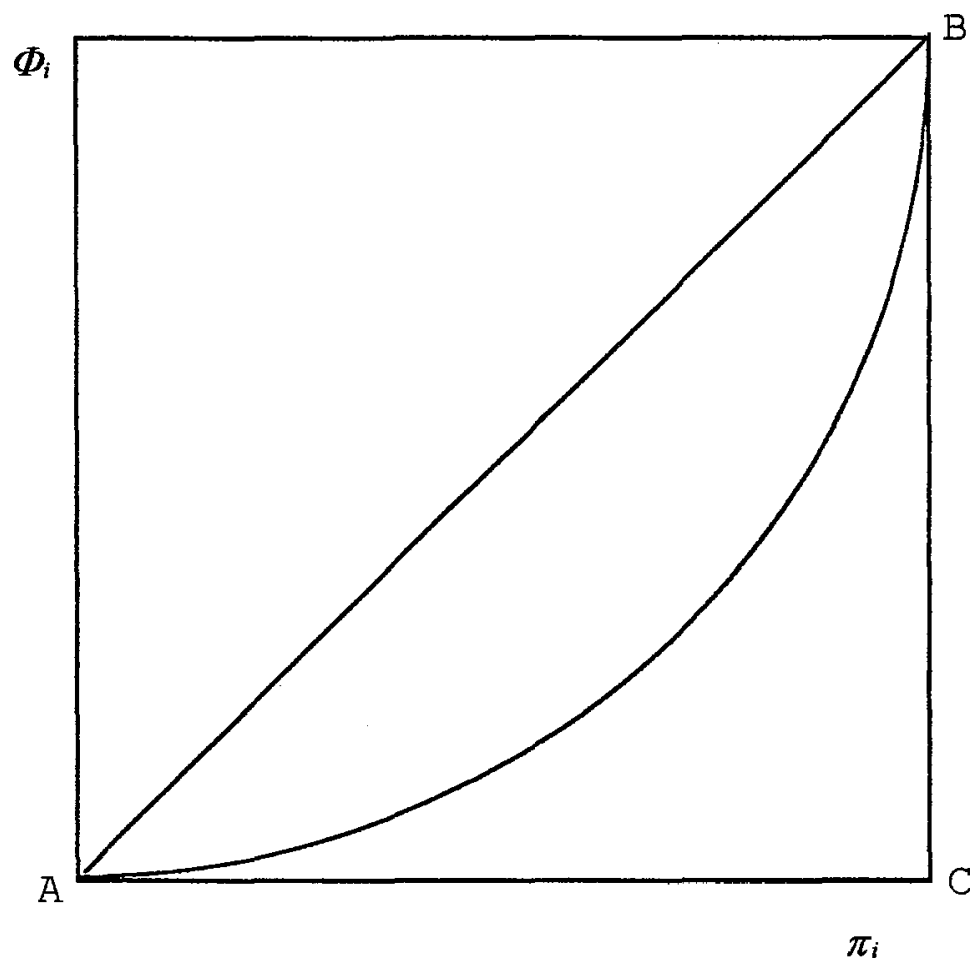

Figura 1. Curva de Segregação

É fácil perceber que quando a distribuição ocupacional dos dois sexos é idêntica, teremos $\frac{F_{i}}{F}=\frac{M_{i}}{M}$ para todo $i$ e, conseqüentemente, $\Phi_{i}=\pi_{i}$. Neste caso, a "curva" de segregação se confunde com a diagonal $A B$ da figura 1. Por outro lado, se a segregação por sexo é total, a "curva" de segregação assume a forma da poligonal ACB. Assim, $A B$ reflete a situação de igualdade absoluta e ACB a de 
desigualdade absoluta da distribuição ocupacional de homens e mulheres.

Dada a evidente analogia entre esta curva e a de Lorenz, as medidas de desigualdade associadas à curva de Lorenz podem ser utilizadas como medidas de segregação, desde que devidamente adaptadas (Hoffmann, 1997).

\subsubsection{O Índice de Dissimilaridade de Duncan}

O índice $D$, de dissimilaridade ou deslocamento, é definido por Duncan \& Duncan (1955) através da expressão:

$$
D=0,5 \sum_{i=1}^{n}\left|\frac{F_{i}}{F}-\frac{M_{i}}{M}\right|
$$

na qual todos os elementos já foram definidos.

o valor obtido pode ser interpretado como a proporção de mulheres que devem ser redistribuídas ou deslocadas (daí a denominação dessa medida) entre as ocupações para que a distribuição ocupacional dos dois sexos se torne idêntica.

$D$ pode assumir valores compreendidos entre zero e um. $D$ é igual a zero quando ocorre perfeita integração dos sexos nas ocupações, o que implica que homens e mulheres tenham a mesma estrutura ocupacional e também em que $\boldsymbol{q}_{i}$ seja igual à $q$ para qualquer valor de $i$. Por outro lado, $D$ é igual a um quando a segregação é total, com as mulheres 
empregadas em ocupações inteiramente femininas e os homens nas completamente masculinas.

Pode-se demonstrar que o índice $D$ corresponde à medida da discrepância máxima, que é definida como o valor máximo da diferença entre a ordenada $\left(\Phi_{i}\right)$ e a abcissa $\left(\pi_{i}\right)$ da curva de segregação $\left(D=\pi_{h}-\Phi_{h}\right)$. Uma vez que na linha de perfeita igualdade a ordenada é sempre igual à abcissa, a discrepância máxima é igual ao valor máximo da diferença entre a ordenada dessa linha e a da curva de segregação. A figura 2 reproduz a curva de segregação da figura 1 e assinala a discrepância máxima.

$\Phi_{i}$

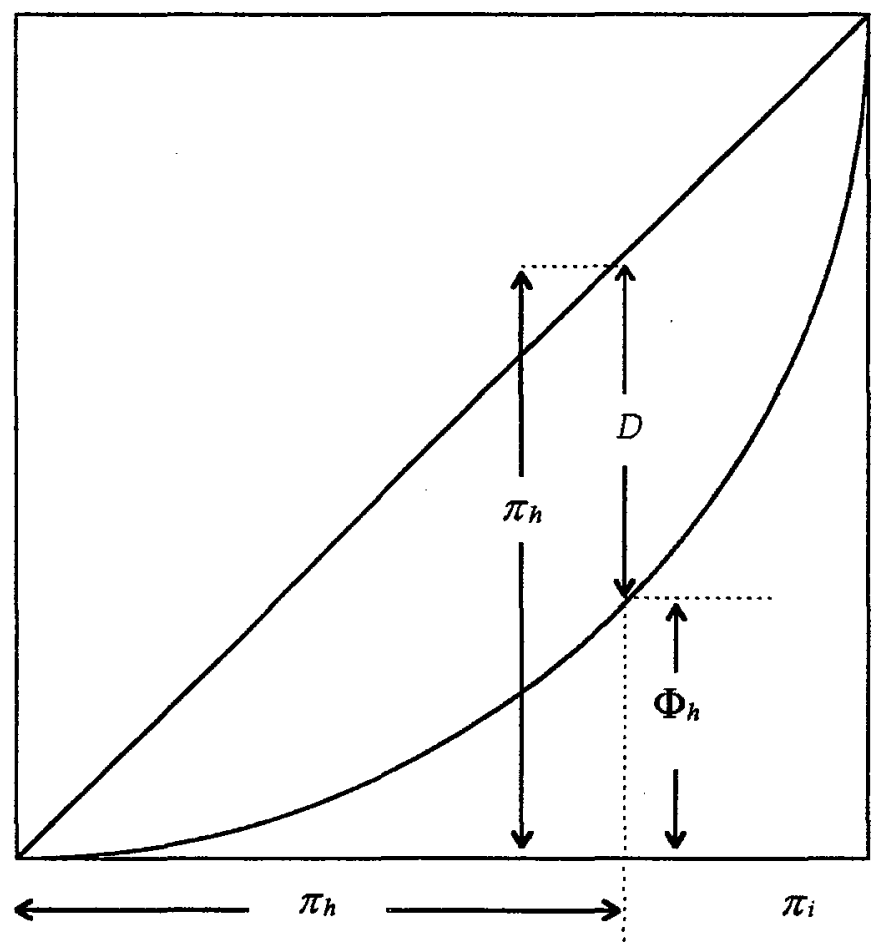

Figura 2.0 Indice de Dissimilaridade $D$ 


\title{
3.3.3. O efeito de alterações na estrutura ocupacional e composição por sexo das ocupações
}

\begin{abstract}
Como assinalado por Fuchs (1975), o valor de $D$ depende do tamanho relativo das várias ocupações e da composição por sexo das mesmas. Assim, alterações no valor de $D$ ao longo do tempo podem decorrer de modificações na estrutura ocupacional da economia como um todo e/ou refletir mudanças na composição sexual de categorias específicas. Tais modificações podem ter a mesma direção, reforçando o impacto no índice, ou direções opostas, mascarando o seu efeito. Por exemplo, um declínio do nível de emprego em ocupações predominantemente masculinas pode provocar a redução do índice mesmo que a composição por sexo das diferentes ocupações permaneça inalterada. Por outro lado, o crescimento da importância relativa de ocupações predominantemente femininas pode mascarar 0 efeito de uma crescente integração da mão-de-obra dos dois sexos nas diferentes ocupações. 0 procedimento de padronização sugerido por Fuchs (1975) permite decompor as alterações observadas em $D$ nas suas duas fontes: as decorrentes de modificações na estrutura ocupacional do emprego (efeito MIX) e as associadas a modificações na composição por sexo das ocupações (efeito COMP).
\end{abstract}

Se $F_{i t}, M_{i t}$ e $T_{i t}$ correspondem, respectivamente, ao número de mulheres, homens e pessoas na ocupação $i$ no ano $t$, a expressão (1) pode ser reescrita da seguinte forma: 


$$
D_{t}=0,5 \sum_{i=1}^{n}\left|\frac{q_{i t} T_{i t}}{\sum_{i=1}^{n} q_{i t} T_{i t}}-\frac{p_{i t} T_{i t}}{\sum_{i=1}^{n} p_{i t} T_{i t}}\right|, \quad \text { para todo } t
$$

onde $q_{i t}=\frac{F_{i t}}{T_{i t}}$

e

$$
p_{i t}=\frac{M_{i t}}{T_{i t}}
$$

A variação do índice de dissimilaridade entre $t=1$ e $t=2$ é $D_{2}-D_{1}=M X+C O M P$,

onde

$M I X=0,5\left[\sum_{i=1}^{n}\left|\frac{q_{i 1} T_{i 2}}{\sum_{i=1}^{n} q_{i 1} T_{i 2}}-\frac{p_{i 1} T_{i 2}}{\sum_{i=1}^{n} p_{i 1} T_{i 2}}\right|-\sum_{i=1}^{n}\left|\frac{q_{i 1} T_{i 1}}{\sum_{i=1}^{n} q_{i 1} T_{i 1}}-\frac{p_{i 1} T_{i 1}}{\sum_{i=1}^{n} p_{i 1} T_{i 1}}\right|\right]$

e

$$
C O M P=0,5\left[\sum_{i=1}^{n}\left|\frac{q_{i 2} T_{i 2}}{\sum_{i=1}^{n} q_{i 2} T_{i 2}}-\frac{p_{i 2} T_{i 2}}{\sum_{i=1}^{n} p_{i 2} T_{i 2}}\right|-\sum_{i=1}^{n}\left|\frac{q_{i 1} T_{i 2}}{\sum_{i=1}^{n} q_{i 1} T_{i 2}}-\frac{p_{i 1} T_{i 2}}{\sum_{i=1}^{n} p_{i 1} T_{i 2}}\right|\right]
$$

Conforme indicado pela equação (3), MIX capta a modificação que ocorre no valor de $D$ entre dois anos considerados, simulando que a composição sexual das ocupações permaneça constante entre esses dois anos. Ou seja, MIX quantifica a alteração do índice $D$ que é provocada exclusivamente pela modificação observada do 
número de pessoas empregadas em cada categoria ocupacional. COMP, por sua vez, capta a mudança no valor de $D$, simulando que o elemento imutável seja a estrutura ocupacional, ou seja, quantifica a alteração de $D$ provocada pela modificação na composição sexual das ocupações.

Pode-se perceber que as expressões (3) e

apresentam o problema familiar da escolha do indice. Como os resultados são diferentes se a modificação inicial for simulada na estrutura ocupacional ou na composição sexual das ocupações, optou-se neste trabalho por efetuar, também, a decomposição alternativa, conforme as expressões (5) e (6), e apresentar os resultados nos pontos médios. Desta forma :

$C O M P^{\star}=0,5\left[\sum_{i=1}^{n}\left|\frac{q_{i 2} T_{i 1}}{\sum_{i=1}^{n} q_{i 2} T_{i 1}}-\frac{p_{i 2} T_{i 1}}{\sum_{i=1}^{n} p_{i 2} T_{i 1}}\right|-\sum_{i=1}^{n} \mid \frac{q_{i 1} T_{i 1}}{\sum_{i=1}^{n} q_{i 1} T_{i 1}}-\frac{p_{i 1} T_{i 1}}{\sum_{i=1}^{n} p_{i 1} T_{i 1} \mid}\right]$

$M I X^{*}=0,5\left[\sum_{i=1}^{n}\left|\frac{q_{i 2} T_{i 2}}{\sum_{i=1}^{n} q_{i 2} T_{i 2}}-\frac{p_{i 2} T_{i 2}}{\sum_{i=1}^{n} p_{i 2} T_{i 2}}\right|-\sum_{i=1}^{n} \mid \frac{q_{i 2} T_{i 1}}{\sum_{i=1}^{n} q_{i 2} T_{i 1}}-\frac{p_{i 2} T_{i 1}}{\sum_{i=1}^{n} p_{i 2} T_{i 1} \mid}\right]$

verificando-se que

$$
D_{2}-D_{1}=\frac{M X+M I X^{*}}{2}+\frac{C O M P+C O M P^{*}}{2}
$$

\subsection{O cálculo da discriminação: o modelo estatístico}

Considera-se que existe discriminação contra a mãode-obra feminina se homens e mulheres, apesar de igualmente qualificados, são remunerados de forma desigual por serem 
diferenciados com base em um atributo não produtivo - o seu sexo.

Desta forma, a primeira dificuldade com que se depara o pesquisador interessado em quantificar diferenças de rendimento de cunho discriminatório está na identificação de características mensuráveis, que reflitam a produtividade da mão-de-obra, e sejam exógenas ao processo em questão.

A identificação dos atributos associados à produtividade da mão-de-obra é tarefa complexa, ${ }^{32}$ ainda mais levando-se em conta as limitações de uma análise realizada através de dados secundários. Contudo, não menos controvertida é a definição dos atributos exógenos à discriminação. ${ }^{33}$

No tocante aos atributos selecionados, as pesquisas de natureza empírica voltadas ao estudo das discrepâncias entre as médias salariais de homens e mulheres podem ser, a grosso modo, agrupadas em duas categorias. A primeira, que abrange os trabalhos que enfocam a discriminação através do paradigma do capital humano, enfatiza a influência das diferenças de escolaridade e experiência. A segunda, por

32 O debate entre a escola credencialista e a do capital humano sobre a influência da escolaridade na produtividade dos trabalhadores é um exemplo objetivo desta questão.

33 Neste sentido, características usualmente percebidas como associadas à produtividade, tais como a escolaridade e a experiência, não são, necessariamente, exógenas ao processo de discriminação. Se, por exemplo, a educação é considerada menos importante para pessoas do sexo feminino, o processo de socialização pode discriminar as jovens, resultando em sua menor escolaridade. Do mesmo modo, se é correta a máxima feminista de que na conjuntura recessiva as mulheres são as primeiras a ser demitidas, e, na recuperação, as últimas admitidas, a 'experiência' não deve ser considerada exógena. Contudo, as evidências empíricas recentes disponíveis para - Brasil, ao relatar maior nível de escolaridade das mulheres e crescimento acentuado de sua participação no mercado de trabalho nas conjunturas recessivas, não sugerem a endogeneidade dessas características. 
sua vez, embasada nos modelos de segmentação do mercado de trabalho, privilegia a vigência de barreiras ocupacionais nesse mercado, enfatizando $\circ$ papel das diferenças observadas na estrutura ocupacional masculina e feminina nos diferenciais médios de salário entre os sexos.

É preciso ficar claro que usualmente os pesquisadores dessas duas vertentes teóricas reconhecem a existência dos dois tipos de influência sobre os rendimentos. Neste sentido, aficcionados à teoria do capital humano, tais como Oaxaca (1973b), Blinder (1973), Makiel \& Makiel (1973), Suter \& Miller (1973), Featherman \& Hauser (1976), ajustaram equações de rendimento que incluem como variável independente a categoria ocupacional. Por outro lado, dentre os que privilegiam a questão das barreiras ocupacionais também podem ser observados aqueles que propõem modelos nos quais as diferenças de produtividade entre homens e mulheres são consideradas ( $p$. ex. Sanborn, 1964, Stevenson, 1975 e Blau \& Beller, 1988).

Brown et alii (1980), percebendo a incongruência de se tentar medir a discriminação utilizando uma variável endógena ao processo, criticam os estudos que incluem a dummy para categoria ocupacional nas regressões, alegando, corretamente, que esse procedimento implica em "tratar todas as diferenças na distribuição ocupacional de homens e mulheres como justificadas e ignorar a natureza potencialmente discriminatória dessas diferenças" (p. 5) .

Através do ajuste de equações de rendimento por categoria ocupacional, conjugado à utilização do modelo logito multinomial para estimativa da distribuição ocupacional que vigoraria na ausência de discriminação, propõem método que permite a comparação da importância relativa das discriminações salarial e ocupacional. 
O presente trabalho pretende analisar a evolução da discriminação contra a mão-de-obra feminina, tomando essa metodologia como referencial básico. Contudo, como ela foi elaborada através de modificação dos modelos tradicionais (que não permitem a decomposição da discriminação nos seus componentes salarial e ocupacional), este capitulo toma como ponto de partida aqueles modelos para, subsequientemente, descrever $\circ$ proposto por Brown e colaboradores.

\subsubsection{A decomposição segundo os modelos tradicionais}

Os primeiros trabalhos empíricos no tema procuravam detectar se homens (ou brancos) eram melhor remunerados do que mulheres (ou negros) igualmente produtivas, considerando uma equação de rendimentos na qual os salários $\left(\boldsymbol{w}_{\boldsymbol{j}}\right)$ eram uma função linear de $k$ variáveis associadas à produtividade da mão-de-obra $\left(X_{\boldsymbol{l}}, \boldsymbol{l}=1, \ldots \ldots, \boldsymbol{k}\right)$ e de uma variável dummy para o sexo $(Z, \operatorname{com} Z=1$ para homens e $Z=0$ para mulheres), conforme a seguinte expressão:

$$
w_{j}=\alpha+\gamma Z_{j}+\sum_{l=1}^{k} \beta_{l} X_{b}+u_{j} \quad(j=1, \ldots, N)
$$

ou ainda, na representação matricial,

$$
\mathbf{w}=\mathbf{X} \boldsymbol{\beta}+\boldsymbol{\gamma} \mathbf{z}+\mathbf{u}
$$

onde $\boldsymbol{u}$ é um vetor de erros aleatórios que obedecem às pressuposições estatísticas usuais. 
Percebe-se pelas expressões (7) e (8) que se $\gamma$ for maior do que zero se configura a situação na qual as mulheres são discriminadas. ${ }^{34}$

A observação de que os impactos nos salários provocados por alterações nas variáveis, tais como a escolaridade e a idade, eram menores para as mulheres do que para os homens, ou em outros termos, de que outros coeficientes além do intercepto deveriam também captar informações sobre a discriminação ${ }^{35}$, levou diferentes autores a propor o ajuste das equações por sexo, conforme as expressões (9) e (10), nas quais o sobrescrito $m$ se refere aos homens e of às mulheres.

$$
\mathbf{w}^{m}=\mathbf{X}^{m} \boldsymbol{\beta}^{m}+\mathbf{u}^{m}
$$

e

$$
\mathbf{w}^{f}=\mathbf{X}^{f} \boldsymbol{\beta}^{f}+\mathbf{u}^{f}
$$

cujas estimativas são:

$$
\begin{aligned}
& \hat{\mathbf{w}}^{m}=\mathbf{X}^{m} \mathbf{b}^{m} \\
& \hat{\mathbf{w}}^{f}=\mathbf{X}^{f} \mathbf{b}^{f}
\end{aligned}
$$

34 Com o objetivo específico de analisar a discriminação, esta abordagem é adotada, entre outros, por OAXACA (1973a) e BLOOM \& KILLINGSWORTH (1982). Alguns trabalhos nacionais recentes sobre distribuição de renda têm ajustado equações de rendimento semelhantes. Conferir HOFFMANN (1993, 1994a, 1994b) e CORREA (1996), entre outros.

35 Deve-se notar que os trabalhos que tentam quantificar a discriminação através de variável binária para o sexo ou mesmo para o sexo e composição por sexo da ocupação na qual o indivíduo se insere (como, p. ex., ○ de BLAU \& BELLER, 1988) não conseguem detectar as diferenças de rendimento entre homens e mulheres que decorrem de um crescimento diferenciado por sexo da remuneração a alterações nas variáveis consideradas ( $p$. ex., a escolaridade ou idade). Portanto, os resultados obtidos nesses trabalhos devem subestimar a discriminação contra a mão-de-obra feminina vigente no mercado de trabalho. 
O acento circunflexo indica os valores estimados dos salários dos homens e mulheres. Cabe lembrar que para toda equação de regressão com um intercepto o valor médio da variável estimada é igual ao da média da variável observada, $\left(\bar{w}^{m}\right.$ ou $\left.\bar{w}^{f}\right)$. Além disso, esse valor médio pode ser obtido da equação de regressão quando é utilizado o valor médio de todas as variáveis explanatórias.

Conforme notado por Blinder (1973) e Oaxaca (1973a), a diferença entre a remuneração dos homens e das mulheres, quando a equação de regressão tem um termo constante, pode ser decomposta através da seguinte expressão:

$$
\bar{W}^{m}-\bar{w}^{f}=\left(\overline{\mathbf{x}}^{m}-\overline{\mathbf{x}}^{f}\right) \mathbf{b}^{m}+\overline{\mathbf{x}}^{f}\left(\mathbf{b}^{m}-\mathbf{b}^{f}\right)
$$

na qual, o primeiro termo do segundo membro $(Q)$ é um escalar, produto de dois vetores - o primeiro com dimensões 1 × $(k+1)$ e 0 segundo $(k+1) \times 1$-, e representa a parcela da desigualdade que é explicada pelas diferenças das médias de qualificação da mão-de-obra. 0 segundo termo do segundo membro (D) é também um escalar, resultante do produto de dois vetores, e quantifica o diferencial de remuneração que decorre da discriminação, ou seja, do fato de que as variáveis referentes à qualificação tomadas em seus pontos médios se associam ao rendimento através de coeficientes ${ }^{36}$ que diferem segundo o sexo. Inúmeros trabalhos foram realizados nos anos subsequientes visando detectar a oçorrência de discriminação no mercado de trabalho, principalmente em economias

\footnotetext{
${ }^{36}$ Notar que o intercepto também está incluido no vetor $\mathbf{b}$.
} 
capitalistas desenvolvidas. Apesar das contribuições que trouxeram no sentido de aprimorar a análise da qualificação da mão-de-obra através da construção de indicadores cada vez mais elaborados e que abrangiam um elenco mais completo de variáveis associadas aos rendimentos, no tocante à consideração da categoria ocupacional as análises foram, de modo geral, omissas ou inadequadas.

Neste sentido, ou os modelos desconsideravam as informações sobre a ocupação, ignorando o óbvio relacionamento estabelecido entre esta e o rendimento, ou a incorporavam de forma inadequada, ignorando os aspectos discriminatórios envolvidos nas diferenças da estrutura ocupacional de homens e mulheres.

\subsubsection{A decomposição considerando os componentes intra e interocupacionais}

A metodologia proposta por Brown et alii (1980) permite considerar as diferenças da estrutura ocupacional masculina e feminina sem introduzir na análise o viés decorrente de ignorar a natureza potencialmente discriminatória dessas diferenças, através do artifício de ajustar equações de rendimento por sexo e por categoria ocupacional. ${ }^{37}$

Considerando que o subscrito $i$ se refere à categoria ocupacional, $p_{i}^{m}$ e $p_{i}^{f}$ às proporções de homens e mulheres, respectivamente, em cada ocupação e $\overline{\boldsymbol{w}}_{i}^{m}$ e $\overline{\boldsymbol{w}}_{i}^{f}$ aos rendimentos médios de homens e de mulheres por ocupação, a diferença entre a remuneração média da força de trabalho

37 Esta metodologia é também utilizada por MILLER (1987) e, com algumas diferenças, por BARROS, RAMOS \& SANTOS (1992). 
masculina e feminina pode ser obtida através da seguinte expressão:

$$
\begin{aligned}
\bar{w}^{m}-\bar{w}^{f}= & \sum_{i}\left(p_{i}^{m} \bar{w}_{i}^{m}-p_{i}^{f} \bar{w}_{i}^{f}\right) \\
& =\sum_{i}\left(p_{i}^{m} \overline{\mathbf{x}}_{i}^{m} \mathbf{b}_{i}^{m}-p_{i}^{f} \overline{\mathbf{x}}_{i}^{f} \mathbf{b}_{i}^{f}\right) \\
& =\sum_{i} p_{i}^{f}\left(\overline{\mathbf{x}}_{i}^{m} \mathbf{b}_{i}^{m}-\overline{\mathbf{x}}_{i}^{f} \mathbf{b}_{i}^{f}\right)+\sum_{i} \overline{\mathbf{x}}_{i}^{m} \mathbf{b}_{i}^{m}\left(p_{i}^{m}-p_{i}^{f}\right)
\end{aligned}
$$

$(\mathrm{R})$

(A)

O primeiro termo à direita (R) da expressão apreende $\circ$ quanto das diferenças da média geral dos rendimentos resulta de diferenças na remuneração média por ocupação, e o segundo (A), o quanto decorre de diferenças na composição ocupacional (ou alocação) .

R, por sua vez, pode ser decomposto (adotando o mesmo procedimento que resultou na expressão (13)) na parcela devida à diferença nos coeficientes das equações de rendimento ajustadas para homens e mulheres (RD) e na referente às diferenças de atributos (RE):

$$
\bar{w}^{m}-\bar{w}^{f}=\sum_{i} p_{i}^{f} \overline{\mathbf{x}}_{i}^{f}\left(\mathbf{b}_{i}^{m}-\mathbf{b}_{i}^{f}\right)+\sum_{i} p_{i}^{f}\left(\overline{\mathbf{x}}_{i}^{m}-\overline{\mathbf{x}}_{i}^{f}\right) \mathbf{b}_{i}^{m}+\mathrm{A}
$$

(RD)

(RE)

Portanto, a discriminação intraocupacional (RD) é computada verificando o quanto cresceria o rendimento médio das mulheres se, dada sua distribuição ocupacional, as suas características passassem a ser remuneradas segundo parâmetros das equações de rendimento ajustadas para os homens. Numa analogia com o proposto em estudos sobre a distribuição de renda, esse componente (RD) passa a ser 
diferenças de remuneração explicada pelas diferenças de atributos (RE) é, por sua vez, denominada "efeito-renda explicado".

Por fim, o diferencial de remuneração decorrente das diferenças de composição ocupacional (A) também pode ser decomposto em dois termos: o primeiro (AE), que reflete as diferenças na estrutura ocupacional devidas à qualificação, e o segundo (AD), que indica a presença de diferenças na composição ocupacional que não se justificam pelos atributos produtivos da mão-de-obra, ou, em outros termos, indica as diferenças discriminatórias na estrutura ocupacional:

$$
\begin{gathered}
\bar{w}^{m}-\bar{w}^{f}=\sum_{i} p_{i}^{f} \overline{\mathbf{x}}_{i}^{f}\left(\mathbf{b}_{i}^{m}-\mathbf{b}_{i}^{f}\right)+\sum_{i} p_{i}^{f}\left(\overline{\mathbf{x}}_{i}^{m}-\overline{\mathbf{x}}_{i}^{f}\right) \mathbf{b}_{i}^{m}+ \\
(\mathrm{RD}) \\
+\sum_{i} \bar{w}_{i}^{m}\left(p_{i}^{m}-p_{i}^{f *}\right)+\sum_{i} \bar{w}_{i}^{m}\left(p_{i}^{f^{*}}-p_{i}^{f}\right)
\end{gathered}
$$

$(\mathrm{AE}) \quad(\mathrm{AD})$

onde $p_{i}^{f^{*}}$ é a proporção de mulheres que estariam na ocupação $i$ se os critérios de contratação fossem iguais aos utilizados para os homens. O primeiro componente (AE) é denominado "efeito-alocação explicado" e o segundo (AD) "efeito-alocação não-explicado".

Assim, percebe-se que RE e AE captam, respectivamente, diferenciais justificáveis, pelos critérios de qualificação, de remuneração por ocupação e de composição ocupacional, enquanto que $\mathrm{RD}$ e $\mathrm{AD}$ captam as 
diferenças de remuneração que resultam da discriminação intra-ocupacional e ocupacional, respectivamente. ${ }^{38}$

Para quantificar a discriminação ocupacional é necessário obter a estrutura ocupacional que vigoraria no mercado de trabalho se os critérios de contratação fossem os mesmos para os dois sexos (ou seja, obter os $p_{i}^{s^{*}}$ ). Isto porque, só assim é possível isolar, na lógica da construção do modelo, as diferenças da estrutura ocupacional decorrentes de eventuais diferenças de qualificação das que resultam da discriminação propriamente dita. ${ }^{39}$

Brown et alii (1980), considerando que a ocupação de um indivíduo depende do interesse do empregador em contratá-lo e do seu próprio interesse em trabalhar em tal ocupação, especificam um modelo no qual a probabilidade do

38 Pode-se perceber que na expressão $\mathrm{AD}$, as diferenças injustificáveis na estrutura ocupacional estão multiplicadas por $\bar{w}_{i}^{m}$ e não por $\bar{w}_{i}^{f}$. Desta forma, enquanto RD indica, conforme o desejado, quanto cresceria $\circ$ rendimento das mulheres se, dada sua composição ocupacional, seus atributos produtivos passassem a ser remunerados de forma não discriminatória, AD quantifica o quanto cresceriam os seus rendimentos se elas já ganhassem o mesmo que os homens por ocupação (independentemente das diferenças de qualificação existentes) e fosse eliminada a discriminação ocupacional. Este problema, conhecido como problema do índice, também ocorre no modelo tradicional. A especificação alternativa do modelo de decomposição apenas transfere o problema para a discriminação salarial:

$\overline{\boldsymbol{W}}^{m}-\overline{\boldsymbol{w}}^{f}=\sum_{i} p_{i}^{m} \overline{\mathbf{x}}_{i}^{m}\left(\mathbf{b}_{i}^{m}-\mathbf{b}_{i}^{f}\right)+\sum_{i} p_{i}^{m}\left(\overline{\mathbf{x}}_{i}^{m}-\overline{\mathbf{x}}_{i}^{f}\right) \mathbf{b}_{i}^{f}+\sum_{i} \bar{w}_{i}^{f}\left(p_{i}^{m}-p_{i}^{f *}\right)+\sum_{i} \bar{w}_{i}^{f}\left(p_{i}^{f^{*}}-p_{i}^{f}\right)$

$\left(\mathrm{RD}^{*}\right)$

$\left(\mathrm{RE}^{*}\right)$

$\left(\mathrm{AE}^{*}\right)$

$\left(\mathrm{AD}^{*}\right)$

Agora $A D^{*}$ capta, conforme esperado, $\circ$ quanto cresceriam os rendimentos femininos se a contratação das mulheres por ocupação fosse isenta de discriminação, mas $\mathrm{RD}^{*}$ obtém $\circ$ efeito do diferencial de parâmetros, considerando a estrutura ocupacional e a qualificação dos homens.

${ }^{39}$ BARROS, RAMOS \& SANTOS (1992)não efetuam esta última decomposição, optando por considerar todas as diferenças na estrutura ocupacional dos dois sexos como discriminatórias. 
indivíduo $j$ conseguir a ocupação $i$, indicada por $p_{i j}$ é função de um conjunto de variáveis $\left(\boldsymbol{v}_{j}\right)$ que afetam as decisões de demanda e oferta.

Desta forma,

$$
p_{i j}=f\left(\mathbf{v}_{j}\right)
$$

onde $v_{j}$ é um vetor de características para o indivíduo $j$.

o modelo logito multinomial, desenvolvido por Nerlove \& Press (1973) permite calcular essas probabilidades através da estimativa da seguinte equação: ${ }^{40}$

$$
\begin{aligned}
p_{i j}=\frac{e^{\gamma_{i}^{\prime} \mathbf{v}_{j}}}{\sum_{k=1}^{n} e_{k}^{\gamma_{k} \mathbf{v}_{j}}} \quad, \text { para } \quad i=1, \ldots, n \\
j=1, \ldots, N
\end{aligned}
$$

na qual $j$ se refere à j-ésima observação, $N$ é o número de pessoas, $\gamma_{i}$ é o vetor de coeficientes que corresponde à ocupação $\boldsymbol{i}$ e $\boldsymbol{n}$ o número de ocupações.

A função de máxima verossimilhança que corresponde à equação (20) é a seguinte:

$$
L=\prod_{J=1}^{N} \prod_{i=1}^{n}\left(p_{i j}\right)^{z_{i j}}
$$

onde $z_{i j}=1$ se a $j$-ésima pessoa está na ocupação $i$ e $z_{i j}=0$ em caso contrário.

Para resolver o problema de indeterminação do modelo procede-se, conforme sugerem schmidt \& Strauss 
(1975), à normalização que assume $\gamma_{1}=0$. As probabilidades são, então, obtidas através das seguintes equações:

$$
\begin{aligned}
& p_{i j}=\frac{e^{\gamma} \mathbf{\gamma}_{i}^{\prime} \mathbf{v}_{j}}{1+\sum_{k=2}^{n} e^{\gamma_{k} \mathbf{v}_{j}}} \quad, \text { para } i=2, \ldots, n \\
& p_{1 j}=\frac{1}{1+\sum_{k=2}^{n} e^{\gamma_{k}^{\prime} \mathbf{v}_{j}}}
\end{aligned}
$$

O procedimento utilizado para a obtenção dos $p_{i}^{f^{*}}$ envolve as seguintes etapas:

1우) Os parâmetros do sistema de equações (22) são obtidos, considerando-se a categorização proposta para as ocupações, com os dados referentes à parcela masculina da amostra.

2ㅇ) Os dados referentes à parcela feminina são substituídos nas equações obtidas gerando, para cada mulher, um vetor de probabilidades de pertencer a cada uma das categorias que compõem a classificação adotada.

3으 As probabilidades geradas para cada categoria são somadas entre as observações para obter os $p_{i}^{f^{*}}$, ou seja, a distribuição ocupacional que as mulheres apresentariam se os critérios de contratação das mulheres fossem iguais aos utilizados para os homens.

\subsubsection{A agregação das ocupações e a seleção das variáveis}

Este tipo de análise apresenta ainda duas questões metodológicas: a primeira, de caráter empírico, liga-se ao procedimento a ser adotado na agregação das ocupações; e a segunda, que envolve um conjunto de aspectos empiricos e teóricos, à seleção das variáveis (e indicadores) a serem utilizadas no modelo. 


\section{a) A agregação das ocupações}

As dificuldades envolvidas na agregação das ocupações decorrem do fato de que a classificação escolhida deve resultar em categorias que contenham observações em número suficiente para evitar problemas de grau de liberdade (portanto, nesse sentido o número de categorias não pode ser grande), mas, por outro lado, deve ser suficientemente detalhada, ou construída de molde a não obscurecer a discriminação ocupacional.

É possível que as dificuldades encontradas por trabalhos empíricos em detectar esse tipo de discriminação em mercados de trabalho claramente segmentados por sexo, deva-se à escolha inadequada do agrupamento das ocupações. ${ }^{41}$ Neste sentido, a categorização do setor urbano em sete grandes grupos fornecida pelo IBGE (classificação em 2 dígitos) e adotada por Barros et alii (1992) é inadequada para se estimar a discriminação ocupacional pela grande diversidade apresentada entre as ocupações que compõem cada categoria no tocante à sua composição por sexo e/ou nível de remuneração.

De maneira geral, os trabalhos desenvolvidos no tema falham em captar a discriminação ocupacional por não

41 BROWN et alii (1980) estratificam a amostra em oito categorias ocupacionais, uma das quais é, por sua vez, subdividida em mais oito grupos. MILLER (1987) utiliza apenas seis categorias (ligadas a administração, profissionais, outras não-manuais, manuais qualificadas, semiqualificadas e não-qualificadas). BARROS et alii (1992) efetuam dois tipos de agregação ocupacional: na primeira as ocupações são subdivididas em sete grupos (técnicas, ligadas à gerência e administração, ligadas ao comércio, ligadas aos transportes, ligadas à produção fabril, ligadas à prestação de serviços, outras); na segunda consideram a estratificação da população segundo sua posição na ocupação e formalização das relações de trabalho (empregadores, servidores públicos, empregados com carteira, empregados sem carteira, trabalhadores conta-própria). Em nenhum desses trabalhos é detectado um montante expressivo de discriminação ocupacional. 
se darem conta de que as ocupações deveriam ser agrupadas com base na remuneração média das pessoas nela inseridas ou na sua composição por sexo. Assim, se as ocupações com maior rendimento médio são predominantemente masculinas ou as ocupações predominantemente femininas têm menor rendimento médio, a discriminação ocupacional poderá ser detectada através do modelo.

No presente trabalho as ocupações estão agrupadas em cinco categorias, conforme sua composição por sexo. 0 percentual de homens que define cada categoria consta da tabela 6 .

Tabela 6. Categorias ocupacionais segundo a composição por sexo das ocupações.

Categoria Ocupacional Percentual de homens na ocupação

\begin{tabular}{ll}
\hline 1 & 0 a $<20$ \\
2 & 20 a $<40$ \\
3 & 40 a $<60$ \\
4 & 60 a $<80$ \\
5 & 80 a 100 \\
\hline
\end{tabular}

Deve-se notar que esse procedimento implica que 0 conjunto de ocupações em cada categoria ocupacional seja redefinido ano a ano. Assim, uma ocupação pode, em um ano qualquer pertencer a uma categoria e, em outro ano, a uma categoria diferente. ${ }^{42}$

42 Poder-se-ia, ao invés disso, manter o elenco de ocupações em cada categoria fixo. Entretanto, dado o crescimento expressivo da parcela feminina da PEA no período considerado, esse procedimento poderia implicar, no caso de feminilização acentuada de determinadas ocupações, na descaracterização da classificação. 
A agregação pelo rendimento médio também foi testada, adotando o seguinte procedimento:

(i) obteve-se para cada ocupação o rendimento médio por hora na ocupação principal dos homens e mulheres nela inseridos;

(ii) as ocupações foram ordenadas pelo rendimento médio obtido;

(iii) esse conjunto ordenado de ocupações foi subdividido segundo estratos de rendimento em cinco categorias. Os limites de rendimento que definem, ano a ano, cada categoria são múltiplos do salário mínimo de agosto de 1980, em moeda corrente, utilizando-se o Índice Nacional de Preços do IBGE (INPC) como deflator. ${ }^{43}$

Entretanto, dada a amplitude limitada de variação dos rendimentos médios das diferentes ocupações, que se concentram em níveis de rendimento médio muito baixo, os limites definidores de cada classe deveriam, necessariamente, ser próximos. Se sua amplitude fosse maior quase todas as pessoas da amostra pertenceriam à mesma classe, inviabilizando o ajuste de equações de rendimento nas demais. Por outro lado, limites que definem como pertencentes ao mesmo estrato apenas as pessoas com renda média da ocupação em que se inserem semelhante, resultam também em ajustes de baixa qualidade para as equações de rendimento, pelos valores dos coeficientes de determinação obtidos. ${ }^{44}$

43 A categorização testada agrupou as ocupações em categorias cujo rendimento médio da ocupação em salários mínimos de agosto de 1980 estava compreendido dentro dos seguintes limites: < $1 ; \geq 1$ a $<1,5$; $\geq 1,5$ a $<2,5 ; \geq 2,5$ a $<5 ; \geq 5$.

44 Os coeficientes de determinação das equações de rendimento ajustadas oscilam ao redor de 10 \% 
Por essas razões, optou-se por apresentar a análise utilizando apenas o agrupamento das ocupações conforme sua composição por sexo.

b) As variáveis selecionadas.

A metodologia adotada exige a definição de dois conjuntos de variáveis: as que "explicam" as diferenças de rendimento entre os indivíduos da amostra e as que "explicam" as diferenças de inserção nas classes ocupacionais consideradas.

b.1. Variáveis utilizadas nas equações de

Para medir a discriminação é necessário computar as diferenças de remuneração dos trabalhadores dos dois sexos, mantendo constantes certas caracteristicas mensuráveis, consideradas determinantes da produtividade da mão-de-obra. Além disso, a obtenção de estimativas não viesadas exige que as variáveis de controle sejam exógenas ao processo de discriminação em análise.

As variáveis selecionadas dependem, logicamente, do modelo teórico que fundamenta o processo de determinação dos salários.

Conforme já mencionamos, uma parcela considerável dos trabalhos neste tema tem se baseado na teoria do capital humano. Segundo essa abordagem, a desigualdade de rendimentos vigente na sociedade reflete a distribuição de atributos pessoais natos, tais como o talento e o tino comercial, ou decisões individuais, tais como a educação formal ou informal e a experiência no mercado de trabalho. 
Dadas as óbvias dificuldades de obter informações adequadas sobre os atributos do primeiro tipo, as pesquisas desenvolvidas nessa linha de interpretação têm, em grande parte, se limitado a considerar como atributos de produtividade a escolaridade e a experiência.

O presente trabalho adota pressuposições diferentes a respeito do processo de formação dos salários. Neste sentido considera que, embora o nível de escolaridade seja uma variável importante no processo de seleção do indivíduo para determinado posto de trabalho (sendo, portanto, uma variável de triagem como alega a escola credencialista), o progresso na carreira e os correlatos ganhos salariais costumam ser frutos de decisões internas das empresas, que se baseiam em planos de carreira pré-estabelecidos, conforme proposto por Doeringer \& Piore (1971).

As especificidades de cada empresa em relação à qualificação, tecnologia e processos de treinamento de mãode-obra, além da expansão do número de postos e funções que respondem à necessidade de normas de controle burocrático das grandes empresas do mundo contemporâneo, fazem com que - mercado de trabalho assuma natureza cada vez mais compartimentalizada. Assim, a tendência a vincular os salários ao nível de produtividade de cada empresa ou setor leva a que o trabalhador, registrado nas grandes empresas ou em setores nos quais mantém canais de representação mais atuantes, obtenha melhor posição na disputa pela distribuição do produto entre o capital e o trabalho.

Portanto, é importante considerar, além da educação e da experiência, variáveis que reflitam a segmentação do mercado de trabalho. Nesta pesquisa, dado o elenco de informações disponíveis na PNAD, optou-se pela inclusão da 
situação do domicílio (urbana e rural) e da posse de carteira de trabalho assinada.

Sabe-se que as diferenças nos rendimentos do trabalho resultam também de diferenças na distribuição prévia da propriedade ou da acumulação de capital físico. ${ }^{45}$ A despeito das limitações e deficiências, admite-se a hipótese de que a posição na ocupação funcione como proxy da acumulação prévia de riqueza.

Por fim, a idade é utilizada como proxy da experiência, captando as diferenças nos rendimentos do trabalho que resultam do aprendizado no próprio trabalho e em outras formas de treinamento (tais como o obtido através de cursos não formais). Esse procedimento, logicamente, apresenta limitações.

A primeira delas, relevante no plano conceitual, liga-se ao fato de que o crescimento da idade pode estar associado ao acúmulo de capital físico. Nestas circunstâncias, a relação direta entre idade e rendimentos é, em parte, o resultado da acumulação de riqueza nas mãos de trabalhadores mais idosos, ao invés de conseqüência da sua maior experiência.

A segunda limitação, mais séria do ponto de vista da estimativa da discriminação, refere-se ao suposto caráter intermitente do trabalho feminino. Se, conforme se alega, este trabalho é mais sujeito a interrupções, um perfil menos inclinado de rendimentos por idade para o sexo feminino pode refletir a menor experiência e não, necessariamente, a ocorrência de discriminação. Além disso, se a intermitência se associa à menor motivação e interesse

45 Deve-se lembrar que nas PNAD os empresários são também considerados trabalhadores e como tais tem os seus rendimentos na ocupação principal declarados como rendimentos do trabalho. 
na carreira, pode levar à redução dos esforços dispendidos na qualificação e, em consequiência, à menor produtividade. Sob este conjunto de suposições, a idade não capta apropriadamente o efeito da maior ou menor experiência no trabalho e os resultados são tendenciosos.

$\mathrm{Na}$ tentativa de contornar esse problema, algumas pesquisas empiricas de âmbito internacional têm se apoiado em bases de dados que informam o tempo de vinculação do indivíduo ao mercado de trabalho (working-time) e aquele no qual ele permanece afastado desse mercado (home-time). ${ }^{46}$

$\mathrm{Na}$ ausência de informações retrospectivas sobre a atividade, e, considerando que o padrão brasileiro de participação feminina por faixa etária, ao contrário do vigente em países desenvolvidos tais como os EUA, Canadá, Alemanha Ocidental, Áustria e Suíça, não indica a ocorrência de afastamento feminino do mercado de trabalho por ocasião da maternidade e educação dos filhos, seguido pelo reingresso posterior dessa força de trabalho no mercado, ${ }^{47}$ optou-se pela inclusão da idade.

Além disso, assumindo-se que $\circ$ progresso do indivíduo na carreira é função de variáveis entre as quais se inclui certamente o tempo de serviço, e lembrando que os anuários RAIS mostram que as mulheres têm salários médios menores do que os homens em quase todos os setores nos quais estão inseridas, a despeito do maior nível de

46 Conferir, por exemplo, MINCER \& POLACHEK (1974), POIACHEK (1979), MILLER (1987), WRIGHT \& ERMISCH (1991) e POLACHEK \& KIM (1994).

47 WAJNMAN \& RIOS-NETO (1994), analisando as taxas específicas de atividade por coortes de nascimento nas PNAD de 1976 a 1990, observam que não há um padrão de saída precoce da força de trabalho associada à gravidez e educação dos filhos e reingresso dessa mãode-obra em fase posterior. Ao invés disso, verificam que 0 crescimento de atividade nas faixas etárias intermediárias observado entre 1976 e 1991 é mero efeito de composição, resultado da elevação do nível das taxas de atividade intercoortes. 
escolaridade e "tempo de casa", julga-se que a exclusão da idade certamente levaria a resultados mais viesados do que os obtidos incluindo essa variável.

Resumindo, o vetor de variáveis explanatórias das diferenças de rendimento é composto pela escolaridade, idade, situação do domicílio, posse de carteira assinada, e posição na ocupação, classificados em categorias conforme descrito no Apêndice A.

b.2. Variáveis utilizadas nos logitos multinomiais estimados.

A escolha desse conjunto de variáveis é dificultada não apenas por limitações inerentes à base de dados utilizada, como também pela inexistência de trabalhos prévios no tema realizados com essa base de dados que apontem para as informações mais relevantes e para as formas de contornar as suas eventuais deficiências. Aliás, pode-se afirmar que mesmo no âmbito internacional o interesse na análise da escolha ocupacional dos indivíduos é relativamente recente, sendo ainda raras as análises empíricas desenvolvidas no tema. ${ }^{48}$

48 BOSKIN (1974) desenvolve modelo objetivando explicar a escolha ocupacional no qual define que a probabilidade de um indivíduo estar numa determinada ocupação é função dos rendimentos que espera auferir ao longo de sua vida, dos custos de treinamento e das perdas de rendimento esperadas devido às taxas de desemprego na ocupação. Para SCHIMIDT \& STRAUSS (1975) a probabilidade de uma pessoa pertencer a uma dada categoria é função do seu sexo, raça, escolaridade e experiência. MILLER (1987) propõe que a escolaridade, experiência, local de nascimento, região de residência e o local de nascimento do pai e da mãe definam a probabilidade de 0 indivíduo estar inserido numa determinada ocupação. BROWN et alii (1980), utilizando dados levantados pelo National Longitudinal Survey dispõem de informações mais abrangentes sobre a atividade pregressa dos indivíduos no mercado de trabalho assim como sobre as que podem ser relevantes na sua escolha de carreira. Adotam como variáveis explanatórias a idade, experiência, o número de crianças no domicílio, o status 
Dadas essas limitações, a opção recai sobre as seguintes variáveis: a escolaridade, a idade, as outras rendas da pessoa e da família, a posição na família, o local de residência, o número de crianças menores de seis anos no domicílio e a posição na ocupação.

A escolha da escolaridade e da idade baseia-se na suposição de que essas variáveis explicam não apenas grande parte das diferenças de remuneração, como também a própria seleção dos indivíduos para determinados postos de trabalho. Se, por exemplo, os homens que estão alocados em ocupações tipicamente masculinas têm maior idade (que, também neste caso é encarada como proxy da experiência), espera-se que, em um processo de seleção não discriminatório, mulheres nas mesmas faixas de idade (além de semelhantes aos homens nas demais caracteristicas) sejam também contratadas para tais postos de trabalho. Da mesma forma, se homens com escolaridade elementar podem ser contratados para determinadas posições, espera-se que, na ausência de discriminação, não se exija das mulheres um nível superior de escolaridade para o ingresso nas mesmas posições.

A inclusão das outras rendas da pessoa ou da familia liga-se à suposição de que esses elementos possam afetar a escolha ocupacional. Por exemplo, pessoas que dispõem de outros rendimentos podem optar por ocupações que ofereçam menores retornos ou retornos mais instáveis, por não dependerem exclusivamente dessa remuneração para a sua subsistência.

ocupacional do pai, a localização da residência (urbano ou rural) aos quinze anos de idade e uma proxy do grau de iniciativa ou de controle sobre as condições externas (um índice construído através de onze variáveis medidas pela escala Rotter). 
A posição do indivíduo na família pode também influenciar a escolha ocupacional. Supõe-se que os chefes de familia procurem se inserir em ocupações que apresentem menor risco e rendimento suficientes para garantir o sustento familiar. Os filhos ou outros parentes podem, por sua vez, optar por ocupações que não ofereçam as mesmas garantias. ${ }^{49}$

A posição na ocupação é encarada como proxy da posse de capital. Se, descontada a influência das demais variáveis, o ingresso de homens em ocupações masculinas não exige que ele esteja na posição de autônomo ou de empregador mas 0 das mulheres sim, tem-se um claro indicativo da existência de discriminação ocupacional no mercado de trabalho.

A inclusão de localização urbano-rural da residência decorre de sua influência no elenco das ocupações com as quais os indivíduos se deparam.

Por fim, o número de crianças menores de seis anos no domicílio é considerado na suposição de que possa também afetar a escolha da carreira. Espera-se que quanto maior esse número, mais importantes se tornem algumas características diretamente ligadas à ocupação na qual se insere $\bigcirc$ individuo, tais como, a estabilidade dos rendimentos que proporciona, a segurança ño emprego, etc. Diferenças de estrutura ocupacional por sexo que decorram do número de crianças são então consideradas discriminatórias. ou seja, práticas de contratação que

49 Deve-se lembrar que os homens casados são classificados como cônjuges pelas PNAD apenas se não-remunerados. Em caso contrário, mesmo que os seus rendimentos sejam menores do que os de sua esposa, são considerados como chefes. Assim, na amostra utilizada estão praticamente ausentes os indivíduos do sexo masculino na posição de cônjuges. 
discriminam a mulher com crianças pequenas são corretamente identificadas pelo modelo, mas não as diferenças de estrutura ocupacional que resultam de uma escolha de carreira diferenciada por sexo em resposta ao número de crianças pequenas, que são erroneamente identificadas no efeito-alocação não-explicado. ${ }^{50}$

As categorias de cada variável nas quais se distribuem os indivíduos estão relacionadas no Apêndice B.

\subsubsection{Algumas limitações da metodologia utilizada}

A metodologia adotada apresenta limitações de três ordens.

A primeira é não dar espaço para diferenças entre a distribuição ocupacional de homens e de mulheres que decorram de uma opção profissional diferenciada por gênero. Conforme alerta Bruschini (1985), o trabalhador não deve ser encarado como uma categoria de análise, mas sim como um ser humano com características biológicas, pessoais, familiares e sociais que orientam e definem sua forma de participação na atividade produtiva. A mulher, mais do que - homem, tem sua participação no trabalho remunerado possibilitada ou constrangida por caracteristicas, tais como, a idade, o estado civil, o número de filhos, o ciclo de vida e a localização rural ou urbana.

Se, em decorrência do próprio processo de socialização, as atividades domésticas e o cuidado dos filhos são considerados responsabilidade feminina, as mulheres podem não apenas adotar um padrão de trabalho remunerado marcado pela intermitência, que registra o

\footnotetext{
${ }^{50}$ BROWN et alii (1980) estimam também equações logitos excluindo essa variável. Verificam que essa exclusão não altera significativamente os resultados.
} 
frágil equilíbrio entre suas atividades produtivas e funções reprodutivas, como também optar por carreiras "adequadas ao seu sexo" e por posiçôes no mercado de trabalho que lhes possibilitem, através da flexibilidade de horário ou redução da jornada de trabalho, conciliar a atividade doméstica com a remunerada. Em decorrência, o impacto da posição na familia, do número de filhos, da idade, etc. na opção profissional podem ser diferentes para homens e mulheres. Essas diferenças não são corretamente identificadas pelo modelo adotado, e o impacto da socialização fica no efeito-alocação não-explicado.

Além disso, se existirem ainda diferenças entre os sexos no tocante à escolha ocupacional ou à qualificação profissional provocadas por variáveis relevantes não consideradas no modelo, as estimativas da discriminação obtidas podem ser tendenciosas.

Por fim, a metodologia adotada procura decompor as diferenças entre os rendimentos de homens e mulheres nas parcelas de interesse, tomando como referência os rendimentos observados.

Blau \& Beller (1988), Reimers (1983) e wright \& Ermisch(1991), entre outros, adotando metodologia sugerida por Heckman (1974) alegam que quando se está interessado em quantificar a discriminação, o enfoque deve ser nos salários ofertados e não nos observados. Desde que os últimos são influenciados pelas decisões dos indivíduos em participar ou não do mercado de trabalho, análises baseadas nos salários observados podem se constituir em estimativas viesadas da média dos salários oferecidos para individuos que apresentam determinadas caracteristicas, assim como dos coeficientes das equações de rendimento. O viés pode ser positivo ou negativo. Se a inserção do individuo no mercado de trabalho é seletiva a favor daqueles com salários oferecidos mais elevados, o viés será positivo, isto é, a 
média dos salários observados será maior do que a média dos salários oferecidos. Por outro lado, se a inclusão é seletiva a favor dos que têm menores salários oferecidos, o viés será negativo. Se os dois grupos diferem na direção ou magnitude desses vieses de seletividade, as estimativas dos diferenciais entre os grupos baseadas nos salários observados serão viesadas. ${ }^{51}$

A técnica sugerida por Heckman para a obtenção de estimativas consistentes dos coeficientes e desvios-padrões da função de salários oferecidos consiste na utilização do seguinte procedimento: numa primeira etapa estima-se um probito objetivando explicar a participação do indivíduo no mercado de trabalho através de um conjunto $Z_{i}$ de variáveis consideradas explicativas; os parâmetros assim obtidos são, numa segunda etapa, utilizados para se estimar o inverso da razão de Mills $\left(\boldsymbol{\lambda}_{i}\right)$; por fim $\hat{\lambda}_{i}$ é incluído como um regressor adicional na equação de salários que é então ajustada através de mínimos quadrados ordinários.

No presente trabalho não se adota o procedimento sugerido por Heckman. Portanto, qualquer tipo de inferência a respeito dos rendimentos oferecidos foge ao escopo desta pesquisa.

51 KASSOUF (1994), utilizando dados levantados pelo IBGE através da Pesquisa Nacional de Saúde e Nutrição (PNSN), compara o procedimento tradicional de estimação de salários com o de Heckman, verificando uma tendenciosidade positiva nos parâmetros estimados através do método tradicional para a amostra dos trabalhadores do sexo masculino e negativa para a dos trabalhadores do sexo feminino. BLAU \& BELLER (1988), objetivando analisar os diferenciais de rendimento por sexo e raça nos EUA, ajustam equações de rendimento utilizando esses dois procedimentos e chegam a conclusões semelhantes quanto ao sinal do viés segundo os sexos. WRIGTH \& ERMISH (1991), utilizando dados da Inglaterra, verificam também a existência de tendenciosidade negativa para as trabalhadoras. 


\section{A EVOLUÇÃo DA SEGREGAÇÃo}

Uma característica marcante do mercado de trabalho nas sociedades capitalistas contemporâneas é a segregação de homens e mulheres em diferentes ocupações. As diferenças de estrutura ocupacional por sexo e seus reflexos nos rendimentos têm sido documentadas em uma série de trabalhos empiricos. De modo geral, as pesquisas voltadas à análise das questões de gênero no mercado de trabalho brasileiro têm mostrado que nossas trabalhadoras estão alocadas em um leque reduzido de ocupações, concentradas no que se considera "trabalhos femininos". 52

Este capítulo analisa a evolução da segregação ocupacional por gênero nos estados de são Paulo e Pernambuco e procura verificar se, nesses estados, as ocupações femininas são apenas distintas das masculinas ou se, ao invés disso, são piores do que elas no tocante aos rendimentos que proporcionam.

52 A análise dos Censos Demográficos de 1970 e de 1980 permitiu a BRUSCHINI (1985), por exemplo, verificar que se em 1970 seis tipos de ocupações, quais sejam, as de empregadas domésticas, trabalhadoras da agropecuária, professoras e auxiliares, secretárias, operárias da indústria do vestuário e balconistas ou lojistas, compreendem 74,28 da PEA feminina, dez anos mais tarde, 65,58 da PEA feminina ainda se encontra alocada nessas mesmas ocupações. 


\subsection{Principais ocupações na absorção da mão-de-obra}

As tabelas 7 e 8 relatam, para os estados de são Paulo e Pernambuco respectivamente, as ocupações que em 1981 absorvem 60\% da mão-de-obra feminina nesses estados, a distribuição percentual das trabalhadoras por essas ocupações nos anos de 1981 e 1990, e a proporção de mulheres em cada uma delas nesses mesmos anos. Essas ocupações estão em ordem decrescente de importância na absorção da mão-de-obra, tomando-se 1981 como referência.

Lembrando que $F, M$ e $T$ indicam respectivamente, o número total de mulheres, de homens e de pessoas ocupadas, e que $F_{i}, M_{i}$ e $T_{i}$ indicam, respectivamente, o número de mulheres, de homens e de pessoas na ocupação $i$, o percentual de trabalhadoras que se insere nas ocupações relacionadas é indicado por $\frac{F_{i}}{F}$ e a proporção de mulheres que compõe cada ocupação é indicada por $\frac{F_{i}}{T_{i}}$.

Adotando-se 0 mesmo procedimento obtém-se as tabelas 9 e 10, que relatam a distribuição dos trabalhadores paulistas e pernambucanos, respectivamente, nas principais ocupações $\left(\frac{M_{i}}{M}\right)$, além da proporção de homens em cada uma delas $\left(\frac{\boldsymbol{M}_{i}}{T_{i}}\right)$ 
Tabela 7. Distribuição percentual da PEA feminina(1) em algumas ocupações e composição por sexo das mesmas. São Paulo, 1981 e 1990.

\begin{tabular}{|c|c|c|c|c|}
\hline \multirow[b]{2}{*}{ OCUPAÇÕES } & \multicolumn{2}{|c|}{1981} & \multicolumn{2}{|c|}{1990} \\
\hline & $\frac{F_{i}}{F}$ & $\frac{F_{i}}{T_{i}}$ & $\frac{F_{i}}{F}$ & $\frac{F_{i}}{T_{i}}$ \\
\hline empregada doméstica & 19,47 & 94,88 & 14,68 & 92,23 \\
\hline auxiliar de escritório & 9,29 & 45,42 & 7,67 & 52,12 \\
\hline costureira & 8,41 & 92,87 & 7,33 & 93,17 \\
\hline outras trab. na agropecuária & 4,72 & 21,55 & 3,00 & 23,42 \\
\hline secretária & 4,46 & 95,93 & 2,84 & 96,43 \\
\hline vendedora & 4,44 & 36,36 & 5,28 & 43,47 \\
\hline lavadeira, passadeira & 2,76 & 95,61 & 2,05 & 91,76 \\
\hline prof. $1^{\mathrm{a}}$ a $4^{\mathrm{a}}$ série & 2,28 & 96,07 & 2,57 & 99,25 \\
\hline enfermeira não diplomada & 1,99 & 79,82 & 2,53 & 87,72 \\
\hline embaladora de mercadorias & 1,90 & 58,33 & 1,87 & 52,26 \\
\hline cozinheira & 1,87 & 70,36 & 2,73 & 75,16 \\
\hline TOTAL NESSAS OCUPAÇÕES & 61,58 & & 52,55 & \\
\hline
\end{tabular}

(1) Inclui apenas as pessoas para as quais os atributos de interesse estão claramente identificados.

Tabela 8. Distribuição percentual da PEA feminina(1) em algumas ocupações e composição por sexo das mesmas. Pernambuco, 1981 e 1990.

\begin{tabular}{|c|c|c|c|c|}
\hline \multirow[b]{2}{*}{ OCUPAÇÕES } & \multicolumn{2}{|c|}{1981} & \multicolumn{2}{|c|}{1990} \\
\hline & $\frac{F_{i}}{F}$ & $\frac{F_{1}}{T_{t}}$ & $\frac{F_{i}}{F}$ & $\frac{F_{1}}{T_{i}}$ \\
\hline outras trab. na agropecuária & 13,56 & 18,10 & 4,30 & 10,97 \\
\hline empregada doméstica & 12,74 & 90,81 & 15,89 & 93,16 \\
\hline costureira & 10,93 & 99,39 & 10,58 & 96,44 \\
\hline lavadeira, passadeira & 6,21 & 99,64 & 5,75 & 98,06 \\
\hline prof. $1^{\mathrm{a}}$ a $4^{\mathrm{a}}$ série & 5,48 & 98,69 & 7,38 & 98,06 \\
\hline produtor agropecuário autônomo & 4,71 & 12,32 & 2,46 & 11,79 \\
\hline auxiliar de escritório & 4,37 & 43,97 & 3,08 & 47,41 \\
\hline vendedora & 3,78 & 37,37 & 3,57 & 34,00 \\
\hline TOTAL NESSAS OCUPAÇÕES & 61,78 & & 53,01 & \\
\hline
\end{tabular}

(1) Inclui apenas as pessoas para as quais os atributos de interesse estão claramente identificados. 
Tabela 9. Distribuição percentual da PEA ocupada masculina(1) em algumas ocupações e composição por sexo das mesmas. São Paulo, 1981 e 1990.

\begin{tabular}{|c|c|c|c|c|}
\hline \multirow[b]{2}{*}{ OCUPAÇÕES } & \multicolumn{2}{|c|}{1981} & \multicolumn{2}{|c|}{1990} \\
\hline & $\frac{M_{1}}{M}$ & $\frac{M_{i}}{T_{i}}$ & $\frac{M_{i}}{M}$ & $\frac{M_{i}}{T_{i}}$ \\
\hline outros trab. na agropecuária & 8,08 & 78,45 & 5,65 & 76,58 \\
\hline motorista & 6,22 & 99,77 & 7,49 & 99,31 \\
\hline pedreiro & 5,31 & 99,86 & 5,58 & 99,80 \\
\hline auxiliar de escritório & 5,25 & 54,58 & 4,07 & 47,89 \\
\hline vendedor & 3,65 & 63,64 & 3,96 & 56,53 \\
\hline servente de pedreiro & 2,75 & 100,00 & 2,42 & 98,99 \\
\hline produtor agropecuário autônomo & 2,54 & 95,66 & 1,67 & 93,81 \\
\hline comerciante conta-própria & 2,47 & 78,70 & 2,63 & 64,20 \\
\hline comerciante & 2,26 & 86,49 & 2,58 & 77,46 \\
\hline encarregado administrativo & 2,23 & 81,38 & 2,32 & 72,29 \\
\hline mecânico & 1,84 & 100,00 & 1,82 & 100,00 \\
\hline mecânico de veículo & 1,76 & 100,00 & 2,44 & 100,00 \\
\hline torneiro mecânico & 1,36 & 98,96 & 1,20 & 98,88 \\
\hline marceneiro & 1,35 & 95,89 & 1,05 & 89,69 \\
\hline administrador ind. de transformação & 1,19 & 89,26 & 1,23 & 84,17 \\
\hline pintor/caiador & 1,19 & 100,00 & 0,88 & 98,48 \\
\hline empresário ind. transformação & 1,19 & 88,22 & 1,55 & 77,80 \\
\hline carpinteiro & 1,14 & 98,75 & 0,77 & 98,27 . \\
\hline ambulante & 1,09 & 57,789 & 0,98 & 43,98 \\
\hline outros proprietários & 1,01 & 92,71 & 1,32 & 80,23 \\
\hline repositor de equipamentos & 1,00 & 100,00 & 0,90 & 100,00 \\
\hline soldador & 0,98 & 95,79 & 0,84 & 95,35 \\
\hline pracista/ viajante & 0,95 & 91,69 & 1,07 & 81,29 \\
\hline ajustador/montador & 0,90 & 83,95 & 0,88 & 89,46 \\
\hline almoxarife & 0,83 & 95,05 & 0,91 & 92,21 \\
\hline inspetor/qualidade & 0,82 & 80,80 & 0,87 & 71,86 \\
\hline administrador comércio de mercadorias & 0,75 & 83,18 & 0,83 & 65,76 \\
\hline TOTAL NESSAS OCUPAÇÕES & 60,09 & & 57,91 & \\
\hline
\end{tabular}


Tabela 10. Distribuição percentual da PEA ocupada masculina(1) en algumas ocupações e composição por sexo das mesmas. Pernambuco, 1981 e 1990.

\begin{tabular}{|c|c|c|c|c|}
\hline \multirow[b]{2}{*}{ OCUPAÇÕES } & \multicolumn{2}{|c|}{1981} & \multicolumn{2}{|c|}{1990} \\
\hline & $\frac{M_{t}}{M}$ & $\frac{M_{1}}{T_{i}}$ & $\frac{M_{L}}{M}$ & $\frac{M_{i}}{T_{i}}$ \\
\hline outros trab. na agropecuária & 25,36 & 81,90 & 19,05 & 89,03 \\
\hline produtor agropecuário autônomo & 13,86 & 87,68 & 10,05 & 88,21 \\
\hline pedreiro & 4,81 & 100,00 & 3,76 & 98,83 \\
\hline motorista & 4,65 & 99,80 & 4,93 & 100,00 \\
\hline servente de pedreiro & 4,24 & 99,78 & 4,25 & 99,59 \\
\hline comerciante conta-própria & 3,79 & 70,95 & 5,56 & 63,82 \\
\hline vendedor & 2,62 & 62,63 & 3,78 & 66,00 \\
\hline auxiliar de escritório & 2,30 & 56,03 & 1,86 & 52,60 \\
\hline TOTAL NESSAS OCUPAÇÕES & 61,62 & & 53,24 & \\
\hline
\end{tabular}

(1) Inclui apenas as pessoas para as quais os atributos de interesse estão claramente identificados.

A maior complexidade da estrutura produtiva paulista espelha-se, consistentemente, num elenco mais diversificado de ocupações. ${ }^{53}$ Entretanto, tais ocupações não são preenchidas por homens ou mulheres indiferentemente. As trabalhadoras paulistas, assim como as pernambucanas, concentram-se em ocupações de baixo prestígio, que em grande parte dos casos representam uma mera extensão de suas atividades domésticas à esfera do mercado. Cerca de 60\% das trabalhadoras de São Paulo e de Pernambuco distribuem-se, em 1981, por onze e oito ocupações, respectivamente, dentre as quais destacam-se os tradicionais guetos femininos constituídos pelas empregadas domésticas, costureiras, lavadeiras e passadeiras, cozinheiras e professoras de $1^{\text {a }}$ a $4^{\text {a }}$ série. Dez anos mais

53 Logicamente essa maior complexidade reflete, em parte, o menor peso do emprego agrícola em São Paulo. Se a comparação da estrutura do emprego nos dois estados se referisse ao emprego urbano as diferenças seriam, provavelmente, menores. 
tarde, aquelas mesmas ocupações absorvem 53\% das trabalhadoras nos dois estados, 0 que aponta para 0 processo de diversificação da estrutura ocupacional no período. ${ }^{54}$

Os paulistas, por sua vez, apresentam uma estrutura ocupacional mais diversificada. Em 1981 são necessárias vinte e sete ocupações, também selecionadas pela sua importância em termos de absorção da mão-de-obra, para abarcar ao redor de $60 \%$ dos trabalhadores do sexo masculino. Destas, apenas quatro integram um contingente apreciável de mulheres, quais sejam, as de auxiliar de escritório, vendedores, ambulantes e trabalhadores da agropecuária. Em 1990, nas vinte e sete ocupações mencionadas estão alocados 57\% dos trabalhadores paulistas, indicando uma maior estabilidade da estrutura ocupacional masculina vis a vis à feminina nesse estado.

Já os pernambucanos estão distribuidos em um elenco mais restrito de ocupações, que apontam para o grande contingente de pessoas com baixo poder aquisitivo e para 0 próprio subdesenvolvimento da região. Oito ocupações abrangem, em 1981, 61,62\% dos trabalhadores desse estado. É interessante notar que as ocupações essencialmente masculinas mais importantes, quais sejam, as de pedreiro, servente de pedreiro e motorista, são também de baixo prestígio e remuneração. Desta forma, diferentemente do que ocorre com os trabalhadores de São Paulo, grande parte da mão-de-obra masculina do estado de Pernambuco não dispõe de oportunidades profissionais muito mais atraentes do que a feminina.

54 Em 1990, 60\% das trabalhadoras paulistas e pernambucanas se inserem em quinze e dez ocupações respectivamente, indicando que o número necessário à absorção desse percentual de mulheres cresce, entre o início e o final do período, 368 em São Paulo e $25 \%$ em Pernambuco. 
As diferenças de estrutura ocupacional por gênero sugeridas por esses dados podem ser analisadas de maneira mais abrangente considerando-se a distribuição ocupacional dos indivíduos em categorias ocupacionais que refletem o grau de feminilidade (ou masculinidade) das ocupações, conforme descrito a seguir.

\subsection{Inserção ocupacional diferenciada por gênero}

Se homens e mulheres fossem dotados do mesmo conjunto de preferências e possibilidades de escolha profissional, a distribuição dos sexos entre as ocupações deveria ser semelhante, com pequenas diferenças aleatórias. Em outros termos, a proporção esperada de postos de trabalho em cada categoria ocupacional preenchidos por homens (ou mulheres) deveria ser similar à sua proporção na força-de-trabalho.

Neste trabalho, como em outras pesquisas do gênero, considera-se que uma ocupação é integrada quando o percentual de homens que a compõe é semelhante à participação masculina na PEA. Assim, a ocupação $i$ é identificada como integrada quando $\frac{M}{T}-0,05 \leq \frac{M_{i}}{T_{i}} \leq \frac{M}{T}+0,05$. Se $\frac{M_{i}}{T_{i}}>\frac{M}{T}+0,05$, a ocupação é classificada como masculina. Finalmente, quando $\frac{M_{i}}{T_{i}}<\frac{M}{T}-0,05$, a ocupação é considerada feminina. A escolha desses limites é arbitrária. ${ }^{55}$ 
Tabela 11. Distribuição das ocupações segundo a composição por sexo. São Paulo e Pernambuco, 1981 a 1990.

\begin{tabular}{|c|c|c|c|c|c|c|}
\hline \multirow[b]{2}{*}{ ANO } & \multicolumn{3}{|c|}{ OCUPAÇÕES EM SÃO PAULO } & \multicolumn{3}{|c|}{ OCUPACÕES EM PERNAMBUCO } \\
\hline & $\begin{array}{c}\text { INTEGRADAS } \\
\text { № (\%) }\end{array}$ & $\begin{array}{c}\text { MASCULINAS } \\
\text { № }(\%)\end{array}$ & $\begin{array}{c}\text { FEMININAS } \\
\text { № }(\%) \\
\end{array}$ & $\begin{array}{c}\text { INTEGRADAS } \\
\text { № }(\%) \\
\end{array}$ & $\begin{array}{c}\text { MASCULINAS } \\
\text { № (\%) }\end{array}$ & $\begin{array}{l}\text { FEMININAS } \\
\text { № (\%) }\end{array}$ \\
\hline 1981 & $21(7,2)$ & $192(65,5)$ & $80(27,3)$ & $12(4,5)$ & $167(63,0)$ & $86(32,5)$ \\
\hline 1983 & $20(6,8)$ & $195(66,3)$ & $79(26,9)$ & $15(5,6)$ & $169(62,8)$ & $85(31,6)$ \\
\hline 1984 & $17(5,7)$ & $201(67,9)$ & $78(26,4)$ & $22(8,1)$ & $170(63,0)$ & $78(28,9)$ \\
\hline 1985 & $20(6,8)$ & $199(68,2)$ & $73(25$, & $12(4,6)$ & $168(63,9)$ & $83(31,6)$ \\
\hline 987 & $24(8,6)$ & $171(61,5)$ & $83(29,9)$ & $15(6,2)$ & $152(62,6)$ & $76(31,3)$ \\
\hline 988 & $16(5,7)$ & $177(62,8)$ & $89(31$ & $11(4,7)$ & $144(61,5)$ & $79(33,8)$ \\
\hline 1989 & $12(4,2)$ & $183(64,0)$ & $91(31,8)$ & $13(5,4)$ & $156(64,5)$ & $73(30,2)$ \\
\hline 1990 & $22(7,6)$ & $185(64,0)$ & $82(28,4)$ & $11(4,5)$ & $148(61,2)$ & $83(34,3)$ \\
\hline
\end{tabular}

Tabela 12. Distribuição percentual de homens e mulheres nas ocupações integradas, masculinas e femininas. São Paulo e Pernambuco, 1981 a 1990.

\begin{tabular}{|c|c|c|c|c|c|c|}
\hline \multirow[b]{2}{*}{ ESTADO/ ANO } & \multicolumn{3}{|c|}{ HOMENS EM OCUPAÇÕES } & \multicolumn{3}{|c|}{ MULHERES EM OCUPAÇÕES } \\
\hline & MASCULINAS & INTEGRADAS & FEMININAS & MASCULINAS & INTEGRADAS & FEMININAS \\
\hline \multicolumn{7}{|l|}{ SÃO PAULO } \\
\hline 1981 & 79,86 & 6,30 & 13,84 & 16,45 & 7,13 & 76,42 \\
\hline 1983 & 78,85 & 6,91 & 14,24 & 15,88 & 6,88 & 77,24 \\
\hline 1984 & 79,54 & 3,51 & 16,95 & 15,45 & 3,53 & 81,02 \\
\hline 1985 & 77,79 & 6,55 & 15,66 & 15,95 & 7,20 & 76,85 \\
\hline 1987 & 76,70 & 8,74 & 14,56 & 16,61 & 9,70 & 73,69 \\
\hline 1988 & 74,78 & 6,65 & 18,57 & 14,31 & 6,36 & 79,33 \\
\hline 1989 & 78,17 & 2,35 & 19,48 & 17,43 & 2,38 & 80,19 \\
\hline 1990 & 74,67 & 7,41 & 17,92 & 15,91 & 7,42 & 76,67 \\
\hline \multicolumn{7}{|l|}{ PERNAMBUCO } \\
\hline 1981 & 80,48 & 9,57 & 9,95 & 21,83 & 9,77 & 68,40 \\
\hline 1983 & 78,49 & 13,55 & 7,96 & 20,39 & 13,35 & 66,26 \\
\hline 1984 & 79,96 & 12,17 & 7,87 & 22,26 & 12,50 & 65,23 \\
\hline 1985 & 80,81 & 9,79 & 9,40 & 22,24 & 10,72 & 67,04 . \\
\hline 1987 & 79,27 & 12,47 & 8,26 & 18,08 & 12,40 & 69,52 \\
\hline 1988 & 79,69 & 10,02 & 10,29 & 18,11 & 10,04 & 71,85 \\
\hline 1989 & 80,35 & 10,65 & 9,00 & 19,94 & 10,69 & 69,38 \\
\hline 1990 & 79,08 & 11,14 & 9,78 & 14,35 & 11,14 & 74,51 \\
\hline
\end{tabular}

As tabelas 11 e 12 evidenciam que a segregação ocupacional é profunda e persistente nos dois estados. A 
grande maioria das ocupações (mais de 60\% delas) é dominada por homens e poucas (entre 4,2\% e $8,6 \%$ delas) podem ser consideradas integradas conforme mostra a tabela 11 . A tabela 12 permite verificar que nesse período, em média, $77,5 \%$ dos trabalhadores paulistas encontram-se em ocupações masculinas, enquanto 77,7\% das trabalhadoras desse mesmo estado estão alocadas em ocupações femininas. Em Pernambuco, por sua vez, $79,8 \%$ dos homens estão em ocupações masculinas e $69,0 \%$ das mulheres nas femininas.

\subsection{A evolução da segregação ocupacional}

A segregação ocupacional indicada por esses dados é quantificada através do índice de Duncan $(D)$ considerandose a classificação ocupacional detalhada pelo IBGE em três dígitos.

Os valores de $D$ obtidos ano a ano para os dois estados encontram-se relacionados na tabela 13.

Tabela 13. Índice de segregação de Duncan. São Paulo e Pernambuco, 1981 a 1990

\begin{tabular}{ccc}
\hline & \multicolumn{2}{c}{ ÍNDICE $\boldsymbol{D}$} \\
\cline { 2 - 3 } ANO & SĀO PAULO & PERNAMBUCO \\
\hline 1981 & 0,6349 & 0,5901 \\
1983 & 0,6326 & 0,5866 \\
1984 & 0,6423 & 0,5801 \\
1985 & 0,6190 & 0,5868 \\
1987 & 0,6027 & 0,6180 \\
1988 & 0,6097 & 0,6171 \\
1989 & 0,6086 & 0,6123 \\
1990 & 0,5902 & 0,6506 \\
\hline
\end{tabular}


Pode-se comprovar que a segregação ocupacional por sexo nesses estados brasileiros é elevada, pois os valores do indice indicam que 58\% a $65 \%$ da força-de-trabalho feminina (ou masculina) deveriam ser realocados para eliminar sua super-representação em determinadas ocupações e sua subrepresentação em outras.

Nota-se, também, que enquanto em São Paulo essa medida cai continuamente (exceto em 1984) ao longo do período analisado, em Pernambuco apresenta valores crescentes, refletindo o aprofundamento do processo de segregação no estado. Como resultado desses movimentos opostos, entre o início e o final do período, $D$ se reduz em São Paulo de 0,635 para 0,590, enquanto se eleva em Pernambuco, de 0,590 para $0,651 .{ }^{56}$

Essas tendências opostas não são de todo inesperadas. Os dados apresentados pela tabela 8 apontam para a perda de espaços significativos na composição do emprego da pernambucana nas ocupações tipicamente masculinas e, concomitantemente, para a maior relevância conquistada pelas ocupações tipicamente femininas. Assim, se em 1981 $18,27 \%$ das pernambucanas ocupadas são trabalhadoras da

56 Deve-se mencionar que esses valores não diferem expressivamente dos relatados em análises empíricas internacionais. Especificamente para a economia norte-americana as pesquisas apontam para um grau de segregação ocupacional notavelmente estável desde a virada do século XX até o início dos anos sessenta, a despeito das grandes mudanças que ocorrem na participação feminina no mercado de trabalho nesse período (GROSS, 1968). O declínio da segregação que se inicia naquela economia nos anos sessenta se acelera nos anos setenta (BELLER, 1982 e FIELDS \& WOLFF, 1991), mas ainda assim em 1980 o valor do índice de Duncan na economia norte-americana é 0,585 (FIELDS \& WOLFF,1991). BARROS et alii (1997), analisando as diferenças da inserção ocupacional por gênero na região metropolitana de São Paulo, com base nas informações da Pesquisa Mensal do Emprego (PME) de 1993, obtiveram valor próximo de 0,40 para o índice $D$. Todavia, essa medida não é comparável às relatadas neste trabalho por ter sido calculada utilizando as ocupações agrupadas en 19 categorias, ao invés de detalhadas segundo a classificação em três dígitos do IBGE. 
agropecuária ou produtoras agropecuárias autônomas, ocupações nas quais os homens têm participação expressiva, em 1990 essas duas categorias absorvem apenas 6,76\% das trabalhadoras desse estado. Por outro lado, as ocupações de empregada doméstica e de professora de $1^{\underline{a}}$ a 4$^{a}$ série, tradicionais guetos ocupacionais da mão-de-obra feminina, ampliam sua participação no emprego de 18,22\% em 1981 para $23,27 \%$ em 1990.57

Já em São Paulo destaca-se, numa estrutura ocupacional bem mais estável, a diminuição da importância do emprego doméstico, que absorve 19,47\% das mulheres ocupadas em 1981 e apenas 14,68\% em 1990, o que, logicamente, contribui para a redução da segregação observada no período. ${ }^{58}$

Ressalta-se, ainda, que as medidas de segregação obtidas devem estar subestimadas pela impossibilidade de se detectar a segregação vertical, assim como a que decorre da alocação diferenciada por empresa dos homens e mulheres de uma mesma categoria ocupacional. Essas limitações são, via de regra, compartilhadas pelos demais trabalhos realizados na área, de forma que os resultados obtidos podem ser comparados sem maiores problemas. Contudo, devese também ter em mente que a exclusão das empregadas domésticas que moram no emprego do conjunto de dados utilizados pode contribuir para reduzir esses índices. ${ }^{59}$

57 As alterações, no período considerado, da importância relativa na composição do emprego apenas dessas quatro categorias ocupacionais são responsáveis pelo crescimento do valor de $D$ em 0,0419 no estado de Pernambuco.

58 As alterações da importância relativa dessa ocupação são, isoladadamente, responsáveis pela redução do valor de $D$ em 0,0250 nesse estado.

59 A análise da estrutura ocupacional através de um conjunto de dados selecionados da mesma base mas que exclui os autônomos e empregadores (limitando-se, portanto, aos empregados) e inclui as 
Objetivando verificar se as alterações observadas no índice de segregação ao longo dos anos considerados refletem uma tendência estatisticamente definida, descontado o efeito das oscilações no ritmo de atividade econômica, procede-se ao ajuste, por estado, de regressão linear onde a variável dependente é 0 índice $D$ e as explicativas o tempo (t) em anos, em relação a 1980, e as taxas de desocupação $(\boldsymbol{u})$ da PEA no período em questão. Essas taxas foram obtidas nos relatórios anuais das PNAD publicados pelo IBGE e encontram-se na tabela 14 .

Tabela 14. Taxa de desocupação da PEA. São Paulo e Pernambuco, 1981 a 1990.

\begin{tabular}{ccc}
\hline \multirow{2}{*}{ ANO } & \multicolumn{2}{c}{ TAXA DE DESOCUPAÇ̄̃ } \\
\cline { 2 - 3 } 1981 & SÃO PAULO & PERNAMBUCO \\
1983 & 5,48 & 4,57 \\
1984 & 6,33 & 5,17 \\
1985 & 5,58 & 5,03 \\
1987 & 4,59 & 3,37 \\
1988 & 4,49 & 4,51 \\
1989 & 4,14 & 5,22 \\
1990 & 2,97 & 3,62 \\
Fonte: & 4,72 & 3,53 \\
\hline IBGE, & Pesquisas & Nacionais por Amostra de domicílios de 1981 a
\end{tabular}

empregadas domésticas que moram no emprego, além de pessoas que se integram na família como agregados, não chega a resultados muito diferentes. Nessa outra composição, o emprego doméstico passa a absorver, entre 0 início e o final do período, 20,18\% e 16,808 das paulistanas e 18,228 e 22,698 das pernambucanas, respectivamente. 0 cálculo das medidas de segregação através desse novo conjunto de dados permite verificar que, no período em questão, os valores de $D$ caem menos substancialmente em São Paulo (de 0,6045 para 0,5866) enquanto se elevam ainda mais espetacularmente em Pernambuco (de $0,5911$ para 0,6949$)$. As principais ocupações na absorção a força de trabalho masculina e feminina nos dois estados em 1981 e 1990, assim como os valores de $D$ em todos os anos do período considerado encontram-se relacionadas no Apêndice D. 
Espera-se que a diminuição do desemprego faça com que as mulheres passem a ser aceitas em posições nas quais seriam preteridas se a mão-de-obra masculina estivesse disponivel. Caso o mercado de trabalho apresente este comportamento, o coeficiente associado à taxa de desocupação deverá ser positivo.

A equação ajustada (teste $t$ entre parênteses) com os dados referentes à PEA paulista é a seguinte:

$$
\begin{gathered}
D=65,69-0,530 t-0,198 u \\
(26,497)(-4,177)(-0,509)
\end{gathered}
$$

com coeficiente de determinação $R^{2}=0,8679$. Para a PEA pernambucana foi obtida a equação

$$
D=\underset{(13,811)}{56,47}+\underset{(3,295)}{0,631 t}+\underset{(0,125)}{0,784} u
$$

com coeficiente de determinação $R^{2}=0,7234$.

Nas duas regressões o coeficiente associado ao tempo é estatisticamente significativo ao nível de 1\%. 0 sinal desse coeficiente é negativo na equação ajustada com os dados referentes à PEA paulista e positivo na que se refere à PEA pernambucana. Ou seja, no período 1981-1990 existe uma tendência estatisticamente definida de redução da segregação ocupacional por gênero em são Paulo e de aumento dessa segregação em Pernambuco.

Os coeficientes associados à taxa de desocupação são, nas duas regressões, não-significativos. Inclusive, na equação estimada para a PEA paulista o sinal desse coeficiente, contrariando as expectativas, é negativo (o que não ocorre na regressão ajustada para Pernambuco). 0 fato de não ter sido possivel obter uma relação estatisticamente definida entre o desemprego e a segregação 
ocupacional pode sugerir que as transformações na medida da segregação têm caráter mais estrutural do que conjuntural.

\subsection{A decomposição da segregação: efeitos MIX e COMP}

A importância relativa das modificações da estrutura ocupacional do mercado de trabalho (efeito MIX) e da composição por sexo das ocupações (efeito COMP) nas alterações de $D$ observadas entre o início e o final do período estão descritas na tabela 15 .

Tabela 15. Decomposição das alterações no índice de segregação entre 1981 e 1990 . São Paulo e Pernambuco.

\begin{tabular}{lrrr}
\hline & \multicolumn{2}{c}{ EFEITO } & \\
\cline { 2 - 3 } \multicolumn{1}{c}{ ESTADO } & \multicolumn{1}{c}{ MIX } & \multicolumn{1}{c}{ COMP } & ALTERAÇÃO TOTAL \\
\hline São Paulo & $-0,0056955$ & $-0,0390695$ & $-0,0447650$ \\
& $(12,72 \%)$ & $(87,28 \%)$ & $(100 \%)$ \\
Pernambuco & 0,0250087 & 0,035476 & 0,0604847 \\
& $(41,35 \%)$ & $(58,65 \%)$ & $(100 \%)$ \\
\hline
\end{tabular}

Pode-se notar que, tanto em São Paulo como em Pernambuco, os efeitos MIX e COMP se reforçam mutuamente, com a diferença de que em são Paulo ambos agem no sentido de reduzir o valor de $D$ e em Pernambuco no sentido de aumentá-1o. Nota-se também que, embora nos dois estados as mudanças na composição por sexo das ocupações sejam mais importantes na explicação da evolução do índice do que as da estrutura ocupacional, ${ }^{60}$ em São Paulo as mudanças de

60 BIAU \& HENDRICKS (1979) analisando a evolução dos índices de segregação na economia norte-americana de 1950 a 1970, chegam a 
composição são responsáveis por quase $90 \%$ da redução do valor de $D$, enquanto que em Pernambuco a alteração da estrutura ocupacional responde por mais de $40 \%$ das modificações dessa medida.

\subsection{Diferenças de inserção ocupacional versus diferenças de rendimentos}

As diferenças por sexo de estrutura ocupacional e seus reflexos nos rendimentos têm sido analisadas em uma série de trabalhos. ${ }^{61}$ Assim, comprovada a existência de considerável segregação ocupacional em São Paulo e em Pernambuco, é importante investigar sua vinculação com o diferencial entre os rendimentos dos sexos que prevalece nessas regiões, ou, em outros termos, verificar se as ocupações femininas são apenas diferentes das masculinas ou. se, ao invés disso, são piores do que elas.

Com esse objetivo, procura-se verificar se os rendimentos das mulheres lotadas em ocupações masculinas são, em média, maiores do que os das alocadas nas que apresentam menor proporção de homens. Se comprovado que a

conclusões semelhantes a respeito da importância relativa dos dois componentes na explicação da modificação das medidas.

61 Vários trabalhos têm procurado descrever a distribuição de homens e mulheres em diferentes categorias ocupacionais e o rendimento médio das mesmas. Dentre os desenvolvidos em periodo relativamente recente com base em evidências empíricas nacionais pode-se consultar, entre outros, os de MELLO (1982), BRIZOLLA (1982), COSTA (1984), BRUSCHINI (1985), MEDICI (1987) e BARROS et alii (1997). Especificamente para a economia norte-americana, BELIER (1982) e BLAU \& BELLER (1988) verificam a persistência de diferenças significativas entre os rendimentos das mulheres alocadas nas ocupações masculinas e o das inseridas nas demais ocupações. A literatura disponível mostra que o declínio da segregação observado naquela economia entre 1970 e 1980 tem, aparentemente, pequeno impacto no diferencial de salários entre os sexos, conforme relatam BELLER (1984) e RYTINA \& BIANCHI (1984), entre outros. 
inserção da mulher em ocupações masculinas contribui para eliminar sua notória inferioridade de remuneração em relação ao sexo oposto, obviamente as políticas voltadas às questões do gênero devem concentrar esforços no sentido de promover a maior integração dos sexos no mercado de trabalho.

A tabela 16, contendo a evolução de alguns salários relativos, permite ilustrar esses aspectos.

Denominando por $\overline{R F}_{m} \circ$ rendimento médio por hora trabalhada na ocupação principal auferido pelas mulheres que se inserem em ocupações masculinas, por $\overline{R F}_{o} \circ$ rendimento das mulheres que se encontram nas demais ocupações. (integradas e femininas) e por $\overline{R F}$ e $\overline{R M}$ respectivamente, 0 de todos os trabalhadores do sexo feminino e do sexo masculino, obtém-se, ano a ano e para os dois estados, as relações $\frac{\overline{R F}_{m}}{\overline{R F}_{o}}, \frac{\overline{R F}_{m}}{\overline{R M}}, \frac{\overline{R F}}{\overline{R M}}$, cuja evolução encontra-se documentada na tabela 16. A apresentação das figuras 3 e 4, construídas com base nesses mesmos dados, objetiva facilitar a análise. 
Tabela 16. Evolução dos rendimentos relativos. São Paulo e Pernambuco, 1981 a 1990 (em o).

\begin{tabular}{|c|c|c|c|c|c|c|}
\hline \multirow[b]{2}{*}{ ANO } & \multicolumn{3}{|c|}{ SÃO PAULO } & \multicolumn{3}{|c|}{ PERNAMBUCO } \\
\hline & $\frac{\overline{R F}_{m}}{\overline{R F}_{o}}$ & $\frac{\overline{R F}_{m}}{\overline{R M}}$ & $\frac{\overline{R F}}{\overline{R M}}$ & $\frac{\overline{R F}_{m}}{\overline{R F}_{o}}$ & $\frac{\overline{R F}_{m}}{\overline{R M}}$ & $\frac{\overline{R F}}{\overline{R M}}$ \\
\hline 1981 & 144,71 & 80,97 & 60,07 & 85,58 & 72,30 & 70,02 \\
\hline 1983 & 137,14 & 75,39 & 58,22 & 108,83 & 70,72 & 71,99 \\
\hline 1984 & 176,04 & 95,07 & 60,35 & 88,22 & 86,48 & 84,21 \\
\hline 1985 & 166,87 & 94,38 & 62,60 & 78,23 & 76,59 & 72,88 \\
\hline 1987 & 182,74 & 103,62 & 64,49 & 88,57 & 71,58 & 70,11 \\
\hline 1988 & 171,91 & 97,37 & 62,47 & 123,12 & 72,96 & 76,00 \\
\hline 1989 & 206,41 & 112,47 & 64,59 & 119,68 & 61,24 & 63,65 \\
\hline 1990 & 165,49 & 107,15 & 71,49 & 118,60 & 80,37 & 82,50 \\
\hline
\end{tabular}

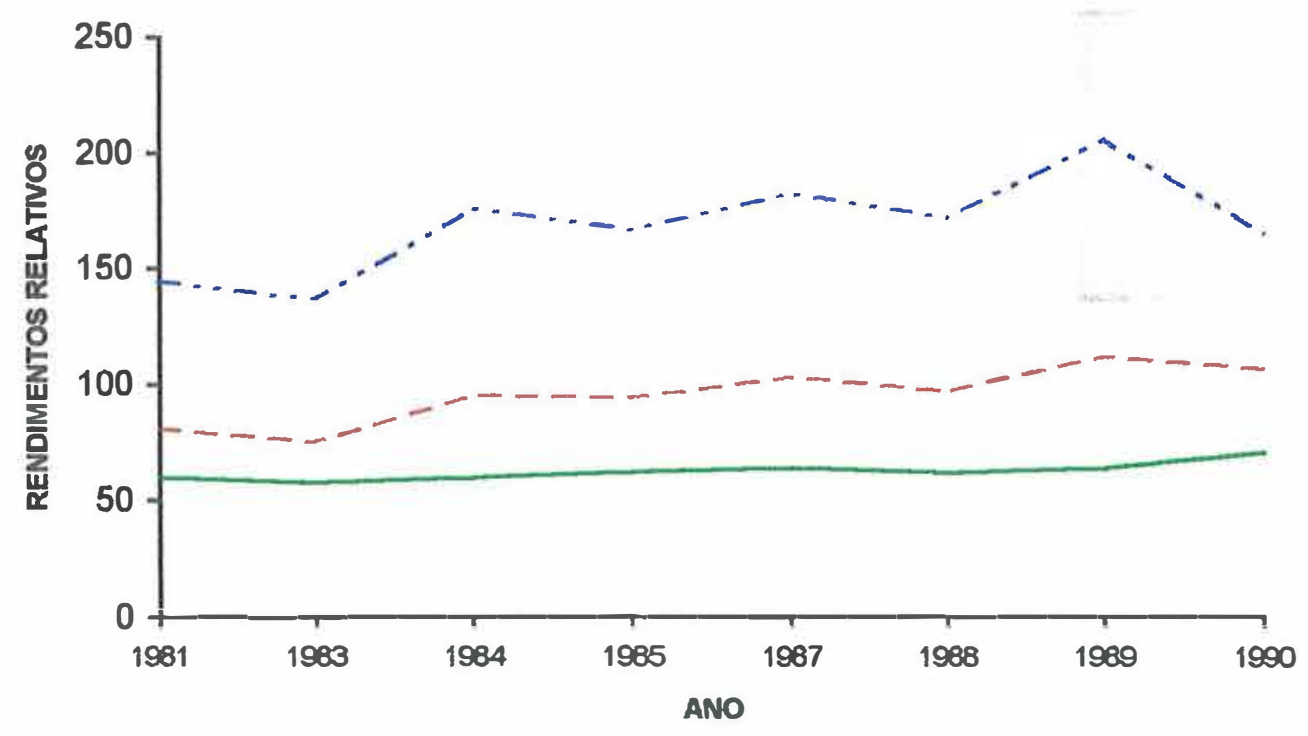

$$
-\cdots-\overline{\mathrm{RF}} \overline{\mathrm{RF}} \mathrm{R}---\overline{\mathrm{RFm}} / \overline{\mathrm{RM}}-\overline{\mathrm{RF}} \overline{\mathrm{RM}}
$$

Figura 3. Evolução dos rendimentos relativos. São Paulo, 1981 a 1990 . 


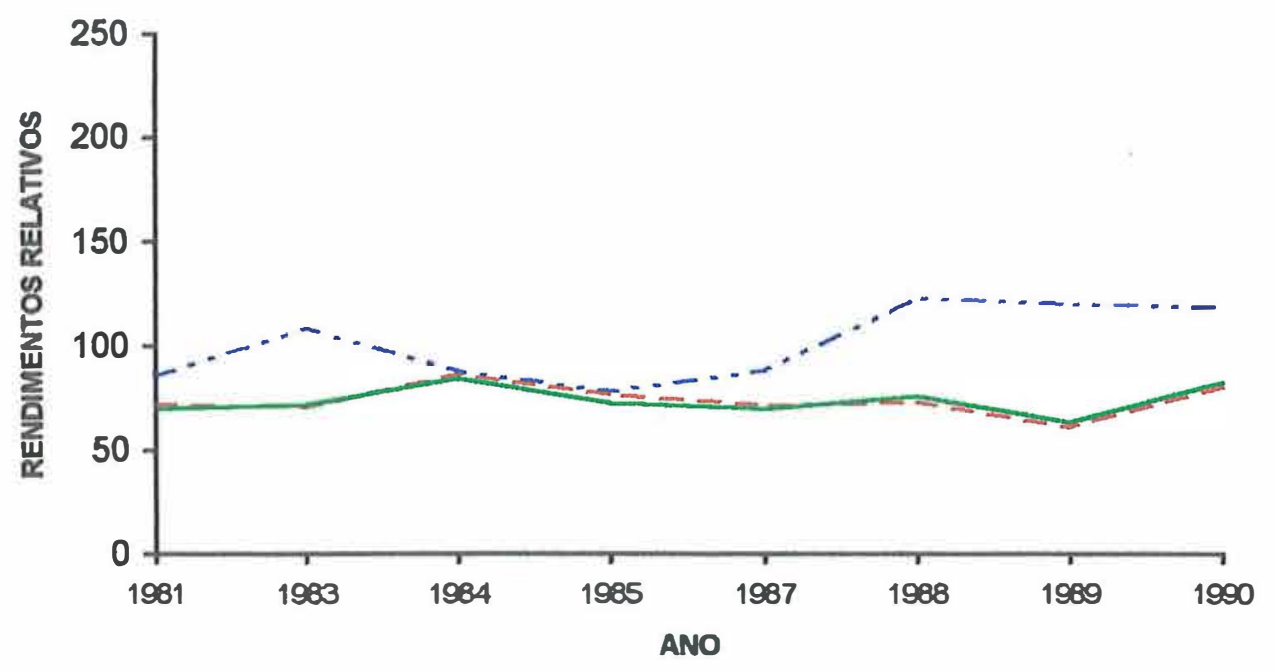

$-\cdots-\overline{\mathrm{RFm}} / \overline{\mathrm{RF}} \mathrm{O}---\overline{\mathrm{RFm}} / \overline{\mathrm{RM}} \longrightarrow \overline{\mathrm{RF} / \mathrm{RM}}$

Figura 4. Evolução dos rendimentos relativos. Pernambuco, 1981 a 1990 .

Em ambos os estados a remuneração feminina por hora trabalhada na ocupação principal (já descontado portanto, o fato de que as responsabilidades domésticas, atribuídas pela sua condição de gênero, thes possibilita uma menor carga horária de trabalho remunerado) é substancialmente menor do que a masculina. Verifica-se, também, que embora em São Paulo essa relação seja mais estável e com tendência ascendente melhor definida, os diferenciais de rendimento por sexo são proporcionalmente menores em Pernambuco.

As diferenças entre os estados são muito mais nitidas quando se analisa os rendimentos das mulheres segundo a composição por sexo das ocupações. Neste sentido, a trabalhadora paulista que tem ocupação masculina aufere remuneração significativamente maior do que as demais, com o diferencial de rendimento entre as mulheres dessas duas categorias oscilando, nesse período, entre $37,14 \%$ e 
106,41\%. Na maior parte dos anos, inclusive, a mulher que tem ocupação masculina apresenta, em média, rendimento equivalente ao dos homens amostrados. Já em Pernambuco, as mulheres que têm ocupação masculina não são necessariamente melhor remuneradas do que as demais. $\mathrm{Na}$ verdade, em quatro dos oito anos considerados, a sua remuneração é menor. Em consequiência, o fato de a pernambucana estar em ocupação masculina não lhe garante uma melhoria na sua relação com os rendimentos dos pernambucanos.

Em resumo, as evidências empiricas relatadas neste capítulo permitem verificar que homens e mulheres nos dois estados encontram-se, em grande parte, segregados em ocupações diferentes. Embora ao longo do período considerado essa segregação manifeste tendência descendente em São Paulo, não apresenta sinais de arrefecimento em Pernambuco. Ao invés disso, nesse último estado a segregação se aprofunda nos anos em questão.

Se o acesso às ocupações é universal, mas homens e mulheres igualmente qualificados encontram-se segregados em diferentes ocupações por escolha ou opção pessoal, as diferenças de remuneração entre os gêneros não exigiriam nenhum tipo de intervenção. Todavia, se o acesso não é universal e ocupações tipicamente masculinas possibilitam a obtenção de rendimentos significativamente maiores, as mulheres que se encontram excluídas de tais ocupações são prejudicadas. As evidências empíricas relatadas sugerem que esforços no sentido de se aumentar a participação feminina nas ocupações tradicionalmente masculinas podem resultar em crescimento do salário feminino médio em São Paulo, mas não necessariamente em Pernambuco, 0 que mostra que mesmo quando se enfocam apenas dois estados brasileiros não se 
pode adotar uma politica uniforme para superar as desigualdades de rendimentos entre os gêneros.

Todavia, é importante ter em mente que é impossível concluir, a priori, que o maior rendimento médio das paulistas posicionadas em ocupações masculinas esteja associado à discriminação ocupacional. Da mesma forma, não se pode afirmar que o diferencial de remuneração por sexo em Pernambuco decorra da discriminação intraocupacional. Para se isolar o componente discriminatório das diferenças de rendimentos é necessário adotar procedimento metodológico que leve em consideração as diferenças de qualificação. Os resultados desse procedimento são apresentados a seguir. 


\section{QUANTIFICANDO A DISCRIMINAÇĀO}

Para decompor os diferenciais de rendimento entre os sexos nas parcelas referentes às diferenças de qualificação e nas que indicam a existência das duas formas de discriminação o procedimento adotado consiste, conforme descrito no capítulo 3, nas seguintes etapas:

19) as ocupações são agrupadas em cinco classes conforme sua composição por sexo (estas classes estão definidas na tabela 6);

2ㅇ) obtêm-se, a seguir, a estrutura ocupacional que vigoraria se os critérios de seleção fossem os mesmos para os dois sexos. Através do ajuste do modelo logito multinomial aos dados referentes à parcela masculina da amostra estimam-se as equações que indicam a probabilidade de o individuo pertencer a cada uma das classes; os dados referentes à parcela feminina da amostra são, então, substituídos nessas equações objetivando obter, para cada mulher, 0 vetor de probabilidades de pertencer a diferentes classes ocupacionais; as probabilidades geradas para cada estrato são, por fim, somadas, resultando na distribuição ocupacional que as mulheres apresentariam se os critérios de contratação fossem iguais aos adotados na seleção da mão-de-obra masculina;

3으 utilizando as informações consideradas relevantes são, também, estimadas equações de rendimento segundo $\circ$ sexo, classe e estado no qual o indivíduo se 
insere, perfazendo, nos oito anos considerados, um total de cento e sessenta regressões;

4) tem-se, então, todos os elementos para, utilizando a equação (18), decompor as diferenças entre a remuneração média dos homens e mulheres que constituem a amostra nas parcelas de interesse - as que buscam quantificar o efeito das suas diferenças de qualificação e as que resultam das duas formas de discriminação.

o presente capítulo apresenta os resultados finais desse procedimento, incluindo, dentre os obtidos nas sucessivas etapas, os considerados mais relevantes para a análise.

\section{1. A estrutura ocupacional vigente}

A evolução da distribuição percentual dos homens e das mulheres de São Paulo e Pernambuco nas cinco categorias ocupacionais está relatada nas tabelas 17 e 18, respectivamente. O número de observações em cada categoria e a estimativa da população nas mesmas, obtida através dos fatores de expansão fornecidos pelo IBGE, encontram-se documentados no Apêndice $\mathrm{E}$. 
Tabela 17. Distribuição percentual da PEA ocupada(1) por classe de percentual de homens na ocupação. (2) São Paulo, 1981 a 1990 .

\begin{tabular}{lccccc}
\hline & \multicolumn{5}{c}{ CLASSE } \\
\cline { 2 - 6 } ANO/SEXO & $\mathbf{1}$ & $\mathbf{2}$ & $\mathbf{3}$ & $\mathbf{4}$ & $\mathbf{5}$ \\
\hline HOMENS & & & & & \\
1981 & 1,44 & 1,35 & 11,01 & 20,79 & 65,41 \\
1983 & 1,75 & 1,47 & 10,73 & 26,07 & 59,98 \\
1984 & 1,76 & 1,96 & 13,22 & 21,48 & 61,57 \\
1985 & 2,07 & 1,60 & 11,92 & 15,30 & 69,10 \\
1987 & 1,73 & 1,70 & 11,13 & 28,40 & 57,04 \\
1988 & 1,95 & 0,71 & 15,90 & 25,00 & 56,43 \\
1989 & 1,99 & 2,18 & 15,40 & 26,70 & 53,73 \\
1990 & 2,08 & 1,62 & 15,21 & 24,82 & 56,27 \\
MULHERES & & & & & \\
1981 & 48,15 & 7,99 & 20,22 & 15,95 & 7,69 \\
1983 & 49,07 & 7,13 & 20,68 & 17,75 & 5,37 \\
1984 & 49,40 & 8,91 & 22,71 & 13,22 & 5,76 \\
1985 & 48,70 & 7,70 & 20,38 & 12,82 & 10,40 \\
1987 & 45,55 & 6,93 & 21,21 & 21,44 & 4,87 \\
1988 & 46,83 & 3,70 & 28,79 & 16,37 & 4,31 \\
1989 & 43,23 & 9,39 & 27,66 & 15,75 & 3,97 \\
1990 & 44,82 & 7,15 & 25,87 & 16,80 & 5,35 \\
\hline (1) & Inclui apenas & as pessoas & para as quais os atributos de & interesse \\
estão claramente identificados. & & & \\
(2) Ver tabela & para a delimitação das cinco classes. & \\
& & &
\end{tabular}


Tabela 18. Distribuição percentual da PEA ocupada(1) por classe de percentual de homens na ocupação. (2) Pernambuco, 1981 a 1990 .

\begin{tabular}{lccccc}
\hline & \multicolumn{5}{c}{ CLASSE } \\
\cline { 2 - 6 } ANO/SEXO & $\mathbf{1}$ & $\mathbf{2}$ & $\mathbf{3}$ & $\mathbf{4}$ & $\mathbf{5}$ \\
\hline HOMENS & & & & & \\
1981 & 1,00 & 0,71 & 4,87 & 14,19 & 79,23 \\
1983 & 1,42 & 0,65 & 5,36 & 18,30 & 74,27 \\
1984 & 1,20 & 0,64 & 5,58 & 13,78 & 78,80 \\
1985 & 1,58 & 0,87 & 6,96 & 14,94 & 75,65 \\
1987 & 1,50 & 1,22 & 3,69 & 19,26 & 74,32 \\
1988 & 1,84 & 1,43 & 6,79 & 15,31 & $.74,64$ \\
1989 & 1,12 & 1,77 & 5,63 & 18,06 & 73,42 \\
1990 & 1,63 & 2,22 & 5,93 & 19,99 & 70,23 \\
MULHERES & & & & & \\
1981 & 49,02 & 4,27 & 10,27 & 15,45 & 20,99 \\
1983 & 51,08 & 2,67 & 11,80 & 16,61 & 17,83 \\
1984 & 49,04 & 3,65 & 11,93 & 13,86 & 21,52 \\
1985 & 49,66 & 4,39 & 12,99 & 13,99 & 18,97 \\
1987 & 54,60 & 5,20 & 7,41 & 18,03 & 14,76 \\
1988 & 52,08 & 7,28 & 12,19 & 13,57 & 14,88 \\
1989 & 50,25 & 7,64 & 10,89 & 15,67 & 15,55 \\
1990 & 54,39 & 9,44 & 10,68 & 16,33 & 9,16 \\
\hline (1) & Inclui apenas & as pessoas & para as quais os atributos de & interesse \\
estão claramente identificados. & & & \\
Ver tabela & para a delimitação das cinco classes. &.. & \\
& & & &
\end{tabular}

É interessante notar que embora uma fração insignificante da PEA ocupada masculina amostrada esteja inserida em ocupações nas quais o percentual de homens é inferior à 40\%, a recíproca não é verdadeira para a PEA feminina. Assim, enquanto menos de 4\% dos trabalhadores do sexo masculino nos dois estados estão em ocupações das categorias 1 e 2 (ou seja, em ocupações que contêm mais de $60 \%$ de mulheres), cerca de $20 \%$ das trabalhadoras paulistas e 30\% das pernambucanas se inserem em ocupações das classes 4 e 5 (ou, em outros termos, em ocupações que contém mais de $60 \%$ de homens). 
Verifica-se, também, a reduzida participação não apenas dos homens como também das mulheres nas ocupações do segundo estrato, o que indica a pequena importância na absorção da mão-de-obra das ocupações femininas que integram uma parcela expressiva de homens.

Ao longo do período analisado a estrutura ocupacional agregada nessas cinco classes apresenta algumas alterações, entre as quais, a perda da importância relativa das ocupações do grupo 5 para os homens nos dois estados e para as mulheres em Pernambuco. ${ }^{62}$ Nota-se também 0 crescimento da importância das ocupações do grupo 3 para os paulistas de ambos os sexos, assim como 0 das que compõem os estratos 1 e 2 para as pernambucanas. Ou seja, são transformações que sugerem a redução da segregação ocupacional em São Paulo (visto que cresce a absorção da mão-de-obra em ocupações relativamente integradas no tocante à sua composição por sexol e o seu crescimento em Pernambuco (pois cai a participação das mulheres em ocupações tipicamente masculinas enquanto se eleva nas tipicamente femininas), o que é consistente com a evolução dos valores de $\mathrm{D}$ calculados para esses dois estados. ${ }^{63}$

62 Deve-se lembrar que, conforme apontado pelas tabelas 8 e 10, uma fração expressiva da mão-de-obra masculina e feminina em Pernambuco está alocada em ocupações ligadas à agropecuária (as quais, dada a sua composição por sexo estão, naquele estado, relacionadas no grupo 5) que perdem espaços significativos na composição do emprego entre 1981 e 1990.

63 Logicamente, mudanças na distribuição dos sexos entre as ocupações de uma mesma classe não podem ser percebidas quando se trabalha com os dados a esse nível de agregação, o que implica a necessidade de se avaliar a segregação através de informações mais detalhadas sobre as categorias ocupacionais, conforme realizado neste trabalho. 


\section{2. A estrutura ocupacional simulada}

Através da estimativa do modelo logito multinomial (descrito na seção 3.4.2), obtém-se a distribuição ocupacional que as mulheres apresentariam se na sua contratação fossem utilizados os critérios adotados na seleção dos homens para as diferentes categorias ocupacionais.

Os coeficientes associados às variáveis explanatórias assim como os valores de $z$ (relação entre a estimativa do coeficiente e do respectivo desvio-padrão) obtidos encontram-se documentados nas tabelas que compõem 0 Apêndice F. Tais dados são apresentados em anexo não apenas pelas dificuldades inerentes à interpretação dos coeficientes estimados, como também pelo fato de que essas estimativas se constituem em uma etapa intermediária na realização desta pesquisa e não em seu objetivo final.

Entre os resultados do ajustamento encontra-se um sumário da capacidade de previsão do modelo. Os percentuais de acertos (homens corretamente identificados nas categorias ocupacionais em relação ao total de homens da amostra) relacionados nesse sumário estão apresentados na tabela 19. Os percentuais de acertos em cada categoria ocupacional estão contidos na tabela 1 do apêndice I. 
Tabela 19. Capacidade de previsão da distribuição da PEA masculina ocupada(1) nos modelos logitos multinomiais estimados. São Paulo e Pernambuco, 1981 a 1990 ( 8 de acertos).

\begin{tabular}{ccc}
\hline ANO & SÃO PAULO & PERNAMBUCO \\
\hline 1981 & 67,42 & $\mathbf{7 2 , 6 3}$ \\
1983 & 63,44 & 68,89 \\
1984 & 64,50 & 72,92 \\
1985 & 69,43 & 70,51 \\
1987 & 58,03 & 68,49 \\
1988 & 57,38 & 68,39 \\
1989 & 55,38 & 68,24 \\
1990 & 57,03 & 66,21 \\
\hline
\end{tabular}

(1) Inclui apenas as pessoas para as quais os atributos de interesse estão claramente identificados.

Considerando que a PEA ocupada masculina é desbalanceada, encontrando-se altamente concentrada nas ocupações das classes 4 e 5 , a regra de previsão pode falhar, como o faz, na identificação dos indivíduos que se encontram nas ocupações das classes 1 e 2 e de grande parte dos indivíduos das classes 3 e $4 .{ }^{64}$ No total, os percentuais de acertos oscilam, em São Paulo, entre 55,38\% e 69,43\% e, em Pernambuco, entre 66,21\% e 72,92\%, podendo ser considerados razoáveis.

O teste de razão de verossimilhança (LRT), que testa a nulidade dos coeficientes das variáveis explanatórias nas equações, é altamente significante em todos os ajustes realizados. Os resultados desse teste estão sintetizados na tabela 20 .

\footnotetext{
$64 \mathrm{Em}$ amostras desbalanceadas é necessário uma configuração extrema dos regressores para que o modelo identifique corretamente os indivíduos das categorias menos populosas (Cf. GREENE, 1993, p. 652 ) .
} 
Tabela 20. Valores de $L R T^{(1)}$ e número de observações (N) nas equações de logitos multinomiais estimadas. São Paulo e Pernambuco, 1981 a 1989.

\begin{tabular}{ccccc}
\hline & \multicolumn{2}{c}{ SÃO PAULO } & \multicolumn{2}{c}{ PERNAMBUCO } \\
\cline { 2 - 5 } ANO & LRT & $\boldsymbol{N}$ & LRT & $\boldsymbol{N}$ \\
\hline 1981 & 2178,84 & 13542 & 1580,04 & 5794 \\
1983 & 2823,24 & 14364 & 1402,28 & 5819 \\
1984 & 2587,50 & 14977 & 1333,30 & 6060 \\
1985 & 2090,49 & 15572 & 1767,70 & 6232 \\
1987 & 1055,82 & 8401 & 848,30 & 3443 \\
1988 & 1295,20 & 8163 & 830,83 & 3319 \\
1989 & 1538,42 & 7951 & 871,62 & 3570 \\
1990 & 1363,63 & 8161 & 989,57 & 3575 \\
\hline (1) & 1 Todos os valores são estatisticamente significativos ao nível de 18 \\
de significância. &
\end{tabular}

A distribuição percentual simulada das mulheres nas categorias ocupacionais $\left(\boldsymbol{p}_{\boldsymbol{i}}^{\boldsymbol{f}^{*}}\right)$ se aproxima da observada para os homens, conforme pode-se notar pela comparação entre as tabelas 17, 18 e 21. Ou seja, se os critérios pelos quais a mão-de-obra é selecionada independessem da sua condição de gênero, homens e mulheres teriam estrutura ocupacional semelhante. 
Tabela 21. Distribuição percentual estimada $\left(p_{i}^{f^{*}}\right)$ da PEA feninina ocupada(1) por classe ocupacional. São Paulo e Pernambuco, 1981 a 1990.

\begin{tabular}{cccccc}
\hline & \multicolumn{5}{c}{ CATEGORIA OCUPACIONAL } \\
\cline { 2 - 6 } ESTADO/ANO & $\mathbf{1}$ & $\mathbf{2}$ & $\mathbf{3}$ & $\mathbf{4}$ & $\mathbf{5}$ \\
\hline SÃO PAULO & & & & & \\
1981 & 1,48 & 1,50 & 15,00 & 21,49 & 60,53 \\
1983 & 1,77 & 1,78 & 15,28 & 27,40 & 53,77 \\
1984 & 1,72 & 2,11 & 17,13 & 21,77 & 57,27 \\
1985 & 2,25 & 1,68 & 15,40 & 16,09 & 64,58 \\
1987 & 1,40 & 1,37 & 16,88 & 24,50 & 55,85 \\
1988 & 2,17 & 0,75 & 19,90 & 25,09 & 52,09 \\
1989 & 2,05 & 2,50 & 19,91 & 25,90 & 49,64 \\
1990 & 2,06 & 1,88 & 18,97 & 25,07 & 52,03 \\
& & & & & \\
PERNAMBUCO & & & & & \\
1981 & 1,31 & 1,22 & 9,03 & 18,30 & 70,14 \\
1983 & 1,56 & 1,12 & 8,21 & 21,99 & 67,11 \\
1984 & 1,31 & 1,13 & 9,21 & 17,07 & 71,28 \\
1985 & 1,99 & 1,61 & 11,40 & 18,55 & 66,45 \\
1987 & 1,84 & 2,31 & 6,05 & 23,09 & 66,70 \\
1988 & 2,41 & 2,07 & 10,52 & 18,64 & 66,37 \\
1989 & 1,38 & 2,44 & 8,85 & 20,48 & 66,85 \\
1990 & 1,94 & 3,28 & 9,07 & 24,05 & 61,66 \\
\hline
\end{tabular}

(1) Inclui apenas as pessoas para as quais os atributos de interesse estão claramente identificados.

\section{3. As equações de rendimento}

Objetivando avaliar os efeitos diferenciados dos condicionantes dos rendimentos do trabalho, por sexo e classe ocupacional, efetua-se uma análise de regressão ponderada. Nessa análise a variável dependente, indicada por $\ln R$, é o logaritmo natural do rendimento por hora trabalhada na ocupação principal, deflacionado pelo INPC 
tomando-se como base agosto de $1980^{65}$. Os efeitos dos condicionantes desse rendimento são captados através de um conjunto de variáveis binárias ${ }^{66}$ que permitem distinguir os efeitos da escolaridade (variáveis $E_{h}$, com $\boldsymbol{h}=1, \ldots, 6$ ) idade (variáveis $I_{k}$, com $k=1, \ldots, 6$ ), posição na ocupação (variável $P)^{67}$, posse de carteira de trabalho assinada (variável $C$ ) e situação do domicílio (variável $S$ ). A forma funcional desse modelo, conhecido como equação de rendimento, é a seguinte:

$$
\ln R_{j}=\alpha+\beta S_{j}+\gamma C_{j}+\phi P_{j}+\sum_{h=1}^{6} \delta_{h} E_{h j}+\sum_{k=1}^{7} \theta_{k} I_{k j}+u_{j}
$$

onde $u$ representa o erro aleatório que obedece às pressuposições estatísticas usuais e $j$ indica os individuos que compõem a amostra.

o grupo de referência compreende os indivíduos da zona rural, com idade entre dez e dezessete anos, sem instrução, que trabalham como assalariados sem carteira de trabalho assinada. A estimativa da constante $(\alpha)$ indica 0 valor médio do logaritmo natural do rendimento por hora trabalhada na ocupação principal de todos os indivíduos do grupo de referência.

65 A opção pelo Índice Nacional de Preços (INPC) do IBGE como deflator decorre da sua abrangência geográfica e da coerência, manifestada quando esse índice é o deflator, entre as variações do valor real dos rendimentos médios da população brasileira e as do PIB per capita (HOFFMANN, 1992a).

66 que assumem $\circ$ valor 1 se $\circ$ indivíduo pertence ao grupo considerado e 0 no caso contrário.

67 a posição na ocupação é uma binária simples, que assume o valor 1 se o indivíduo é empregador ou autonômo e 0 se é empregado. Inicialmente pretendia-se separar os empregadores dos autonômos, mas a subdivisão dos elementos da amostra por sexo e em cinco categorias ocupacionais inviabilizou o procedimento por gerar número excessivamente reduzido ou a ausência de empregadores em algumas categorias. 
A equação foi ajustada para cada um dos 160 conjuntos de dados (dois sexos, 5 classes de ocupação, 2 estados e 8 anos).

A adoção da função log-linear, utilizada em grande parte dos ajustes de equações de rendimento realizados em pesquisas de âmbito nacional ou internacional, liga-se ao reconhecimento de que o efeito das variáveis explanatórias é proporcional e não absoluto.

Os parâmetros estimados indicam o diferencial de rendimentos dos vários grupos de cada variável em relação ao de referência. Por exemplo, o exponencial de $\boldsymbol{\beta}$, $\exp (\boldsymbol{\beta})$, indica quantas vezes é maior, em média, o rendimento por hora trabalhada na ocupação principal $(R)$ de uma pessoa residente na zona urbana em relação ao de outra com as mesmas características mas residente da zona rural. A exponencial de $\boldsymbol{\theta}_{k}$, exp $\left(\boldsymbol{\theta}_{k}\right)$, por sua vez, indica quantas vezes o rendimento de uma pessoa de determinada faixa etária é maior, em média, do que o de outra com as mesmas características e idade compreendida entre 10 e 17 anos.

As tabelas 22 e 23 apresentam para são Paulo e Pernambuco, respectivamente, os valores de $F$ e do coeficiente de determinação $\left(R^{2}\right)$ das regressões ajustadas com base nas informações referentes aos homens e às mulheres de cada uma das cinco classes ocupacionais, nos oito anos considerados na análise. O número de homens e de mulheres em cada categoria e ano para os dois estados encontra-se nas tabelas 24 e $25 .{ }^{68}$

68 A diferença entre o número de observações por classe, apresentado no Apêndice $E$, e $O$ número de elementos considerado nessa análise (relatado nas tabelas 24 e 25) corresponde a observações com rendimento na ocupação principal indeterminado. 


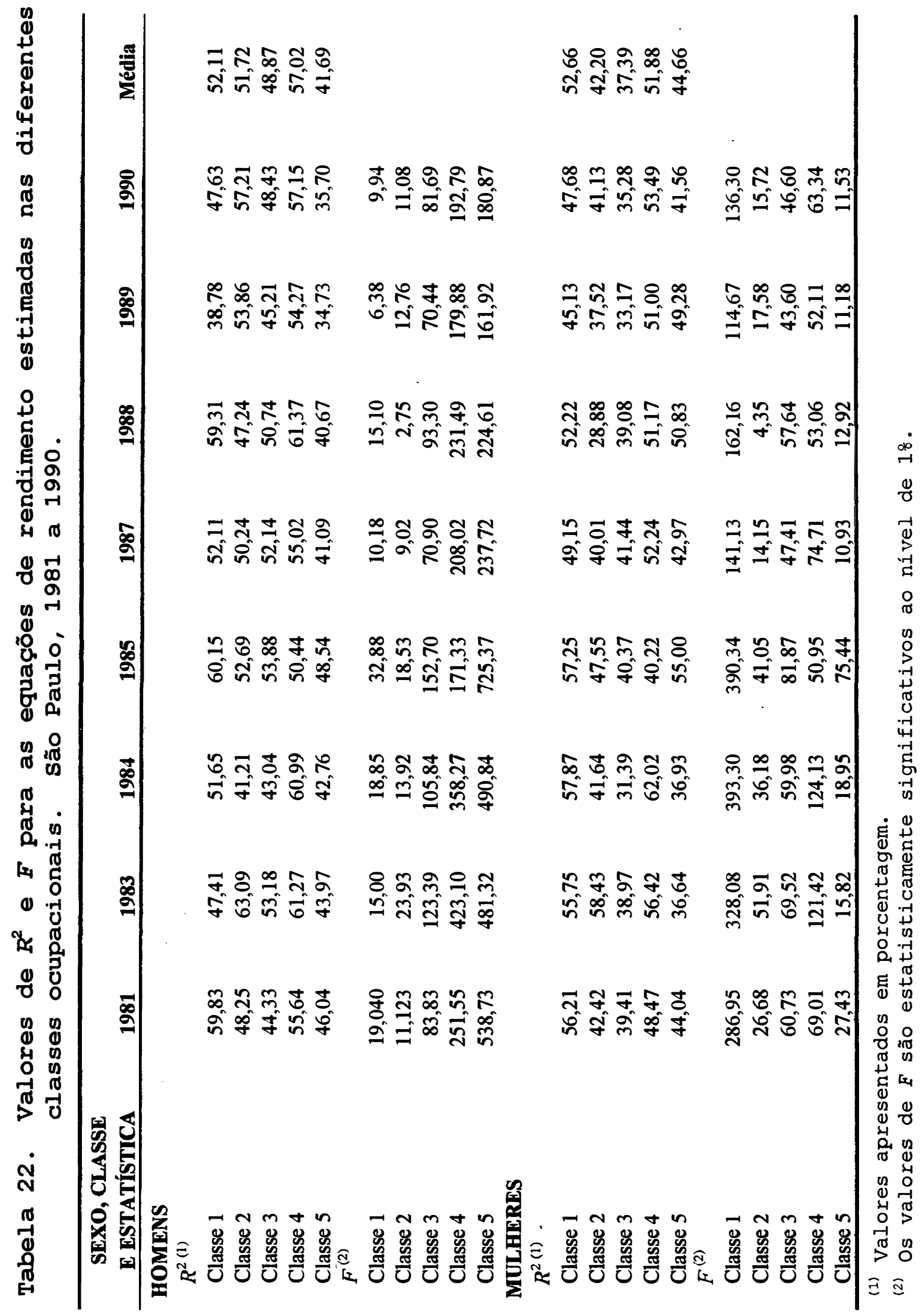




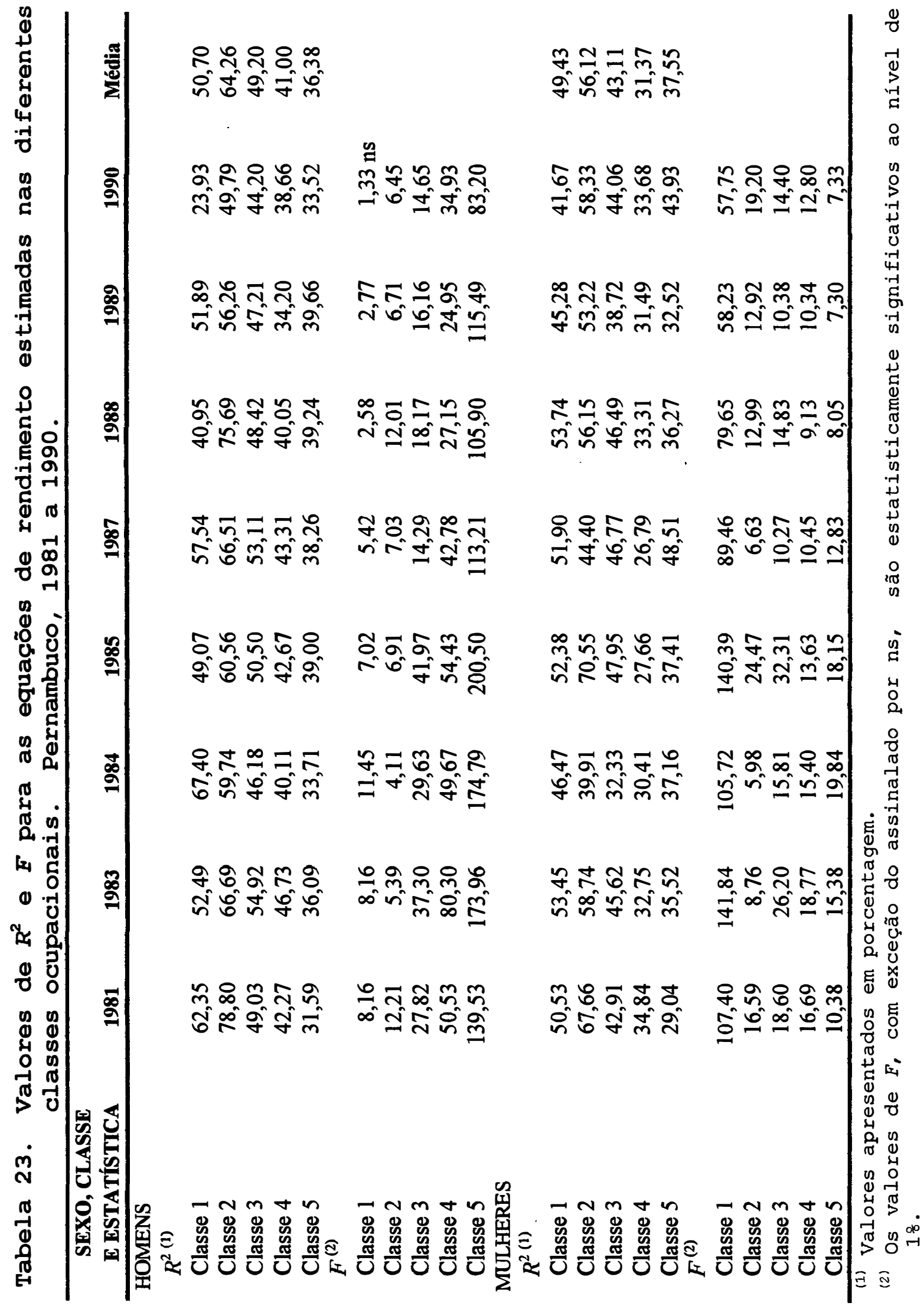


Tabela 24. Número de observações ${ }^{(1)}$ nas equações de rendimento estimadas por classe e sexo. São Paulo, 1981 a 1990 .

\begin{tabular}{|c|c|c|c|c|c|c|}
\hline \multirow[b]{2}{*}{ ANO/NÚMERO } & \multicolumn{6}{|c|}{ CLASSE } \\
\hline & 1 & 2 & 3 & 4 & 5 & TOTAL \\
\hline \multicolumn{7}{|l|}{1981} \\
\hline $\mathrm{n}_{1}$ & 194 & 182 & 1489 & 2823 & 8853 & 13541 \\
\hline $\mathrm{n}_{2}$ & 3145 & 522 & 1322 & 1042 & 503 & 6534 \\
\hline \multicolumn{7}{|l|}{1983} \\
\hline $\mathrm{n}_{1}$ & 248 & 211 & 1536 & 3760 & 8603 & 14358 \\
\hline $\mathrm{n}_{2}$ & 3661 & 532 & 1539 & 1328 & 398 & 7458 \\
\hline \multicolumn{7}{|l|}{1984} \\
\hline $\mathrm{n}_{1}$ & 262 & 293 & 1976 & 3223 & 9215 & 14969 \\
\hline $\mathrm{n}_{2}$ & 4023 & 725 & 1850 & 1079 & 468 & 8145 \\
\hline \multicolumn{7}{|l|}{1985} \\
\hline $\mathrm{n}_{1}$ & 320 & 248 & 1845 & 2372 & 10781 & 15566 \\
\hline $\mathrm{n}_{2}$ & 4095 & 649 & 1708 & 1075 & 879 & 8406 \\
\hline \multicolumn{7}{|l|}{1987} \\
\hline $\mathrm{n}_{1}$ & 146 & 140 & 926 & 2396 & 4786 & 8394 \\
\hline $\mathrm{n}_{2}$ & 2059 & 312 & 953 & 971 & 218 & 4513 \\
\hline \multicolumn{7}{|l|}{1988} \\
\hline $\mathrm{n}_{1}$ & 160 & 58 & 1283 & 2055 & 4602 & 8158 \\
\hline $\mathrm{n}_{2}$ & 2092 & 165 & 1273 & 724 & 190 & 4444 \\
\hline \multicolumn{7}{|l|}{1989} \\
\hline $\mathrm{n}_{1}$ & 156 & 168 & 1210 & 2137 & 4275 & 7946 \\
\hline $\mathrm{n}_{2}$ & 1967 & 425 & 1245 & 716 & 176 & 4529 \\
\hline \multicolumn{7}{|l|}{1990} \\
\hline $\mathrm{n}_{1}$ & 168 & 131 & 1233 & 2039 & 4575 & 8146 \\
\hline $\mathrm{n}_{2}$ & 2109 & 330 & 1211 & 786 & 242 & 4678 \\
\hline
\end{tabular}

(1) $n_{1}$ refere-se ao número de observações do sexo masculino na amostra e $\mathrm{n}_{2}$ às do sexo feminino. 
Tabela 25. Número de observações(1) nas equações de rendimento estimadas por classe e sexo. Pernambuco, 1981 a 1990.

\begin{tabular}{|c|c|c|c|c|c|c|}
\hline \multirow[b]{2}{*}{ ANO/NÚMERO } & \multicolumn{6}{|c|}{ CLASSE } \\
\hline & 1 & 2 & 3 & 4 & 5 & TOTAL \\
\hline \multicolumn{7}{|l|}{1981} \\
\hline$n_{1}$ & 84 & 61 & 420 & 981 & 4246 & 5792 \\
\hline $\mathbf{n}_{2}$ & 1487 & 126 & 361 & 452 & 370 & 2796 \\
\hline \multicolumn{7}{|l|}{1983} \\
\hline $\mathrm{n}_{1}$ & 110 & 49 & 412 & 1204 & 4018 & 5793 \\
\hline $\mathbf{n}_{2}$ & 1620 & 94 & 420 & 515 & 377 & 3026 \\
\hline \multicolumn{7}{|l|}{1984} \\
\hline $\mathrm{n}_{1}$ & 86 & 50 & 463 & 978 & 4483 & 6060 \\
\hline $\mathbf{n}_{2}$ & 1597 & 131 & 444 & 472 & 450 & 3094 \\
\hline \multicolumn{7}{|l|}{1985} \\
\hline $\mathrm{n}_{1}$ & 117 & 78 & 591 & 1039 & 4406 & 6231 \\
\hline $\mathrm{n}_{2}$ & 1802 & 158 & 506 & 514 & 440 & 3420 \\
\hline \multicolumn{7}{|l|}{1987} \\
\hline $\mathrm{n}_{1}$ & 66 & 60 & 178 & 742 & 2389 & 3435 \\
\hline $\mathbf{n}_{2}$ & 1092 & 122 & 166 & 385 & 191 & 1956 \\
\hline \multicolumn{7}{|l|}{1988} \\
\hline $\mathrm{n}_{1}$ & 67 & 69 & 286 & 584 & 2311 & 3317 \\
\hline $\mathrm{n}_{2}$ & 975 & 157 & 254 & 271 & 213 & 1870 \\
\hline \multicolumn{7}{|l|}{1989} \\
\hline $\mathrm{n}_{1}$ & 51 & 88 & 268 & 687 & 2475 & 3569 \\
\hline $\mathrm{n}_{2}$ & 1000 & 174 & 245 & 330 & 227 & 1976 \\
\hline \multicolumn{7}{|l|}{1990} \\
\hline $\mathrm{n}_{1}$ & 74 & 106 & 274 & 791 & 2325 & 3570 \\
\hline $\mathrm{n}_{2}$ & 1147 & 207 & 271 & 368 & 146 & 2139 \\
\hline
\end{tabular}

(1) $\mathrm{n}_{1}$ refere-se ao número de observações do sexo masculino na amostra e $\mathrm{n}_{2}$ às do sexo feminino.

Os coeficientes de determinação das equações de rendimento estimadas para a parcela masculina da PEA paulista oscilam, erraticamente, entre um mínimo de 34,73\% e um máximo de 63,09\% no período entre 1981 e 1990. A média desses coeficientes por classe nos oito anos considerados varia entre $41,69 \%$ e 57,02\%. Por fim, a média geral de 
todos os $R^{2}$ obtidos com os dados dos trabalhadores masculinos nesse estado é de 50,28\%.

o ajuste do modelo utilizando as informações referentes às trabalhadoras paulistas, por sua vez, é inferior, com os valores médios de $R^{2}$ por classe oscilando entre $37,39 \%$ e $52,66 \%$ e média geral próxima de $46 \%$ $(45,76 \%)$.

De maneira geral, esses resultados refletem um bom ajustamento, dada a natureza das informações em que se basearam. ${ }^{69}$

A amplitude de variação dos valores de $R^{2}$ obtidos nas regressões estimadas para os trabalhadores de Pernambuco é expressivamente maior, pois esse coeficiente oscila entre $23,93 \%$ e $78,80 \%$ nas equações que objetivam explicar os rendimentos dos homens e $26,79 \%$ e 70,55\% nas voltadas às mulheres. O ajuste do modelo mostra-se também, em média, melhor para os pernambucanos $\left(R^{2}\right.$ médio de $\left.48,31 \%\right)$ do que para as pernambucanas $\left(R^{2}\right.$ de $\left.43,52 \%\right)$ e para ambos os sexos inferior ao de são Paulo. Ou seja, a escolaridade,

LANGONI (1973), em regressões que procuravam explicar rendimentos pessoais com base em dados do Censo Demográfico Brasileiro de 1960 e 1970 obtém $R^{2}$ de 50,74\% e 57,20\%, respectivamente. RAMOS (1993), analisando a desigualdade de rendimentos dos homens ocupados do setor urbano brasileiro de 1976 a 1985, estima regressões nas quais valores de $R^{2}$ oscilam em torno de 48\%. KASSOUF (1994), utilizando dados coletados em 1989 pela Pesquisa Nacional de Saúde e Nutrição (PNSN), obtém valores de $R^{2}$ de 438 na equação de rendimento estimada para a parcela masculina da amostra e de 45 \% na referente à parcela feminina. Pesquisas voltadas à análise da desigualdade de rendimentos entre pessoas ocupadas no setor agrícola têm, em alguns casos relatado valores inferiores de $R^{2}$. HOFFMANN $(1993,1994$ a e 1994b) relata valores de $R^{2}$ correspondente a $46,4 \%, 48,2 \%$ e 37\% em regressões ajustadas com as informações referentes a pessoas da zona rural de São Paulo, Goiás e Rio Grande do Sul, respectivamente. CORRÊA (1996), utilizando dados do Brasil rural das PNAD de 1981 a 1990 estima equações de rendimento onde $\circ R^{2}$ médio da década no modelo ajustado para o Brasil como um todo é $32,27 \%$. 
idade, posição na ocupação, posse de carteira de trabalho assinada e situação do domicílio "explicam" melhor os rendimentos masculinos do que os femininos $e \circ$ dos paulistas do que o dos pernambucanos.

Os valores de $F$ são estatisticamente significativos ao nível de $1 \%$ em praticamente todas as regressões ajustadas (em apenas uma das cento e sessenta equações estimadas o valor de $F$ não é significativo ao nível de $1 \%$ ).

Objetivando verificar, ainda, se as equações de rendimento estimadas com os dados referentes à parcela masculina e feminina de cada classe ocupacional são estatísticamente diferentes entre si é aplicado o teste de Chow. ${ }^{70}$ Os valores de $F$ calculados e os respectivos graus de significância encontram-se na tabela 26.

70 A realização deste teste exige que também sejam estimadas equações de rendimento por classe ocupacional, sem distinção de sexo (perfazendo, nos oito anos considerados, cinco classes e dois estados, um total de 80 regressões). Denominando por $S, S_{1}$ e $S_{2}$ as somas dos quadrados dos resíduos obtidas respectivamente, nas regressões ajustadas por classe para o conjunto dos trabalhadores, para os do sexo masculino e para os do sexo feminino, por $\boldsymbol{n}_{\boldsymbol{n}} \boldsymbol{n}_{\mathbf{1}}$ e $\boldsymbol{n}_{\mathbf{2}}$ o número de observações em que se basearam as regressões estimadas, e por $p$ o número de parâmetros utilizados, o valor de $F$ é calculado através da seguinte expressão:

$$
F=\frac{\frac{S-\left(S_{1}+S_{2}\right)}{p}}{\frac{\left(S_{1}+S_{2}\right)}{n_{1}+n_{2}-2 p}}
$$

o valor crítico de $F$ é obtido nas tabelas publicadas considerandose $p$ graus de liberdade para $\circ$ numerador e $\left(n_{1}+n_{2}-2 p\right)$ para $\circ$ denominador. 
Tabela 26. Valores de $F$ obtidos ${ }^{(1)}$ para 0 teste de Chow para diferença estrutural entre as equações de rendimento para homens e mulheres, dentro de cada classe ocupacional. São Paulo e Pernambuco, 1981 a 1990.

\begin{tabular}{cllrrr}
\hline & \multicolumn{5}{c}{ CLASSE } \\
\cline { 2 - 6 } ANO/SEXO & \multicolumn{1}{c}{$\mathbf{1}$} & \multicolumn{1}{c}{$\mathbf{2}$} & $\mathbf{3}$ & \multicolumn{1}{c}{$\mathbf{5}$} \\
\hline SÃO PAULO & & & & & \\
1981 & 3,880 & 3,471 & 6,792 & 8,444 & 3,365 \\
1983 & 2,715 & 5,485 & 10,632 & 10,204 & 2,188 \\
1984 & 3,272 & 3,682 & 3,167 & 7,926 & 3,105 \\
1985 & 3,849 & 3,670 & 6,774 & 12,087 & 5,284 \\
1987 & $1,371 \mathrm{~ns}$ & $1,454 \mathrm{~ns}$ & 5,252 & 6,466 & $1,900 \mathrm{~ns}$ \\
1988 & 3,797 & $1,577^{*}$ & 9,318 & 6,698 & $2,036^{* *}$ \\
1989 & $1,982^{* *}$ & 2,260 & 5,719 & 4,625 & 3,288 \\
1990 & $1,889^{* *}$ & $1,709^{*}$ & 6,209 & 2,969 & 2,664 \\
& & & & & \\
PERNAMBUCO & & & & & \\
1981 & $1,325 \mathrm{~ns}$ & $1,082 \mathrm{~ns}$ & 4,292 & 6,337 & 7,753 \\
1983 & 2,555 & $1,735^{*}$ & 4,893 & 8,911 & 17,506 \\
1984 & 3,994 & $0,897 \mathrm{~ns}$ & 4,882 & 10,104 & 10,953 \\
1985 & 6,859 & $1,384 \mathrm{~ns}$ & 4,813 & 16,594 & 17,393 \\
1987 & 2,979 & $0,750 \mathrm{~ns}$ & 2,787 & 4,888 & 3,308 \\
1988 & 3,462 & $1,576^{*}$ & 2,930 & 4,063 & 3,730 \\
1989 & $0,868 \mathrm{~ns}$ & $0,943 \mathrm{~ns}$ & $1,463 \mathrm{~ns}$ & 5,629 & 3,532 \\
1990 & $1,679^{*}$ & $1,470 \mathrm{~ns}$ & 1,764 & 6,676 & 3,719 \\
\hline
\end{tabular}

(1) Os valores de $F$ são estatisticamente significativos ao nível de $1 \%$, com exceção dos assinalados por ns (que são não significativos), por * (significativos a 5\%) e por ** (significativos a $10 \%$ ).

Os resultados desse teste permitem verificar que, de modo geral, as equações estimadas para os homens diferem estatisticamente das obtidas para as mulheres, ao nível de significância de 1\%. Entretanto, deve-se notar que, provavelmente em decorrência do número reduzido de observações na classe 2, o teste $F$ não se mostrou 
significativo em grande parte das equações estimadas para os pernambucanos inseridos nessa classe.

Os coeficientes associados às variáveis explanatórias das cento e sessenta regressões assim como os seus respectivos antilogaritmos encontram-se relacionados nas trinta e duas tabelas que compõem o Apêndice G. Tais dados estão colocados em apêndice não apenas porque a análise de cada caso em particular é inviável, pelo grande volume de informações, como também desnecessária, visto que eles também se constituem numa etapa intermediária na execução desse trabalho. Todavia, para enfatizar alguns pontos de interesse, julga-se conveniente apresentar os coeficientes das equações de rendimento estimadas por sexo, classe e estado para um ano selecionado. A opção por 1984 decorre do fato de que os coeficientes do modelo ajustado para esse ano revelam comportamento similar ao dos obtidos na maioria dos anos considerados.

As estimativas dos diferenciais de rendimentos dos homens e das mulheres alocados nas cinco classes ocupacionais no estado de São Paulo associados às variáveis selecionadas estão relatados na tabela 27 . A tabela subsequente registra os números indices proporcionais às estimativas desses diferenciais, isto é, o valor esperado do rendimento de uma dada categoria de cada um dos fatores em relação ao rendimento médio da categoria definida como base nesse fator. 
Tabela 27. Estimativa dos coeficientes das equações de rendimento ajustadas para a PEA ocupada, (1) por sexo e classe ocupacional. São Paulo, 1984.(2)

\begin{tabular}{|c|c|c|c|c|c|}
\hline \multirow[t]{2}{*}{ SEXO/FATOR } & \multicolumn{5}{|c|}{ CLASSES } \\
\hline & 1 & 2 & 3 & 4 & 5 \\
\hline \multicolumn{6}{|l|}{ HOMENS } \\
\hline INTERCEPTO & 6,833179 & 7,253827 & 6,755756 & 7,003151 & 6,920788 \\
\hline \multicolumn{6}{|l|}{ ESCOLARIDADE } \\
\hline Primánio Incompleto & $0,13899 \mathrm{~ns}$ & $0,28724 \mathrm{~ns}$ & 0,33237 & 0,34929 & 0,30175 \\
\hline Primário Completo & 0,33580 & 0,58119 & 0,55402 & 0,62711 & 0,51488 \\
\hline Ginásio Incompleto & 0,62635 & 0,62583 & 0,72908 & 0,71061 & 0,66970 \\
\hline Ginásio Completo & 0,67329 & 0,61363 & 0,92408 & 1,02372 & 0,93279 \\
\hline Colegial e Superior & 1,44328 & 1,36014 & 1,23066 & 1,76205 & 1,51567 \\
\hline \multicolumn{6}{|l|}{ IDADE } \\
\hline 18 a 19 anos & $0,12121 \mathrm{~ns}$ & 0,56094 & 0,30036 & $0,12958 *$ & 0,18194 \\
\hline 20 a 24 anos & $0,21507 \mathrm{~ns}$ & $0,40118 \mathrm{~ns}$ & 0,57540 & 0,25052 & 0,49734 \\
\hline 25 a 29 anos & 0,59180 & 0,67195 & 0,89607 & 0,52308 & 0,88293 \\
\hline 30 a 39 anos & 0,88305 & 0,99353 & 1,09878 & 0,83271 & 1,15212 \\
\hline 40 a 49 anos & 0,98272 & 1,17492 & 1,33531 & 0,90006 & 1,28499 \\
\hline 50 anos ou mais & 0,69332 & 1,06385 & 1,29095 & 0,85886 & 1,32621 \\
\hline \multicolumn{6}{|l|}{ SITUAÇÃO } \\
\hline Região Urbana & 0,36833 & $0,14163 \mathrm{~ns}$ & $0,12342 \mathrm{~ns}$ & 0,27182 & 0,16966 \\
\hline \multicolumn{6}{|l|}{ POSIÇÃO NA OCUPAÇÃO } \\
\hline Autônomos e empregadores & 0,49315 & $0,25830 *$ & 0,40808 & 0,27175 & 0,44936 \\
\hline \multicolumn{6}{|c|}{ POSSE DE CARTEIRA ASSINADA } \\
\hline Com Carteira Assinada & 0,27512 & $0,09480 \mathrm{~ns}$ & 0,44381 & 0,52954 & 0,42570 \\
\hline \multicolumn{6}{|l|}{ MULHERES } \\
\hline INTERCEPTO & 6,606025 & 7,133882 & 7,257078 & 6,873895 & 7,086533 \\
\hline \multicolumn{6}{|l|}{ ESCOLARIDADE } \\
\hline Primário Incompleto & 0,14045 & 0,55107 & $0,06756 \mathrm{~ns}$ & 0,37633 & $0,44368^{*}$ \\
\hline Primário Completo & 0,32047 & 0,73220 & 0,26030 & 0,60479 & 0,70158 \\
\hline Ginásio Incompleto & 0,55851 & 0,89375 & 0,47011 & 0,73463 & 0,86615 \\
\hline Ginásio Completo & 0,77994 & 1,05577 & 0,54888 & 0,99118 & 0,77421 \\
\hline Colegial e Superior & 1,65625 & 1,74525 & 0,89984 & 1,90089 & 1,51532 \\
\hline \multicolumn{6}{|l|}{ IDADE } \\
\hline 18 a 19 anos & 0,20385 & $-0,24636 \mathrm{~ns}$ & 0,12924 & $0,14434 \mathrm{~ns}$ & $-0,05408 \mathrm{~ns}$ \\
\hline 20 a 24 anos & 0,42751 & $0,28577^{*}$ & 0,34055 & 0,18324 & $0,39251^{*}$ \\
\hline 25 a 29 anos & 0,72257 & 0,56039 & 0,71011 & 0,41817 & 0,90881 \\
\hline 30 a 39 anos & 0,96070 & 0,59827 & 0,82815 & 0,72088 & 0,98321 \\
\hline 40 a 49 anos & 1,04860 & 0,80521 & 0,95360 & 0,74453 & 1,02411 \\
\hline 50 anos ou mais & 0,90907 & 0,84691 & 0,76098 & 0,69068 & 0,95825 \\
\hline \multicolumn{6}{|l|}{ SITUAÇÃO } \\
\hline Região Urbana & 0,12681 & $0,09711 \mathrm{~ns}$ & $0,01275 \mathrm{~ns}$ & 0,31493 & $-0,12157 \mathrm{~ns}$ \\
\hline \multicolumn{6}{|l|}{ POSIÇÃO NA OCUPAÇÃO } \\
\hline Autônomos e empregadores & 0,22320 & 0,16416 & 0,28078 & 0,16535 & 0,57277 \\
\hline \multicolumn{6}{|c|}{ POSSE DE CARTEIRA ASSINADA } \\
\hline Com Carteira Assinada & 0,42158 & $-0,07862 \mathrm{~ns}$ & 0,39243 & 0,33312 & 0.37320 \\
\hline
\end{tabular}

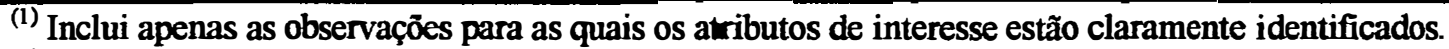

(2) Todos os coeficientes são estatisticamente significativos ao nível de $5 \%$, com exceção dos assinalados por asterisco (que são significativos ao nível de 10\%) e por ns (que são não-significativos). 
Tabela 28. Números-índices obtidos dos coeficientes das equações de rendimento ajustadas para a PEA

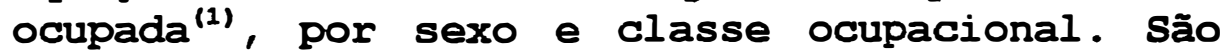
Paulo, 1984. (2)

\begin{tabular}{|c|c|c|c|c|c|}
\hline \multirow[t]{2}{*}{ SEXO/FATOR } & \multicolumn{5}{|c|}{ CLASSES } \\
\hline & 1 & 2 & 3 & 4 & 5 \\
\hline \multicolumn{6}{|l|}{ HOMENS } \\
\hline INTERCEPTO & 928,14 & 1413,50 & 858,99 & 1100,10 & 1013,12 \\
\hline \multicolumn{6}{|l|}{ ESCOLARIDADE } \\
\hline Primánio Incompleto & $1,149 \mathrm{~ns}$ & $1,333 \mathrm{~ns}$ & 1,394 & 1,418 & 1,352 \\
\hline Primário Completo & 1,399 & 1,788 & 1,740 & 1,872 & 1,673 \\
\hline Ginásio Incompleto & 1,871 & 1,870 & 2,073 & 2,035 & 1,954 \\
\hline Ginásio Completo & 1,961 & 1,847 & 2,520 & 2,784 & 2,542 \\
\hline Colegial e Superior & 4,235 & 3,897 & 3,423 & 5,824 & 4,552 \\
\hline \multicolumn{6}{|l|}{ DADE } \\
\hline 18 a 19 anos & $1,129 \mathrm{~ns}$ & 1,752 & 1,350 & $1,138^{*}$ & 1,200 \\
\hline 20 a 24 anos & $1,240 \mathrm{~ns}$ & $1,494 \mathrm{~ns}$ & 1,778 & 1,285 & 1,644 \\
\hline 25 a 29 anos & 1,807 & 1,958 & 2,450 & 1,687 & 2,418 \\
\hline 30 a 39 anos & 2,418 & 2,701 & 3,001 & 2,300 & 3,165 \\
\hline 40 a 49 anos & 2,672 & 3,238 & 3,801 & 2,460 & 3,615 \\
\hline 50 anos ou mais & 2,000 & 2,898 & 3,636 & 2,360 & 3,767 \\
\hline \multicolumn{6}{|l|}{ SITUAÇÃO } \\
\hline Região Urbana & 1,445 & $1,152 \mathrm{~ns}$ & $1,131 \mathrm{~ns}$ & 1,312 & 1,185 \\
\hline \multicolumn{6}{|l|}{ POSIÇÃO NA OCUPAÇÃO } \\
\hline Autônomos e empregadores & 1,637 & $1,295^{*}$ & 1,504 & 1,312 & 1,567 \\
\hline \multicolumn{6}{|c|}{ POSSE DE CARTEIRA ASSINADA } \\
\hline Com Carteira Assinada & 1,317 & $1,099 \mathrm{~ns}$ & 1,559 & 1,698 & 1,531 \\
\hline \multicolumn{6}{|l|}{ MULHERES } \\
\hline INTERCEPTO & 739,54 & 1253,74 & 1418,11 & 966,71 & 1195,76 \\
\hline \multicolumn{6}{|l|}{ ESCOLARIDADE } \\
\hline Primário Incompleto & 1,151 & 1,735 & $1,070 \mathrm{~ns}$ & 1,457 & $1,558^{*}$ \\
\hline Primário Completo & 1,378 & 2,080 & 1,297 & 1,831 & 2,017 \\
\hline Ginásio Incompleto & 1,748 & 2,444 & 1,600 & 2,085 & 2,378 \\
\hline Ginásio Completo & 2,181 & 2,874 & 1,731 & 2,694 & 2,169 \\
\hline Colegial e Superior & 5,240 & 5,727 & 2,459 & 6,692 & 4,551 \\
\hline \multicolumn{6}{|l|}{ IDADE } \\
\hline 18 a 19 anos & 1,226 & $0,782 \mathrm{~ns}$ & 1,138 & $1,155 \mathrm{~ns}$ & $0,947 \mathrm{~ns}$ \\
\hline 20 a 24 anos & 1,533 & $1,331^{*}$ & 1,406 & 1,201 & $1,481^{*}$ \\
\hline 25 a 29 anos & 2,060 & 1,751 & 2,034 & 1,519 & 2,481 \\
\hline 30 a 39 anos & 2,614 & 1,819 & 2,289 & 2,056 & 2,673 \\
\hline 40 a 49 anos & 2,854 & 2,237 & 2,595 & 2,105 & 2,785 \\
\hline \multirow{2}{*}{\multicolumn{6}{|c|}{$\begin{array}{l}\text { so anos ou mais } \\
\text { SITUAÇÃO }\end{array}$}} \\
\hline & & & & & \\
\hline Região Urbana & 1,135 & $1,102 \mathrm{~ns}$ & $1,013 \mathrm{~ns}$ & 1,370 & $0,886 \mathrm{~ns}$ \\
\hline POSIÇÃOO NA OCUPAÇÃO & & & & & \\
\hline \multirow{2}{*}{\multicolumn{6}{|c|}{ POSSE DE CARTEIRA ASSINADA }} \\
\hline & & & & & \\
\hline Com Carteira Assinada & 1,524 & 0,924 ns & 1,481 & 1,395 & 1,452 \\
\hline
\end{tabular}

${ }^{1}$ Inclui apenas as observações para as quais os atributos de interesse estão claramente identificados.

(2) Todos os coeficientes são estatisticamente significativos ao nível de $5 \%$, com exceção dos assinalados por asterisco (que são significativos ao nível de 10\%) e por ns (que são não-significativos). 
A análise desses coeficientes permite apontar para alguns comportamentos que podem ser considerados gerais, no sentido de compartilhados pelas equações ajustadas para os dois sexos e cinco classes, e outros especificos. Dentre os primeiros nota-se que, consistentemente com o relatado em outras pesquisas empíricas realizadas no tema, rendimento e educação são positivamente relacionados. Da mesma forma, a remuneração média tende a aumentar com a idade. Tomando-se como base o rendimento médio das pessoas que têm de 10 a 17 anos verifica-se que, depois de descontados os efeitos das demais variáveis incluídas no modelo, o valor esperado da renda do trabalho na ocupação principal cresce conforme aumenta a faixa etária, atingindo o máximo, na maioria dos casos, entre quarenta e quarenta e nove anos e reduzindo-se ligeiramente para os que têm cinqüenta anos ou mais. Notase, também, que os rendimentos do trabalhador da zona urbana são quase sempre maiores do que os da zona rural, como o são os auferidos pelos trabalhadores com carteira assinada em relação aos dos que estão em situação de informalidade. Os rendimentos dos empregadores e autônomos são também, conforme esperado, maiores do que 0 dos empregados. Ressalte-se que, provavelmente por problemas de multicolinearidade entre as variáveis, alguns coeficientes são não-significativos.

A análise da evolução dos rendimentos por faixa etária é detalhada a seguir para levar em consideração as diferenças dos coeficientes por sexo e estrato ocupacional. objetiva-se com esse procedimento verificar se a interpretação oferecida por Polachek (1979) para a segregação de homens e de mulheres em diferentes ocupações encontra suporte empírico nos resultados da presente pesquisa. 
Conforme descrito no Capítulo 2, Polachek alega que as mulheres, antecipando interrupções ou a saída precoce do mercado de trabalho, optam por ocupações nas quais a remuneração inicial é mais elevada, mas os aumentos salariais decorrentes da maior experiência (assim como a depreciação dos rendimentos auferidos devido à interrupção da atividade produtiva) são menores. Assim, se válida a argumentação, esperar-se-ia que as trabalhadoras inseridas em ocupações tipicamente femininas auferissem remuneração inicial maior e taxas de crescimento dos rendimentos com a idade menores do que as alocadas nas ocupações tipicamente masculinas. Ora, as informações contidas na tabela 28 não confirmam tais hipóteses. A análise das equações de rendimento estimadas para as mulheres paulistas alocadas nas ocupações das classes extremas permite notar que embora o crescimento do rendimento esperado com o aumento da idade seja ligeiramente mais nítido nas ocupações com maior proporção de homens, as ocupações femininas não são compensadas por uma remuneração inicial maior. Ao contrário, a renda do trabalho na ocupação principal auferida pelas mulheres do grupo de referência - que têm menos de dezessete anos sendo, portanto, ingressantes no mercado de trabalho - das trabalhadoras inseridas em ocupações tipicamente femininas é significativamente menor do que a das alocadas em ocupações tipicamente masculinas, conforme descrito pelos interceptos das equações das classes 1 e 5, respectivamente.

Os dados mostram, também, que quando são analisadas as equações ajustadas para a parcela masculina da PEA paulista o crescimento da remuneração por idade nas ocupações tipicamente masculinas é significativamente maior. A figura 5 mostra a evolução segundo a idade da 
renda estimada para os homens inseridos nas ocupações do quinto estrato em relação a dos que se encontram nas ocupações do primeiro. Documenta, também, a evolução dos rendimentos relativos das mulheres desses dois grupos nas faixas etárias consideradas, ilustrando as diferenças mencionadas.

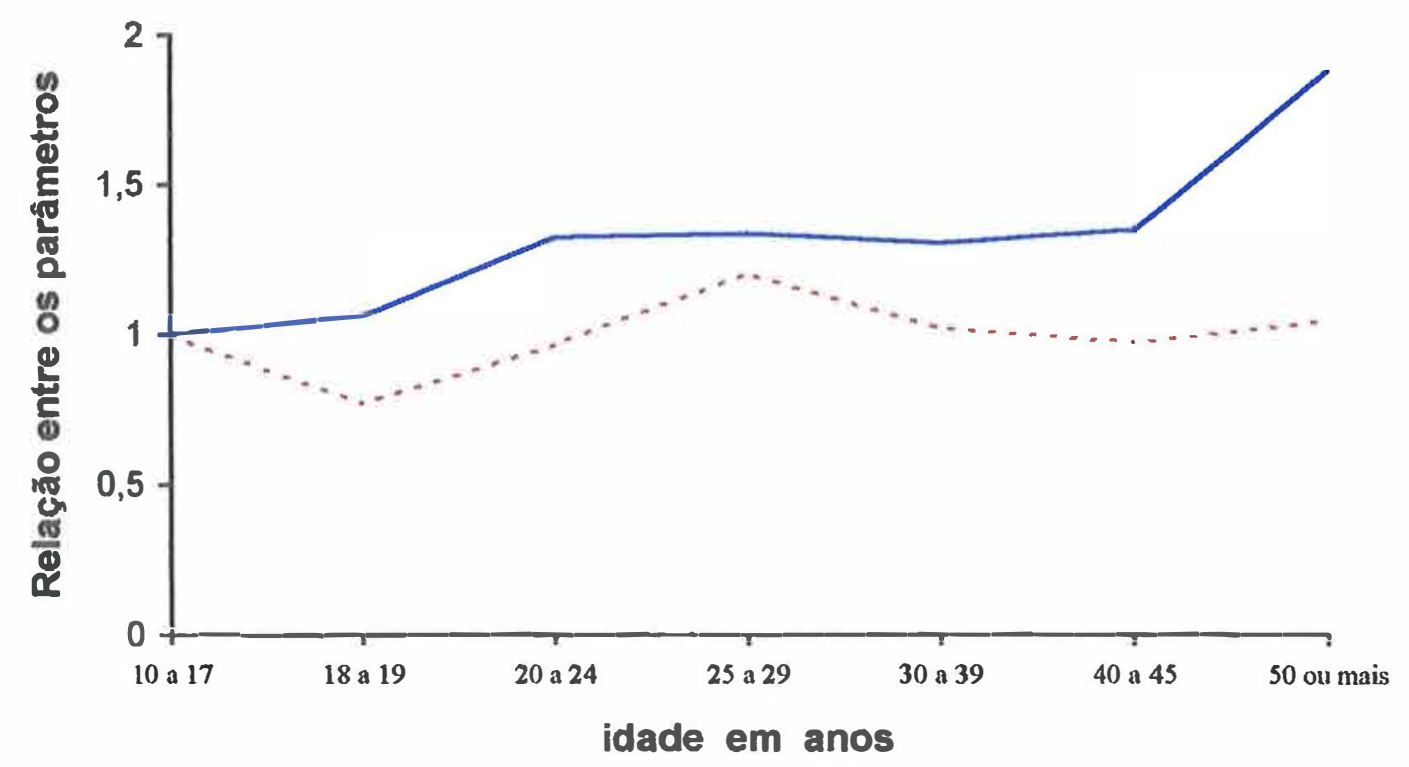

-... - antilogaritmos dos coeficientes associados à idade de mulheres nas ocupaçōes da classe 5 em relaçă aos das alocadas nas ocupaçỏes da classe 1.

antilogaritmos dos coeficientes associados à idade dos homens em ocupações da classe 5 em relaçăo aos dos alocados em ocupações da classe 1.

Figura 5. Relação entre os rendimentos por idade dos trabalhadores das classes extremas. São Paulo, 1984 . 
Verifica-se que com o crescimento da idade os homens alocados em ocupações masculinas auferem aumentos de remuneração muito mais significativos do que os que estão em ocupações femininas. Já para as mulheres, o acesso a uma ocupação masculina não lhes garante que as recompensas pecuniárias à experiência sejam maiores do que as obtidas pelas suas congêneres alocadas em ocupações femininas.

A análise das informações referentes a Pernambuco, apresentadas nas tabelas 29 e 30, confirma a existência de algumas similaridades com os resultados descritos para são Paulo, mas também a existência de divergências intrigantes. Dentre as primeiras nota-se que, descontada a influência das demais variáveis, rendimento e educação, assim como rendimento e idade, são positivamente correlacionados. Verifica-se, também, que a posse de carteira de trabalho assinada, residência na zona urbana e posição de autônomo ou empregador na ocupação implicam, na maioria das classes, rendimentos esperados maiores. 
Tabela 29. Estimativa dos coeficientes das equações de rendimento ajustadas para a PEA ocupada, (1) por sexo e classe ocupacional. Pernambuco, 1984.

\begin{tabular}{|c|c|c|c|c|c|}
\hline \multirow{2}{*}{ SEXO/FATOR } & \multicolumn{5}{|c|}{ CLASSES } \\
\hline & 1 & 2 & 3 & 4 & 5 \\
\hline \multicolumn{6}{|l|}{ HOMENS } \\
\hline INTERCEPTO & 6,35574 & 6,64027 & 7,00538 & 6,86574 & 7,14985 \\
\hline \multicolumn{6}{|l|}{ ESCOLARIDADE } \\
\hline Primário Incompleto & $-0,03063 \mathrm{~ns}$ & $0,86426 \mathrm{~ns}$ & $0,04226 \mathrm{~ns}$ & $-0,04860 \mathrm{~ns}$ & 0,14638 \\
\hline Primário Completo & $0,45588 \mathrm{~ns}$ & 1,53119 & $0,02094 \mathrm{~ns}$ & 0,22753 & 0,34806 \\
\hline Ginásio & 0,51766 & $0,87867 \mathrm{~ns}$ & $0,28245 *$ & 0,33693 & 0,43806 \\
\hline Colegial & 1,03848 & 1,22922 & 0,78305 & 1,37086 & 1,31982 \\
\hline \multicolumn{6}{|l|}{ IDADE } \\
\hline 18 a 19 anos & $0,43640 \mathrm{~ns}$ & $0,22323 \mathrm{~ns}$ & $0,35727 \mathrm{~ns}$ & $0,30043 *$ & 0,15253 \\
\hline 20 a 24 a & 0,85193 & $0,54826 \mathrm{~ns}$ & 0,79378 & 0,65484 & 0,30780 \\
\hline 25 a 2 & 1,15201 & $0,93635 *$ & 0,95413 & 0,80366 & 0,48436 \\
\hline 30 a 39 & 0,83320 & 1,59720 & 1,34285 & 1,12323 & 0,59428 \\
\hline $40 \mathrm{a}$ & 1,12079 & 1,89851 & 1,60106 & 1,27084 & 0,73824 \\
\hline 50 anos ou mais & 0,89653 & 1,35141 & 1,65682 & 1,08774 & 0,48527 \\
\hline \multicolumn{6}{|l|}{ SITUAÇÃO } \\
\hline \multirow{2}{*}{\multicolumn{6}{|c|}{ POSIÇÃO NA OCUPAÇÃO }} \\
\hline & & & & & \\
\hline Autônomos e empregadores & 1,12770 & $-0,22107 \mathrm{~ns}$ & $-0,15964 \mathrm{~ns}$ & 0,45219 & 0,18013 \\
\hline \multicolumn{6}{|c|}{ POSSE DE CARTEIRA ASSINADA } \\
\hline Com Carteira Assinada & 0,51501 & $0,19071 \mathrm{~ns}$ & 0,36005 & 0,46275 & 0,49693 \\
\hline \multicolumn{6}{|l|}{ MULHERES } \\
\hline INTERCEPTO & 6,36047 & 7,95366 & 7,14619 & 7,00250 & 6,99389 \\
\hline \multicolumn{6}{|l|}{ ESCOLARIDADE } \\
\hline Primário Incompleto & $0,06136 \mathrm{~ns}$ & $-0,61772 \mathrm{~ns}$ & $-0,51255$ & $-0,13333 \mathrm{~ns}$ & $0,17355 \mathrm{n}$ \\
\hline Primánio Completo & 0,28714 & $-0,37984 \mathrm{~ns}$ & 0,22919 ns & $0,08854 \mathrm{~ns}$ & 0,40456 \\
\hline Ginásio & 0,34662 & $-0,58407 \mathrm{~ns}$ & $0,04881 \mathrm{~ns}$ & $0,11842 \mathrm{~ns}$ & $0,18700 \mathrm{~ns}$ \\
\hline Colegial e Su & 1,27948 & $0,28853 \mathrm{~ns}$ & 0,95292 & 1,13369 & 1,66290 \\
\hline \multicolumn{6}{|l|}{ IDADE } \\
\hline 18 a 19 anos & $0,15117 \mathrm{~ns}$ & $-0,26404 \mathrm{~ns}$ & $0,51883 \mathrm{~ns}$ & $-0,18667 \mathrm{~ns}$ & $-0,04018 \mathrm{~ns}$ \\
\hline 20 a 24 anos & 0,38388 & $0,20813 \mathrm{~ns}$ & 0,65227 & $-0,07535 \mathrm{~ns}$ & $0,27439 \mathrm{~ns}$ \\
\hline 25 a 29 & 0,60788 & $0,32863 \mathrm{~ns}$ & 0,98570 & $0,11778 \mathrm{~ns}$ & 0,41839 \\
\hline 30 a 39 anos & 0,72193 & $0,60035 \mathrm{~ns}$ & 1,12279 & 0,75106 & 0,33259 \\
\hline 40 a 49 anos & 0,72491 & $0,74911 \mathrm{~ns}$ & 1,08095 & 0,70792 & 0,40550 \\
\hline 50 anos ou mais & 0,64066 & $0,56247 \mathrm{~ns}$ & 1,69613 & $0,39309 \mathrm{~ns}$ & $0,06996 \mathrm{n}$ \\
\hline \multicolumn{6}{|l|}{ SITUAÇÃO } \\
\hline Região Urbana & $-0,05457 \mathrm{~ns}$ & $0,50724 \mathrm{~ns}$ & $-0,21756 \mathrm{~ns}$ & $0,18195 \mathrm{~ns}$ & $0,09491 \mathrm{~ns}$ \\
\hline \multicolumn{6}{|l|}{ POSIÇÃO NA OCUPAÇÃO } \\
\hline Autônomos e empregadores & 0,34709 & $-0,79157$ & $0,23802 *$ & $0,23892 \mathrm{~ns}$ & $0,07803 n$ \\
\hline \multicolumn{6}{|c|}{ POSSE DE CARTEIRA ASSINADA } \\
\hline Com Carteira Assinada & 0,79201 & $0,03006 \mathrm{~ns}$ & $0,20760 *$ & 0,53132 & 0,82069 \\
\hline
\end{tabular}

(1) Inclui apenas as observações para as quais os atributos de interesse estão claramente identificados.

(2) Todos os coeficientes são estatisticamente significativos ao nível de $5 \%$, com exceção dos assinalados por asterisco (que são significativos ao nivel de 10\%) e por ns (que são não-significativos). 
Tabela 30. Números-índices obtidos dos coeficientes das equações de rendimento ajustadas para a PEA ocupada (1), por sexo e classe ocupacional. Pernambuco, 1984. (2)

\begin{tabular}{|c|c|c|c|c|c|}
\hline \multirow[t]{2}{*}{ SEXO/FATOR } & \multicolumn{5}{|c|}{ CLASSES } \\
\hline & 1 & 2 & 3 & 4 & 5 \\
\hline \multicolumn{6}{|l|}{ HOMENS } \\
\hline INTERCEPTO & 575,791 & 765,298 & 1102,553 & 958,859 & 1273,920 \\
\hline \multicolumn{6}{|l|}{ ESCOLARIDADE } \\
\hline Primário Incompleto & $0,970 \mathrm{~ns}$ & $2,373 \mathrm{~ns}$ & $1,043 \mathrm{~ns}$ & $0,953 \mathrm{~ns}$ & 1,158 \\
\hline Primário Completo & $1,578 \mathrm{~ns}$ & 4,624 & $1,021 \mathrm{~ns}$ & 1,255 & 1,416 \\
\hline Ginásio & 1,678 & $2,408 \mathrm{~ns}$ & $1,326^{*}$ & 1,401 & 1,550 \\
\hline Colegial e Superior & 2,825 & 3,419 & 2,188 & 3,939 & 3,743 \\
\hline \multicolumn{6}{|l|}{ IDADE } \\
\hline 18 a 19 anos & $1,547 \mathrm{~ns}$ & $1,250 \mathrm{~ns}$ & $1,429 \mathrm{~ns}$ & $1,350 *$ & 1,165 \\
\hline 20 a 24 anos & 2,344 & $1,730 \mathrm{~ns}$ & 2,212 & 1,925 & 1,360 \\
\hline 25 a 29 anos & 3,165 & $2,551 *$ & 2,596 & 2,234 & 1,623 \\
\hline 30 a 39 anos & 2,301 & 4,939 & 3,830 & 3,075 & 1,812 \\
\hline 40 a 49 anos & 3,067 & 6,676 & 4,958 & 3,564 & 2,092 \\
\hline 50 anos ou mais & 2,451 & 3,863 & 5,243 & 2,968 & 1,625 \\
\hline \multicolumn{6}{|l|}{ SITUAÇÃO } \\
\hline Região Urbana & $1,163 \mathrm{~ns}$ & $0,865 \mathrm{~ns}$ & $1,220 \mathrm{~ns}$ & $1,156 *$ & 1,276 \\
\hline \multicolumn{6}{|l|}{ POSIČÃO NA OCUPAÇÃO } \\
\hline Autônomos e empregadores & 3,089 & $0,802 \mathrm{~ns}$ & $0,852 \mathrm{~ns}$ & 1,572 & 1,197 \\
\hline \multicolumn{6}{|c|}{ POSSE DE CARTEIRA ASSINADA } \\
\hline Com Carteira Assinada & 1,674 & $1,210 \mathrm{~ns}$ & 1,433 & 1,588 & 1,644 \\
\hline \multicolumn{6}{|l|}{ MULHERES } \\
\hline INTERCEPTO & 578,520 & 2845,981 & 1269,257 & 1099,373 & 1089,955 \\
\hline \multicolumn{6}{|l|}{ ESCOLARIDADE } \\
\hline Primário Incompleto & $1,063 \mathrm{~ns}$ & $0,539 \mathrm{~ns}$ & 0,599 & $0,875 \mathrm{~ns}$ & $1,190 \mathrm{~ns}$ \\
\hline Primário Completo & 1,333 & $0,684 \mathrm{~ns}$ & $1,258 \mathrm{~ns}$ & $1,093 \mathrm{~ns}$ & 1,499 \\
\hline Ginásio & 1,414 & $0,558 \mathrm{~ns}$ & $1,050 \mathrm{~ns}$ & $1,126 \mathrm{~ns}$ & $1,206 \mathrm{~ns}$ \\
\hline Colegial e Superior & 3,595 & $1,334 \mathrm{~ns}$ & 2,593 & 3,107 & 5,275 \\
\hline \multicolumn{6}{|l|}{ IDADE } \\
\hline 18 a 19 anos & $1,163 \mathrm{~ns}$ & $0,768 \mathrm{~ns}$ & $1,680 \mathrm{~ns}$ & $0,830 \mathrm{~ns}$ & $0,961 \mathrm{~ns}$ \\
\hline 20 a 24 anos & 1,468 & $1,231 \mathrm{~ns}$ & 1,920 & $0,927 \mathrm{~ns}$ & $1,316 \mathrm{~ns}$ \\
\hline 25 a 29 anos & 1,837 & $1,389 \mathrm{~ns}$ & 2,680 & $1,125 \mathrm{~ns}$ & 1,520 \\
\hline 30 a 39 anos & 2,058 & $1,823 \mathrm{~ns}$ & 3,073 & 2,119 & 1,395 \\
\hline 40 a 49 anos & 2,065 & $2,115 \mathrm{~ns}$ & 2,947 & 2,030 & 1,500 \\
\hline 50 anos ou mais & 1,898 & $1,755 \mathrm{~ns}$ & 5,453 & $1,482 \mathrm{~ns}$ & $1,072 \mathrm{~ns}$ \\
\hline \multicolumn{6}{|l|}{ SITUAÇÃO } \\
\hline Região Urbana & $0,947 \mathrm{~ns}$ & $1,661 \mathrm{~ns}$ & 0,804 ns & $1,200 \mathrm{~ns}$ & $1,100 \mathrm{~ns}$ \\
\hline \multicolumn{6}{|l|}{ POSIÇÃO NA OCUPAÇÃO } \\
\hline Autônomos e empregadores & 1,415 & 0,453 & $1,269 *$ & $1,270 \mathrm{~ns}$ & $1,081 \mathrm{~ns}$ \\
\hline \multicolumn{6}{|c|}{ POSSE DE CARTEIRA ASSINADA } \\
\hline Com Carteira Assinada & 2,208 & $1,031 \mathrm{~ns}$ & $1,231 *$ & 1,701 & 2,272 \\
\hline
\end{tabular}

(1) Inclui apenas as observações para as quais os atributos de interesse estão claramente identificados.

(2) Todos os coeficientes são estatisticamente significativos ao nível de $5 \%$, com exceção dos assinalados por asterisco (que são significativos ao nivel de 10\%) e por ns (que são não-significativos). 
Quando se procura estabelecer comparações entre os coeficientes das regressões ajustadas para as trabalhadoras (e trabalhadores) das diferentes classes é que as divergências se manifestam. A magnitude dos interceptos mostra que justamente nas ocupações com maior grau de masculinidade (as da classe 5) a remuneração dos ingressantes no mercado de trabalho é maior enquanto que o crescimento dos coeficientes associados à idade é menor. Ou seja, os argumentos de Polachek parecem se ajustar perfeitamente para sugerir que as mulheres desse estado deveriam, se racionais, estar concentradas nas ocupações masculinas ao invés de nas femininas.

A figura 6 ilustra esses aspectos documentando 0 crescimento com a idade dos rendimentos das mulheres lotadas nas ocupações do grupo 5 em relação aos das inseridas nas ocupações do grupo 1. O crescimento dos rendimentos relativos dos homens dessas duas classes também é apresentado nessa figura. 


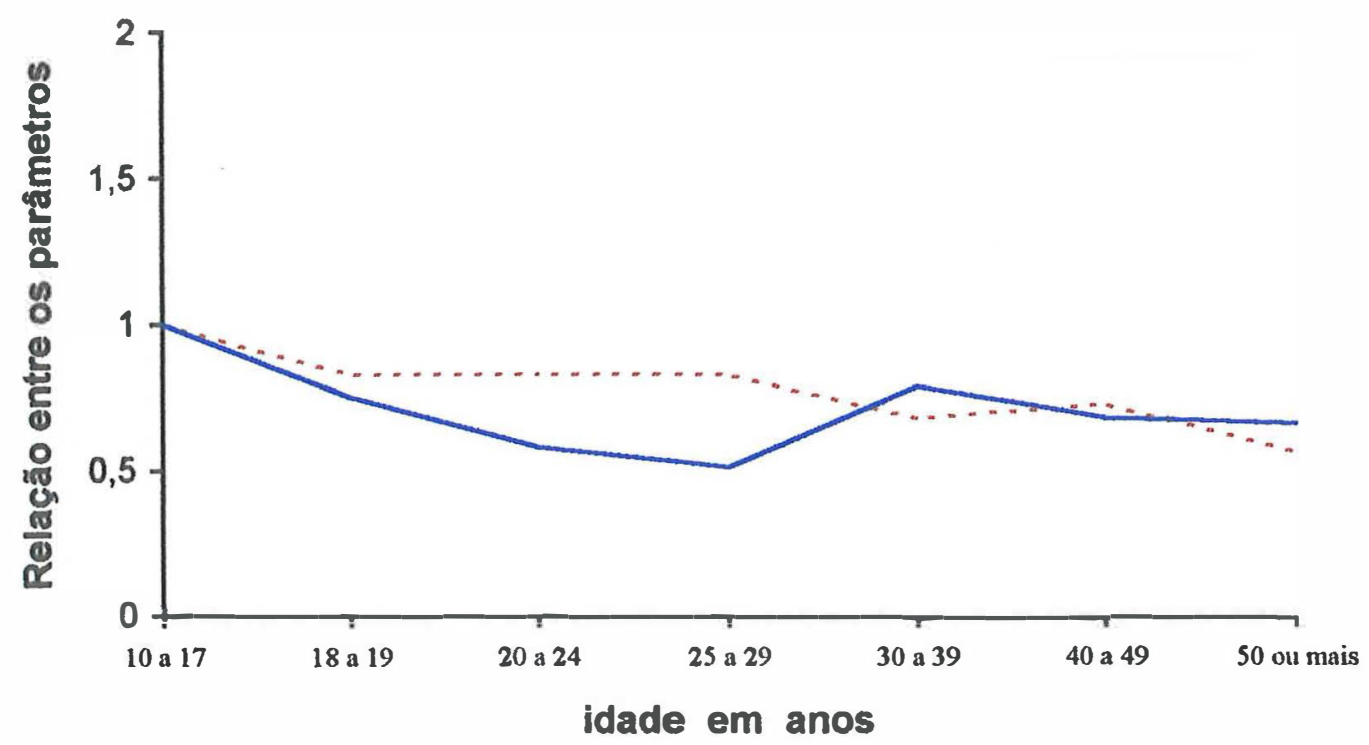

-. . - antilogaritmos dos coeficientes associados à idade de mulheres nas ocupaçס̋es da classe 5 em relaçåo aos das alocadas nas ocupaçōes da classe 1.

antilogaritmos dos coeficientes associados à idade dos homens em ocupaçס̋es da classe 5 em relaçăo aos dos alocados em ocupaçōes da classe 1.

Figura 6. Relação entre os rendimentos por idade dos trabalhadores das classes extremas. Pernambuco, 1984 .

É interessante notar que quando se comparam os resultados do ajuste do modelo no primeiro estrato com, por exemplo, os obtidos no quarto ou mesmo no terceiro, chegase a conclusões muito próximas às geradas nas comparações das regressões ajustadas para homens e mulheres das classes extremas no estado de São Paulo. Assim, embora o crescimento da remuneração esperada com o aumento da idade, descontada a influência das demais variáveis, seja mais nítido nas ocupações masculinas (categoria 4), as femininas (ocupações da categoria 1) não são compensadas por uma remuneração inicial maior. E mais, o crescimento da 
remuneração com a idade também é muito mais nitido para os homens inseridos em ocupações masculinas do que para as mulheres que se encontram em ocupações dessa mesma classe.

objetivando investigar as razões que levam os pernambucanos lotados nas ocupações da classe 5 a obter menores retornos à experiência, procura-se identificar as principais ocupações desse estrato. As tabelas 31 e 32 especificam quais são essas ocupações e o percentual da mão-de-obra masculina e feminina que absorvem em relação ao total incorporado na classe.

Tabela 31. Principais ocupações da classe 5 quanto à absorção da mão-de-obra masculina. Pernambuco, 1984 .

\begin{tabular}{lrc}
\hline \multicolumn{1}{c}{ OCUPAÇÃo } & No & $\begin{array}{c}\text { \% dos Trabalhadores } \\
\text { da classe 5 }\end{array}$ \\
\hline Trabalhador da agropecuária & 293936 & 30,96 \\
Produtor agropecuário autônomo & 184395 & 19,42 \\
Motorista & 51082 & 5,38 \\
Pedreiro & 47367 & 4,99 \\
Servente de pedreiro & 36697 & 3,86 \\
$\quad$ Total nessas ocupações & 613473 & 64,61 \\
Total de homens na classe & 949497 & \\
\hline
\end{tabular}

Tabela 32. Principais ocupações da classe 5 quanto à absorção da mão-de-obra feminina. Pernambuco, 1984 .

\begin{tabular}{lrc}
\hline \multicolumn{1}{c}{ OCUPAÇÃo } & № & $\begin{array}{c}\text { \% das Trabalhadoras } \\
\text { da classe 5 }\end{array}$ \\
\hline Trabalhador da agropecuária & 66605 & 56,87 \\
Produtor agropecuário autônomo & 31378 & 26,79 \\
Total nessas ocupações & 97983 & 83,66 \\
Total de mulheres na classe & 117115 & \\
\hline
\end{tabular}


Nota-se que cerca de 65\% dos trabalhadores do sexo masculino do estado de Pernambuco que estão alocados nas ocupações tipicamente masculinas se distribuem em apenas cinco categorias ocupacionais: trabalhadores da agropecuária, produtores agropecuários autônomos, motoristas, pedreiros e serventes de pedreiro. De maneira geral, são ocupações que se associam à baixa remuneração e reduzida possibilidade de ascensão profissional, o que pode explicar a estabilidade dos rendimentos dos trabalhadores de diferentes faixas etárias nesse grupo.

A situação das pernambucanas desse estrato é ainda pior, pois $84 \%$ das trabalhadoras que se inserem em ocupações da classe 5 estão concentradas no trabalho agropecuário, como empregadas ou autônomas.

A comparação dessa estrutura ocupacional com a dos trabalhadores paulistas da mesma categoria se faz através da análise das tabelas 33 e 34, que identificam as principais ocupações do grupo 5 para os trabalhadores e trabalhadoras de São Paulo. 
Tabela 33. Principais ocupações da classe 5 quanto à absorção da mão-de-obra masculina. São Paulo, 1984 .

\begin{tabular}{lcc}
\hline \multicolumn{1}{c}{ OCUPAÇÃo } & No & $\begin{array}{c}\text { \% dos Trabalhadores } \\
\text { da classe 5 }\end{array}$ \\
\hline Motorista & 406374 & 10,28 \\
Pedreiro & 314756 & 7,96 \\
Servente de pedreiro & 156370 & 3,96 \\
Produtor agropecuário autônomo & 142466 & 3,60 \\
Comerciante & 125341 & 3,17 \\
Mecânico de veículos & 113854 & 2,88 \\
Pracista e Viajante & 93975 & 2,38 \\
Empresário Ind. transformação & 92867 & 2,35 \\
Mecânico & 84384 & 2,13 \\
Outros proprietários & 83778 & 2,12 \\
Pintor & 81022 & 2,05 \\
Soldador & 75932 & 1,92 \\
Torneiro Mecânico & 75674 & 1,91 \\
Rep. Equipamentos & 74008 & 1,87 \\
Administrador ind. transformação & 72461 & 1,83 \\
Marceneiro & 71278 & 1,80 \\
Ajustador/Montador & 54170 & 1,37 \\
Técnico ind. transformação & 53013 & 1,34 \\
Administrador comércio mercadoria & 51510 & 1,30 \\
Desenhista & 50008 & 1,27 \\
Carpinteiro & 48743 & 1,23 \\
Tratorista agrícola & 45743 & 1,16 \\
Engenheiro & 43950 & 1,11 \\
Almoxarifes & 43007 & 1,09 \\
Encanador & 41174 & 1,04 \\
Pintores a pistola & 40421 & 1,02 \\
Expedidor & 3952496 & 1,00 \\
$\quad$ Total nessas ocupações & & \\
Total de homens na classe & 563 & \\
\hline & & \\
\hline
\end{tabular}


Tabela 34. Principais ocupações da classe 5 quanto à absorção da mão-de-obra feminina. São Paulo, 1984 .

\begin{tabular}{lrr}
\hline \multicolumn{1}{c}{ OCUPAÇÃO } & No & $\begin{array}{c}\text { \% dos Trabalhadores } \\
\text { da classe 5 }\end{array}$ \\
\hline Comerciante & 26571 & 13,41 \\
Outros proprietários & 13587 & 6,86 \\
Administrador comércio de mercadorias & 11400 & 5,75 \\
Administrador ind. transformação & 9379 & 4,73 \\
Feirante & 8951 & 4,52 \\
Pracista e viajante & 8512 & 4,30 \\
Empresário ind. transformação & 8501 & 4,29 \\
Ajustador/Montador & 8116 & 4,10 \\
Operador de prensa & 7226 & 3,65 \\
Repositores de mercadorias & 5084 & 2,57 \\
Trabalhador da indústria papel & 4666 & 2,35 \\
$\quad$ Total nessas ocupações & 111995 & 56,52 \\
$\quad$ Total na classe & 198115 & 100,00 \\
\hline
\end{tabular}

Verifica-se que o elenco de ocupações nas quais se distribui a mão-de-obra masculina paulista inserida nesta classe é muito mais diversificado, com as ocupações de motorista, pedreiro, servente de pedreiro e produtor agropecuário autônomo absorvendo apenas $25,80 \%$ dos postos de trabalhos da classe. Os demais trabalhadores encontramse espalhados por um grupo variado de ocupações ligadas à indústria de transformação, da construção civil e aos serviços, além de ocupar espaços significativos como empresários ou administradores nos diferentes setores. Tal diversidade pode justificar $\circ$ crescimento mais acentuado dos rendimentos esperados dos trabalhadores deste grupo com a idade.

A estrutura ocupacional das trabalhadoras paulistas na classe 5 mostra-se, conforme o esperado, mais limitada, 
embora mais heterogênea do que a apresentada pelas pernambucanas. Neste sentido, as onze principais ocupações absorvem 57\% das trabalhadoras paulistas desta classe, enquanto que em Pernambuco esse mesmo percentual de trabalhadoras está em uma única ocupação - a de trabalhadora da agropecuária.

A análise dessas onze ocupações revela, entretanto, um aspecto surpreendente: dentre as mais importantes em termos de absorção da mão-de-obra, cinco são ocupações nas quais as trabalhadoras são proprietárias ou administradoras (o que pode significar que detêm também algum tipo de participação acionária na empresa). Ou seja, grande parte das trabalhadoras paulistas que em 1984 ingressam em ocupação tipicamente masculina o fazem, não porque venceram as barreiras do mercado de trabalho e foram selecionadas para aquela posição, mas porque detêm a propriedade da empresa. E mais, se parcela substancial das trabalhadoras incorporadas em ocupações desta classe são empresárias, os saltos observados no rendimento com o crescimento da idade podem não ser, necessariamente, uma resposta à maior experiência adquirida, mas sim ao acúmulo de capital nas mãos das pessoas mais idosas.

Os dados contidos nas tabelas que compõem 0 Apêndice C permitem verificar que esta situação não reflete uma especificidade do ano considerado e sim tem caráter geral. Em todos os anos considerados as trabalhadoras pernambucanas de classe 5 estão concentradas nas ocupações da agropecuária, como empregadas ou como autônomas. Percebe-se, também, que uma parcela marginal das mulheres deste estado e classe é empresária (comerciantes, agricultoras, criadoras bovinas, empresárias da indústria de transformação ou da construção civil e outras 
proprietárias) ou administradora (da indústria de transformação e do comércio de mercadorias). Entretanto, dada a grande concentração relatada nas ocupações da agropecuária, caracteristicamente mal remuneradas e sem possibilidades de nenhum tipo de ascensão, entende-se os resultados do ajuste do modelo às pernambucanas desta classe.

As paulistas, por sua vez, apresentam-se distribuidas por um elenco mais diversificado de ocupações. Além disso, confirmando o observado em 1984, encontram-se concentradas em ocupações nas quais são empresárias (da indústria de transformação, do comércio, outras proprietárias, etc.) ou administradoras (do comércio, da indústria de transformação, de financeiras), além de apresentar participação secundária em ocupações que são redutos masculinos tradicionais, tais como as de contador, almoxarife, ajustador/montador e expedidor, entre outras, o que também pode justificar o crescimento mais acentuado da remuneração com a idade.

\section{4. As diferenças de qualificação}

o conjunto de informações apresentadas a seguir objetiva permitir a análise das diferenças entre os homens e mulheres da amostra no tocante ao conjunto de caracteristicas pessoais consideradas explicativas dos rendimentos e da alocação dos indivíduos no mercado de trabalho. Esses dados possibilitam também observar a evolução dessas diferenças no período em questão. 
As diferenças de qualificação entre os homens e mulheres em cada classe ocupacional estão relatadas nas tabelas que compõem o Apêndice $H$.
a) a escolaridade
As tabelas 35 e 36 relatam a distribuição por níveis de escolaridade dos trabalhadores dos estados de São Paulo e Pernambuco, respectivamente, confirmando não apenas a existência de diferenças regionais significativas, como também a de disparidades substanciais por gênero.

Tabela 35. Distribuição percentual de homens e mulheres da PEA ocupada(1) por níveis de escolaridade. São Paulo, 1981 a 1990.

\begin{tabular}{lrrrrrrrr}
\hline $\begin{array}{l}\text { SEXO E NiVEIS DE } \\
\text { ESCOLARIDADE }\end{array}$ & 1981 & 1983 & 1984 & 1985 & 1987 & 1988 & 1989 & \multicolumn{1}{c}{1990} \\
\hline HOMENS & 100,00 & 100,00 & 100,00 & 100,00 & 100,00 & 100,00 & 100,00 & 100,00 \\
Sem Instrução & 9,45 & 8,95 & 8,70 & 8,01 & 6,80 & 6,46 & 6,63 & 6,36 \\
Primário Incompleto & 20,74 & 19,26 & 17,84 & 17,28 & 16,65 & 16,82 & 15,31 & 15,34 \\
Primánio Completo & 27,59 & 27,14 & 26,02 & 26,18 & 25,11 & 24,13 & 23,88 & 22,81 \\
Ginásio Incompleto & 12,52 & 12,36 & 13,20 & 13,71 & 14,37 & 15,37 & 16,55 & 16,32 \\
Ginásio Completo & 8,44 & 8,81 & 10,04 & 9,81 & 10,58 & 10,51 & 10,76 & 10,33 \\
Colegial $^{(2)}$ & 11,90 & 13,18 & 13,46 & 14,37 & 15,42 & 14,88 & 15,46 & 16,83 \\
Superior ${ }^{(3)}$ & 9,36 & 10,30 & 10,74 & 10,65 & 11,09 & 11,84 & 11,41 & 12,01 \\
MULHERES & 100,00 & 100,00 & 100,00 & 100,00 & 100,00 & 100,00 & 100,00 & 100,00 \\
Sem Instrução & 9,35 & 8,38 & 8,50 & 7,75 & 6,77 & 5,98 & 6,26 & 5,65 \\
Primário Incompleto & 15,99 & 16,27 & 15,99 & 14,19 & 13,10 & 12,85 & 12,94 & 12,02 \\
Primário Completo & 22,74 & 22,08 & 21,42 & 21,42 & 19,11 & 18,19 & 18,74 & 17,63 \\
Ginásio Incompleto & 12,88 & 13,11 & 13,42 & 13,69 & 15,77 & 15,41 & 15,02 & 15,17 \\
Ginásio Completo & 8,50 & 9,20 & 9,15 & 9,52 & 10,21 & 10,15 & 10,30 & 10,60 \\
Colegial ${ }^{(2)}$ & 17,41 & 17,96 & 17,94 & 19,01 & 19,83 & 20,99 & 20,47 & 21,82 \\
Superior ${ }^{(3)}$ & 13,12 & 13,01 & 13,58 & 14,44 & 15,20 & 16,45 & 16,29 & 17,12 \\
\hline
\end{tabular}

(1) Inclui apenas as pessoas para as quais os atributos de interesse

estão claramente identificados.

(2) O nível colegial corresponde a nove, dez ou onze anos de escolaridade.

(3) O nível superior corresponde a doze ou mais anos de escolaridade. 
Tabela 36. Distribuição percentual de homens e mulheres da PEA ocupada ${ }^{(1)}$ por níveis de escolaridade. Pernambuco, 1981 a 1990.

\begin{tabular}{|c|c|c|c|c|c|c|c|c|}
\hline $\begin{array}{l}\text { SEXO E NÍVEIS DE } \\
\text { ESCOLARIDADE }\end{array}$ & 1981 & 1983 & 1984 & 1985 & 1987 & 1988 & 1989 & 1990 \\
\hline HOMENS & 100,00 & 100,00 & 100,00 & 100,00 & 100,00 & 100,00 & 100,00 & 100,00 \\
\hline Sem Instrução & 41,76 & 36,16 & 39,97 & 38,51 & 33,36 & 34,08 & 32,09 & 30,53 \\
\hline Primário Incompleto & 23,80 & 22,60 & 22,77 & 21,94 & 24,79 & 22,89 & 22,82 & 22,09 \\
\hline Primáno Completo & 12,13 & 14,46 & 12,91 & 13,65 & 12,81 & 12,57 & 12,88 & 12,96 \\
\hline Ginásio Incompleto & 7,94 & 10,43 & 9,17 & 10,82 & 11,74 & 11,16 & 13,52 & 14,32 \\
\hline Ginásio Completo & 3,82 & 4,38 & 3,74 & 4,17 & 4,51 & 4,56 & 4,96 & 5,05 \\
\hline Colegial $^{(2)}$ & 6,75 & 7,77 & 7,48 & 7,15 & 8,47 & 9,53 & 8,85 & 9,63 \\
\hline Superior ${ }^{(3)}$ & 3,81 & 4,21 & 3,94 & 3,76 & 4,32 & 5,21 & 4,88 & 5,42 \\
\hline MULHERES & 100,00 & 100,00 & 100,00 & 100,00 & 100,00 & 100,00 & 100,00 & 100,00 \\
\hline Sem Instrução & 30,10 & 27,68 & 28,98 & 25,84 & 23,57 & 22,72 & 21,06 & 17,68 \\
\hline Primánio Incompleto & 17,86 & 17,98 & 18,25 & 18,04 & 18,16 & 18,33 & 17,39 & 17,02 \\
\hline Primário Completo & 12,29 & 14,62 & 11,64 & 13,33 & 12,80 & 12,03 & 12,58 & 13,20 \\
\hline Ginásio Incompleto & 10,06 & 10,37 & 11,17 & 12,74 & 11,75 & 12,93 & 15,70 & 13,45 \\
\hline Ginásio Completo & 5,35 & 5,19 & 4,90 & 5,19 & 5,73 & 5,69 & 5,55 & 4,92 \\
\hline Colegial $^{(2)}$ & 15,48 & 15,51 & 15,33 & 15,92 & 18,75 & 17,87 & 17,82 & 20,96 \\
\hline Superior ${ }^{(3)}$ & 8,87 & 8,65 & 9,74 & 8,94 & 9,22 & 10,44 & 9,89 & 12,77 \\
\hline
\end{tabular}

(1) Inclui apenas as pessoas para as quais os atributos de interesse

está claramente identificados.

(2) O nível colegial corresponde a nove, dez ou onze anos de escolaridade.

(3) O nível superior corresponde a doze ou mais anos de escolaridade.

No tocante ao primeiro aspecto nota-se que a PEA ocupada pernambucana encontra-se concentrada nos niveis mais baixos de escolaridade, enquanto a paulista se distribui de forma mais homogênea entre as diferentes faixas. Verifica-se também que, apesar da melhoria expressiva observada no nível educacional das pessoas ocupadas nos dois estados, ao fim do período ainda mais de $50 \%$ dos trabalhadores pernambucanos do sexo masculino e cerca de $20 \%$ dos paulistas têm escolaridade inferior ao primário completo. 
Essas disparidades regionais são conhecidas. Menos discutidas são as que nos interessam mais especificamente neste trabalho, quais sejam, as referentes ao nível de instrução por sexo do trabalhador. AS figuras 7 e 8, elaboradas através de dados selecionados das tabelas 35 e 36, facilitam a percepção não apenas de que a escolaridade das trabalhadoras é substancialmente maior do que a dos trabalhadores, como também de que essas diferenças se ampliam ao longo do período considerado.

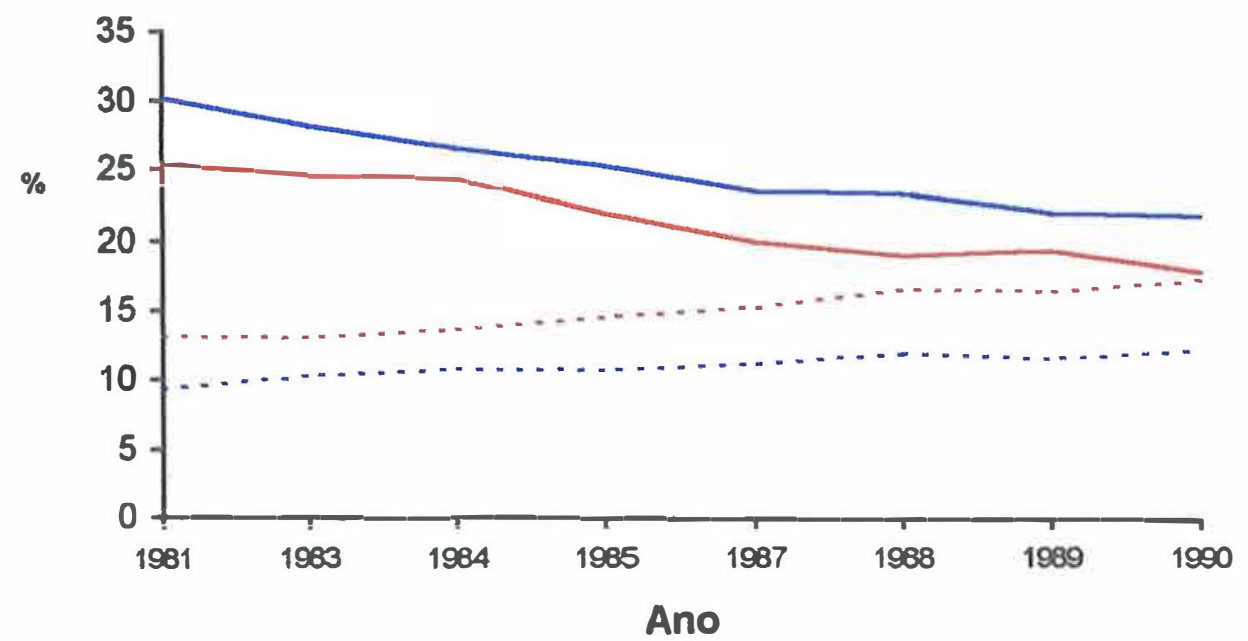

\begin{tabular}{|l|}
\hline$\ldots$ Sem instruçåo e 10. grau incompleto (homens) \\
$\ldots-$ Superior (homens) \\
$\ldots$ Sem instruçâo e 10. grau incompleto (mulheres) \\
$\ldots$. Superior (mulheres)
\end{tabular}

Figura 7. Evolução da distribuição percentual de homens e mulheres da PEA ocupada por níveis de escolaridade. São Paulo, 1981 a 1990. 

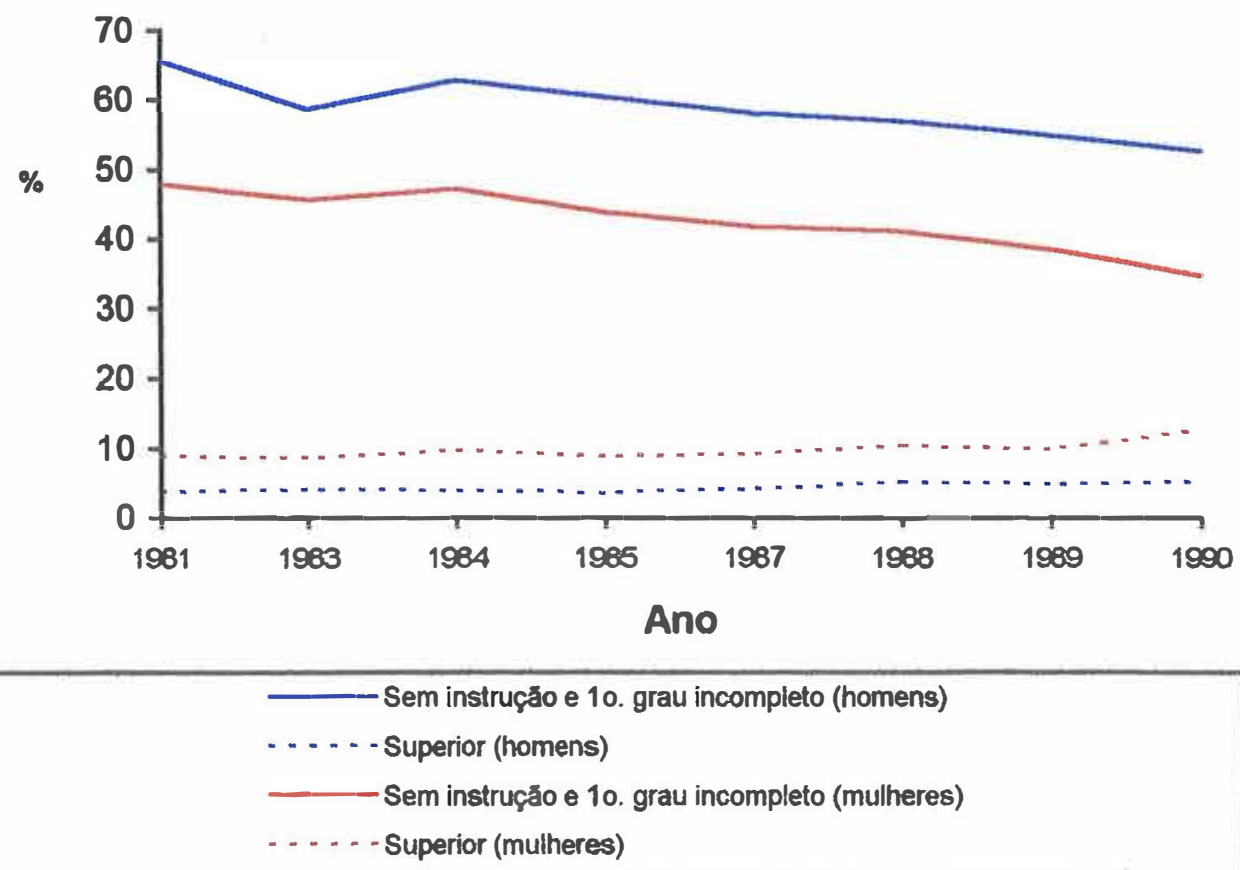

Figura 8. Evolução da distribuição percentual de homens e mulheres da PEA ocupada por níveis de escolaridade. Pernambuco, 1981 a 1990.

Assim, se no início do período 30\% dos trabalhadores paulistas e apenas 25\% das trabalhadoras desse mesmo estado têm "escolaridade inferior ao primário completo, ao fim do período esses percentuais se reduzem a $22 \%$ e $17 \%$, representando uma queda de $27 \%$ no percentual de homens com esse nível de escolaridade e de 32\% no das mulheres. Por outro lado, no extremo superior da escolaridade a participação dos trabalhadores paulistas se eleva de 9\% para 12\%, enquanto o das trabalhadoras se eleva de $13 \%$ para $17 \%$, indicando um crescimento do percentual de trabalhadores com nível universitário na amostra de 28\% para os de sexo masculino e de mais de $30 \%$ para os do sexo 
feminino, o que confirma a superioridade crescente da mãode-obra feminina paulista no tocante a esse aspecto.

Os dados da tabela 36, parcialmente ilustrados na figura 8, permitem visualizar diferenças de qualificação educacional por sexo ainda mais significativas em Pernambuco, e também o crescimento dessas disparidades ao longo da década. Assim, enquanto $\circ$ percentual de trabalhadores desse estado com instrução inferior ao primário completo se reduz de 66\% para 53\%, 0 das trabalhadoras com esse nível de escolaridade se reduz de 48\% para 35\% (portanto, em cerca de 20\% para os do sexo masculino e de 27\% para os do sexo feminino). Já a participação de trabalhadores com nivel universitário se eleva de 4\% para 5\%, enquanto a das trabalhadoras se eleva de 9\% para 13\%. Ou seja, ao final do período, o percentual de trabalhadoras com nível universitário em Pernambuco é cerca de duas vezes e meia o dos trabalhadores, enquanto que $\circ$ das que não completaram $\circ$ primário é significativamente inferior (cerca de 66\% do apresentado pelos trabalhadores do sexo masculino com essa escolaridade).

b) a estrutura etária

A estrutura etária dos trabalhadores do sexo masculino nesses dois estados, apresentada nas tabelas 37 e 38, mostra-se estável ao longo do período analisado. Além disso, como a idade é encarada como proxy da experiência, a parcela masculina da PEA pode, no tocante a esse quesito, ser considerada mais qualificada do que a feminina. Contudo, deve-se ressaltar que as diferenças de estrutura etária por sexo são menos significativas em Pernambuco. Nesse sentido, verifica-se que enquanto em Pernambuco 0 
percentual de trabalhadores na amostra com menos de 25 anos é praticamente 0 mesmo para os dois sexos e o dos trabalhadores com 40 anos ou mais é pouco maior para os do sexo masculino (cerca de 35\% dos homens e de 30\% das mulheres têm 40 anos ou mais), em São Paulo as mulheres não apenas têm participação maior do que os homens nas faixas etárias mais jovens, como também têm participação proporcionalmente menor nas faixas de maior idade (32\% dos homens e apenas 22\% das mulheres da amostra em São Paulo têm 40 anos ou mais).

Tabela 37. Distribuição percentual de homens e mulheres da PEA ocupada ${ }^{(1)}$ por faixas de idade. São Paulo, 1981 a 1990.

\begin{tabular}{lrrrrrrrr}
\hline $\begin{array}{l}\text { SEXO E NÍVEIS } \\
\text { DE IDADE }\end{array}$ & 1981 & 1983 & 1984 & 1985 & 1987 & 1988 & 1989 & 1990 \\
\hline HOMENS & 100,00 & 100,00 & 100,00 & 100,00 & 100,00 & 100,00 & 100,00 & 100,00 \\
10 a 14 anos & 2,07 & 1,83 & 1,63 & 2,16 & 2,10 & 2,14 & 1,82 & 1,85 \\
15 a 17 anos & 5,88 & 4,98 & 4,60 & 5,25 & 5,21 & 5,30 & 5,32 & 5,32 \\
18 a 19 anos & 5,03 & 4,81 & 4,91 & 5,19 & 4,68 & 5,15 & 5,30 & 4,37 \\
20 a 24 anos & 14,81 & 15,12 & 15,03 & 15,08 & 14,45 & 13,87 & 13,85 & 13,53 \\
25 a 29 anos & 15,97 & 15,97 & 16,64 & 15,64 & 15,36 & 14,04 & 13,94 & 13,87 \\
30 a 39 anos & 24,83 & 26,47 & 26,77 & 26,95 & 26,94 & 27,75 & 27,86 & 28,23 \\
40 a 49 anos & 17,35 & 16,33 & 16,96 & 16,48 & 17,26 & 17,06 & 18,09 & 18,37 \\
50 anos ou mais & 14,07 & 14,49 & 13,45 & 13,25 & 14,00 & 14,70 & 13,82 & 14,47 \\
MULHERES & 100,00 & 100,00 & 100,00 & 100,00 & 100,00 & 100,00 & 100,00 & 100,00 \\
10 a 14 anos & 3,60 & 3,32 & 3,31 & 3,32 & 2,71 & 2,35 & 3,01 & 2,13 \\
15 a 17 anos & 10,07 & 8,43 & 8,10 & 8,19 & 8,11 & 6,48 & 7,64 & 7,04 \\
18 a 19 anos & 7,84 & 8,06 & 7,50 & 7,31 & 7,06 & 6,79 & 6,77 & 6,68 \\
20 a 24 anos & 19,39 & 18,78 & 18,77 & 18,50 & 18,27 & 17,91 & 16,36 & 16,85 \\
25 a 29 anos & 15,71 & 15,63 & 15,88 & 16,12 & 15,75 & 15,63 & 15,73 & 16,22 \\
30 a 39 anos & 21,93 & 23,66 & 23,85 & 25,05 & 25,74 & 26,80 & 25,78 & 27,51 \\
40 a 49 anos & 13,02 & 13,58 & 14,07 & 13,62 & 13,74 & 15,53 & 15,17 & 14,74 \\
50 anos ou mais & 8,43 & 8,54 & 8,52 & 7,90 & 8,61 & 8,52 & 9,54 & 8,84 \\
\hline
\end{tabular}


Tabela 38. Distribuição percentual de homens e mulheres da PEA ocupada(1) por faixas de idade. Pernambuco, 1981 a 1990.

\begin{tabular}{lrrrrrrrr}
\hline $\begin{array}{c}\text { SEXO E NÍVEIS } \\
\text { DE IDADE }\end{array}$ & 1981 & 1983 & 1984 & 1985 & 1987 & 1988 & 1989 & 1990 \\
\hline HOMENS & 100,00 & 100,00 & 100,00 & 100,00 & 100,00 & 100,00 & 100,00 & 100,00 \\
10 a 14 anos & 4,45 & 4,10 & 4,14 & 3,96 & 3,81 & 3,50 & 4,11 & 3,83 \\
15 a 17 anos & 6,07 & 6,43 & 6,72 & 6,71 & 6,13 & 6,17 & 6,52 & 7,06 \\
18 a 19 anos & 5,13 & 5,41 & 4,99 & 5,23 & 5,25 & 4,85 & 5,63 & 4,87 \\
20 a 24 anos & 13,32 & 13,32 & 13,12 & 13,98 & 14,32 & 13,17 & 13,93 & 13,88 \\
25 a 29 anos & 11,60 & 12,67 & 13,00 & 12,86 & 13,12 & 15,11 & 13,04 & 12,49 \\
30 a 39 anos & 22,59 & 21,98 & 22,36 & 20,88 & 22,68 & 21,60 & 22,00 & 22,57 \\
40 a 49 anos & 16,35 & 16,76 & 17,02 & 16,57 & 16,58 & 16,19 & 16,59 & 16,24 \\
50 anos ou mais & 20,49 & 19,34 & 18,63 & 19,82 & 18,10 & 19,42 & 18,18 & 19,06 \\
MULHERES & 100,00 & 100,00 & 100,00 & 100,00 & 100,00 & 100,00 & 100,00 & 100,00 \\
10 a 14 anos & 4,22 & 3,70 & 2,87 & 3,08 & 2,32 & 3,24 & 3,31 & 3,09 \\
15 a 17 anos & 7,62 & 5,78 & 5,98 & 6,94 & 6,16 & 6,03 & 7,35 & 5,64 \\
18 a 19 anos & 5,76 & 4,84 & 4,35 & 6,07 & 4,37 & 5,61 & 5,29 & 5,75 \\
20 a 24 anos & 13,84 & 14,87 & 14,83 & 15,74 & 14,52 & 15,04 & 14,94 & 13,91 \\
25 a 29 anos & 14,05 & 14,34 & 13,92 & 13,09 & 14,69 & 13,16 & 14,85 & 15,98 \\
30 a 39 anos & 24,11 & 24,43 & 25,78 & 24,51 & 25,45 & 24,74 & 24,09 & 26,67 \\
40 a 49 anos & 17,39 & 19,06 & 17,97 & 17,77 & 17,76 & 18,76 & 17,34 & 16,87 \\
50 anos ou mais & 13,02 & 12,98 & 14,30 & 12,80 & 14,72 & 13,42 & 12,82 & 12,09 \\
\hline
\end{tabular}

(1) Inclui apenas as pessoas para as quais os atributos de interesse estão claramente identificados.

Os dados mostram, também, a transformação da estrutura etária da PEA ocupada feminina ao longo do período. Nota-se o processo do "envelhecimento" das trabalhadoras, que se reflete na perda de importância relativa das mais jovens e no crescimento das que têm entre 25 e 39 anos. Nesse sentido é particularmente notável o incremento da participação das mulheres com idade entre 30 e 39 anos na PEA ocupada paulista, que correspondem a 22\% das trabalhadoras em 1981 e a 28\% em 1990. Assim, a evolução da estrutura etária mostra que, embora os 
trabalhadores do sexo feminino sejam mais jovens do que os do masculino, ao longo do período essas diferenças se reduzem.

A apresentação das figuras 9 e 10 objetiva facilitar a comparação da evolução da composição etária de homens e mulheres, nos dois estados, ao longo do período em questão.

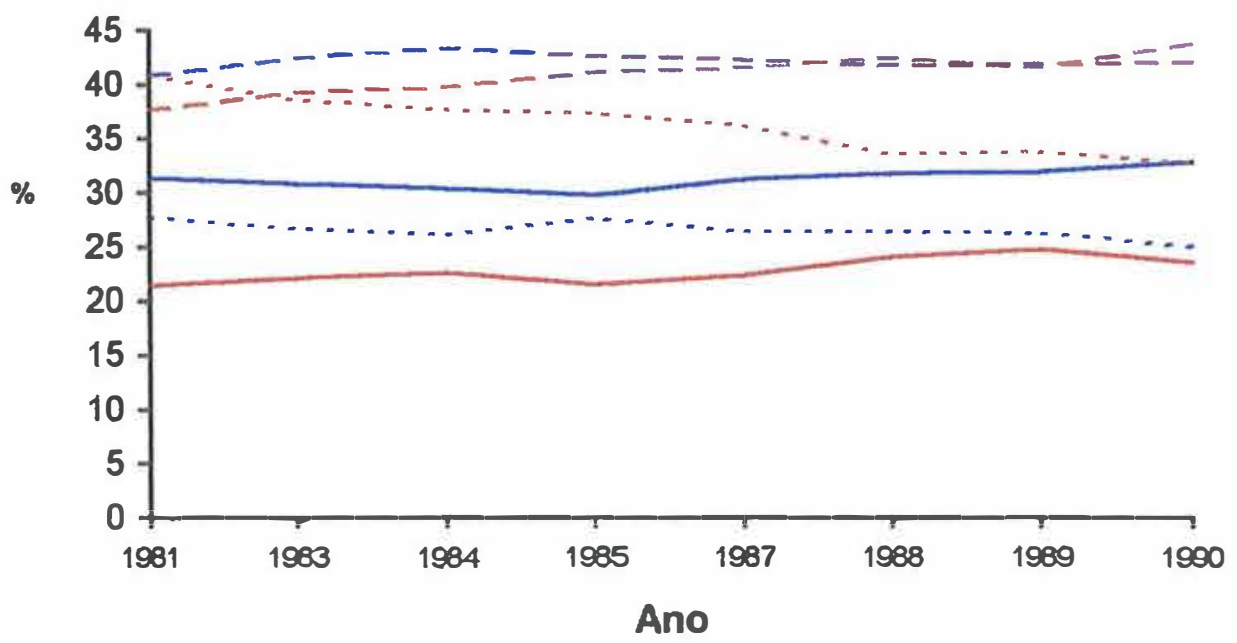

\begin{tabular}{|lr|}
\hline$\ldots-10$ a 24 anos (homens) & ---25 a 39 anos (homens) \\
\hline-40 anos ou mais (homens) & $-\cdots-10$ a 24 anos (mulheres) \\
---25 a 39 anos (mulheres) & -40 anos ou mais (mulheres) \\
\hline
\end{tabular}

Figura 9. Evolução da distribuição percentual de homens e mulheres da PEA ocupada segundo faixas etárias. São Paulo, 1981 a 1990. 


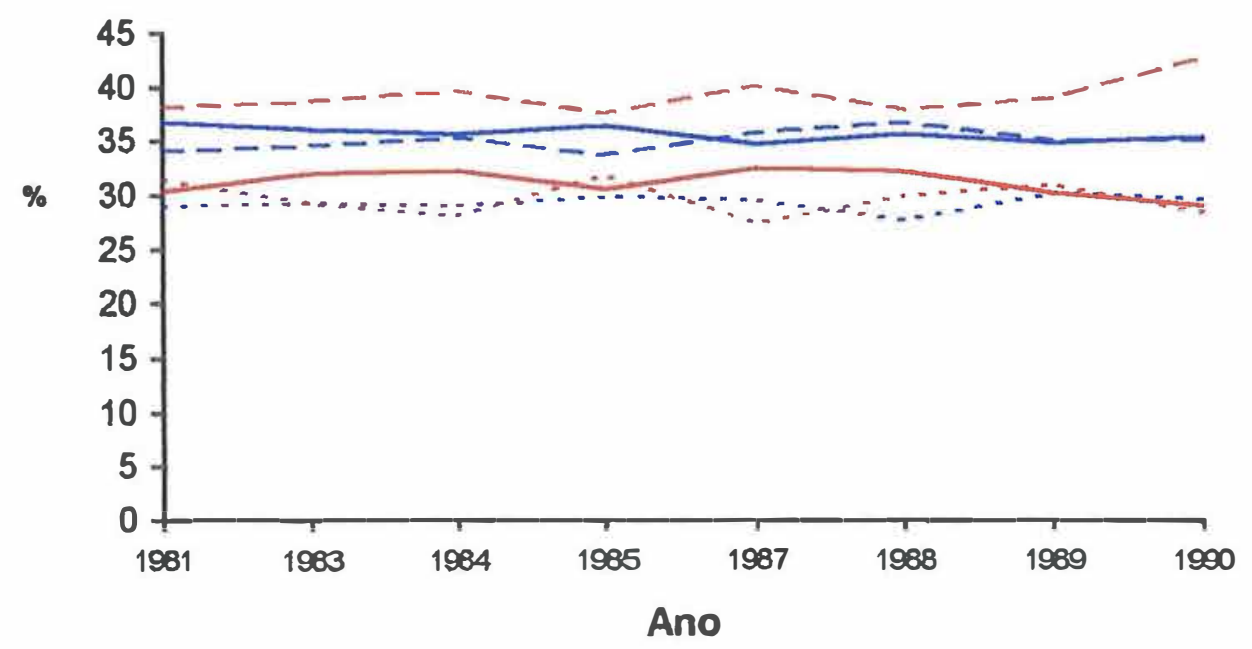

\begin{tabular}{|ll|}
\hline$\cdots-10$ a 24 anos (homens) & ---25 a 39 anos (homens) \\
\hline-40 anos ou mais (homens) & $-\cdots-10$ a 24 anos (mulheres) \\
---25 a 39 anos (mulheres) & --40 anos ou mais (mulheres) \\
\hline
\end{tabular}

Figura 10. Evolução da distribuição percentual de homens e mulheres da PEA ocupada segundo faixas etárias. Pernambuco, 1981 a 1990.

C) situação do domicílio

A distribuição percentual da PEA ocupada por situação do domicílio, relatada na tabela 39, comprova a existência de diferenças regionais que apontam para a maior urbanização da PEA paulista. Entretanto, deve-se lembrar que a classificação do domicílio como "rural" ou "urbano" nas PNAD de 1981 a 1990 depende da delimitação legal das áreas urbanas vigente por ocasião do Censo de 1980. Assim, a participação crescente de trabalhadores com domicílio rural na PEA ocupada paulista pode, ao invés de significar uma "inversão do processo histórico de urbanização" da PEA nesse estado, como os dados sugerem, resultar do fato do 
crescimento das regiões urbanas no período não ser captado pelas PNAD.

De qualquer modo, como a comparação por gênero entre as taxas de urbanização da PEA não é muito afetada por esse problema pode-se concluir que a taxa de urbanização da PEA feminina é pouco maior do que a masculina (entre três e quatro pontos percentuais no período) em São Paulo mas é significativamente maior (entre oito e doze pontos percentuais) em Pernambuco.

Tabela 39. Distribuição percentual de homens e mulheres da PEA ocupada(1) que têm domicílio na área urbana.

\begin{tabular}{cccccc}
\hline \multirow{2}{*}{ ANO } & \multicolumn{2}{c}{ SÃO PAULO } & & \multicolumn{2}{c}{ PERNAMBUCO } \\
\cline { 2 - 3 } \cline { 5 - 6 } & HOMENS & MULHERES & & HOMENS & MULHERES \\
\hline 1981 & 90,21 & 94,52 & & 72,33 & 84,76 \\
1983 & 89,62 & 93,76 & & 74,81 & 82,78 \\
1984 & 90,14 & 94,28 & & 71,04 & 81,57 \\
1985 & 90,57 & 94,41 & & 71,12 & 82,16 \\
1987 & 90,11 & 93,49 & & 72,52 & 83,38 \\
1988 & 89,15 & 93,44 & & 73,28 & 84,23 \\
1989 & 89,35 & 92,87 & & 73,67 & 83,11 \\
1990 & 88,54 & 92,27 & & 76,03 & 84,29 \\
\hline
\end{tabular}

(1) Inclui apenas as pessoas para as quais os atributos de interesse estão claramente identificados.

d) a posição na ocupação

A tabela 40 relata a distribuição dos trabalhadores paulistas segundo a posição que assumem na ocupação. Para facilitar a análise esses dados são também apresentados na figura 11. 
Tabela 40. Distribuição percentual de homens e mulheres da PEA ocupada(1) segundo a posição na ocupação. São Paulo, 1981 a 1990 .

\begin{tabular}{lrrrrrrrr}
\hline SEXO E POSIÇÃO & $\mathbf{1 9 8 1}$ & $\mathbf{1 9 8 3}$ & $\mathbf{1 9 8 4}$ & $\mathbf{1 9 8 5}$ & $\mathbf{1 9 8 7}$ & $\mathbf{1 9 8 8}$ & $\mathbf{1 9 8 9}$ & $\mathbf{1 9 9 0}$ \\
\hline NA OCUPAÇÃO & & & & & & & \\
HOMENS & 100,00 & 100,00 & 100,00 & 100,00 & 100,00 & 100,00 & 100,00 & 100,00 \\
assalariados & 75,57 & 75,16 & 75,76 & 77,14 & 76,01 & 75,72 & 75,18 & 73,78 \\
autônomos & 18,11 & 18,38 & 17,90 & 16,98 & 18,09 & 17,91 & 17,92 & 19,01 \\
empregadores & 6,31 & 6,46 & 6,35 & 5,88 & 5,90 & 6,36 & 6,90 & 7,21 \\
MULHERES & 100,00 & 100,00 & 100,00 & 100,00 & 100,00 & 100,00 & 100,00 & 100,00 \\
assalariadas & 82,31 & 82,38 & 81,42 & 82,59 & 83,69 & 81,48 & 83,58 & 80,05 \\
autônomas & 16,28 & 16,20 & 17,06 & 15,48 & 14,31 & 16,61 & 13,84 & 16,86 \\
empregadoras & 1,41 & 1,42 & 1,52 & 1,93 & 1,99 & 1,90 & 2,58 & 3,09 \\
\hline
\end{tabular}

(1) Inclui apenas as pessoas cujos atributos de interesse estão claramente identificados.

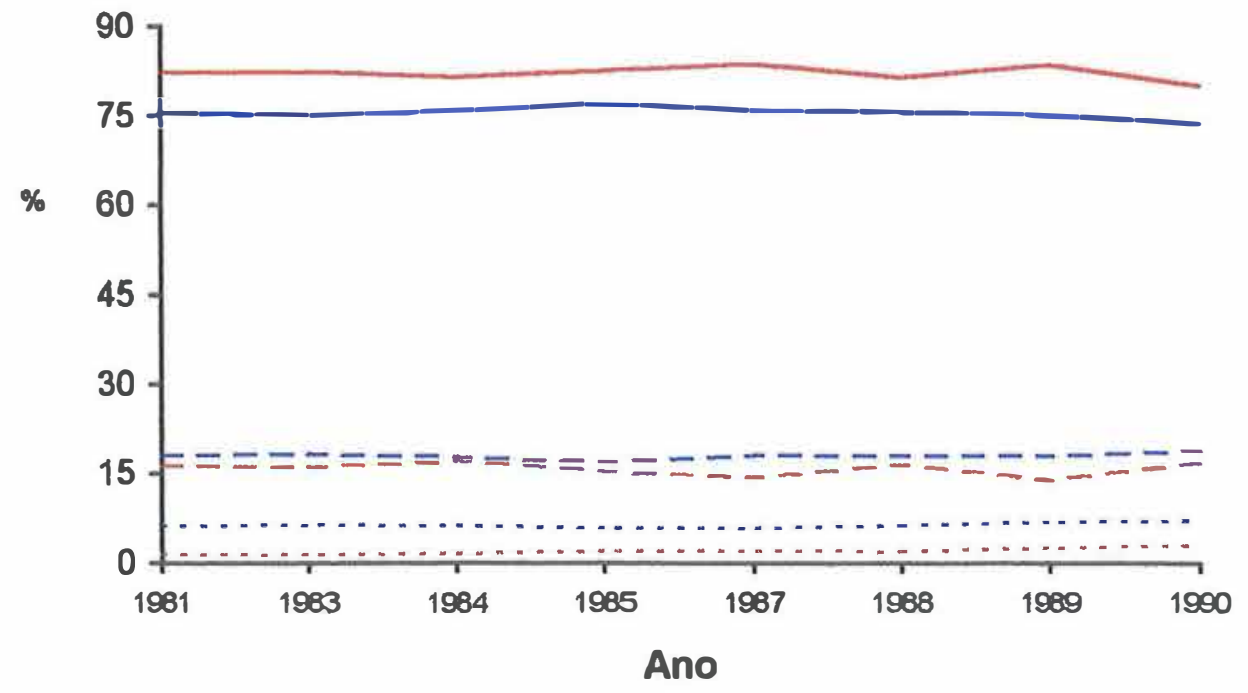

\begin{tabular}{|c|c|c|}
\hline - assalariados & --- autónomos & ..... empregadores \\
\hline - assalariadas & -- autónomas & .... - empregadoras \\
\hline
\end{tabular}

Figura 11. Evolução da distribuição percentual de homens e mulheres da PEA ocupada segundo a posição na ocupação. São Paulo, 1981 a 1990. 
Verifica-se a concentração dos trabalhadores na posição de assalariados, assim como a existência de algumas diferenças na distribuição dos homens e das mulheres pelas posições consideradas. Nota-se que, enquanto cerca de 75\% dos trabalhadores do sexo masculino de São Paulo são assalariados, mais de $80 \%$ das mulheres desse estado estão nessa mesma posição. Por outro lado, se apenas perto de 7\% dos homens ocupados nesse estado são empregadores, a parcela feminina que ascende a essa posição é, embora crescente, ainda significativamente inferior, variando, entre o início e o final do período, de 1,4\% a 3,1\%. Notase também que o percentual de mulheres autônomas é menor do que o dos homens, o que se contrapõe ao argumento de que as mulheres se concentram no trabalho autônomo porque este lhes permite, através da jornada de trabalho mais flexível, conciliar sua atividade doméstica com a remunerada.

A distribuição da PEA ocupada pernambucana segundo a posição na ocupação está descrita na tabela 41 e na figura 12. Nota-se que, nesse estado, o trabalho autônomo absorve uma parcela mais expressiva dos trabalhadores, pois quase um terço das pessoas que trabalham estão nessa categoria. Nos três anos iniciais do período em análise a participação das pernambucanas nessa posição é maior do que a dos pernambucanos. A partir da metade da década de oitenta essa relação se inverte, embora as diferenças por sexo no trabalho autônomo permaneçam de pequeno porte. Já a participação feminina na categoria das empregadoras é, em contrapartida, irrisória, oscilando entre 1\% e 2\% ao longo do período, enquanto a masculina se mantém, de modo geral, entre $4 \%$ e $5 \%$. 
Tabela 41. Distribuição percentual de homens e mulheres da PEA ocupada(1) segundo a posição na ocupação. Pernambuco, 1981 a 1990.

\begin{tabular}{|c|c|c|c|c|c|c|c|c|}
\hline $\begin{array}{l}\text { SEXO E POSICC̄ĀO } \\
\text { NA OCUPAÇÃO }\end{array}$ & 1981 & 1983 & 1984 & 1985 & 1987 & 1988 & 1989 & 1990 \\
\hline HOMENS & 100,00 & 100,00 & 100,00 & 100,00 & 100,00 & 100,00 & 100,00 & 100,00 \\
\hline assalariados & 64,44 & 66,58 & 62,58 & 64,52 & 65,82 & 63,60 & 63,43 & 64,37 \\
\hline autônomos & 31,46 & 29,62 & 33,08 & 31,21 & 29,85 & 31,89 & 31,23 & 30,39 \\
\hline empregadores & 4,09 & 3,80 & 4,34 & 4,27 & 4,33 & 4,51 & 5,34 & 5,24 \\
\hline MULHERES & 100,00 & 100,00 & 100,00 & 100,00 & 100,00 & 100,00 & 100,00 & 100,00 \\
\hline assalariadas & 66,66 & 66,80 & 62,77 & 68,66 & 67,11 & 70,49 & 71,03 & 68,46 \\
\hline autônomas & 32,24 & 32,26 & 35,60 & 30,52 & 31,64 & 28,48 & 26,99 & 29,86 \\
\hline empregadoras & 1,10 & 0,94 & 1,63 & 0,82 & 1,25 & 1,03 & 1,98 & 1,69 \\
\hline
\end{tabular}

(1) Inclui apenas as pessoas para as quais os atributos de interesse estão claramente identificados.

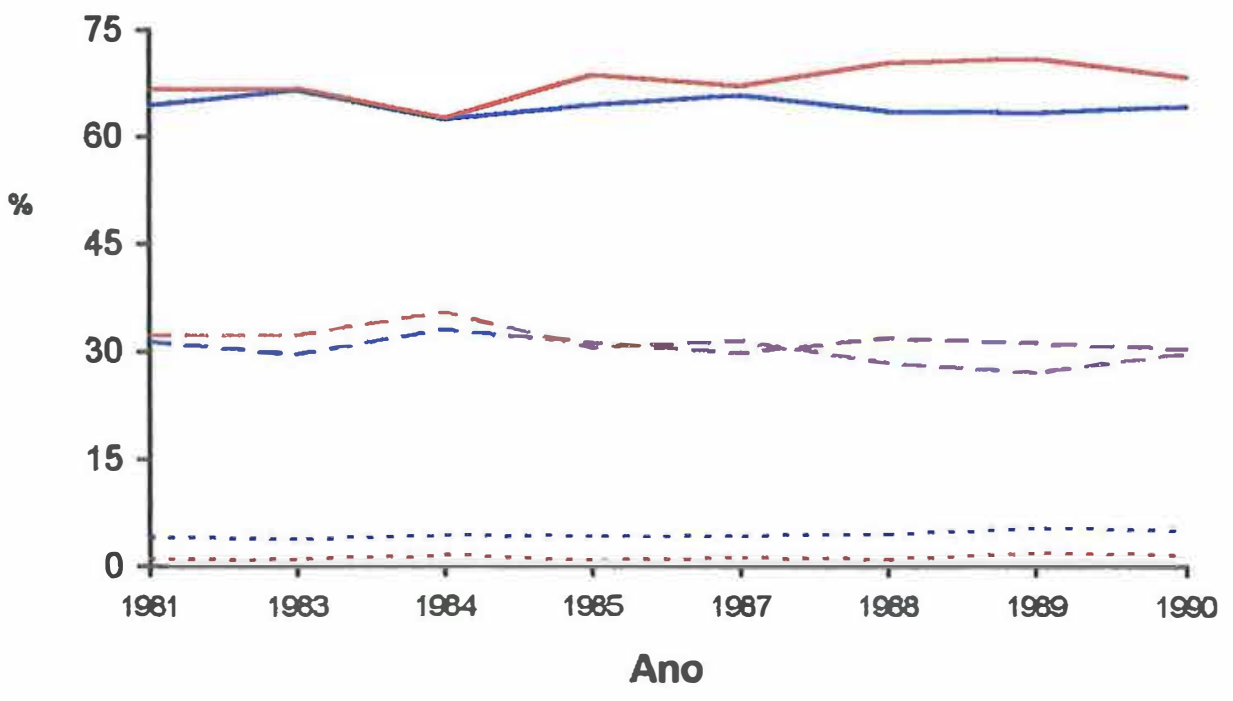

Figura 12. Evolução da distribuição percentual de homens e mulheres da PEA ocupada segundo a posição na ocupação. Pernambuco, 1981 a 1990. 
e) a posse de carteira de trabalho assinada

- percentual de trabalhadores assalariados com carteira de trabalho assinada é também maior em São Paulo. Os dados da tabela 42 evidenciam que cerca de três quartos dos trabalhadores e de dois terços das trabalhadoras paulistas têm carteira de trabalho assinada. Já em Pernambuco, menos da metade dos trabalhadores assalariados de ambos os sexos tem esse direito assegurado. De modo geral esses percentuais oscilam de maneira procíclica ao longo do período, se reduzindo nos anos da crise que assola a economia brasileira no início da década e se elevando na recuperação do triênio 1985-87.

Tabela 42. Distribuição percentual de assalariados(1) do sexo masculino e feminino com carteira de trabalho assinada. São Paulo e Pernambuco, 1981 a 1990 .

\begin{tabular}{cccccc}
\hline & \multicolumn{2}{c}{ SÃO PAULO } & & \multicolumn{2}{c}{ PERNAMBUCO } \\
\cline { 2 - 3 } \cline { 5 - 6 } ANO & HOMENS & MULHERES & & HOMENS & MULHERES \\
\hline 1981 & 75,51 & 60,80 & & 50,13 & 48,59 \\
1983 & 72,35 & 56,45 & & 41,03 & 44,61 \\
1984 & 73,58 & 56,46 & & 41,06 & 45,81 \\
1985 & 76,37 & 57,97 & & 45,01 & 41,33 \\
1987 & 78,49 & 62,88 & & 47,40 & 44,69 \\
1988 & 77,88 & 64,02 & & 48,51 & 43,79 \\
1989 & 77,23 & 63,05 & & 50,01 & 41,19 \\
1990 & 77,91 & 64,25 & & 49,81 & 47,75 \\
\hline
\end{tabular}

(1) Inclui apenas as pessoas para as quais os atributos de interesse está claramente identificados.

Em resumo, as diferenças de qualificação entre os sexos, mensuráveis pelas variáveis utilizadas neste 
trabalho, são de pequeno porte. Nos dois estados a PEA ocupada feminina tem, em média, maior escolaridade e grau de urbanização, mas menor participação na posição de empregador. Além disso, apenas em São Paulo o percentual de trabalhadoras com carteira de trabalho assinada é menor do que $o$ dos trabalhadores. Ou seja, as diferenças apresentadas são, em geral, de pequeno porte e se em alguns casos desfavorecem a mão-de-obra feminina em outros a favorecem.

Os dados mostram também que 0 diferencial de qualificação entre homens e mulheres tende, em geral, a beneficiar mais (ou prejudicar menos, conforme o aspecto considerado) a pernambucana do que a paulista. Neste sentido verifica-se que em Pernambuco as diferenças de escolaridade (que favorecem as mulheres) são maiores e as de idade (que as prejudicam) menores. Alem disso, nesse estado os percentuais de assalariados e de trabalhadores sem carteira de trabalho assinada praticamente não diferem por sexo.

Por fim, as evidências empiricas relatadas sugerem que, ao longo dos anos considerados, o aprimoramento da qualificação é mais acentuado para a parcela feminina da PEA.

\subsection{A decomposição das diferenças entre os rendimentos de homens e mulheres.}

As equações de rendimento estimadas por sexo e categoria ocupacional combinadas com a distribuição ocupacional simulada para a parcela feminina da amostra permitem derivar a decomposição proposta pela expressão (18), ou seja, possibilitam a decomposição do diferencial de rendimentos entre homens e mulheres da amostra não apenas 
em parcelas que podem ser consideradas como justificadas ou não, como o fazem os modelos tradicionais, mas também separar os efeitos que decorrem das diferenças intraocupacionais (efeito-renda) dos que resultam das diferenças de alocação da mão-de-obra entre as ocupações (efeitoalocação) .

Para facilitar a análise dos resultados, evitando a necessidade de se recorrer constantemente ao Capitulo 3, a equação (18), que expressa matematicamente essa decomposição é reapresentada, já considerando que a variável dependente é, efetivamente, o logaritmo do rendimento:

$$
\begin{aligned}
\overline{\ln R^{m}}-\overline{\ln R^{f}} & =\sum_{i} p_{i}^{f} \overline{\mathbf{x}}_{i}^{f}\left(\mathbf{b}^{m}-\mathbf{b}^{f}\right)+\sum_{i} p_{i}^{f}\left(\overline{\mathbf{x}}_{i}^{m}-\overline{\mathbf{x}}_{i}^{f}\right) \mathbf{b}^{m} \\
& +\sum_{i} \overline{\mathbf{x}}_{i}^{m} \mathbf{b}_{i}^{m}\left(p_{i}^{m}-p_{i}^{f *}\right)+\sum_{i} \overline{\mathbf{x}}_{i}^{m} \mathbf{b}_{i}^{m}\left(p_{i}^{f^{*}}-p_{i}^{f}\right)
\end{aligned}
$$

$\mathrm{AE}$

$\mathrm{AD}$

Conforme já definido, as duas primeiras parcelas do segundo membro da expressão (24) representam o impacto das diferenças intraocupacionais (indicam, respectivamente, as parcelas da desigualdade associadas à discriminação intraocupacional e as que podem ser explicadas pelas diferenças de qualificaçãol e as duas parcelas seguintes medem os efeitos das diferenças de alocação (decompostas em frações justificáveis ou não pelas diferenças de qualificação) .

Os resultados da decomposição das diferenças entre a média dos logaritmos naturais dos rendimentos da PEA ocupada masculina e feminina no estado de São Paulo encontram-se identificados na tabela 43. Para facilitar a 
interpretação obtêm-se também os antilogaritmos desses resultados ${ }^{71}$ apresentados na tabela 44 .

Tabela 43. Decomposição das diferenças entre a média dos logaritmos naturais dos rendimentos ${ }^{(1)}$ dos homens e mulheres na ocupação principal. São Paulo, 1981 a 1990 .

\begin{tabular}{|c|c|c|c|c|c|c|c|}
\hline \multirow[b]{2}{*}{ ANO } & \multirow[b]{2}{*}{$\overline{\ln R^{m}}-\overline{\ln R^{f}}$} & \multicolumn{2}{|c|}{$\begin{array}{c}\text { DIFERENÇAS } \\
\text { INTRAOCUPACIONAIS }\end{array}$} & \multicolumn{2}{|c|}{$\begin{array}{l}\text { DIFERENÇAS DE } \\
\text { DISTRIBUIÇÃO } \\
\text { OCUPACIONAL }\end{array}$} & \multicolumn{2}{|c|}{ DIFERENÇAS TOTAIS } \\
\hline & & $\begin{array}{l}\text { JUSTIFI- (RE) } \\
\text { CÁVEIS }\end{array}$ & $\begin{array}{l}\text { INJUSTI- (RD) } \\
\text { FICÁVEIS }\end{array}$ & $\begin{array}{l}\text { JUSTIFI- (AE) } \\
\text { CÁVEIS }\end{array}$ & $\begin{array}{l}\text { INJUSTI- (AD) } \\
\text { FICÁVEIS }\end{array}$ & $\begin{array}{l}\text { JUSTIFI- } \\
\text { CÁVEIS }\end{array}$ & $\begin{array}{l}\text { INJUSTT- } \\
\text { FICÁVEIS }\end{array}$ \\
\hline 1981 & 0,4909 & 0,0395 & 0,2486 & 0,0107 & 0,1921 & 0,0501 & 0,4407 \\
\hline 1983 & 0,4988 & $-0,0050$ & 0,2645 & 0,0117 & 0,2275 & 0,0068 & 0,4920 \\
\hline 1984 & 0,5481 & $-0,0470$ & 0,2645 & 0,0152 & 0,3152 & $-0,0318$ & 0,5797 \\
\hline 1985 & 0,4862 & 0,0337 & 0,2580 & 0,0005 & 0,1938 & 0,0342 & 0,4517 \\
\hline 1987 & 0,4034 & 0,0055 & 0,1737 & 0,0094 & 0,2148 & 0,0149 & 0,3885 \\
\hline 1988 & 0,4341 & $-0,0547$ & 0,3403 & 0,0044 & 0,1441 & $-0,0503$ & 0,4844 \\
\hline 1989 & 0,4339 & $-0,0024$ & 0,2767 & 0,0085 & 0,1511 & 0,0061 & 0,4278 \\
\hline 1990 & 0,3522 & $-0,0497$ & 0,1649 & 0,0068 & 0,2302 & $-0,0429$ & 0,3951 \\
\hline
\end{tabular}

(1) Corresponde ao logaritmo da média geométrica desses rendimentos.

\footnotetext{
${ }^{71}$ É claro que a soma desses componentes não resulta no total. Como os componentes descritos na tabela 44 são os antilogaritmos dos elementos correspondente da tabela 43 subtraidos de um, para se obter a diferença percentual entre a renda média (geométrica) de homens e mulheres relatada nessa tabela é necessário acrescentar um a esses componentes e multiplicá-los ao invés de somá-los.
} 
Tabela 44. Decomposição da diferença relativa entre as médias geométricas dos rendimentos dos homens $\left(G^{m}\right)$ e mulheres $\left(G^{f}\right)$ na ocupação principal. São Paulo, 1981 a 1990 .

\begin{tabular}{|c|c|c|c|c|c|c|c|}
\hline \multirow[b]{2}{*}{ ANO } & \multirow[b]{2}{*}{$\frac{G^{m}-G^{f}}{G^{f}}$} & \multicolumn{2}{|c|}{$\begin{array}{c}\text { DIFERENÇAS } \\
\text { INTRAOCUPACIONAIS }\end{array}$} & \multicolumn{2}{|c|}{$\begin{array}{c}\text { DIFERENÇAS DE } \\
\text { DISTRIBUIÇÃO } \\
\text { OCUPACIONAL }\end{array}$} & \multicolumn{2}{|c|}{ DIFERENÇAS TOTAIS } \\
\hline & & $\begin{array}{l}\text { JUSTIFI- } \\
\text { CÁVEIS }^{(1)}\end{array}$ & $\begin{array}{l}\text { INJUSTI- } \\
\text { FICÁVEIS }^{(1)}\end{array}$ & $\begin{array}{l}\text { JUSTIFI- } \\
\text { CÁVEIS }^{(1)}\end{array}$ & $\begin{array}{l}\text { INJUSTI- } \\
\text { FICÁVEIS }^{(1)}\end{array}$ & $\begin{array}{l}\text { JUSTIFI- } \\
\text { CÁVEIS }^{(1)}\end{array}$ & $\begin{array}{l}\text { INJUSTI- } \\
\text { FICÁVEIS }^{(1)}\end{array}$ \\
\hline 1981 & 0,6338 & 0,0403 & 0,2822 & 0,0107 & 0,2118 & 0,0514 & 0,5538 \\
\hline 1983 & 0,6467 & $-0,0050$ & 0,3028 & 0,0118 & 0,2555 & 0,0068 & 0,6356 \\
\hline 1984 & 0,7300 & $-0,0459$ & 0,3028 & 0,0153 & 0,3705 & $-0,0313$ & 0,7855 \\
\hline 1985 & 0,6261 & 0,0343 & 0,2943 & 0,0005 & 0,2138 & 0,0348 & 0,5710 \\
\hline 1987 & 0,4970 & 0,0055 & 0,1897 & 0,0094 & 0,2396 & 0,0150 & 0,4747 \\
\hline 1988 & 0,5436 & $-0,0532$ & 0,4054 & 0,0044 & 0,1550 & $-0,0491$ & 0,6232 \\
\hline 1989 & 0,5433 & $-0,0024$ & 0,3188 & 0,0085 & 0,1631 & 0,0061 & 0,5339 \\
\hline 1990 & 0,4222 & $-0,0485$ & 0,1793 & 0,0069 & 0,2589 & $-0,0419$ & 0,4846 \\
\hline
\end{tabular}

(1) Valores obtidos subtraindo-se um dos antilogaritmos dos valores correspondentes da tabela 43.

Esses dados permitem notar que, ao longo do período analisado, as diferenças de qualificação explicam uma parcela desprezível das diferenças intraocupacionais de remuneração entre os homens e mulheres desse estado. Admitindo-se que as caracteristicas femininas sejam remuneradas da mesma forma que as masculinas, verifica-se que em cinco dos oito anos considerados os rendimentos femininos inclusive cairiam se as diferenças intraocupacionais de qualificação entre homens e mulheres fossem eliminadas.

O impacto das diferenças de distribuição ocupacional justificáveis pela desigualdade entre os gêneros no tocante aos seus atributos produtivos é também irrisório. Nesse sentido, nota-se que nos três primeiros anos os rendimentos femininos cresceriam menos de $2 \%$ se essa desigualdade fosse eliminada, admitindo-se que a 
remuneração média por categoria ocupacional e os critérios de contratação sejam iguais para os dois sexos. Nos demais anos o efeito desse elemento é ainda menor, pois o término dessas diferenças resultaria na elevação dos rendimentos femininos em menos de 1\% do seu valor.

Por outro lado, se as diferenças entre os critérios adotados na remuneração dos atributos produtivos de homens e mulheres desaparecessem, a remuneração feminina cresceria substancialmente. O impacto desse elemento provocaria, na primeira metade de período, uma elevação em cerca de $30 \%$ da remuneração auferida pelas paulistas. A partir de então esse percentual apresentaria oscilações substanciais, atingindo seu valor máximo em $1988(40,54 \%)$ e mínimo em $1990(17,93 \%)$.

Esses dados apontam também para a existência de considerável discriminação ocupacional no estado. Admitindo-se que a remuneração média por categoria ocupacional seja igual para homens e mulheres, verifica-se que se as trabalhadoras passassem a ser contratadas pelos mesmos critérios utilizados na seleção dos trabalhadores os seus rendimentos cresceriam significativamente. No ano inicial da década o impacto de se eliminar as diferenças de alocação que não podem ser justificadas pela qualificação provocaria o incremento da remuneração das trabalhadoras paulistas em 21,18\%. O efeito é crescente até 1984 (quando chega a 37,05\%) e, a partir de então, volta a cair, atingindo o seu valor mínimo em 1987 (15,50\%). Ressalte-se, também, que as magnitudes dos componentes discriminatórios dos efeitos-renda e alocação são, em boa parte dos anos, similares. Inclusive, deve-se ressaltar que em três desses anos (1984, 1987 e 1990) a discriminação ocupacional 
"explica" a maior parte das diferenças de renda entre os sexos que vigoram em São Paulo ${ }^{72}$.

Todavia, deve-se ter em mente que, dada a incapacidade do modelo em captar as diferenças de alocação da força de trabalho decorrentes da escolha ocupacional diferenciada por gênero, a discriminação ocupacional calculada pode estar sendo, por esse motivo, superestimada. Por outro lado, a agregação das ocupações em classes deve, provavelmente, contribuir para a subestimação dessa discriminação.

As informações contidas na tabela 45 objetivam facilitar a apreensão das magnitudes relativas (e não das absolutas como 0 fazem as tabelas anteriores) dos componentes justificáveis ou não por diferenças de qualificação. Esses dados permitem comprovar que, de modo geral, a desigualdade de atributos explica uma fração muito pequena das diferenças de renda entre os gêneros nesse estado. Nota-se, ainda, que em três dos anos considerados as diferenças de qualificação entre os gêneros contribuem para reduzir a desigualdade, ou seja, se elas fossem eliminadas as mulheres receberiam remuneração ainda menor.

72 Esses resultados contradizem os relatados por BARROS et alii (1992), que não detectam presença de discriminação ocupacional no mercado de trabalho brasileiro. Muito provavelmente as dificuldades enfrentadas por esses autores, assim como as relatadas por BROWN et alii (1980) e por MILLER (1987) decorrem do processo utilizado para agregar ao ocupações, conforme discutido no capítulo 3 . 
Tabela 45. Decomposição percentual das diferenças entre a média dos logaritmos dos rendimentos dos homens e mulheres na ocupação principal. São Paulo, 1981 a 1990 .

\begin{tabular}{crc}
\hline & \multicolumn{3}{c}{ DIFERENÇAS } \\
\cline { 2 - 3 } ANO & $\begin{array}{r}\text { JUSTIFICÁVEIS } \\
(\mathrm{em} \mathrm{\% )}\end{array}$ & $\begin{array}{c}\text { INJSTIFICÁVEIS } \\
\text { (em \%) }\end{array}$ \\
\hline 1981 & 10,22 & 89,78 \\
1983 & 1,36 & 98,64 \\
1984 & $-5,80$ & 105,80 \\
1985 & 7,04 & 92,96 \\
1987 & 3,68 & 96,32 \\
1988 & $-11,59$ & 111,59 \\
1989 & 1,40 & 98,60 \\
1990 & $-12,17$ & 112,17 \\
\hline
\end{tabular}

Os resultados da decomposição das diferenças entre os rendimentos dos trabalhadores e trabalhadoras do estado de Pernambuco, apresentados na forma logarítmica e em seus antilogaritmos nas tabelas 46 e 47 respectivamente, divergem em uma série de aspectos dos obtidos para os trabalhadores paulistas. 
Tabela 46. Decomposição das diferenças entre as médias dos logaritmos naturais dos rendimentos(1) dos homens e mulheres na ocupação principal. Pernambuco, 1981 a 1990.

\begin{tabular}{|c|c|c|c|c|c|c|c|}
\hline \multirow[b]{2}{*}{ ANO } & \multirow[b]{2}{*}{$\overline{\ln R^{m}}-\overline{\ln R^{f}}$} & \multicolumn{2}{|c|}{$\begin{array}{c}\text { DIFERENÇAS } \\
\text { INTRAOCUPACIONAIS }\end{array}$} & \multicolumn{2}{|c|}{$\begin{array}{l}\text { DIFERENÇAS DE } \\
\text { DISTRIBUIÇÃO } \\
\text { OCUPACIONAL } \\
\end{array}$} & \multicolumn{2}{|c|}{ DIFERENÇAS TOTAIS } \\
\hline & & $\begin{array}{l}\text { JUSTIFI- (RE) } \\
\text { CÁVEIS }\end{array}$ & $\begin{array}{l}\text { INJUSTI- (RD) } \\
\text { FICÁVEIS }\end{array}$ & $\begin{array}{l}\text { JUSTIFI- (AE) } \\
\text { CÁVEIS }\end{array}$ & $\begin{array}{l}\text { INJUUSTI- (AD) } \\
\text { FICÁVEIS }\end{array}$ & $\begin{array}{l}\text { JUSTIFI- } \\
\text { CÁVEIS }\end{array}$ & $\begin{array}{l}\text { INJUSTI- } \\
\text { FICÁVEIS }\end{array}$ \\
\hline 1981 & 0,3902 & $-0,0843$ & 0,4612 & $-0,0463$ & 0,0597 & $-0,1306$ & 0,5209 \\
\hline 1983 & 0,4505 & $-0,0258$ & 0,4493 & $-0,0326$ & 0,0595 & $-0,0584$ & 0,5088 \\
\hline 1984 & 0,4108 & $-0,1537$ & 0,5435 & $-0,0461$ & 0,0670 & $-0,1997$ & 0,6105 \\
\hline 1985 & 0,5176 & $-0,0602$ & 0,6614 & $-0,0543$ & $-0,0291$ & $-0,1145$ & 0,6322 \\
\hline 1987 & 0,3222 & $-0,0091$ & 0,4482 & $-0,0361$ & $-0,0808$ & $-0,0452$ & 0,3674 \\
\hline 1988 & 0,3725 & 0,0346 & 0,5050 & $-0,0584$ & $-0,1088$ & $-0,0237$ & 0,3962 \\
\hline 1989 & 0,3936 & $-0,0971$ & 0,4271 & $-0,0332$ & 0,0968 & $-0,1303$ & 0,5239 \\
\hline 1990 & 0,2404 & $-0,1172$ & 0,3397 & $-0,0442$ & 0,0624 & $-0,1614$ & 0,4020 \\
\hline
\end{tabular}

(1) Corresponde ao logaritmo da média geométrica desses rendimentos.

Tabela 47. Decomposição da diferença relativa entre as médias geométricas dos rendimentos dos homens $\left(G^{m}\right)$ e mulheres $\left(G^{f}\right)$ na ocupação principal. Pernambuco, 1981 a 1990.

\begin{tabular}{|c|c|c|c|c|c|c|c|}
\hline \multirow[b]{2}{*}{ ANO } & \multirow[b]{2}{*}{$\frac{G^{m}-G^{f}}{G^{f}}$} & \multicolumn{2}{|c|}{$\begin{array}{c}\text { DIFERENÇAS } \\
\text { INTRAOCUPACIONAIS }\end{array}$} & \multicolumn{2}{|c|}{$\begin{array}{l}\text { DIFERENÇAS DE } \\
\text { DISTRIBUIÇÃO } \\
\text { OCUPACIONAL }\end{array}$} & \multicolumn{2}{|c|}{ DIFERENCCAS TOTAIS } \\
\hline & & $\begin{array}{l}\text { JUSTIFI- } \\
\text { CÁVEIS }^{(1)}\end{array}$ & $\begin{array}{l}\text { INJUSTI- } \\
\text { FICÁVEIS }^{(1)}\end{array}$ & $\begin{array}{l}\text { JUSTIFI- } \\
\text { CÁVEIS }^{(1)}\end{array}$ & $\begin{array}{l}\text { INJUSTI- } \\
\text { FICÁVEIS }^{(1)}\end{array}$ & $\begin{array}{l}\text { JUSTIFI- } \\
\text { CÁVEIS }^{(1)}\end{array}$ & $\begin{array}{l}\text { INJUSTI- } \\
\text { FICÁVEIS }^{(1)}\end{array}$ \\
\hline 1981 & 0,4773 & $-0,0809$ & 0,5860 & $-0,0453$ & 0,0615 & $-0,1224$ & 0,6835 \\
\hline 1983 & 0,5691 & $-0,0255$ & 0,5672 & $-0,0321$ & 0,0613 & $-0,0567$ & 0,6633 \\
\hline 1984 & 0,5080 & $-0,1424$ & 0,7220 & $-0,0450$ & 0,0693 & $-0,1810$ & 0,8414 \\
\hline 1985 & 0,6780 & $-0,0584$ & 0,9374 & $-0,0528$ & $-0,0287$ & $-0,1082$ & 0,8817 \\
\hline 1987 & 0,3802 & $-0,0091$ & 0,5654 & $-0,0355$ & $-0,0776$ & $-0,0442$ & 0,4440 \\
\hline 1988 & 0,4514 & 0,0352 & 0,6570 & $-0,0567$ & $-0,1031$ & $-0,0234$ & 0,4862 \\
\hline 1989 & 0,4823 & $-0,0925$ & 0,5328 & $-0,0327$ & 0,1016 & $-0,1222$ & 0,6886 \\
\hline 1990 & 0,2718 & $-0,1106$ & 0,4045 & $-0,0433$ & 0,0643 & $-0,1490$ & 0,4948 \\
\hline
\end{tabular}

(1) Valores obtidos subtraindo-se um dos antilogaritmos dos valores correspondentes da tabela 46 . 
Em primeiro lugar, pode-se notar que as diferenças de qualificação têm, em geral, o efeito de reduzir a desigualdade de rendimentos por gênero. Neste sentido, verifica-se que se as diferenças de qualificação intraocupacionais fossem eliminadas, admitindo-se que os atributos produtivos considerados sejam remunerados da mesma maneira para homens e mulheres, os rendimentos femininos cairiam em sete dos oito anos analisados. Da mesma forma, considerando-se que homens e mulheres obtenham a mesma remuneração média por categoria ocupacional e sejam selecionadas segundo os mesmos critérios, o impacto de se eliminar as diferenças de qualificação entre os sexos contribuiria, em todos os anos considerados, para ampliar a desigualdade de renda entre os homens e mulheres de Pernambuco.

A comparação desses resultados com os descritos para a PEA paulista conduz à conclusão de que o efeito das diferenças de qualificação entre os sexos no diferencial entre os rendimentos auferidos por homens e mulheres desses estados favorece mais a pernambucana do que a paulista, o que é, de certa forma, coerente com a desigualdade entre os sexos no tocante aos atributos produtivos considerados que vigora nesses estados. Contudo, deve-se notar que, como expresso na equação (24), o impacto de se eliminar essas diferenças depende da forma como cada atributo é remunerado e considerado na alocação da mão-de-obra, assim como das diferenças que existem entre as remunerações médias das ocupações por categoria, o que impede qualquer conclusão aprioristica a respeito da magnitude relativa desses componentes.

Além disso, deve-se ressaltar que as maiores diferenças regionais, em termos da magnitude dos 
componentes, não se referem à desigualdade de qualificação e sim às duas formas de discriminação.

Nesse sentido, os dados apresentados permitem verificar que o efeito-renda é significativamente maior em Pernambuco. Na verdade, se as características femininas das pernambucanas passassem a ser remuneradas da mesma forma que as masculinas (ou em outros termos, se se eliminasse aquilo que, com as devidas ressalvas, é considerado como discriminação intra-ocupacional), a desigualdade se inverteria a favor da parcela feminina de PEA, e a remuneração feminina se tornaria maior do que a masculina em quase todos os anos do período considerado.

Por outro lado, caso as diferenças de alocação que não podem ser justificadas pelas diferenças de qualificação fossem eliminadas, 0 impacto nos rendimentos das pernambucanas seria pequeno. Mais do que isso, em três dos oito anos considerados esses rendimentos seriam inclusive reduzidos. Ou seja, o que se considera como discriminação ocupacional tem pequena importância na explicação da desigualdade entre os homens e mulheres desse estado. 0 menor rendimento das pernambucanas decorre, basicamente, do fato das suas características não serem remuneradas da mesma forma que as masculinas, ou seja, da discriminação intra-ocupacional.

A apresentação da tabela 48 objetiva facilitar a apreensão das magnitudes relativas dos componentes justificáveis ou não pelas diferenças de qualificação. 
Tabela 48. Decomposição percentual das diferenças entre a média dos logaritmos dos rendimentos dos homens e mulheres na ocupação principal. Pernambuco, 1981 a 1990 .

\begin{tabular}{ccc}
\hline & \multicolumn{3}{c}{ DIFERENÇAS } \\
\cline { 2 - 3 } ANO & $\begin{array}{c}\text { JUSTIFICÁVEIS } \\
(\mathrm{em} \%)\end{array}$ & $\begin{array}{c}\text { INJUSTIFICÁVEIS } \\
(\mathrm{em} \%)\end{array}$ \\
\hline 1981 & $-33,46$ & 133,46 \\
1983 & $-12,97$ & 112,97 \\
1984 & $-48,61$ & 148,61 \\
1985 & $-22,12$ & 122,12 \\
1987 & $-14,03$ & 114,03 \\
1988 & $-6,36$ & 106,36 \\
1989 & $-33,10$ & 133,10 \\
1990 & $-67,08$ & 167,08 \\
\hline
\end{tabular}

Verifica-se que em Pernambuco, em todos os anos considerados, as diferenças de qualificação entre os gêneros contribuem para reduzir a desigualdade.

\subsection{Discriminação, desemprego e inflação}

Há evidências empíricas de que a desigualdade de renda está associada às oscilações do ritmo da atividade econômica, aumentando durante as recessões e diminuindo durante os períodos de retomada do crescimento econômico. ${ }^{73}$

o relatório Poverty and Income Distribution in Latin América: the story of 1980's (1993), do Banco Mundial, analisa o comportamento anticíclico da desigualdade às condições macro-econômicas nos países da América Latina. Especificamente para a economia brasileira pode-se consultar RAMOS (1991), que verifica a existência do comportamento anticíclico da desigualdade entre 1976 e 1985 através de dados referentes à PEA urbana, e CORRÊA (1996) que, com base em dados da PEA rural, comprova esse comportamento ao longo dos anos oitenta. 
Algumas análises empiricas têm também detectado a existência de correlação entre desigualdade e inflação, atribuindo o crescimento da desigualdade em épocas de inflação acelerada às maiores dificuldades enfrentadas pelas pessoas de baixo poder aquisitivo para proteger os seus rendimentos da corrosão inflacionária (Hoffmann, 1992a e 1992b, e Corrêa, 1996).

Também a discriminação contra a mão-de-obra feminina pode vir a ser afetada por esses elementos conjunturais. Nos períodos de crise o excedente da força de trabalho certamente estabelece condições mais propicias à vigência de práticas discriminatórias. O crescimento do ritmo inflacionário, por sua vez, pode levar ao aumento da desigualdade entre os rendimentos de homens e mulheres pela maior concentração feminina em postos de trabalho mal remunerados, como assalariadas e em categorias ocupacionais atreladas a sindicatos menos atuantes.

Objetivando verificar se a parcela da desigualdade de rendimentos por gênero que decorre da discriminação é também afetada por esșes elementos conjunturais, procede-se ao ajuste, por estado, de modelos de regressão linear nos quais a variável dependente é a parcela da desigualdade que decorre da discriminação (indicada, alternativamente, por $\mathrm{RD}$ e $\mathrm{AD})$ e as independentes o tempo em anos $(\boldsymbol{t})$ e as taxas de desemprego $(\boldsymbol{u})$ ou de inflação $(\boldsymbol{\pi})$. Pretende-se, com esse procedimento, verificar a existência de alguma forma de tendência na discriminação que atinge as trabalhadoras de São Paulo e Pernambuco ao longo da década analisada, assim como a associação que existe entre a discriminação e os elementos conjunturais considerados.

As taxas de desemprego ou desocupação $(\boldsymbol{u})$, obtidas nos relatórios anuais do IBGE, estão definidas na tabela 14 
do presente trabalho. As taxas mensais de inflação estão relacionadas na tabela 49.

Tabela 49. Taxas de Inflação. Brasil, 1981 a 1990.

\begin{tabular}{cc}
\hline ANO & $\begin{array}{c}\text { INFLAÇÃO } \\
\text { MENSAI } \\
\text { (em } 8 \text { ) }\end{array}$ \\
\hline 1981 & 4,6 \\
1983 & 11,3 \\
1984 & 11,1 \\
1985 & 10,1 \\
1987 & 7,2 \\
1988 & 26,9 \\
1989 & 36,3 \\
1990 & 14,3 \\
\hline
\end{tabular}

Fonte: HOFFMANN (1992b). Crescimento percentual no mês de referência das PNAD em relação ao INPC do mês anterior.

Nos dois estados o ajuste de regressões nas quais a variável dependente é $\mathrm{AD}$ são não-significativos, indicando que, talvez devido ao número reduzido de observações, não existe relação estatisticamente significativa entre aquilo que, com as devidas ressalvas, se considera como discriminação ocupacional e as variáveis explicativas escolhidas (o tempo e o desemprego no primeiro modelo e o tempo e a inflação no segundo).

Por outro lado, o modelo de regressão linear, aplicado aos dados de São Paulo, que relaciona a parcela da desigualdade de rendimentos por gênero considerada como discriminação intraocupacional com o tempo e a inflação é estatisticamente significativo ao nível de 5\% (o valor de $F$ é 5,99). A equação ajustada (teste $t$ entre parênteses) é a seguinte: 


$$
\begin{aligned}
& \mathrm{RD}=0,256-0,0158 t+0,00562 \pi \\
& (8,851) \quad(-2,763) \quad(3,376) \\
& R^{2}=0,7055
\end{aligned}
$$

Os coeficientes dessa regressão são todos estatisticamente diferentes de zero ao nível de significância de $5 \%$. O sinal negativo do coeficiente de $\boldsymbol{t}$ indica tendência de redução, ao longo dos anos considerados, da discriminação intraocupacional no estado de São Paulo. O sinal positivo do coeficiente de $\pi$, por sua vez, indica que essa forma de discriminação é função crescente da inflação.

o ajuste desse mesmo modelo aos dados referentes a Pernambuco resultou não-significativo, assim como também o do modelo que relaciona a discriminação intraocupacional com o desemprego nos dois estados.

Em resumo, pelos resultados da estimação de equações de regressão que buscam verificar a existência de tendência na discriminação que atinge as trabalhadoras dos estados de São Paulo e de Pernambuco, assim como estabelecer relações entre a discriminação e alguns elementos conjunturais, existe respaldo estatístico para afirmar que a discriminação intraocupacional no estado de São Paulo apresenta tendência decrescente e é função crescente da inflação. Ou seja, o controle do processo inflacionário pode contribuir não apenas para reduzir a desigualdade de renda e o nível de pobreza em São Paulo, como também a discriminação que afeta as trabalhadoras desse estado. No entanto, deve-se considerar que como a discriminação ocupacional nesse estado também é considerável e não apresenta tendência decrescente, nem resposta ao controle da inflação, a sua superação não pode 
ser deixada a cargo das "forças do mercado". Ao invés disso, é necessário a adoção de um conjunto de políticas específicas, que visem o aumento da participação feminina em carreiras e posições nas quais a participação masculina é preponderante. Por outro lado, a magnitude da discriminação intraocupacional em Pernambuco, assim como a ausência de qualquer manifestação que indique sua redução ao longo do tempo ou mesmo resposta à redução da inflação sugerem a necessidade de uma politica mais ativa nesse estado objetivando coibir diferenças entre os critérios adotados para remunerar os atributos produtivos dos trabalhadores e trabalhadoras do estado. 


\section{CONCLUSÕES}

Apesar dos graves problemas conjunturais que afetam a economia brasileira ao longo dos anos oitenta, provocando a virtual estagnação do PIB per capita no período, o processo de incorporação da mulher no mercado de trabalho não se interrompe. Ao contrário, o crescimento substancial das taxas de atividade feminina observado entre 1981 e 1990 nos estados de São Paulo e de Pernambuco resulta em uma elevação da proporção feminina da PEA entre esses dois anos de 32,3\% para 36,3\% em São Paulo e de 31,1\% para 34,6\% em Pernambuco.

A incorporação da mão-de-obra feminina na PEA é acompanhada por mudanças de composição dessa força-detrabalho que podem impactar na evolução dos seus rendimentos, assim como na do diferencial de remuneração por gênero dos trabalhadores desses dois estados.

As diferenças entre os gêneros, medidas através dos níveis de escolaridade, idade, situação do domicílio, posse de carteira de trabalho assinada e posição na ocupação - considerados como proxies que captam a contribuição do treinamento e experiência, da segmentação do mercado, bem como de posse prévia da propriedade para a explicação das diferenças pessoais de rendimento - são, em geral, de pequeno porte. Nos dois estados a PEA ocupada feminina tem, em média, maior escolaridade e concentração 
na zona urbana (o que, teoricamente, deveria contribuir para um rendimento feminino maior do que o masculinol, mas menor idade média e participação na posição de empregador (o que deveria ter o efeito oposto) e, apenas em São Paulo, - percentual de trabalhadoras com carteira de trabalho assinada é substancialmente menor do que 0 de trabalhadores. As evidências empíricas analisadas mostram também que o diferencial entre homens e mulheres no tocante às características consideradas tende, em geral, a beneficiar mais (ou prejudicar menos, conforme o aspecto analisado) a pernambucana do que a paulista. Além disso, nos dois estados o aprimoramento da qualificação ao longo dos anos considerados é mais acentuado para a parcela feminina da PEA.

A despeito das semelhanças verificadas, a remuneração feminina por hora trabalhada na ocupação principal corresponde, em média, nos anos considerados, a 63,0\% da masculina em São Paulo e a 73,9\% em Pernambuco.

A análise da estrutura ocupacional nesses dois estados permite verificar que homens e mulheres encontram-se, em grande parte, segregados em ocupações diferentes. Os valores do índice de segregação de Duncan indicam que entre $58,0 \%$ e $65,1 \%$ da força-de-trabalho feminina (ou masculina) deveria ser realocada para eliminar sua super-representação em determinadas ocupações e sua subrepresentação em outras. Ao longo do período considerado essa segregação manifesta tendência descendente em São Paulo, mas não apresenta sinais de arrefecimento em Pernambuco. Ao contrário, neste último estado a segregação se aprofunda nos anos em questão.

o procedimento adotado na presente pesquisa permite decompor as mudanças no grau de segregação em duas 
parcelas: uma associada às modificações nas proporções de homens e mulheres em cada ocupação e outra associada às alterações na distribuição da PEA pelas ocupações (estrutura ocupacional). Embora nos dois estados a parcela mais importante das mudanças na segregação seja a primeira, em São Paulo ela é responsável por quase $90 \%$ da redução no valor de $D$, enquanto em Pernambuco as alterações da estrutura ocupacional provocam mais de $40 \%$ da elevação do valor dessa medida.

Se as ocupações femininas fossem diferentes das masculinas mas não pior remuneradas, a segregação ocupacional não se constituiria num problema a ser resolvido para reduzir as profundas desigualdades que caracterizam a nossa sociedade. Entretanto, quando ocupações masculinas possibilitam a obtenção de rendimentos substancialmente maiores, a igualdade da distribuição ocupacional por gênero se torna uma das bandeiras empunhadas pelos movimentos sociais que almejam uma sociedade mais igualitária. As evidências empiricas relatadas neste trabalho sugerem que os esforços no sentido de aumentar a participação feminina em ocupações tipicamente masculinas podem resultar na elevação do rendimento feminino, médio em São Paulo, onde a mulher que se insere em ocupações masculinas tem remuneração expressivamente maior do que as demais, mas não necessariamente em Pernambuco, onde o acesso a uma ocupação masculina não garante à mulher melhor remuneração.

As equações de rendimento estimadas por sexo e categoria ocupacional combinadas com a distribuição ocupacional simulada para a parcela feminina da amostra possibilitam aprofundar a análise, identificando o impacto nas diferenças de rendimento por gênero decorrentes das 
mulheres passarem a ser selecionadas ou remuneradas pelos critérios adotados para a parcela masculina da amostra.

A utilização dessa metodologia permite verificar que as diferenças de qualificação não apenas explicam uma parcela desprezível da desigualdade de remuneração entre homens e mulheres no estado de São Paulo, como ainda contribuem para reduzir essa desigualdade em Pernambuco. Ou seja, políticas que procurem superar a desigualdade de rendimentos através do estímulo à maior escolaridade da trabalhadora ou à redução do seu abandono precoce do mercado de trabalho podem não atingir os resultados esperados. Como as diferenças de remuneração não podem ser explicadas pela qualificação, ao menos pela que é identificada através das informações dessa base de dados, o enfoque das políticas na área deve, se não exclusivamente pelo menos prioritariamente, se concentrar na superação dos critérios de seleção de mão-de-obra e de remuneração que distinguem os trabalhadores com base em seu sexo.

A ênfase das propostas deve ainda ser diferente nos dois estados. A tendência decrescente da discriminação intraocupacional ao longo dos anos analisados e sua associação positiva com as taxas de inflação em São Paulo sugerem que, nesse aspecto, a desigualdade entre os rendimentos de homens e mulheres pode vir a ser reduzida sem a adoção de políticas complementares. Todavia, como nesse mesmo estado a desigualdade de rendimentos por gênero que decorre de diferenças de estrutura ocupacional que não se justificam pela qualificação é considerável e aparenta ter caráter mais estrutural do que conjuntural, visto que não é afetada pela redução do desemprego e nem pela da inflação, a sua superação implica na adoção de um conjunto de politicas específicas que objetivem propiciar o 
crescimento da participação feminina em carreiras predominantemente masculinas.

Por outro lado, a magnitude da discriminação intraocupacional em Pernambuco, assim como a ausência de qualquer indicativo que sugira a redução desse tipo de discriminação ao longo do tempo ou em resposta ao controle do processo inflacionário apontam para a preemência de uma politica mais ativa no sentido de penalizar a existência de critérios diferentes para remunerar os atributos produtivos dos trabalhadores e trabalhadoras. A igualdade de remuneração para o mesmo trabalho, garantida pela Constituição, deve ainda ser objeto de cuidadosa atenção nesse estado.

Por fim, deve-se ressaltar que o presente trabalho tem cunho essencialmente empírico. A interpretação dos resultados obtidos com base na seleção de uma das alternativas teóricas, dentre as discutidas no presente trabalho, é, logicamente, inviabilizada pelas limitações dos dados disponíveis. $\mathrm{Na}$ verdade, como essas alternativas correspondem a diferentes formas de perceber 0 funcionamento do mercado de trabalho, a opção por uma delas dificilmente pode resultar da manipulação de dados secundários. Todavia, deve-se mencionar que as evidências empiricas utilizadas apontam para a inadequação da abordagem do capital humano para explicar a segregação ocupacional. Neste sentido, as mulheres que se encontram em ocupações femininas, na maior parte dos anos e nos dois estados, não auferem crescimento dos rendimentos com a idade substancialmente menor do que as que se inserem nas ocupações masculinas e nem, muito menos, são compensadas por uma remuneração inicial mais elevada. Entretanto, se tais resultados em certo sentido desqualificam a adequação 
da teoria do capital humano para justificar a segregação de homens e mulheres em diferentes ocupações, as limitações das informações disponiveis não possibilitam eleger uma dentre as demais alternativas como mais adequada.

De qualquer forma deve-se reafirmar que a opção por uma das alternativas teóricas não conduz, necessariamente, a propostas politicas diferenciadas.

Se $\circ$ padrão de divisão familiar do trabalho que confere às mulheres a responsabilidade pelo trabalho doméstico e cuidado dos filhos é provocado por seus rendimentos potenciais menores no mercado de trabalho, um tratamento igualitário nesse mercado elimina as razões para a perpetuação desse padrão de divisão do trabalho. Oportunidades iguais encorajarão as jovens a se preparar para a atividade profissional e, no longo prazo, a alegada inferioridade da mão-de-obra feminina em termos do seu "capital humano" (a qual, deve-se ressaltar, não foi comprovada, ao menos de forma inequívoca, no presente trabalho) tenderá a desaparecer.

Da mesma forma, uma estrutura de incentivos que ofereça às mulheres oportunidades de treinamento e o acesso a postos superiores na hierarquia, deve provocar a diminuição da sua alegada maior rotatividade e taxas de absenteísmo, quebrando o círculo vicioso que, na abordagem da teoria do mercado de trabalho segmentado, as condena às posições pior remuneradas. 


\section{REFERÊNCIAS BIBLIOGRÁFICAS}

ASHENFELTER, 0 . Discrimination and trade unions. In: ASHENFELTER, O. \& REES, A. (Eds.) Discrimination in Labor Markets. Princeton: Princeton University, p. 88$112,1973$.

ALBELDA, R. P. Occupational segregation by race and gender, 1958-1981. Industrial and Labor Relations Review, 39 (3): 404-411, 1986.

ARROW, K. Models of job discrimination, In: PASCAL, A. H. (Ed.), Racial Discrimination in Economic Life, Lexington, Mass: Lexington Books, 83-102, 1972.

ARROW, K. The theory of discrimination, In: ASHENFELTER, O. \& REES, A. (Eds.) Discrimination in Labor Markets. Princeton, N.J.: Princeton University Press, 3-33. 1973.

BARROS, R. P., RODRIGUES, J.; ALMEIDA REIS, J. G. Segmentação no mercado de trabalho: a carteira de trabalho na construção civil. INPES/IPEA, Mimeo, 1989.

BARROS, R. P.; RAMOS, L.; SANTOS, E. Gender differences in brasilian labor markets. IPEA, mimeo, 1992.

BARROS, R. P.; MACHADO, A. F.; MENDONÇA, R. S. P. A desigualdade da pobreza: estratégias ocupacionais e diferenciais por gênero. Texto para discussão no 453 . IPEA, 1997 . 
BECKER, G. S. The Economics of Discrimination. Chicago: University of Chicago Press, 1957. 137 p.

BECKER, G. S. Human Capital. New York: Columbia University Press, 1975.

BECKER, G. S. A Treatise on the Family. Cambridge, M. A.: Harvad University Press, 1981 (second printing).

BECKER, G. S. The allocation of effort, specific human capital and differences between men and women in earnings and occupations. Journal of Labor Economics, $3(1), 1985$.

BELLER, A. H. Occupational segregation by sex: determinants and changes. The Journal of Human Resources, 17(3): 371-392, 1982.

BELLER, A. H. Trends in occupational segregation by sex and race, 1960-1981. In: RESKIN, B. (ed.). Sex Segregation in the Workplace: Trends, Explanations, Remedies. Washington D.C.: National Academy Press, 1984. p. 11-26.

BELLER, A. H. Changes in the sex composition of U.S. occupations, 1960-1981. The Journal of Human Resources, 20 (2): 235-250, 1985.

BERGMAN, B. R. Occupational segregation, wages and profits when employers discriminate by race or sex. Eastern Economic Journal, 1:103-110, 1974.

BERQUÓ, E.; OLIVEIRA, M. C.; CAVENAGHI. Arranjos Familiares não-canônicos no Brasil. In: ENCONTRO NACIONAL DE ESTUDOS POPULACIONAIS,VII. Anais. vol. 1: 99-135, 1990. 
BIELBY, W.; BARON, S. A woman's place is with other women: sex segregation within organizations. In: RESKIN, B. (ed.). Sex Segregation in the Workplace: Trends, Explanations, Remedies. Washington, D.C.: National Academy Press, 1984. p. 27-55.

BLAU, F. D. Equal Pay in the Office. Lexington, Mass: D.C. Heath, 1977 .

BLAU, F. D.; HENDRICKS, W. E. Occupational segregation by sex: trends and prospects. The Journal of Human Resources, 14 (2): 197-210, 1979.

BLAU, F. D.; BELLER, A. H. Trends in earnings differentials by gender, 1971-1981. Industrial and Labor Relations Review, 41 (4): 513-529, 1988.

BLAU, F. D.; FERBER, M. A. Women in the labor market - the last twenty years. In: LARWOOD,L.; STROMBERG, A. H.; GUTEK, B. A. (Eds.). Women and Work. Beverly Hills: Sage Publications, 19-49, 1988.

BLINDER, A. S. Wage discrimination: reduced form and strutural variables. Journal of Human Resources. 8:436-455, 1973 .

BLOOM, D. E.; KILLINGSWORTH, M. R. Pay discrimination research and litigation: the use of regression, Industrial Relations, 21: 318-339, 1982.

BOSKIN, M. A conditional logit model of occupation choice. Journal of Political Economy, 82(2): 389-98, 1974.

BRIZOLLA, S. N. Formas de inserção da mulher no mercado de trabalho - o caso do Brasil. UNICAMP, 1982 (Tese de doutoramento) . 
BROWN, R. S.; MOON, M.; ZOLOTH, B. S. Incorporating occupacional attainment in studies of male-female earnings differentials. Journal of Human Resources. 15 (1): 1-28, Winter 1980.

BRUSCHINI, C. Mulher e trabalho - uma avaliação da década da mulher. São Paulo, Nobel - Conselho Estadual da Condição Feminina, 1985.

BUCKLEY, J. Pay differences between men and women in the same job. Monthly Labor Review. 94(11): 36-9, 1971.

BUDD, E.; RADNER, D. B. The OBE Size distribution series methods and tentative results for 1964. American Economic Review. 59(2): 435-49, 1969.

CACCIAMALI, M. C. Características e evolução do mercado de trabalho não-regulamentado na Grande São Paulo. Trabalho apresentado no Seminário Instituciones laborales frente a los cambios en América Latina. Santiago: III S/Prealc, 24-27, mai 1993.

CAIN, G. G. Labor market discrimination. In: ASHENFELTER, O. \& RAYARD, R. (Eds). Handbook of Labor Economics, vol. 1, ch 13, 1986.

CAMARGO, J. M.; SERRANO, F. Os dois mercados: homens e mulheres na indústria paulista. Revista Brasileira da Economia. 37(4): 435-48, out/dez 1983.

CARLSON, L. A.; SWARTZ, C. The earnings of women and etnic minorities, 1959-1979. Industrial and Labor Relations Review, 41 (4): 530-552, 1988.

COHEN, M. S. Sex differences in compensation. Journal of Human Resources. 6(4): 434-47, 1971. 
CORCORAN, M.; DUNCAN, G. J. Work history, labor force attachment and earnings differences between races and sexes. Journal of Human Resources, 14:497-520, 1979.

CORREA, A. M. C. J. Distribuição de Rendimentos e Pobreza na Agricultura Brasileira: 1981-1990. Piracicaba, 1996, 353p. Tese (Doutorado) - Escola Superior de Agricultura.

COSTA, I. N.; NOZOE, N. H.; PORTO, C.N. Estrutura das Familias e dos Domicílios no Brasil: Mudanças Quantitativas e Linhas de Convergência. Estudos Econômicos. São Paulo, $17(3): 367-403$, set/dez 1987.

COSTA, L. B. Participação da mulher no mercado de trabalho. São Paulo: ed. IPE/USP-CNPq, 1984.

DARITY, W. A. Economic theory and racial economic inequality. Review of Black Political Economy, 5 (spring 1975): 225-49.

DOERINGER, P. B.; PIORE, M. J. Internal Labor Makets and Manpower Analysis. Lexington, M.A.: D.C. Heath, 1971.

DOLTON, P.J.; MAKEPEACE, G.H. Marital status, child rearing and earnings differentials in the graduate labour market. The Economic Journal, 97:897-922, 1987.

DUNCAN, D.; DUNCAN, B. A methodological analysis of segregation index. American Sociological Review, $20(2): 210-217,1955$.

EDGEWORTH, F. Y. Equal pay for men and women for equal work. Economic Journal. (dec): 431-57, 1922. 
ENGLAND. P. The failure of human capital theory to explain occupational sex segregation. The Journal of Human Resources, 17(3): 358-370, 1982 .

FEATHERMAN, D. L.; HAUSER. Sexual inequalities and socioeconomic achievement in the U.S.A, 1962-1973. American Sociological Review. 41:462-483, 1976.

FIELDS, J.; WOLFF, E. N. The decline of sex segregation and the wage gap, 1970-1980. The Journal of Human Resources, 26(4): 608-622, 1991.

FUCHS, V. R. A note on sex segregation in professional occupations. Explorations in Economic Research, 2(1):105-111, 1975.

GÁTICA, D.; MIZALA, A.; ROMANGUERRA, P. Estrutura salarial $y$ diferenciales de salário en la indústria de transformación Brasileña, Projeto PNUD/DIT/BRA, mimeo, 1990.

GITAHY, L. et alii. Trabalho assalariado, sindicalização e reivindicação das operárias (1970-1980). São Paulo, 1981, mimeo.

GERHART, B. Gender diferences in current and starting salaries: the role of performance, college major and job tittle. Incustrial and Labor Relations Review. 43(4): 418-433, 1990 .

GOLDSMITH, S.F. Statistical information on the distribution of income by size in the United States. Americam Economic Review, 40(2):321-41, 1950.

GREENE, W. Econometric Analysis. New York: Macmillan Publishing Company, 1993. 
GROSHEN, E. I. The structure of the female/male wage differential. Journal of Human Resources. XXVI (3): $457-472,1991$.

GROSS, E. Plus ca changes...? The sexual structure of occupations over time. Social Problems. 16: 198-208. 1968 .

HECKMAN, J. Shadow prices, market wages and labor supply. Econometrica. 1:679-94, 1974 .

HERSCH, J. Male-female differences in Hourly wages: the role of human capital, working conditions and housework. Industrial and Labor Relations Review. $44(4)$ : 746-759, 1991 .

HOFFMANN, R. A subdeclaração dos rendimentos. São Paulo em Perspectiva - SEADE, São Paulo, 2(1); 50-54, jan./mar. 1988 .

HOFFMANN, R. Crise econômica e pobreza no Brasil no período 1979-90. Piracicaba - SP: Departamento de Economia e Sociologia Rural, ESALQ/USP (Relatório de Pesquisa), $1992 a$.

HOFFMANN, R. Desigualdade e pobreza no Brasil no período 1979-90. In: ENCONTRO BRASILEIRO DE ECONOMETRIA, XIV. Anais. Vol. 1. p: 311-36. Campos do Jordão, 1992b.

HOFFMANN, R. Distribuição da renda e pobreza na agricultura paulista. São Paulo em Perspectiva. São Paulo, 7(3): 107-115, jul./set. 1993.

HOFFMANN, R. Desigualdade e pobreza na agricultura de Goiás: 1970-1990. Revista de Economia e Sociologia Rural, Brasilia, 1994 . 
HOFFMANN, R. Distribuição de renda e pobreza na agricultura gaúcha. Indicadores econômicos. Porto Alegre, RS, 21(4): 201-216, jan. 1994b.

HOFEMANN, R. Distribuição da renda: medidas de desigualdade e pobreza. Editora da Universidade de São Paulo (no prelo), 1997.

HOFFMANN, R.; KAGEYAMA, A.A. Distribuição da renda no Brasil, entre familias e entre pessoas, em 1970 e 1980. Estudos Econômicos, São Paulo, 16(1): 25-51, jan./abr. 1986.

JENKINS, S. P. Earnings discrimination measurement - a distributional approach. Journal of Econometrics. 61:81-102, 1994 .

JUSENIUS, C. L. The influence of work experience, skill requirement and occupational segregation on women's earnings. Journal of Economics and Business. 29:10715. 1977.

KAGEYAMA, A. Problemas metodológicos na Mensuração do Emprego Agrícola. Campinas:UNICAMP (mimeo), 1986.

KASSOUF, A. L. The wage rate estimation using the Heckman procedure. Revista de Econometria. 14(1):89-107, 1994.

KING, A. G. Is occupational segregation the cause of the flatter experience-earnings profiles of women? Journal of Human Resources. 12(fall 1977): 541-59.

KON, A. A segmentação ocupacional no mercado de trabalho brasileiro em um abordagem regional. Estudos Econômicos, 19(especial): 63-98, 1989. 
LANGONI, C. G. Distribuição de renda e desenvolvimento econômico do Brasil. Rio de Janeiro: Expressão e Cultura, 1973. $315 \mathrm{p}$.

LEONE, E. T. Pobreza e trabalho no Brasil: análise das condições de vida e ocupação das famílias agrícolas nos anos 80. Campinas, 1994. 233p. Tese (Doutorado) Departamento de Ciências Sociais do Instituto de Filosofia e Ciências Humanas/Universidade Estadual de Campinas.

LEWIN, H. Educação e força de trabalho feminina no Brasil. Cadernos de Pesquisa. $\mathrm{n} \subseteq 32,1980$.

LLUCH, C. Sobre medições de renda a partir dos Censos e das Contas Nacionais no Brasil. Pesquisa e Planejamento Econômico. 12(1):133-48, abril/1982.

LUNDBERG, S. J.; STARTZ, R. Private discrimination and social intervention in competitive labor market. American Economic Review, 73: 340-347, 1983.

MACEDO, R. Os salários nas Empresas Estatais. ed. Nobel, 1985.

MACEDO, R. Diferenciais de salários entre empresas estatais e privadas: novos resultados.

Estudos Econômicos, vol. 16, 1986.

MADDEN, J. F. The Economics of Sex Discrimination. Lexington, Mass: D.C. Heath and Co. 1973.

MADDEN, J. F. The persistence of pay differencials (The economics of sex discrimination), In: LARWOOD, L. STROMBERG, A. H. \& GUTEK, B. A. (Eds)., Women and Work. Beverly Hills: Sage Publications, 76-114, 1988. (second printing). 
MAKIEL, B. G.; MAKIEL, J. A. Male-female pay differentials in professional employment. American Economic Review, 63: 693-705, 1973.

MARSHALL, F. R. The economics of racial discrimination: a survey. Journal of Economic Literature, 12: 849-871, 1974 .

MCCALL, J. F. The simple mathematics of information, job search and prejudice. In: PASCAL, A. (ed.) Racial Discrimination in Economic Life, Lexington, Mass: Lexingotn Books, 205-224, 1972 .

MCNULTY, D. Differences in pay between man and women workers. Monthly Labor Review. 90(12): 40-3, 1967.

MEDICI, A. C. Mulher brasileira: muito prazer. Revista Brasileira de Estatística. 48:189-190, 1987.

MELLO, M. Uma análise da participação feminina no mercado de trabalho no Brasil. PUC, 1982 (Dissertação de Mestrado).

MENESES, W. F. Parcela salarial na indústria de transformação no Brasil:1970-1981. In: ENCONTRO NACIONAL DE ECONOMIA, XVI. Anais. Belo Horizonte, vol. 5. Porto Alegre: Gráfica e Editora NBS Ltda., 1988 .

MILLER, P.; VOLKER, P.A. On the determination of occupational attainment and mobility. Journal of Human Resources. 20(2):197-213, 1985.

MILLER, $P$. The wage effect of the occupational segregation of women in Britain. The Economic Journal, 97(dezembro 1987) :885-896. 
MINCER, J. Labor force participation of married women: A study of labor supply. In: National Bureau of Economic Research, Aspects of Labor Economics. Princeton, N.J: Princeton University Press, 1962.

MINCER, J. Schooling, experience and earning. New York, National Bureau of Economic Research, 1974.

MINCER, J.; POLACHEK, S. Family investments in human capital earnings of women. Journal of Political Economy. $82(2): 576-5108,1974$.

MINCER, J.; OFEK, H. Interrupted work careers: Depreciation and restoration of human capital. The Journal of Human Resources, 17 (1), 3-24, 1982.

NERVOLE, M.; PRESS, S. J. Univariate and Multivariate LogLinear and Logistic Models. Manuscript R-1306-EDA/NIH. Santa Mônica, Calif.: Rand Corporations, 1973.

O'NEILL, J. Role differentiation and the gender gap in wage rates. In: LARWOOD, L.; STROMBERG, A. H.; GUTEK, B. A. (eds). Women and Work, Beverly Hills: Sage Publications, 1988, 50-75.

OAXACA, R. L. Male-female wage differentials in urban labor markets. International Economic Review. 14:693709, 1973a.

OAXACA, R. Sex discrimination in wages. In: ASHENFELTER, O.; REES, A. (Eds.) Discrimination in labor markets. Princeton, N. J.: Princeton University Press, p. 124$151,1973 b$.

OLIVEIRA, M. C.; BERQUÓ, E. A familia no Brasil: análise demográfica e tendências recentes. In: ENCONTRO ANUAL DA ANPOCS, XII. 1990. 
OLIVEIRA, Z. L. C. A crise os arranjos familiares de trabalho urbano. In: ENCONTRO NACIONAL DA ANPOCS, XI. Águas de São Pedro, 1987.

PAIVA, P. T. A mulher no mercado de trabalho Urbano. In: ENCONTRO NACIONAL DE ESTUDOS POPULACIONAIS, II. Águas de São Pedro, out. 1980.

PHELPS, E. S. The Statistical theory of racism and sexism. American Economic Review, 62: 533-63, 1972.

PNAD 81. Pesquisa Nacional por Amostra de Domicílios (Mãode-Obra). Rio de Janeiro. IBGE. v. 5, tomo 2 e tomo 6,1981 .

PNAD 83. Pesquisa Nacional por Amostra de Domicílios (Mãode-Obra). Rio de Janeiro. IBGE. v. 7, tomo 12 e tomo, 1983.

PNAD 84. Pesquisa Nacional por Amostra de Domicílios (Mãode-Obra). Rio de Janeiro. IBGE. v. 8, tomo 4 e tomo 5,1984 .

PNAD 86. Pesquisa Nacional por Amostra de Domicílios (Mãode-Obra). Revisão da PNAD 85. Rio de Janeiro. IBGE. v. 10, tomo 4 e tomo 5, 1986.

PNAD 87. Pesquisa Nacional por Amostra de Domicílios (Mãode-Obra). Rio de Janeiro. IBGE. v. 11, tomo 4 e tomo 5,1987 .

PNAD 88. Pesquisa Nacional por Amostra de Domicílios (Mãode-Obra). Rio de Janeiro. IBGE. v. 12, tomo 4 e tomo 5,1988 .

PNAD 89. Pesquisa Nacional por Amostra de Domicílios (Mãode-Obra). Rio de Janeiro. IBGE. v. 13, tomo 4 e tomo $5,1989$. 
PNAD 90. Pesquisa Nacional por Amostra de Domicílios (Mãode-Obra). Rio de Janeiro. IBGE. v. 14, tomo 4 e 5, 1990 .

PNAD. Síntese de indicadores da pesquisa básica da PNAD de 1981 a 1989. Rio de Janeiro. IBGE, 1990. 99 p.

POLACHEK, S. W. Occupational segregation: an alternative hypotesis. Journal of Contemporary Business, 5: 1-12, 1976.

POLACHEK, S. W. Occupational segregation among women: theory, evidence, and prognosis, In: LOYD, ANDREWS, GILROY, (eds). Women in the Labor Market. New York: Columbia University Press, 137-157, 1979.

POLACHEK, S. W.; KIM, M.-K. Panel estimates of the gender earnings gap. Journal of Econometrics. 61: 23-42, 1994 .

RAMOS, L. R. A. Educação, desigualdade de renda e ciclo econômico no Brasil. Pesquisa e Planejamento Econômico, 21(3):423-448, 1991 .

RAMOS, L. R. A. A distribuição de rendimentos no Brasil: 1976/85. Rio de Janeiro, IPEA (Série IPEA, 141), 1993. $135 \mathrm{p}$.

REIMERS, C. W. Labor Market Discrimination against hispanic and blackmen. Review of Economics and Statistics. 65(4):570-79, 1983.

REIS, J. G. A.; BARROS, R.P. Desigualdade Salarial: resultados de pesquisas recentes. In: CAMARGO, J. M.; GIAMBIAGI, F. (orgs.) Distribuição de Renda no Brasil. São Paulo: ed. Paz e Terra, 1991, p. 69-81. 
RYTINA, N. F.; BIANCHI, S. M. Occupational reclassification and changes in distribution by gender. Montly Labor Review. 107(3):11-17, 1984.

SANBORN, H. Pay differences between men and women, Industrial and Labor Relations Review, 17:534-550, 1964 .

SAVEDOFF, W. D. Os diferenciais regionais de salários no Brasil: segmentação versus dinamismo da demanda, Pesquisa e Planejamento Econômico, 20(3):521-556, 1990. SAWHILL, J. The economics of discrimination against women: some new findings. Journal of Human Resources. 8:383396, 1973 .

SCHMIDT, P. J.; STRAUSS, R. The Prediction of Occupation Using Multiple Logit Models. International Economic Review, 16(June 1975):471-85.

SOUZA, P. R. Emprego, Salários e Pobreza. São Paulo: HUCITEC/FUCAMP, 1980.

SOWELL, T. Economics and black people. Review of Black Political Economy, 1:3-21, 1971.

SPENCE, M. Job market signalling. Quarterly Journal of Economics, 87: 355-74, 1973.

STEVENSON, M. H. Relative wages and sex segregation by occupation. In: LLOYD, C. B. (ed.). Sex, Discrimination and the Division of Labor, New York. Columbia University Press, 1975.

STIGLITZ, J. Approaches to the economics of discrimination. American Economic Review, Papers and Proceedings, 63: 287-95. 1973. 
SUTER, L. E; MILLER, H. P. Income differences between men and career women. American Journal of Sociology. 78: 962-974, 1973 .

WAJNMAN, S.; RIOS-NETO, E. L. G. Participação feminina na população economicamente ativa no Brasil: alternativas para projeções de niveis e padrões. Pesquisa $\boldsymbol{e}$ Planejamento Econômico. 24(2): 203-304, 1994.

WEISS, Y.; GRONAU, R. Expected interruptions in labor force participation and sex-related differences in earnings growth. Review of Economic Studies, XIVIII: $607-619,1981$.

WEISSKOFF, F. Women's place in the labor market. American Economic Review 62(5): 161-66, 1972 .

WELCH, F. Human capital theory: education, discrimination, and life cycles. American Economic Review, 65: 63-73, 1975.

WRIGHT, R. E.; ERMISCH, J. F. Gender discrimination in the british labour market: a reassessment. The Economic Journal, 101: 508-522, 1991.

ZELNER, H. Discrimination against women, occupational segregation and the relative wage. American Economic Review 62(5):157-60, 1972. 
APÊNDICES 


\section{APÊNDICE A}

Nas equações de rendimento estimadas os indivíduos são agregados em categorias, para cada variável considerada, da seguinte maneira:

\section{Educação:}

(1) sem instrução: menos de um ano completo de escolaridade

(2) primário incompleto: de 1 a 3 anos de escolaridade

(3) primário completo: 4 anos de escolaridade

(4) ginasial incompleto: de 5 a 7 anos de escolaridade

(5) ginásio completo: 8 anos de escolaridade

(6) colegial ou superior: de 9 anos de escolaridade ou mais

\section{Idade:}

(1) de 10 a 17 anos de idade

(2) de 18 a 19 anos de idade

(3) de 20 a 24 anos de idade

(4) de 25 a 29 anos de idade

(5) de 30 a 39 anos de idade

(6) de 40 a 49 anos de idade

(7) 50 ou mais anos de idade

Situação do domicílio

(1) rural

(2) urbano

Posse de carteira assinada

(1) sim

(2) não

Posição na ocupação

(1) empregado

(2) autônomo ou empregador 


\section{APÊNDICE B}

Nos logitos multinomiais estimados os indivíduos são agregados em categorias para cada variável considerada, da seguinte maneira:

\section{Educação:}

(1) sem instrução: menos de um ano completo de escolaridade

(2) primário incompleto: de 1 a 3 anos de escolaridade

(3) primário completo: 4 anos de escolaridade

(4) ginasial incompleto: de 5 a 7 anos de escolaridade

(5) ginásio completo: 8 anos de escolaridade

(6) colegial ou superior: de 9 anos ou mais de escolaridade

\section{Idade:}

(1) de 10 a 17 anos de idade

(2) de 18 a 19 anos de idade

(3) de 20 a 24 anos de idade

(4) de 25 a 29 anos de idade

(5) de 30 a 39 anos de idade

(6) de 40 a 49 anos de idade

(7) 50 ou mais anos de idade

\section{Posição na ocupação:}

(1) empregado

(2) autônomo ou empregador

\section{Situação do domicílio:}

(1) rural

(2) urbano 
Número de crianças:

(1) nenhuma criança menor de 6 anos no domicílio

(2) uma criança menor de 6 anos no domicílio

(3) duas crianças menores de 6 anos no domicílio

(4) três ou mais crianças menores de 6 anos no domicílio

\section{Posição na família:}

(1) chefe e cônjuge

(2) filho

(3) outro parente

\section{Outras variáveis}

As variáveis "outras rendas da pessoa" e "outras rendas da família", consideradas na análise, não são classificadas em categorias. 


\section{APÊNDICE C}

Tabela C1. Sessenta ocupações mais importantes na absorção da mão-de-obra feminina. São Paulo, 1981.

Tabela C2. Sessenta ocupações mais importantes na absorção da mão-de-obra masculina. São

Paulo, 1981.

Tabela C3. Sessenta ocupações mais importantes na absorção da mão-de-obra feminina. São Paulo, 1983.

Tabela C4. Sessenta ocupações mais importantes na absorção da mão-de-obra masculina. São Paulo, 1983

Tabela C5. Sessenta ocupações mais importantes na absorção da mão-de-obra feminina. São Paulo, 1984.

Tabela C6. Sessenta ocupações mais importantes na absorção da mão-de-obra masculina. São Paulo, 1984.

Tabela C7. Sessenta ocupações mais importantes na absorção da mão-de-obra feminina. São Paulo, 1985.

Tabela C8. Sessenta ocupações mais importantes na absorção da mão-de-obra masculina. São Paulo, 1985.

Tabela C9. Sessenta ocupações mais importantes na absorção da mão-de-obra feminina. São Paulo, 1987.

Tabela C10. Sessenta ocupações mais importantes na absorção da mão-de-obra masculina. São Paulo, 1987.

Tabela C11. Sessenta ocupações mais importantes na absorção da mão-de-obra feminina. São Paulo, 1988.

Tabela C12. Sessenta ocupações mais importantes na absorção da mão-de-obra masculina. São Paulo, 1988

Tabela C13. Sessenta ocupações mais importantes na absorção da mão-de-obra feminina. São Paulo, 1989

Tabela C14. Sessenta ocupações mais importantes na absorção da mão-de-obra masculina. São Paulo, 1989

Tabela C15. Sessenta ocupações mais importantes na absorção da mão-de-obra feminina. São Paulo, 1990

Tabela C16. Sessenta ocupações mais importantes na absorção da mão-de-obra masculina. São Paulo, 1990

Tabela C17. Sessenta ocupações mais importantes na absorção da mão-de-obra feminina. Pemambuco, 1981.

Tabela C18. Sessenta ocupações mais importantes na absorção da mão-de-obra masculina. Permambuco, 1981.

Tabela C19. Sessenta ocupações mais importantes na absorção da mão-de-obra feminina.

Pernambuco, 1983. 
Tabela C20. Sessenta ocupações mais importantes na absorção da mão-de-obra masculina. Pernambuco, 1983.

Tabela C21. Sessenta ocupações mais importantes na absorção da mão-de-obra feminina Pernambuco, 1984.

Tabela C22. Sessenta ocupações mais importantes na absorção da mão-de-obra masculina. Pernambuco, 1984.

Tabela C23. Sessenta ocupações mais importantes na absorção da mão-de-obra feminina. Pernambuco, 1985.

Tabela C24. Sessenta ocupações mais importantes na absorção da mão-de-obra masculina. Pernambuco, 1985.

Tabela C25. Sessenta ocupações mais importantes na absorção da mão-de-obra feminina. Pernambuco, 1987.

Tabela C26. Sessenta ocupações mais importantes na absorção da mão-de-obra masculina. Pernambuco, 1987.

Tabela C27. Sessenta ocupações mais importantes na absorção da mão-de-obra feminina. Pernambuco, 1988.

Tabela C28. Sessenta ocupaçōes mais importantes na absorção da mão-de-obra masculina. Pernambuco, 1988.

Tabela C29. Sessenta ocupações mais importantes na absorção da mão-de-obra feminina. Pernambuco, 1989.

Tabela C30. Sessenta ocupações mais importantes na absorção da mão-de-obra masculina. Pernambuco, 1989.

Tabela C31. Sessenta ocupações mais importantes na absorção da mão-de-obra feminina. Pernambuco, 1990.

Tabela C32. Sessenta ocupações mais importantes na absorção da mão-de-obra masculina. Pernambuco, 1990. 
Tabela C1. Sessenta ocupações mais importantes na absorção da mão-de-obra feninina ${ }^{(1)}$. São Paulo, 1981.

\begin{tabular}{|c|c|c|c|c|}
\hline OCUPAÇÕES & $F_{i}$ & $\frac{F_{i}}{T_{i}}(\%)$ & $\frac{F_{1}}{F}(\%)$ & $\pi_{i}(\%)$ \\
\hline Empregada doméstica & 539743 & 94,88 & 19,47 & 19,47 \\
\hline Auxiliar de escritónio & 257422 & 45,42 & 9,29 & 28,76 \\
\hline Alfaiate/Costureiras & 233171 & 92,87 & 8,41 & 37,17 \\
\hline Outros trab. na agropecuária & 130934 & 21,55 & 4,72 & 41,89 \\
\hline Secretária & 123719 & 95,93 & 4,46 & 46,35 \\
\hline Vendedora & 123019 & 36,36 & 4,44 & 50,79 \\
\hline Lavadeira/Passadeira & 76404 & 95,61 & 2,76 & 53,55 \\
\hline Professora de $1^{3}$ a $4^{\frac{2}{2}}$ séries & 63233 & 96,07 & 2,28 & 55,83 \\
\hline Enfermeira não diplomada & 55123 & 79,82 & 1,99 & 57,82 \\
\hline Embaladora de mercadorias & 52573 & 58,33 & 1,90 & 59,71 \\
\hline Cozinheira & 51746 & 70,36 & 1,87 & 61,58 \\
\hline Recepcionista & 46655 & 85,61 & 1,68 & 63,26 \\
\hline Outras ocupações ambulantes & 46625 & 42,11 & 1,68 & 64,94 \\
\hline Bordadeira/Cerzideira & 45424 & 96,29 & 1,64 & 66,58 \\
\hline Comerciante comta-própria & 39451 & 21,30 & 1,42 & 68,00 \\
\hline Trabalhadora de fábrica de sapato & 31866 & 46,11 & 1,15 & 69,15 \\
\hline Professora de 5 a 8 séries & 31405 & 91,16 & 1,13 & 70,29 \\
\hline Encarregada da administração & 30080 & 18,62 & 1,09 & 71,37 \\
\hline Atendente de bar & 29231 & 42,12 & 1,05 & 72,43 \\
\hline Operadora de Caixa & 28430 & 77,47 & 1,03 & 73,45 \\
\hline Manicure e Pedicure & 25439 & 100,00 & 0,92 & 74,37 \\
\hline Cabeleireira & 25017 & 91,98 & 0,90 & 75,27 \\
\hline Professora de 20. grau & 24607 & 74,80 & 0,89 & 76,16 \\
\hline Tecelã & 23326 & 49,82 & 0,84 & 77,00 \\
\hline Operadora de máquinas p. automáticas & 22027 & 50,65 & 0,80 & $\mathbf{7 7 , 8 0}$ \\
\hline Caixa & 21613 & 41,81 & 0,78 & 78,58 \\
\hline Comerciante & 20774 & 13,51 & 0,75 & 79,32 \\
\hline Auxiliar de costura & 20756 & 85,55 & 0,75 & 80,07 \\
\hline Telefonista & 19075 & 97,79 & 0,69 & 80,76 \\
\hline Dirctora/Assessora & 17385 & 40,77 & 0,63 & 81,39 \\
\hline Professora de 10. grau & 16536 & 94,96 & 0,60 & 81,98 \\
\hline Auxiliar de comtabilidade & 14839 & 33,99 & 0,54 & 82,52 \\
\hline Outras ocupações na incústria de transformação & 13563 & 25,66 & 0,49 & 83,01 \\
\hline Oleira & 11898 & 33,36 & 0,43 & 83,44 \\
\hline Inspetora de qualidade & 11435 & 19,20 & 0,41 & 83,85 \\
\hline Ocupações na indústria de artefätos de borracha & 11432 & 26,59 & 0,41 & 84,26 \\
\hline Professora de préescola & 11023 & 100,00 & 0,40 & 84,66 \\
\hline Feirante & 11014 & 22,63 & 0,40 & 85,06 \\
\hline Fiandeira & 10608 & 60,38 & 0,38 & 85,44 \\
\hline Datilógrafa & 10588 & 72,85 & 0,38 & 85,82 \\
\hline Acabadora de pano & 10179 & 55,13 & 0,37 & 86,19 \\
\hline Ajustadora/Montadora & 10177 & 16,05 & 0,37 & 86,56 \\
\hline Maçaroqueira & 9760 & 73,60 & 0,35 & 86,91 \\
\hline Professora & 9751 & 88,16 & 0,35 & 87,26 \\
\hline Orientadora de ensino & 9340 & 84,28 & 0,34 & 87,60 \\
\hline Empresária na incústria de transformação & 9323 & 11,78 & 0,34 & 87,93 \\
\hline Administradora de comércio de mercadorias & 8909 & 16,82 & 0,32 & 88,26 \\
\hline Professora profissionalizante & 8906 & 54,71 & 0,32 & 88,58 \\
\hline Montadora de equipamentos elétricos & 8899 & 31,12 & 0,32 & 88,90 \\
\hline Administradora na inciestria de transformação & 8469 & 10,74 & 0,31 & 89,20 \\
\hline Assistertes sociais & 8064 & 86,03 & 0,29 & 89,49 \\
\hline Assistente administrativo & 8061 & 42,47 & 0,29 & 89,78 \\
\hline Médica & 8048 & 25,12 & 0,29 & 90,08 \\
\hline Expedidora & 7631 & 16,39 & 0,28 & 90,35 \\
\hline Dentista & 7207 & 32,72 & 0,26 & 90,61 \\
\hline Advogada etc & 7203 & 19,04 & 0,26 & 90,87 \\
\hline Produtora agropecuária autônoma & 6801 & 4,34 & 0,25 & 91,12 \\
\hline Montadora de Rádio/TV & 6777 & 88,61 & 0,25 & 91,36 \\
\hline Inspetora de alunos & 6359 & 67,52 & 0,23 & 91,59 \\
\hline Auxiliar administrativo & 6356 & 28,80 & 0,23 & 91,82 \\
\hline
\end{tabular}

${ }^{(1)}$ Inclui apenas as pessoas para as quais os atributos de interesse estão claramente identificados. 
Tabela C2. Sessenta ocupações mais importantes na absorção da mão-de-obra masculina(1). São Paulo, 1981.

\begin{tabular}{|c|c|c|c|c|}
\hline OCUPAÇŌES & $M_{i}$ & $\frac{M_{i}}{T_{i}}(\%)$ & $\frac{M_{t}(\%)}{M}$ & $\Phi_{i}(\%)$ \\
\hline Outros trab. na agropecuária & 476546 & 78,45 & 8,08 & 8,08 \\
\hline Motorista & 366689 & 99,77 & 6,21 & 14,30 \\
\hline Pedreiro & 313260 & 99,86 & 5,31 & 19,62 \\
\hline Auxiliar de escritónio & 309363 & $.54,58$ & 5,25 & 24,86 \\
\hline Vendedor & 215306 & 63,64 & 3,65 & 28,51 \\
\hline Servente de pedreiro & 161983 & 100,00 & 2,75 & 31,26 \\
\hline Produtor agopecuário autônomo & 149880 & 95,66 & 2,54 & 33,80 \\
\hline Comerciante conta-própria & 145799 & 78,70 & 2,47 & 36,28 \\
\hline Comerciante & 132964 & 86,49 & 2,26 & 38,53 \\
\hline Encarreggdo da administração & 131484 & 81,38 & 2,23 & 40,76 \\
\hline Mecânico & 108525 & 100,00 & 1,84 & 42,60 \\
\hline Mecînico de veículo & 104070 & 100,00 & 1,77 & 44,37 \\
\hline Tomeiro Mecânico & 80291 & 98,96 & 1,36 & 45,73 \\
\hline Marceneiro & 79355 & 95,89 & 1,35 & 47,08 \\
\hline Administrador na incústria de transformação & 70381 & 89,259 & 1,19 & 48,27 \\
\hline Pintor/Caiador & 70035 & 100,00 & 1,19 & 49,46 \\
\hline Empresário na inđústria de transformação & 69816 & 88,22 & 1,18 & 50,64 \\
\hline Carpinteiro & 66931 & 98,75 & 1,14 & 51,78 \\
\hline Outras ocupações ambulantes & 64094 & 57,89 & 1,09 & 52,86 \\
\hline Outros proprietánios & 59332 & 92,71 & 1,01 & 53,87 \\
\hline Repositor de equipamentos & 58854 & 100,00 & 0,10 & 54,87 \\
\hline Soldador & 57858 & 95,79 & 0,98 & 55,85 \\
\hline Pracista e viajante & 55985 & 91,69 & 0,95 & 56,80 \\
\hline Ajustador/Montador & 53217 & 83,95 & 0,90 & 57,70 \\
\hline Almoxarife & 48855 & 95,05 & 0,83 & 58,53 \\
\hline Inspetor de qualidade & 48118 & 80,80 & 0,82 & 59,35 \\
\hline Administrador de comércio de mercadorias & 44071 & 83,18 & 0,75 & 60,09 \\
\hline Encanador & 42695 & 100,00 & 0,72 & 60,82 \\
\hline Ferreiro/Serralheiro & 42251 & 98,04 & 0,72 & 61,53 \\
\hline Engenheiro & 41101 & 95,10 & 0,70 & 62,23 \\
\hline Contador & 41083 & 88,98 & 0,70 & 62,93 \\
\hline Atendente de bar & 40163 & 57,88 & 0,68 & 63,61 \\
\hline Outras ocupações na indústria de transformação & 39290 & 74,34 & 0,67 & 64,27 \\
\hline Expedidor & 38938 & 83,61 & 0,66 & 64,94 \\
\hline Eletricista instalador & 38740 & 100,00 & 0,66 & 65,59 \\
\hline Feirante & 37659 & 77,37 & 0,64 & 66,23 \\
\hline Embalador de mercadorias & 37551 & 41,67 & 0,64 & 66,87 \\
\hline Pintor à pistola & 37538 & 96,72 & 0,64 & 67,51 \\
\hline Trabalhador de fábrica de sapato & 37241 & 53,89 & 0,63 & 68,14 \\
\hline Agricultor & 37177 & 98,88 & 0,63 & 68,77 \\
\hline Tratorista agricola & 34093 & 98,77 & 0,58 & 69,35 \\
\hline Desenhista & 33659 & 91,91 & 0,57 & 69,92 \\
\hline Técrico na inchistria de transformação & 33159 & 97,50 & 0,56 & 70,48 \\
\hline Empregado da construção civil & 33059 & 100,00 & 0,56 & 71,04 \\
\hline Ocupações na indústria de antefatos de borracha & 31563 & 73,41 & 0,54 & 71,58 \\
\hline Advogado etc & 30625 & 80,96 & 0,52 & 72,10 \\
\hline Caixa & 30078 & 58,19 & 0,51 & 72,61 \\
\hline Lantemeiro & 29222 & 100,00 & 0,50 & 73,10 \\
\hline Empregado doméstico & 29128 & 5,12 & 0,49 & 73,59 \\
\hline Auxiliar de contabilidade & 28822 & 66,01 & 0,49 & 74,08 \\
\hline Trocador & 27942 & 91,66 & 0,47 & 74,56 \\
\hline Corretor de imóveis & 27926 & 87,98 & 0,47 & 75,03 \\
\hline Tomeiro metalúrgico & 27421 & 100,00 & 0,47 & 75,50 \\
\hline Garçon & 26613 & 89,97 & 0,45 & 75,95 \\
\hline Padeiro & 26560 & 95,42 & 0,45 & 76,40 \\
\hline Operador de máquinas de construção civil & 26064 & . 100,00 & 0,44 & 76,84 \\
\hline Ferramenteiro & 25815 & 100,00 & 0,44 & 77,28 \\
\hline Administrador de financeiras & 25740 & 93,82 & 0,44 & 77,71 \\
\hline Representante comercial & 25690 & 93,82 & 0,44 & 78,15 \\
\hline Operador de prensa & 25389 & 89,53 & 0,43 & 78,58 \\
\hline
\end{tabular}

${ }^{(I)}$ Inclui apenas as pessoas para as quais os atributos de interesse estão claramente identificados. 
Tabela C3. Sessenta ocupações mais importantes na absorção da mão-de-obra feminina(1). São Paulo, 1983.

\begin{tabular}{|c|c|c|c|c|}
\hline OCUPAÇŌES & $F_{i}$ & $\frac{F_{i}}{T_{i}}(\%)$ & $\frac{F_{i}}{F}(\%)$ & $\pi_{i}(\%)$ \\
\hline Empregada doméstica & 666655 & 94,07 & 21,19 & 21,19 \\
\hline Auxiliar de escritónio & 304535 & 49,05 & 9,69 & 30,87 \\
\hline Alfaiate/Costureiras & 230860 & 93,84 & 7,3 & 38,20 \\
\hline Oriros trab. na agropecuánia & 147329 & 21,10 & 4,68 & 42,88 \\
\hline Vendedora & 126611 & 34,61 & 4,02 & 46,91 \\
\hline Secretária & 106969 & 96,53 & 3,40 & 50,31 \\
\hline Professora de 1 a 4 série & 91701 & 97,74 & 2,91 & 53,22 \\
\hline Lavadeira/Passadeira & 72761 & 93,41 & 2,31 & 55,53 \\
\hline Enfermeira não diplomada & 72025 & 82,35 & 2,29 & 57,82 \\
\hline Embaladora de mercadorias & 71529 & 58,13 & 2,27 & 60,10 \\
\hline Cozinheira & 66684 & 67,05 & 2,12 & 62,22 \\
\hline Reoepcionista & 56097 & 89,71 & 1,78 & 63,10 \\
\hline Comerciante corrta-própria & 49798 & 22,89 & 1,58 & 65,58 \\
\hline Bordadeira/Ceraideira & 48794 & 97,45 & 1,55 & 67,13 \\
\hline Atendente de bar & 48043 & 50,85 & 1,53 & 68,66 \\
\hline Outras ocupacōes ambulantes & 40866 & 50,49 & 1,30 & 69,96 \\
\hline Professora de 5 a 8 séries & 38660 & 77,60 & 1,23 & 71,19 \\
\hline Trabalhadora de fäbrica de sapato & 37252 & 50,01 & 1,18 & 72,37 \\
\hline Operadora de caixa & 36207 & 79,27 & 1,15 & 73,52 \\
\hline Manicure e Pedicure & 35408 & 100,00 & 1,13 & 74,65 \\
\hline Encarregada da administracão & 31491 & 23,36 & 1,00 & 75,65 \\
\hline Cabeleireira & 29274 & 87,08 & 0,93 & 76,58 \\
\hline Caixa & 28803 & 47,86 & 0,92 & 77,49 \\
\hline Telefonista & 23738 & 94,81 & 0,75 & 78,25 \\
\hline Auxiliar de costura & 21715 & 92,62 & 0,69 & 78,94 \\
\hline Professora de 20. grau & 20593 & 71,77 & 0,65 & 79,59 \\
\hline Comerciante & 20145 & 13,14 & 0,64 & 80,23 \\
\hline Inspetora de qualidade & 18170 & 29,86 & 0,58 & 80,81 \\
\hline Operadora de máquinas p. automáticas & 17016 & 42,17 & 0,54 & 81,35 \\
\hline Diretora/Ascessora & 16986 & 35,57 & 0,54 & 81,89 \\
\hline Anxiliar de contabilidade & 16149 & 40,89 & 0,51 & 82,40 \\
\hline Professora de Préescola & 15742 & 100,00 & 0,50 & 82,90 \\
\hline Professora profissionalizante & 15643 & 61,35 & 0,50 & 83,40 \\
\hline Pracista e viajante & 14922 & 20,08 & 0,47 & 83,88 \\
\hline Assistente administrativo & 14782 & 54,00 & 0,47 & 84,34 \\
\hline Outras ocupaçōes na indústria de transformação & 14481 & 28,90 & 0,46 & 84,81 \\
\hline Ocupacões na incústria de artefatos de borracha & 14126 & 26,78 & 0,45 & 85,25 \\
\hline Professora & 13939 & 84,33 & 0,44 & 85,70 \\
\hline Orientadora de ensino & 13106 & 81,41 & 0,42 & 86,11 \\
\hline Administradora de comércio de mercadorias & 11453 & 19,62 & 0,36 & 86,48 \\
\hline Tecelã & 11302 & 39,14 & 0,36 & 86,84 \\
\hline Outras Proprietárias & 11096 & 12,81 & 0,35 & 87,19 \\
\hline Feirante & 10683 & 18,63 & 0,34 & 87,53 \\
\hline Doceira/oonfeiteira & 9263 & 48,39 & 0,29 & 87,82 \\
\hline Montadora de Rádio/TV & 8550 & 71,07 & 0,27 & 88,10 \\
\hline Inspetora de alunos & 8503 & 79,82 & 0,27 & 88,37 \\
\hline Produtora agropecuíria autônoma & 8278 & 5,48 & 0,26 & 88,63 \\
\hline Doceirs etc & 8083 & 24,94 & 0,26 & 88,89 \\
\hline Médica & 7994 & 26,79 & 0,25 & 89,14 \\
\hline Professora superior & 7660 & 42,60 & 0,24 & 89,38 \\
\hline Psicóloga & 7636 & 89,70 & 0,24 & 89,63 \\
\hline Fiandeira & 7085 & 46,41 & 0,23 & 89,85 \\
\hline Modelista & 6867 & 53,10 & 0,22 & 90,07 \\
\hline Dentista & 6775 & 36,69 & 0,22 & 90,28 \\
\hline Maçaroqueira & 6741 & 61,37 & 0,21 & 90,50 \\
\hline Acabadora de Pano & 6737 & - $\quad 50,96$ & 0,21 & 90,71 \\
\hline Auxiliar administrativo & 6411 & 37,17 & 0,20 & 90,92 \\
\hline Administradora na incuistria de transformação & 6383 & 8,30 & 0,20 & 91,12 \\
\hline Professora de lo. grau & 6356 & 93,77 & 0,20 & 91,32 \\
\hline Encademadora & 6342 & 44,83 & 0,20 & 91,52 \\
\hline
\end{tabular}

(1) Inclui apenas as pessoas para as quais os atributos de interesse estão claramente identificados. 
Tabela C4. Sessenta ocupações mais importantes na absorção da mão-de-obra masculina ${ }^{(1)}$. São Paulo, 1983.

\begin{tabular}{|c|c|c|c|c|}
\hline OCUPAÇÕES & $M_{i}$ & $\frac{M_{i}}{T_{i}}(\%)$ & $\frac{M_{i}}{M}(\%)$ & $\Phi_{i}(\%)$ \\
\hline Outros trab. na agropecuária & 550955 & 78,90 & 8,94 & 8,94 \\
\hline Motorista & 421809 & 99,70 & 6,85 & 15,79 \\
\hline Auxiliar de escritório & 316319 & 50,95 & 5,13 & 20,92 \\
\hline Pedreiro & 312839 & 100,00 & 5,08 & 26,00 \\
\hline Vendedor & 239200 & 65,39 & 3,88 & 29,88 \\
\hline Comerciante conta-própria & 167788 & 77,11 & 2,72 & 32,61 \\
\hline Servente de pedreiro & 159997 & 99,74 & 2,60 & 35,20 \\
\hline Produttor agropecuánio autônomo & 142664 & 94,52 & 2,32 & 37,52 \\
\hline Comerciante & 133214 & 86,86 & 2,16 & 39,68 \\
\hline Mecânico de veículo & 111160 & 100,00 & 1,80 & 41,49 \\
\hline Encarregado da adnninistração & 103310 & 76,64 & 1,68 & 43,16 \\
\hline Mecânico & 92750 & 100,00 & 1,51 & 44,67 \\
\hline Pintor/Caiador & 83416 & 100,00 & 1,35 & 46,02 \\
\hline Empresário na indústria de transformação & 78284 & 92,55 & 1,27 & 47,29 \\
\hline Tomeiro Mecânico & 75559 & 99,43 & 1,23 & 48,52 \\
\hline Outros proprietários & 75522 & 87,19 & 1,23 & 49,75 \\
\hline Marceneiso & 74108 & 97,25 & 1,20 & 50,95 \\
\hline Administrador na indústria de transformação & 70529 & 91,70 & 1,14 & 52,09 \\
\hline Carpinteiro & 60574 & 98,66 & 0,98 & 53,08 \\
\hline Pracista e viajante & 59403 & 79,92 & 0,96 & 54,04 \\
\hline Repositor de equipamentos & 59017 & 100,00 & 0,96 & 54,10 \\
\hline Técnico na inđústria de transformação & 58440 & 94,44 & 0,95 & 55,95 \\
\hline Soldador & 56728 & 92,98 & 0,92 & 56,87 \\
\hline Ajustador/Montador & 52987 & 93,22 & 0,86 & 57,73 \\
\hline Tratorista agrícola & 51751 & 98,43 & 0,84 & 58,57 \\
\hline Embalador de mercadorias & 51513 & 41,87 & 0,84 & 59,40 \\
\hline Desenhista & 47258 & 93,25 & 0,77 & 60,17 \\
\hline Expedidor & 47218 & 93,31 & 0,77 & 60,94 \\
\hline Administsador de comércio de mercadorias & 46934 & 80,38 & 0,76 & 61,70 \\
\hline Feirante & 46660 & 81,37 & 0,76 & 62,46 \\
\hline Atendente de bar & 46432 & 49,15 & 0,75 & 63,21 \\
\hline Encanador & 45637 & 100,00 & 0,74 & 63,95 \\
\hline Engenheiro & 44843 & 98,19 & 0,73 & 64,68 \\
\hline Inspetor de qualidade & 42678 & 70,14 & 0,69 & 65,37 \\
\hline Empregado doméstico & 42047 & 5,93 & 0,68 & 66,05 \\
\hline Outras ocupações ambulantes & 40080 & 49,51 & 0,65 & 66,71 \\
\hline Almoxarife & 39509 & 88,55 & 0,64 & 67,35 \\
\hline Agricultor & 39162 & 100,00 & 0,64 & 67,98 \\
\hline Ocupaçōes na indústria de artefatos de borracha & 38629 & 73,22 & 0,63 & 68,61 \\
\hline Trabalhador de fábrica de sapato & 37233 & 49,99 & 0,60 & 69,21 \\
\hline Eletricista instalador & 36874 & 100,00 & 0,60 & 69,81 \\
\hline Ourras ocupações na indústria de transformação & 35619 & 71,10 & 0,58 & 70,39 \\
\hline Ferriro/Serralheiro & 35320 & 98,79 & 0,57 & 70,96 \\
\hline Pintor à pistola & 34539 & 96,40 & 0,56 & 71,52 \\
\hline Represertante comercial & 34387 & 92,09 & 0,56 & 72,08 \\
\hline Administador de financeiras & 34381 & 90,01 & 0,56 & 72,64 \\
\hline Cozinheiros & 32777 & 32,96 & 0,53 & 73,17 \\
\hline Operador de prensa & 32235 & 89,36 & 0,52 & 73,70 \\
\hline Contador & 31499 & 85,11 & 0,51 & 74,21 \\
\hline Caixa & 31384 & 52,14 & 0,51 & 74,72 \\
\hline Empresánio da construģão civil & 30914 & 100,00 & 0,50 & 75,22 \\
\hline Dirtor/Assessor & 30769 & 64,43 & 0,50 & 75,72 \\
\hline Corrator de imóveis & 30486 & 95,99 & 0,49 & 76,21 \\
\hline Operador de máquinas de construção civil & 28685 & 100,00 & 0,47 & 76,68 \\
\hline Trocador & 26742 & 92,72 & 0,43 & 77,11 \\
\hline Polidor/Esmerilhador & 26390 & 95,40 & 0,43 & 77,54 \\
\hline Ferramenterio & 26028 & 98,38 & 0,42 & 77,96 \\
\hline Lantemeiro & 24582 & 100,00 & 0,40 & 78,36 \\
\hline Doceiro etc & 24327 & 75,06 & 0,39 & 78,76 \\
\hline Auxiliar de contabilidade & 23349 & 59,11 & 0,38 & 79,14 \\
\hline
\end{tabular}

(1) Inclui apenas as pessoas para as quais os atributos de interesse estão claramente identificados. 
Tabela C5. Sessenta ocupações mais importantes na absorção da mão-de-obra feninina(1). São Paulo, 1984.

\begin{tabular}{|c|c|c|c|c|}
\hline OCUPAÇŌES & $F_{i}$ & $\frac{F_{1}}{T_{1}}(\%)$ & $\frac{F_{t}}{F}(\%)$ & $\pi_{i}(\%)$ \\
\hline Empregada doméstica & 783688 & 94,44 & 22,77 & 22,77 \\
\hline Auxiliar de escritório & 297066 & 49,79 & 8,63 & 31,40 \\
\hline AlfaiaterCosturcira & 254159 & 94,10 & 7,38 & 38,78 \\
\hline Oritros trab. na agropecuária & 148599 & 21,55 & 4,32 & 43,10 \\
\hline Vendedora & 147332 & 40,54 & 4,28 & 47,38 \\
\hline Secretaria & 126927 & 96,75 & 3,69 & 51,06 \\
\hline Professora de 1 a 4 série & 91670 & 96,85 & 2,66 & 53,73 \\
\hline Lavadeira Passadeira & 73045 & 90,34 & 2,12 & 55,85 \\
\hline Recepcionista & 71882 & 86,60 & 2,09 & 57,94 \\
\hline Outras ocapaçōes ambulantes & 71650 & 51,31 & 2,08 & 60,02 \\
\hline Enfermeira não diplomada & 71099 & 78,68 & 2,07 & 62,09 \\
\hline Embaladora de mercadorias & 65704 & 55,43 & 1,91 & 63,10 \\
\hline Cozinheira & 57452 & 64,02 & 1,67 & 65,66 \\
\hline BordadeiraiCerzideira & 56974 & 98,50 & 1,66 & 67,32 \\
\hline Alendente de bar & 49558 & 54,85 & 1,44 & 68,76 \\
\hline Comeriane conta-própria & 46001 & 21,17 & 1,34 & 70,09 \\
\hline Operadora de caixa & 45960 & 82,28 & 1,34 & 71,43 \\
\hline Trabalhadora de fábrica de sapato & 42184 & 47,35 & 1,23 & 72,65 \\
\hline Manicure e Pedicure & 40092 & 100,00 & 1,16 & 73,82 \\
\hline Encartegada da administração & 36010 & 21,70 & 1,05 & $\mathbf{7 4 , 8 7}$ \\
\hline Professora de 5 a 8 série & 35000 & 81,19 & 1,02 & 75,88 \\
\hline Cabeleirira & 30886 & 77,29 & 0,90 & 76,78 \\
\hline Telefonista & 28467 & 95,69 & 0,83 & 77,60 \\
\hline Caixa & 27481 & 41,84 & 0,80 & 78,40 \\
\hline Comeriante & 26571 & 17,49 & 0,77 & 79,18 \\
\hline Professora de 20. grau & 26450 & 68,03 & 0,77 & 79,94 \\
\hline Outras ocupações na indústria de transformação & 24177 & 31,92 & 0,70 & 80,65 \\
\hline Auxiliar de costura & 23778 & 93,20 & 0,69 & 81,34 \\
\hline Professora de próescola & 23587 & 100,00 & 0,69 & 82,02 \\
\hline Auxiliar de contabilidade & 20431 & 48,71 & 0,59 & 82,62 \\
\hline Dinatora Assessora & 18588 & 37,24 & 0,54 & 83,16 \\
\hline Inspetora de qualidade & 18585 & 25,69 & 0,54 & 83,70 \\
\hline Ocupacōes na indústria de artefatos de borracha & 17891 & 25,99 & 0,52 & 84,22 \\
\hline Operadora de máquinas p. automátjcas & 17437 & 35,66 & 0,51 & 84,72 \\
\hline Tecelã & 15614 & 36,98 & 0,45 & 85,18 \\
\hline Assistente administrativo & 14334 & 60,17 & 0,42 & 85,59 \\
\hline Outras Propriaárias & 13587 & 13,96 & 0,39 & 85,99 \\
\hline Professora profissionalizante & 13584 & 70,80 & 0,39 & 86,38 \\
\hline Adminiessdora do comércio de mercadorias & 11400 & 18,12 & 0,33 & 86,71 \\
\hline Orientadora de ensino & 11345 & 78,98 & 0,33 & 87,04 \\
\hline Docsira confeiteira & 10537 & 60,42 & 0,31 & 87,35 \\
\hline Contadora & 10196 & 24,75 & 0,30 & 87,65 \\
\hline Datilógrafa & 9802 & 71,49 & 0,28 & 87,93 \\
\hline Doceira ac & 9770 & 21,95 & 0,28 & 88,21 \\
\hline Professora & 9726 & 71,45 & 0,28 & 88,50 \\
\hline Adminissadora na incústria de transformação & 9379 & 11,46 & 0,27 & 88,77 \\
\hline Auxiliar administrativo & 9316 & 35,1 & 0,27 & 89,04 \\
\hline Maçaroquira & 9276 & 70,77 & $\mathbf{0 , 2 7}$ & 89,31 \\
\hline Inspetore de alunos & 9262 & 78,19 & 0,27 & 89,58 \\
\hline Assistente social & 9253 & 91,42 & 0,27 & 89,85 \\
\hline Feiramte & 8951 & 18,54 & 0,26 & 90,11 \\
\hline Acabadora de Pano & 8861 & 40,73 & 0,26 & 90,36 \\
\hline Pracista e viajante & 8512 & 8,31 & 0,25 & 90,61 \\
\hline Emprexiria na incústria de transformação & 8501 & 8,39 & 0,25 & 90,86 \\
\hline Mortadora de equipamentos elétricos & 8491 & 35,33 & 0,25 & 91,11 \\
\hline Médica & 8440 & - 22,45 & 0,25 & 91,35 \\
\hline Camareis & 8385 & 100,00 & 0,24 & 91,59 \\
\hline Ajustadha/Montadora & 8116 & 13,03 & 0,24 & 91,83 \\
\hline Advogada etc & 8036 & 24,66 & 0,23 & 92,06 \\
\hline Fiandeira & 7970 & 62,75 & 0,23 & 92,29 \\
\hline
\end{tabular}

(1) Inclui apenas as pessoas para as quais os atributos de interesse estão claramente identificados. 
Tabela C6. Sessenta ocupações mais importantes na absorção da mão-de-obra masculina(1). São Paulo, 1984.

\begin{tabular}{|c|c|c|c|c|}
\hline OCUPAÇÕES & $M_{i}$ & $\frac{M}{T:}(\%)$ & $\frac{M i(\%)}{M}$ & $\Phi_{i}(\%)$ \\
\hline Oriros trab. na agrupecuária & 540790 & 78,45 & 8,42 & 8,42 \\
\hline Motorista & 406374 & 99,90 & 6,33 & 14,75 \\
\hline Patreiro & 314756 & 100,00 & 4,90 & 19,66 \\
\hline Awxiliar de escritório & 299525 & 50,21 & 4,67 & 24,32 \\
\hline Vendedor & 216072 & 59,46 & 3,37 & 27,69 \\
\hline Comerciante conta-própria & 171258 & 78,83 & 2,67 & 30,36 \\
\hline Servente de pedreiro & 156370 & 99,47 & 2,44 & 32,79 \\
\hline Produtor agropecuánio autônomo & 142466 & 97,10 & 2,22 & 35,01 \\
\hline Encarregado da administração & 129973 & 78,31 & 2,02 & 37,04 \\
\hline Comerciante & 125341 & 82,51 & 1,95 & 38,99 \\
\hline Mecânico de veículo & 113854 & 100,00 & 1,77 & 40,76 \\
\hline Pracista e viajante & 93975 & 91,70 & 1,46 & 42,23 \\
\hline Empresário na indústria de transformação & 92867 & 91,61 & 1,45 & 43,67 \\
\hline Mecânico & 84384 & 99,51 & 1,31 & 44,99 \\
\hline Outros proprietários & 83778 & 86,05 & 1,31 & 46,29 \\
\hline Pintor/Caiador & 81022 & 100,00 & 1,26 & 47,56 \\
\hline Soldador & 75932 & 96,76 & 1,18 & 48,74 \\
\hline Tomeiro Mecânico & 75674 & 98,88 & 1,18 & 49,92 \\
\hline Repositor de equipamentos & 74008 & 98,86 & 1,15 & 51,07 \\
\hline Administrador na indústria de transformação & 72461 & 88,54 & 1,13 & 52,20 \\
\hline Marceneiro & 71278 & 98,85 & 1,11 & 53,31 \\
\hline Outras ocupaçōes ambulantes & 67971 & 48,68 & 1,06 & 54,37 \\
\hline Ajustador/Montador & 54170 & 86,97 & 0,84 & 55,21 \\
\hline Inspetor de qualidade & 53762 & 74,31 & 0,84 & 56,05 \\
\hline Técnico na incústria de transformação & 53013 & 91,93 & 0,83 & 56,87 \\
\hline Embalador de mercadorias & 52821 & 44,57 & 0,82 & 57,70 \\
\hline Outras ocupaçōes na indústria de transformação & 51564 & 68,08 & 0,80 & 58,50 \\
\hline Administrador do comércio de mercadorias & 51510 & 81,88 & 0,80 & 59,30 \\
\hline Ocupaçōes na indústria de artefatos de borracha & 50946 & 74,01 & 0,79 & 60,10 \\
\hline Desenhista & 50008 & 92,21 & 0,78 & 60,88 \\
\hline Carpinteiro & 48743 & 95,91 & 0,76 & 61,64 \\
\hline Trabalhador de fábrica de sapato & 46909 & 52,65 & 0,73 & 62,37 \\
\hline Empregado doméstico & 46127 & 5,56 & 0,72 & 63,08 \\
\hline Tratorista agricola & 45743 & 100,00 & 0,71 & 63,79 \\
\hline Engenheiro & 43950 & 93,67 & 0,68 & 64,48 \\
\hline Almoxarife & 43007 & 93,54 & 0,67 & 65,15 \\
\hline Encanador & 41174 & 100,00 & 0,64 & 65,79 \\
\hline Atendente de bar & 40798 & 45,15 & 0,64 & 66,43 \\
\hline Pintor à pistola & 40421 & 98,96 & 0,63 & 67,06 \\
\hline Expedidor & 39584 & 91,26 & 0,62 & 67,67 \\
\hline Feirante & 39323 & 81,46 & 0,61 & 68,29 \\
\hline Eletricista instalador & 38573 & 100,00 & 0,60 & 68,89 \\
\hline Caixa & 38203 & 58,16 & 0,60 & 69,48 \\
\hline Operador de prensa & 37936 & 84,00 & 0,59 & 70,07 \\
\hline Agricultor & 37701 & 100,00 & 0,58 & 70,66 \\
\hline Doceiro etc & 34743 & 78,05 & 0,54 & 71,20 \\
\hline Representante comercial & 34650 & 90,12 & 0,54 & 71,74 \\
\hline Polidor/Esmerilhador & 34524 & 98,78 & 0,54 & 72,28 \\
\hline Ferreiro/Serralheiro & 34461 & 100,00 & 0,54 & 72,82 \\
\hline Adrninistrador de financeiras & 34283 & 93,10 & 0,53 & 73,35 \\
\hline Trocador & 34039 & 96,37 & 0,53 & $\mathbf{7 3 , 8 8}$ \\
\hline Padeiro & 33921 & 96,36 & 0,53 & 74,41 \\
\hline Cozinheiro & 32289 & 35,98 & 0,50 & 74,91 \\
\hline Operador de máquinas p. automáticas & 31466 & 64,34 & 0,49 & 75,40 \\
\hline Diretor/Assessor & 31328 & 62,76 & 0,49 & 75,89 \\
\hline Contador & 30997 & 75,25 & 0,48 & 76,37 \\
\hline Gargon & 30958 & 90,12 & 0,48 & 76,86 \\
\hline Corretor de imóveis & 30087 & 95,95 & 0,47 & 77,32 \\
\hline Tomeiro metalúrgico & 29578 & 100,00 & 0,46 & 77,79 \\
\hline Médico & 29163 & 77,56 & $.0,45$ & 78,24 \\
\hline
\end{tabular}

(1) Inclui apenas as pessoas para as quais os atributos de interesse estão claramente identificados. 
Tabela C7. Sessenta ocupações mais importantes na absorção da mão-de-obra feminina ${ }^{(1)}$. São Paulo, 1985.

\begin{tabular}{|c|c|c|c|c|}
\hline OCUPAÇŌES & $F_{i}$ & $\frac{F_{i}}{T_{i}}(\%)$ & $\frac{F_{i}}{F}(\%)$ & $\pi_{i}(\%)$ \\
\hline Empregada doméstica & 755429 & 94,38 & 20,94 & 20,94 \\
\hline Auxiliar de escritório & 338175 & 48,56 & 9,38 & 30,32 \\
\hline Alfaiate/Costureira & 272750 & 92,95 & 7,56 & 37,88 \\
\hline Vendedora & 154274 & 36,71 & 4,28 & 42,16 \\
\hline Outros trab. na agropecuária & 128529 & 19,45 & 3,56 & 45,72 \\
\hline Secretána & 127735 & 96,09 & 3,54 & 49,26 \\
\hline Professora de 1 a 4 série & 92256 & 98,12 & 2,56 & 51,82 \\
\hline Enfermeira não diplomada & 83835 & 80,54 & 2,32 & 54,14 \\
\hline Cozinheira & 82298 & 70,74 & 2,28 & 56,42 \\
\hline Embaladora de mercadorias & 76010 & 54,39 & 2,11 & 58,53 \\
\hline Recepcionista & 72611 & 82,56 & 2,01 & 60,54 \\
\hline Comerciante conta-própria & 66439 & 28,88 & 1,84 & 62,39 \\
\hline Lavadeira/Passadeira & 59974 & 86,82 & 1,66 & 64,05 \\
\hline Outras ocupaçōes ambulantes & 59102 & 42,71 & 1,64 & 65,69 \\
\hline Professora de 5 a 8 séries & 49719 & 83,90 & 1,38 & 67,07 \\
\hline Atendente de bar & 45350 & 46,23 & 1,26 & 68,32 \\
\hline Operadora de Caixa & 42904 & 78,94 & 1,19 & 69,51 \\
\hline Trabalhadora de fäbrica de sapato & 41557 & 46,11 & 1,15 & 70,67 \\
\hline Manicure e Pedicure & 41143 & 98,90 & 1,14 & 71,81 \\
\hline Bordadeira/Cerzideira & 38573 & 96,64 & 1,07 & 72,87 \\
\hline Outras ocupaçōes na indústria de transformação & 36887 & 37,76 & 1,02 & 73,90 \\
\hline Caixa & 31448 & 42,77 & 0,87 & 74,77 \\
\hline Professora de 20. grau & 30395 & 74,97 & 0,84 & 75,61 \\
\hline Encarreggda da administração & 29169 & 16,52 & 0,81 & 76,42 \\
\hline Comerciante & 28816 & 17,09 & 0,80 & 77,22 \\
\hline Cabeleireira & 27627 & 71,17 & 0,77 & 77,99 \\
\hline Professora de próescola & 24889 & 100,00 & 0,69 & 78,68 \\
\hline Diretora/Assessora & 24469 & 43,37 & 0,68 & 79,35 \\
\hline Outras proprietáias & 22876 & 20,19 & 0,63 & 79,99 \\
\hline Auxiliar de costura & 22597 & 92,62 & 0,63 & 80,61 \\
\hline Tecelã & 22521 & 38,71 & 0,62 & 81,24 \\
\hline Operadora de máquinas p. automáticas & 20963 & 40,34 & 0,58 & 81,82 \\
\hline Telefonista & 19581 & 95,68 & 0,54 & 82,36 \\
\hline Oampações na incústria de artefatos de borracha & 19344 & 26,65 & 0,54 & 82,90 \\
\hline Auxiliar de cormabilidade & 19019 & 43,39 & 0,53 & 83,43 \\
\hline Inspetora de qualidade & 18896 & 23,75 & 0,52 & 83,95 \\
\hline Professora & 18548 & 85,64 & 0,51 & 84,46 \\
\hline Pracista e viajante & 17919 & 18,90 & 0,50 & 84,96 \\
\hline Assistente administrativo & 17469 & 67,51 & 0,48 & 85,45 \\
\hline Administradora do cumércio de mercadorias & 14409 & 21,92 & 0,40 & 85,84 \\
\hline Empresária na incústria de transformação & 13882 & 15,16 & 0,38 & 86,23 \\
\hline Montadora de Rádio/TV & 13137 & 78,49 & 0,36 & 86,59 \\
\hline Fiandeira & 13108 & 64,75 & 0,36 & 86,96 \\
\hline Professora profissionalizamte & 12873 & 62,12 & 0,36 & 87,31 \\
\hline Ajustadora/Montadora & 11786 & 16,59 & 0,33 & 87,64 \\
\hline Outras administradoras & 11745 & 40,38 & 0,33 & 87,97 \\
\hline Professora de 10. grau & 11310 & 100,00 & 0,31 & 88,28 \\
\hline Acabadora de Pano & 10775 & 53,51 & 0,30 & 88,58 \\
\hline Auxiliar administrativo & 10034 & 37,92 & 0,28 & 88,86 \\
\hline Enfermeira diplomada & 9921 & 85,12 & 0,27 & 89,13 \\
\hline Inspetora de alunos & 9918 & 76,33 & 0,27 & 89,41 \\
\hline Dentista & 9740 & 47,89 & 0,27 & 89,68 \\
\hline Feirante & 9685 & 19,75 & 0,27 & 89,95 \\
\hline Orientadora de ensino & 9417 & 87,81 & 0,26 & 90,21 \\
\hline Maçaroqueira & 9389 & 66,14 & 0,26 & 90,47 \\
\hline Médica & 9149 & 24,05 & 0,25 & 90,72 \\
\hline Psicóloga & 9091 & 83,99 & 0,25 & 90,97 \\
\hline Administradora na incústria de transformação & 8739 & 12,73 & 0,24 & 91,21 \\
\hline Assistente social & 8207 & 95,08 & 0,23 & 91,44 \\
\hline Doceira/confeiteira & 7856 & 48,30 & $\mathbf{0 , 2 2}$ & 91,66 \\
\hline
\end{tabular}

${ }^{(1)}$ Inclui apenas as pessoas para as quais os atributos de interesse estão claramente identificados. 
Tabela C8. Sessenta ocupações mais importantes na absorção da mão-de-obra masculina ${ }^{(1)}$. São Paulo, 1985.

\begin{tabular}{|c|c|c|c|c|}
\hline OCUPAÇŌES & $M_{i}$ & $\frac{M_{i}}{T_{i}}(\%)$ & $\frac{M_{i}(\%)}{M}$ & $\Phi_{i}(\%)$ \\
\hline $\begin{array}{l}\text { Outros trab. na agropecuária } \\
\text { Motorista }\end{array}$ & $\begin{array}{l}532215 \\
432772\end{array}$ & $\begin{array}{l}80,55 \\
99,90\end{array}$ & $\begin{array}{l}7,75 \\
6,30\end{array}$ & $\begin{array}{r}7,75 \\
14,05\end{array}$ \\
\hline Auxiliar de escritório & 358218 & 51,44 & 5,22 & 19,27 \\
\hline Pedreiro & 322179 & 100,00 & 4,69 & 23,96 \\
\hline Vendedor & 266013 & 63,29 & 3,87 & 27,83 \\
\hline Servente de pedreiro & 184107 & 99,76 & 2,68 & 30,51 \\
\hline Comerciante conta-própria & 163622 & 71,12 & 2,38 & 32,90 \\
\hline Encarregado da admimistração & 147415 & 83,48 & 2,15 & 35,04 \\
\hline Comerciante & 139794 & 82,91 & 2,04 & 37,08 \\
\hline Produtor agropecuário autônomo & 136035 & 98,21 & 1,98 & 39,06 \\
\hline Mecânico de veículo & 121990 & 99,28 & 1,78 & 40,83 \\
\hline Mecânico & 106611 & 100,00 & 1,55 & 42,39 \\
\hline Outros proprietánios & 90425 & 79,81 & 1,32 & 43,70 \\
\hline Tomeiro Mecânico & 89247 & 98,53 & 1,30 & 45,00 \\
\hline Pimtor/Caiador & 82218 & 100,00 & 1,20 & 46,20 \\
\hline Marceneiro & 80666 & 99,45 & 1,17 & 47,37 \\
\hline Outras ocupaçōes ambulantes & 79290 & 57,29 & 1,15 & 48,53 \\
\hline Soldador & 77755 & 95,64 & 1,13 & 49,66 \\
\hline Empresário na indústria de transformação & 77668 & 84,84 & 1,13 & 50,79 \\
\hline Pracista e viajante & 76886 & 81,10 & 1,12 & 51,91 \\
\hline Carpinteiro & 68953 & 98,77 & 1,05 & 52,92 \\
\hline Embalador de mercadorias & 63742 & 45,61 & 0,93 & 53,84 \\
\hline Repositor de equipamentos & 63445 & 100,00 & 0,92 & 54,77 \\
\hline Téonico na indústria de transformaçăo & 61354 & 91,66 & 0,89 & 55,66 \\
\hline Oưtras ocupações na indústria de transformação & 60800 & 62,24 & 0,89 & 56,55 \\
\hline Inspetor de qualidade & 60653 & 76,25 & 0,88 & 57,43 \\
\hline Administrador na inchistria de transformação & 59924 & 87,27 & 0,87 & 58,30 \\
\hline Ajustador/Montador & 59242 & 83,41 & 0,86 & 59,16 \\
\hline Almoxarife & 57960 & 93,70 & 0,84 & 60,01 \\
\hline Ocupaçães na indústria de artefatos de borracha & 53232 & 73,35 & 0,77 & 60,78 \\
\hline Atendente de bar & 52754 & 53,77 & 0,77 & 61,55 \\
\hline Pintor à pistola & 52229 & 100,00 & 0,76 & 62,31 \\
\hline Administrador do comércio de mercadorias & 51316 & 78,08 & 0,75 & 63,06 \\
\hline Operador de prensa & 50381 & 95,04 & 0,73 & 63,79 \\
\hline Fenciro/Serralheiro & 50077 & 100,00 & 0,73 & 64,52 \\
\hline Trabalhador de fábrica de sapato & 48572 & 53,89 & 0,71 & 65,23 \\
\hline Encanador & 46762 & 100,00 & 0,68 & 65,91 \\
\hline Tratorista agricola & 46007 & 99,11 & 0,67 & 66,58 \\
\hline Enpręado doméstico & 44983 & 5,62 & 0,66 & 67,24 \\
\hline Engenheiro & 42272 & 95,28 & 0,62 & 67,85 \\
\hline Caixa & 42073 & 57,23 & 0,61 & 68,46 \\
\hline Agricultor & 40918 & 96,12 & 0,60 & 69,06 \\
\hline Desenhista & 40449 & 89,61 & 0,59 & 69,65 \\
\hline Expedidor & 40393 & 89,47 & 0,59 & 70,24 \\
\hline Representante comercial & 40326 & 87,79 & 0,59 & 70,82 \\
\hline Eletricista instalador & 40172 & 98,91 & 0,58 & 71,41 \\
\hline Administrador de financeiras & 39428 & 85,69 & 0,57 & 71,98 \\
\hline Feirante & 39354 & 80,25 & 0,57 & 72,56 \\
\hline Contador & 39317 & 88,33 & 0,57 & 73,13 \\
\hline Lantemeiro & 38931 & 100,00 & 0,57 & 73,70 \\
\hline Ferramenteiro & 37386 & 100,00 & 0,54 & 74,24 \\
\hline Fresador/Furador & 37149 & 91,36 & 0,54 & 74,78 \\
\hline Trocador & 35974 & 94,35 & 0,52 & 75,30 \\
\hline Tecelāo & 35661 & 61,29 & 0,52 & 75,82 \\
\hline Padeiro & 34157 & 98,72 & 0,50 & 76,32 \\
\hline Cozinheiro & 34038 & 29,26 & 0,50 & 76,82 \\
\hline Polidor/Esmerithador & 32276 & 92,47 & 0,47 & 77,29 \\
\hline Diretor/Assessor & 31957 & 56,64 & 0,47 & 77,75 \\
\hline Operador de máquinas p. automáticas & 31002 & 59,66 & 0,45 & 78,20 \\
\hline Operador de máquinas de construção civil & 31000 & 100,00 & 0,45 & 78,65 \\
\hline
\end{tabular}

(1) Inclui apenas as pessoas para as quais os atributos de interesse estảo claramente identificados. 
Tabela C9. Sessenta ocupações mais importantes na absorção da mão-de-obra feminina(1). São Paulo, 1987.

\begin{tabular}{|c|c|c|c|c|}
\hline OCUPAÇŌES & $F_{i}$ & $\frac{F_{i}}{T_{1}}(\%)$ & $\frac{F_{i}}{F}(\%)$ & $\pi_{i}(\%)$ \\
\hline Empregada doméstica & 642927 & 95,54 & 16,34 & 16,34 \\
\hline Auxiliar de escritório & 378438 & 52,25 & 9,62 & 25,95 \\
\hline Alfaiate/Costureira & 297162 & 95,75 & 7,55 & 33,50 \\
\hline Vendedora & 198561 & 38,83 & 5,05 & 38,55 \\
\hline Outros trab. na agropecuária & 158534 & 23,34 & 4,03 & 42,58 \\
\hline Professora de 1 a 4 série & 126393 & 96,72 & 3,21 & 45,79 \\
\hline Secrétía & 100434 & 94,25 & 2,55 & 48,34 \\
\hline Embaladora de mercadorias & 91991 & 53,64 & 2,34 & 50,68 \\
\hline Lavadeira/Passadeira & 89554 & 91,63 & 2,28 & 52,95 \\
\hline Cozinheira & 88594 & 70,24 & 2,25 & 55,20 \\
\hline Comerciante conta-própria & 81961 & 28,79 & 2,08 & 57,28 \\
\hline Recepcionista & 80334 & 85,44 & 2,04 & 59,33 \\
\hline Enfermeira não diplomada & 78589 & 83,78 & 1,10 & 61,32 \\
\hline Outras ocupaçöes ambulantes & 56432 & 46,59 & 1,43 & 62,76 \\
\hline Operadora de caixa & 55088 & 83,96 & 1,40 & 64,16 \\
\hline Atendente de bar & 48329 & 54,48 & 1,23 & 65,38 \\
\hline Encarregada da administração & 43956 & 23,51 & 1,12 & 66,50 \\
\hline Manicure e Pedicure & 40040 & 98,00 & 1,02 & 67,52 \\
\hline Bordadeira/Cerzideira & 39299 & 100,00 & 0,10 & 68,52 \\
\hline Comenciante & 38639 & 20,72 & 0,98 & 69,50 \\
\hline Trabalhadora de fäbrica de sapato & 38567 & 46,42 & 0,98 & 70,48 \\
\hline Oưras ocupaçōes na indústria de transformação & 37849 & 39,01 & 0,96 & 71,44 \\
\hline Professora de 5 a 8 séries & 33405 & 84,94 & 0,85 & 72,29 \\
\hline Professora de 20. grau & 32270 & 72,29 & 0,82 & 73,11 \\
\hline Auxiljar de contabilidade & 31793 & 57,91 & 0,81 & 73,92 \\
\hline Cabeleireira & 31058 & 66,52 & 0,79 & 74,71 \\
\hline Outras administradoras & 30980 & 37,77 & 0,79 & 75,49 \\
\hline Telefonista & 30979 & 92,39 & 0,79 & 76,28 \\
\hline Caixa & 28215 & 42,86 & 0,72 & 76,10 \\
\hline Allxiliar de costura & 27211 & 86,38 & 0,69 & 77,69 \\
\hline Operadora de máquinas p. automáticas & 26901 & 39,02 & 0,68 & 78,37 \\
\hline Professor de préescola & 26586 & 97,02 & 0,68 & 79,05 \\
\hline Diretora/Assessora & 24926 & 47,37 & 0,63 & 79,68 \\
\hline Ocupações na indústria de artefatos de borracha & 22822 & 31,16 & 0,58 & 80,26 \\
\hline Tecelã & 22480 & 40,51 & 0,57 & 80,83 \\
\hline Inspetora de qualidade & 22187 & 22,15 & 0,56 & 81,40 \\
\hline Outras Proprietárias & 21583 & 24,79 & 0,55 & 81,94 \\
\hline Professora & 20742 & 86,02 & 0,53 & 82,47 \\
\hline Administradora do comércio de mercadorias & 20030 & 25,35 & 0,51 & 82,98 \\
\hline Doceira/confeiteira & 17478 & 62,18 & 0,44 & 83,42 \\
\hline Adrninistradora na indústria de transformação & 17476 & 18,46 & 0,44 & 83,87 \\
\hline Inspetora de alunos & 16660 & 71,20 & 0,42 & 84,29 \\
\hline Orientadora de ensino & 16659 & 90,56 & 0,42 & 84,72 \\
\hline Assistente administrativo & 15950 & 41,71 & 0,41 & 85,12 \\
\hline Montadora de Rádio/TV & 15554 & 65,23 & 0,40 & 85,52 \\
\hline Montadora de equipamentos eletrônicos & 15346 & 57,05 & 0,39 & 85,91 \\
\hline Professora profissionalizante & 14211 & 58,19 & 0,36 & 86,27 \\
\hline Auxiliar administrativo & 14108 & 35,48 & 0,36 & 86,63 \\
\hline Pracista e viajante & 13711 & 14,33 & 0,35 & 86,97 \\
\hline Enfermeira diplomada & 13293 & 87,83 & 0,34 & 87,31 \\
\hline Professora de 10. grau & 13290 & 94,22 & 0,34 & 87,65 \\
\hline Advogada etc & 12580 & 28,15 & 0,32 & 87,97 \\
\hline Empresária na indústria de transformação & 11346 & 9,75 & 0,29 & 88,26 \\
\hline Datilógrafa & 10948 & 71,36 & 0,28 & 88,53 \\
\hline Montadora de equipamentos elétricos & 10844 & 49,34 & 0,28 & 88,81 \\
\hline Escrivã & 10424 & - $\quad 66,67$ & 0,26 & 89,08 \\
\hline Técnica em Estatística & 10131 & 73,89 & 0,26 & 89,33 \\
\hline Contadora & 10026 & 25,15 & 0,25 & 89,59 \\
\hline Artesã & 9816 & 58,19 & 0,25 & 89,84 \\
\hline Proprietária & 9712 & 15,80 & 0,25 & 90,08 \\
\hline
\end{tabular}

(1) Inclui apenas as pessoas para as quais os atributos de interesse estão claramente identificados. 
Tabela C10. Sessenta ocupações mais importantes na absorção da mão-de-obra masculina ${ }^{(1)}$. São Paulo, 1987.

\begin{tabular}{|c|c|c|c|c|}
\hline OCUPAÇÕES & $M_{i}$ & $\frac{M_{i}}{T_{i}}(\%)$ & $\frac{M_{1}(\%)}{M}$ & $\Phi_{i}(\%)$ \\
\hline $\begin{array}{l}\text { Outros trab. na agropecuária } \\
\text { Motorista }\end{array}$ & $\begin{array}{l}520618 \\
515502\end{array}$ & $\begin{array}{l}76,66 \\
99,64\end{array}$ & $\begin{array}{l}7,15 \\
7,09\end{array}$ & $\begin{array}{r}7,16 \\
14,24\end{array}$ \\
\hline Pedreiro & 388315 & 99,79 & 5,34 & 19,58 \\
\hline Auxiliar de escritório & 345871 & 47,75 & 4,75 & 24,34 \\
\hline Vendedor & 312781 & 61,17 & 4,30 & 28,63 \\
\hline Comerciante conta-própria & 202731 & 71,21 & 2,79 & 31,42 \\
\hline Servente de pedreiro & 164986 & 99,44 & 2,27 & 33,69 \\
\hline Comerciante & 147843 & 79,28 & 2,03 & 35,72 \\
\hline Proctutor agropecuário autônomo & 147837 & 96,73 & 2,03 & 37,75 \\
\hline Encarregado da administração & 143026 & 76,49 & 1,97 & 39,72 \\
\hline Mecânico de veículo & 133442 & 100,00 & 1,83 & 41,55 \\
\hline Mecânico & 114365 & 100,00 & 1,57 & 43,13 \\
\hline Tomeiro mecânico & 111206 & 97,06 & 1,53 & 44,66 \\
\hline Marceneiro & 110789 & 96,27 & 1,52 & 46,18 \\
\hline Empresário na incústria de transformação & 104970 & 90,25 & 1,44 & 47,62 \\
\hline Repositor de equipamentos & 97093 & 99,06 & 1,33 & 48,96 \\
\hline Pracista e viajante & 81959 & 85,67 & 1,13 & 50,08 \\
\hline Pintor/Caiador & 81439 & 98,88 & 1,12 & 51,20 \\
\hline Embalador de mercadorias & 79493 & 46,36 & 1,09 & 52,29 \\
\hline Inspetor de qualidade & 77993 & 77,85 & 1,07 & 53,37 \\
\hline Administrador na incústria de transformação & 77177 & 81,54 & 1,06 & 54,43 \\
\hline Soldador & 75468 & 96,60 & 1,04 & 55,47 \\
\hline Outros proprietários & 65491 & 75,21 & 0,90 & 56,37 \\
\hline Outras ocupações ambulantes & 64697 & 53,41 & 0,89 & 57,25 \\
\hline Carpinteiro & 63458 & 100,00 & 0,87 & 58,13 \\
\hline Ajustador/Montador & 59593 & 86,88 & 0,82 & 58,95 \\
\hline Engenheiro & 59194 & 95,70 & 0,81 & 59,76 \\
\hline Oúras ocupaçōes na incústria de transformação & 59169 & 60,99 & 0,81 & 60,57 \\
\hline Administrador do comércio de mercadorias & 58983 & 74,65 & 0,81 & 61,38 \\
\hline Técnico na indústria de transformação & 53165 & 88,13 & 0,73 & 62,12 \\
\hline Expedidor & 53061 & 89,64 & 0,73 & 62,84 \\
\hline Encanador & 52827 & 100,00 & 0,73 & 63,57 \\
\hline Proprietário & 51744 & 84,20 & 0,71 & 64,28 \\
\hline Outros administradores & 51036 & 62,23 & 0,70 & 64,98 \\
\hline Ocupap̧ões na indústria de artefatos de borracha & 50425 & 68,84 & 0,69 & 65,68 \\
\hline Tratorista agrícola & 48963 & 100,00 & 0,67 & 66,35 \\
\hline Almoxarife & 48038 & 93,26 & 0,66 & 67,01 \\
\hline Trabalhador de fábrica de sapato & 44510 & 53,58 & 0,61 & 67,62 \\
\hline Garçon & 43875 & 89,38 & 0,60 & 68,23 \\
\hline Pintor à pistola & 43241 & 98,15 & 0,59 & 68,82 \\
\hline Agricultor & 42543 & 96,30 & 0,58 & 69,40 \\
\hline Desenhista & 42216 & 90,37 & 0,58 & 69,98 \\
\hline Operador de máquinas p. automáticas & 42035 & 60,98 & 0,58 & 70,56 \\
\hline Atendente de bar & 40375 & 45,52 & 0,56 & 71,12 \\
\hline Feirante & 38451 & 82,64 & 0,53 & 71,65 \\
\hline Ferramenteiro & 37847 & 100,00 & 0,52 & 72,17 \\
\hline Caixa & 37613 & 57,14 & 0,52 & 72,68 \\
\hline Cozinheiro & 37529 & 29,76 & 0,52 & $\mathbf{7 3 , 2 0}$ \\
\hline Administrador de financeiras & 36906 & 81,85 & 0,51 & 73,71 \\
\hline Corretor de imóveis & 35347 & 95,32 & 0,49 & 74,19 \\
\hline Operador de prensa & 35271 & 85,18 & 0,48 & 74,68 \\
\hline Representante comercial & 33511 & 92,92 & 0,46 & 75,14 \\
\hline Tecelão & 33006 & 59,49 & 0,45 & 75,59 \\
\hline Eletricista instalador & 32375 & 100,00 & 0,45 & 76,04 \\
\hline Advogado etc & 32109 & 71,85 & 0,44 & 76,48 \\
\hline Ferreiro/Searalheiro & 30872 & 100,00 & 0,42 & 76,90 \\
\hline Comprador & 30163 & 94,56 & 0,41 & $\mathbf{7 7 , 3 2}$ \\
\hline Empregado doméstico & 30032 & 4,46 & 0,41 & $\mathbf{7 7 , 7 3}$ \\
\hline Contador & 29846 & 74,86 & 0,41 & 78,14 \\
\hline Operador de máquinas de construção civil & 28588 & 100,00 & 0,39 & 78,53 \\
\hline
\end{tabular}

(1) Inclui apenas as pessoas para as quais os atributos de interesse estão claramente identificados. 
Tabela C11. Sessenta ocupações mais importantes na absorção da mão-de-obra feminina(1). São Paulo, 1988.

\begin{tabular}{|c|c|c|c|c|}
\hline OCUPAÇŌES & $F_{i}$ & $\frac{F_{i}}{T_{i}}(\%)$ & $\frac{F_{l}}{F}(\%)$ & $\pi_{i}(\%)$ \\
\hline Empregada doméstica & 644898 & 93,94 & 15,97 & 15,97 \\
\hline Auxiliar de escritório & 343613 & 52,49 & 8,51 & 24,49 \\
\hline Alfaiate/Costureira & 280799 & 97,49 & 6,96 & 31,44 \\
\hline Vendedora & 190145 & 41,55 & 4,71 & 36,15 \\
\hline Professora de 1 a 4 série & 129676 & 97,96 & 3,21 & 39,36 \\
\hline Outros trab. na agropecuária & 121839 & 20,29 & 3,02 & 42,38 \\
\hline Secrétária & 105295 & 95,09 & 2,61 & 44,99 \\
\hline Reospcionista & 104041 & 84,19 & 2,58 & 47,57 \\
\hline Comerciante conta-própria & 96613 & 32,79 & 2,39 & 49,96 \\
\hline Enfermeira não diplomada & 91272 & 85,82 & 2,26 & 52,22 \\
\hline Cozinheira & 82171 & 56,01 & 2,04 & 54,26 \\
\hline Embaladora de mercadorias & 71774 & 48,24 & 1,79 & 56,04 \\
\hline Lavadeira/Passadeira & 71053 & 86,30 & 1,76 & 57,80 \\
\hline Outras ocupaçōes ambulantes & 63873 & 52,04 & 1,58 & 59,38 \\
\hline Professora de 5 a 8 séries & 61823 & 87,92 & 1,53 & 60,91 \\
\hline Encarregada da administração & 61161 & 27,49 & 1,52 & 62,42 \\
\hline Operadora de caixa & 58031 & 84,21 & 1,44 & 63,86 \\
\hline Atendente de bar & 55915 & 52,69 & 1,39 & 65,25 \\
\hline Manicure e Pedicure & 45874 & 100,00 & 1,14 & 66,38 \\
\hline Cabeleireira & 43685 & 78,85 & 1,08 & 67,47 \\
\hline Comerciante & 42956 & 22,01 & 1,06 & 68,53 \\
\hline Outras administradoras & 42758 & 47,73 & 1,06 & 69,59 \\
\hline Outras ocupações na inđústria de transformação & 39866 & 35,12 & 0,99 & 70,58 \\
\hline Telefonista & 36811 & 95,64 & 0,91 & 71,49 \\
\hline Administradora do comércio de mercadorias & 35535 & 39,65 & 0,88 & 72,37 \\
\hline Caixa & 35159 & 56,65 & 0,87 & 73,24 \\
\hline Bordadeira/Cerzideira & 33672 & 100,00 & 0,83 & 74,07 \\
\hline Trabalhadora de fäbrica de sapato & 32567 & 47,57 & 0,81 & 74,88 \\
\hline Auxiliar de costura & 31203 & 89,59 & 0,77 & 75,65 \\
\hline Professora de 20. grau & 30991 & 85,38 & 0,77 & 76,42 \\
\hline Tecelã & 30289 & 58,35 & 0,75 & 77,17 \\
\hline Auxiliar de contabilidade & 29285 & 52,63 & 0,73 & 77,90 \\
\hline Inspetora de alunos & 28178 & 75,66 & 0,70 & 78,59 \\
\hline Assistente administrativo & 26901 & 57,29 & 0,67 & 79,26 \\
\hline Inspetora de qualidade & 26467 & 22,74 & 0,66 & 79,92 \\
\hline Diretora/Assessora & 26364 & 44,78 & 0,65 & 80,57 \\
\hline Professora & 23573 & 86,67 & 0,58 & 81,15 \\
\hline Professora de pré-escola & 22464 & 100,00 & 0,56 & 81,71 \\
\hline Auxiliar administrativo & 22299 & 33,52 & 0,55 & 82,26 \\
\hline Proprictária & 22299 & 27,35 & 0,55 & 82,81 \\
\hline Operadora de máquinas p. automáticas & 19648 & 30,79 & 0,49 & 83,30 \\
\hline Professora de 10. grau & 19349 & 91,43 & 0,48 & 83,78 \\
\hline Médica & 18002 & 36,86 & 0,45 & 84,23 \\
\hline Administadora na incústria de transformação & 17266 & 20,18 & 0,43 & 84,65 \\
\hline Ocupações na inđústria de artefatos de borracha & 17129 & 24,94 & 0,42 & 85,08 \\
\hline Dentista & 16589 & 44,07 & 0,41 & 85,49 \\
\hline Acabadora de pano & 16317 & 72,68 & 0,40 & 85,89 \\
\hline Assistente social & 16051 & 100,00 & 0,40 & 86,29 \\
\hline Doceira/confeiteira & 14506 & 51,24 & 0,36 & 86,65 \\
\hline Contadora & 13235 & 26,45 & $\mathbf{0 , 3 3}$ & 86,98 \\
\hline Pracista e viajante & 13232 & 12,97 & 0,33 & 87,31 \\
\hline Psicóloga & 12829 & 100,00 & 0,32 & 87,62 \\
\hline Outras Proprietárias & 12695 & 11,84 & 0,31 & 87,94 \\
\hline Montadora de Rádio/TV & 12662 & 81,96 & 0,31 & 88,25 \\
\hline Advogada etc & 11988 & 22,40 & 0,30 & 88,55 \\
\hline Massagista & 11720 & 80,79 & 0,29 & 88,84 \\
\hline Professora profissionalizante & 11150 & 70,79 & 0,28 & 89,12 \\
\hline Empresária na indústria de transformação & 10614 & 8,53 & 0,26 & 89,38 \\
\hline Almoxarife & 10608 & 16,25 & 0,26 & 89,64 \\
\hline Expedidora & 10445 & 16,51 & 0,26 & 89,90 \\
\hline
\end{tabular}

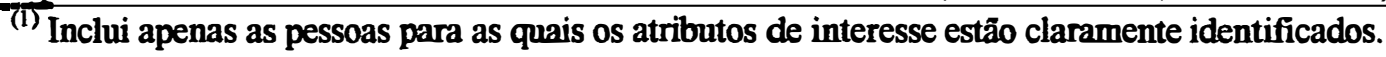


Tabela C12. Sessenta ocupações mais importantes na absorção da mão-de-obra masculina(1). São Paulo, 1988.

\begin{tabular}{|c|c|c|c|c|}
\hline OCUPAÇÕES & $M_{i}$ & $\frac{M_{i}}{T_{i}}(\%)$ & $\frac{M,(\%)}{M}$ & $\Phi_{i}(\%)$ \\
\hline Motorista & 496717 & 99,50 & 6,75 & 6,75 \\
\hline Ourros trab. na agropecuária & 478639 & 79,71 & 6,50 & 13,25 \\
\hline Pectriro & 364742 & 100,00 & 4,95 & 18,20 \\
\hline Auxiliar de escritório & 311067 & 47,51 & 4,22 & 22,43 \\
\hline Vendedor & 267508 & 58,45 & 3,63 & 26,06 \\
\hline Servente de pedreiro & 219359 & 97,76 & 2,98 & 29,04 \\
\hline Comerciante conta-própria & 198215 & 67,23 & 2,69 & 31,73 \\
\hline Mecânico de veículo & 162833 & 98,40 & 2,21 & 33,94 \\
\hline Encarregado da administração & 161297 & 72,51 & 2,19 & 36,13 \\
\hline Comerciante & 152195 & 77,99 & 2,07 & 38,20 \\
\hline Procintor agropecuário autônomo & 151985 & 97,84 & 2,06 & 40,26 \\
\hline Empresário na incústria de transformação & 113817 & 91,47 & 1,55 & 41,81 \\
\hline Mecânico & 106427 & 99,09 & 1,45 & 43,26 \\
\hline Marconeiro & 100545 & 98,23 & 1,37 & 44,62 \\
\hline Tomeiro Mecânico & 95643 & 98,99 & 1,30 & 45,92 \\
\hline Ourros proprietários & 94497 & 88,16 & 1,28 . & 47,20 \\
\hline Soldador & 90298 & 95,15 & 1,23 & 48,43 \\
\hline Inspetor de qualidade & 89907 & 77,26 & 1,22 & 49,65 \\
\hline Pracista e viajante & 88801 & 87,03 & 1,21 & 50,86 \\
\hline Ajustador/Montador & 82550 & 92,51 & 1,12 & 51,98 \\
\hline Repositor de equipamentos & 81381 & 100,00 & 1,11 & 53,08 \\
\hline Pintor/Caiador & 79758 & 100,00 & 1,08 & 54,18 \\
\hline Embalador de mercadorias & 77004 & 51,76 & 1,05 & 55,21 \\
\hline Outras ocupaçōes na incuistria de transformação & 73642 & 64,88 & 1,00 & 56,21 \\
\hline Administrador na inđústria de transformação & 68315 & 79,83 & 0,93 & 57,14 \\
\hline Carpinteiro & 64912 & 98,72 & 0,88 & 58,02 \\
\hline Cozinheiro & 64544 & 43,99 & 0,88 & 58,90 \\
\hline Engenheiro & 62432 & 95,92 & 0,85 & 59,75 \\
\hline Propriaário & 59241 & 72,65 & 0,80 & 60,55 \\
\hline Outras ocupaçōes ambulantes & 58867 & 47,96 & 0,80 & 61,35 \\
\hline Almoxarife & 54671 & 83,75 & 0,74 & 62,09 \\
\hline Administrador do comércio de mercadorias & 54099 & 60,34 & 0,73 & 62,83 \\
\hline Expectidor & 52825 & 83,49 & 0,72 & 63,55 \\
\hline Ocupaçöes na incústria de artefatos de borracha & 51550 & 75,06 & 0,70 & 64,25 \\
\hline Eletricista instalador & 51077 & 98,38 & 0,69 & 64,94 \\
\hline Ateodente de bar & 50207 & 47,31 & 0,68 & 65,62 \\
\hline Representante comencial & 49365 & 92,68 & 0,67 & 66,29 \\
\hline Ferreiro/Sesralheiro & 46848 & 100,00 & 0,64 & 66,93 \\
\hline Outros administradores & 46817 & 52,27 & 0,64 & 67,57 \\
\hline Desenhista & 46577 & 90,77 & 0,63 & 68,20 \\
\hline Auxiliar administrativo & 44220 & 66,48 & 0,60 & 68,80 \\
\hline Operador de máquinas p. automáticas & 44166 & 69,21 & 0,60 & 69,40 \\
\hline Tratorista agrícola & 43648 & 100,00 & 0,59 & 69,99 \\
\hline Pintor à pistola & 42111 & 100,00 & 0,57 & 70,56 \\
\hline Esmpregido doméstico & 41636 & 6,07 & 0,57 & 71,13 \\
\hline Advogado etc & 41543 & 77,61 & 0,56 & 71,69 \\
\hline Operador de prensa & 40540 & 83,88 & 0,55 & 72,24 \\
\hline Ferramenteiro & 39830 & 100,00 & 0,54 & 72,79 \\
\hline Feirante & 39566 & 84,27 & 0,54 & 73,32 \\
\hline Encanador & 38484 & 100,00 & 0,52 & 73,85 \\
\hline Contador & 36806 & 73,55 & 0,50 & 74,34 \\
\hline Fresador/Furador & 35967 & 89,25 & 0,49 & 74,83 \\
\hline Trabalhador de fäbrica de sapato & 35893 & 52,43 & 0,49 & 75,32 \\
\hline Funileiro & 34158 & 100,00 & 0,46 & 75,78 \\
\hline Técrico na inđústria de transformação & 33617 & 92,00 & 0,46 & 76,24 \\
\hline Trocador & 33046 & 89,45 & 0,45 & 76,69 \\
\hline Dirztor/Assessor & 32505 & 55,22 & 0,44 & 77,13 \\
\hline Operador de empilhadeira & 31934 & 100,00 & 0,43 & 77,57 \\
\hline Mético & 30831 & 63,13 & 0,42 & 77,98 \\
\hline Corrator de imóveis & 30556 & 94,40 & 0,42 & 78,40 \\
\hline
\end{tabular}

${ }^{(1)}$ Inclui apenas as pessoas para as quais os atributos de interesse estão claramente identificados. 
Tabela C13. Sessenta ocupações mais importantes na absorção da mão-de-obra feminina(1). São Paulo, 1989.

\begin{tabular}{|c|c|c|c|c|}
\hline OCUPAÇŌES & $F_{i}$ & $\frac{F_{1}}{T_{1}}(\%)$ & $\frac{F_{i}}{F}(\%)$ & $\pi_{i}(\%)$ \\
\hline Empregada doméstica & 680044 & 94,45 & 15,83 & 15,83 \\
\hline Ausiliar de escritório & 396801 & 54,66 & 9,24 & 25,06 \\
\hline Alfaiate/Costureira & 270263 & 90,68 & 6,29 & 31,35 \\
\hline Vendedora & 212797 & 41,44 & 4,95 & 36,30 \\
\hline Professora de 1 a 4 série & 147836 & 94,59 & 3,44 & 39,74 \\
\hline Outras trab. na agropecuária & 146930 & 24,80 & 3,42 & 43,16 \\
\hline Secretáia & 121330 & 95,64 & 2,82 & 45,99 \\
\hline Enfermeira não diplomada & 112790 & 87,42 & 2,63 & 48,61 \\
\hline Cozinheira & 109688 & 68,67 & 2,55 & 51,17 \\
\hline Recepcionista & 85475 & 91,83 & 1,99 & 53,15 \\
\hline Embaladora de mercadorias & 84127 & 58,95 & 1,96 & 55,11 \\
\hline Lavadeira/Pascadeira & 76751 & 90,45 & 1,79 & 56,90 \\
\hline Comeciante conta-própria & 73941 & 24,62 & 1,72 & 58,62 \\
\hline Outras ocupapōes ambulantes & 69594 & 57,23 & 1,62 & 60,24 \\
\hline Alendente de bar & 65103 & 55,69 & 1,51 & 61,75 \\
\hline Operadora de caixa & 61834 & 78,53 & 1,44 & 63,19 \\
\hline Trabalhadora de fäbrica de sapato & 53467 & 54,23 & 1,24 & 64,44 \\
\hline Professora de 5 a 8 série & 53237 & 83,48 & 1,24 & 65,68 \\
\hline Outras administradoras & 53129 & 58,88 & 1,24 & 66,91 \\
\hline Encarreggada da administração & 51777 & 20,93 & 1,21 & 68,12 \\
\hline Comeriante & 51148 & 21,36 & 1,19 & 69,31 \\
\hline Professora de préescola & 42155 & 100,00 & 0,98 & 70,29 \\
\hline Cabeleirica & 41459 & 78,97 & 0,97 & 71,25 \\
\hline Outras ocupaçōes na incústria de transformação & 41419 & 38,26 & 0,96 & 72,22 \\
\hline Caixa & 40574 & 49,37 & 0,94 & 73,16 \\
\hline Bordadeira/Cerzideira & 36669 & 97,26 & 0,85 & 74,02 \\
\hline Manicure e Pedicure & 36624 & 90,23 & 0,85 & 74,87 \\
\hline Aluxiliar de costura & 35910 & 76,21 & 0,84 & 75,70 \\
\hline Operadora de máquinas p. automáticas & 35546 & 48,46 & 0,83 & 76,53 \\
\hline Telefonista & 35401 & 100,00 & 0,82 & 77,36 \\
\hline Professora & 32801 & 82,62 & 0,76 & 78,12 \\
\hline Professora de 20. grau & 29740 & 71,09 & 0,69 & 78,81 \\
\hline Diretora/Assessora & 28668 & 45,84 & 0,67 & 79,48 \\
\hline Administadora do comércio de mercadorias & 27291 & 27,34 & 0,64 & 80,11 \\
\hline Assisterte administrativo & 26239 & 60,31 & 0,61 & 80,72 \\
\hline Administradora na inđústria de transformação & 25711 & 26,94 & 0,60 & 81,32 \\
\hline Empresinia na indústria de transformação & 24339 & 17,75 & 0,57 & 81,89 \\
\hline Auxiliar administrativo & 24173 & 48,11 & 0,56 & 82,45 \\
\hline Outras proprietárias & 23642 & 21,29 & 0,55 & 83,00 \\
\hline Tecelã & 23472 & 42,23 & 0,55 & 83,55 \\
\hline Auxiliar de contabilidade & 23138 & 48,57 & 0,54 & 84,09 \\
\hline Pracista e viajante & 19846 & 20,71 & 0,46 & 84,55 \\
\hline Inspetora de alunos & 19332 & 84,19 & 0,45 & 85,00 \\
\hline Oaqpąües na incuistria de artefatos de borracha & 18976 & 25,39 & 0,44 & 85,44 \\
\hline Adrministsadora de financeiras & 18111 & 39,03 & 0,42 & 85,86 \\
\hline Advogada etc & 15705 & 31,25 & 0,37 & 86,23 \\
\hline Inspeica de qualidade & 15367 & 20,51 & 0,36 & 86,58 \\
\hline Popriaína & 15010 & 21,16 & 0,35 & 86,93 \\
\hline Psicóloga & 14840 & 93,49 & 0,35 & 87,28 \\
\hline Moniadora de equipamentos elétricos & 14311 & 45,08 & 0,33 & 87,61 \\
\hline Enfermeirs diplomada & 13994 & 82,67 & 0,33 & 87,94 \\
\hline Doceira/confeiteira & 13826 & 60,20 & 0,32 & 88,26 \\
\hline Médica & 13297 & 30,79 & 0,31 & 88,57 \\
\hline Feirante & 12601 & 23,03 & 0,29 & 88,86 \\
\hline Orientadora de ensino & 12265 & 81,60 & 0,29 & 89,15 \\
\hline Montadora de equipamentos eletrônicos & 12245 & 76,32 & 0,29 & 89,43 \\
\hline Comadors & 11739 & 23,69 & 0,27 & 89,71 \\
\hline Motiadora de Rádio/TV & 11379 & 68,76 & 0,27 & 89,97 \\
\hline Professora de 10. grau & 10701 & 91,19 & 0,25 & 90,22 \\
\hline Artecà & 10533 & 59,84 & 0,25 & 90,46 \\
\hline
\end{tabular}

${ }^{(1)}$ Inclui apenas as pessoas para as quais os atributos de interesse estão claramente identificados. 
Tabela C14. Sessenta ocupações mais importantes na absorção da mão-de-obra masculina(1). São Paulo, 1989.

\begin{tabular}{|c|c|c|c|c|}
\hline OCUPAÇÕES & $M_{i}$ & $\frac{M_{i}}{T_{1}}$ (\%) & $\frac{M_{i}(\%)}{M}$ & $\Phi_{i}(\%)$ \\
\hline Motorista & 546653 & 99,44 & 7,28 & 7,28 \\
\hline Outros trab. na agropecuária & 445446 & 75,20 & 5,93 & 13,2 \\
\hline Pedreiro & 398617 & 100,00 & 5,31 & 18,51 \\
\hline Aluxiliar de escritório & 329099 & 45,34 & 4,38 & 22,89 \\
\hline Vendedor & 300766 & 58,57 & 4,00 & 26,89 \\
\hline Comerciarte conta-própria & 226445 & 75,39 & 3,01 & 29,90 \\
\hline Encarregado da administração & 195601 & 79,07 & 2,60 & 32,51 \\
\hline Comerciante & 188290 & 78,64 & 2,51 & 35,01 \\
\hline Servente de pedreiro & 186724 & 98,01 & 2,49 & 37,50 \\
\hline Mecânico de veículo & 180853 & 100,00 & 2,41 & 39,90 \\
\hline Produtor agropecuáio autônomo & 123900 & 95,34 & 1,63 & 41,55 \\
\hline Emprecário na indústria de transformação & 112771 & 82,25 & 1,50 & 43,05 \\
\hline Mecânico & 112069 & 99,09 & 1,49 & 44,55 \\
\hline Marceneiro & 107681 & 95,85 & 1,43 & 45,98 \\
\hline Ajustador/Montador & 100,11 & 91,92 & 1,33 & 47,31 \\
\hline Repositor de equipamentos & 99506 & 100,00 & 1,32 & 48,63 \\
\hline Tomeiro Mecânico & 98229 & 98,96 & 1,31 & 49,94 \\
\hline Outros proprietários & 87414 & 78,71 & 1,16 & 51,11 \\
\hline Pintor/Caiador & 84835 & 100,00 & 1,13 & 52,23 \\
\hline Pracista e viajante & 75969 & 79,29 & 1,01 & 53,25 \\
\hline Almoxarife & 73874 & 92,64 & 0,98 & 54,23 \\
\hline Administrador do comércio de mercadorias & 72532 & 72,66 & 0,97 & 55,19 \\
\hline Engenheiro & 70591 & 96,01 & 0,94 & 56,13 \\
\hline Administrador na incústria de transformação & 69740 & 73,06 & 0,93 & 57,06 \\
\hline Outras ocupações na indústria de transformação & 66825 & 61,74 & 0,89 & 57,95 \\
\hline Pintor à pistola & 66292 & 100,00 & 0,88 & 58,83 \\
\hline Soldador & 65309 & 92,64 & 0,87 & 59,70 \\
\hline Inspetor de qualidade & 59554 & 79,49 & 0,79 & 60,49 \\
\hline Embalador de mercadorias & 58584 & 41,05 & 0,78 & 61,27 \\
\hline Carpinteiro & 57335 & 100,00 & 0,76 & 62,04 \\
\hline Proprietários & 55917 & 78,84 & 0,74 & 62,78 \\
\hline Ocupações na indústria de artefatos de borracha & 55771 & 74,61 & 0,74 & 63,52 \\
\hline Outras ocupações ambulantes & 52011 & 42,77 & 0,69 & 64,22 \\
\hline Atendente de bar & 51804 & 44,31 & 0,69 & 64,91 \\
\hline Expedidor & 51257 & 86,59 & 0,68 & 65,59 \\
\hline Cozinheiro & 50047 & 31,33 & 0,67 & 66,25 \\
\hline Eletricista instalador & 49734 & 100,00 & 0,66 & 66,92 \\
\hline Ferreiro/Serralheiro & 47832 & 100,00 & 0,64 & 67,55 \\
\hline Operador de prensa & 46589 & 86,55 & 0,62 & 68,17 \\
\hline Tratorista agricola & 45867 & 100,00 & 0,61 & 68,78 \\
\hline Trabalhador de fábrica de sapato & 45123 & 45,77 & 0,60 & 69,38 \\
\hline Encanador & 45088 & 100,00 & 0,60 & 69,98 \\
\hline Garcon & 43340 & 84,80 & 0,58 & 70,56 \\
\hline Técnico na incústria de transformação & 42815 & 95,75 & 0,57 & 71,13 \\
\hline Feirante & 42112 & 76,97 & 0,56 & 71,69 \\
\hline Caixa & 41605 & 50,63 & 0,55 & 72,24 \\
\hline Polidor/Esmerilhador & 41104 & 95,21 & 0,55 & 72,79 \\
\hline Desenhista & 40589 & 88,01 & 0,54 & 73,33 \\
\hline Empregado doméstico & 39942 & 5,55 & 0,53 & 73,86 \\
\hline Agricultor & 39623 & 97,86 & 0,53 & 74,39 \\
\hline Operador de máquinas p. automáticas & 37809 & 51,54 & 0,50 & 74,89 \\
\hline Contador & 37809 & 76,31 & 0,50 & 75,40 \\
\hline Outros administradores & 37111 & 41,13 & 0,49 & 75,89 \\
\hline Lanterneiro & 35589 & 100,00 & 0,47 & 76,36 \\
\hline Advogado etc & 34552 & 68,75 & 0,46 & 76,82 \\
\hline Dirctor/Assessor & 33877 & 54,16 & 0,45 & $\mathbf{7 7 , 2 7}$ \\
\hline Trocador & 33479 & 82,90 & 0,45 & 77,72 \\
\hline Tecelão & 32106 & 57,77 & 0,43 & 78,15 \\
\hline Corretor de imóveis & 31771 & 88,90 & 0,42 & 78,57 \\
\hline Médico & 29891 & 69,21 & 0,40 & 78,97 \\
\hline
\end{tabular}

${ }^{(1)}$ Inclui apenas as pessoas para as quais os atributos de interesse estão claramente identificados. 
Tabela C15. Sessenta ocupações mais importantes na absorção da mão-de-obra feninina ${ }^{(1)}$. São Paulo, 1990.

\begin{tabular}{|c|c|c|c|c|}
\hline OCUPAÇÕES & $F_{i}$ & $\frac{F_{1}}{T_{i}}(\%)$ & $\frac{F_{i}}{F}(\%)$ & $\pi_{i}(\%)$ \\
\hline Empregada doméstica & 637832 & 92,23 & 14,68 & 14,68 \\
\hline Auxiliar de escritório & 333288 & 52,12 & 7,67 & 22,35 \\
\hline Alfaiate/Costureira & 318586 & 93,17 & 7,33 & 29,68 \\
\hline Vendedora & 229260 & 43,47 & 5,28 & 34,96 \\
\hline Outros trab. na agropecuária & 130139 & 23,42 & 3,00 & 37,95 \\
\hline Secretánia & 123296 & 96,43 & 2,84 & 40,79 \\
\hline Cozinheira & 118456 & 75,16 & 2,73 & 43,52 \\
\hline Professora de 1 a 4 série & 111748 & 99,25 & 2,57 & 46,09 \\
\hline Comerciante conta-própria & 110464 & 35,80 & 2,54 & 48,63 \\
\hline Enfermeira não diplomada & 109815 & 87,72 & 2,53 & 51,16 \\
\hline Recepcionista & 101556 & 87,08 & 2,34 & 53,50 \\
\hline Outras ocupaçōes ambulames & 93895 & 56,02 & 2,16 & 55,66 \\
\hline Lavadeira/Passadeira & 88947 & 91,76 & 2,05 & 57,71 \\
\hline Embaladora de mercadorias & 81231 & 52,26 & 1,87 & 59,58 \\
\hline Operadora de caixa & 69886 & 83,44 & 1,61 & 61,18 \\
\hline Atendente de bar & 67733 & 58,91 & 1,56 & 62,74 \\
\hline Encarregada da administração & 67036 & 27,71 & 1,54 & 64,29 \\
\hline Comerciante & 56611 & 22,54 & 1,30 & 65,59 \\
\hline Professora de 5 a 8 série & 55107 & 90,09 & 1,27 & 66,86 \\
\hline Bondadeira/Cerzideira & 47525 & 95,88 & 1,09 & 67,95 \\
\hline Mamicure e Pedicure & 44199 & 100,00 & 1,02 & 68,97 \\
\hline Cabeleireira & 42877 & 74,70 & 0,99 & 69,95 \\
\hline Auxiliar de cortabilidade & 41540 & 55,22 & 0,96 & 70,91 \\
\hline Trabalhadora de fäbrica de sapato & 40369 & 45,11 & 0,93 & 71,84 \\
\hline Telefonista & 39451 & 97,92 & 0,91 & 72,75 \\
\hline Caixa & 36200 & 53,22 & 0,83 & 73,58 \\
\hline Professora de 20. grau & 36093 & 68,54 & 0,83 & 74,42 \\
\hline Professora de préescola & 35002 & 97,16 & 0,81 & 75,22 \\
\hline Operadora de máquinas p. automáticas & 34776 & 37,11 & 0,80 & 76,02 \\
\hline Empreśria na incuistria de transformação & 33209 & 22,20 & 0,76 & 76,78 \\
\hline Administradora do comércio de mercadorias & 32547 & 34,24 & 0,75 & 77,53 \\
\hline Diretora/Assessora & 31162 & 44,13 & 0,72 & 78,25 \\
\hline Assistente administrativo & 27187 & 61,21 & 0,63 & 78,87 \\
\hline Auxiliar de costura & 26242 & 84,69 & 0,60 & 79,48 \\
\hline Outras administradoras & 26056 & 41,06 & 0,60 & 80,08 \\
\hline Inspetora de qualidade & 25763 & 28,14 & 0,59 & 80,67 \\
\hline Auxiliar administrativo & 25474 & 37,94 & 0,59 & 81,26 \\
\hline Outras proprictárias & 24561 & 19,77 & 0,57 & 81,82 \\
\hline Ocupacoōes na indústria de anefatos de borracha & 22294 & 30,56 & 0,51 & 82,33 \\
\hline Professora de 10. grau & 22045 & 100,00 & 0,51 & 82,84 \\
\hline Oưras ocupacōes na indistria de transformação & 20547 & 29,14 & 0,47 & 83,31 \\
\hline Orientadora de ensino & 18607 & 80,95 & 0,43 & 83,74 \\
\hline Pracista e viajante & 18499 & 18,71 & 0,43 & 84,17 \\
\hline Tecelã & 18250 & 40,69 & 0,42 & 84,59 \\
\hline Proprietária & 17771 & 19,59 & 0,41 & 85,00 \\
\hline Administradora na indústria de transformação & 17479 & 15,83 & 0,40 & 85,40 \\
\hline Assistente social & 16093 & 100,00 & 0,37 & 85,77 \\
\hline Professora & 15909 & 77,03 & 0,37 & 86,14 \\
\hline Médica & 15730 & 28,70 & 0,36 & 86,50 \\
\hline Advogada etc & 15617 & 37,15 & 0,36 & 86,86 \\
\hline Inspetora de alunos & 14886 & 77,27 & 0,34 & 87,20 \\
\hline Contadora & 13209 & 24,04 & 0,30 & 87,50 \\
\hline Feirante & 12916 & 25,88 & 0,30 & 87,80 \\
\hline Psicóloga & 12736 & 100,00 & 0,29 & 88,10 \\
\hline Acabadora de Pano & 12368 & 52,55 & 0,29 & 88,38 \\
\hline Analista de Sisternas & 11893 & 34,49 & 0,27 & 88,65 \\
\hline Dertista & 11825 & 51,43 & 0,27 & $\mathbf{8 8 , 9 3}$ \\
\hline Artesä & 11056 & 56,63 & 0,26 & 89,18 \\
\hline Doceira/confeitcira & 10987 & 54,15 & 0,25 & 89,43 \\
\hline Montadora de equipamentos eletrônioos & 10875 & 66,08 & 0,25 & 89,68 \\
\hline
\end{tabular}

${ }^{(1)}$ Inclui apenas as pessoas para as quais os atributos de interesse estão claramente identificados. 
Tabela c16. Sessenta ocupações mais importantes na absorção da mão-de-obra masculina(1). São Paulo, 1990.

\begin{tabular}{|c|c|c|c|c|}
\hline OCUPAÇŌES & $M_{i}$ & $\frac{M_{i}}{T_{i}}(\%)$ & $\frac{M t(\%)}{M}$ & $\Phi_{i}(\%)$ \\
\hline $\begin{array}{l}\text { Motorista } \\
\text { Outros trab. na agropecuánia }\end{array}$ & $\begin{array}{l}563751 \\
425627\end{array}$ & $\begin{array}{l}99,31 \\
76,58\end{array}$ & $\begin{array}{l}7,49 \\
5,65\end{array}$ & $\begin{array}{r}7,49 \\
13,13\end{array}$ \\
\hline $\begin{array}{l}\text { Oritros trab. na agropecuana } \\
\text { Pedreiro }\end{array}$ & 420261 & 99,80 & 5,58 & 18,72 \\
\hline Auxiliar de escritónio & 306235 & 47,89 & 4,07 & 22,78 \\
\hline Vendedor & 298162 & 56,53 & 3,96 & 26,74 \\
\hline Comerciante conta-própria & 198059 & 64,20 & 2,63 & 29,37 \\
\hline Comerciante & 194554 & 77,46 & 2,58 & 31,96 \\
\hline Mecânico de veículo & 183688 & 100,00 & 2,44 & 34,40 \\
\hline Servente de pedreiro & 182156 & 98,99 & 2,42 & 36,81 \\
\hline Encarregado da administração & 174877 & 72,29 & 2,32 & 39,14 \\
\hline Mecânico & 136454 & 100,00 & 1,81 & 40,95 \\
\hline Prochutor agropecuário autônomo & 125606 & 93,81 & 1,67 & 42,62 \\
\hline Empresário na indústria de transformação & 116410 & 77,80 & 1,55 & 44,16 \\
\hline Outros propriatánios & 99659 & 80,23 & 1,32 & 45,49 \\
\hline Administrador na indústria de transfomação & 92949 & 84,17 & 1,23 & 46,72 \\
\hline Tomeiro Mecânico & 90321 & 98,88 & 1,20 & 47,92 \\
\hline Pracista e viajante & 80355 & 81,29 & 1,07 & 48,99 \\
\hline Marceneiro & 79379 & 89,69 & 1,05 & 50,04 \\
\hline Embalador de mercadorias & 74202 & 47,74 & 0,99 & 51,03 \\
\hline Outras ocupações ambulantes & 73719 & 43,98 & 0,98 & 52,00 \\
\hline Proprietário & 72949 & 80,41 & 0,97 & 52,97 \\
\hline Almoxarife & 68203 & 92,21 & 0,91 & 53,88 \\
\hline Repositor de equipamentos & 67730 & 100,00 & 0,90 & 54,78 \\
\hline Ajustador/Montador & 66301 & 89,46 & 0,88 & 55,66 \\
\hline Pintor/Caiador & 66094 & 98,48 & 0,88 & 56,54 \\
\hline Inspetor de qualidade & 65801 & 71,86 & 0,87 & 57,41 \\
\hline Soldador & 62919 & 95,35 & 0,84 & 58,24 \\
\hline Administrador do coméscio de mercadorias & 62517 & 65,76 & 0,83 & 59,07 \\
\hline Operador de prensa & 59771 & 92,39 & 0,78 & 59,87 \\
\hline Operador de máquinas p. automáticas & 58924 & 62,89 & 0,78 & 60,65 \\
\hline Carpinteiro & 57925 & 98,27 & 0,77 & 61,42 \\
\hline Pintor à pistola & 57587 & 98,56 & 0,77 & 62,18 \\
\hline Técnico na indústria de transformação & 56161 & 91,93 & 0,75 & 62,93 \\
\hline Empregado doméstico & 53766 & 7,78 & 0,71 & 63,64 \\
\hline Desenhista & 53097 & 93,45 & 0,71 & 64,35 \\
\hline Engenheiro & 52544 & 96,58 & 0,70 & 65,05 \\
\hline Eletricista instalador & 51449 & 100,00 & 0,68 & 65,73 \\
\hline Ocupações na indústria de artefatos de borracha & 50654 & 69,44 & 0,67 & 66,40 \\
\hline Outras ocupações na indústria de transformação & 49963 & 70,86 & 0,66 & 67,07 \\
\hline Trabalhador de fábrica de sapato & 49124 & 54,89 & 0,65 & 67,72 \\
\hline Atendente de bar & 47253 & 41,10 & 0,63 & 68,35 \\
\hline Encanador & 45875 & 100,00 & 0,61 & 68,96 \\
\hline Tratorista agricola & 44671 & 98,16 & 0,59 & 69,55 \\
\hline Ferreiro/Serralheiro & 43179 & 97,69 & 0,57 & 70,12 \\
\hline Representante comercial & 42989 & 82,67 & 0,57 & 70,69 \\
\hline Contador & 41740 & 75,96 & 0,55 & 71,25 \\
\hline Auxiliar administrativo & 41677 & 62,07 & 0,55 & 71,80 \\
\hline Trocador & 40724 & 100,00 & 0,54 & 72,34 \\
\hline Expedidor & 39999 & 80,83 & 0,53 & 72,87 \\
\hline Agricultor & 39644 & 95,94 & 0,53 & 73,40 \\
\hline Diretor/Assessor & 39453 & 55,87 & 0,52 & 73,92 \\
\hline Cozinheiro & 39160 & 24,85 & 0,52 & 74,44 \\
\hline Médico & 39084 & 71,30 & 0,52 & 74,96 \\
\hline Orros administradores & 37405 & 58,94 & 0,50 & 75,46 \\
\hline Feirante & 36999 & 74,12 & 0,49 & 75,95 \\
\hline Tomeiro metalúrgico & 34931 & 100,00 & 0.46 & 76.41 \\
\hline Garcen & 34415 & 79,92 & 0,46 & 76,87 \\
\hline Auxiliar de contabilidade & 33683 & 44.78 & 0,45 & 77,32 \\
\hline Enpresário da construção civil & 32229 & 94,54 & 0,43 & 77,75 \\
\hline Caixa & 31822 & 46.78 & 0.42 & 78.17 \\
\hline
\end{tabular}

${ }^{(1)}$ Inclui apenas as pessoas para as quais os atributos de interesse estão claramente identificados. 
Tabela c17. Sessenta ocupações mais importantes na absorção da mão-de-obra feninina(1). Pernambuco, 1981.

\begin{tabular}{|c|c|c|c|c|}
\hline OCUPAÇŌES & $F_{i}$ & $\frac{F_{i}}{T_{i}}(\%)$ & $\frac{F_{t}}{F}(\%)$ & $\pi_{i}(\%)$ \\
\hline Outros trab. na agropecuária & 63576 & 18,10 & 13,56 & 13,56 \\
\hline Empregada doméstica & 59716 & 90,81 & 12,74 & 26,30 \\
\hline Alfaiate/Coshreira & 51238 & 99,39 & 10,93 & 37,22 \\
\hline Lavadeira/Passadeira & 29135 & 99,64 & 6,21 & 43,44 \\
\hline Professora de 1 a 4 séries & 25686 & 98,69 & 5,48 & 48,92 \\
\hline Prodirtora agropecuánia autônoma & 22091 & 12,32 & 4,71 & 53,63 \\
\hline Auxiliar de escritório & 20499 & 43,97 & 4,37 & 58,00 \\
\hline Vendedora & 17703 & 37,37 & 3,78 & 61,78 \\
\hline Comerciante conta-própria & 17626 & 29,05 & 3,76 & 65,53 \\
\hline Enfermeira não diplomada & 12082 & 90,93 & 2,58 & 68,11 \\
\hline Outras ocapaçōes ambulantes & 11194 & 33,57 & 2,39 & 70,50 \\
\hline Secretária & 9766 & 97,90 & 2,08 & 72,58 \\
\hline Feirante & 8684 & 26,40 & 1,85 & 74,43 \\
\hline Redeira & 7587 & 100,00 & 1,62 & 76,05 \\
\hline Operadora de caixa & 5596 & 81,33 & 1,19 & 77,25 \\
\hline Recepcionista & 5219 & 83,22 & 1,11 & 78,36 \\
\hline Embaladora de mercadorias & 5174 & 48,70 & 1,10 & 79,46 \\
\hline Cozinheira & 4793 & 71,42 & 1,02 & 80,48 \\
\hline Manicure e Pedicure & 4149 & 100,00 & 0,89 & 81,37 \\
\hline Trabalhadora de fábrica de sapato & 3872 & 31,23 & 0,83 & 82,20 \\
\hline Atendente de bar & 3813 & 52,40 & 0,81 & 83,01 \\
\hline Assistente administrativo & 3764 & 49,39 & 0,80 & 83,81 \\
\hline Professora de 5 a 8 séries & 3004 & 71,37 & 0,64 & 84,45 \\
\hline Telefonista & 2980 & 96,57 & 0,64 & 85,09 \\
\hline Diretora/Assessura & 2876 & 42,32 & 0,61 & 85,70 \\
\hline Auxiliar administrativo & 2701 & 42,00 & 0,58 & 86,28 \\
\hline Ausiliar de contabilidade & 2669 & 59,52 & 0,57 & 86,85 \\
\hline Professora de 20. grau & 2460 & 72,23 & 0,53 & 87,37 \\
\hline Caixa & 2252 & 46,42 & 0,48 & 87,85 \\
\hline Comerciante & 2150 & 15,47 & 0,46 & 88,31 \\
\hline Professora & 2150 & 87,22 & 0,46 & 88,77 \\
\hline Tecelã & 2023 & 37,95 & 0,43 & 89,20 \\
\hline Magarefe & 1678 & 75,31 & 0,36 & 89,56 \\
\hline FarinheiraMoleira & 1675 & 62,18 & 0,36 & 89,92 \\
\hline Encarregada da administração & 1663 & 18,07 & 0,36 & 90,27 \\
\hline Garconete & 1502 & 30,55 & 0,32 & 90,59 \\
\hline Orientadora de ensimo & 1479 & 87,46 & 0,32 & 90,91 \\
\hline Datilógrafa & 1454 & 51,54 & 0,31 & 91,22 \\
\hline Administradora do comércio de mercadorias & 1269 & 20,73 & 0,27 & 91,49 \\
\hline Bordadeira/Cerzideira & 1190 & 100,00 & 0,25 & 91,74 \\
\hline Advogada etc & 1168 & 34,55 & 0,25 & 91,99 \\
\hline Inspetora de alumos & 1167 & 100,00 & 0,25 & 92,24 \\
\hline Cabeleireira & 1166 & 78,68 & 0,25 & 92,49 \\
\hline Psioóloga & 1087 & 100,00 & 0,23 & 92,72 \\
\hline Outras proprieárias & 1062 & 21,11 & 0,23 & 92,95 \\
\hline Médica & 1040 & 29,84 & 0,22 & 93,17 \\
\hline Professora superior & 1040 & 52,34 & 0,22 & 93,39 \\
\hline Oleira & 1007 & 9,79 & 0,21 & 93,60 \\
\hline Auxiliar de costura & 983 & 100,00 & 0,21 & 93,81 \\
\hline Dentista & 960 & 75,29 & 0,21 & 94,02 \\
\hline Contadora & 959 & 23,64 & 0,21 & 94,22 \\
\hline Trocadora & 831 & 18,66 & 0,18 & 94,40 \\
\hline Modelista & 775 & 88,07 & 0,17 & 94,57 \\
\hline Quitandeira etc. & 775 & 70,97 & 0,17 & 94,73 \\
\hline Professora profissionalizante & 774 & 71,01 & 0,17 & 94,90 \\
\hline Engenheira & 751 & 17,68 & 0,16 & 95,06 \\
\hline Rendeira & 672 & 100,00 & 0,14 & 95,20 \\
\hline Técnica em administração & 624 & 74,82 & 0,13 & 95,33 \\
\hline Assistente social & 624 & 100,00 & 0,13 & 95,47 \\
\hline Camareira & 624 & 100.00 & 0.13 & 95,60 \\
\hline
\end{tabular}

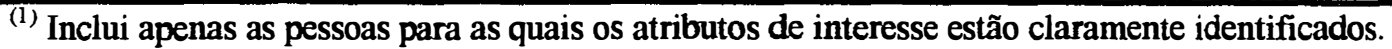


Tabela C18. Sessenta ocupações mais importantes na absorção da mão-de-obra masculina(1). Pernambuco, 1981.

\begin{tabular}{|c|c|c|c|c|}
\hline OCUPAÇO์ES & $M_{i}$ & $\frac{M_{i}}{T_{i}}$ (\%) & $\frac{M_{i}(\%)}{M}$ & $\Phi_{i}(\%)$ \\
\hline Outros trab. na agropecuánia & 287682 & 81,90 & 25,36 & 25,36 \\
\hline Produtor agropecuário autônomo & 157157 & 87,68 & 13,86 & 39,22 \\
\hline Pedreiro & 54549 & 100,00 & 4,81 & 44,03 \\
\hline Motorista & 52689 & 99,80 & 4,65 & 48,67 \\
\hline Servente de pedreiro & 48062 & 99,78 & 4,24 & 52,91 \\
\hline Comerciante conta-própria & 43041 & 70,95 & 3,80 & 56,71 \\
\hline Vendedor & 29666 & 62,63 & 2,62 & 59,32 \\
\hline Auxiliar de escritório & 26118 & 56,03 & 2,30 & 61,63 \\
\hline Feirante & 24214 & 73,60 & 2,14 & 63,76 \\
\hline Outras ocapações ambulantes & 22156 & 66,44 & 1,95 & 65,71 \\
\hline Mecânico de veículo & 18636 & 100,00 & 1,64 & 67,36 \\
\hline Agricultor & 12290 & 97,35 & 1,08 & 68,44 \\
\hline Comerciante & 11751 & 84,53 & 1,04 & 69,48 \\
\hline Carpinteiro & 9856 & 96,70 & 0,87 & 70,35 \\
\hline Pintor/Caiador & 9771 & 98,95 & 0,86 & 71,21 \\
\hline Oleiro & 9276 & 90,21 & 0,82 & 72,02 \\
\hline Marceneiro & 9213 & 100,00 & 0,81 & 72,84 \\
\hline Trabalhador de fábrica de sapato & 8528 & 68,78 & 0,75 & 73,59 \\
\hline Encarregado da administração & 7538 & 81,93 & 0,67 & 74,25 \\
\hline Carroceiro/Tropeiro & 7274 & 100,00 & 0,64 & 74,89 \\
\hline Ocupações na indústria de açúcar & 6723 & 100,00 & 0,59 & 75,49 \\
\hline Empresário na indústria de transformação & 6708 & 92,51 & 0,59 & 76,08 \\
\hline Meçânico & 6332 & 100,00 & 0,56 & 76,64 \\
\hline Empregado domético & 6042 & 9,19 & 0,53 & 77,17 \\
\hline Padeiro & 5816 & 100,00 & 0,51 & 77,68 \\
\hline Soldador & 5712 & 100,00 & 0,50 & 78,19 \\
\hline Repositor de equipamentos & 5572 & 100,00 & 0,49 & 78,68 \\
\hline Embalador de mercadorias & 5451 & 51,30 & 0,48 & 79,16 \\
\hline Administrador na indústria de transformação & 5232 & 92,24 & 0,46 & 79,62 \\
\hline Criador bovino & 5097 & 100,00 & 0,45 & 80,07 \\
\hline Aduninistrador do comércio de mercadorias & 4854 & 79,28 & 0,43 & 80,50 \\
\hline Administrador agropecuário & 4815 & 100,00 & 0,43 & 80,92 \\
\hline Encanador & 4805 & 100,00 & 0,42 & 81,34 \\
\hline Almoxarife & 4231 & 93,13 & 0,37 & 81,72 \\
\hline Outros proprietários & 3968 & 78,89 & 0,35 & 82,07 \\
\hline Pintor à pistola & 3963 & 100,00 & 0,35 & 82,42 \\
\hline Diretor/Assessor & 3920 & 57,68 & 0,35 & 82,76 \\
\hline Ferreiro/Serralheiro & 3882 & 100,00 & 0,34 & 83,10 \\
\hline Pescador & 3858 & 94,88 & 0,34 & 83,45 \\
\hline Assistente administrativo & 3857 & 50,61 & 0,34 & 83,79 \\
\hline Expedidor & 3782 & 89,60 & 0,33 & 84,12 \\
\hline Auxiliar administrativo & 3730 & 58,00 & 0,33 & 84,45 \\
\hline Pracista e viajante & 3708 & 97,27 & 0,33 & 84,77 \\
\hline Mestre na construção civil & 3697 & 100,00 & 0,33 & 85,10 \\
\hline Trocador & 3623 & 81,34 & 0,32 & 85,42 \\
\hline Tratorista agrícola & 3610 & 100,00 & 0,32 & 85,74 \\
\hline Engenheiro & 3496 & 82,32 & 0,32 & 86,05 \\
\hline Atendente de bar & 3464 & 47,60 & 0,32 & 86,35 \\
\hline Eletricista instalador & 3463 & 100,00 & 0,32 & 86,66 \\
\hline Garçon & 3414 & 69,45 & 0,30 & 86,96 \\
\hline Doceiro atc & 3384 & 94,21 & 0,30 & 87,26 \\
\hline Tecelão & 3308 & 62,05 & 0,29 & 87,55 \\
\hline Fiscal de tributos & 3306 & 91,38 & 0,29 & 87,84 \\
\hline Contador & 3098 & 76,36 & 0,27 & 88,11 \\
\hline Carvoeiro & 3056 & 100,00 & 0,27 & 88,38 \\
\hline Operador de máquinas de construção civil & 2833 & 100.00 & 0,25 & 88,63 \\
\hline Empresário da construção civil & 2830 & 100,00 & 0,25 & 88,88 \\
\hline Repositor de mercadorias & 2701 & 100,00 & 0,24 & 89,12 \\
\hline Sapateiro & 2620 & 100,00 & 0,23 & 89,35 \\
\hline Caixa & 2599 & 53.58 & 0,23 & 89.58 \\
\hline
\end{tabular}

${ }^{(1)}$ Inclui apenas as pessoas para as quais os atributos de interesse estão claramente identificados. 
Tabela c19. Sessenta ocupações mais importantes na absorção da mão-de-obra feminina ${ }^{(1)}$. Pernambuco, 1983.

\begin{tabular}{|c|c|c|c|c|}
\hline OCUPAÇŌES & $F_{i}$ & $\frac{F_{i}}{T_{i}}(\%)$ & $\frac{F_{i}}{F}(\%)$ & $\pi_{i}(\%)$ \\
\hline Empregada doméstica & 61568 & 90,73 & 12,21 & 12,21 \\
\hline Outros trab. na agropecuária & 59406 & 18,70 & 11,79 & 24,00 \\
\hline Alfaiate/Costureira & 56558 & 96,87 & 11,22 & 35,22 \\
\hline Comerciante conta-própria & 31430 & 30,32 & 6,24 & 41,46 \\
\hline Lavadeira/Passadeira & 29950 & 99,64 & 5,94 & 47,40 \\
\hline Professora de 1 a 4 série & 23840 & 99,54 & 4,73 & 52,13 \\
\hline Auxiliar de escritório & 22861 & 52,45 & 4,54 & 56,66 \\
\hline Vendedora & 17823 & 32,08 & 3,54 & 60,20 \\
\hline Produtora agropecuária autônoma & 14996 & 13,19 & 2,98 & 63,17 \\
\hline Enfermeira não diplomada & 11125 & 90,39 & 2,21 & 65,38 \\
\hline Rendeira & 9820 & 100,00 & 1,95 & 67,33 \\
\hline Feirante & 9540 & 34,32 & 1,89 & 69,22 \\
\hline Outras ocupações ambulantes & 9207 & 48,71 & 1,83 & 71,05 \\
\hline Cozinheira & 8384 & 81,09 & 1,66 & 72,71 \\
\hline Secretária & 8178 & 100,00 & 1,62 & 74,33 \\
\hline Assistente administrativo & 7658 & 55,91 & 1,52 & 75,85 \\
\hline Operadora de caixa & 7155 & 91,84 & 1,42 & 77,27 \\
\hline Recepcionista & 6056 & 86,26 & 1,20 & 78,47 \\
\hline Manicure e Pedicure & 4870 & 100,00 & 0,97 & 79,44 \\
\hline Professora de 5 a 8 séries & 4630 & 87,89 & 0,92 & 80,36 \\
\hline Atendente de bar & 3773 & 53,88 & 0,75 & 81,11 \\
\hline Embaladora de mercadorias & 3616 & 46,94 & 0,72 & 81,83 \\
\hline Trabalhadora de fábrica de sapato & 3397 & 21,09 & 0,67 & 82,50 \\
\hline Bordadeira/Cerzideira & 3247 & 100,00 & 0,64 & 83,14 \\
\hline Ocupações na incústria de papel & 2981 & 84,45 & 0,59 & 83,73 \\
\hline Orientadora de ensino & 2868 & 100,00 & 0,57 & 84,30 \\
\hline Auxiliar administrativo & 2834 & 36,45 & 0,56 & 84,87 \\
\hline Diretora/Assessora & 2786 & 49,72 & 0,55 & 85,42 \\
\hline Garçonete & 2696 & 38,26 & 0,54 & 85,95 \\
\hline Encarregada da administração & 2348 & 21,55 & 0,47 & 86,42 \\
\hline Professora de 20. grau & 2324 & 60,43 & 0,46 & 86,88 \\
\hline Comerciante & 2259 & 21,08 & 0,45 & 87,32 \\
\hline Telefonista & 2199 & 678,00 & 0,44 & 87,76 \\
\hline Oleira & 2144 & 17,13 & 0,43 & 88,19 \\
\hline Professora profissionalizante & 1887 & 85,19 & 0,37 & 88,57 \\
\hline Professora de 10. grau & 1885 & 94,49 & 0,37 & 88,94 \\
\hline Cesteira e Esteireira & 1843 & 61,72 & 0,37 & 89,30 \\
\hline Datilógrafa & 1734 & 83,97 & 0,34 & 89,65 \\
\hline Doceira etc. & 1583 & 19,06 & 0,31 & 89,96 \\
\hline Camareira & 1577 & 100,00 & 0,31 & 90,27 \\
\hline Administradora do comércio de mercadorias & 1537 & 15,48 & 0,31 & 90,58 \\
\hline Auxiliar de contabilidade & 1514 & 53,44 & 0,30 & 90,88 \\
\hline Farinheira/Moleira & 1448 & 40,20 & 0,29 & 91,17 \\
\hline Professora de pré-escola & 1429 & 100,00 & 0,28 & 91,45 \\
\hline Professora & 1428 & 100,00 & 0,28 & 91,73 \\
\hline Cabeleireira & 1426 & 72,90 & 0,28 & 92,02 \\
\hline Fiandeira & 1206 & 61,09 & 0,24 & 92,26 \\
\hline Quitandeira etc. & 1139 & 31,87 & 0,23 & 92,48 \\
\hline Pracista e viajante & 1099 & 24,14 & 0,22 & 92,70 \\
\hline Advogada etc. & 1095 & 45,34 & 0,22 & 92,92 \\
\hline Operadora de máquinas p. automáticas & 989 & 49,95 & 0,20 & 93,11 \\
\hline Médica & 989 & 34,08 & 0,20 & 93,31 \\
\hline Professora superior & 965 & 34,31 & 0,19 & 93,50 \\
\hline Outras ocupações na indústria de transformação & 879 & 19,40 & 0,17 & 93,68 \\
\hline Comtadora & 877 & 44,84 & 0,17 & 93,85 \\
\hline Empresária na incústria de transformação & 856 & 9,06 & 0,17 & 94.02 \\
\hline Outras administradoras & 770 & 24,48 & 0,15 & 94,17 \\
\hline Caixa & 770 & 14,59 & 0,15 & 94,33 \\
\hline Assistente social & 767 & 87,46 & 0,15 & 94.48 \\
\hline Técnica em contabilidade & 725 & 62,29 & 0,14 & 94.62 \\
\hline
\end{tabular}

(1) Inclui apenas as pessoas para as quais os atributos de interesse estão claramente identificados. 
Tabela C20. Sessenta ocupações mais importantes na absorção da mão-de-obra masculina ${ }^{(1)}$. Pernambuco, 1983.

\begin{tabular}{|c|c|c|c|c|}
\hline OCUPAÇŌES & $M_{i}$ & $\frac{M_{i}}{T_{i}}(\%)$ & $\frac{M_{i}}{M}(\%)$ & $\Phi_{i}(\%)$ \\
\hline Outros trab. na agropecuánia & 258350 & 81,31 & 24,15 & 24,15 \\
\hline Prochutor agropecuánio aưônomo & 98695 & 86,81 & 9,23 & 33,37 \\
\hline Comerciante conta-própria & 72243 & 69,68 & 6,75 & 40,12 \\
\hline Motonista & 52754 & 99,79 & 4,93 & 45,06 \\
\hline Petreiro & 48869 & 100,00 & 4,57 & 49,62 \\
\hline Vendedor & 37736 & 67,92 & 3,53 & 53,15 \\
\hline Servente de pedreiro & 36920 & 99,71 & 3,45 & 56,60 \\
\hline Auxiliar de escritório & 20729 & 47,55 & 1,94 & 58,54 \\
\hline Mecânico de veículo & 19015 & 100,00 & 1,78 & 60,32 \\
\hline Feirante & 18254 & 65,68 & 1,71 & 62,02 \\
\hline Trabalhador de fäbrica de sapato & 12710 & 78,91 & 1,19 & 63,21 \\
\hline Carpinteiro & 11293 & 100,00 & 1,06 & 64,26 \\
\hline Pintor/Caiador & 10747 & 100,00 & 1,01 & 65,27 \\
\hline Oleiro & 10375 & 82,87 & 0,97 & 66,24 \\
\hline Agricultor & 10037 & 93,28 & 0,94 & 67,18 \\
\hline Carroceiro/Tropeiro & 9919 & 100,00 & 0,93 & 68,10 \\
\hline Outras ocupações ambulantes & 9696 & 51,29 & 0,91 & 69,01 \\
\hline Empresário na incústria de transformação & 8592 & 90,94 & 0,80 & 69,81 \\
\hline Encarregado da administração & 8549 & 78,45 & 0,80 & 70,61 \\
\hline Comerciante & 8458 & 78,92 & 0,79 & 71,40 \\
\hline Administrador do comércio de mercadorias & 8391 & 84,52 & 0,78 & 72,19 \\
\hline Marceneiro & 7841 & 100,00 & 0,73 & 72,92 \\
\hline Mecânico & 7474 & 100,00 & 0,70 & 73,62 \\
\hline Doceiro atc & 6722 & 80,94 & 0,63 & 74,25 \\
\hline Padeiro & 6660 & 98,38 & 0,63 & 74,87 \\
\hline Empregado doméstico & 6292 & 9,27 & 0,59 & 75,46 \\
\hline Criador bovino & 6057 & 100,00 & 0,57 & 76,02 \\
\hline Assistente administrativo & 6039 & 44,09 & 0,56 & 76,59 \\
\hline Eletricista instalador & 5848 & 100,00 & 0,55 & 77,13 \\
\hline Administrador agropecuário & 5827 & 100,00 & 0,55 & 77,68 \\
\hline Repositor de equipamentos & 5803 & 100,00 & 0,54 & 78,22 \\
\hline Pintor à pistola & 5738 & 100,00 & 0,54 & 78,76 \\
\hline Soldador & 5170 & 100,00 & 0,48 & 79,24 \\
\hline Encanador & 5160 & 100,00 & 0,48 & 79,72 \\
\hline Auxiliar administrativo & 4942 & 63,56 & 0,46 & 80,19 \\
\hline Ferreiro/Serralheiro & 4748 & 100,00 & 0,44 & 80,63 \\
\hline Caixa & 4506 & 85,41 & 0,42 & 81,05 \\
\hline Garçon & 4350 & 61,74 & 0,41 & 81,46 \\
\hline Operador de máquinas de construção civil & 4310 & 93,37 & 0,40 & 81,86 \\
\hline Trocador & 4111 & 86,64 & 0,38 & 82,24 \\
\hline Embalador de mercadorias & 4088 & 53,06 & 0,38 & 82,63 \\
\hline Expedidor & 3888 & 94,65 & 0,36 & 82,99 \\
\hline Oưras ocupações na indústria de transformação & 3652 & 80,60 & 0,34 & 83,33 \\
\hline Pracista e viajante & 3453 & 75,86 & 0,32 & 83,65 \\
\hline Administrador na indústria de transformação & 3280 & 86,16 & 0,31 & 83,96 \\
\hline Alendente de bar & 3230 & 46,12 & 0,30 & 84,26 \\
\hline Carvoeiro & 3192 & 83,87 & 0,30 & 84,56 \\
\hline Lamtemeiro & 3162 & 100,00 & 0,30 & 84,86 \\
\hline Ocupações na indústria de açúcar & 3100 & 100,00 & 0,29 & 85,15 \\
\hline Outros proprictários & 2986 & 84,45 & 0,28 & 85,42 \\
\hline Almoxarife & 2939 & 93,07 & 0,28 & 85,70 \\
\hline Engenheiro & 2862 & 92,86 & 0,27 & 85,97 \\
\hline Diretor/Assessor & 2817 & 50,28 & 0,26 & 86.23 \\
\hline Administrador de financeiras & 2811 & 92,74 & 0,26 & 86,49 \\
\hline Pescador & 2793 & 89,43 & 0,26 & 86,75 \\
\hline Lenhador & 2702 & 100,00 & 0,25 & 87,01 \\
\hline Corretor de imóveis & 2685 & 96,10 & 0.25 & 87.26 \\
\hline Tratorista agricola & 2682 & 100,00 & 0,25 & 87,51 \\
\hline Bonacheiro & 2618 & 100,00 & 0,25 & 87,75 \\
\hline Repositor de mercadorias & 2569 & 83,01 & 0.24 & 87.99 \\
\hline
\end{tabular}

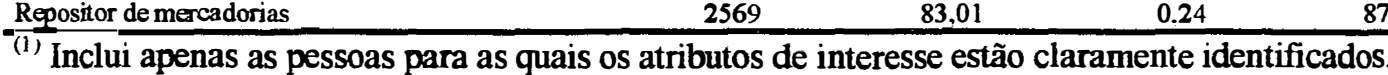


Tabela C21. Sessenta ocupações mais importantes na absorção da mão-de-obra feminina(1). Pernambuco, 1984.

\begin{tabular}{|c|c|c|c|c|}
\hline OCUPAÇŌES & $F_{i}$ & $\frac{F_{1}}{T_{1}}(\%)$ & $\frac{F_{1}}{F}(\%)$ & $\pi_{i}(\%)$ \\
\hline Empregada doméstica & 70817 & 92,01 & 13,01 & 13,01 \\
\hline Outros trab. na agropecuária & 66605 & 18,47 & 12,24 & 25,25 \\
\hline Alfaiate/Costureira & 59489 & 94,83 & 10,93 & 36,18 \\
\hline Professora de 1 a 4 série & 33241 & 99,07 & 6,11 & 42,29 \\
\hline Procurtora agropecuánia autônoma & 31378 & 14,54 & 5,77 & 48,06 \\
\hline Lavadeira/Passadeira & 30762 & 99,63 & 5,65 & 53,71 \\
\hline Comerciante conta-própria & 28608 & 30,54 & 5,26 & 58,97 \\
\hline Auxiliar de escritório & 20552 & 50,98 & 3,78 & 62,74 \\
\hline Vendedora & 15255 & 32,93 & 2,80 & 65,55 \\
\hline Ourras ocupaçōes ambulantes & 12749 & 44,23 & 2,34 & 67,89 \\
\hline Feirante & 12220 & 35,19 & 2,25 & 70,14 \\
\hline Rendeiro & 11049 & 100,00 & 2,03 & 72,17 \\
\hline Cozinheira & 10060 & 88,18 & 1,85 & 74,01 \\
\hline Enfermeira não diplomada & 8624 & 86,50 & 1,59 & 75,60 \\
\hline Secretária & 6992 & 95,30 & 1,29 & 76,88 \\
\hline Assistente adminisrativo & . 6847 & 58,57 & 1,26 & 78,14 \\
\hline Operadora de Caixa & 5875 & 94,45 & 1,08 & 79,22 \\
\hline Manicure e Pedicure & 5788 & 100,00 & 1,06 & 80,29 \\
\hline Professora de 5 a 8 séries & 5271 & 78,66 & 0,97 & 81,25 \\
\hline Professora 2 grau & 4618 & 73,56 & 0,85 & 82,10 \\
\hline Diretora/Assessora & 4210 & 43,63 & 0,77 & 82,88 \\
\hline Recepcionista & 4186 & 90,10 & 0,77 & 83,65 \\
\hline Auxiliar administrativo. & 4185 & 59,85 & 0,77 & 84,41 \\
\hline Atendente de bar & 3520 & 46,24 & 0,65 & 85,06 \\
\hline Comerciante & 3358 & 19,84 & 0,62 & 85,68 \\
\hline Cabeleireira & 3065 & 69,96 & 0,56 & 86,24 \\
\hline Caixa & 2925 & 43,61 & 0,54 & 86,78 \\
\hline Bordadeira/Cerzideira & 2842 & 100,00 & 0,52 & 87,30 \\
\hline Orientadora de ensino & 2638 & 91,98 & 0,49 & 87,79 \\
\hline Embaladora de mercadorias & 2611 & 31,33 & 0,48 & 88,27 \\
\hline Outras proprietánias & 2351 & 29,09 & 0,432 & 88,70 \\
\hline Datilógrafa & 2010 & 60,45 & 0,369 & 89,07 \\
\hline Encarregada da administração & 1836 & 14,14 & 0,34 & 89,40 \\
\hline Doceira etc. & 1663 & 14,17 & 0,31 & 89,71 \\
\hline Dertista & 1662 & 58,05 & 0,31 & 90,02 \\
\hline Trabalhadora de fábrica de sapato & 1579 & 12,16 & 0,29 & 90,31 \\
\hline Telefonista & 1577 & 93,26 & 0,29 & 90,60 \\
\hline Farinheira/Moleira & 1378 & 81,49 & 0,25 & 90,85 \\
\hline Operadora de máquinas p. automáticas. & 1375 & 44,40 & 0,25 & 91,10 \\
\hline Técnica quimica & 1318 & 44,71 & 0,24 & 91,34 \\
\hline Professora de 10. grau & 1318 & 100,00 & 0,24 & 91,59 \\
\hline Administradora na indústria de transformação & 1148 & 20,74 & 0,21 & 91,80 \\
\hline Enfermeira diplomada & 1117 & 100,00 & 0,21 & 92,00 \\
\hline Administradora do comércio de mercadorias & 1092 & 17,95 & 0,20 & 92,20 \\
\hline Fiandeira & 1031 & 47,34 & 0,19 & 92,39 \\
\hline Garçonete & 1004 & 27,78 & 0,19 & 92,58 \\
\hline Auxiliar de costura & 975 & 75,70 & 0,18 & 92,76 \\
\hline Ocupações na ind. alimentos & 947 & 40,38 & 0,17 & 92,93 \\
\hline Professora superior & 917 & 38,08 & 0,17 & 93,10 \\
\hline Pracista e viajante & 917 & 13,79 & 0,17 & 93,27 \\
\hline Professora profissionalizante & 891 & 49,23 & 0,16 & 93,43 \\
\hline Assistente social & 889 & 100,00 & 0,16 & 93,60 \\
\hline Inspetora de alunos & 889 & 100,00 & 0,16 & 93,76 \\
\hline Trocadora & 888 & 23,11 & 0,16 & 93,92 \\
\hline Professora & 804 & 77,76 & 0.15 & 94,07 \\
\hline Advogada atc. & 803 & 27,95 & 0.15 & 94,22 \\
\hline Camareira & 803 & 100.00 & 0,15 & 94,36 \\
\hline Tecelã & 802 & 30,76 & 0,15 & 94,51 \\
\hline Contadora & 774 & 28,72 & 0,14 & 94,65 \\
\hline Empresária na indústria de transformação & 747 & 7.49 & 0.14 & 94.79 \\
\hline
\end{tabular}

${ }^{(1)}$ Inclui apenas as pessoas para as quais os atributos de interesse estão claramente identificados. 
Tabela C22. Sessenta ocupações mais importantes na absorção da mão-de-obra masculina(1). Pernambuco, 1984.

\begin{tabular}{|c|c|c|c|c|}
\hline OCUPAÇŌES & $M_{i}$ & $\frac{M_{i}}{T_{i}}(\%)$ & $\frac{M_{i}(\%)}{M}$ & $\Phi_{i}(\%)$ \\
\hline Oriras trab. na agropecuária & 293936 & 81,53 & 24,39 & 24,39 \\
\hline Produtor agropearánio autônomo & 184395 & 85,46 & 15,30 & 39,69 \\
\hline Comerciante conta-própria & 65082 & 69,47 & 5,40 & 45,10 \\
\hline Motorista & 51062 & 100,00 & 4,24 & 49,33 \\
\hline Pedreiro & 47367 & 100,00 & 3,93 & 53,26 \\
\hline Servente de pedreiro & 36697 & 100,00 & 3,05 & 56,30 \\
\hline Vendedor & 31071 & 67,07 & 2,58 & 58,89 \\
\hline Feirante & 22509 & 64,81 & 1,87 & 60,76 \\
\hline Mecânico de veículo & 20873 & 100,00 & 1,73 & 62,49 \\
\hline Auxiliar de escritório & 19763 & 49,02 & 1,64 & 64,13 \\
\hline Outras ocupaçöes ambulantes & 16077 & 55,77 & 1,33 & 65,46 \\
\hline Agricultor & 14256 & 97,07 & 1,18 & 66,65 \\
\hline Comerciante & 13564 & 80,16 & 1,13 & 67,77 \\
\hline Carroceiro/Tropeiro & 13450 & 100,00 & 1,12 & 68,89 \\
\hline Marceneiro & 12871 & 99,11 & 1,07 & 69,96 \\
\hline Trabalhador de fábrica de sapato & 11403 & 87,84 & 0,95 & 70,90 \\
\hline Encarregado da administraçã́o & 11147 & 85,86 & 0,93 & 71,83 \\
\hline Oleiro & 10343 & 94,24 & 0,86 & 72,69 \\
\hline Doceiro etc & 10076 & 85,83 & 0,84 & 73,52 \\
\hline Empresário na industria de transformação & 9231 & 92,51 & 0,77 & 74,29 \\
\hline Padeiro & 8543 & 100,00 & 0,71 & 75,00 \\
\hline Pintor/Caiador & 8506 & 100,00 & 0,71 & 75,70 \\
\hline Carpinteiro & 7713 & 100,00 & 0,64 & 76,34 \\
\hline Mecânico & 7602 & 100,00 & 0,63 & 76,97 \\
\hline Repositor de equipamentos & 7013 & $\mathbf{9 8 , 4 0}$ & 0,58 & 77,55 \\
\hline Empregado doméstico & 6148 & 7,99 & 0,51 & $\mathbf{7 8 , 0 7}$ \\
\hline Pracista e viajante & 5734 & 86,21 & 0,48 & 78,54 \\
\hline Outros proprietánios & 5732 & 70,91 & 0,48 & 79,01 \\
\hline Embalador de mercadorias & 5724 & 68,67 & 0,48 & $\mathbf{7 9 , 4 9}$ \\
\hline Criador bovino & 5441 & 87,96 & 0,45 & 79,94 \\
\hline Diretor/Assessor & 5439 & 56,37 & 0,45 & 80,39 \\
\hline Administrador agropecuánio & 5055 & 97,80 & 0,42 & 80,81 \\
\hline Administrador do comércio de mercadorias & 4993 & 82,05 & 0,41 & 81,23 \\
\hline Tratorista agricola & 4927 & 100,00 & 0,41 & 81,64 \\
\hline Assistente administrativo & 4844 & 41,43 & 0,40 & 82,04 \\
\hline Ferreiro/Serralheiro & 4440 & 100,00 & 0,37 & 82,41 \\
\hline Administrador na indusstria de transformação & 4386 & 79,26 & 0,36 & 82,77 \\
\hline Eletricista instalador & 4230 & 100,00 & 0,35 & 83,12 \\
\hline Ocupaçêes na industria de açúcar & 4112 & 100,00 & 0,34 & 83,46 \\
\hline Atendente de bar & 4093 & 53,76 & 0,34 & 83,80 \\
\hline Operador de máquinas de construção civil & 3947 & 100,00 & $\mathbf{0 , 3 3}$ & 84,13 \\
\hline Magarefe & 3822 & 85,85 & 0,32 & 84,45 \\
\hline Caixa & 3782 & 56,39 & 0,31 & 84,76 \\
\hline Encanador & 3611 & 100,00 & 0,30 & 85,06 \\
\hline Almomarife & 3379 & 86,13 & 0,28 & 85,34 \\
\hline Carvoeiro & 3248 & 91,13 & 0,27 & 85,61 \\
\hline Alfaiate/Costureira & 3246 & 5,17 & 0,27 & 85,88 \\
\hline Lenhador & 3195 & 100,00 & 0,27 & 86,15 \\
\hline Pescador & 3122 & 84,49 & 0,26 & 86,40 \\
\hline Reparador de Radio/TV & 3091 & 100,00 & 0,26 & 86,66 \\
\hline Soldador & 3066 & 100,00 & 0,25 & 86,92 \\
\hline Pintor à pistola & 3008 & 100,00 & 0,25 & 87,17 \\
\hline Fotógrafo & 2967 & 96,27 & 0,25 & 87,41 \\
\hline Trocador & 2954 & 76,89 & 0,25 & 87,66 \\
\hline Repositor de mercadorias & 2953 & 96,28 & 0,25 & 87,90 \\
\hline Quitandeiro etc & 2925 & 92,71 & 0.24 & 88,15 \\
\hline Auxiliar administrativo & 2808 & 40,15 & 0,23 & 88,38 \\
\hline Tripeiro etc & 2716 & 95,94 & 0,23 & 88,60 \\
\hline Estofador & 2715 & 100,00 & 0,23 & 88,83 \\
\hline Garcon & 2610 & 72.22 & 0.22 & 89,05 \\
\hline
\end{tabular}

(1) Inclui apenas as pessoas para as quais os atributos de interesse estão claramente identificados. 
Tabela C23. Sessenta ocupações mais importantes na absorção da mão-de-obra feminina(1). Pernambuco, 1985.

\begin{tabular}{|c|c|c|c|c|}
\hline OCUPAÇŌES & $F_{i}$ & $\frac{F_{i}}{T_{i}}(\%)$ & $\frac{F_{1}}{F}(\%)$ & $\pi_{i}(\%)$ \\
\hline Empregada domética & 86938 & 93,22 & 14,28 & 14,28 \\
\hline Oriros trab. na agropecuária & 78727 & 19,78 & 12,94 & 27,22 \\
\hline Alfaiate/Costureiros & 67843 & 94,53 & 11,15 & 38,37 \\
\hline Comerciante conta-própria & 37877 & 34,37 & 6,22 & 44,59 \\
\hline Professora de 1 a 4 séries & 37256 & 97,68 & 6,12 & 50,71 \\
\hline Lavadeira/Passadeira & 32806 & 99,08 & 5,39 & 56,10 \\
\hline Produtora agropecuária autônoma & 24395 & 13,40 & 4,01 & 60,11 \\
\hline Aluxiliar de escritónio & 22203 & 47,30 & 3,65 & 63,76 \\
\hline Vendedora & 21364 & 37,31 & 3,51 & 67,27 \\
\hline Outras ocupações ambulantes & 14414 & 46,56 & 2,37 & 69,64 \\
\hline Enfermeiras não diplomados & 10566 & 82,81 & 1,74 & 71,37 \\
\hline Cozinheira & 10299 & 76,05 & 1,69 & 73,06 \\
\hline Secretória & 8786 & 96,66 & 1,44 & 74,51 \\
\hline Feirante & 8161 & 27,38 & 1,34 & 75,85 \\
\hline Rendeira & 7846 & 100,00 & 1,29 & 77,14 \\
\hline Recepcionista & 7264 & 85,02 & 1,19 & 78,33 \\
\hline Manicure e Pedicure & 7054 & 96,80 & 1,16 & 79,49 \\
\hline Bordadeira/Cerzideira & 6678 & 95,65 & 1,10 & 80,59 \\
\hline Embaladora de mercadorias & 6521 & 53,63 & 1,07 & 81,66 \\
\hline Assistente administrativo. & 6458 & 57,59 & 1,06 & 82,72 \\
\hline Operadora de caixa & 5647 & 83,47 & 0,93 & 83,65 \\
\hline Professora de 5 a 8 série & 5382 & 70,40 & 0,88 & 84,53 \\
\hline Farinheira/Moleira & 4393 & 81,04 & 0,72 & 85,25 \\
\hline Auxiliar administrativo & 4334 & 40,32 & 0,71 & 85,97 \\
\hline Atendente de bar & 4282 & 50,39 & 0,70 & 86,67 \\
\hline Professora de 20. grau & 3572 & 69,89 & 0,59 & 87,26 \\
\hline Cabeleireira & 3385 & 90,65 & 0,56 & 87,81 \\
\hline Diretora/Assessora & 2795 & 40,23 & 0,46 & 88,27 \\
\hline Trabalhadora de fábrica de sapato & 2755 & 21,25 & 0,45 & 88,72 \\
\hline Comerciante & 2611 & 20,61 & 0,43 & 89,15 \\
\hline Doceira etc. & 2444 & 22,59 & 0,40 & 89,55 \\
\hline Orientadora de ensino & 2260 & 80,77 & 0,37 & 89,93 \\
\hline Encarregada da administração & 2258 & 22,32 & 0,37 & 90,30 \\
\hline Telefonista & 2140 & 83,59 & 0,35 & 90,65 \\
\hline Caixa & 1967 & 46,27 & 0,32 & 90,97 \\
\hline Professora de préescola & 1850 & 100,00 & 0,30 & 91,28 \\
\hline Oleira & 1808 & 18,90 & 0,30 & 91,57 \\
\hline Dentista & 1677 & 67,24 & 0,28 & 91,85 \\
\hline Datilógrafa & 1601 & 54,18 & 0,26 & 92,11 \\
\hline Médica & 1535 & 36,18 & 0,25 & 92,36 \\
\hline Professora superior & 1300 & 48,17 & 0,21 & 92,58 \\
\hline Auxiliar de contabilidade & 1299 & 65,02 & 0,21 & 92,79 \\
\hline Contadora & 1248 & 51,72 & 0,21 & 93,00 \\
\hline Fiandeira & 1248 & 60,49 & 0,21 & 93,20 \\
\hline Assistente social & 1247 & 100,00 & 0,21 & 93,41 \\
\hline Auxiliar de costura & 1208 & 44,30 & 0,20 & 93,60 \\
\hline Administradora na indústria de transformação & 1193 & 28,06 & 0,20 & 93,80 \\
\hline Administradora do comércio de mercadorias & 1182 & 19,60 & 0,19 & 93,99 \\
\hline Parteira & 1143 & 100,00 & 0,19 & 94,18 \\
\hline Fiscal de tributos & 1077 & 40,49 & 0,18 & 94,36 \\
\hline Inspetora de alunos & 1013 & 58,32 & 0,17 & 94,53 \\
\hline Camareira & 947 & 100,00 & 0,16 & 94,68 \\
\hline Operador de máquinas p. automáticas & 945 & 53,69 & 0,16 & 94,84 \\
\hline Outras administradoras & 891 & 28,05 & 0,15 & 94,98 \\
\hline Ocupações na ind. alimentos & 841 & 64,25 & 0,14 & 95,12 \\
\hline Pracista e viajante & 829 & 10,15 & 0,14 & 95,26 \\
\hline Massagista & 827 & 100,00 & 0,14 & 95,39 \\
\hline Doccira/confeiteira & 777 & 56,10 & 0,13 & 95,52 \\
\hline Outras proprietarias & 774 & 12,39 & 0,13 & 95,65 \\
\hline Emp. ind transformação & 773 & 9.434 & 0.13 & 95,78 \\
\hline
\end{tabular}

(1) Inclui apenas as pessoas para as quais os atributos de interesse estão claramente identificados. 
Tabela C24. Sessenta ocupações mais importantes na absorção da mão-de-obra masculina(1) . Pernambuco, 1985.

\begin{tabular}{|c|c|c|c|c|}
\hline OCUPAÇÕES & $M_{l}$ & $\frac{M_{i}}{T_{1}}(\%)$ & $\frac{M_{i}}{M}(\%)$ & $\Phi_{i}(\%)$ \\
\hline Outros trab. na agropecuária & 319298 & 80,22 & 25,88 & 25,88 \\
\hline Produtor agropecuário autônomo & 157728 & 86,61 & 12,78 & 38,66 \\
\hline Comenciante conta-própria & 72318 & 65,63 & 5,86 & 44,52 \\
\hline Motorista & 55781 & 99,79 & 4,52 & 49,04 \\
\hline Pedreiro & 47178 & 100,00 & 3,82 & 52,87 \\
\hline Servente de pedreiro & 39348 & 100,00 & 3,19 & 56,06 \\
\hline Vendedor & 35902 & 62,69 & 2,91 & 58,97 \\
\hline Auxiliar de escritório & 24738 & 52,70 & 2,01 & 60,97 \\
\hline Feirante & 21650 & 72,62 & 1,75 & 62,73 \\
\hline Mecânico de veículo & 19932 & 100,00 & 1,62 & 64,34 \\
\hline Agricultor & 18086 & 98,36 & 1,47 & 65,81 \\
\hline Oưtras ocupações ambulantes & 16542 & 53,44 & 1,34 & 67,15 \\
\hline Marceneiro & 12828 & 100,00 & 1,04 & 68,19 \\
\hline Mecânico & 12744 & 100,00 & 1,04 & 69,22 \\
\hline Trabalhador de fábrica de sapato & 10209 & 78,75 & 0,83 & 70,05 \\
\hline Comerciante & 100,56 & 79,39 & 0,82 & 70,86 \\
\hline Doceiro etc & 8375 & 77,41 & 0,68 & 71,54 \\
\hline Pintor/Caiador & 7928 & 100,00 & 0,64 & 72,18 \\
\hline Encarregado da administração & 7859 & 77,68 & 0,64 & 72,82 \\
\hline Oleiro & 7756 & 81,10 & 0,63 & 73,45 \\
\hline Repositor de equipamentos & 7634 & 100,00 & 0,62 & 74,07 \\
\hline Carpinteiro & 7511 & 100,00 & 0,61 & 74,68 \\
\hline Empresário na indústria de transformação & 7421 & 90,57 & 0,60 & 75,28 \\
\hline Pracista e viajante & 7341 & 89,85 & 0,60 & 75,87 \\
\hline Criador bovino & 6914 & 95,82 & 0,56 & 76,43 \\
\hline Auxiliar administrativo & 6416 & 59,68 & 0,52 & 76,95 \\
\hline Empregado doméstico & 6319 & 6,78 & 0,51 & 77,46 \\
\hline Carrociro/Tropeiro & 6124 & 100,00 & 0,50 & 77,96 \\
\hline Padeiro & 5905 & 100,00 & 0,48 & 78,44 \\
\hline Embalador de mercadorias & 5638 & 46,37 & 0,46 & 78,90 \\
\hline Ferreiro/Serralheiro & 5479 & 100,00 & 0,44 & 79,34 \\
\hline Outros proprietários & 5473 & 87,61 & 0,44 & 79,78 \\
\hline Soldador & 5343 & 97,84 & 0,43 & 80,22 \\
\hline Ocupações na indústria de açucar & 5260 & 100,00 & 0,43 & 80,64 \\
\hline Carvoeiro & 5165 & 89,55 & 0,42 & 81,06 \\
\hline Encanador & 5012 & 100,00 & 0,41 & 81,47 \\
\hline Pimtor à pistola & 4896 & 100,00 & 0,40 & 81.87 \\
\hline Administrador do comércio de mercadorias & 4850 & 80,41 & 0,39 & 82.26 \\
\hline Operador de máquinas de construção civil & 4811 & 100,00 & 0,39 & 82,65 \\
\hline Assistente administrativo & 4755 & 42,41 & 0,39 & 83,03 \\
\hline Pescador & 4740 & 90,94 & 0,38 & 83,42 \\
\hline Atendente de bar & 4216 & 49,61 & 0,34 & 83,76 \\
\hline Administrador agropecuário & 4183 & 100,00 & 0,34 & 84,10 \\
\hline Repositor de mercadorias & 4174 & 86,40 & 0,34 & 84.43 \\
\hline Diretor/Assessor & 4152 & 59,77 & 0,34 & 84,77 \\
\hline Alfaiate/Costureira & 3926 & 5,47 & 0,32 & 85,09 \\
\hline Trocador & 3822 & 91,52 & 0,31 & 85,40 \\
\hline Reparador Radio/TV & 3779 & 100,00 & 0,31 & 85,71 \\
\hline Eletricista instalador & 3615 & 100,00 & 0,29 & 86,00 \\
\hline Almoxarife & 3522 & 93,70 & 0,29 & 86,29 \\
\hline Tratorista agricola & 3390 & 100,00 & 0,28 & 86,56 \\
\hline Garçon & 3313 & 93,35 & 0,27 & 86,83 \\
\hline Cozinheiro & 3243 & 23.95 & 0,26 & 87,09 \\
\hline Fotógrafo & 3107 & 92.94 & 0,25 & 87,34 \\
\hline Adrninistrador na indústria de transformação & 3058 & 71,94 & 0,25 & 87,59 \\
\hline Expedidor & 3051 & 87.93 & 0,25 & 87,84 \\
\hline Lantemeiro & 2892 & 100,00 & 0,23 & 88,07 \\
\hline Médico & 2708 & 63,82 & 0,22 & 88,29 \\
\hline Outras ocupaçōes na indústria de transformação & 2706 & 95.82 & 0,22 & 88,51 \\
\hline Desenhista & 2678 & 91.87 & 0.22 & 88,73 \\
\hline
\end{tabular}

(1) Inclui apenas as pessoas para as quais os atributos de interesse estão claramente identificados. 
Tabela C25. Sessenta ocupações mais importantes na absorção da mão-de-obra feminina(1). Pernambuco, 1987.

\begin{tabular}{|c|c|c|c|c|}
\hline OCUPAÇŌES & $F_{i}$ & $\frac{F_{i}}{T_{i}}(\%)$ & $\frac{F_{i}(\%)}{F}$ & $\pi_{i}(\%)$ \\
\hline $\begin{array}{l}\text { Empregada domśtica } \\
\text { Alfaiate/Coshreira }\end{array}$ & $\begin{array}{l}95021 \\
78780\end{array}$ & $\begin{array}{l}93,89 \\
96,91\end{array}$ & $\begin{array}{l}14,12 \\
11,71\end{array}$ & $\begin{array}{l}14,12 \\
25,83\end{array}$ \\
\hline Outros trab. na agropecuária & 69750 & 19,25 & 10,37 & 36,20 \\
\hline Lavadeira/Passadeira & 41453 & 97,51 & 6,16 & 42,36 \\
\hline Comerciante comta-própria & 37643 & 35,41 & 5,60 & 47,95 \\
\hline Professora de 1 a 4 série & 37423 & 98,83 & 5,56 & 53,52 \\
\hline Auxiliar de escritónio & 26341 & 55,68 & 3,92 & 57,43 \\
\hline Vendedora & 25486 & 31,72 & 3,79 & 61,22 \\
\hline Produtora agropecuária autônoma & 16891 & 10,24 & 2,51 & 63,73 \\
\hline Cozinheira & 15624 & 84,63 & 2,32 & 66,05 \\
\hline Ourras ocupaçōes ambulantes & 15521 & 39,06 & 2,31 & 68,36 \\
\hline Enfermeira não diplomada & 14376 & 94,18 & 2,14 & 70,50 \\
\hline Assistemte administrativo & 13742 & 65,51 & 2,04 & 72,54 \\
\hline Feirante & 10885 & 26,95 & 1,62 & 74,16 \\
\hline Manicure e Pedicure & 10699 & 100,00 & 1,59 & 75,75 \\
\hline Rendeira & 8003 & 100,00 & 1,19 & 76,94 \\
\hline Operadora de caixa & 7226 & 87,20 & 1,07 & 78,01 \\
\hline Recepcionista & 6289 & 82,50 & 0,94 & $\mathbf{7 8 , 9 4}$ \\
\hline Embaladora de mercadorias & 6014 & 36,21 & 0,89 & 79,84 \\
\hline Professora de 5 a 8 séries & 5572 & 81,31 & 0,83 & 80,67 \\
\hline Orientadora de ensino & 5400 & 96,05 & 0,80 & 81,47 \\
\hline Professora de 20. grau & 5351 & 73,31 & 0,80 & 82,26 \\
\hline Secretária & 5057 & 95,80 & 0,75 & 83,02 \\
\hline Atendente de bar & 4957 & 70,04 & 0,74 & 83,75 \\
\hline Farinheira/Moleira & 4923 & 88,88 & 0,73 & 84,48 \\
\hline Auxiliar administrativo & 4512 & 40,94 & 0,67 & 85,16 \\
\hline Doceira etc & 4461 & 42,37 & 0,66 & 85,82 \\
\hline Bordadeira/Ceraideira & 4017 & 100,00 & 0,60 & 86,42 \\
\hline Cabeleireira & 3502 & 69,94 & 0,52 & 86,94 \\
\hline Datilógrafa & 2837 & 92,74 & 0,42 & 87,36 \\
\hline Auxiliar de contabilidade & 2785 & 64,93 & 0,41 & 87,77 \\
\hline Telefonista & 2668 & 100,00 & 0,40 & 88,17 \\
\hline Diretora/Assessora & 2618 & 34,57 & 0,39 & 88,56 \\
\hline Bibliotecária & 2342 & 100,00 & 0,35 & 88,91 \\
\hline Tecelã & 2342 & 42,05 & 0,35 & 89,25 \\
\hline Emp. ind. de transformação & 2341 & 23,06 & 0,35 & 89,60 \\
\hline Caixa & 2169 & 29,05 & 0,32 & 89,92 \\
\hline Comerciante & 2119 & 12,42 & 0,32 & 90,24 \\
\hline Professora 1o. grau & 2119 & 100,00 & 0,32 & 90,55 \\
\hline Trabalhadora fábrica de sapatos & 2119 & 28,12 & 0,32 & 90,87 \\
\hline Doceira/confeiteira & 2068 & 100,00 & 0,32 & 91,18 \\
\hline Pracista e viajamte & 1949 & 29,70 & 0,30 & 91,47 \\
\hline Professora preescola & 1896 & 100,00 & 0,28 & 91,75 \\
\hline Agricultora & 1846 & 9,65 & 0,27 & 92,02 \\
\hline Adrainistradora do comércio de mercadorias & 1726 & 24,82 & 0,26 & 92,28 \\
\hline Gargonete & 1726 & 22,29 & 0,26 & 92,53 \\
\hline Outras administradoras & 1556 & 35,42 & 0,23 & 92,77 \\
\hline Assisteme social & 1504 & 87,09 & 0,22 & 92,99 \\
\hline Maçaroqueira & 1454 & 76,61 & 0,22 & 93,21 \\
\hline Inspetora de qualidade & 1453 & 46,45 & 0,22 & 93,42 \\
\hline Contadora & 1334 & 28,91 & 0,20 & 93,62 \\
\hline Fiandeira & 1333 & 46,99 & 0,20 & 93,82 \\
\hline Arquiteta & 1282 & 85,24 & 0,19 & 94,01 \\
\hline Tripeira ac & 1232 & 53,73 & 0,18 & 94,19 \\
\hline Vassoureira & 1231 & 100,00 & 0,18 & 94,37 \\
\hline Ceramista/Louceira & 1230 & 37,27 & 0,18 & 94,56 \\
\hline Artesã & 1111 & 31,72 & 0.17 & 94,72 \\
\hline Acabadora de pano & 1111 & 55,55 & 0,17 & 94,89 \\
\hline Médica & 1110 & 22.96 & 0,17 & 95,05 \\
\hline Técnica em administração & 1110 & 83,33 & 0,17 & 95.22 \\
\hline
\end{tabular}

(1) Inclui apenas as pessoas para as quais os atributos de interesse estão claramente identificados. 
Tabela C26. Sessenta ocupações mais importantes na absorção da mão-de-obra masculina(1). Pernambuco, 1987.

\begin{tabular}{|c|c|c|c|c|}
\hline OCUPAÇŌES & $M_{t}$ & $\frac{M_{i}}{T_{i}}(\%)$ & $\frac{M_{i}(\%)}{M}$ & $\Phi_{i}(\%)$ \\
\hline Outros trab. na agropecuária & 292505 & 80,75 & 22,23 & 22,23 \\
\hline Produrtor agropecuário autônomo & 148098 & 89,76 & 11,26 & 33,49 \\
\hline Comerciante conta-própria & 68654 & 64,59 & 5,22 & 38,71 \\
\hline Motorista & 64453 & 100,00 & 4,90 & 43,61 \\
\hline Pedreiro & 59913 & 100,00 & 4,55 & 48,16 \\
\hline Vendedor & 54863 & 68,28 & 4,17 & 52,33 \\
\hline Servente de pedreiro & 45496 & 99,51 & 3,46 & 55,79 \\
\hline Mecânico de veículo & 29878 & 100,00 & 2,27 & 58,06 \\
\hline Feirante & 29507 & 73,05 & 2,24 & 60,31 \\
\hline Outras ocupaçōes ambulantes & 24214 & 60,94 & 1,84 & 62,15 \\
\hline Auxiliar de escritório & 20964 & 44,32 & 1,59 & 63,74 \\
\hline Carroceiro/Tropeiro & 19012 & 100,00 & 1,45 & 65,19 \\
\hline Agricultor & 17286 & 90,35 & 1,31 & 66,50 \\
\hline Oleiro & 14994 & 96,05 & 1,14 & 67,64 \\
\hline Comerciante & 14938 & 87,58 & 1,14 & 68,78 \\
\hline Pintor/Caiador & 12922 & 100,00 & 0,98 & 69,76 \\
\hline Carpinteiro & 12496 & 100,00 & 0,95 & 70,71 \\
\hline Meçânico & 11845 & 100,00 & 0,90 & 71,61 \\
\hline Marceneiro & 10976 & 100,00 & 0,83 & 72,44 \\
\hline Embalador de mercadorias & 10594 & 63,79 & 0,81 & 73,25 \\
\hline Encarregado da administração & 9125 & 95,36 & 0,69 & 73,94 \\
\hline Ferreiro/Serralheiro & 9072 & 100,00 & 0,69 & 74,63 \\
\hline Empresário na indústria de transformação & 7813 & 76,95 & 0,59 & 75,22 \\
\hline Assistente administrativo & 7236 & 34,49 & 0,55 & 75,77 \\
\hline Soldador & 7023 & 96,94 & 0,53 & 76,31 \\
\hline Padeiro & 6856 & 100,00 & 0,52 & 76,83 \\
\hline Outsos propriatinios & 6514 & 86,02 & 0,50 & 77,32 \\
\hline Anxiliar administativo & 6509 & 59,06 & 0,50 & 77,82 \\
\hline Pintor à pistola & 6288 & 100,00 & 0,48 & 78,30 \\
\hline Administrador agropecuário & 6257 & 100,00 & 0,48 & 78,77 \\
\hline Empregado doméstico & 6189 & 6,12 & 0,47 & 79,24 \\
\hline Doceiro atc & 6069 & 57,64 & 0,46 & 79,71 \\
\hline Garçon & 6016 & 77,71 & 0,46 & 80,16 \\
\hline Quitandeiro etc & 5896 & 86,90 & 0,45 & 80,61 \\
\hline Reparador de Radio/TV & 5690 & 100,00 & 0,43 & 81,04 \\
\hline Trabalhador de fábrica de sapato & 5418 & 71,89 & 0,41 & 81,45 \\
\hline Pescador & 5352 & 86,46 & 0,41 & 81,86 \\
\hline Caixa & 5298 & 70,95 & 0,40 & 82,26 \\
\hline Administrador do comércio de mercadorias & 5229 & 75,18 & 0,40 & 82,66 \\
\hline Diretor/Assessor & 4956 & 65,43 & 0,38 & 83,04 \\
\hline Tratorista agricola & 4752 & 100,00 & 0,36 & 83,40 \\
\hline Pracista e viajante & 4614 & 70,30 & 0,35 & 83,75 \\
\hline Repositor de equipamentos & 4564 & 100,00 & 0,35 & 84,10 \\
\hline Encanador & 4117 & 100,00 & 0,31 & 84,41 \\
\hline Trocador & 3949 & 94,68 & 0,30 & 84,71 \\
\hline Instalador rep. linhas elet. equip. telefồnicos & 3726 & 100,00 & 0,28 & 84,99 \\
\hline Almoxarife & 3725 & 100,00 & 0,28 & 85,28 \\
\hline Médico & 3725 & 77,04 & 0,28 & 85,56 \\
\hline Criador bovino & 3692 & 100,00 & 0,28 & 85,84 \\
\hline Expedidor & 3673 & 100,00 & 0,28 & 86,12 \\
\hline Operador de máquinas p. automáticas & 3554 & 80,01 & 0,27 & 86,39 \\
\hline Madeireiro & 3523 & 100,00 & 0,27 & 86,66 \\
\hline Eletricista instalador & 3454 & 100,00 & 0,26 & 86,92 \\
\hline Estofador & 3404 & 80,25 & 0,26 & 87,18 \\
\hline Fotógrafo & 3400 & 100,00 & 0,26 & 87,44 \\
\hline Modelista & 3299 & 100,00 & 0,25 & 87,69 \\
\hline Contador & 3280 & 71,09 & 0,25 & 87,94 \\
\hline Tecelão & 3228 & 57,95 & 0,25 & 88,18 \\
\hline Corrator de imóveis & 3008 & 93,13 & 0.23 & 88,41 \\
\hline Ortros administradores & 2837 & 64,58 & 0.22 & 88,63 \\
\hline
\end{tabular}

(1) Inclui apenas as pessoas para as quais os atributos de interesse estão claramente identificados. 
Tabela C27. Sessenta ocupações mais importantes na absorção da mão-de-obra feminina ${ }^{(1)}$. Pernambuco, 1988.

\begin{tabular}{|c|c|c|c|c|}
\hline OCUPAÇÕES & $F_{i}$ & $\frac{F_{i}}{T_{i}}(\%)$ & $\frac{F_{i}}{F}(\%)$ & $\pi_{i}(\%)$ \\
\hline Empregada doméstica & 102322 & 95,23 & 15,47 & 15,47 \\
\hline Alfaiate/Costureira & 82339 & 92,33 & 12,45 & 27,92 \\
\hline Outros trab. na agropecuária & 64056 & 19,67 & 9,68 & 37,60 \\
\hline Professora de 1 a 4 série & 38555 & 91,48 & 5,83 & 43,43 \\
\hline Comerciante conta-própria & 34529 & 33,43 & 5,22 & 48,65 \\
\hline Lavadeira/Passadeira & 33605 & 96,54 & 5,08 & 53,73 \\
\hline Vendedora & 20644 & 33,48 & 3,12 & 56,85 \\
\hline Auxiliar de escritónio & 20421 & 47,96 & 3,09 & 59,94 \\
\hline Procutora agropecuánia autônoma & 15980 & 9,16 & 2,42 & 62,35 \\
\hline Enfermeira não diplomada & 15754 & 83,55 & 2,38 & 64,73 \\
\hline Outras ocupações ambulantes & 15630 & 46,74 & 2,36 & 67,10 \\
\hline Cozinheira & 13524 & 79,69 & 2,05 & 69,14 \\
\hline Secretána & 12984 & 100,00 & 1,96 & 71,10 \\
\hline Professora de 5 a 8 série & 9700 & 86,23 & 1,47 & 72,57 \\
\hline Feirante & 9332 & 26,21 & 1,41 & 73,98 \\
\hline Operador de caixa & 9083 & 89,41 & 1,37 & 75,35 \\
\hline Manicure e Pedicure & 8460 & 100,00 & 1,28 & 76,63 \\
\hline Rendeira & 8418 & 100,00 & 1,27 & 77,91 \\
\hline Auxiliar administrativo & 7622 & 51,16 & 1,15 & 79,06 \\
\hline Recepcionista & 7368 & 74,68 & 1,11 & 80,17 \\
\hline Assistente administrativo & 7237 & 63,51 & 1,09 & 81,27 \\
\hline Diretora/Assessora & 6456 & 51,08 & 0,98 & 82,24 \\
\hline Atendente de bar & 5834 & 50,48 & 0,88 & 83,12 \\
\hline Cabeleireira & 5469 & 70,74 & 0,83 & 83,95 \\
\hline Doceira etc & 4508 & 20,00 & 0,68 & 84,63 \\
\hline Embaladora de mercadorias & 3828 & 37,70 & 0,58 & 85,21 \\
\hline Adrninistradora do comércio de mercadorias & 3574 & 36,16 & 0,54 & 85,75 \\
\hline Caixa & 3339 & 43,08 & 0,51 & 86,26 \\
\hline Orientadora de ensino & 3337 & 100,00 & 0,51 & 86,76 \\
\hline Tecelã & 3226 & 42,23 & 0,49 & 87,25 \\
\hline Magarefe & 3006 & 69,62 & 0,45 & 87,70 \\
\hline Encarregada da adnninistração & 2973 & 20,33 & 0,45 & 88,15 \\
\hline Professora de 2o. grau & 2972 & 75,82 & 0,45 & 88,60 \\
\hline Auxiliar de contabilidade & 2862 & 48,02 & 0,43 & 89,03 \\
\hline Telefonista & 2754 & 85,29 & 0,42 & 89,45 \\
\hline Ocupaçōes na indústria de papel & 2642 & 73,57 & 0,40 & 89,85 \\
\hline Outras proprietárias & 2608 & 16,56 & 0,39 & 90,24 \\
\hline Contadora & 2150 & 25,09 & 0,33 & 90,57 \\
\hline Comerciante & 2024 & 10,79 & 0,31 & 90,88 \\
\hline Professora profissionalizante & 2023 & 39,50 & 0,31 & 91,18 \\
\hline Bordadeira/Cerzideira & 1914 & 100,00 & 0,30 & 91,47 \\
\hline Advogada etc & 1787 & 40,49 & 0,27 & 91,74 \\
\hline Pracista e viajante & 1787 & 23,84 & 0,27 & 92,01 \\
\hline Assistente social & 1661 & 87,51 & 0,25 & 92,26 \\
\hline Operadora de máquinas p. automáticas & 1659 & 45,03 & 0,25 & 92,51 \\
\hline Trabalhadora de fábrica de sapato & 1549 & 19,58 & 0,23 & 92,75 \\
\hline Ceramista/Louceira & 1440 & 85,87 & 0,22 & 92,96 \\
\hline Farinheira/Moleira & 1439 & 54,47 & 0,22 & 93,18 \\
\hline Tripeira etc & 1439 & 57,24 & 0,22 & 93,40 \\
\hline Dentista & 1423 & 60,02 & 0,22 & 93,62 \\
\hline Docaira/confeiteira & 1422 & 62,87 & 0,22 & 93,83 \\
\hline Fiscal de tributos & 1313 & 42,37 & 0,20 & 94,03 \\
\hline Repositora de mercadorias & 1313 & 23,39 & 0,20 & 94,23 \\
\hline Chapeileira palha & 1202 & 100,00 & 0,18 & 94,41 \\
\hline Ocupações na indusstria de açúcar & 1202 & 34,55 & 0,18 & 94,59 \\
\hline Outras administradoras & 1188 & 26,26 & 0,18 & 94,77 \\
\hline Acabadora de pano & 1187 & 52,45 & 0,18 & 94,95 \\
\hline Arquitata & 1186 & 71,45 & 0,18 & 95,13 \\
\hline Médica & 1186 & 41,67 & 0,18 & 95,31 \\
\hline Enfermeira diplomada & 1186 & 83,35 & 0,18 & 95,49 \\
\hline
\end{tabular}

"Inclui apenas as pessoas para as quais os atributos de interesse estão claramente identificados. 
Tabela C28. Sessenta ocupações mais importantes na absorção da mão-de-obra masculina ${ }^{(1)}$. Pernambuco, 1988.

\begin{tabular}{|c|c|c|c|c|}
\hline OCUPAÇŌES & $M_{i}$ & $\frac{M_{i}}{T_{i}}(\%)$ & $\frac{M_{1}(\%)}{M}$ & $\Phi_{i}(\%)$ \\
\hline $\begin{array}{l}\text { Outros trab. na agropecuária } \\
\text { Prochutor agropecuário autônomo }\end{array}$ & $\begin{array}{l}261621 \\
158574\end{array}$ & $\begin{array}{l}80,33 \\
90,85\end{array}$ & $\begin{array}{l}20,13 \\
12,20\end{array}$ & $\begin{array}{l}20,13 \\
32,34\end{array}$ \\
\hline Pedreiro & 73640 & 100,00 & 5,67 & 38,00 \\
\hline Comerciante conta-própria & 68749 & 66,57 & 5,29 & 43,29 \\
\hline Motorista & 65808 & 100,00 & 5,06 & 48,36 \\
\hline Vendedor & 41024 & 66,52 & 3,16 & 51,52 \\
\hline Servente de pedreiro & 38882 & 98,79 & 2,99 & 54,51 \\
\hline Feirante & 26280 & 73,80 & 2,02 & 56,53 \\
\hline Mecânico de veículo & 22679 & 97,95 & 1,75 & 58,28 \\
\hline Auxiliar de escritório & 22159 & 52,04 & 1,71 & 59,98 \\
\hline Marceneiro & 18358 & 100,00 & 1,41 & 61,39 \\
\hline Doceiro etc & 18034 & 80,00 & 1,39 & 62,78 \\
\hline Outras ocupaçōes ambulartes & 17809 & 53,26 & 1,37 & 64,15 \\
\hline Comerciante & 16733 & 89,21 & 1,29 & 65,44 \\
\hline Outros proprietários & 13143 & 83,44 & 1,01 & 66,45 \\
\hline Encarregado da administração & 11651 & 79,67 & 0,90 & 67,35 \\
\hline Pintor/Caiador & 11579 & 100,00 & 0,89 & 68,24 \\
\hline Ferreiro/Serralheiro & 10992 & 100,00 & 0,85 & 69,09 \\
\hline Agricultor & 10935 & 100,00 & 0,84 & 69,93 \\
\hline Carpinteiro & 10886 & 100,00 & 0,84 & 70,76 \\
\hline Mecânico & 10601 & 97,81 & 0,82 & 71,58 \\
\hline Empresário na indústria de transformaçāo & 8384 & 88,64 & 0,65 & 72,23 \\
\hline Oleiro & 8053 & 100,00 & 0,62 & 72,85 \\
\hline Garçon & 7766 & 86,76 & 0,60 & 73,44 \\
\hline Soldador & 7641 & 100,00 & 0,59 & 74,03 \\
\hline Almoxarife & 7382 & 100,00 & 0,57 & 74,60 \\
\hline Auxiliar administrativo & 7276 & 48,84 & 0,56 & 75,16 \\
\hline Alfaiate/Costureira & 6836 & 7,67 & 0,53 & 75,68 \\
\hline Padeiro & 6471 & 100,00 & 0,50 & 76,18 \\
\hline Contador & 6418 & 74,91 & 0,49 & 76,68 \\
\hline Trabalhador de fábrica de sapato & 6361 & 80,42 & 0,49 & 77,17 \\
\hline Embalador de mercadorias & 6325 & 62,30 & 0,49 & 77,65 \\
\hline Administrador do comércio de mercadorias & 6309 & 63,84 & 0,49 & 78,14 \\
\hline Criador bovino & 6251 & 91,23 & 0,48 & 78,62 \\
\hline Diretor/Assessor & 6183 & 48,92 & 0,48 & 79,10 \\
\hline Pintor à pistola & 5964 & 100,00 & 0,46 & 79,55 \\
\hline Tratorista agrícola & 5887 & 100,00 & 0,45 & 80,01 \\
\hline Atendente de bar & 5724 & 49,52 & 0,44 & 80,45 \\
\hline Pracista e viajante & 5710 & 76,16 & 0,44 & 80,89 \\
\hline Empregado doméstico & 5123 & 4,77 & 0,39 & 81,28 \\
\hline Madeireiro & 5047 & 100,00 & 0,39 & 81,67 \\
\hline Administrador agropecuário & 5046 & 100,00 & 0,39 & 82,06 \\
\hline Encanador & 4998 & 100,00 & 0,39 & 82,44 \\
\hline Barbeiro & 4922 & 100,00 & 0,38 & 82,82 \\
\hline Reparador Radio/TV & 4776 & 100,00 & 0,37 & 83,19 \\
\hline Inst Rep Lin Ele Eq Tele & 4652 & 100,00 & 0,36 & 83,55 \\
\hline Tecelão & 4414 & 57,78 & 0,34 & 83,89 \\
\hline Caixa & 4411 & 56,92 & 0,34 & 84,23 \\
\hline Repositor de mescadorias & 4300 & 76,61 & 0,33 & 84,56 \\
\hline Engenheiro & 4269 & 100,00 & 0,33 & 84,89 \\
\hline Auxiliar de costura & 4209 & 87,49 & 0,32 & 85,21 \\
\hline Assisterte administrativo & 4158 & 36,49 & 0,32 & 85,53 \\
\hline Administrador na incústria de transformação & 3813 & 88,92 & 0,29 & 85,82 \\
\hline Pescador & 3810 & 100,00 & 0,29 & 86,12 \\
\hline Eletricista instalador & 3793 & 100,00 & 0,29 & 86,41 \\
\hline Sapateiro & 3717 & 100,00 & 0,29 & 86,69 \\
\hline Professor de 1 a 4 série & 3592 & 8,52 & 0,28 & 86,97 \\
\hline Operador de máquinas de construção civil & 3480 & 100,00 & 0,27 & 87.24 \\
\hline Expedidor & 3446 & 93,57 & 0,27 & 87,50 \\
\hline Cozinheiro & 3446 & 20,31 & 0,27 & 87.77 \\
\hline
\end{tabular}

${ }^{(1)}$ Inclui apenas as pessoas para as quais os atributos de interesse estão claramente identificados. 
Tabela C29. Sessenta ocupações mais importantes na absorção da mão-de-obra feminina ${ }^{(1)}$. Pernambuco, 1989.

\begin{tabular}{|c|c|c|c|c|}
\hline OCUPAÇŌES & $F_{i}$ & $\frac{F_{i}}{T_{i}}(\%)$ & $\frac{F_{i}}{F}(\%)$ & $\pi_{i}(\%)$ \\
\hline Empregada doméstica & 102534 & 96,11 & 14,81 & 14,81 \\
\hline Alfaiate/Costuraira & 81727 & 98,72 & 11,80 & 26,61 \\
\hline Outros trab. na agropecuária & 62409 & 19,29 & 9,01 & 35,62 \\
\hline Professora de 1 a 4 série & 35043 & 97,70 & 5,06 & 40,69 \\
\hline Comerciante conta-própria & 31303 & 30,55 & 4,52 & 45,21 \\
\hline Lavadeira/Passadeira & 31213 & 93,32 & 4,51 & 49,71 \\
\hline Vendedora & 28623 & 38,68 & 4,13 & 53,85 \\
\hline Produttora agropecuánia autônoma & 22519 & 11,29 & 3,25 & 57,10 \\
\hline Auxiliar de escritório & 21684 & 46,54 & 3,13 & 60,23 \\
\hline Rendeira & 16424 & 100,00 & 2,37 & 62,60 \\
\hline Cozinheira & 16158 & 68,38 & 2,33 & 64,94 \\
\hline Enfermeiras não diplomados & 14543 & 87,84 & 2,10 & 67,04 \\
\hline Feirante & 12971 & 26,62 & 1,87 & 68,91 \\
\hline Outras ocupaçōes ambulantes & 12926 & 54,81 & 1,87 & 70,78 \\
\hline Operadora de Caixa & 11244 & 84,81 & 1,62 & 72,40 \\
\hline Assistente administrativo & 9264 & 64,46 & 1,34 & 73,74 \\
\hline Embaladora de mercadorias & 9050 & 45,12 & 1,307 & 75,05 \\
\hline Secretária & 8661 & 97,33 & 1,25 & 76,30 \\
\hline Recepcionista & 7727 & 78,44 & 1,12 & 77,41 \\
\hline Diretora/Assessora & 7088 & 59,28 & 1,02 & 78,44 \\
\hline Cabeleireira & 6388 & 85,75 & 0,92 & 79,36 \\
\hline Manicure e Pedicure & 6280 & 100,00 & 0,91 & 80,27 \\
\hline Comerciante & 6153 & 22,75 & 0,89 & 81,15 \\
\hline Atendente de bar & 5932 & 64,92 & 0,86 & 82,01 \\
\hline Professora de 5 a 8 série & 5058 & 91,40 & 0,73 & 82,74 \\
\hline Auxiliar administrativo & 4981 & 43,25 & 0,72 & 83,46 \\
\hline Professora de préescola & 4817 & 100,00 & 0,70 & 84,16 \\
\hline Professora de 2o. grau & 4742 & 58,06 & 0,69 & 84,84 \\
\hline Administradora do comércio de mercadorias & 4140 & 39,31 & 0,60 & 85,44 \\
\hline Orientadora de ensino & 4139 & 89,69 & 0,60 & 86,04 \\
\hline Encarregada da administração & 3553 & 22,72 & 0,51 & 86,55 \\
\hline Telefonista & 3093 & 100,00 & 0,45 & 87,00 \\
\hline Bordadeira/Cerzideira & 3059 & 100,00 & 0,44 & 87,44 \\
\hline Datilógrafa & 2728 & 79,26 & 0,39 & 87,83 \\
\hline Caixa & 2710 & 49,83 & 0,39 & 88,22 \\
\hline Trabalhadora de fábrica de sapato & 2710 & 30,32 & 0,39 & 88,62 \\
\hline Doceira etc & 2491 & 14,72 & 0,36 & 88,98 \\
\hline Artesã & 2490 & 48,92 & 0,36 & 89,33 \\
\hline Repositora de mercadorias & 2474 & 34,29 & 0,36 & 89,69 \\
\hline Assistente social & 2379 & 83,33 & 0,34 & 90,04 \\
\hline Outras administradoras & 2378 & 35,20 & 0,34 & 90,38 \\
\hline Empresária na indústria de transformação & 2363 & 12,09 & 0,34 & 90,72 \\
\hline Auxiliar de contabilidade & 2361 & 62,30 & 0,34 & 91,06 \\
\hline Oleira & 2346 & 20,01 & 0,34 & 91,40 \\
\hline Farinheira/Moleira & 2345 & 62,43 & 0,34 & 91,74 \\
\hline Outras proprietárias & 2251 & 16,98 & 0,33 & 92,06 \\
\hline Agricultora & 2236 & 15,99 & 0,32 & 92,39 \\
\hline Operadora de máquinas p. automáticas & 1904 & 33,35 & 0,28 & 92,66 \\
\hline Pracista e viajante & 1777 & 19,69 & 0,26 & 92,92 \\
\hline Contadora & 1776 & 28,28 & 0,26 & 93,17 \\
\hline Camareira & 1666 & 100,00 & 0,24 & 93,42 \\
\hline Técnica química & 1650 & 55,93 & 0,24 & 93,65 \\
\hline Docira/confeiteira & 1537 & 86,59 & 0,22 & 93,88 \\
\hline Médica & 1428 & 40,20 & 0,21 & 94,08 \\
\hline Ceramista/Louceira & 1412 & 57,07 & 0,20 & 94,29 \\
\hline Fiandeira & 1300 & 33,19 & 0,19 & 94,47 \\
\hline Macarroneira & 1300 & 73,20 & 0,19 & 94,66 \\
\hline Outras ocupaçōes na indústria de transformação & 1300 & 14,79 & 0,19 & 94,85 \\
\hline Garcunde & 1300 & 18,02 & 0,19 & 95,04 \\
\hline Administradora na indústria de transformação & 1190 & 22,26 & 0,17 & 95,21 \\
\hline
\end{tabular}

\footnotetext{
(1) Inclui apenas as pessoas para as quais os atributos de interesse estão claramente identificados.
} 
Tabela C30. Sessenta ocupações mais importantes na absorção da mão-de-obra masculina ${ }^{(1)}$. Pernambuco, 1989.

\begin{tabular}{|c|c|c|c|c|}
\hline OCUPAÇŌES & $M_{i}$ & $\frac{M_{i}}{T_{i}}(\%)$ & $\frac{M_{i}}{M}(\%)$ & $\Phi_{i}(\%)$ \\
\hline Outros trab. na agropecuária & 261094 & 80,71 & 19,19 & 19,19 \\
\hline Produtor agropecuário autônomo & 176930 & 88,71 & 13,00 & 32,19 \\
\hline Comerciante conta-própria & 71177 & 69,46 & 5,23 & 37,42 \\
\hline Matorista & 61559 & 100,00 & 4,52 & 41,95 \\
\hline Pedreiro & 56651 & 100,00 & 4,16 & 46,11 \\
\hline Servente de pedreiro & 49183 & 99,52 & 3,62 & 49,72 \\
\hline Vendedor & 45382 & 61,32 & 3,34 & 53,06 \\
\hline Feirante & 35758 & 73,38 & 2,63 & 55,69 \\
\hline Auxiliar de escritório & 24905 & 53,46 & 1,83 & 57,52 \\
\hline Mecânico de veículo & 24449 & 100,00 & 1,80 & 59,32 \\
\hline Comerciante & 20898 & 77,25 & 1,54 & 60,85 \\
\hline Empresário na indústria de transformação & 17183 & 87,91 & 1,26 & 62,11 \\
\hline Marceneiro & 16522 & 100,00 & 1,21 & 63,33 \\
\hline Daceiro etc & 14434 & 85,28 & 1,06 & 64,39 \\
\hline Carpinteiro & 13925 & 100,00 & 1,02 & 65,41 \\
\hline Encarregado da administração & 12087 & 77,28 & 0,89 & 66,30 \\
\hline Pintor/Caiador & 12069 & 100,00 & 0,89 & 67,19 \\
\hline Agricultor & 11744 & 84,01 & 0,86 & 68,05 \\
\hline Embalador de mercadorias & 11008 & 54,88 & 0,81 & 68,86 \\
\hline Outros proprieários & 11004 & 83,02 & 0,81 & 69,67 \\
\hline Outras ocupações ambulantes & 10658 & 45,19 & 0,78 & 70,45 \\
\hline Oleiro & 9381 & 80,00 & 0,69 & 71,14 \\
\hline Carroceiro/Tropeiro & 9270 & 100,00 & 0,68 & 71,82 \\
\hline Mecânico & 9263 & 100,00 & 0,68 & 72,50 \\
\hline Padeiro & 8022 & 100,00 & 0,59 & 73,09 \\
\hline Outras ocupações na inđústria de transformação & 7489 & 85,21 & 0,55 & 73,64 \\
\hline Eletricista instalador & 7471 & 100,00 & 0,55 & 74,19 \\
\hline Cozinheiro & 7471 & 31,62 & 0,55 & 74,74 \\
\hline Ferreiro/Serralheiro & 7341 & 96,86 & 0,54 & 75,28 \\
\hline Pracista e viajante & 7248 & 80,31 & 0,53 & 75,81 \\
\hline Auxiliar administrativo & 6535 & 56,75 & 0,48 & 76,29 \\
\hline Trocador & 6503 & 100,00 & 0,48 & 76,77 \\
\hline Administrador do comércio de mercadorias & 6392 & 60,69 & 0,47 & 77,24 \\
\hline Pintor à pistola & 6263 & 100,00 & 0,46 & 77,70 \\
\hline Trabalhador de fábrica de sapato & 6229 & 69,68 & 0,46 & 78,16 \\
\hline Borracheiro & 6007 & 100,00 & 0,44 & 78,60 \\
\hline Garçon & 5915 & 81,98 & 0,44 & 79,04 \\
\hline Administrador agropecuário & 5863 & 90,91 & 0,43 & 79,47 \\
\hline Repositor de equipamentos & 5804 & 100,00 & 0,43 & 79,89 \\
\hline Expedidor & 5438 & 91,95 & 0,40 & 80,29 \\
\hline Proprietánios & 5292 & 100,00 & 0,39 & 80,68 \\
\hline Advogado atc & 5217 & 87,96 & 0,38 & 81,06 \\
\hline Pescador & 5186 & 100,00 & 0,38 & 81,45 \\
\hline Assistente administrativo & 5108 & 35,54 & 0,38 & 81,82 \\
\hline Operador de máquinas de construção civil & 4946 & 100,00 & 0,36 & 82,18 \\
\hline Tomeiro mecânico & 4870 & 100,00 & 0,36 & 82,54 \\
\hline Diretor/Assessor & 4869 & 40,72 & 0,36 & 82,90 \\
\hline Soldador & 4850 & 100,00 & 0,36 & 83,26 \\
\hline Repositor de mercadorias & 4742 & 65,72 & 0,35 & 83,61 \\
\hline Contador & 4505 & 71,72 & 0,33 & 83,94 \\
\hline Empresário da construção civil & 4486 & 94,96 & 0,33 & 84,27 \\
\hline Oritos administadores & 4377 & 64,80 & 0,32 & 84,59 \\
\hline Administrador na indústria de transformação & 4157 & 77,75 & 0,31 & 84,90 \\
\hline Empregado doméstico & 4156 & 3,90 & 0,31 & 85,20 \\
\hline Instalador rep. linhas elet. equip. telefônicos & 4046 & 100,00 & 0,30 & 85,50 \\
\hline Tecelão & 3918 & 89,19 & 0,29 & 85,78 \\
\hline Operador de máquinas p. automáticas & 3806 & 66,66 & 0,28 & 86,06 \\
\hline Lanterneiro & 3790 & 100,00 & 0,28 & 86,34 \\
\hline Administrador de financeiras & 3662 & 88,50 & 0,27 & 86,61 \\
\hline Ocupacooes na indústria de artefatos de borracha & 3553 & 83,27 & 0,26 & 86,87 \\
\hline
\end{tabular}

(1) Inclui apenas as pessoas para as quais os atributos de interesse estão claramente identificados. 
Tabela c31. Sessenta ocupações mais importantes na absorção da mão-de-obra feminina ${ }^{(1)}$. Pernambuco, 1990.

\begin{tabular}{|c|c|c|c|c|}
\hline OCUPAÇŌES & $F_{i}$ & $\frac{F_{i}}{T_{i}}(\%)$ & $\frac{F_{t}}{F}(\%)$ & $\pi_{i}(\%)$ \\
\hline Empregada domética & 117001 & 93,16 & 15,89 & 15,89 \\
\hline Alfaiate/Costuraira & 77908 & 96,44 & 10,58 & 26,47 \\
\hline Professora de 1 a 4 série & 54332 & 98,06 & 7,38 & 33,84 \\
\hline Comerciante conta-própria & 42537 & 36,18 & 5,78 & 39,62 \\
\hline Lavadeira/Passadeira & 42310 & 98,06 & 5,75 & 45,36 \\
\hline Outros trab. na agropecuária & 31677 & 10,97 & 4,30 & 49,67 \\
\hline Vendedora & 26271 & 34,00 & 3,57 & 53,23 \\
\hline Auxiliar de escritório & 22682 & 47,41 & 3,08 & 56,31 \\
\hline Outras ocuspações ambulantes & 19695 & 50,78 & 2,67 & 58,99 \\
\hline Cozinheira & 18791 & 74,86 & 2,55 & 61,54 \\
\hline Produtora agropecuária autônoma & 18114 & 11,79 & 2,46 & 64,00 \\
\hline Enfermeira não diplomada & 15740 & 87,42 & 2,14 & 66,13 \\
\hline Secretária & 12864 & 92,28 & 1,75 & 67,88 \\
\hline Feirante & 12696 & 24,36 & 1,72 & 69,61 \\
\hline Assistente administrativo & 12645 & 61,28 & 1,72 & 71,32 \\
\hline Manicure e Pedicure & 12313 & 100,00 & 1,67 & 72,99 \\
\hline Recepcionista & 11445 & 84,24 & 1,55 & 74,55 \\
\hline Rendeira & 10800 & 100,00 & 1,47 & 76,01 \\
\hline Ausiliar administrativo & 8816 & 55,18 & 1,20 & 77,21 \\
\hline Cabeleireira & 7760 & 78,29 & 1,05 & 78,27 \\
\hline Operadora de Caixa & 7515 & 86,32 & 1,02 & 79,29 \\
\hline Atendente de bar & 6684 & 55,35 & 0,91 & 80,19 \\
\hline Diretora/Assessora & 6094 & 37,27 & 0,83 & 81,02 \\
\hline Embaladora de mercadorias & 5971 & 40,66 & 0,81 & 81,83 \\
\hline Comerciante & 5970 & 23,91 & 0,81 & 82,64 \\
\hline Professora de 20. grau & 5484 & 71,91 & 0,75 & 83,39 \\
\hline Encarregada da administração & 4885 & 25,77 & 0,66 & 84,05 \\
\hline Professora de 5 a 8 série & 4294 & 85,73 & 0,58 & 84,63 \\
\hline Orientadora de ensino & 4171 & 94,60 & 0,57 & 85,20 \\
\hline Artesã & 3942 & 60,00 & 0,54 & 85,73 \\
\hline Outras proprietánias & 3932 & 25,74 & 0,53 & 86,27 \\
\hline Trabalhadoras construção de rodovias & 3601 & 66,67 & 0,49 & 86,76 \\
\hline Aguadeira & 3600 & 75,00 & 0,49 & 87,25 \\
\hline Doceira at & 3456 & 22,29 & 0,47 & 87,72 \\
\hline Professora de pré-escola & 3228 & 100,00 & 0,44 & 88,15 \\
\hline Doceira/confeiteira & 3104 & 78,74 & 0,42 & 88,58 \\
\hline Telefonista & 2990 & 100,00 & 0,41 & 88,98 \\
\hline Ausiliar de contabilidade & 2867 & 60,09 & 0,39 & 89.37 \\
\hline Operadora de máquinas p. automáticas & 2856 & 52,17 & 0,39 & 89,76 \\
\hline Médico & 2618 & 43,10 & 0,36 & 90,11 \\
\hline Camareira & 2514 & 100,00 & 0,34 & 90,46 \\
\hline Farinheira/Moleira & 2400 & 90,98 & 0,33 & 90,78 \\
\hline Repositora de mercadorias & 2276 & 25,72 & 0,31 & 91,09 \\
\hline Demtista & 2152 & 66,67 & 0,29 & 91,38 \\
\hline Professora & 2038 & 89,54 & 0,28 & 91,66 \\
\hline Administradora do comércio de mercadorias & 2028 & 19,31 & 0,28 & 91,93 \\
\hline Contadora & 1914 & 32,06 & 0,26 & 92,19 \\
\hline Trabalhadora de fábrica de sapato & 1790 & 16,99 & 0,24 & 92,44 \\
\hline Bordadeira/Cerzideira & 1676 & 100,00 & 0,23 & 92,67 \\
\hline Caixa & 1666 & 38,80 & 0,23 & 92,89 \\
\hline Proprietária & 1552 & 15,26 & 0,21 & 93,10 \\
\hline Ceramista/Louceira & 1438 & 85,80 & 0,20 & 93,30 \\
\hline Administradora na indústria de transformação & 1429 & 18,73 & 0,19 & 93,49 \\
\hline Psicóloga & 1428 & 100,00 & 0,19 & 93.69 \\
\hline Inspetora de alunos & 1428 & 85,71 & 0,19 & 93,88 \\
\hline Tecelã & 1428 & 41,32 & 0,19 & 94.08 \\
\hline Datilógrafa & 1315 & 64,81 & 0,18 & 94,25 \\
\hline Outros administradores & 1314 & 22,96 & 0,18 & 94,43 \\
\hline Técnica em Análises Clínicas & 1314 & 100,00 & 0,18 & 94,61 \\
\hline Ausiliar de costura & 1314 & 100.00 & 0,18 & 94.79 \\
\hline
\end{tabular}

(1) Inclui apenas as pessoas para as quais os atributos de interesse estão claramente identificados. 
Tabela C32. Sessenta ocupações mais importantes na absorção da mão-de-obra masculina(1). Pernambuco, 1990.

\begin{tabular}{|c|c|c|c|c|}
\hline OCUPAÇŌES & $M_{i}$ & $\frac{M_{i}}{T_{i}}(\%)$ & $\frac{M,(\%)}{M}$ & $\Phi_{i}(\%)$ \\
\hline Outros trab. na agropecuária & 257068 & 89,03 & 19,05 & 19,05 \\
\hline Produtor agropecusário autônomo & 135576 & 88,21 & 10,05 & 29,10 \\
\hline Comerciante conta-própria & 75019 & 63,82 & 5,56 & 34,66 \\
\hline Motorista & 66460 & 100,00 & 4,93 & 39,58 \\
\hline Servente de pedreiro & 57418 & 99,59 & 4,26 & 43,84 \\
\hline Vendedor & 51000 & 66,00 & 3,78 & 47,62 \\
\hline Pedreiro & 50690 & 98,83 & 3,76 & 51,37 \\
\hline Feirante & 39419 & 75,64 & 2,92 & 54,29 \\
\hline Auxiliar de escritório & 25165 & 52,60 & 1,87 & 56,16 \\
\hline Marceneiro & 21387 & 100,00 & 1,59 & 57,74 \\
\hline Mecânico de veículo & 21226 & 98,89 & 1,57 & 59,32 \\
\hline Outras ocupaçōes ambulantes & 19094 & 49,23 & 1,42 & 60,73 \\
\hline Comerciante & 18998 & 76,09 & 1,41 & 62,14 \\
\hline Empresário na indústria de transformação & 15322 & 98,47 & 1,14 & 63,27 \\
\hline Encarregado da administração & 14073 & 74,23 & 1,04 & 64,32 \\
\hline Oleiro & 13200 & 95,65 & 0,98 & 65,29 \\
\hline Agricultor & 12841 & 95,54 & 0,95 & 66,25 \\
\hline Repositor de equipamentos & 12645 & 100,00 & 0,94 & 67,18 \\
\hline Doceiro etc & 12049 & 77,71 & 0,89 & 68,08 \\
\hline Outros proprietários & 11342 & 74,26 & 0,84 & 68,92 \\
\hline Mecânico & 11334 & 97,94 & 0,84 & 69,76 \\
\hline Pintor/Caiador & 10390 & 100,00 & 0,77 & 70,53 \\
\hline Diretor/Assessor & 10257 & 62,73 & 0,76 & 71,29 \\
\hline Carpinteiro & 9809 & 100,00 & 0,73 & 72,01 \\
\hline Padeiro & 9087 & 100,00 & 0,67 & 72,69 \\
\hline Trabalhador de fábrica de sapato & 8743 & 83,01 & 0,65 & 73,33 \\
\hline Embalador de mercadorias & 8713 & 59,34 & 0,65 & 73,98 \\
\hline Proprietário & 8619 & 84,74 & 0,64 & 74,62 \\
\hline Empregado doméstico & 8589 & 6,84 & 0,64 & 75,26 \\
\hline Administrador do comércio de mercadorias & 8474 & 80,69 & 0,63 & 75,88 \\
\hline Carroceiro/Tropeiro & 8276 & 100,00 & 0,61 & 76,50 \\
\hline Pintor à pistola & 8112 & 100,00 & 0,60 & 77,10 \\
\hline Assistente administrativo & 7990 & 38,72 & 0,59 & 77,69 \\
\hline Garçon & 7522 & 88,76 & 0,56 & 78,25 \\
\hline Auxiliar administrativo & 7161 & 44,82 & 0,53 & 78,78 \\
\hline Repositor de mercadorias & 6572 & 74,28 & 0,49 & 79,27 \\
\hline Pracista e viajante & 6446 & 83,07 & 0,48 & 79,74 \\
\hline Cozinheiro & 6313 & 25,15 & 0,47 & 80,21 \\
\hline Administrador na indústria de transformação & 6199 & 81,27 & 0,46 & 80,67 \\
\hline Ferreiro/Serralheiro & 6086 & 100,00 & 0,45 & 81,12 \\
\hline Soldador & 6084 & 100,00 & 0,45 & 81,57 \\
\hline Modelista & 5876 & 90,74 & 0,44 & 82,01 \\
\hline Atendente de bar & 5391 & 44,65 & 0,40 & 82,41 \\
\hline Reparador Radio/TV & 5363 & 100,00 & 0,40 & 82,80 \\
\hline Administrador agropecuário & 5277 & 100,00 & 0,39 & 83,20 \\
\hline Serradores & 5153 & 100,00 & 0,38 & 83,58 \\
\hline Encanador & 5132 & 100,00 & 0,38 & 83,96 \\
\hline Trocador & 5122 & 95,56 & 0,38 & 84,34 \\
\hline Lamtemeiro & 4884 & 100,00 & 0,36 & 84,70 \\
\hline Ocupações na indústria de açúcar & 4552 & 100,00 & 0,34 & 85,04 \\
\hline Tripeiro etc & 4533 & 90,50 & 0,34 & 85,37 \\
\hline Tratorista agricola & 4438 & 100,00 & 0,33 & 85,70 \\
\hline Outros administradores & 4410 & 77,04 & 0,33 & 86,03 \\
\hline Pescador & 4066 & 94,47 & 0,30 & 86,33 \\
\hline Contador & 4056 & 67,94 & 0,30 & 86,63 \\
\hline Empresário do transporte & 3942 & 100,00 & 0,29 & 86,92 \\
\hline Sapateiro & 3942 & 100,00 & 0,29 & 87.21 \\
\hline Instalador rep. linhas elet. equip. telefồnicos & 3932 & 100,00 & 0,29 & 87,51 \\
\hline Administrador de financeiras & 3704 & 93,96 & 0,28 & 87.78 \\
\hline Quitandeiro etc & 3694 & 83,80 & 0,27 & 88.05 \\
\hline
\end{tabular}

\footnotetext{
(1) Inclui apenas as pessoas para as quais os atributos de interesse estão claramente identificados.
} 


\section{APÊNDICE D}

Tabela D1. Principais ocupações na absorção da mão-de-obra feminina assalariada. São Paulo, 1981..

Tabela D2. Principais ocupações na absorção da mão-de-obra masculina assalariada. São Paulo, 1981...

Tabela D3. Principais ocupações na absorção da mão-de-obra feminina assalariada. São Paulo, 1990.

Tabela D4. Principais ocupações na absorção da mão-de-obra masculina assalariada. São Paulo, 1990.

Tabela D5. Principais ocupações na absorção da mão-de-obra feminina assalariada. Pernambuco, 1981.

Tabela D6. Principais ocupações na absorção da mão-de-obra masculina assalariada. Pemambuco, 1981.

Tabela D7. Principais ocupações na absorção da mão-de-obra feminina assalariada. Pernambuco, 1990.

Tabela D8. Principais ocupações na absorção da mão-de-obra masculina assalariada. Pernambuco, 1990. 225

Tabela D9. Índice de segregação de Duncan. São Paulo e Pernambuco, 1981 a 1990. 221 
Tabela D1. Principais ocupações na absorção da mão-de-obra feminina assalariada. (1) são Paulo, 1981.

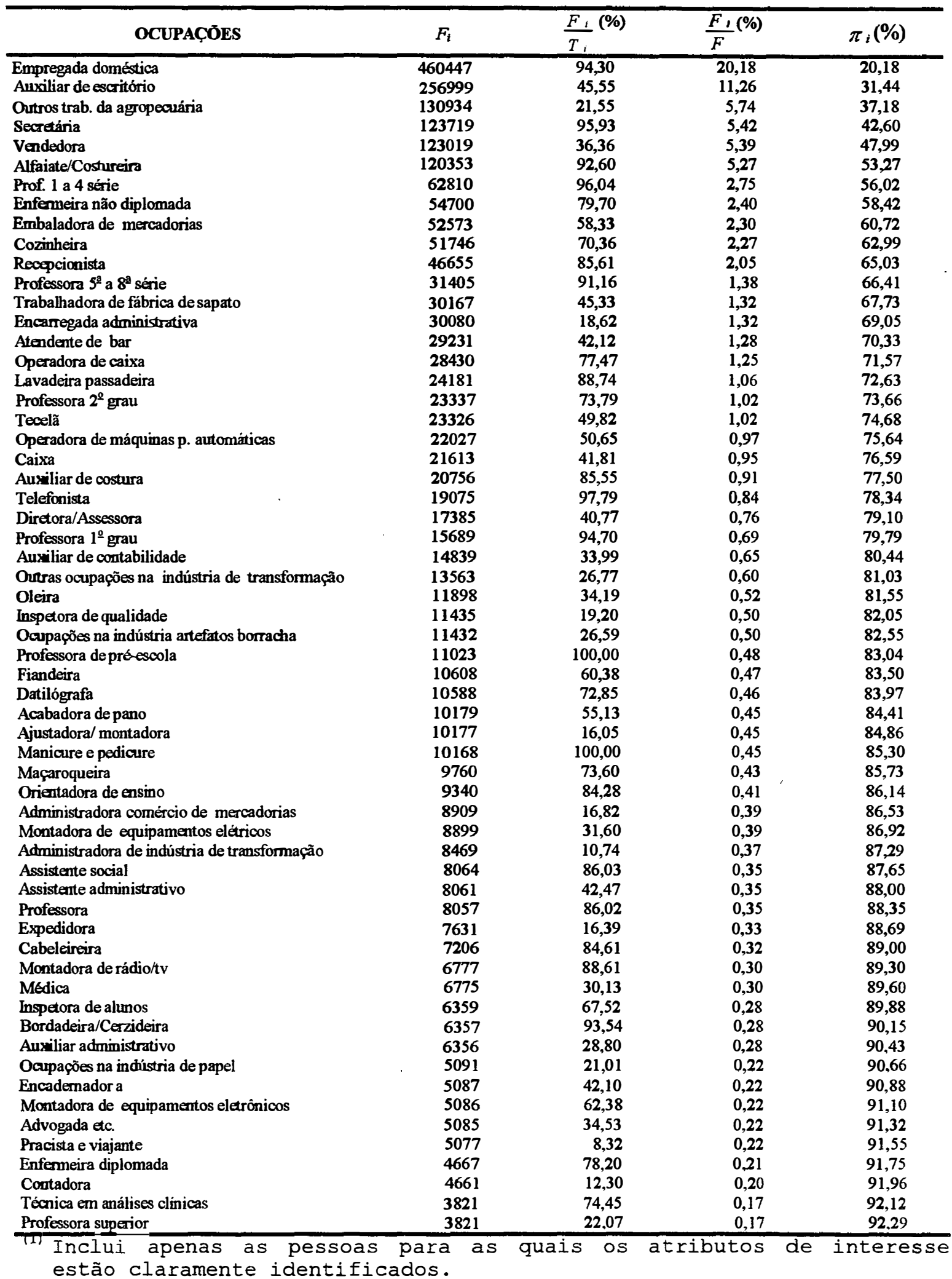


Tabela D2. Principais ocupações na absorção da mão-de-obra masculina assalariada. (1) São Paulo, 1981.

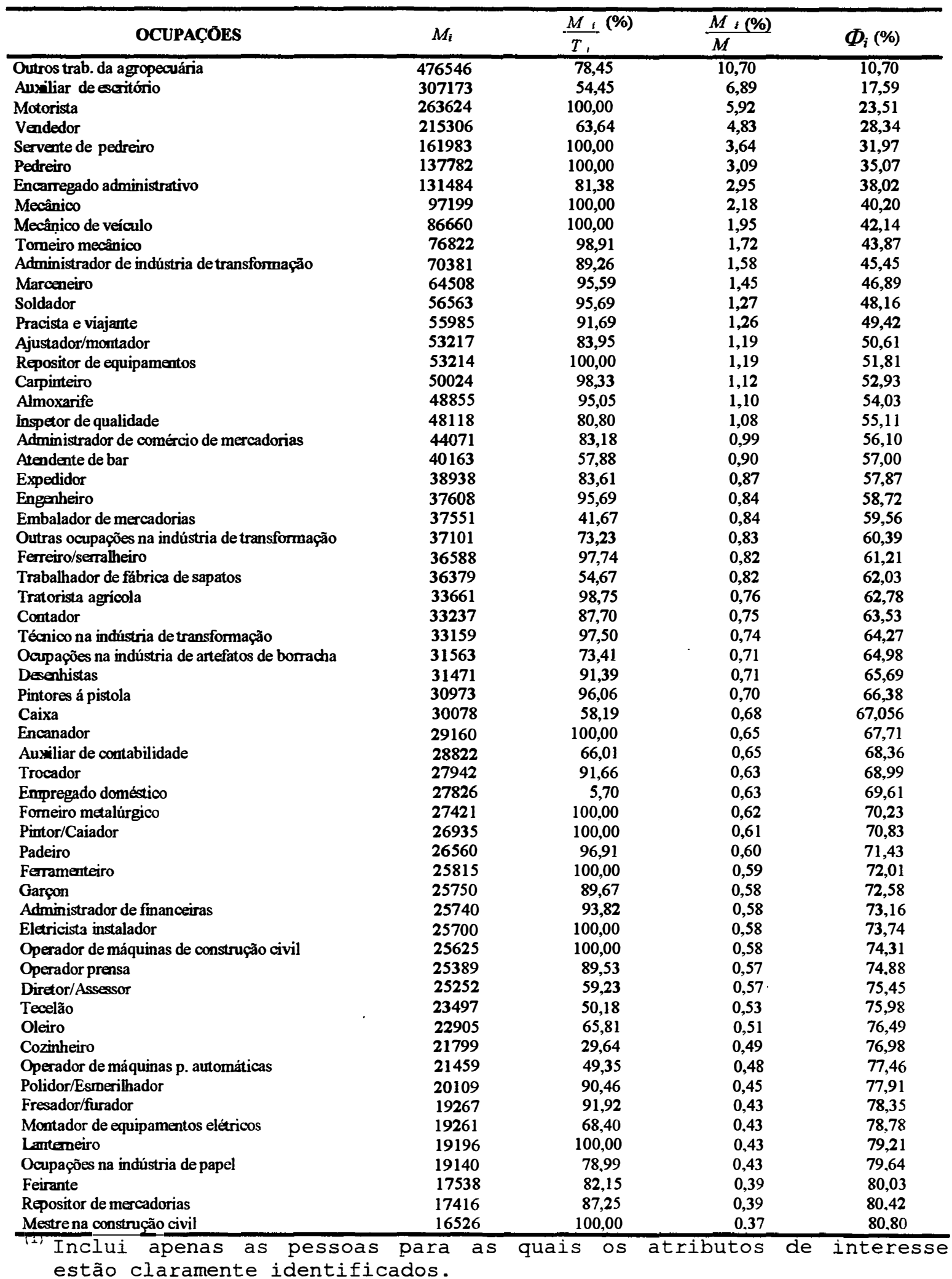


Tabela D3. Principais ocupações na absorção da mão-de-obra feminina assalariada. (1) são Paulo, 1990.

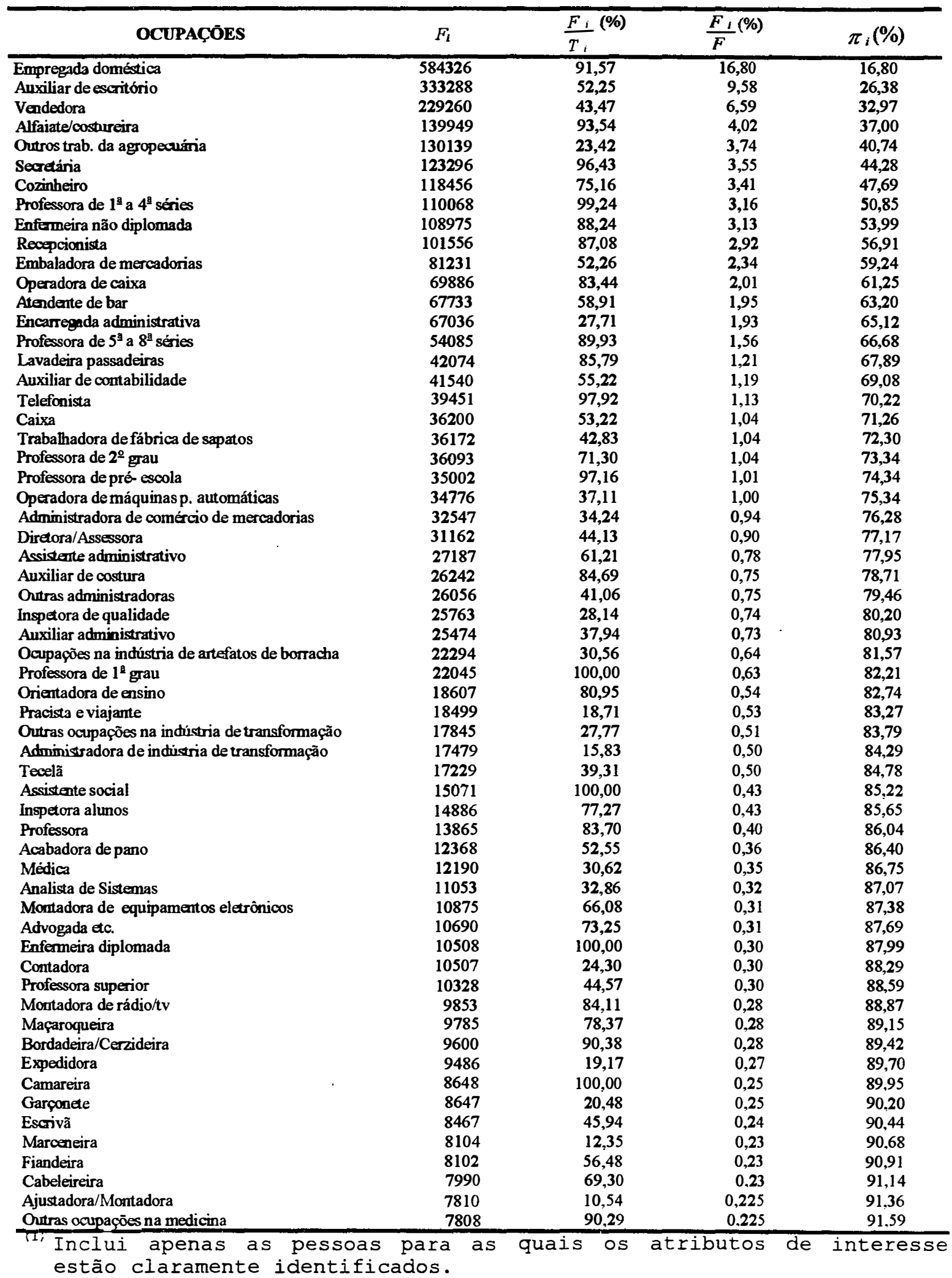


Tabela D4. Principais ocupações na absorção da mão-de-obra masculina assalariada. (1) são Paulo, 1990.

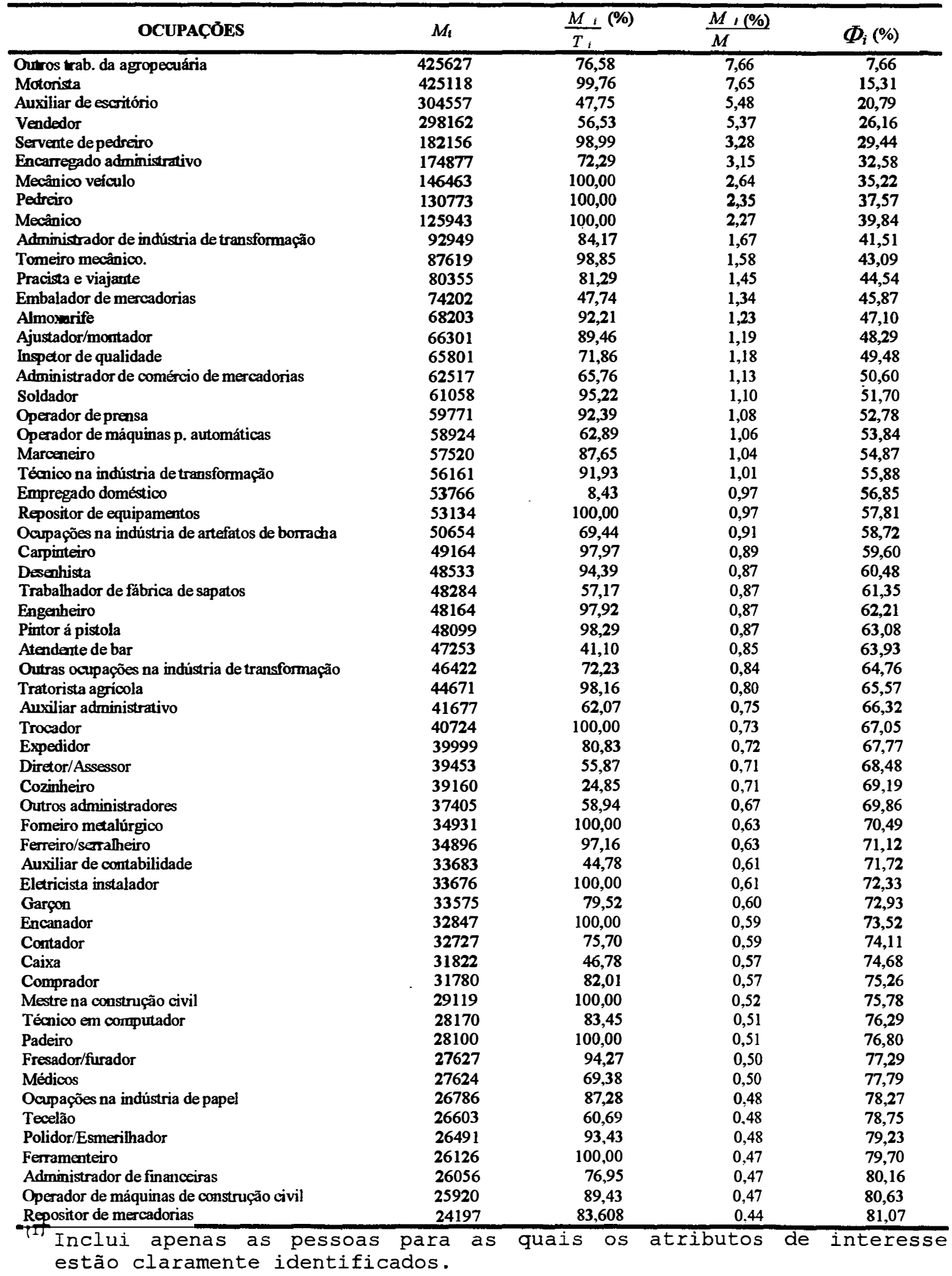


Tabela D5. Principais ocupações na absorção da mão-de-obra feminina assalariada. (1) Pernambuco, 1981.

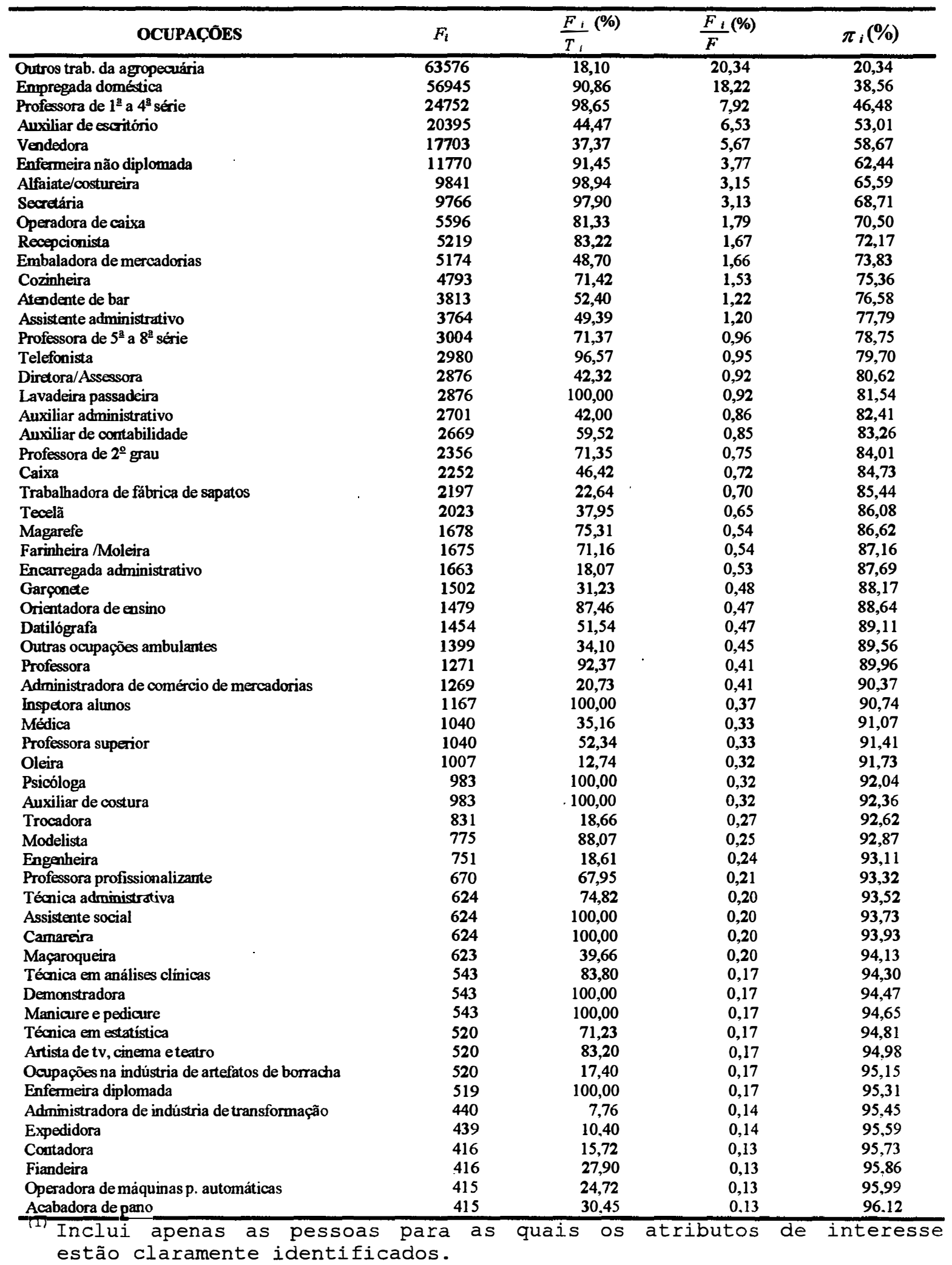


Tabela D6. Principais ocupações na absorção da mão-de-obra masculina assalariada. (1) Pernambuco, 1981.

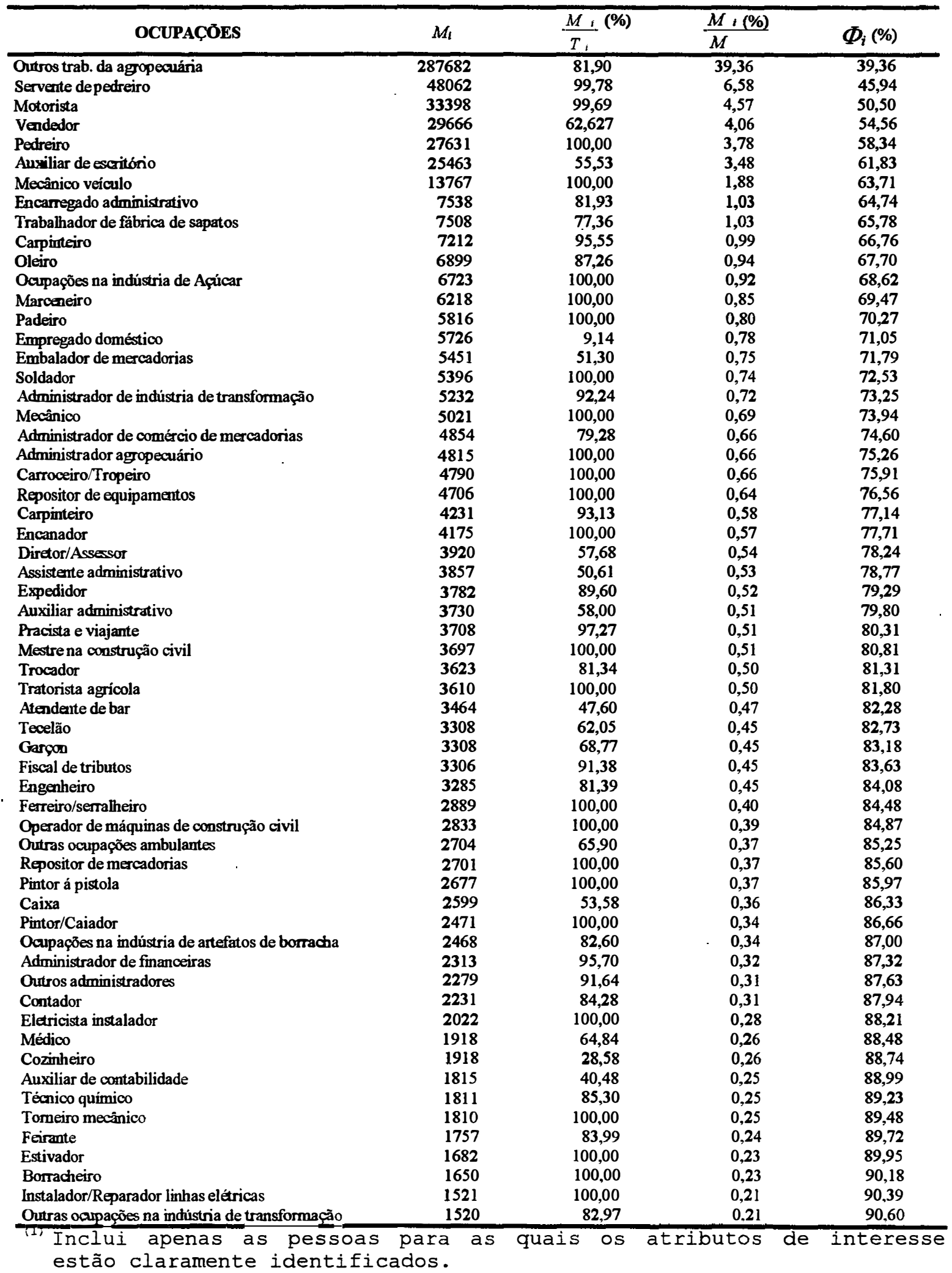


Tabela D7. Principais ocupações na absorção da mão-de-obra feminina assalariada. (1) Pernambuco, 1990.

\begin{tabular}{|c|c|c|c|c|}
\hline OCUPAÇŌES & $F_{i}$ & $\frac{F_{i}}{T_{i}}(\%)$ & $\frac{F_{i}}{F}(\%)$ & $\pi_{i}(\%)$ \\
\hline Émpregada doméstica & 114372 & 93,56 & 22,69 & 22,69 \\
\hline Professora de $1^{\mathrm{a}}$ a $4^{\mathrm{a}}$ séries & 52904 & 98,88 & 10,50 & 33,18 \\
\hline Alfaiate/costureira & 38550 & 96,40 & 7,65 & 40,83 \\
\hline Outros trab. da agropecuária & 31677 & 10,97 & 6,28 & 47,11 \\
\hline Vendedora & 26271 & 34,00 & 5,21 & 52,32 \\
\hline Auxiliar de escritónio & 22682 & 47,64 & 4,50 & 56,82 \\
\hline Cozinheira & 18791 & 74,85 & 3,73 & 60,55 \\
\hline Enfermeira não diplomada & 15264 & 87,07 & 3,03 & 63,58 \\
\hline Secretária & 12864 & 92,28 & 2,55 & 66,12 \\
\hline Assistente administrativa & 12645 & 61,28 & 2,51 & 68,63 \\
\hline Recepcionista & 11445 & 84,24 & 2,27 & 70,90 \\
\hline Lavadeira passadeira & 8858 & 93,66 & 1,76 & 72,66 \\
\hline Auxiliar administrativa & 8816 & 55,18 & 1,75 & 74,41 \\
\hline Operadora de caixa & 7515 & 86,32 & 1,49 & 75,90 \\
\hline Atendente de bar & 6684 & 55,35 & 1,33 & 77,23 \\
\hline Diretora/Assessora & 6094 & 37,27 & 1,21 & 78,43 \\
\hline Embaladora de mescadorias & 5971 & 40,66 & 1,18 & 79,62 \\
\hline Professora de $2^{\circ}$ grau & 5246 & 73,37 & 1,04 & 80,66 \\
\hline Encarregada administrativo & 4885 & 25,77 & 0,97 & 81,63 \\
\hline Orientadora de ensino & 4171 & 94,60 & 0,83 & 82,46 \\
\hline Professora de $5^{\mathrm{a}}$ a $8^{\mathrm{a}}$ séries & 3818 & 84,23 & 0,76 & 83,21 \\
\hline Trabalhadora Cons Rodoviário & 3601 & 66,67 & 0,71 & 83,93 \\
\hline Professora de pré.escola & 2990 & 100,00 & 0,59 & 84,52 \\
\hline Telefonista & 2990 & 100,00 & 0,59 & 85,11 \\
\hline Auxiliar de contabilidade & 2867 & 60,09 & 0,57 & 85,68 \\
\hline Operadora de máquinas p. automáticas & 2856 & 52,17 & 0,57 & 86,25 \\
\hline Camareira & 2514 & 100,00 & 0,50 & 86,75 \\
\hline Farinheira/ moleira & 2400 & 90,98 & 0,48 & 87,22 \\
\hline Repositora de mercadorias & 2276 & 25,72 & 0,45 & 87,67 \\
\hline Ouiras ocupaçōes ambulantes & 2143 & 49,90 & 0,43 & 88,10 \\
\hline Administradora de comércio de mercadorias & 2028 & 19,31 & 0,40 & 88,50 \\
\hline Manicure/pedicure & 1915 & 100,00 & 0,38 & 88,88 \\
\hline Cabeleireira & 1914 & 88,94 & 0,38 & 89,26 \\
\hline Trabalhadora de fábrica de sapatos & 1790 & 16,99 & 0,36 & 89,62 \\
\hline Caixa & 1666 & 38,80 & 0,33 & 89,95 \\
\hline Médica & 1666 & 35,86 & 0,33 & 90,28 \\
\hline Professora & 1438 & 100,00 & 0,29 & 90,56 \\
\hline Administradora de indústria de transformação & 1429 & 18,73 & 0,28 & 90,85 \\
\hline Inspetora alunos & 1428 & 85,71 & 0,28 & 91,13 \\
\hline Tecelã & 1428 & 41,32 & 0,28 & 91,41 \\
\hline Datilógrafa & 1315 & 64,81 & 0,26 & 91,67 \\
\hline Outras administradoras & 1314 & 22,96 & 0,26 & 91,93 \\
\hline Técnica em análises clínicas & 1314 & 100,00 & 0,26 & 92,19 \\
\hline Auxiliar de costura & 1314 & 100,00 & 0,26 & 92,45 \\
\hline Pracista e viajante & 1314 & 16,93 & 0,26 & 92,72 \\
\hline Aguadeira & 1200 & 100,00 & 0,24 & 92,95 \\
\hline Assistente social & 1191 & 100,00 & 0,24 & 93,19 \\
\hline Professora superior & 1190 & 71,43 & 0,24 & 93,43 \\
\hline Doceira/confeiteira & 1190 & 100,00 & 0,24 & 93,66 \\
\hline Outras Agentes Corretoras & 1190 & 62,50 & 0,24 & 93,90 \\
\hline Escritora/Jomalista & 1076 & 69,33 & 0,21 & 94,11 \\
\hline Advogada etc. & 953 & 33,24 & 0,19 & 94,30 \\
\hline Gargonete & 953 & 11,25 & 0,19 & 94,49 \\
\hline Psicóloga & 952 & 100,00 & 0,19 & 94,68 \\
\hline Carpinteira & 839 & 20,11 & 0,17 & 94,84 \\
\hline Outras Auxiliares da Justiça & 838 & 100,00 & 0,17 & 95,01 \\
\hline Magarefe & 838 & 30,45 & 0.17 & 95,18 \\
\hline Maçaroqueira & 715 & 60,03 & 0,14 & 95,32 \\
\hline Fiscal de tributos & 714 & 21,36 & 0.14 & 95,46 \\
\hline Bibliotecária & 714 & 100,00 & 0.14 & 95.60 \\
\hline
\end{tabular}


Tabela D8. Principais ocupações na absorção da mão-de-obra masculina assalariada.(1) Pernambuco, 1990.

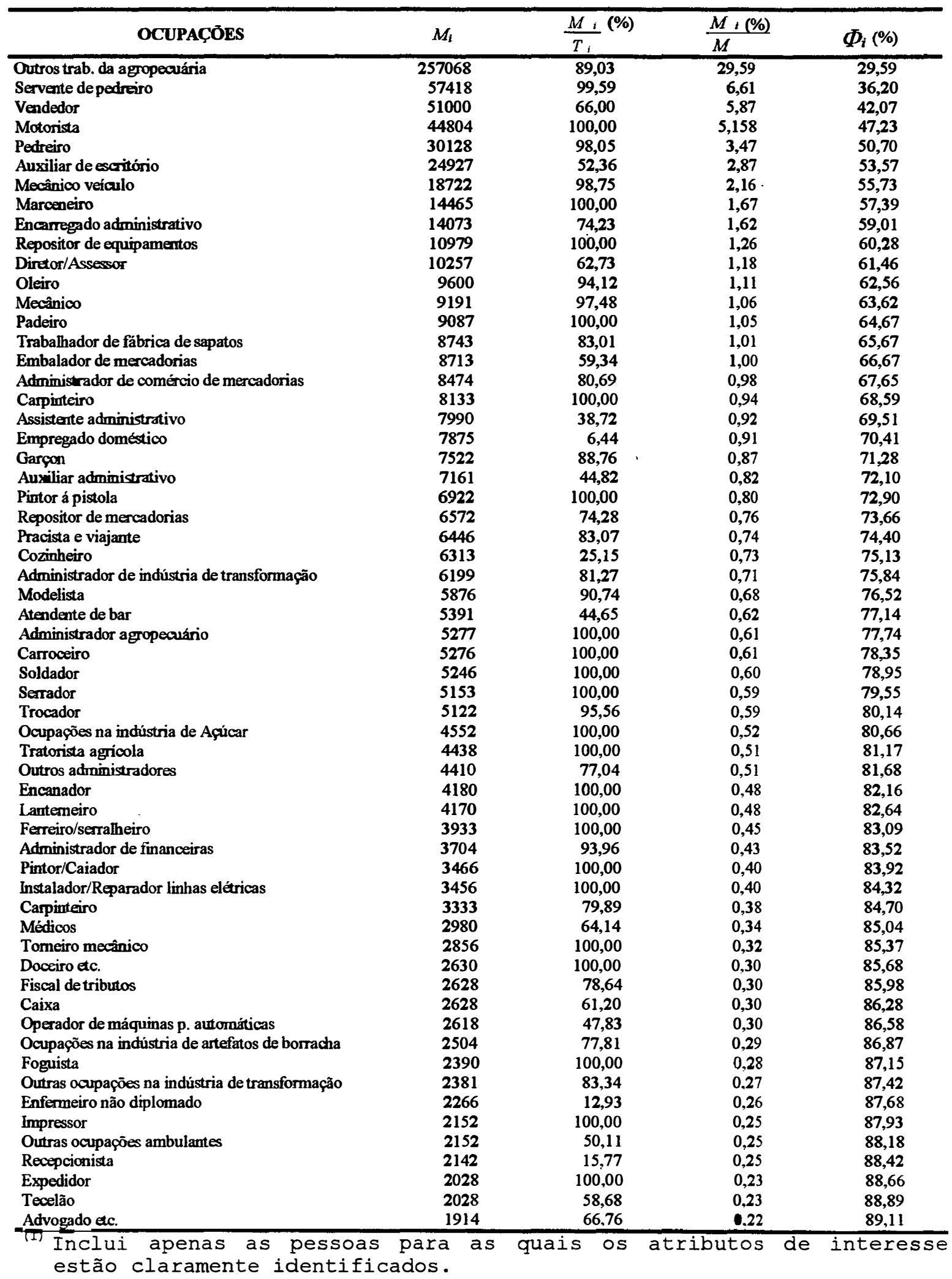


Tabela D9. Índice de segregação de Duncan (1). são Paulo e Pernambuco, 1981 a 1990.

\begin{tabular}{ccc}
\hline & \multicolumn{3}{c}{ INDICE D } \\
\cline { 2 - 3 } ANO & SÃO PAULO & PERNAMBUCO \\
\hline 1981 & 0,6045 & 0,5911 \\
1983 & 0,6045 & 0,5993 \\
1984 & 0,6197 & 0,6008 \\
1987 & 0,6053 & 0,6030 \\
1988 & 0,5877 & 0,6343 \\
1989 & 0,5988 & 0,6251 \\
1990 & 0,5965 & 0,6268 \\
\hline
\end{tabular}

(1) Calculado considerando-se apenas as pessoas ocupadas assalariadas que têm os atributos de interesse claramente identificados. 


\section{APÊNDICE E}

Tabela E1. Distribuição da PEA ocupada por classe. São Paulo, 1981 a 1990 ............................ 228

Tabela E2. Distribuição da PEA ocupada por classe. Pemambuco, 1981 a 1990 ....................... 229 
Tabela E1. Distribuição da PEA ocupada(1) por classe. São Paulo, 1981 a 1990.

\begin{tabular}{|c|c|c|c|c|c|c|}
\hline \multirow{2}{*}{ SEXO/ANO } & \multicolumn{6}{|c|}{ CLASSE } \\
\hline & 1 & 2 & 3 & 4 & 5 & TOTAL \\
\hline \multicolumn{7}{|l|}{ HOMENS } \\
\hline 1981 & $\begin{array}{r}84.999 \\
(195)\end{array}$ & $\begin{array}{r}79.365 \\
(182)\end{array}$ & $\begin{array}{r}649.318 \\
(1489)\end{array}$ & $\begin{array}{r}1.225 .890 \\
(2.823)\end{array}$ & $\begin{array}{r}3.856 .326 \\
(8853)\end{array}$ & $\begin{array}{r}5895.898 \\
(13542)\end{array}$ \\
\hline 1983 & $\begin{array}{r}107.883 \\
(251)\end{array}$ & $\begin{array}{r}90717 \\
(211)\end{array}$ & $\begin{array}{r}661266 \\
(1536)\end{array}$ & $\begin{array}{r}1605972 \\
(3761)\end{array}$ & $\begin{array}{r}3695024 \\
(8605)\end{array}$ & $\begin{array}{r}6160862 \\
(14364)\end{array}$ \\
\hline 1984 & $\begin{array}{r}113148 \\
(264)\end{array}$ & $\begin{array}{r}126057 \\
(293)\end{array}$ & $\begin{array}{r}848749 \\
(1976)\end{array}$ & $\begin{array}{r}1379053 \\
(3227)\end{array}$ & $\begin{array}{r}3952496 \\
(9217)\end{array}$ & $\begin{array}{r}6419503 \\
(14977)\end{array}$ \\
\hline 1985 & $\begin{array}{r}142352 \\
(322)\end{array}$ & $\begin{array}{r}110075 \\
(248)\end{array}$ & $\begin{array}{r}818899 \\
(1846)\end{array}$ & $\begin{array}{r}1050631 \\
(2372)\end{array}$ & $\begin{array}{r}4745729 \\
(10784)\end{array}$ & $\begin{array}{r}6867686 \\
(15572)\end{array}$ \\
\hline 1987 & $\begin{array}{r}125973 \\
(146)\end{array}$ & $\begin{array}{r}123592 \\
(140)\end{array}$ & $\begin{array}{r}809406 \\
(928)\end{array}$ & $\begin{array}{r}2065979 \\
(2399)\end{array}$ & $\begin{array}{r}4149703 \\
(4788)\end{array}$ & $\begin{array}{r}7274653 \\
(8401)\end{array}$ \\
\hline 1988 & $\begin{array}{r}143890 \\
(161)\end{array}$ & $\begin{array}{r}52317 \\
(58)\end{array}$ & $\begin{array}{r}1170669 \\
(1284)\end{array}$ & $\begin{array}{r}1840884 \\
(2057)\end{array}$ & $\begin{array}{r}4154873 \\
(4603)\end{array}$ & $\begin{array}{r}7362633 \\
(8163)\end{array}$ \\
\hline 1989 & $\begin{array}{r}149394 \\
(157)\end{array}$ & $\begin{array}{r}163797 \\
(168)\end{array}$ & $\begin{array}{r}1157158 \\
(1210)\end{array}$ & $\begin{array}{r}2006278 \\
(2140)\end{array}$ & $\begin{array}{r}4037652 \\
(4276)\end{array}$ & $\begin{array}{r}7514279 \\
(7951)\end{array}$ \\
\hline 1990 & $\begin{array}{r}156613 \\
(172)\end{array}$ & $\begin{array}{r}122366 \\
(131)\end{array}$ & $\begin{array}{r}1145130 \\
(1236)\end{array}$ & $\begin{array}{r}1869008 \\
(2042)\end{array}$ & $\begin{array}{r}4237972 \\
(4580)\end{array}$ & $\begin{array}{r}7531089 \\
(8161)\end{array}$ \\
\hline \multicolumn{7}{|l|}{ MULHERES } \\
\hline 1981 & $\begin{array}{r}1334845 \\
(3147)\end{array}$ & $\begin{array}{r}221396 \\
(522)\end{array}$ & 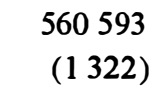 & $\begin{array}{r}442203 \\
\left(\begin{array}{ll}1 & 042\end{array}\right)\end{array}$ & $\begin{array}{r}213213 \\
(503)\end{array}$ & $\begin{array}{r}2772250 \\
(6536)\end{array}$ \\
\hline 1983 & $\begin{array}{r}1544017 \\
(3663)\end{array}$ & $\begin{array}{r}224494 \\
(532)\end{array}$ & $\begin{array}{r}650599 \\
(1539)\end{array}$ & $\begin{array}{r}558591 \\
(1 \quad 329)\end{array}$ & $\begin{array}{r}168849 \\
(399)\end{array}$ & $\begin{array}{r}3146550 \\
(7462)\end{array}$ \\
\hline 1984 & $\begin{array}{r}1700397 \\
(4033)\end{array}$ & $\begin{array}{r}306802 \\
(726)\end{array}$ & $\begin{array}{r}781770 \\
(1850)\end{array}$ & $\begin{array}{r}455132 \\
(1081)\end{array}$ & $\begin{array}{r}198155 \\
(468)\end{array}$ & $\begin{array}{r}3442256 \\
(8158)\end{array}$ \\
\hline 1985 & $\begin{array}{r}1756538 \\
(4 \quad 103)\end{array}$ & $\begin{array}{r}277952 \\
(649)\end{array}$ & $\begin{array}{r}735027 \\
(1709)\end{array}$ & $\begin{array}{r}462574 \\
(1075)\end{array}$ & $\begin{array}{r}375012 \\
(879)\end{array}$ & $\begin{array}{r}3607103 \\
(8415)\end{array}$ \\
\hline 1987 & $\begin{array}{r}1792599 \\
(2063)\end{array}$ & $\begin{array}{r}272885 \\
(312)\end{array}$ & $\begin{array}{r}834873 \\
(953)\end{array}$ & $\begin{array}{r}843860 \\
(972)\end{array}$ & $\begin{array}{r}191460 \\
(218)\end{array}$ & $\begin{array}{r}3935677 \\
(4518)\end{array}$ \\
\hline 1988 & $\begin{array}{r}1890532 \\
(2093)\end{array}$ & $\begin{array}{r}149402 \\
(165)\end{array}$ & $\begin{array}{r}1162425 \\
\quad(1274)\end{array}$ & $\begin{array}{r}660697 \\
(726)\end{array}$ & $\begin{array}{r}173890 \\
(190)\end{array}$ & $\begin{array}{r}4036946 \\
(4448)\end{array}$ \\
\hline 1989 & $\begin{array}{r}1857772 \\
(1968)\end{array}$ & $\begin{array}{r}403642 \\
(425)\end{array}$ & $\begin{array}{r}1188450 \\
(1245)\end{array}$ & $\begin{array}{r}676599 \\
(717)\end{array}$ & $\begin{array}{r}170405 \\
(176)\end{array}$ & $\begin{array}{r}4296868 \\
(4531)\end{array}$ \\
\hline 1990 & $\begin{array}{r}1947609 \\
(2112)\end{array}$ & $\begin{array}{r}310847 \\
(331)\end{array}$ & $\begin{array}{r}1124194 \\
\quad(1213)\end{array}$ & $\begin{array}{r}729996 \\
(786)\end{array}$ & $\begin{array}{r}232352 \\
(244)\end{array}$ & $\begin{array}{r}4344998 \\
(4686)\end{array}$ \\
\hline
\end{tabular}

Fonte: : Dados individuais das PNAD - 1981 a 1990.

(1) Número de observações para as quais os atributos de interesse estão claramente identificados. Os números entre parênteses referem-se ao tamanho da amostra. Os demais valores à população estimada através dos fatores de expansão.

(2) Porcentagem de mulheres ocupadas em relação à PEA ocupada. 
Tabela E2. Distribuição da PEA ocupada ${ }^{(1)}$ por classe. Pernambuco, 1981 a 1990 .

\begin{tabular}{|c|c|c|c|c|c|c|}
\hline \multirow[b]{2}{*}{ SEXO/ANO } & \multicolumn{6}{|c|}{ CLASSE } \\
\hline & 1 & 2 & 3 & 4 & 5 & TOTAL \\
\hline \multicolumn{7}{|l|}{ HOMENS } \\
\hline 1981 & $\begin{array}{r}11397 \\
(86)\end{array}$ & $\begin{array}{r}8057 \\
(61)\end{array}$ & $\begin{array}{r}55210 \\
(420)\end{array}$ & $\begin{array}{r}160940 \\
(981)\end{array}$ & $\begin{array}{r}898620 \\
(4246)\end{array}$ & $\begin{array}{r}1134224 \\
\quad(5794)\end{array}$ \\
\hline 1983 & $\begin{array}{r}15141 \\
(111)\end{array}$ & $\begin{array}{r}6976 \\
(49)\end{array}$ & $\begin{array}{r}57354 \\
(412)\end{array}$ & $\begin{array}{r}195776 \\
(1204)\end{array}$ & $\begin{array}{r}794660 \\
(4043)\end{array}$ & $\begin{array}{r}1069907 \\
(5819)\end{array}$ \\
\hline 1984 & $\begin{array}{r}14437 \\
(86)\end{array}$ & $\begin{array}{r}7727 \\
(50)\end{array}$ & $\begin{array}{r}67256 \\
(463)\end{array}$ & $\begin{array}{r}166108 \\
(978)\end{array}$ & $\begin{array}{r}949497 \\
(4483)\end{array}$ & $\begin{array}{r}1205025 \\
(6060)\end{array}$ \\
\hline 1985 & $\begin{array}{r}19434 \\
(117)\end{array}$ & $\begin{array}{r}10778 \\
(78)\end{array}$ & $\begin{array}{r}85822 \\
(592)\end{array}$ & $\begin{array}{r}184359 \\
(1039)\end{array}$ & $\begin{array}{r}933473 \\
(4406)\end{array}$ & $\begin{array}{r}1233866 \\
(6232)\end{array}$ \\
\hline 1987 & $\begin{array}{r}19781 \\
(66)\end{array}$ & $\begin{array}{r}16092 \\
(60)\end{array}$ & $\begin{array}{r}48585 \\
(178)\end{array}$ & $\begin{array}{r}253395 \\
(744)\end{array}$ & $\begin{array}{r}977704 \\
(2395)\end{array}$ & $\begin{array}{r}1315557 \\
(3443)\end{array}$ \\
\hline 1988 & $\begin{array}{r}23904 \\
(67)\end{array}$ & $\begin{array}{r}18546 \\
(69)\end{array}$ & $\begin{array}{r}88219 \\
(286)\end{array}$ & $\begin{array}{r}198919 \\
(584)\end{array}$ & $\begin{array}{r}969855 \\
(2313)\end{array}$ & $\begin{array}{r}1299443 \\
(3319)\end{array}$ \\
\hline 1989 & $\begin{array}{r}15270 \\
(51)\end{array}$ & $\begin{array}{r}24079 \\
(88)\end{array}$ & $\begin{array}{r}76671 \\
(268)\end{array}$ & $\begin{array}{r}245704 \\
(687)\end{array}$ & $\begin{array}{r}998969 \\
(2476)\end{array}$ & $\begin{array}{r}1360693 \\
(3570)\end{array}$ \\
\hline 1990 & $\begin{array}{r}21960 \\
(74)\end{array}$ & $\begin{array}{r}29939 \\
(106)\end{array}$ & $\begin{array}{r}80062 \\
(274)\end{array}$ & $\begin{array}{r}269743 \\
(791)\end{array}$ & $\begin{array}{r}947751 \\
(2330)\end{array}$ & $\begin{array}{r}1349455 \\
\quad(3575)\end{array}$ \\
\hline \multicolumn{7}{|l|}{ MULHERES } \\
\hline 1981 & $\begin{array}{r}229817 \\
(1492)\end{array}$ & $\begin{array}{r}20037 \\
(126)\end{array}$ & $\begin{array}{r}48159 \\
(361)\end{array}$ & $\begin{array}{r}72430 \\
(452)\end{array}$ & $\begin{array}{r}98425 \\
(370)\end{array}$ & $\begin{array}{r}468868 \\
(2801)\end{array}$ \\
\hline 1983 & $\begin{array}{r}257486 \\
(1623)\end{array}$ & $\begin{array}{r}13476 \\
(94)\end{array}$ & $\begin{array}{r}59483 \\
(420)\end{array}$ & $\begin{array}{r}83722 \\
(515)\end{array}$ & $\begin{array}{r}89892 \\
(379)\end{array}$ & $\begin{array}{r}504059 \\
(3031)\end{array}$ \\
\hline 1984 & $\begin{array}{r}266895 \\
(1601)\end{array}$ & $\begin{array}{r}19843 \\
(131)\end{array}$ & $\begin{array}{r}64937 \\
(444)\end{array}$ & $\begin{array}{r}75408 \\
(472) .\end{array}$ & $\begin{array}{r}117115 \\
(450)\end{array}$ & $\begin{array}{r}544198 \\
(3098)\end{array}$ \\
\hline 1985 & $\begin{array}{r}302222 \\
(1 \quad 807)\end{array}$ & $\begin{array}{r}26747 \\
(158)\end{array}$ & $\begin{array}{r}79072 \\
(506)\end{array}$ & $\begin{array}{r}85143 \\
(514)\end{array}$ & $\begin{array}{r}115447 \\
(440)\end{array}$ & $\begin{array}{r}608631 \\
(3425)\end{array}$ \\
\hline 1987 & $\begin{array}{r}367377 \\
(1096)\end{array}$ & $\begin{array}{r}34970 \\
(122)\end{array}$ & $\begin{array}{r}49864 \\
(166)\end{array}$ & $\begin{array}{r}121323 \\
(385)\end{array}$ & $\begin{array}{r}99288 \\
(192)\end{array}$ & $\begin{array}{r}672822 \\
(1961)\end{array}$ \\
\hline 1988 & $\begin{array}{r}344487 \\
(975)\end{array}$ & $\begin{array}{r}48146 \\
(157)\end{array}$ & $\begin{array}{r}80634 \\
(254)\end{array}$ & $\begin{array}{r}89760 \\
(271)\end{array}$ & $\begin{array}{r}98458 \\
(214)\end{array}$ & $\begin{array}{r}661485 \\
(1871)\end{array}$ \\
\hline 1989 & $\begin{array}{r}347973 \\
(1001)\end{array}$ & $\begin{array}{r}52907 \\
(174)\end{array}$ & $\begin{array}{r}75380 \\
(245)\end{array}$ & $\begin{array}{r}108499 \\
(330)\end{array}$ & $\begin{array}{r}107670 \\
(227)\end{array}$ & $\begin{array}{r}692429 \\
(1977)\end{array}$ \\
\hline 1990 & $\begin{array}{r}400564 \\
(1 \quad 149)\end{array}$ & $\begin{array}{r}69546 \\
(207) \\
\end{array}$ & $\begin{array}{r}78624 \\
(271)\end{array}$ & $\begin{array}{r}120289 \\
(370)\end{array}$ & $\begin{array}{r}67446 \\
(148) \\
\end{array}$ & $\begin{array}{r}736469 \\
(2145) \\
\end{array}$ \\
\hline
\end{tabular}

Fonte: : Dados individuais das PNAD - 1981 a 1990 .

(1) Número de observações para as quais os atributos de interesse estão claramente identificados. Os números entre parenteses referem-se ao tamanho da amostra. Os demais valores à população estimada através dos fatores de expansão.

(2) Porcentagem de mulheres ocupadas em relação à PEA ocupada. 


\section{APÊNDICE F}

Tabela F1. Coeficientes dos logitos multinomiais estimados (valores de $\mathrm{z}$ entre parênteses).

Pernambuco, 1981.

Tabela F2. Coeficientes dos logitos multinomiais estimados (valores de $z$ entre parênteses). Pernambuco, 1983.

Tabela F3. Coeficientes dos logitos multinomiais estimados (valores de $z$ entre parênteses). Pernambuco, 1984.

Tabela F4. Coeficientes dos logitos multinomiais estimados (valores de $z$ entre parênteses). Pernambuco, 1985.

Tabela F5. Coeficientes dos logitos multinomiais estimados (valores de $z$ entre parênteses). Pernambuco, 1987.

Tabela F6. Coeficientes dos logitos multinomiais estimados (valores de $z$ entre parênteses). Pernambuco, 1988.

Tabela F7. Coeficientes dos logitos multinomiais estimados (valores de $z$ entre parênteses). Pernambuco, 1989.

Tabela F8. Coeficientes dos logitos multinomiais estimados (valores de $z$ entre parênteses). Pernambuco, 1990.

Tabela F9. Coeficientes dos logitos multinomiais estimados (valores de $z$ entre parênteses). São Paulo, 1981.

Tabela F10. Coeficientes dos logitos multinomiais estimados (valores de $z$ entre parênteses). São Paulo, 1983.

Tabela F11. Coeficientes dos logitos multinomiais estimados (valores de $z$ entre parênteses). São Paulo, 1984.

Tabela F12. Coeficientes dos logitos multinomiais estimados (valores de $z$ entre parênteses). São Paulo, 1985.

Tabela F13. Coeficientes dos logitos multinomiais estimados (valores de $z$ entre parênteses). São Paulo, 1987.

Tabela F14. Coeficientes dos logitos multinomiais estimados (valores de $z$ entre parênteses). São Paulo, 1988.

Tabela F15. Coeficientes dos logitos multinomiais estimados (valores de $z$ entre parênteses). São Paulo, 1989.

Tabela F16. Coeficientes dos logitos multinomiais estimados (valores de $z$ entre parênteses). São Paulo, 1990. 
Tabela F1. Coeficientes dos logitos multinomiais estimados (valores de $z$ entre parênteses). Pernambuco, 1981.

\begin{tabular}{|c|c|c|c|c|}
\hline \multirow[b]{2}{*}{ VARIÁVEIS } & \multicolumn{4}{|c|}{ CLASSES } \\
\hline & 2 & 3 & 4 & 5 \\
\hline CONSTANTE & $\begin{array}{l}-2.3436 \\
(-1.756)\end{array}$ & $\begin{array}{c}-0.49634 \\
(-0.639)\end{array}$ & $\begin{array}{l}0.40277 \\
(0.581)\end{array}$ & $\begin{array}{l}3.6349 \\
(5.610)\end{array}$ \\
\hline OUTRAS RENDAS PESSOAIS & $\begin{array}{c}0.33494 \mathrm{E}-05 \\
(0.187)\end{array}$ & $\begin{array}{c}0.62741 \mathrm{E}-05 \\
(0.409)\end{array}$ & $\begin{array}{c}-0.57375 \mathrm{E}-06 \\
(-0.037)\end{array}$ & $\begin{array}{c}0.60274 \mathrm{E}-05 \\
(0.396)\end{array}$ \\
\hline OUTRAS RENDAS & $\begin{array}{c}-0.21459 \mathrm{E}-05 \\
(-0.446)\end{array}$ & $\begin{array}{c}-0.97071 \mathrm{E}-06 \\
(-0.422)\end{array}$ & $\begin{array}{c}-0.60578 \mathrm{E}-06 \\
(-0.277)\end{array}$ & $\begin{array}{c}-0.27543 \mathrm{E}-06 \\
(-0.133)\end{array}$ \\
\hline \multicolumn{5}{|l|}{ SITUAÇÃO } \\
\hline Região Urbana & $\begin{array}{r}0.56918 \\
(0.696)\end{array}$ & $\begin{array}{r}-0.57565 \\
(-1.238)\end{array}$ & $\begin{array}{r}0.37226 \\
(0.883)\end{array}$ & $\begin{array}{l}-1.4821 \\
(-3.654)\end{array}$ \\
\hline \multicolumn{5}{|l|}{ CRIANÇAS MENORES 6 ANOS } \\
\hline 1 & $\begin{array}{l}0.25661 \\
(0.540)\end{array}$ & $\begin{array}{r}-0.28910 \\
(-0.818)\end{array}$ & $\begin{array}{r}-0.14824 \\
(-0.450)\end{array}$ & $\begin{array}{r}-0.16639 \\
(-0.522)\end{array}$ \\
\hline 2 & $\begin{array}{r}-0.50020 \\
(-0.557)\end{array}$ & $\begin{array}{r}0.54100 \\
(1.000)\end{array}$ & $\begin{array}{r}0.50483 \\
(0.975)\end{array}$ & $\begin{array}{r}0.54907 \\
(1.083)\end{array}$ \\
\hline 3 ou mais & $\begin{array}{l}-1.9805 \\
(-1.336)\end{array}$ & $\begin{array}{r}-0.58817 \\
(-1.035)\end{array}$ & $\begin{array}{r}-0.13196 \\
(-0.262)\end{array}$ & $\begin{array}{c}-0.73120 \mathrm{E}-01 \\
(-0.150)\end{array}$ \\
\hline \multicolumn{5}{|l|}{ SITUAÇÃO NA FAMÍLIA } \\
\hline Chefe e Cônjuge & $\begin{array}{r}0.34260 \\
(0.343)\end{array}$ & $\begin{array}{r}0.14072 \\
(0.236)\end{array}$ & $\begin{array}{r}0.56720 \\
(0.987)\end{array}$ & $\begin{array}{c}0.90914 \\
(1.686)\end{array}$ \\
\hline Filho & $\begin{array}{l}1.2405 \\
(1.230)\end{array}$ & $\begin{array}{r}0.67000 \\
(1.141)\end{array}$ & $\begin{array}{l}1.2723 \\
(2.257)\end{array}$ & $\begin{array}{l}1.3955 \\
(2.638)\end{array}$ \\
\hline \multicolumn{5}{|l|}{ ESCOLARDADE } \\
\hline Primário Incompleto & $\begin{array}{c}0.80641 \mathrm{E}-02 \\
(0.011)\end{array}$ & $\begin{array}{l}1.0091 \\
(2.003)\end{array}$ & $\begin{array}{r}0.34554 \\
(0.860)\end{array}$ & $\begin{array}{c}-0.12164 \mathrm{E}-01 \\
(-0.031)\end{array}$ \\
\hline Primário Completo & $\begin{array}{l}0.31877 \\
(0.423)\end{array}$ & $\begin{array}{l}1.5280 \\
(2.711)\end{array}$ & $\begin{array}{r}0.16600 \\
(0.347)\end{array}$ & $\begin{array}{r}-0.11079 \\
(-0.239)\end{array}$ \\
\hline Ginásio Incompleto & $\begin{array}{r}-0.50032 \\
(-0.489)\end{array}$ & $\begin{array}{l}1.9672 \\
(3.279)\end{array}$ & $\begin{array}{c}0.33899 \\
(0.642)\end{array}$ & $\begin{array}{r}-0.37185 \\
(-0.722)\end{array}$ \\
\hline Ginásio Completo & $\begin{array}{l}1.5338 \\
(1.436)\end{array}$ & $\begin{array}{l}2.9997 \\
(3.328)\end{array}$ & $\begin{array}{r}0.89497 \\
(1.042)\end{array}$ & $\begin{array}{c}0.91292 \mathrm{E}-01 \\
(0.108)\end{array}$ \\
\hline Colegial e Superior & $\begin{array}{r}0.92439 \\
(1.426)\end{array}$ & $\begin{array}{l}2.1984 \\
(4.360)\end{array}$ & $\begin{array}{c}0.46759 \mathrm{E}-02 \\
(0.011)\end{array}$ & $\begin{array}{l}-1.3987 \\
(-3.345)\end{array}$ \\
\hline IDADE & & & & \\
\hline 18 a 19 anos & $\begin{array}{l}-1.3323 \\
(-0.829)\end{array}$ & $\begin{array}{r}0.22292 \\
(0.290)\end{array}$ & $\begin{array}{r}0.20537 \\
(0.296)\end{array}$ & $\begin{array}{r}0.76070 \\
(1.134)\end{array}$ \\
\hline 20 a 24 anos & $\begin{array}{c}0.13539 \\
(0.158)\end{array}$ & $\begin{array}{l}1.0170 \\
(1.697)\end{array}$ & $\begin{array}{r}0.15832 \\
(0.286)\end{array}$ & $\begin{array}{r}0.76618 \\
(1.436)\end{array}$ \\
\hline 25 a 29 anos & $\begin{array}{l}1.2916 \\
(1.261)\end{array}$ & $\begin{array}{l}1.8094 \\
(2.315)\end{array}$ & $\begin{array}{c}0.94476 \\
(1.271)\end{array}$ & $\begin{array}{l}1.6040 \\
(2.210)\end{array}$ \\
\hline 30 a 39 anos & $\begin{array}{l}1.0870 \\
(1.073)\end{array}$ & $\begin{array}{l}1.1769 \\
(1.589)\end{array}$ & $\begin{array}{r}0.79395 \\
(1.148)\end{array}$ & $\begin{array}{l}1.5067 \\
(2.243)\end{array}$ \\
\hline 40 a 49 anos & $\begin{array}{c}-0.62307 \mathrm{E}-02 \\
(-0.006)\end{array}$ & $\begin{array}{c}0.19260 \\
(0.268)\end{array}$ & $\begin{array}{r}-0.15723 \\
(-0.240)\end{array}$ & $\begin{array}{c}0.57624 \\
(0.912)\end{array}$ \\
\hline 50 anos ou mais & $\begin{array}{r}0.64884 \\
(0.634)\end{array}$ & $\begin{array}{r}0.52807 \\
(0.726)\end{array}$ & $\begin{array}{r}-0.31565 \\
(-0.476)\end{array}$ & $\begin{array}{r}0.23959 \\
(0.376)\end{array}$ \\
\hline POSIÇÃO NA OCUPAÇÃO & & & & \\
\hline Autônomo ou empregador & $\begin{array}{r}0.92794 \\
(1.395)\end{array}$ & $\begin{array}{r}-0.88466 \\
(-1.429)\end{array}$ & $\begin{array}{l}3.0258 \\
(6.104)\end{array}$ & $\begin{array}{l}1.6359 \\
(3.334) \\
\end{array}$ \\
\hline
\end{tabular}


Tabela F2. Coeficientes dos logitos multinomiais estimados (valores de $z$ entre parênteses). Pernambuco, 1983.

\begin{tabular}{|c|c|c|c|c|}
\hline \multirow[b]{2}{*}{ VARIÁVEIS } & \multicolumn{4}{|c|}{ CLASSES } \\
\hline & 2 & 3 & 4 & 5 \\
\hline CONSTANTE & $\begin{array}{l}-21.752 \\
(-0.001)\end{array}$ & $\begin{array}{r}0.96984 \\
(0.888)\end{array}$ & $\begin{array}{l}2.3306 \\
(2.256)\end{array}$ & $\begin{array}{l}5.3038 \\
(5.223)\end{array}$ \\
\hline OUTRAS RENDAS PESSOAIS & $\begin{array}{c}0.55084 \mathrm{E}-05 \\
(0.643)\end{array}$ & $\begin{array}{c}0.68785 \mathrm{E}-05 \\
(0.814)\end{array}$ & $\begin{array}{c}0.64693 E-05 \\
(0.766)\end{array}$ & $\begin{array}{c}0.68714 \mathrm{E}-05 \\
(0.814)\end{array}$ \\
\hline OUTRAS RENDAS & $\begin{array}{c}0.25891 \mathrm{E}-05 \\
(1.365)\end{array}$ & $\begin{array}{c}0.30772 \mathrm{E}-05 \\
(1.832)\end{array}$ & $\begin{array}{c}0.28731 \mathrm{E}-05 \\
(1.720)\end{array}$ & $\begin{array}{c}0.24524 \mathrm{E}-05 \\
(1.476)\end{array}$ \\
\hline SITUAÇÃO & & & & \\
\hline Região Urbana & $\begin{array}{l}-1.0467 \\
(-1.648)\end{array}$ & $\begin{array}{r}-0.46905 \\
(-1.117)\end{array}$ & $\begin{array}{l}0.13975 \\
(0.364)\end{array}$ & $\begin{array}{l}-1.5772 \\
(-4.270)\end{array}$ \\
\hline CRIANÇAS MENORES 6 ANOS & & & & \\
\hline 1 & $\begin{array}{r}0.14063 \\
(0.284)\end{array}$ & $\begin{array}{r}0.25004 \\
(0.788)\end{array}$ & $\begin{array}{r}0.26133 \\
(0.891)\end{array}$ & $\begin{array}{r}0.27699 \\
(0.974)\end{array}$ \\
\hline 2 & $\begin{array}{r}-0.43764 \\
(-0.577)\end{array}$ & $\begin{array}{r}0.52567 \\
(1.227)\end{array}$ & $\begin{array}{r}0.68886 \\
(1.727)\end{array}$ & $\begin{array}{r}0.67632 \\
(1.734)\end{array}$ \\
\hline 3 ou mais & $\begin{array}{l}0.36871 \\
(0.406)\end{array}$ & $\begin{array}{r}0.67720 \\
(1.158)\end{array}$ & $\begin{array}{r}0.93450 \\
(1.727)\end{array}$ & $\begin{array}{r}0.97708 \\
(1.842)\end{array}$ \\
\hline SITUAÇÃO NA FAMÍLIA & & & & \\
\hline Chefe e Cônjuge & $\begin{array}{r}-0.32840 \\
(-0.197)\end{array}$ & $\begin{array}{r}-0.98233 \\
(-0.947)\end{array}$ & $\begin{array}{l}-1.1299 \\
(-1.134)\end{array}$ & $\begin{array}{r}-0.82752 \\
(-0.841)\end{array}$ \\
\hline Filho & $\begin{array}{c}-0.91575 \mathrm{E}-01 \\
(-0.056)\end{array}$ & $\begin{array}{r}-0.86530 \\
(-0.871)\end{array}$ & $\begin{array}{l}-1.1939 \\
(-1.249)\end{array}$ & $\begin{array}{r}-0.93425 \\
(-0.990)\end{array}$ \\
\hline ESCOLARIDADE & & & & \\
\hline Primário Incompleto & $\begin{array}{l}-1.8390 \\
(-1.294)\end{array}$ & $\begin{array}{l}0.59927 \\
(1.403)\end{array}$ & $\begin{array}{c}0.18453 \\
(0.512)\end{array}$ & $\begin{array}{r}-0.12024 \\
(-0.344)\end{array}$ \\
\hline Pnináno Completo & $\begin{array}{r}-0.16873 \\
(-0.189)\end{array}$ & $\begin{array}{l}0.95833 \\
(2.113)\end{array}$ & $\begin{array}{r}0.17320 \\
(0.440)\end{array}$ & $\begin{array}{r}-0.14504 \\
(-0.381)\end{array}$ \\
\hline Ginásio Incompleto & $\begin{array}{l}1.0697 \\
(1.464)\end{array}$ & $\begin{array}{l}1.0464 \\
(2.268)\end{array}$ & $\begin{array}{r}0.13640 \\
(0.338)\end{array}$ & $\begin{array}{r}-0.44509 \\
(-1.137)\end{array}$ \\
\hline Ginásio Completo & $\begin{array}{r}-0.13127 \\
(-0.142)\end{array}$ & $\begin{array}{r}0.70240 \\
(1.402)\end{array}$ & $\begin{array}{r}-0.36994 \\
(-0.838)\end{array}$ & $\begin{array}{l}-1.3865 \\
(-3.262)\end{array}$ \\
\hline Colegial e Superior & $\begin{array}{l}1.5397 \\
(2.203)\end{array}$ & $\begin{array}{l}1.7412 \\
(3.830)\end{array}$ & $\begin{array}{r}0.45611 \\
(1.117)\end{array}$ & $\begin{array}{l}-1.0855 \\
(-2.723)\end{array}$ \\
\hline İDÁDE & & & & \\
\hline 18 a 19 anos & $\begin{array}{l}21.008 \\
(0.001)\end{array}$ & $\begin{array}{r}0.37602 \\
(0.562)\end{array}$ & $\begin{array}{r}0.47494 \\
(0.773)\end{array}$ & $\begin{array}{r}0.67163 \\
(1.125)\end{array}$ \\
\hline 20 a 24 anos & $\begin{array}{l}21.013 \\
(0.001)\end{array}$ & $\begin{array}{c}0.43593 E-01 \\
(0.087)\end{array}$ & $\begin{array}{r}-0.22911 \\
(-0.498)\end{array}$ & $\begin{array}{r}0.32819 \\
(0.743)\end{array}$ \\
\hline 25 a 29 anos & $\begin{array}{l}22.088 \\
(0.001)\end{array}$ & $\begin{array}{l}1.0664 \\
(1.610)\end{array}$ & $\begin{array}{r}0.68872 \\
(1.102)\end{array}$ & $\begin{array}{l}1.3723 \\
(2.250)\end{array}$ \\
\hline 30 a 39 anos & $\begin{array}{l}21.953 \\
(0.001)\end{array}$ & $\begin{array}{r}0.33117 \\
(0.550)\end{array}$ & $\begin{array}{c}0.70709 \mathrm{E}-01 \\
(0.127)\end{array}$ & $\begin{array}{r}0.73691 \\
(1.373)\end{array}$ \\
\hline 40 a 49 anos & $\begin{array}{l}20.883 \\
(0.001)\end{array}$ & $\begin{array}{r}0.31277 \\
(0.493)\end{array}$ & $\begin{array}{c}-0.23822 \mathrm{E}-01 \\
(-0.041)\end{array}$ & $\begin{array}{r}0.45241 \\
(0.804)\end{array}$ \\
\hline 50 anos ou mais & $\begin{array}{l}20.683 \\
(0.001)\end{array}$ & $\begin{array}{r}0.17037 \\
(0.258)\end{array}$ & $\begin{array}{c}-0.19308 \\
(-0.322)\end{array}$ & $\begin{array}{r}0.34780 \\
(0.599)\end{array}$ \\
\hline $\begin{array}{l}\text { POSIÇÃO NA OCUPAÇÃO } \\
\text { Autônomo ou empregador }\end{array}$ & $\begin{array}{r}0.73230 \\
(1.453) \\
\end{array}$ & $\begin{array}{r}0.22045 \\
(0.647) \\
\end{array}$ & $\begin{array}{r}1.8457 \\
(5.966) \\
\end{array}$ & $\begin{array}{r}0.44570 \\
(1.464) \\
\end{array}$ \\
\hline
\end{tabular}


Tabela F3. Coeficientes dos logitos multinomiais estimados (valores de $z$ entre parênteses). Pernambuco, 1984.

\begin{tabular}{|c|c|c|c|c|}
\hline \multirow[b]{2}{*}{ VARIAVEIS } & \multicolumn{4}{|c|}{ CLASSES } \\
\hline & 2 & 3 & 4 & 5 \\
\hline CONSTANTE & $\begin{array}{l}-2.9231 \\
(-1.681)\end{array}$ & $\begin{array}{c}-0.15288 \\
(-0.177)\end{array}$ & $\begin{array}{l}0.86229 \\
(1.076)\end{array}$ & $\begin{array}{l}4.4783 \\
(5.867)\end{array}$ \\
\hline OUTRAS RENDAS PESSOAIS & $\begin{array}{c}-0.15924 \mathrm{E}-04 \\
(-0.910)\end{array}$ & $\begin{array}{c}0.28275 E-05 \\
(0.700)\end{array}$ & $\begin{array}{c}0.28042 \mathrm{E}-05 \\
(0.695)\end{array}$ & $\begin{array}{c}0.25833 E-05 \\
(0.640)\end{array}$ \\
\hline OUTRAS RENDAS & $\begin{array}{c}0.13746 \mathrm{E}-06 \\
(0.303)\end{array}$ & $\begin{array}{c}0.22043 E-06 \\
(0.581)\end{array}$ & $\begin{array}{c}0.21329 E-06 \\
(0.564)\end{array}$ & $\begin{array}{c}0.21319 E-06 \\
(0.568)\end{array}$ \\
\hline \multicolumn{5}{|l|}{ SITUAÇÃO } \\
\hline Região Urbana & $\begin{array}{c}0.59034 \mathrm{E}-01 \\
(0.092)\end{array}$ & $\begin{array}{r}0.52263 \\
(1.368)\end{array}$ & $\begin{array}{r}0.52672 \\
(1.619)\end{array}$ & $\begin{array}{r}-0.95214 \\
(-3.090)\end{array}$ \\
\hline \multicolumn{5}{|l|}{ CRIANÇAS MENORES 6 ANOS } \\
\hline 1 & $\begin{array}{r}0.20502 \\
(0.381)\end{array}$ & $\begin{array}{c}0.42450 \mathrm{E}-01 \\
(0.122)\end{array}$ & $\begin{array}{r}0.19300 \\
(0.585)\end{array}$ & $\begin{array}{r}0.22744 \\
(0.713)\end{array}$ \\
\hline 2 & $\begin{array}{c}0.12295 E-01 \\
(0.022)\end{array}$ & $\begin{array}{r}-0.43836 \\
(-1.194)\end{array}$ & $\begin{array}{r}-0.27815 \\
(-0.817)\end{array}$ & $\begin{array}{c}-0.32253 \\
(-0.991)\end{array}$ \\
\hline 3 ou mais & $\begin{array}{r}0.57232 \\
(0.608)\end{array}$ & $\begin{array}{r}-0.21059 \\
(-0.322)\end{array}$ & $\begin{array}{r}0.52362 \\
(0.911)\end{array}$ & $\begin{array}{r}0.77860 \\
(1.398)\end{array}$ \\
\hline \multicolumn{5}{|l|}{ SITUAÇÃO NA FAMÍLIA } \\
\hline Chefe e Cônjuge & $\begin{array}{c}0.59523 \\
(0.380)\end{array}$ & $\begin{array}{c}-0.91153 E-01 \\
(-0.113)\end{array}$ & $\begin{array}{c}-0.14383 \\
(-0.186)\end{array}$ & $\begin{array}{c}0.80736 \mathrm{E}-02 \\
(0.011)\end{array}$ \\
\hline Filho & $\begin{array}{r}0.63655 \\
(0.418)\end{array}$ & $\begin{array}{r}-0.27077 \\
(-0.358)\end{array}$ & $\begin{array}{r}-0.54012 \\
(-0.743)\end{array}$ & $\begin{array}{r}-0.31212 \\
(-0.446)\end{array}$ \\
\hline \multicolumn{5}{|l|}{ ESCOLARIDADE } \\
\hline Primário Incompleto & $\begin{array}{r}0.54039 \\
(0.630)\end{array}$ & $\begin{array}{r}0.72131 \\
(1.704)\end{array}$ & $\begin{array}{c}0.34678 \\
(1.005)\end{array}$ & $\begin{array}{r}-0.13747 \\
(-0.417)\end{array}$ \\
\hline Primário Completo & $\begin{array}{l}1.9489 \\
(2.099)\end{array}$ & $\begin{array}{l}2.0038 \\
(3.534)\end{array}$ & $\begin{array}{l}1.2215 \\
(2.368)\end{array}$ & $\begin{array}{c}0.54316 \\
(1.078)\end{array}$ \\
\hline Ginásio Incompleto & $\begin{array}{l}1.1970 \\
(1.328)\end{array}$ & $\begin{array}{l}1.3832 \\
(2.893)\end{array}$ & $\begin{array}{c}0.50128 \\
(1.193)\end{array}$ & $\begin{array}{r}-0.53959 \\
(-1.336)\end{array}$ \\
\hline Ginásio Completo & $\begin{array}{l}-9.4959 \\
(-0.072)\end{array}$ & $\begin{array}{l}1.3576 \\
(2.475)\end{array}$ & $\begin{array}{r}-0.19197 \\
(-0.383)\end{array}$ & $\begin{array}{l}-1.0405 \\
(-2.190)\end{array}$ \\
\hline Colegial e Superior & $\begin{array}{l}3.0609 \\
(3.799)\end{array}$ & $\begin{array}{l}2.5538 \\
(5.304)\end{array}$ & $\begin{array}{r}0.86612 \\
(1.994)\end{array}$ & $\begin{array}{r}-0.68357 \\
(-1.624)\end{array}$ \\
\hline \multicolumn{5}{|l|}{ IDADE } \\
\hline 18 a 19 anos & $\begin{array}{r}-0.74149 \\
(-0.467)\end{array}$ & $\begin{array}{r}0.40076 \\
(0.540)\end{array}$ & $\begin{array}{r}0.97219 \\
(1.370)\end{array}$ & $\begin{array}{r}0.96775 \\
(1.424)\end{array}$ \\
\hline 20 a 24 anos & $\begin{array}{r}0.38775 \\
(0.446)\end{array}$ & $\begin{array}{l}0.49253 \\
(0.892)\end{array}$ & $\begin{array}{r}0.83395 \\
(1.568)\end{array}$ & $\begin{array}{r}0.86045 \\
(1.703)\end{array}$ \\
\hline 25 a 29 anos & $\begin{array}{r}-0.20081 \\
(-0.216)\end{array}$ & $\begin{array}{r}-0.10724 \\
(-0.183)\end{array}$ & $\begin{array}{r}0.13656 \\
(0.243)\end{array}$ & $\begin{array}{r}0.46115 \\
(0.868)\end{array}$ \\
\hline 30 a 39 anos & $\begin{array}{c}-0.67298 \mathrm{E}-01 \\
(-0.071)\end{array}$ & $\begin{array}{r}-0.41498 \\
(-0.699)\end{array}$ & $\begin{array}{r}0.11253 \\
(0.199)\end{array}$ & $\begin{array}{r}0.37280 \\
(0.696)\end{array}$ \\
\hline 40 a 49 anos & $\begin{array}{r}-0.38849 \\
(-0.367)\end{array}$ & $\begin{array}{r}-0.55934 \\
(-0.858)\end{array}$ & $\begin{array}{r}0.21665 \\
(0.352)\end{array}$ & $\begin{array}{r}0.21457 \\
(0.366)\end{array}$ \\
\hline 50 anos ou mais & $\begin{array}{r}-0.35586 \\
(-0.306)\end{array}$ & $\begin{array}{l}-0.38062 \\
(-0.553)\end{array}$ & $\begin{array}{c}0.70659 \mathrm{E}-01 \\
(0.109)\end{array}$ & $\begin{array}{l}0.20783 \\
(0.334)\end{array}$ \\
\hline POSIÇÃO NA OCUPAÇÃO & & & & \\
\hline Autônomo ou empregador & $\begin{array}{r}0.81565 \\
(1.669) \\
\end{array}$ & $\begin{array}{r}0.50832 \\
(1.531) \\
\end{array}$ & $\begin{array}{r}1.6466 \\
(5.306) \\
\end{array}$ & $\begin{array}{l}0.43961 \\
(1.453)\end{array}$ \\
\hline
\end{tabular}


Tabela F4. Coeficientes dos logitos multinomiais estimados (valores de $z$ entre parênteses). Pernambuco, 1985.

\begin{tabular}{|c|c|c|c|c|}
\hline \multirow[b]{2}{*}{ VARIÁVEIS } & \multicolumn{4}{|c|}{ CLASSES } \\
\hline & 2 & 3 & 4 & 5 \\
\hline CONSTANTE & $\begin{array}{l}-2.7293 \\
(-2.031)\end{array}$ & $\begin{array}{r}-0.65202 \\
(-0.845)\end{array}$ & $\begin{array}{l}0.79721 \\
(1.114)\end{array}$ & $\begin{array}{l}4.4392 \\
(6.582)\end{array}$ \\
\hline OUTRAS RENDAS PESSOAIS & $\begin{array}{c}0.52402 \mathrm{E}-06 \\
(0.879)\end{array}$ & $\begin{array}{c}0.24899 \mathrm{E}-06 \\
(0.427)\end{array}$ & $\begin{array}{c}0.40195 \mathrm{E}-06 \\
(0.694)\end{array}$ & $\begin{array}{c}0.39255 \mathrm{E}-06 \\
(0.682)\end{array}$ \\
\hline OUTRAS RENDAS & $\begin{array}{c}0.83648 \mathrm{E}-07 \\
(0.763)\end{array}$ & $\begin{array}{c}0.20027 \mathrm{E}-07 \\
(0.217)\end{array}$ & $\begin{array}{c}0.77954 \mathrm{E}-07 \\
(0.848)\end{array}$ & $\begin{array}{c}-0.41984 \mathrm{E}-07 \\
(-0.462)\end{array}$ \\
\hline SITUAÇÃO & & & & \\
\hline Região Urbana & $\begin{array}{r}0.77335 \\
(1.037)\end{array}$ & $\begin{array}{l}1.1036 \\
(3.011)\end{array}$ & $\begin{array}{r}0.58485 \\
(1.970)\end{array}$ & $\begin{array}{l}-1.0316 \\
(-3.688)\end{array}$ \\
\hline CRIANÇAS MENORES 6 ANOS & & & & \\
\hline 1 & $\begin{array}{r}0.23784 \\
(0.540)\end{array}$ & $\begin{array}{c}0.15260 \\
(0.517)\end{array}$ & $\begin{array}{l}0.13779 \\
(0.493)\end{array}$ & $\begin{array}{r}0.29119 \\
(1.091)\end{array}$ \\
\hline 2 & $\begin{array}{r}-0.18809 \\
(-0.308)\end{array}$ & $\begin{array}{r}0.24626 \\
(0.663)\end{array}$ & $\begin{array}{r}0.26295 \\
(0.748)\end{array}$ & $\begin{array}{r}0.17609 \\
(0.522)\end{array}$ \\
\hline 3 ou mais & $\begin{array}{c}-0.57465 \mathrm{E}-01 \\
(-0.051)\end{array}$ & $\begin{array}{l}1.0186 \\
(1.637)\end{array}$ & $\begin{array}{r}0.85604 \\
(1.431)\end{array}$ & $\begin{array}{l}1.2656 \\
(2.172)\end{array}$ \\
\hline SITUAÇÃO NA FAMÍLIA & & & & \\
\hline Chefe e Cônjuge & $\begin{array}{l}-1.1527 \\
(-1.277)\end{array}$ & $\begin{array}{r}-0.70720 \\
(-0.992)\end{array}$ & $\begin{array}{r}-0.15063 \\
(-0.216)\end{array}$ & $\begin{array}{r}-0.41494 \\
(-0.625)\end{array}$ \\
\hline Filho & $\begin{array}{l}-1.3318 \\
(-1.567)\end{array}$ & $\begin{array}{r}-0.41591 \\
(-0.627)\end{array}$ & $\begin{array}{r}-0.29678 \\
(-0.458)\end{array}$ & $\begin{array}{r}-0.47497 \\
(-0.771)\end{array}$ \\
\hline ESCOLARIDADE & & & & \\
\hline Primário Incompleto & $\begin{array}{c}0.30948 \\
(0.369)\end{array}$ & $\begin{array}{r}0.60719 \\
(1.618)\end{array}$ & $\begin{array}{r}0.32130 \\
(0.998)\end{array}$ & $\begin{array}{r}-0.35285 \\
(-1.149)\end{array}$ \\
\hline Primário Completo & $\begin{array}{l}1.0880 \\
(1.415)\end{array}$ & $\begin{array}{c}0.97376 \\
(2.416)\end{array}$ & $\begin{array}{c}0.23745 \\
(0.657)\end{array}$ & $\begin{array}{r}-0.34621 \\
(-1.003)\end{array}$ \\
\hline Ginásio Incompleto & $\begin{array}{l}1.4871 \\
(1.957)\end{array}$ & $\begin{array}{r}0.96601 \\
(2.312)\end{array}$ & $\begin{array}{c}0.20620 \\
(0.547)\end{array}$ & $\begin{array}{r}-0.46023 \\
(-1.279)\end{array}$ \\
\hline Ginásio Completo & $\begin{array}{l}1.7610 \\
(1.881)\end{array}$ & $\begin{array}{l}1.8768 \\
(3.160)\end{array}$ & $\begin{array}{c}0.63359 \\
(1.107)\end{array}$ & $\begin{array}{r}-0.38412 \\
(-0.693)\end{array}$ \\
\hline Colegial e Superior & $\begin{array}{l}1.8741 \\
(2.625)\end{array}$ & $\begin{array}{l}1.6449 \\
(4.134)\end{array}$ & $\begin{array}{c}0.49140 \mathrm{E}-01 \\
(0.133)\end{array}$ & $\begin{array}{l}-1.4117 \\
(-4.008)\end{array}$ \\
\hline DADE & & & & \\
\hline 18 a 19 anos & $\begin{array}{r}0.94842 \\
(0.822)\end{array}$ & $\begin{array}{r}0.50786 \\
(0.864)\end{array}$ & $\begin{array}{r}0.45351 \\
(0.816)\end{array}$ & $\begin{array}{r}0.83597 \\
(1.581)\end{array}$ \\
\hline 20 a 24 anos & $\begin{array}{r}0.94028 \\
(1.017)\end{array}$ & $\begin{array}{r}0.24888 \\
(0.588)\end{array}$ & $\begin{array}{r}-0.17269 \\
(-0.433)\end{array}$ & $\begin{array}{r}0.47160 \\
(1.268)\end{array}$ \\
\hline 25 a 29 anos & $\begin{array}{l}1.5684 \\
(1.610)\end{array}$ & $\begin{array}{r}0.38042 \\
(0.751)\end{array}$ & $\begin{array}{c}0.73384 \mathrm{E}-01 \\
(0.153)\end{array}$ & $\begin{array}{r}0.83446 \\
(1.841)\end{array}$ \\
\hline 30 a 39 anos & $\begin{array}{l}1.2725 \\
(1.259)\end{array}$ & $\begin{array}{r}0.66847 \\
(1.277)\end{array}$ & $\begin{array}{l}0.16522 \\
(0.332)\end{array}$ & $\begin{array}{r}0.96470 \\
(2.044)\end{array}$ \\
\hline 40 a 49 anos & $\begin{array}{l}1.4128 \\
(1.335)\end{array}$ & $\begin{array}{r}0.61047 \\
(1.079)\end{array}$ & $\begin{array}{c}0.69941 E-02 \\
(0.013)\end{array}$ & $\begin{array}{r}0.78490 \\
(1.550)\end{array}$ \\
\hline 50 anos ou mais & $\begin{array}{l}1.4471 \\
(1.342)\end{array}$ & $\begin{array}{r}0.82266 \\
(1.434)\end{array}$ & $\begin{array}{r}-0.35009 \\
(-0.647)\end{array}$ & $\begin{array}{r}0.48863 \\
(0.954)\end{array}$ \\
\hline POSIÇÃO NA OCUPAÇÃO & & & & \\
\hline Autônomo ou empregador & $\begin{array}{l}0.11562 \\
(0.236)\end{array}$ & $\begin{array}{l}0.42161 \\
(1.310) \\
\end{array}$ & $\begin{array}{l}2.2460 \\
(7.402)\end{array}$ & $\begin{array}{l}0.61858 \\
(2.085)\end{array}$ \\
\hline
\end{tabular}


Tabela F5. Coeficientes dos logitos multinomiais estimados (valores de $z$ entre parênteses). Pernambuco, 1987.

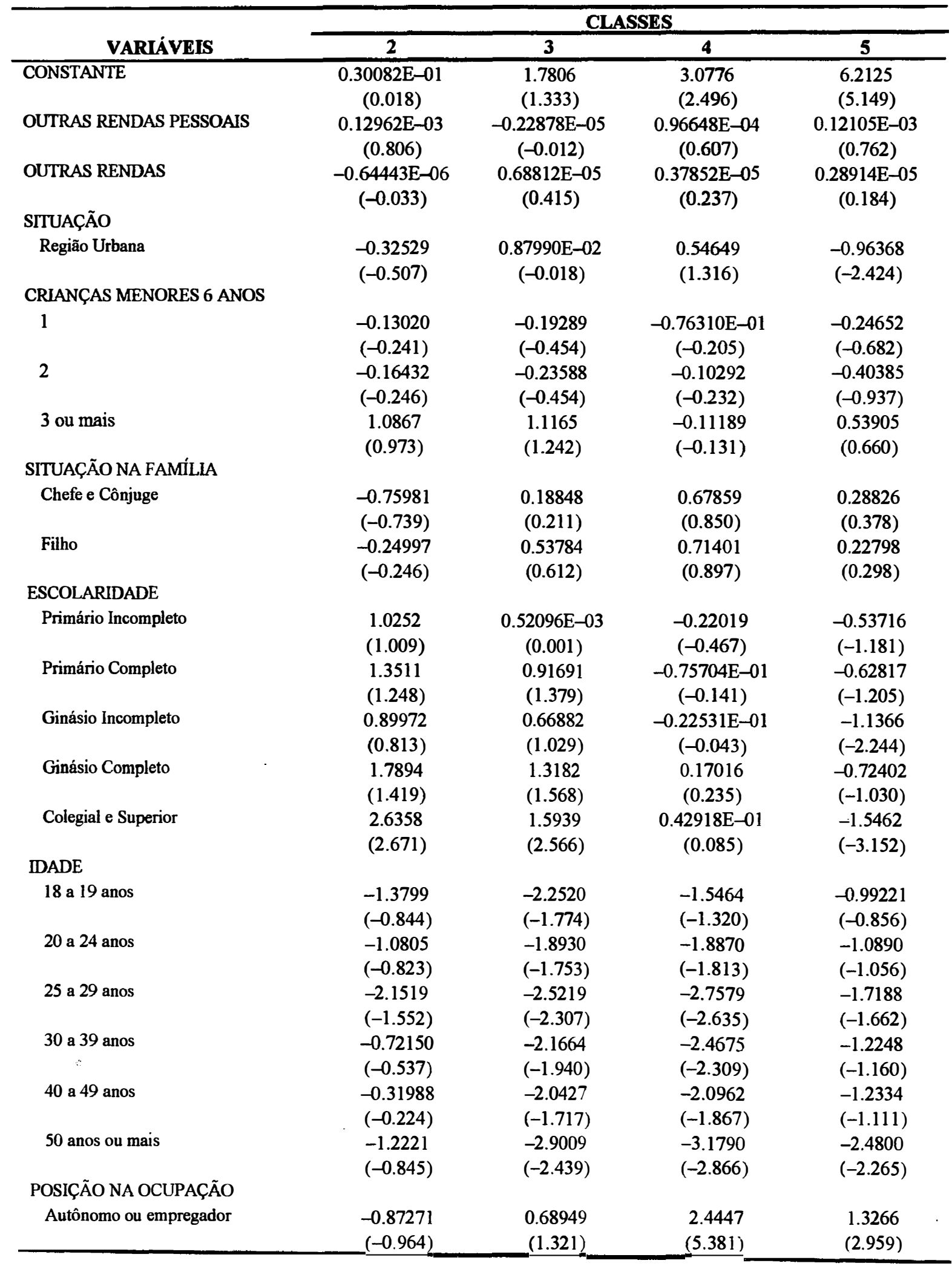


Tabela F6. Coeficientes dos logitos multinomiais estimados (valores de $z$ entre parênteses). Pernambuco, 1988.

\begin{tabular}{|c|c|c|c|c|}
\hline \multirow[b]{2}{*}{ VARIÁVEIS } & \multicolumn{4}{|c|}{ CLASSES } \\
\hline & 2 & 3 & 4 & 5 \\
\hline CONSTANTE & $\begin{array}{l}-2.9128 \\
(-1.875)\end{array}$ & $\begin{array}{c}-0.15093 \\
(-0.157)\end{array}$ & $\begin{array}{l}1.7109 \\
(1.953)\end{array}$ & $\begin{array}{l}4.6772 \\
(5.647)\end{array}$ \\
\hline OUTRAS RENDAS PESSOAIS & $\begin{array}{c}0.35931 \mathrm{E}-04 \\
(1.125)\end{array}$ & $\begin{array}{c}0.39331 \mathrm{E}-04 \\
(1.238)\end{array}$ & $\begin{array}{c}0.36276 \mathrm{E}-04 \\
(1.142)\end{array}$ & $\begin{array}{c}0.37680 \mathrm{E}-04 \\
(1.188)\end{array}$ \\
\hline OUTRAS RENDAS & $\begin{array}{c}-0.62031 E-07 \\
(-0.047)\end{array}$ & $\begin{array}{c}0.10727 \mathrm{E}-06 \\
(0.118)\end{array}$ & $\begin{array}{c}0.61150 \mathrm{E}-06 \\
(0.704)\end{array}$ & $\begin{array}{c}-0.10995 E-06 \\
(-0.124)\end{array}$ \\
\hline \multicolumn{5}{|l|}{ SITUAÇÃO } \\
\hline Região Urbana & $\begin{array}{l}1.4625 \\
(1.707)\end{array}$ & $\begin{array}{r}0.63680 \\
(1.421)\end{array}$ & $\begin{array}{r}0.21952 \\
(0.568)\end{array}$ & $\begin{array}{r}-0.76844 \\
(-2.118)\end{array}$ \\
\hline \multicolumn{5}{|l|}{ CRIANÇAS MENORES 6 ANOS } \\
\hline 1 & $\begin{array}{c}0.34726 \\
(0.680)\end{array}$ & $\begin{array}{c}0.46456 \\
(1.186)\end{array}$ & $\begin{array}{r}0.11882 \\
(0.318)\end{array}$ & $\begin{array}{l}0.13716 \\
(0.381)\end{array}$ \\
\hline 2 & $\begin{array}{c}0.80838 \mathrm{E}-01 \\
(0.122)\end{array}$ & $\begin{array}{c}0.11242 E-01 \\
(0.022)\end{array}$ & $\begin{array}{r}-0.24769 \\
(-0.518)\end{array}$ & $\begin{array}{c}-0.35447 \mathrm{E}-01 \\
(-0.077)\end{array}$ \\
\hline 3 ou mais & $\begin{array}{r}0.16591 \\
(0.161)\end{array}$ & $\begin{array}{c}0.24919 \\
(0.331)\end{array}$ & $\begin{array}{c}-0.50890 \mathrm{E}-01 \\
(-0.073)\end{array}$ & $\begin{array}{r}0.48226 \\
(0.736)\end{array}$ \\
\hline \multicolumn{5}{|l|}{ SITUAÇÃO NA FAMÍLIA } \\
\hline Chefe e Cônjuge & $\begin{array}{c}-0.77157 \mathrm{E}-01 \\
(-0.082)\end{array}$ & $\begin{array}{r}-0.51310 \\
(-0.699)\end{array}$ & $\begin{array}{r}0.22092 \\
(0.309)\end{array}$ & $\begin{array}{r}0.17535 \\
(0.256)\end{array}$ \\
\hline Filho & $\begin{array}{c}-0.65610 \\
(-0.714)\end{array}$ & $\begin{array}{r}-0.75189 \\
(-1.052)\end{array}$ & $\begin{array}{r}-0.93645 \\
(-1.348)\end{array}$ & $\begin{array}{r}-0.62517 \\
(-0.944)\end{array}$ \\
\hline \multicolumn{5}{|l|}{ ESCOLARIDADE } \\
\hline Primário Incompleto & $\begin{array}{l}-0.12017 \\
(-0.148)\end{array}$ & $\begin{array}{c}-0.47201 \mathrm{E}-01 \\
(-0.088)\end{array}$ & $\begin{array}{c}-0.24158 \\
(-0.509)\end{array}$ & $\begin{array}{c}-0.54409 \\
(-1.211)\end{array}$ \\
\hline Primário Completo & $\begin{array}{c}0.34744 \mathrm{E}-01 \\
(0.045)\end{array}$ & $\begin{array}{r}-0.40439 \\
(-0.730)\end{array}$ & $\begin{array}{r}-0.61837 \\
(-1.271)\end{array}$ & $\begin{array}{l}-1.0936 \\
(-2.400)\end{array}$ \\
\hline Ginásio Incompleto & $\begin{array}{r}0.66542 \\
(0.762)\end{array}$ & $\begin{array}{r}0.94602 \\
(1.466)\end{array}$ & $\begin{array}{r}0.58484 \\
(0.976)\end{array}$ & $\begin{array}{c}-0.44808 \\
(-0.774)\end{array}$ \\
\hline Ginásio Completo & $\begin{array}{l}1.0668 \\
(0.959)\end{array}$ & $\begin{array}{r}0.99183 \\
(1.088)\end{array}$ & $\begin{array}{l}1.0191 \\
(1.183)\end{array}$ & $\begin{array}{r}-0.30999 \\
(-0.368)\end{array}$ \\
\hline Colegial e Superior & $\begin{array}{r}0.29435 \\
(0.400)\end{array}$ & $\begin{array}{r}0.66684 \\
(1.283)\end{array}$ & $\begin{array}{r}-0.11571 \\
(-0.243)\end{array}$ & $\begin{array}{l}-2.0311 \\
(-4.451)\end{array}$ \\
\hline \multicolumn{5}{|l|}{ IDADE } \\
\hline 18 a 19 anos & $\begin{array}{l}3.2373 \\
(2.415)\end{array}$ & $\begin{array}{l}1.8135 \\
(1.713)\end{array}$ & $\begin{array}{l}1.7676 \\
(1.765)\end{array}$ & $\begin{array}{l}1.4578 \\
(1.490)\end{array}$ \\
\hline 20 a 24 anos & $\begin{array}{l}1.4482 \\
(1.427)\end{array}$ & $\begin{array}{r}0.96213 \\
(1.649)\end{array}$ & $\begin{array}{c}-0.79137 \mathrm{E}-01 \\
(-0.151)\end{array}$ & $\begin{array}{r}0.12765 \\
(0.265)\end{array}$ \\
\hline 25 a 29 anos & $\begin{array}{l}1.2269 \\
(1.159)\end{array}$ & $\begin{array}{c}0.68288 \\
(1.097)\end{array}$ & $\begin{array}{r}-0.26214 \\
(-0.470)\end{array}$ & $\begin{array}{c}-0.40460 \mathrm{E}-01 \\
(-0.078)\end{array}$ \\
\hline 30 a 39 anos & $\begin{array}{l}1.2617 \\
(1.147)\end{array}$ & $\begin{array}{r}0.82087 \\
(1.228)\end{array}$ & $\begin{array}{r}-0.10664 \\
(-0.176)\end{array}$ & $\begin{array}{l}0.32183 \\
(0.570)\end{array}$ \\
\hline 40 a 49 anos & $\begin{array}{l}1.5628 \\
(1.266)\end{array}$ & $\begin{array}{l}1.6546 \\
(2.045)\end{array}$ & $\begin{array}{c}0.58087 \mathrm{E}-01 \\
(0.077)\end{array}$ & $\begin{array}{r}0.49040 \\
(0.683)\end{array}$ \\
\hline 50 anos ou mais & $\begin{array}{r}0.12902 \\
(0.107)\end{array}$ & $\begin{array}{r}-0.15214 \\
(-0.206)\end{array}$ & $\begin{array}{l}-1.4453 \\
(-2.178)\end{array}$ & $\begin{array}{l}-1.0407 \\
(-1.678)\end{array}$ \\
\hline POSIÇÃO NA OCUPAÇÃO & & & & \\
\hline Autônomo ou empregador & $\begin{array}{r}1.0574 \\
(1.489) \\
\end{array}$ & $\begin{array}{l}1.5611 \\
(2.679) \\
\end{array}$ & $\begin{array}{l}2.8326 \\
(5.023)\end{array}$ & $\begin{array}{l}2.0007 \\
(3.589)\end{array}$ \\
\hline
\end{tabular}


Tabela F7. Coeficientes dos logitos multinomiais estimados (valores de $z$ entre parênteses). Pernambuco, 1989.

\begin{tabular}{|c|c|c|c|c|}
\hline \multirow[b]{2}{*}{ VARIÁVEIS } & \multicolumn{4}{|c|}{ CLASSES } \\
\hline & 2 & 3 & 4 & $\mathbf{5}$ \\
\hline CONSTANTE & $\begin{array}{l}0.28241 \\
(0.226)\end{array}$ & $\begin{array}{c}-0.70628 \mathrm{E}-01 \\
(-0.064)\end{array}$ & $\begin{array}{l}1.7063 \\
(1.699)\end{array}$ & $\begin{array}{l}4.6473 \\
(4.780)\end{array}$ \\
\hline OUTRAS RENDAS PESSOAIS & $\begin{array}{c}-0.28392 \mathrm{E}-02 \\
(-0.891)\end{array}$ & $\begin{array}{c}-0.14039 \mathrm{E}-04 \\
(-0.043)\end{array}$ & $\begin{array}{c}-0.55212 E-04 \\
(-0.178)\end{array}$ & $\begin{array}{c}-0.18192 \mathrm{E}-03 \\
(-0.573)\end{array}$ \\
\hline OUTRAS RENDAS & $\begin{array}{c}0.93021 \mathrm{E}-04 \\
(0.599)\end{array}$ & $\begin{array}{c}0.10589 E-03 \\
(0.749)\end{array}$ & $\begin{array}{c}0.10428 \mathrm{E}-03 \\
(0.739)\end{array}$ & $\begin{array}{c}0.95628 \mathrm{E}-04 \\
(0.679)\end{array}$ \\
\hline SITUAÇÃO & & & & \\
\hline Região Urbana & $\begin{array}{r}-0.32410 \\
(-0.532)\end{array}$ & $\begin{array}{c}-0.46682 \mathrm{E}-01 \\
(-0.088)\end{array}$ & $\begin{array}{l}0.32288 \\
(0.662)\end{array}$ & $\begin{array}{l}-1.0720 \\
(-2.268)\end{array}$ \\
\hline CRIANÇAS MENORES 6 ANOS & & & & . \\
\hline 1 & $\begin{array}{r}0.14087 \\
(0.264)\end{array}$ & $\begin{array}{c}0.19113 E-01 \\
(0.041)\end{array}$ & $\begin{array}{r}0.20137 \\
(0.457)\end{array}$ & $\begin{array}{r}0.26498 \\
(0.614)\end{array}$ \\
\hline 2 & $\begin{array}{r}-0.97289 \\
(-1.207)\end{array}$ & $\begin{array}{r}0.13245 \\
(0.230)\end{array}$ & $\begin{array}{r}-0.15546 \\
(-0.285)\end{array}$ & $\begin{array}{c}0.10515 E-01 \\
(0.020)\end{array}$ \\
\hline 3 ou mais & $\begin{array}{r}-0.14259 \\
(-0.113)\end{array}$ & $\begin{array}{r}0.55167 \\
(0.534)\end{array}$ & $\begin{array}{c}0.36236 \\
(0.373)\end{array}$ & $\begin{array}{r}0.59694 \\
(0.627)\end{array}$ \\
\hline SITUAÇÃO NA FAMÍLIA & & & & \\
\hline Chefe e Cônjuge & $\begin{array}{r}0.65309 \\
(0.697)\end{array}$ & $\begin{array}{r}0.32095 \\
(0.408)\end{array}$ & $\begin{array}{r}0.44418 \\
(0.611)\end{array}$ & $\begin{array}{r}0.78694 \\
(1.119)\end{array}$ \\
\hline Filho & $\begin{array}{r}0.48294 \\
(0.544)\end{array}$ & $\begin{array}{r}0.63896 \\
(0.857)\end{array}$ & $\begin{array}{l}0.16920 \\
(0.247)\end{array}$ & $\begin{array}{r}0.28667 \\
(0.434)\end{array}$ \\
\hline ESCOLARIDADE & & & & \\
\hline Primário Incompleto & $\begin{array}{c}0.40821 \mathrm{E}-01 \\
(0.047)\end{array}$ & $\begin{array}{l}1.0942 \\
(1.525)\end{array}$ & $\begin{array}{c}0.89408 \\
(1.375)\end{array}$ & $\begin{array}{r}0.70413 \\
(1.105)\end{array}$ \\
\hline Primário Completo & $\begin{array}{r}-0.24870 \\
(-0.343)\end{array}$ & $\begin{array}{c}-0.64010 \mathrm{E}-01 \\
(-0.102)\end{array}$ & $\begin{array}{r}-0.18587 \\
(-0.350)\end{array}$ & $\begin{array}{r}-0.76071 \\
(-1.480)\end{array}$ \\
\hline Ginásio Incompleto & $\begin{array}{l}1.8202 \\
(2.218)\end{array}$ & $\begin{array}{l}1.7969 \\
(2.328)\end{array}$ & $\begin{array}{l}1.4001 \\
(1.957)\end{array}$ & $\begin{array}{r}0.59792 \\
(0.850)\end{array}$ \\
\hline Ginásio Completo & $\begin{array}{r}-0.40160 \\
(-0.487)\end{array}$ & $\begin{array}{r}0.73851 \\
(1.113)\end{array}$ & $\begin{array}{r}-0.34265 \\
(-0.568)\end{array}$ & $\begin{array}{l}-1.3735 \\
(-2.367)\end{array}$ \\
\hline Colegial e Superior & $\begin{array}{r}0.69389 \\
(1.012)\end{array}$ & $\begin{array}{l}1.7942 \\
(2.971)\end{array}$ & $\begin{array}{c}0.39091 \\
(0.710)\end{array}$ & $\begin{array}{r}-0.96202 \\
(-1.791)\end{array}$ \\
\hline IDADE & & & & \\
\hline 18 a 19 anos & $\begin{array}{l}-1.1005 \\
(-1.116)\end{array}$ & $\begin{array}{r}-0.46652 \\
(-0.543)\end{array}$ & $\begin{array}{l}-1.1990 \\
(-1.494)\end{array}$ & $\begin{array}{r}-0.76919 \\
(-0.993)\end{array}$ \\
\hline 20 a 24 anos & $\begin{array}{r}-0.34135 \\
(-0.406)\end{array}$ & $\begin{array}{r}-0.32445 \\
(-0.419)\end{array}$ & $\begin{array}{r}-0.63525 \\
(-0.883)\end{array}$ & $\begin{array}{r}-0.66337 \\
(-0.943)\end{array}$ \\
\hline 25 a 29 anos & $\begin{array}{r}-0.42281 \\
(-0.440)\end{array}$ & $\begin{array}{r}-0.53595 \\
(-0.613)\end{array}$ & $\begin{array}{r}-0.65849 \\
(-0.813)\end{array}$ & $\begin{array}{r}-0.23054 \\
(-0.291)\end{array}$ \\
\hline 30 a 39 anos & $\begin{array}{l}-1.2980 \\
(-1.261)\end{array}$ & $\begin{array}{r}0.21556 \\
(0.247)\end{array}$ & $\begin{array}{r}-0.88999 \\
(-1.089)\end{array}$ & $\begin{array}{r}-0.57980 \\
(-0.726)\end{array}$ \\
\hline 40 a 49 anos & $\begin{array}{l}0.64009 \\
(0.552)\end{array}$ & $\begin{array}{l}1.1444 \\
(1.084)\end{array}$ & $\begin{array}{l}0.10045 \\
(0.100)\end{array}$ & $\begin{array}{l}0.31921 \\
(0.324)\end{array}$ \\
\hline 50 anos ou mais & $\begin{array}{r}-0.19294 \\
(-0.175)\end{array}$ & $\begin{array}{r}-0.14512 \\
(-0.147)\end{array}$ & $\begin{array}{l}-1.0649 \\
(-1.167)\end{array}$ & $\begin{array}{r}-0.80304 \\
(-0.901)\end{array}$ \\
\hline $\begin{array}{l}\text { POSIÇÃO NA OCUPAÇÃO } \\
\text { Autônomo ou empregador }\end{array}$ & $\begin{array}{c}-1.6823 \\
(-1.592) \\
\end{array}$ & $\begin{array}{r}0.84387 \\
(1.491) \\
\end{array}$ & $\begin{array}{r}2.4301 \\
(4.510) \\
\end{array}$ & $\begin{array}{r}1.2114 \\
(2.269) \\
\end{array}$ \\
\hline
\end{tabular}


Tabela F8. Coeficientes dos logitos multinomiais estimados (valores de $z$ entre parênteses). Pernambuco, 1990.

\begin{tabular}{|c|c|c|c|c|}
\hline \multirow[b]{2}{*}{ VARIÁVEIS } & \multicolumn{4}{|c|}{ CLASSES } \\
\hline & 2 & 3 & 4 & 5 \\
\hline CONSTANTE & $\begin{array}{l}-1.6206 \\
(-1.452)\end{array}$ & $\begin{array}{l}-1.0182 \\
(-1.159)\end{array}$ & $\begin{array}{l}1.0408 \\
(1.416)\end{array}$ & $\begin{array}{l}3.9183 \\
(5.674)\end{array}$ \\
\hline OUTRAS RENDAS PESSOAIS & $\begin{array}{c}0.16224 E-04 \\
(0.388)\end{array}$ & $\begin{array}{c}0.17789 \mathrm{E}-04 \\
(0.434)\end{array}$ & $\begin{array}{c}0.18826 \mathrm{E}-04 \\
(0.463)\end{array}$ & $\begin{array}{c}0.21513 E-04 \\
(0.529)\end{array}$ \\
\hline OUTRAS RENDAS & $\begin{array}{c}0.77406 \mathrm{E}-05 \\
(1.328)\end{array}$ & $\begin{array}{c}0.32599 \mathrm{E}-05 \\
(0.555)\end{array}$ & $\begin{array}{c}0.78630 \mathrm{E}-05 \\
(1.388)\end{array}$ & $\begin{array}{c}0.60154 \mathrm{E}-05 \\
(1.067)\end{array}$ \\
\hline SITUAÇÃO & & & & \\
\hline Região Urbana & $\begin{array}{c}0.64154 \\
(1.156)\end{array}$ & $\begin{array}{r}0.46394 \\
(1.040)\end{array}$ & $\begin{array}{l}0.50980 \\
(1.320)\end{array}$ & $\begin{array}{r}-0.66522 \\
(-1.806)\end{array}$ \\
\hline CRIANÇAS MENORES 6 ANOS & & & & \\
\hline 1 & $\begin{array}{c}0.62913 \mathrm{E}-01 \\
(0.130)\end{array}$ & $\begin{array}{c}0.81397 \mathrm{E}-01 \\
(0.192)\end{array}$ & $\begin{array}{r}0.19389 \\
(0.490)\end{array}$ & $\begin{array}{r}0.10992 \\
(0.285)\end{array}$ \\
\hline 2 & $\begin{array}{l}-1.1661 \\
(-1.949)\end{array}$ & $\begin{array}{r}-0.72271 \\
(-1.570)\end{array}$ & $\begin{array}{r}-0.70511 \\
(-1.715)\end{array}$ & $\begin{array}{r}-0.40202 \\
(-1.028)\end{array}$ \\
\hline 3 ou mais & $\begin{array}{l}0.61095 \\
(0.775)\end{array}$ & $\begin{array}{c}-0.84229 \mathrm{E}-01 \\
(-0.112)\end{array}$ & $\begin{array}{r}-0.20578 \\
(-0.304)\end{array}$ & $\begin{array}{c}0.80900 \mathrm{E}-01 \\
(0.125)\end{array}$ \\
\hline SITUAÇÃO NA FAMÍLIA & & & & \\
\hline Chefe e Cônjuge & $\begin{array}{l}1.0273 \\
(1.280)\end{array}$ & $\begin{array}{l}1.0702 \\
(1.559)\end{array}$ & $\begin{array}{l}1.2952 \\
(2.153)\end{array}$ & $\begin{array}{l}1.0440 \\
(1.851)\end{array}$ \\
\hline Filho & $\begin{array}{r}-0.11308 \\
(-0.141)\end{array}$ & $\begin{array}{l}0.71565 \\
(1.082)\end{array}$ & $\begin{array}{r}0.16633 \\
(0.289)\end{array}$ & $\begin{array}{c}0.80273 \mathrm{E}-01 \\
(0.149)\end{array}$ \\
\hline ESCOLARIDADE & & & & \\
\hline Primário Incompleto & $\begin{array}{l}0.30182 \\
(0.462)\end{array}$ & $\begin{array}{l}1.0997 \\
(1.848)\end{array}$ & $\begin{array}{l}0.31614 \\
(0.637)\end{array}$ & $\begin{array}{c}0.37968 \mathrm{E}-01 \\
(0.079)\end{array}$ \\
\hline Primário Completo & $\begin{array}{l}-1.0061 \\
(-1.419)\end{array}$ & $\begin{array}{l}0.18976 \\
(0.327)\end{array}$ & $\begin{array}{r}-0.41674 \\
(-0.901)\end{array}$ & $\begin{array}{l}-1.0544 \\
(-2.393)\end{array}$ \\
\hline Ginásio Incompleto & $\begin{array}{l}0.33823 \\
(0.506)\end{array}$ & $\begin{array}{l}1.2289 \\
(2.035)\end{array}$ & $\begin{array}{l}0.22493 \\
(0.440)\end{array}$ & $\begin{array}{r}-0.57407 \\
(-1.167)\end{array}$ \\
\hline Ginásio Completo & $\begin{array}{l}1.3526 \\
(1.412)\end{array}$ & $\begin{array}{l}2.1784 \\
(2.407)\end{array}$ & $\begin{array}{l}1.2505 \\
(1.491)\end{array}$ & $\begin{array}{r}-0.33200 \\
(-0.402)\end{array}$ \\
\hline Colegial e Superior & $\begin{array}{l}0.52463 \\
(0.838)\end{array}$ & $\begin{array}{l}1.6933 \\
(2.879)\end{array}$ & $\begin{array}{r}0.38431 \\
(0.767)\end{array}$ & $\begin{array}{l}-1.5919 \\
(-3.284)\end{array}$ \\
\hline DADE & & & & \\
\hline 18 a 19 anos & $\begin{array}{r}-0.81181 \\
(-0.687)\end{array}$ & $\begin{array}{r}-0.14331 \\
(-0.224)\end{array}$ & $\begin{array}{r}-0.75306 \\
(-1.259)\end{array}$ & $\begin{array}{r}-0.16186 \\
(-0.287)\end{array}$ \\
\hline 20 a 24 anos & $\begin{array}{c}0.61364 \\
(0.783)\end{array}$ & $\begin{array}{r}-0.16948 \\
(-0.311)\end{array}$ & $\begin{array}{r}-0.73791 \\
(-1.463)\end{array}$ & $\begin{array}{c}0.82807 \mathrm{E}-01 \\
(0.173)\end{array}$ \\
\hline 25 a 29 anos & $\begin{array}{r}0.52754 \\
(0.603)\end{array}$ & $\begin{array}{c}0.52851 \mathrm{E}-01 \\
(0.083)\end{array}$ & $\begin{array}{r}-0.75493 \\
(-1.267)\end{array}$ & $\begin{array}{r}0.18989 \\
(0.332)\end{array}$ \\
\hline 30 a 39 anos & $\begin{array}{l}0.97689 \\
(1.147)\end{array}$ & $\begin{array}{r}-0,21945 \\
(-0,346)\end{array}$ & $\begin{array}{r}-0.80535 \\
(-1.372)\end{array}$ & $\begin{array}{c}0.31702 \\
(0.563)\end{array}$ \\
\hline 40 a 49 anos & $\begin{array}{c}-0.23117 \mathrm{E}-01 \\
(-0.025)\end{array}$ & $\begin{array}{r}-0.69179 \\
(-0.981)\end{array}$ & $\begin{array}{l}-1.2044 \\
(-1.875)\end{array}$ & $\begin{array}{r}-0.16357 \\
(-0.265)\end{array}$ \\
\hline 50 anos ou mais & $\begin{array}{l}0.42937 \\
(0.455)\end{array}$ & $\begin{array}{r}-0.70317 \\
(-0.965)\end{array}$ & $\begin{array}{l}-1.3908 \\
(-2.103)\end{array}$ & $\begin{array}{r}-0.48811 \\
(-0.768)\end{array}$ \\
\hline POSIÇÃO NA OCUPAÇÃO & & & & \\
\hline Autônomo ou empregador & $\begin{array}{c}0.58224 \mathrm{E}-01 \\
(0.113) \\
\end{array}$ & $\begin{array}{l}1.0010 \\
(2.304) \\
\end{array}$ & $\begin{array}{r}2.2189 \\
(5.434) \\
\end{array}$ & $\begin{array}{r}0.64585 \\
(1.606) \\
\end{array}$ \\
\hline
\end{tabular}



Tabela F9. Coeficientes dos logitos multinomiais estimados
(valores de $z$ entre parênteses). São Paulo, 1981.

\begin{tabular}{|c|c|c|c|c|}
\hline \multirow[b]{2}{*}{ VARIÁVEIS } & \multicolumn{4}{|c|}{ CLASSES } \\
\hline & 2 & 3 & 4 & 5 \\
\hline CONSTANTE & $\begin{array}{l}-3.2539 \\
(-3.227)\end{array}$ & $\begin{array}{r}0.78219 \\
(1.347)\end{array}$ & $\begin{array}{l}3.7471 \\
(6.926)\end{array}$ & $\begin{array}{l}2.6657 \\
(5.009)\end{array}$ \\
\hline OUTRAS RENDAS PESSOAIS & $\begin{array}{c}0.21332 \mathrm{E}-04 \\
(1.526)\end{array}$ & $\begin{array}{c}0.20044 \mathrm{E}-04 \\
(1.751)\end{array}$ & $\begin{array}{c}0.21915 \mathrm{E}-04 \\
(1.935)\end{array}$ & $\begin{array}{c}0.21280 \mathrm{E}-04 \\
(1.902)\end{array}$ \\
\hline OUTRAS RENDAS & $\begin{array}{c}0.57578 \mathrm{E}-06 \\
(0.219)\end{array}$ & $\begin{array}{c}0.89881 E-06 \\
(0.465)\end{array}$ & $\begin{array}{c}-0.50943 E-06 \\
(-0.262)\end{array}$ & $\begin{array}{c}-0.72236 \mathrm{E}-06 \\
(-0.385)\end{array}$ \\
\hline \multicolumn{5}{|l|}{ SITUAÇÃO } \\
\hline Região Urbana & $\begin{array}{l}1.9450 \\
(3.088)\end{array}$ & $\begin{array}{l}1.3016 \\
(4.541)\end{array}$ & $\begin{array}{r}-0.39169 \\
(-1.648)\end{array}$ & $\begin{array}{c}0.62473 \\
(2.644)\end{array}$ \\
\hline \multicolumn{5}{|l|}{ CRIANÇAS MENORES 6 ANOS } \\
\hline 1 & $\begin{array}{r}-0.31641 \\
(-1.082)\end{array}$ & $\begin{array}{c}0.94960 \mathrm{E}-01 \\
(0.442)\end{array}$ & $\begin{array}{r}0.21672 \\
(1.037)\end{array}$ & $\begin{array}{r}0.23907 \\
(1.168)\end{array}$ \\
\hline 2 & $\begin{array}{r}-0.18146 \\
(-0.497)\end{array}$ & $\begin{array}{c}-0.32072 \mathrm{E}-01 \\
(-0.114)\end{array}$ & $\begin{array}{r}0.28252 \\
(1.040)\end{array}$ & $\begin{array}{r}0.19699 \\
(0.739)\end{array}$ \\
\hline 3 ou mais & $\begin{array}{c}-0.96298 \mathrm{E}-01 \\
(-0.174)\end{array}$ & $\begin{array}{r}-0.44120 \\
(-0.979)\end{array}$ & $\begin{array}{r}0.35103 \\
(0.850)\end{array}$ & $\begin{array}{c}0.99198 \mathrm{E}-01 \\
(0.244)\end{array}$ \\
\hline \multicolumn{5}{|l|}{ SITUAÇÃO NA FAMÍLIA } \\
\hline Chefe e Cônjuge & $\begin{array}{c}0.75887 \\
(1.402)\end{array}$ & $\begin{array}{c}0.82355 \mathrm{E}-01 \\
(0.221)\end{array}$ & $\begin{array}{l}0.78441 \\
(2.127)\end{array}$ & $\begin{array}{c}0.63118 \\
(1.775)\end{array}$ \\
\hline Filho & $\begin{array}{r}0.26905 \\
(0.489)\end{array}$ & $\begin{array}{c}0.92318 \mathrm{E}-02 \\
(0.024)\end{array}$ & $\begin{array}{r}0.64428 \\
(1.674)\end{array}$ & $\begin{array}{r}0.14477 \\
(0.388)\end{array}$ \\
\hline \multicolumn{5}{|l|}{ ESCOLARIDADE } \\
\hline Primário Incompleto & $\begin{array}{c}0.95923 \\
(1.933)\end{array}$ & $\begin{array}{r}0.52714 \\
(1.638)\end{array}$ & $\begin{array}{c}-0.89918 \mathrm{E}-01 \\
(-0.323)\end{array}$ & $\begin{array}{r}0.37490 \\
(1.363)\end{array}$ \\
\hline Primário Completo & $\begin{array}{r}0.63690 \\
(1.318)\end{array}$ & $\begin{array}{r}0.61880 \\
(2.024)\end{array}$ & $\begin{array}{r}-0.48895 \\
(-1.837)\end{array}$ & $\begin{array}{r}0.10835 \\
(0.414)\end{array}$ \\
\hline Ginásio Incompleto & $\begin{array}{c}0.54514 \\
(1.014)\end{array}$ & $\begin{array}{r}0.59442 \\
(1.668)\end{array}$ & $\begin{array}{r}-0.98994 \\
(-3.053)\end{array}$ & $\begin{array}{r}-0.16695 \\
(-0.525)\end{array}$ \\
\hline Ginásio Completo & $\begin{array}{l}0.72248 \\
(1.262)\end{array}$ & $\begin{array}{l}0.95916 \\
(2.438)\end{array}$ & $\begin{array}{r}-0.78208 \\
(-2.138)\end{array}$ & $\begin{array}{c}0.80927 \mathrm{E}-01 \\
\quad(0.227)\end{array}$ \\
\hline Colegial e Superior & $\begin{array}{r}0.32147 \\
(0.640)\end{array}$ & $\begin{array}{l}1.0111 \\
(3.150)\end{array}$ & $\begin{array}{r}-0.86618 \\
(-3.020)\end{array}$ & $\begin{array}{r}-0.33937 \\
(-1.208)\end{array}$ \\
\hline \multicolumn{5}{|l|}{ IDADE } \\
\hline 18 a 19 anos & $\begin{array}{l}1.0078 \\
(1.532)\end{array}$ & $\begin{array}{c}0.86372 \mathrm{E}-01 \\
(0.186)\end{array}$ & $\begin{array}{r}-0.24326 \\
(-0.528)\end{array}$ & $\begin{array}{c}0.24439 \\
(0.534)\end{array}$ \\
\hline 20 a 24 anos & $\begin{array}{l}1.1538 \\
(2.017)\end{array}$ & $\begin{array}{r}0.14389 \\
(0.368)\end{array}$ & $\begin{array}{r}-0.34316 \\
(-0.888)\end{array}$ & $\begin{array}{r}0.58058 \\
(1.513)\end{array}$ \\
\hline 25 a 29 anos & $\begin{array}{r}0.81326 \\
(1.357)\end{array}$ & $\begin{array}{r}-0.45814 \\
(-1.121)\end{array}$ & $\begin{array}{r}-0.82946 \\
(-2.060)\end{array}$ & $\begin{array}{r}0.31747 \\
(0.798)\end{array}$ \\
\hline 30 a 39 anos & $\begin{array}{r}0.52214 \\
(0.875)\end{array}$ & $\begin{array}{l}-1.2239 \\
(-3.019)\end{array}$ & $\begin{array}{l}-1.3650 \\
(-3.442)\end{array}$ & $\begin{array}{r}-0.17795 \\
(-0.454)\end{array}$ \\
\hline 40 a 49 anos & $\begin{array}{c}0.63023 \mathrm{E}-01 \\
(0.099)\end{array}$ & $\begin{array}{l}-1.4717 \\
(-3.383)\end{array}$ & $\begin{array}{l}-1.6026 \\
(-3.781)\end{array}$ & $\begin{array}{r}-0.58955 \\
(-1.410)\end{array}$ \\
\hline 50 anos ou mais & $\begin{array}{r}-0.82380 \\
(-1.211)\end{array}$ & $\begin{array}{l}-1.9353 \\
(-4.277)\end{array}$ & $\begin{array}{l}-2.0486 \\
(-4.672)\end{array}$ & $\begin{array}{l}-1.1794 \\
(-2.731)\end{array}$ \\
\hline POSIÇÃO NA OCUPAÇÃO & & & & \\
\hline Autônomo ou empregador & $\begin{array}{l}-3.1721 \\
(-3.104)\end{array}$ & $\begin{array}{r}0.14695 \\
(0.642)\end{array}$ & $\begin{array}{r}0.44677 \\
(2.058)\end{array}$ & $\begin{array}{l}1.1515 \\
(5.436)\end{array}$ \\
\hline
\end{tabular}


Tabela F10. Coeficientes dos logitos multinomiais estimados (valores de $z$ entre parênteses). São Paulo, 1983.

\begin{tabular}{|c|c|c|c|c|}
\hline \multirow[b]{2}{*}{ VARIÁVEIS } & \multicolumn{4}{|c|}{ CLASSES } \\
\hline & 2 & 3 & 4 & 5 \\
\hline CONSTANTE & $\begin{array}{l}-1.2200 \\
(-1.615)\end{array}$ & $\begin{array}{c}0.95835 \mathrm{E}-01 \\
(0.169)\end{array}$ & $\begin{array}{l}3.4755 \\
(6.882)\end{array}$ & $\begin{array}{l}1.7774 \\
(3.529)\end{array}$ \\
\hline OUTRAS RENDAS PESSOAIS & $\begin{array}{c}0.17109 \mathrm{E}-05 \\
(0.646)\end{array}$ & $\begin{array}{c}0.65037 \mathrm{E}-06 \\
(0.306)\end{array}$ & $\begin{array}{c}0.38639 \mathrm{E}-05 \\
(2.012)\end{array}$ & $\begin{array}{c}0.33437 \mathrm{E}-05 \\
(1.749)\end{array}$ \\
\hline OUTRAS RENDAS & $\begin{array}{c}0.67955 \mathrm{E}-07 \\
(0.138)\end{array}$ & $\begin{array}{c}-0.20915 E-06 \\
(-0.565)\end{array}$ & $\begin{array}{c}-0.55849 \mathrm{E}-06 \\
(-1.519)\end{array}$ & $\begin{array}{c}-0.75463 \mathrm{E}-06 \\
(-2.083)\end{array}$ \\
\hline \multicolumn{5}{|l|}{ SITUAÇÃO } \\
\hline Região Urbana & $\begin{array}{c}0.98558 \\
(2.781)\end{array}$ & $\begin{array}{l}1.3843 \\
(5.807)\end{array}$ & $\begin{array}{c}0.19632 \mathrm{E}-01 \\
(0.105)\end{array}$ & $\begin{array}{l}0.88613 \\
(4.764)\end{array}$ \\
\hline \multicolumn{5}{|l|}{ CRIANÇAS MENORES 6 ANOS } \\
\hline 1 & $\begin{array}{l}0.65384 \\
(2.617)\end{array}$ & $\begin{array}{c}0.36404 \\
(1.871)\end{array}$ & $\begin{array}{c}0.44159 \\
(2.381)\end{array}$ & $\begin{array}{r}0.41517 \\
(2.270)\end{array}$ \\
\hline 2 & $\begin{array}{r}0.24468 \\
(0.707)\end{array}$ & $\begin{array}{r}0.17506 \\
(0.672)\end{array}$ & $\begin{array}{r}0.44401 \\
(1.809)\end{array}$ & $\begin{array}{r}0.46527 \\
(1.923)\end{array}$ \\
\hline 3 ou mais & $\begin{array}{r}-0.38707 \\
(-0.738)\end{array}$ & $\begin{array}{r}-0.28356 \\
(-0.815)\end{array}$ & $\begin{array}{c}-0.99629 \mathrm{E}-01 \\
(-0.316)\end{array}$ & $\begin{array}{c}0.23026 \mathrm{E}-01 \\
(0.075)\end{array}$ \\
\hline \multicolumn{5}{|l|}{ SITUAÇÃO NA FAMÍLIA } \\
\hline Chefe e Cônjuge & $\begin{array}{r}-0.36626 \\
(-0.737)\end{array}$ & $\begin{array}{r}-0.59980 \\
(-1.544)\end{array}$ & $\begin{array}{r}-0.16945 \\
(-0.451)\end{array}$ & $\begin{array}{c}0.16234 \mathrm{E}-01 \\
(0.044)\end{array}$ \\
\hline Filho & $\begin{array}{r}-0.11309 \\
(-0.225)\end{array}$ & $\begin{array}{r}0.30601 \\
(0.783)\end{array}$ & $\begin{array}{r}0.43299 \\
(1.132)\end{array}$ & $\begin{array}{r}0.45876 \\
(1.210)\end{array}$ \\
\hline \multicolumn{5}{|l|}{ ESCOLARIDADE } \\
\hline Primário Incompleto & $\begin{array}{r}0.39935 \\
(1.013)\end{array}$ & $\begin{array}{r}0.82682 \\
(2.554)\end{array}$ & $\begin{array}{c}-0.85332 \mathrm{E}-01 \\
(-0.357)\end{array}$ & $\begin{array}{r}0.31376 \\
(1.328)\end{array}$ \\
\hline Primário Completo & $\begin{array}{c}0.75641 \mathrm{E}-01 \\
(0.193)\end{array}$ & $\begin{array}{l}1.1514 \\
(3.669)\end{array}$ & $\begin{array}{r}-0.31432 \\
(-1.343)\end{array}$ & $\begin{array}{r}0.32284 \\
(1.399)\end{array}$ \\
\hline Ginásio Incompleto & $\begin{array}{c}0.69791 \mathrm{E}-01 \\
(0.158)\end{array}$ & $\begin{array}{l}1.1152 \\
(3.183)\end{array}$ & $\begin{array}{r}-0.78576 \\
(-2.784)\end{array}$ & $\begin{array}{c}-0.53643 \mathrm{E}-04 \\
(0.000)\end{array}$ \\
\hline Ginásio Completo & $\begin{array}{c}-0.72532 \mathrm{E}-01 \\
(-0.148)\end{array}$ & $\begin{array}{l}1.6719 \\
(4.506)\end{array}$ & $\begin{array}{r}-0.46073 \\
(-1.496)\end{array}$ & $\begin{array}{c}0.39832 E-01 \\
(0.131)\end{array}$ \\
\hline Colegial e Superior & $\begin{array}{r}0.55662 \\
(1.413)\end{array}$ & $\begin{array}{l}1.9148 \\
(5.924)\end{array}$ & $\begin{array}{r}-0.33201 \\
(-1.325)\end{array}$ & $\begin{array}{r}-0.30906 \\
(-1.248)\end{array}$ \\
\hline IDADE & & & & \\
\hline 18 a 19 anos & $\begin{array}{r}-0.30903 \\
(-0.518)\end{array}$ & $\begin{array}{r}-0.52049 \\
(-1.292)\end{array}$ & $\begin{array}{r}-0.61202 \\
(-1.543)\end{array}$ & $\begin{array}{c}-0.16586 \mathrm{E}-01 \\
(-0.042)\end{array}$ \\
\hline 20 a 24 anos & $\begin{array}{l}0.53443 \\
(1.071)\end{array}$ & $\begin{array}{r}-0.21189 \\
(-0.583)\end{array}$ & $\begin{array}{r}-0.30760 \\
(-0.860)\end{array}$ & $\begin{array}{r}0.66876 \\
(1.869)\end{array}$ \\
\hline 25 a 29 anos & $\begin{array}{l}0.58989 \\
(1.085)\end{array}$ & $\begin{array}{r}-0.33703 \\
(-0.840)\end{array}$ & $\begin{array}{r}-0.21236 \\
(-0.540)\end{array}$ & $\begin{array}{r}0.88239 \\
(2.249)\end{array}$ \\
\hline 30 a 39 anos & $\begin{array}{c}0.40407 \mathrm{E}-01 \\
(0.074)\end{array}$ & $\begin{array}{r}-0.80681 \\
(-2.030)\end{array}$ & $\begin{array}{r}-0.62031 \\
(-1.603)\end{array}$ & $\begin{array}{r}0.67611 \\
(1.752)\end{array}$ \\
\hline 40 a 49 anos & $\begin{array}{c}0.13598 \\
(0.238)\end{array}$ & $\begin{array}{l}-1.1518 \\
(-2.746)\end{array}$ & $\begin{array}{r}-0.86579 \\
(-2.145)\end{array}$ & $\begin{array}{c}0.38778 \\
(0.965)\end{array}$ \\
\hline 50 anos ou mais & $\begin{array}{r}-0.36756 \\
(-0.610)\end{array}$ & $\begin{array}{l}-1.4897 \\
(-3.434)\end{array}$ & $\begin{array}{l}-1.1201 \\
(-2.723)\end{array}$ & $\begin{array}{c}-0.95257 \mathrm{E}-01 \\
(-0.233)\end{array}$ \\
\hline POSIÇÃONA OCUPAÇÃO & & & & \\
\hline Autônomo ou empregador & $\begin{array}{l}-1.2368 \\
(-3.326) \\
\end{array}$ & $\begin{array}{r}-0.40609 \\
(-2.014) \\
\end{array}$ & $\begin{array}{r}0.12889 \\
(0.713) \\
\end{array}$ & $\begin{array}{r}1.0493 \\
(5.949) \\
\end{array}$ \\
\hline
\end{tabular}


Tabela F11. Coeficientes dos logitos multinomiais estimados (valores de $z$ entre parênteses). São Paulo, 1984.

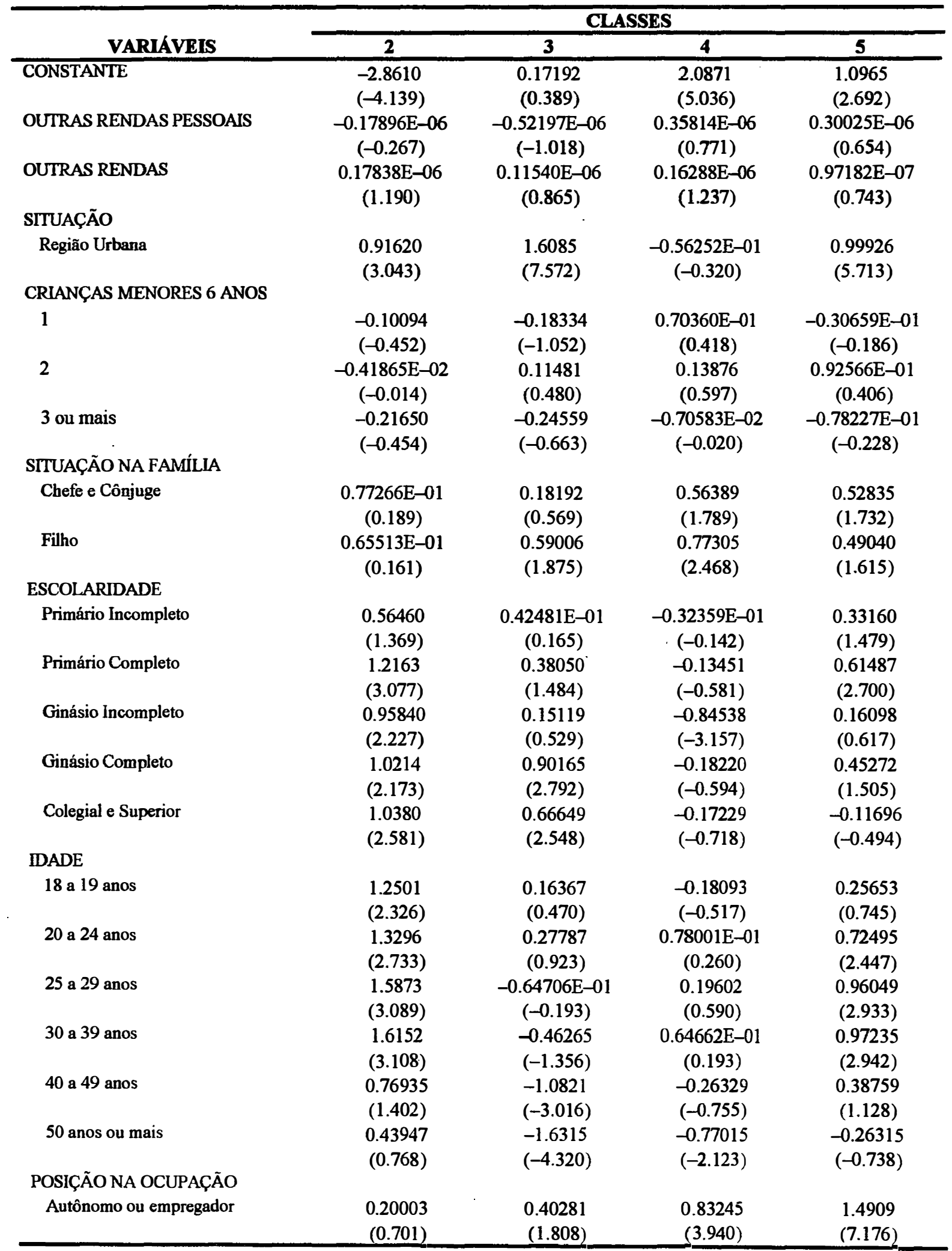


Tabela F12. Coeficientes dos logitos multinomiais estimados (valores de $z$ entre parênteses). São Paulo, 1985.

\begin{tabular}{|c|c|c|c|c|}
\hline \multirow[b]{2}{*}{ VARIÁVEIS } & \multicolumn{4}{|c|}{ CLASSES } \\
\hline & 2 & 3 & 4 & 5 \\
\hline CONSTANTE & $\begin{array}{l}-3.6931 \\
(-4.256)\end{array}$ & $\begin{array}{c}-0.17836 \mathrm{E}-01 \\
(-0.039)\end{array}$ & $\begin{array}{c}-0.27186 \mathrm{E}-01 \\
(-0.061)\end{array}$ & $\begin{array}{l}2.7511 \\
(6.828)\end{array}$ \\
\hline OUTRAS RENDAS PESSOAIS & $\begin{array}{c}0.16950 \mathrm{E}-06 \\
(0.803)\end{array}$ & $\begin{array}{c}-0.26376 \mathrm{E}-07 \\
(-0.147)\end{array}$ & $\begin{array}{c}0.25082 \mathrm{E}-06 \\
(1.541)\end{array}$ & $\begin{array}{c}0.18931 \mathrm{E}-06 \\
(1.171)\end{array}$ \\
\hline OUTRAS RENDAS & $\begin{array}{c}-0.99319 \mathrm{E}-07 \\
(-2.039)\end{array}$ & $\begin{array}{c}-0.58281 \mathrm{E}-07 \\
(-2.151)\end{array}$ & $\begin{array}{c}-0.59523 \mathrm{E}-07 \\
(-2.175)\end{array}$ & $\begin{array}{c}-0.83879 \mathrm{E}-07 \\
(-3.210)\end{array}$ \\
\hline \multicolumn{5}{|l|}{ SITUAÇÃO } \\
\hline Região Urbana & $\begin{array}{l}2.7436 \\
(4.556)\end{array}$ & $\begin{array}{l}1.8704 \\
(8.303)\end{array}$ & $\begin{array}{l}1.8600 \\
(8.967)\end{array}$ & $\begin{array}{r}0.55549 \\
(3.344)\end{array}$ \\
\hline \multicolumn{5}{|l|}{ CRIANÇAS MENORES 6 ANOS } \\
\hline 1 & $\begin{array}{c}0.81191 \mathrm{E}-01 \\
(0.362)\end{array}$ & $\begin{array}{c}0.63222 \mathrm{E}-01 \\
(0.386)\end{array}$ & $\begin{array}{c}0.13729 \\
(0.858)\end{array}$ & $\begin{array}{r}0.15390 \\
(1.008)\end{array}$ \\
\hline 2 & $\begin{array}{c}-0.87099 \mathrm{E}-01 \\
(-0.282)\end{array}$ & $\begin{array}{c}0.16129 \mathrm{E}-01 \\
(0.072)\end{array}$ & $\begin{array}{c}0.17876 \\
(0.829)\end{array}$ & $\begin{array}{l}0.16143 \\
(0.783)\end{array}$ \\
\hline 3 ou mais & $\begin{array}{l}0.14561 \\
(0.285)\end{array}$ & $\begin{array}{c}0.44982 \\
(1.191)\end{array}$ & $\begin{array}{r}0.13012 \\
(0.350)\end{array}$ & $\begin{array}{r}0.36835 \\
(1.045)\end{array}$ \\
\hline \multicolumn{5}{|l|}{ SITUAÇÃO NA FAMÍLIA } \\
\hline Chefe e Cônjuge & $\begin{array}{l}-0.77503 \\
(-1.871)\end{array}$ & $\begin{array}{l}-0.30901 \\
(-0.946)\end{array}$ & $\begin{array}{l}-0.14719 \\
(-0.458)\end{array}$ & $\begin{array}{c}-0.90949 \mathrm{E}-01 \\
(-0.297)\end{array}$ \\
\hline Filho & $\begin{array}{r}-0.16438 \\
(-0.403)\end{array}$ & $\begin{array}{r}0.40237 \\
(1.275)\end{array}$ & $\begin{array}{c}-0.38202 E-01 \\
(-0.122)\end{array}$ & $\begin{array}{r}0.28321 \\
(0.951)\end{array}$ \\
\hline \multicolumn{5}{|l|}{ ESCOLARIDADE } \\
\hline Primário Incompleto & $\begin{array}{r}0.46271 \\
(1.116)\end{array}$ & $\begin{array}{c}-0.61269 \mathrm{E}-01 \\
(-0.215)\end{array}$ & $\begin{array}{r}0.12855 \\
(0.480)\end{array}$ & $\begin{array}{r}-0.12537 \\
(-0.519)\end{array}$ \\
\hline Primário Completo & $\begin{array}{c}0.54840 \\
(1.350)\end{array}$ & $\begin{array}{r}0.22562 \\
(0.803)\end{array}$ & $\begin{array}{r}0.49209 \\
(1.861)\end{array}$ & $\begin{array}{c}0.33224 \mathrm{E}-02 \\
(0.014)\end{array}$ \\
\hline Ginásio Incompleto & $\begin{array}{l}-0.13121 \\
(-0.292)\end{array}$ & $\begin{array}{l}-0.12258 \\
(-0.405)\end{array}$ & $\begin{array}{c}0.26993 \\
(0.937)\end{array}$ & $\begin{array}{r}-0.58537 \\
(-2.207)\end{array}$ \\
\hline Ginásio Completo & $\begin{array}{l}0.96881 \mathrm{E}-01 \\
(0.212)\end{array}$ & $\begin{array}{c}0.35348 \\
(1.124)\end{array}$ & $\begin{array}{l}0.34326 \\
(1.140)\end{array}$ & $\begin{array}{r}-0.61964 \\
(-2.222)\end{array}$ \\
\hline Colegial e Superior & $\begin{array}{c}0.82229 \mathrm{E}-01 \\
(0.199)\end{array}$ & $\begin{array}{r}0.82192 \\
(2.917)\end{array}$ & $\begin{array}{c}0.39773 \\
(1.482)\end{array}$ & $\begin{array}{r}-0.81652 \\
(-3.313)\end{array}$ \\
\hline \multicolumn{5}{|l|}{ IDADE } \\
\hline 18 a 19 anos & $\begin{array}{c}0.85408 \\
(1.517)\end{array}$ & $\begin{array}{r}0.14403 \\
(0.450)\end{array}$ & $\begin{array}{r}0.17077 \\
(0.528)\end{array}$ & $\begin{array}{r}0.40212 \\
(1.302)\end{array}$ \\
\hline 20 a 24 anos & $\begin{array}{l}1.3221 \\
(2.905)\end{array}$ & $\begin{array}{r}-0.12432 \\
(-0.491)\end{array}$ & $\begin{array}{r}-0.11706 \\
(-0.459)\end{array}$ & $\begin{array}{r}0.35864 \\
(1.481)\end{array}$ \\
\hline 25 a 29 anos & $\begin{array}{l}1.6980 \\
(3.452)\end{array}$ & $\begin{array}{c}-0.96493 \mathrm{E}-02 \\
(-0.033)\end{array}$ & $\begin{array}{c}0.13426 \mathrm{E}-01 \\
(0.045)\end{array}$ & $\begin{array}{c}0.76823 \\
(2.715)\end{array}$ \\
\hline 30 a 39 anos & $\begin{array}{l}1.6005 \\
(3.231)\end{array}$ & $\begin{array}{r}-0.43534 \\
(-1.458)\end{array}$ & $\begin{array}{c}-0.54340 \mathrm{E}-01 \\
(-0.183)\end{array}$ & $\begin{array}{c}0.77188 \\
(2.731)\end{array}$ \\
\hline 40 a 49 anos & $\begin{array}{l}1.5047 \\
(2.832)\end{array}$ & $\begin{array}{r}-0.50275 \\
(-1.521)\end{array}$ & $\begin{array}{l}-0.10777 \\
(-0.331)\end{array}$ & $\begin{array}{r}0.67930 \\
(2.192)\end{array}$ \\
\hline 50 anos ou mais & $\begin{array}{r}0.99380 \\
(1.798)\end{array}$ & $\begin{array}{l}-1.0202 \\
(-2.986)\end{array}$ & $\begin{array}{r}-0.87774 \\
(-2.625)\end{array}$ & $\begin{array}{c}0.64531 \mathrm{E}-02 \\
(0.020)\end{array}$ \\
\hline POSIÇÃO NA OCUPAÇÃO & & & & \\
\hline Autônomo ou empregador & $\begin{array}{c}-0.27308 \\
(-0.944) \\
\end{array}$ & $\begin{array}{r}0.41559 \\
(2.161) \\
\end{array}$ & $\begin{array}{l}1.2789 \\
(6.972) \\
\end{array}$ & $\begin{array}{c}0.89554 \\
(5.023)\end{array}$ \\
\hline
\end{tabular}


Tabela F13. Coeficientes dos logitos multinomiais estimados
(valores de $z$ entre parênteses). são Paulo, 1987.

\begin{tabular}{|c|c|c|c|c|}
\hline \multirow[b]{2}{*}{ VARIÁVEIS } & \multicolumn{4}{|c|}{ CLASSES } \\
\hline & 2 & 3 & 4 & 5 \\
\hline CONSTANTE & $\begin{array}{l}-2.2124 \\
(-1.886)\end{array}$ & $\begin{array}{l}1.8884 \\
(2.556)\end{array}$ & $\begin{array}{l}3.8725 \\
(5.570)\end{array}$ & $\begin{array}{l}3.0666 \\
(4.455)\end{array}$ \\
\hline OUTRAS RENDAS PESSOAIS & $\begin{array}{c}0.48805 E-04 \\
(0.998)\end{array}$ & $\begin{array}{c}0.45993 E-04 \\
(0.942)\end{array}$ & $\begin{array}{c}0.80675 E-04 \\
(1.654)\end{array}$ & $\begin{array}{c}0.64061 \mathrm{E}-04 \\
(1.314)\end{array}$ \\
\hline OUTRAS RENDAS & $\begin{array}{c}-0.26824 \mathrm{E}-05 \\
(-0.693)\end{array}$ & $\begin{array}{c}-0.91542 \mathrm{E}-05 \\
(-3.200)\end{array}$ & $\begin{array}{c}-0.50102 E-05 \\
(-2.249)\end{array}$ & $\begin{array}{c}-0.33835 \mathrm{E}-05 \\
(-1.856)\end{array}$ \\
\hline SITUAÇÃO & & & & \\
\hline Região Urbana & $\begin{array}{l}1.7787 \\
(2.779)\end{array}$ & $\begin{array}{l}1.2592 \\
(3.886)\end{array}$ & $\begin{array}{r}-0.16356 \\
(-0.600)\end{array}$ & $\begin{array}{l}0.57097 \\
(2.105)\end{array}$ \\
\hline CRIANÇAS MENORES 6 ANO & & & & \\
\hline 1 & $\begin{array}{l}-0.16595 \\
(-0.540)\end{array}$ & $\begin{array}{r}-0.29196 \\
(-1.234)\end{array}$ & $\begin{array}{c}0.33302 E-01 \\
(0.148)\end{array}$ & $\begin{array}{c}0.18684 \mathrm{E}-01 \\
(0.084)\end{array}$ \\
\hline 2 & $\begin{array}{r}-0.25906 \\
(-0.596)\end{array}$ & $\begin{array}{r}-0.25029 \\
(-0.745)\end{array}$ & $\begin{array}{c}0.44060 \mathrm{E}-01 \\
(0.139)\end{array}$ & $\begin{array}{c}0.86939 \mathrm{E}-01 \\
(0.278)\end{array}$ \\
\hline 3 ou mais & $\begin{array}{r}-0.31740 \\
(-0.395)\end{array}$ & $\begin{array}{r}-0.34029 \\
(-0.563)\end{array}$ & $\begin{array}{c}0.62098 \mathrm{E}-01 \\
(0.112)\end{array}$ & $\begin{array}{l}0.22262 \\
(0.406)\end{array}$ \\
\hline SITUAÇÃO NA FAMÍLIA & & & & \\
\hline Chefe e Cônjuge & $\begin{array}{c}0.10336 \\
(0.156)\end{array}$ & $\begin{array}{r}-0.78684 \\
(-1.589)\end{array}$ & $\begin{array}{l}-0.21886 \\
(-0.450)\end{array}$ & $\begin{array}{r}-0.41861 \\
(-0.878)\end{array}$ \\
\hline Filho & $\begin{array}{r}-0.25297 \\
(-0.376)\end{array}$ & $\begin{array}{r}-0.37123 \\
(-0.747)\end{array}$ & $\begin{array}{r}-0.13223 \\
(-0.270)\end{array}$ & $\begin{array}{r}-0.40438 \\
(-0.839)\end{array}$ \\
\hline ESCOLARDADE & & & & \\
\hline Primário Incompleto & $\begin{array}{l}0.63555 \mathrm{E}-01 \\
(0.105)\end{array}$ & $\begin{array}{c}0.99128 \mathrm{E}-01 \\
(0.229)\end{array}$ & $\begin{array}{r}-0.33438 \\
(-0.862)\end{array}$ & $\begin{array}{l}0.10090 \\
(0.263)\end{array}$ \\
\hline Primário Completo & $\begin{array}{r}0.39100 \\
(0.677)\end{array}$ & $\begin{array}{r}0.15508 \\
(0.365)\end{array}$ & $\begin{array}{r}-0.38800 \\
(-1.015)\end{array}$ & $\begin{array}{r}0.16776 \\
(0.444)\end{array}$ \\
\hline Ginásio Incompleto & $\begin{array}{l}-0.11908 \\
(-0.186)\end{array}$ & $\begin{array}{c}0.97305 \mathrm{E}-01 \\
(0.211)\end{array}$ & $\begin{array}{r}-0.50612 \\
(-1.199)\end{array}$ & $\begin{array}{c}-0.85124 \mathrm{E}-01 \\
(-0.204)\end{array}$ \\
\hline Ginásio Completo & $\begin{array}{l}0.20114 \mathrm{E}-01 \\
(0.031)\end{array}$ & $\begin{array}{r}0.51040 \\
(1.091)\end{array}$ & $\begin{array}{l}-0.52861 \\
(-1.225)\end{array}$ & $\begin{array}{r}-0.28264 \\
(-0.663)\end{array}$ \\
\hline Colegial e Superior & $\begin{array}{r}0.19499 \\
(0.336)\end{array}$ & $\begin{array}{r}0.65679 \\
(1.544)\end{array}$ & $\begin{array}{r}-0.21818 \\
(-0.565)\end{array}$ & $\begin{array}{r}-0.63325 \\
(-1.653)\end{array}$ \\
\hline IDADE & & & & \\
\hline 18 a 19 anos & $\begin{array}{r}0.48508 \\
(0.540)\end{array}$ & $\begin{array}{r}0.10432 \\
(0.184)\end{array}$ & $\begin{array}{c}-0.70668 \mathrm{E}-01 \\
(-0.126)\end{array}$ & $\begin{array}{r}0.53617 \\
(0.960)\end{array}$ \\
\hline 20 a 24 anos & $\begin{array}{r}0.58980 \\
(0.888)\end{array}$ & $\begin{array}{r}-0.90857 \\
(-2.253)\end{array}$ & $\begin{array}{l}-0.99171 \\
(-2.506)\end{array}$ & $\begin{array}{r}-0.17708 \\
(-0.450)\end{array}$ \\
\hline 25 a 29 anos & $\begin{array}{l}0.58991 \\
(0.819)\end{array}$ & $\begin{array}{r}-0.84492 \\
(-1.840)\end{array}$ & $\begin{array}{r}-0.54409 \\
(-1.214)\end{array}$ & $\begin{array}{l}0.44028 \\
(0.990)\end{array}$ \\
\hline 30 a 39 anos & $\begin{array}{r}0.49729 \\
(0.687)\end{array}$ & $\begin{array}{l}-1.0149 \\
(-2.184)\end{array}$ & $\begin{array}{r}-0.60387 \\
(-1.337)\end{array}$ & $\begin{array}{r}0.45341 \\
(1.011)\end{array}$ \\
\hline 40 a 49 anos & $\begin{array}{r}0.45561 \\
(0.585)\end{array}$ & $\begin{array}{r}-0.83579 \\
(-1.608)\end{array}$ & $\begin{array}{r}-0.34650 \\
(-0.689)\end{array}$ & $\begin{array}{r}0.53295 \\
(1.068)\end{array}$ \\
\hline 50 anos ou mais & $\begin{array}{r}-0.42721 \\
(-0.540)\end{array}$ & $\begin{array}{l}-1.4078 \\
(-2.746)\end{array}$ & $\begin{array}{l}-1.3174 \\
(-2.659)\end{array}$ & $\begin{array}{r}-0.53972 \\
(-1.100)\end{array}$ \\
\hline $\begin{array}{l}\text { POSIÇÃO NA OCUPAÇÃO } \\
\text { Autônomo ou empregador }\end{array}$ & $\begin{array}{l}0.98037 \\
(2.145)\end{array}$ & $\begin{array}{r}0.79183 \\
(2.004) \\
\end{array}$ & $\begin{array}{r}1.8687 \\
(4.928) \\
\end{array}$ & $\begin{array}{l}1.9620 \\
(5.198) \\
\end{array}$ \\
\hline
\end{tabular}


Tabela F14. Coeficientes dos logitos multinomiais estimados (valores de $z$ entre parênteses). São Paulo, 1988.

\begin{tabular}{|c|c|c|c|c|}
\hline \multirow[b]{2}{*}{ VARIÁVEIS } & \multicolumn{4}{|c|}{ CLASSES } \\
\hline & 2 & 3 & 4 & 5 \\
\hline CONSTANTE & $\begin{array}{l}-3.4762 \\
(-2.314)\end{array}$ & $\begin{array}{l}1.1311 \\
(1.690)\end{array}$ & $\begin{array}{l}2.4025 \\
(3.722)\end{array}$ & $\begin{array}{l}2.5320 \\
(4.019)\end{array}$ \\
\hline OUTRAS RENDAS PESSOAIS & $\begin{array}{c}-0.38296 \mathrm{E}-05 \\
(-0.467)\end{array}$ & $\begin{array}{c}-0.58067 \mathrm{E}-06 \\
(-0.183)\end{array}$ & $\begin{array}{c}0.22196 \mathrm{E}-05 \\
(0.765)\end{array}$ & $\begin{array}{c}0.21526 \mathrm{E}-05 \\
(0.743)\end{array}$ \\
\hline OUTRAS RENDAS & $\begin{array}{c}-0.84731 \mathrm{E}-06 \\
(-0.839)\end{array}$ & $\begin{array}{c}-0.94510 \mathrm{E}-06 \\
(-2.110)\end{array}$ & $\begin{array}{c}-0.83745 \mathrm{E}-06 \\
(-1.900)\end{array}$ & $\begin{array}{c}-0.13289 \mathrm{E}-05 \\
(-3.020)\end{array}$ \\
\hline \multicolumn{5}{|l|}{ SITUAÇÃO } \\
\hline Região Urbana & $\begin{array}{l}1.0816 \\
(1.690)\end{array}$ & $\begin{array}{l}1.4081 \\
(5.105)\end{array}$ & $\begin{array}{r}-0.10132 \\
(-0.421)\end{array}$ & $\begin{array}{r}0.74501 \\
(3.123)\end{array}$ \\
\hline \multicolumn{5}{|l|}{ CRIANÇAS MENORES 6 ANOS } \\
\hline 1 & $\begin{array}{r}0.54893 \\
(1.395)\end{array}$ & $\begin{array}{c}-0.76019 \mathrm{E}-01 \\
(-0.325)\end{array}$ & $\begin{array}{c}0.71492 \mathrm{E}-01 \\
(0.313)\end{array}$ & $\begin{array}{c}0.63297 \mathrm{E}-01 \\
(0.282)\end{array}$ \\
\hline 2 & $\begin{array}{r}0.33470 \\
(0.607)\end{array}$ & $\begin{array}{r}-0.14946 \\
(-0.466)\end{array}$ & $\begin{array}{c}-0.26266 \mathrm{E}-01 \\
(-0.084)\end{array}$ & $\begin{array}{c}-0.97371 \mathrm{E}-01 \\
(-0.317)\end{array}$ \\
\hline 3 ou mais & $\begin{array}{l}-10.116 \\
(-0.074)\end{array}$ & $\begin{array}{r}-0.25573 \\
(-0.478)\end{array}$ & $\begin{array}{r}-0.21057 \\
(-0.409)\end{array}$ & $\begin{array}{r}-0.55070 \\
(-1.084)\end{array}$ \\
\hline \multicolumn{5}{|l|}{ SITUAÇÃO NA FAMÍLIA } \\
\hline Chefe e Cônjuge & $\begin{array}{r}-0.26693 \\
(-0.329)\end{array}$ & $\begin{array}{r}-0.24920 \\
(-0.511)\end{array}$ & $\begin{array}{r}0.40267 \\
(0.822)\end{array}$ & $\begin{array}{c}-0.92186 \mathrm{E}-01 \\
(-0.194)\end{array}$ \\
\hline Filho & $\begin{array}{r}-0.54388 \\
(-0.662)\end{array}$ & $\begin{array}{r}-0.57797 \\
(-1.172)\end{array}$ & $\begin{array}{r}-0.14887 \\
(-0.299)\end{array}$ & $\begin{array}{r}-0.66713 \\
(-1.382)\end{array}$ \\
\hline \multicolumn{5}{|l|}{ ESCOLARIDADE } \\
\hline Primário Incompleto & $\begin{array}{l}1.7187 \\
(1.567)\end{array}$ & $\begin{array}{l}1.0650 \\
(2.893)\end{array}$ & $\begin{array}{r}0.82924 \\
(2.520)\end{array}$ & $\begin{array}{l}1.0175 \\
(3.157)\end{array}$ \\
\hline Primário Completo & $\begin{array}{l}2.1701 \\
(2.081)\end{array}$ & $\begin{array}{l}1.0016 \\
(2.916)\end{array}$ & $\begin{array}{r}0.43132 \\
(1.407)\end{array}$ & $\begin{array}{c}0.85328 \\
(2.858)\end{array}$ \\
\hline Ginásio Incompleto & $\begin{array}{l}1.9284 \\
(1.780)\end{array}$ & $\begin{array}{r}0.95456 \\
(2.541)\end{array}$ & $\begin{array}{c}-0.57035 \mathrm{E}-01 \\
(-0.165)\end{array}$ & $\begin{array}{r}0.48143 \\
(1.433)\end{array}$ \\
\hline Ginásio Completo & $\begin{array}{l}1.9289 \\
(1.638)\end{array}$ & $\begin{array}{l}1.7340 \\
(3.776)\end{array}$ & $\begin{array}{r}0.83559 \\
(1.925)\end{array}$ & $\begin{array}{l}1.0380 \\
(2.438)\end{array}$ \\
\hline Colegial e Superior & $\begin{array}{l}1.8043 \\
(1.715)\end{array}$ & $\begin{array}{l}1.2812 \\
(3.752)\end{array}$ & $\begin{array}{r}0.48666 \\
(1.584)\end{array}$ & $\begin{array}{r}-0.23678 \\
(-0.787)\end{array}$ \\
\hline \multicolumn{5}{|l|}{ IDADE } \\
\hline 18 a 19 anos & $\begin{array}{c}0.46158 \\
(0.547)\end{array}$ & $\begin{array}{c}-0.10868 \\
(-0.229)\end{array}$ & $\begin{array}{l}-0.12405 \\
(-0.259)\end{array}$ & $\begin{array}{c}0.20914 \\
(0.444)\end{array}$ \\
\hline 20 a 24 anos & $\begin{array}{c}0.14887 \mathrm{E}-01 \\
(0.020)\end{array}$ & $\begin{array}{r}-0.43313 \\
(-1.130)\end{array}$ & $\begin{array}{r}-0.30913 \\
(-0.803)\end{array}$ & $\begin{array}{c}0.23558 \\
(0.624)\end{array}$ \\
\hline 25 a 29 anos & $\begin{array}{c}0.27875 E-01 \\
(0.035)\end{array}$ & $\begin{array}{r}-0.67879 \\
(-1.589)\end{array}$ & $\begin{array}{r}-0.18515 \\
(-0.435)\end{array}$ & $\begin{array}{c}0.30364 \\
(0.725)\end{array}$ \\
\hline 30 a 39 anos & $\begin{array}{r}-0.46630 \\
(-0.577)\end{array}$ & $\begin{array}{l}-1.2313 \\
(-2.904)\end{array}$ & $\begin{array}{l}-0.60967 \\
(-1.447)\end{array}$ & $\begin{array}{r}-0.10941 \\
(-0.265)\end{array}$ \\
\hline 40 a 49 anos & $\begin{array}{c}-0.91398 \mathrm{E}-01 \\
(-0.106\end{array}$ & $\begin{array}{l}-1.3994 \\
(-2.992)\end{array}$ & $\begin{array}{l}-0.76604 \\
(-1.658)\end{array}$ & $\begin{array}{r}-0.34117 \\
(-0.752)\end{array}$ \\
\hline 50 anos ou mais & $\begin{array}{r}-0.56460 \\
(-0.611)\end{array}$ & $\begin{array}{l}-1.9697 \\
(-4.037)\end{array}$ & $\begin{array}{l}-1.4342 \\
(-2.993)\end{array}$ & $\begin{array}{l}-1.0089 \\
(-2.147)\end{array}$ \\
\hline POSIÇÃO NA OCUPAÇÃO & & & & \\
\hline Autônomo ou empregador & $\begin{array}{r}1.2602 \\
(2.802) \\
\end{array}$ & $\begin{array}{r}0.28122 \\
(0.895) \\
\end{array}$ & $\begin{array}{l}1.5947 \\
(5.327)\end{array}$ & $\begin{array}{l}1.6458 \\
(5.537)\end{array}$ \\
\hline
\end{tabular}


Tabela F15. Coeficientes dos logitos multinomiais estimados (valores de $z$ entre parênteses). São Paulo, 1989.

\begin{tabular}{|c|c|c|c|c|}
\hline \multirow[b]{2}{*}{ VARIÁVEIS } & \multicolumn{4}{|c|}{ CLASSES } \\
\hline & 2 & 3 & 4 & 5 \\
\hline CONSTANTE & $\begin{array}{l}-1.8128 \\
(-2.153)\end{array}$ & $\begin{array}{l}0.38615 \\
(0.635)\end{array}$ & $\begin{array}{l}1.6449 \\
(2.864)\end{array}$ & $\begin{array}{l}1.5106 \\
(2.688)\end{array}$ \\
\hline OUTRAS RENDAS PESSOAIS & $\begin{array}{c}-0.88879 \mathrm{E}-04 \\
(-0.293)\end{array}$ & $\begin{array}{c}0.42118 \mathrm{E}-04 \\
(0.328)\end{array}$ & $\begin{array}{c}0.36287 \mathrm{E}-04 \\
(0.292)\end{array}$ & $\begin{array}{c}0.11183 \mathrm{E}-04 \\
(0.090)\end{array}$ \\
\hline OUTRAS RENDAS & $\begin{array}{c}0.35182 \mathrm{E}-04 \\
(0.627)\end{array}$ & $\begin{array}{c}0.48937 \mathrm{E}-04 \\
(1.079)\end{array}$ & $\begin{array}{c}0.51403 E-04 \\
(1.142)\end{array}$ & $\begin{array}{c}0.30023 \mathrm{E}-04 \\
(0.669)\end{array}$ \\
\hline SITUAÇÃo & & & & \\
\hline Região Urbana & $\begin{array}{l}1.2654 \\
(2.880)\end{array}$ & $\begin{array}{l}1.3056 \\
(4.616)\end{array}$ & $\begin{array}{c}-0.70675 E-01 \\
(-0.284)\end{array}$ & $\begin{array}{l}0.71454 \\
(2.901)\end{array}$ \\
\hline CRIANÇAS MENORES 6 ANOS & & & & \\
\hline 1 & $\begin{array}{c}0.55234 \mathrm{E}-01 \\
(0.186)\end{array}$ & $\begin{array}{r}0.23023 \\
(0.993)\end{array}$ & $\begin{array}{l}0.34219 \\
(1.521)\end{array}$ & $\begin{array}{l}0.32898 \\
(1.486)\end{array}$ \\
\hline 2 & $\begin{array}{l}0.44782 \\
(0.880)\end{array}$ & $\begin{array}{r}0.92755 \\
(2.245)\end{array}$ & $\begin{array}{r}1.0048 \\
(2.487)\end{array}$ & $\begin{array}{l}0.91232 \\
(2.277)\end{array}$ \\
\hline 3 ou mais & $\begin{array}{c}-0.24224 \mathrm{E}-01 \\
(-0.029)\end{array}$ & $\begin{array}{c}-0.44155 \mathrm{E}-02 \\
(-0.007)\end{array}$ & $\begin{array}{l}0.43048 \\
(0.713)\end{array}$ & $\begin{array}{l}0.22599 \\
(0.378)\end{array}$ \\
\hline SITUAÇÃO NA FAMÍLIA & & & & \\
\hline Chefe e Cônjuge & $\begin{array}{r}0.21807 \\
(0.471)\end{array}$ & $\begin{array}{r}0.27192 \\
(0.753)\end{array}$ & $\begin{array}{l}0.81363 \\
(2.279)\end{array}$ & $\begin{array}{r}0.76929 \\
(2.229)\end{array}$ \\
\hline Filho & $\begin{array}{r}0.19726 \\
(0.420)\end{array}$ & $\begin{array}{r}0.64148 \\
(1.730)\end{array}$ & $\begin{array}{l}0.81190 \\
(2.179)\end{array}$ & $\begin{array}{l}0.79949 \\
(2.216)\end{array}$ \\
\hline ESCOLARIDADE & & & & \\
\hline Primário Incompleto & $\begin{array}{r}0.43121 \\
(0.787)\end{array}$ & $\begin{array}{l}0.34778 \\
(0.883)\end{array}$ & $\begin{array}{r}-0.11855 \\
(-0.346)\end{array}$ & $\begin{array}{l}0.17573 \\
(0.523)\end{array}$ \\
\hline Primário Completo & $\begin{array}{r}0.48391 \\
(0.923)\end{array}$ & $\begin{array}{r}0.56330 \\
(1.492)\end{array}$ & $\begin{array}{c}-0.27408 \mathrm{E}-01 \\
(-0.083)\end{array}$ & $\begin{array}{r}0.21779 \\
(0.674)\end{array}$ \\
\hline Ginásio Incompleto & $\begin{array}{r}1.2273 \\
(2.125)\end{array}$ & $\begin{array}{r}1.0878 \\
(2.468)\end{array}$ & $\begin{array}{c}0.52334 \mathrm{E}-02 \\
(0.013)\end{array}$ & $\begin{array}{l}0.47560 \\
(1.199)\end{array}$ \\
\hline Ginásio Completo & $\begin{array}{l}0.67201 \\
(1.020)\end{array}$ & $\begin{array}{r}1.5177 \\
(3.055)\end{array}$ & $\begin{array}{l}0.57732 \\
(1.245)\end{array}$ & $\begin{array}{l}0.49561 \\
(1.084)\end{array}$ \\
\hline Colegial e Superior & $\begin{array}{r}0.20334 \\
(0.389)\end{array}$ & $\begin{array}{l}0.74263 \\
(1.976)\end{array}$ & $\begin{array}{r}-0.11468 \\
(-0.346)\end{array}$ & $\begin{array}{l}-1.0213 \\
(-3.128)\end{array}$ \\
\hline IDADE & & & & \\
\hline 18 a 19 anos & $\begin{array}{c}0.30443 \\
(0.467)\end{array}$ & $\begin{array}{r}-0.19205 \\
(-0.370)\end{array}$ & $\begin{array}{l}0.10285 \\
(-0.196)\end{array}$ & $\begin{array}{r}0.21108 \\
(0.409)\end{array}$ \\
\hline 20 a 24 anos & $\begin{array}{r}0.46905 \\
(0.848)\end{array}$ & $\begin{array}{r}-0.28545 \\
(-0.648)\end{array}$ & $\begin{array}{c}0.21283 \mathrm{E}-02 \\
(0.005)\end{array}$ & $\begin{array}{l}0.53087 \\
(1.219)\end{array}$ \\
\hline 25 a 29 anos & $\begin{array}{r}0.49501 \\
(0.839)\end{array}$ & $\begin{array}{l}-0.48217 \\
(-1.030)\end{array}$ & $\begin{array}{c}-0.24645 \mathrm{E}-01 \\
(-0.053)\end{array}$ & $\begin{array}{r}0.51653 \\
(1.121)\end{array}$ \\
\hline 30 a 39 anos & $\begin{array}{c}0.50892 E-01 \\
(0.086)\end{array}$ & $\begin{array}{l}-1.0645 \\
(-2.321)\end{array}$ & $\begin{array}{r}-0.21894 \\
(-0.480)\end{array}$ & $\begin{array}{c}0.30478 \\
(0.680)\end{array}$ \\
\hline 40 a 49 anos & $\begin{array}{c}0.33846 \\
(0.538)\end{array}$ & $\begin{array}{r}-0.94307 \\
(-1.909)\end{array}$ & $\begin{array}{c}-0.37191 \mathrm{E}-01 \\
(-0.076)\end{array}$ & $\begin{array}{c}0.30551 \\
(0.637)\end{array}$ \\
\hline 50 anos ou mais & $\begin{array}{r}-0.41229 \\
(-0.626)\end{array}$ & $\begin{array}{l}-1.5612 \\
(-3.113)\end{array}$ & $\begin{array}{r}-0.61745 \\
(-1.260)\end{array}$ & $\begin{array}{r}-0.38053 \\
(-0.791)\end{array}$ \\
\hline $\begin{array}{l}\text { POSIÇÃO NA OCUPAÇÃO } \\
\text { Autônomo ou empregador }\end{array}$ & $\begin{array}{l}-1.5191 \\
(-3.523) \\
\end{array}$ & $\begin{array}{l}-1.0269 \\
(-4.188) \\
\end{array}$ & $\begin{array}{l}0.89011 \\
(4.174) \\
\end{array}$ & $\begin{array}{l}0.53443 \\
(2.527) \\
\end{array}$ \\
\hline
\end{tabular}



Tabela F16. Coeficientes dos logitos multinomiais estimados
(valores de $z$ entre parênteses). são Paulo, 1990.

\begin{tabular}{|c|c|c|c|c|}
\hline \multirow[b]{2}{*}{ VARIÁVEIS } & \multicolumn{4}{|c|}{ CLASSES } \\
\hline & 2 & 3 & 4 & 5 \\
\hline CONSTANTE & $\begin{array}{l}-1.9956 \\
(-2.381)\end{array}$ & $\begin{array}{l}0.89571 \\
(1.602)\end{array}$ & $\begin{array}{l}2.2345 \\
(4.111)\end{array}$ & $\begin{array}{r}1.6647 \\
(3.101)\end{array}$ \\
\hline OUTRAS RENDAS PESSOAIS & $\begin{array}{c}-0.58424 \mathrm{E}-05 \\
(-0.694)\end{array}$ & $\begin{array}{c}-0.11266 \mathrm{E}-05 \\
(-0.294)\end{array}$ & $\begin{array}{c}-0.18263 \mathrm{E}-05 \\
(-0.520)\end{array}$ & $\begin{array}{c}-0.72565 \mathrm{E}-05 \\
(-1.943)\end{array}$ \\
\hline OUTRAS RENDAS & $\begin{array}{c}-0.26521 \mathrm{E}-05 \\
(-1.187)\end{array}$ & $\begin{array}{c}-0.18844 \mathrm{E}-05 \\
(-1.215)\end{array}$ & $\begin{array}{c}-0.10059 \mathrm{E}-05 \\
(-0.664)\end{array}$ & $\begin{array}{c}-0.26317 \mathrm{E}-05 \\
(-1.744)\end{array}$ \\
\hline SITUAÇÃO & & & & \\
\hline Região Urbana & $\begin{array}{l}1.5462 \\
(3.355)\end{array}$ & $\begin{array}{l}1.5852 \\
(6.619)\end{array}$ & $\begin{array}{c}0.33532 \\
(1.609)\end{array}$ & $\begin{array}{r}1.1159 \\
(5.461)\end{array}$ \\
\hline CRIANÇAS MENORES 6 ANOS & & & & \\
\hline 1 & $\begin{array}{r}0.12807 \\
(0.388)\end{array}$ & $\begin{array}{r}0.14957 \\
(0.650)\end{array}$ & $\begin{array}{c}0.31104 \\
(1.395)\end{array}$ & $\begin{array}{l}0.29008 \\
(1.325)\end{array}$ \\
\hline 2 & $\begin{array}{l}0.82187 \\
(1.742)\end{array}$ & $\begin{array}{r}0.53609 \\
(1.480)\end{array}$ & $\begin{array}{l}0.43158 \\
(1.222)\end{array}$ & $\begin{array}{l}0.59033 \\
(1.702)\end{array}$ \\
\hline 3 ou mais & $\begin{array}{c}0.50696 \\
(0.656)\end{array}$ & $\begin{array}{r}-0.27461 \\
(-0.475)\end{array}$ & $\begin{array}{c}-0.29637 \mathrm{E}-01 \\
(-0.055)\end{array}$ & $\begin{array}{c}0.83279 \mathrm{E}-01 \\
(0.159)\end{array}$ \\
\hline SITUAÇÃO NA FAMÍLIA & & & & \\
\hline Chefe e Cônjuge & $\begin{array}{l}-0.80292 \\
(-1.300)\end{array}$ & $\begin{array}{l}-0.67241 \\
(-1.441)\end{array}$ & $\begin{array}{r}-0.43113 \\
(-0.936)\end{array}$ & $\begin{array}{l}-0.19141 \\
(-0.422)\end{array}$ \\
\hline Filho & $\begin{array}{c}0.41473 E-01 \\
(0.068)\end{array}$ & $\begin{array}{c}-0.94501 \mathrm{E}-01 \\
(-0.202)\end{array}$ & $\begin{array}{r}-0.20631 \\
(-0.444)\end{array}$ & $\begin{array}{c}0.91676 \mathrm{E}-01 \\
(0.200)\end{array}$ \\
\hline ESCOLARIDADE & & & & \\
\hline Primário Completo & $\begin{array}{c}0.52188 \mathrm{E}-01 \\
(0.124)\end{array}$ & $\begin{array}{l}0.59747 \\
(2.321)\end{array}$ & $\begin{array}{c}-0.28480 \mathrm{E}-02 \\
(-0.012)\end{array}$ & $\begin{array}{c}0.35548 \\
(1.520)\end{array}$ \\
\hline Ginásio Incompleto & $\begin{array}{c}0.63546 \\
(1.506)\end{array}$ & $\begin{array}{l}0.70678 \\
(2.429)\end{array}$ & $\begin{array}{l}-0.16286 \\
(-0.579)\end{array}$ & $\begin{array}{c}0.13980 \\
(0.511)\end{array}$ \\
\hline Ginásio Completo & $\begin{array}{l}0.42434 \\
(0.908)\end{array}$ & $\begin{array}{c}0.64638 \\
(2.035)\end{array}$ & $\begin{array}{r}-0.14379 \\
(-0.470)\end{array}$ & $\begin{array}{r}-0.13362 \\
(-0.448)\end{array}$ \\
\hline Colegial e Superior & $\begin{array}{r}0.99744 \\
(2.668)\end{array}$ & $\begin{array}{r}1.0518 \\
(4.062)\end{array}$ & $\begin{array}{l}0.46740 \\
(1.905)\end{array}$ & $\begin{array}{r}-0.34133 \\
(-1.413)\end{array}$ \\
\hline IDADE & & & & \\
\hline 18 a 19 anos & $\begin{array}{r}0.25714 \\
(0.337)\end{array}$ & $\begin{array}{l}0.39085 \\
(0.725)\end{array}$ & $\begin{array}{l}0.14109 \\
(0.259)\end{array}$ & $\begin{array}{c}0.96586 \\
(1.808)\end{array}$ \\
\hline 20 a 24 anos & $\begin{array}{l}(1.471) \\
0.28008\end{array}$ & $\begin{array}{l}(-0.104) \\
-0.41168\end{array}$ & $\begin{array}{c}(-0.114) \\
-0.71551 \mathrm{E}-01\end{array}$ & $\begin{array}{l}(2.218) \\
0.69708\end{array}$ \\
\hline 25 a 29 anos & $\begin{array}{l}(0.484) \\
0.15453\end{array}$ & $\begin{array}{r}(-1.002) \\
-0.80412\end{array}$ & $\begin{array}{l}(-0.175) \\
-0.11417\end{array}$ & $\begin{array}{l}(1.732) \\
0.62478\end{array}$ \\
\hline 30 a 39 anos & $\begin{array}{l}(0.264) \\
0.99481\end{array}$ & $\begin{array}{l}(-1.957) \\
-0.42680\end{array}$ & $\begin{array}{l}(-0.281) \\
0.21257\end{array}$ & $\begin{array}{l}(1.562) \\
0.92241\end{array}$ \\
\hline $\begin{array}{l}40 \text { a } 49 \text { anos } \\
50 \text { anos ou mais }\end{array}$ & $\begin{array}{l}(1.547) \\
-0.15021 \\
(-0.224)\end{array}$ & $\begin{array}{l}(-0.921) \\
-1.4038 \\
(-3.096)\end{array}$ & $\begin{array}{c}(0.466) \\
-0.79835 \\
(-1.806)\end{array}$ & $\begin{array}{c}(2.055) \\
-0.70762 E-01 \\
(-0.163)\end{array}$ \\
\hline $\begin{array}{l}\text { POSIÇÃO NA OCUPAÇÃO } \\
\text { Autônomo ou empregador }\end{array}$ & $\begin{array}{r}0.52513 \\
(1.424) \\
\end{array}$ & $\begin{array}{l}0.15188 \\
(0.545) \\
\end{array}$ & $\begin{array}{r}1.6622 \\
(6.343) \\
\end{array}$ & $\begin{array}{r}1.4049 \\
(5.407) \\
\end{array}$ \\
\hline
\end{tabular}




\section{APÊNDICE G}

Tabela G1. Estimativas dos coeficientes das equações de rendimento ajustadas para a PEA ocupada por sexo e classe ocupacional. São Paulo, 1981

Tabela G2. Números-índices obtidos dos coeficientes das equações de rendimento ajustadas para a PEA ocupada por sexo e classe ocupacional. São Paulo, 1981.

Tabela G3. Estimativas dos coeficientes das equações de rendimento ajustadas para a PEA ocupada por sexo e classe ocupacional. São Paulo, 1983.

Tabela G4. Números-índices obtidos dos coeficientes das equacōes de rendimento ajustadas para a PEA ocupada por sexo e classe ocupacional. São Paulo, 1983

Tabela G5. Estimativas dos coeficientes das equações de rendimento ajustadas para a PEA ocupada por sexo e classe coupacional. São Paulo, 1985.

Tabela G6. Números-índices obtidos dos coeficientes das equações de rendimento ajustadas para a PEA ocupada por sexo e classe ocupacional. São Paulo, 1985.

Tabela G7. Estimativas dos coeficientes das equações de rendimento ajustadas para a PEA ocupada por sexo e classe ocupacional. São Paulo, 1987.

Tabela G8. Números-índices obtidos dos coeficientes das equações de rendimento ajustadas para a PEA ocupada por sexo e classe ocupacional. São Paulo, 1987.

Tabela G9. Estimativas dos coeficientes das equações de rendimento ajustadas para a PEA ocupada por sexo e classe ocupacional. São Paulo, 1988

Tabela G10. Números-índices obtidos dos coeficientes das equações de rendimento ajustadas para a PEA ocupada por sexo e classe ocupacional. São Paulo, 1988.

Tabela G11. Estimativas dos coeficientes das equações de rendimento ajustadas para a PEA ocupada por sexo e classe ocupacional. São Paulo, 1989.

Tabela G12. Números-índices obtidos dos coeficientes das equações de rendimento ajustadas para a PEA ocupada por sexo e classe ocupacional. São Paulo, 1989.

Tabela G13. Estimativas dos coeficientes das equações de rendimento ajustadas para a PEA ocupada por sexo e classe ocupacional. São Paulo, 1990

Tabela G14. Números-índices obtidos dos coeficientes das equações de rendimento ajustadas para a PEA ocupada por sexo e classe ocupacional. São Paulo, 1990.

Tabela G15. Estimativas dos coeficientes das equações de rendimento ajustadas para a PEA ocupada por sexo e classe ocupacional. Pernambuco, 1981.

Tabela G16. Números-índices obtidos dos coeficientes das equações de rendimento ajustadas para a PEA ocupada por sexo e classe ocupacional. Pernambuco, 1981.

Tabela G17. Estimativas dos coeficientes das equações de rendimento ajustadas para a PEA ocupada por sexo e classe ocupacional. Pemambuco, 1983.

Tabela G18. Números-índices obtidos dos coeficientes das equações de rendimento ajustadas para a PEA ocupada por sexo e classe ocupacional. Pernambuco, 1983.

Tabela G19. Estimativas dos coeficientes das equações de rendimento ajustadas para a PEA ocupada por sexo e classe ocupacional. Pernambuco, 1985. 
Tabela G20. Números-índices obtidos dos coeficientes das equações de rendimento ajustadas para a PEA ocupada por sexo e classe ocupacional. Pernambuco. 1985.

Tabela G21. Estimativas dos coeficientes das equações de rendimento ajustadas para a PEA ocupada por sexo e classe ocupacional. Pernambuco, 1987.

Tabela G22. Números-índices obtidos dos coeficientes das equações de rendimento ajustadas para a PEA ocupada por sexo e classe ocupacional. Pernambuco, 1987.

Tabela G23. Estimativas dos coeficientes das equações de rendimento ajustadas para a PEA ocupada por sexo e classe ocupacional. Pernambuco, 1988.

Tabela G24. Números-índices obtidos dos coeficientes das equações de rendimento ajustadas para a PEA ocupada por sexo e classe ocupacional. Pernambuco, 1988.

Tabela G25. Estimativas dos coeficientes das equações de rendimento ajustadas para a PEA ocupada por sexo e classe ocupacional. Pernambuco, 1989.

Tabela G26. Números-índices obtidos dos coeficientes das equações de rendimento ajustadas para a PEA ocupada por sexo e classe ocupacional. Pernambuco, 1989.

Tabela G27. Estimativas dos coeficientes das equações de rendimento ajustadas para a PEA ocupada por sexo e classe ocupacional. Pernambuco, 1990.

Tabela G28. Números-índices obtidos dos coeficientes das equações de rendimento ajustadas para a PEA ocupada por sexo e classe ocupacional. Pernambuco, 1990. 
Tabela GI. Estimativas dos coeficientes das equações de rendimento ajustadas para a PEA ocupada(1), por sexo e classe ocupacional. São Paulo, 1981. ${ }^{(2)}$

\begin{tabular}{|c|c|c|c|c|c|}
\hline \multirow[t]{2}{*}{ SEXO/FATOR } & \multicolumn{5}{|c|}{ CLASSES } \\
\hline & 1 & 2 & 3 & 4 & 5 \\
\hline \multicolumn{6}{|l|}{ HOMENS } \\
\hline INTERCEPTO & 7.219075 & 7.902064 & 7.256856 & 7.197140 & 7.146245 \\
\hline \multicolumn{6}{|l|}{ ESCOLARIDADE } \\
\hline Primário Incompleto & $-0.09615 \mathrm{~ns}$ & $0.37444 \mathrm{~ns}$ & 0.42807 & 0.23136 & 0.25332 \\
\hline Primário Completo & 0.33103 & $0.36522 \mathrm{~ns}$ & 0.52848 & 0.48916 & 0.50392 \\
\hline Ginásio Incompleto & 0.64598 & 0.55029 & 0.68811 & 0.56792 & 0.60841 \\
\hline Ginásio Completo & 0.57777 & 0.69306 & 0.90202 & 0.77202 & 0.87596 \\
\hline Colegial e Superior & 1.71693 & 1.30242 & 1.25284 & 1.52858 & 1.46224 \\
\hline \multicolumn{6}{|l|}{$\mathrm{IDADE}$} \\
\hline 18 a 19 anos & $0.04210 \mathrm{~ns}$ & $0.26682 \mathrm{~ns}$ & 0.20943 & $0.04865 \mathrm{~ns}$ & 0.36794 \\
\hline 20 a 24 anos & $-0.25524 \mathrm{~ns}$ & 0.68405 & 0.55861 & 0.33004 & 0.62536 \\
\hline 25 a 29 anos & $0.42370^{*}$ & 0.68365 & 0.86910 & 0.62252 & 0.98594 \\
\hline 30 a 39 anos & 0.52356 & 1.04023 & 1.06094 & 0.85545 & 1.19082 \\
\hline 40 a 49 anos & 0.78254 & 1.23236 & 1.20850 & 0.92607 & 1.35066 \\
\hline 50 anos ou mais & 0.64635 & 1.09191 & 1.22456 & 0.87076 & 1.29626 \\
\hline \multicolumn{6}{|l|}{ SITUAÇÃO } \\
\hline Região Urbana & 0.33821 & $-0.27928 \mathrm{~ns}$ & $0.11600 \mathrm{~ns}$ & 0.31231 & 0.23475 \\
\hline \multicolumn{6}{|l|}{ POSIÇÃO NA OCUPAÇÃO } \\
\hline \multicolumn{6}{|l|}{ POSSE DE CARTEIRA ASSINADA } \\
\hline Com Carteira Assinada & 0.57489 & $0.11014 \mathrm{~ns}$ & 0.33014 & 0.38264 & 0.40952 \\
\hline \multicolumn{6}{|l|}{ MULHERES } \\
\hline NTERCEPTO & 6.934676 & 7.091518 & 7.674284 & 7.381396 & 7.318769 \\
\hline \multicolumn{6}{|l|}{ ESCOLARIDADE } \\
\hline Primário Incompleto & 0.13755 & $0.24151^{*}$ & 0.26428 & 0.19878 & 0.43034 \\
\hline Primário Completo & 0.33854 & 0.45729 & 0.29931 & 0.42027 & 0.72312 \\
\hline Ginásio Incompleto & 0.58683 & 0.68339 & 0.47870 & 0.38241 & 0.82227 \\
\hline Ginásio Completo & 0.77641 & 0.72174 & 0.73813 & 0.59244 & 0.98877 \\
\hline Colegial e Superior & 1.49500 & 1.35290 & 1.08821 & 1.25411 & 1.60582 \\
\hline \multicolumn{6}{|l|}{ IDADE } \\
\hline 18 a 19 anos & 0.25701 & $0.17441 \mathrm{~ns}$ & $0.05513 \mathrm{~ns}$ & $-0.07392 \mathrm{~ns}$ & $0.14743 \mathrm{~ns}$ \\
\hline 20 a 24 anos & 0.49132 & 0.54269 & 0.38149 & 0.16892 & 0.65734 \\
\hline 25 a 29 anos & 0.81419 & 0.73285 & 0.66688 & 0.55625 & 0.82832 \\
\hline 30 a 39 anos & 1.03548 & 0.81346 & 0.88700 & 0.60867 & 1.14020 \\
\hline 40 a 49 anos & 0.99155 & 0.87971 & 0.84569 & 0.72046 & 1.24095 \\
\hline 50 anos ou mais & 0.89437 & 0.84179 & 0.88776 & 0.42217 & 1.03406 \\
\hline \multicolumn{6}{|l|}{ SITUAÇÃO } \\
\hline Região Urbana & 0.14344 & 0.38425 & $-0.00680 \mathrm{~ns}$ & 0.15343 & $0.20250 \mathrm{~ns}$ \\
\hline POSIÇÃO NA OCUPAÇÃO & & & & & \\
\hline $\begin{array}{l}\text { Autônomos e empregadores } \\
\text { POSSE DE CARTEIRA ASSINADA }\end{array}$ & 0.10418 & $0.00386 \mathrm{~ns}$ & 0.19052 & 0.54171 & $-0.05247 \mathrm{~ns}$ \\
\hline Com Carteira Assinada & 0.37887 & $0.06206 \mathrm{~ns}$ & 0.16859 & 0.35406 & $-0.03802 \mathrm{~ns}$ \\
\hline
\end{tabular}

(1) Inclui apenas as observações para as quais os atributos de interesse estão claramente identificados.

(2) Todos os coeficientes são estatisticamente significativos ao nível de $5 \%$, com exceção dos assinalados por asterisco (que são significativos ao nível de $10 \%$ ) e por ns (que são nâo-significativos). 
Tabela G2. Números-indices obtidos dos coeficientes das equações de rendimento ajustadas para a PEA ocupada(1), por sexo e classe ocupacional. São Paulo, 1981. (2)

\begin{tabular}{|c|c|c|c|c|c|}
\hline \multirow[t]{2}{*}{ SEXO/FATOR } & \multicolumn{5}{|c|}{ CLASSES } \\
\hline & 1 & 2 & 3 & 4 & 5 \\
\hline \multicolumn{6}{|l|}{ HOMENS } \\
\hline NTERCEPTO & 1365.226 & 2702.855 & 1417.792 & 1335.605 & 1269.331 \\
\hline \multicolumn{6}{|l|}{ ESCOLARIDADE } \\
\hline Primário Incompleto & $0.908 \mathrm{~ns}$ & $1.454 \mathrm{~ns}$ & 1.534 & 1.260 & 1.288 \\
\hline Primário Completo & 1.392 & $1.441 \mathrm{~ns}$ & 1.696 & 1.631 & 1.655 \\
\hline Ginásio Incompleto & 1.908 & 1.734 & 1.990 & 1.765 & 1.838 \\
\hline Ginásio Completo & 1.782 & 2.000 & 2.465 & 2.164 & 2.401 \\
\hline Colegial e Superior & 5.567 & 3.678 & 3.500 & 4.612 & 4.316 \\
\hline \multicolumn{6}{|l|}{ IDADE } \\
\hline 18 a 19 anos & $1.043 \mathrm{~ns}$ & $1.306 \mathrm{~ns}$ & 1.233 & $1.050 \mathrm{~ns}$ & 1.445 \\
\hline 20 a 24 anos & $0.775 \mathrm{~ns}$ & 1.982 & 1.748 & 1.391 & 1.869 \\
\hline 25 a 29 anos & $1.528 *$ & 1.981 & 2.385 & 1.864 & 2.680 \\
\hline 30 a 39 anos & 1.688 & 2.830 & 2.889 & 2.352 & 3.290 \\
\hline 40 a 49 anos & 2.187 & 3.429 & 3.348 & 2.525 & 3.860 \\
\hline 50 anos ou mais & 1.909 & 2.980 & 3.403 & 2.389 & 3.656 \\
\hline \multicolumn{6}{|l|}{ SITUAÇÃO } \\
\hline Região Urbana & 1.402 & $0.756 \mathrm{~ns}$ & $1.123 \mathrm{~ns}$ & 1.367 & 1.265 \\
\hline \multicolumn{6}{|l|}{ POSIÇÃO NA OCUPAÇÃO } \\
\hline & \multicolumn{2}{|c|}{ POSSE DE CARTEIRA ASSINADA } & 1.496 & 1.604 & 1.344 \\
\hline Com Carteira Assinada & 1.777 & $1.116 \mathrm{~ns}$ & 1.391 & 1.466 & 1.506 \\
\hline \multicolumn{6}{|l|}{ MULHERES } \\
\hline NTERCEPTO & 1027.286 & 1201.731 & 2152.282 & 1605.830 & 1508.346 \\
\hline \multicolumn{6}{|l|}{ ESCOLARIDADE } \\
\hline Primánio Incompleto & 1.147 & $1.273^{*}$ & 1.302 & 1.220 & 1.538 \\
\hline Primário Completo & 1.403 & 1.580 & 1.349 & 1.522 & 2.061 \\
\hline Ginásio Incompleto & 1.798 & 1.981 & 1.614 & 1.466 & 2.276 \\
\hline Ginásio Completo & 2.174 & 2.058 & 2.092 & 1.808 & 2.688 \\
\hline Colegial e Superior & 4.459 & 3.869 & 2.969 & 3.505 & 4.982 \\
\hline \multicolumn{6}{|l|}{ IDADE } \\
\hline 18 a 19 anos & 1.293 & $1.191 \mathrm{~ns}$ & $1.057 \mathrm{~ns}$ & $0.929 \mathrm{~ns}$ & $1.159 \mathrm{~ns}$ \\
\hline 20 a 24 anos & 1.634 & 1.721 & 1.464 & 1.184 & 1.930 \\
\hline 25 a 29 anos & 2.257 & 2.081 & 1.948 & 1.744 & 2.289 \\
\hline 30 a 39 anos & 2.816 & 2.256 & 2.428 & 1.838 & 3.127 \\
\hline 40 a 49 anos & 2.695 & 2.410 & 2.330 & 2.055 & 3.459 \\
\hline 50 anos ou mais & 2.446 & 2.321 & 2.430 & 1.525 & 2.812 \\
\hline \multicolumn{6}{|l|}{ SITUAÇÃo } \\
\hline Região Urbana & 1.154 & 1.469 & $0.993 \mathrm{~ns}$ & 1.166 & $1.224 \mathrm{~ns}$ \\
\hline \multicolumn{6}{|l|}{ POSIÇÃO NA OCUPAÇÃO } \\
\hline \multirow{2}{*}{\multicolumn{6}{|c|}{ POSSE DE CARTEIRA ASSINADA }} \\
\hline & & & & & \\
\hline Com Carteira Assinada & 1.461 & $1.064 \mathrm{~ns}$ & 1.184 & 1.425 & $0.963 \mathrm{~ns}$ \\
\hline
\end{tabular}

(1) Inclui apenas as observaçōes para as quais os atributos de interesse estão claramente identificados.

(2) Todos os coeficientes são estatisticamente significativos ao nivel de $5 \%$, com exceção dos assinalados por asterisco (que são significativos ao nivel de $10 \%$ ) e por ns (que são não-significativos). 
Tabela G3. Estimativas dos coeficientes das equações de rendimento ajustadas para a PEA ocupada(1), por sexo e classe ocupacional. São Paulo, 1983.(2)

\begin{tabular}{|c|c|c|c|c|c|}
\hline \multirow[t]{2}{*}{ SEXO/FATOR } & \multicolumn{5}{|c|}{ CLASSES } \\
\hline & 1 & 2 & 3 & 4 & 5 \\
\hline \multicolumn{6}{|l|}{ HOMENS } \\
\hline INTERCEPTO & 7.079643 & 6.445635 & 7.018235 & 6.928527 & 6.975463 \\
\hline \multicolumn{6}{|l|}{ ESCOLARIDADE } \\
\hline Primário Incompleto & $0.28273^{*}$ & 0.63493 & $0.15082 \mathrm{~ns}$ & 0.34023 & 0.24284 \\
\hline Primário Completo & 0.53074 & 0.72436 & 0.30292 & 0.63099 & 0.48759 \\
\hline Ginásio Incompleto & 0.64508 & 0.82745 & 0.51125 & 0.74857 & 0.68211 \\
\hline Ginásio Completo & 0.79188 & 0.79256 & 0.70583 & 1.04864 & 0.86187 \\
\hline Colegial e Superior & 1.47333 & 1.56037 & 1.05646 & 1.66955 & 1.46653 \\
\hline \multicolumn{6}{|l|}{ IDADE } \\
\hline 18 a 19 anos & $0.05211 \mathrm{~ns}$ & $0.27662 \mathrm{~ns}$ & 0.36395 & 0.10577 & 0.23519 \\
\hline 20 a 24 anos & $0.32676 \mathrm{~ns}$ & 0.51059 & 0.59745 & 0.31385 & 0.50189 \\
\hline 25 a 29 anos & 0.73144 & 0.79437 & 0.96930 & 0.68481 & 0.85325 \\
\hline 30 a 39 anos & 0.77007 & 1.39887 & 1.29288 & 1.02205 & 1.12172 \\
\hline 40 a 49 anos & 0.81365 & 1.48200 & 1.39743 & 1.05513 & 1.25574 \\
\hline 50 anos ou mais & 0.52481 & 1.42209 & 1.23260 & 1.00617 & 1.19312 \\
\hline \multicolumn{6}{|l|}{ SITUAÇÃO } \\
\hline Região Urbana & $0.20888 \mathrm{~ns}$ & 0.47246 & $0.15837^{*}$ & 0.20707 & 0.25480 \\
\hline \multicolumn{6}{|l|}{ POSIÇÃO NA OCUPAÇÃO } \\
\hline Autônomos e empregadores & 0.27246 & $0.20938 \mathrm{~ns}$ & 0.39870 & 0.36933 & 0.38619 \\
\hline \multicolumn{6}{|c|}{ POSSE DE CARTEIRA ASSINADA } \\
\hline Com Carteira Assinada & 0.19866 & 0.31151 & 0.44754 & 0.40192 & 0.41825 \\
\hline \multicolumn{6}{|l|}{ MULHERES } \\
\hline INTERCEPTO & 6.746336 & 7.115566 & 6.927435 & 6.824337 & 7.022822 \\
\hline \multicolumn{6}{|l|}{ ESCOLARIDADE } \\
\hline Primário Incompleto & 0.23326 & 0.34933 & 0.26520 & 0.40299 & $-0.07033 \mathrm{~ns}$ \\
\hline Primário Completo & 0.44023 & 0.61619 & 0.42290 & 0.60754 & $0.29840 \mathrm{~ns}$ \\
\hline Ginásio Incompleto & 0.56410 & 0.77058 & 0.67895 & 0.78318 & $0.44174 *$ \\
\hline Ginásio Completo & 0.89953 & 0.92256 & 0.81784 & 0.89218 & 0.69644 \\
\hline Colegial e Superior & 1.59121 & 1.69928 & 1.21469 & 1.57399 & 1.15761 \\
\hline \multicolumn{6}{|l|}{ IDADE } \\
\hline 18 a 19 anos & 0.21180 & $0.06490 \mathrm{~ns}$ & $0.07219 \mathrm{~ns}$ & 0.14644 & $0.20928 \mathrm{~ns}$ \\
\hline 20 a 24 anos & 0.48343 & $0.18647 \mathrm{~ns}$ & 0.38375 & 0.22929 & 0.43879 \\
\hline 25 a 29 anos & 0.72796 & 0.57837 & 0.73938 & 0.60104 & 0.75973 \\
\hline 30 a 39 anos & 0.96906 & 0.79791 & 0.83000 & 0.81999 & 1.05468 \\
\hline 40 a 49 anos & 0.99140 & 0.83308 & 0.98380 & 0.95636 & 1.15177 \\
\hline 50 anos ou mais & 0.95174 & 0.84251 & 0.93063 & 0.92152 & 0.86680 \\
\hline \multicolumn{6}{|l|}{ STIUAÇÃO } \\
\hline Região Utbana & $0.07359 \mathrm{~ns}$ & $0.12060 \mathrm{~ns}$ & 0.32395 & 0.23294 & 0.36840 \\
\hline \multicolumn{6}{|l|}{ POSIÇÃO NA OCUPAÇÃO } \\
\hline Autônomos e empregedores & 0.17489 & $0.24618^{*}$ & 0.17682 & 0.32191 & 0.49742 \\
\hline \multicolumn{6}{|c|}{ POSSE DE CARTEIRA ASSINADA } \\
\hline Com Carteira Assinada & 0.34017 & $0.00430 \mathrm{~ns}$ & 0.25373 & 0.32906 & 0.35968 \\
\hline
\end{tabular}

(1) Inclui apenas as observaçỏes para as quais os atributos de interesse estão claramente identificados.

(2) Todos os coeficientes são estatisticamente significativos ao nível de $5 \%$, com exceção dos assinalados por asterisco (que são significativos ao nível de $10 \%$ ) e por ns (que são não-significativos). 
Tabela G4. Números-indices obtidos dos coeficientes das equações de rendimento ajustadas para a PEA

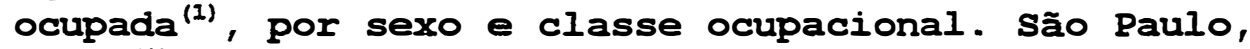
1983. (2)

\begin{tabular}{|c|c|c|c|c|c|}
\hline \multirow[t]{2}{*}{ SEXO/FATOR } & \multicolumn{5}{|c|}{ CLASSES } \\
\hline & 1 & 2 & 3 & 4 & 5 \\
\hline \multicolumn{6}{|l|}{ HOMENS } \\
\hline INTERCEPTO & 1187.544 & 629.947 & 1116.814 & 1020.989 & 1070.053 \\
\hline \multicolumn{6}{|l|}{ ESCOLARIDADE } \\
\hline Primário Incompleto & $1.327^{*}$ & 1.887 & $1.163 \mathrm{~ns}$ & 1.405 & 1.275 \\
\hline Primánio Completo & 1.700 & 2.063 & 1.354 & 1.879 & 1.628 \\
\hline Ginásio Incompleto & 1.906 & 2.287 & 1.667 & 2.114 & 1.978 \\
\hline Ginásio Completo & 2.208 & 2.209 & 2.026 & 2.854 & 2.368 \\
\hline Colegial e Superior & 4.364 & 4.761 & 2.876 & 5.310 & 4.334 \\
\hline \multicolumn{6}{|l|}{ IDADE } \\
\hline 18 a 19 anos & $1.053 \mathrm{~ns}$ & $1.319 \mathrm{~ns}$ & 1.439 & 1.112 & 1.265 \\
\hline 20 a 24 anos & $1.386 \mathrm{~ns}$ & 1.666 & 1.817 & 1.369 & 1.652 \\
\hline 25 a 29 anos & 2.078 & 2.213 & 2.636 & 1.983 & 2.347 \\
\hline 30 a 39 anos & 2.160 & 4.051 & 3.643 & 2.779 & 3.070 \\
\hline 40 a 49 anos & 2.256 & 4.402 & 4.045 & 2.872 & 3.510 \\
\hline 50 anos ou mais & 1.690 & 4.146 & 3.430 & 2.735 & 3.297 \\
\hline \multicolumn{6}{|l|}{ SITUAÇÃO } \\
\hline Região Urbana & $1.232 \mathrm{~ns}$ & 1.604 & $1.172^{*}$ & 1.230 & 1.290 \\
\hline \multicolumn{6}{|l|}{ POSIÇÃO NA OCUPAÇÃO } \\
\hline Autônomos e empregadores & 1.313 & $1.233 \mathrm{~ns}$ & 1.490 & 1.447 & 1.471 \\
\hline \multicolumn{6}{|c|}{ POSSE DE CARTEIRA ASSINADA } \\
\hline Com Carteira Assinada & 1.220 & 1.365 & 1.564 & 1.495 & 1.519 \\
\hline \multicolumn{6}{|l|}{ MULHERES } \\
\hline INTERCEPTO & 850.935 & 1230.980 & 1019.875 & 919.966 & 1121.948 \\
\hline \multicolumn{6}{|l|}{ ESCOLARIDADE } \\
\hline Primário Incompleto & 1.263 & 1.418 & 1.304 & 1.496 & $0.932 \mathrm{~ns}$ \\
\hline Primário Completo & 1.553 & 1.852 & 1.526 & 1.836 & $1.348 \mathrm{~ns}$ \\
\hline Ginásio Incompleto & 1.758 & 2.161 & 1.972 & 2.188 & $1.555 *$ \\
\hline Ginásio Completo & 2.458 & 2.516 & 2.266 & 2.440 & 2.007 \\
\hline Colegial e Superior & 4.910 & 5.470 & 3.369 & 4.826 & 3.182 \\
\hline \multicolumn{6}{|l|}{ IDADE } \\
\hline 18 a 19 anos & 1.236 & $1.067 \mathrm{~ns}$ & $1.075 \mathrm{~ns}$ & 1.158 & $1.233 \mathrm{~ns}$ \\
\hline 20 a 24 anos & 1.622 & $1.205 \mathrm{~ns}$ & 1.468 & 1.258 & 1.551 \\
\hline 25 a 29 anos & 2.071 & 1.783 & 2.095 & 1.824 & 2.138 \\
\hline 30 a 39 anos & 2.635 & 2.221 & 2.293 & 2.270 & 2.871 \\
\hline 40 a 49 anos & 2.695 & 2.300 & 2.675 & 2.602 & 3.164 \\
\hline 50 anos ou mais & 2.590 & 2.322 & 2.536 & 2.513 & 2.379 \\
\hline \multicolumn{6}{|l|}{ SITUAÇĀO } \\
\hline Região Urbana & $1.076 \mathrm{~ns}$ & $1.128 \mathrm{~ns}$ & 1.383 & 1.262 & 1.445 \\
\hline \multicolumn{6}{|l|}{ POSIÇÃO NA OCUPAÇÃO } \\
\hline Autônomos e empregadores & 1.191 & $1.279 *$ & 1.193 & 1.380 & 1.644 \\
\hline \multicolumn{6}{|c|}{ POSSE DE CARTEIRA ASSINADA } \\
\hline Com Carteira Assinada & 1.405 & $1.004 \mathrm{~ns}$ & 1.289 & 1.390 & 1.433 \\
\hline
\end{tabular}

(1) Inclui apenas as observações para as quais os atributos de interesse estão claramente identificados.

(2) Todos os coeficientes são estatisticamente significativos ao nivel de $5 \%$, com exceção dos assinalados por asterisco (que são significativos ao nível de $10 \%$ ) e por ns (que são não-significativos). 
Tabela G5. Estimativas dos coeficientes das equações de rendimento ajustadas para a PEA ocupada(1), por sexo e classe ocupacional. São Paulo, 1985. (2)

\begin{tabular}{|c|c|c|c|c|c|}
\hline \multirow[t]{2}{*}{ SEXO/FATOR } & \multicolumn{5}{|c|}{ CLASSES } \\
\hline & 1 & 2 & 3 & 4 & 5 \\
\hline \multicolumn{6}{|l|}{ HOMENS } \\
\hline INTERCEPTO & 6.947421 & 7.870158 & 6.931407 & 6.876525 & 7.072459 \\
\hline \multicolumn{6}{|l|}{ ESCOLARIDADE } \\
\hline Primário Incompleto & $0.29081^{*}$ & $0.19583 \mathrm{~ns}$ & 0.27311 & 0.34777 & 0.25584 \\
\hline Primánio Completo & 0.75658 & 0.44639 & 0.50578 & 0.59017 & 0.51428 \\
\hline Ginásio Incormpleto & 0.71154 & 0.44798 & 0.77522 & 0.76231 & 0.61126 \\
\hline Ginásio Completo & 1.13257 & 0.64944 & 1.00237 & 0.91970 & 0.86724 \\
\hline Colegial e Superior & 1.87375 & 1.56873 & 1.41080 & 1.48646 & 1.49487 \\
\hline \multicolumn{6}{|l|}{ IDADE } \\
\hline 18 a 19 anos & $0.10496 \mathrm{~ns}$ & $0.29273 \mathrm{~ns}$ & 0.37421 & 0.27786 & 0.23545 \\
\hline 20 a 24 anos & 0.36460 & $0.22440 \mathrm{~ns}$ & 0.59998 & 0.53355 & 0.41665 \\
\hline 25 a 29 anos & 0.50127 & 0.62638 & 0.97144 & 0.90114 & 0.75736 \\
\hline 30 a 39 anos & 0.72343 & 0.90075 & 1.36577 & 1.27131 & 0.99016 \\
\hline 40 a 49 anos & 0.80198 & 0.89395 & 1.51924 & 1.37899 & 1.11684 \\
\hline 50 anos ou mais & 0.75828 & 0.95085 & 1.47533 & 1.30586 & 1.02827 \\
\hline \multicolumn{6}{|l|}{ SITUAÇÃO } \\
\hline Região Urbana & $0.18544 *$ & $-0.32322 \mathrm{~ns}$ & $0.13266 \mathrm{~ns}$ & 0.23980 & 0.26897 \\
\hline \multicolumn{6}{|l|}{ POSIÇÃO NA OCUPAÇÃO } \\
\hline Autônomos e empregadores & 0.34158 & $0.16487 \mathrm{~ns}$ & $0.06481 \mathrm{~ns}$ & 0.44803 & 0.48595 \\
\hline \multicolumn{6}{|c|}{ POSSE DE CARTEIRA ASSINADA } \\
\hline Com Carteira Assinada & 0.19475 & 0.30135 & 0.27116 & 0.37499 & 0.44768 \\
\hline \multicolumn{6}{|l|}{ MULHERES } \\
\hline INTERCEPTO & 6.788853 & 7.242259 & 7.222838 & 7.032589 & 7.213600 \\
\hline \multicolumn{6}{|l|}{ ESCOLARIDADE } \\
\hline Primário Incompleto & 0.15226 & 0.35642 & $0.15206 \mathrm{~ns}$ & 0.52603 & 0.22776 \\
\hline Primáno Completo & 0.41210 & 0.59023 & 0.40400 & 0.69120 & 0.51297 \\
\hline Ginásio Incompleto & 0.58385 & 0.73287 & 0.56991 & 0.83364 & 0.62431 \\
\hline Ginásio Completo & 0.81666 & 0.82800 & 0.84821 & 0.88680 & 0.95183 \\
\hline Colegial e Superior & 1.70517 & 1.59886 & 1.25378 & 1.49903 & 1.54790 \\
\hline \multicolumn{6}{|l|}{ IDADE } \\
\hline 18 a 19 anos & 0.17155 & $0.12670 \mathrm{~ns}$ & $0.12875^{*}$ & $0.08893 \mathrm{~ns}$ & $0.12288 \mathrm{~ns}$ \\
\hline 20 a 24 anos & 0.40695 & $0.20784^{*}$ & 0.34733 & 0.31201 & 0.26093 \\
\hline 25 a 29 anos & 0.73197 & 0.53674 & 0.65306 & 0.70525 & 0.47923 \\
\hline 30 a 39 anos & 0.91461 & 0.74108 & 0.98962 & 0.86867 & 0.65431 \\
\hline 40 a 49 anos & 0.99190 & 0.81056 & 1.13720 & 1.02074 & 0.76369 \\
\hline 50 anos ou mais & 0.90844 & 0.83795 & 0.91431 & 0.81491 & 0.73736 \\
\hline \multicolumn{6}{|l|}{ SITUAÇÃO } \\
\hline Região Urbana & 0.09444 & $0.12599 \mathrm{~ns}$ & $0.18235^{*}$ & $0.02424 \mathrm{~ns}$ & 0.19921 \\
\hline \multicolumn{6}{|l|}{ POSIÇÃO NA OCUPAÇÃO } \\
\hline Autônomos e empregadores & 0.20228 & 0.25309 & 0.29000 & 0.42030 & 0.51906 \\
\hline \multicolumn{6}{|c|}{ POSSE DE CARTEIRA ASSINADA } \\
\hline Com Carteira Assinada & 0.31617 & $0.06835 \mathrm{~ns}$ & 0.13786 & 0.27866 & 0.36261 \\
\hline
\end{tabular}

(1) Inclui apenas as observaçōes para as quais os atributos de interesse estão claramente identificados.

(2) Todos os coeficientes são estatisticamente significativos ao nível de $5 \%$, com exceção dos assinalados por asterisco (que são significativos ao nível de 10\%) e por ns (que são não-significativos). 
Tabela G6. Números-indices obtidos dos coeficientes das equações de rendimento ajustadas para a PEA ocupada (1), por sexo e classe ocupacional. São Paulo, 1985. (2)

\begin{tabular}{|c|c|c|c|c|c|}
\hline \multirow[t]{2}{*}{ SEXO/FATOR } & \multicolumn{5}{|c|}{ CLASSES } \\
\hline & 1 & 2 & 3 & 4 & 5 \\
\hline \multicolumn{6}{|l|}{ HOMENS } \\
\hline INTERCEPTO & 1040.463 & 2617.979 & 1023.934 & 969.252 & 1179.044 \\
\hline \multicolumn{6}{|l|}{ ESCOLARIDADE } \\
\hline Primário Incompleto & $1.338 *$ & $1.216 \mathrm{~ns}$ & 1.314 & 1.416 & 1.292 \\
\hline Primáno Completo & 2.131 & 1.563 & 1.658 & 1.804 & 1.672 \\
\hline Ginásio Incompleto & 2.037 & 1.565 & 2.171 . & 2.143 & 1.843 \\
\hline Ginásio Completo & 3.104 & 1.914 & 2.725 & 2.509 & 2.380 \\
\hline Colegial e Superior & 6.513 & 4.801 & 4.099 & 4.421 & 4.459 \\
\hline IDADE & & & & · & \\
\hline 18 a 19 anos & $1.111 \mathrm{~ns}$ & $1.340 \mathrm{~ns}$ & 1.454 & 1.320 & 1.265 \\
\hline 20 a 24 anos & 1.440 & $1.252 \mathrm{~ns}$ & 1.822 & 1.705 & 1.517 \\
\hline 25 a 29 anos & 1.651 & 1.871 & 2.642 & 2.462 & 2.133 \\
\hline 30 a 39 anos & 2.062 & 2.461 & 3.919 & 3.566 & 2.692 \\
\hline 40 a 49 anos & 2.230 & 2.445 & 4.569 & 3.971 & 3.055 \\
\hline 50 anos ou mais & 2.135 & 2.588 & 4.372 & 3.691 & 2.796 \\
\hline \multicolumn{6}{|l|}{ SITUAÇĀO } \\
\hline Região Urbana & $1.204 *$ & $0.724 \mathrm{~ns}$ & $1.142 \mathrm{~ns}$ & 1.271 & 1.309 \\
\hline \multicolumn{6}{|l|}{ POSIÇÃO NA OCUPAÇÃO } \\
\hline Autônomos e empregadores & 1.407 & $1.179 \mathrm{~ns}$ & $1.067 \mathrm{~ns}$ & 1.565 & 1.626 \\
\hline \multicolumn{6}{|c|}{ POSSE DE CARTEIRA ASSINADA } \\
\hline Com Carteira Assinada & 1.215 & 1.352 & 1.311 & 1.455 & 1.565 \\
\hline \multicolumn{6}{|l|}{ MULHERES } \\
\hline INTERCEPTO & 887.895 & 1397.247 & 1370.373 & 1132.960 & 1357.771 \\
\hline \multicolumn{6}{|l|}{ ESCOLARIDADE } \\
\hline Primário Incompleto & 1.164 & 1.428 & $1.164 \mathrm{~ns}$ & 1.692 & 1.256 \\
\hline Primánio Completo & 1.510 & 1.804 & 1.498 & 1.996 & 1.670 \\
\hline Ginásio Incompleto & 1.793 & 2.081 & 1.768 & 2.302 & 1.867 \\
\hline Ginásio Completo & 2.263 & 2.289 & 2.335 & 2.427 & 2.590 \\
\hline Colegial e Superior & 5.502 & 4.947 & 3.504 & 4.477 & 4.702 \\
\hline \multicolumn{6}{|l|}{ IDADE } \\
\hline 18 a 19 anos & 1.187 & $1.135 \mathrm{~ns}$ & $1.137^{*}$ & $1.093 \mathrm{~ns}$ & $1.131 \mathrm{~ns}$ \\
\hline 20 a 24 anos & 1.502 & $1.231^{*}$ & 1.415 & 1.366 & 1.298 \\
\hline 25 a 29 anos & 2.079 & 1.710 & 1.921 & 2.024 & 1.615 \\
\hline 30 a 39 anos & 2.496 & 2.098 & 2.690 & 2.384 & 1.924 \\
\hline 40 a 49 anos & 2.696 & 2.249 & 3.118 & 2.775 & 2.146 \\
\hline 50 anos ou mais & 2.480 & 2.312 & 2.495 & 2.259 & 2.090 \\
\hline \multicolumn{6}{|l|}{ SITUAÇÃO } \\
\hline Região Urbana & 1.099 & $1.134 \mathrm{~ns}$ & $1.200^{*}$ & $1.025 \mathrm{~ns}$ & 1.220 \\
\hline \multicolumn{6}{|l|}{ POSIÇÃO NA OCUPAÇÃO } \\
\hline Autônomos e empregadores & 1.224 & 1.288 & 1.336 & 1.522 & 1.680 \\
\hline \multicolumn{6}{|c|}{ POSSE DE CARTEIRA ASSINADA } \\
\hline Com Carteira Assinada & 1.372 & $1.071 \mathrm{~ns}$ & 1.148 & 1.321 & 1.437 \\
\hline
\end{tabular}

(1) Inclui apenas as observaçőes para as quais os atributos de interesse estão claramente identificados.

(2) Todos os coeficientes são estatisticamente significativos ao nível de $5 \%$, com exceção dos assinalados por asterisco (que são significativos ao nível de $10 \%$ e por ns (que são não-significativos). 
Tabela G7. Estimativas dos coeficientes das equações de rendimento ajustadas para a PEA ocupada(1), por sexo e classe ocupacional. São Paulo, 1987. (2)

\begin{tabular}{|c|c|c|c|c|c|}
\hline \multirow{2}{*}{ SEXO/FATOR } & \multicolumn{5}{|c|}{ CLASSES } \\
\hline & 1 & 2 & 3 & 4 & 5 \\
\hline \multicolumn{6}{|l|}{ HOMENS } \\
\hline INTERCEPTO & 6.450418 & 8.098516 & 7.231496 & 7.154761 & 7.264900 \\
\hline \multicolumn{6}{|l|}{ ESCOLARIDADE } \\
\hline Primário Incompleto & $0.37809 \mathrm{~ns}$ & $0.06706 \mathrm{~ns}$ & 0.29618 & 0.21669 & 0.27064 \\
\hline Primánio Completo & $0.48225^{*}$ & $0.15588 \mathrm{~ns}$ & 0.44159 & 0.53416 & 0.43548 \\
\hline Ginásio Incompleto & 1.01913 & $0.18755 \mathrm{~ns}$ & 0.71685 & 0.67889 & 0.58100 \\
\hline Ginásio Completo & 0.90878 & $0.60928 *$ & 0.92891 & 0.95164 & 0.81193 \\
\hline Colegial e Superior & 1.55068 & 1.16489 & 1.21134 & 1.48818 & 1.37815 \\
\hline \multicolumn{6}{|l|}{ IDADE } \\
\hline 18 a 19 anos & $0.21839 \mathrm{~ns}$ & $0.56389 \mathrm{~ns}$ & 0.34908 & $0.14263 *$ & 0.37966 \\
\hline 20 a 24 anos & 0.52467 & $0.40214 \mathrm{~ns}$ & 0.57583 & 0.39487 & 0.51899 \\
\hline 25 a 29 anos & 0.89732 & $0.58148 \mathrm{~ns}$ & 0.88199 & 0.71358 & 0.80013 \\
\hline 30 a 39 anos & 1.35443 & 0.79723 & 1.18850 & 0.96175 & 1.06650 \\
\hline 40 a 49 anos & 1.42375 & 1.03099 & 1.26597 & 1.11360 & 1.20476 \\
\hline 50 anos ou mais & 1.33096 & 0.97529 & 1.12481 & 1.02433 & 1.18509 \\
\hline \multicolumn{6}{|l|}{ SITUAÇÃO } \\
\hline Região Urbana & 0.46847 & $0.06433 \mathrm{~ns}$ & $0.05262 \mathrm{~ns}$ & 0.31310 & 0.25799 \\
\hline \multicolumn{6}{|l|}{ POSIÇÃO NA OCUPAÇÃO } \\
\hline Aưtônomos e empregadores & $0.23429 \mathrm{~ns}$ & $-0.02840 \mathrm{~ns}$ & 0.25265 & 0.49724 & 0.36240 \\
\hline \multicolumn{6}{|c|}{ POSSE DE CARTEIRA ASSINADA } \\
\hline Com Carteira Assinada & $0.23131 *$ & $-0.08675 \mathrm{~ns}$ & $0: 32350$ & 0.38393 & 0.31013 \\
\hline \multicolumn{6}{|l|}{ MULHERES } \\
\hline INTERCEPTO & 7.196302 & 7.722847 & 7.525918 & 7.065289 & 7.725445 \\
\hline \multicolumn{6}{|l|}{ ESCOLARIDADE } \\
\hline Primário Incompleto & 0.18069 & $0.17094 \mathrm{~ns}$ & $0.24035^{*}$ & 0.35964 & $0.43659 \mathrm{~ns}$ \\
\hline Primário Completo & 0.37381 & $0.15178 \mathrm{~ns}$ & 0.38156 & 0.50176 & $0.37251 \mathrm{~ns}$ \\
\hline Ginásio Incompleto & 0.53180 & 0.39823 & 0.65949 & 0.72444 & $0.43462 \mathrm{~ns}$ \\
\hline Ginásio Completo & 0.82094 & 0.58818 & 0.77777 & 0.92010 & 1.09612 \\
\hline Colegial e Superior & 1.48964 & 1.17877 & 1.21891 & 1.44215 & 1.47988 \\
\hline \multicolumn{6}{|l|}{ IDADE } \\
\hline 18 a 19 anos & $0.12533 *$ & $0.08431 \mathrm{~ns}$ & $0.09196 \mathrm{~ns}$ & $0.18284^{*}$ & $-0.03708 \mathrm{~ns}$ \\
\hline 20 a 24 anos & 0.41198 & 0.56185 & 0.28963 & 0.38252 & $0.04310 \mathrm{~ns}$ \\
\hline 25 a 29 anos & 0.56991 & 0.74944 & 0.46816 & 0.67396 & $0.40175 \mathrm{~ns}$ \\
\hline 30 a 39 anos & 0.81253 & 0.93964 & 0.79833 & 0.91458 & 0.76855 \\
\hline 40 a 49 anos & 0.94608 & 0.92512 & 0.95691 & 0.89807 & 0.84079 \\
\hline 50 anos ou mais & 0.79392 & 1.08517 & 0.62485 & 0.89298 & 1.02997 \\
\hline \multicolumn{6}{|l|}{ SITUAÇÃO } \\
\hline Região Urbana & 0.13370 & $-0.00221 \mathrm{~ns}$ & $0.00451 \mathrm{~ns}$ & 0.20433 & $-0.01989 \mathrm{~ns}$ \\
\hline \multicolumn{6}{|l|}{ POSIÇÃO NA OCUPAÇÃO } \\
\hline Autônomos e empregadores & 0.12210 & $0.01768 \mathrm{~ns}$ & 0.30602 & 0.59900 & $0.26996 \mathrm{~ns}$ \\
\hline \multicolumn{6}{|c|}{ POSSE DE CARTEIRA ASSINADA } \\
\hline Com Carteira Assinada & 0.17086 & $-0.05431 \mathrm{~ns}$ & 0.18743 & 0.32840 & $0.32815^{*}$ \\
\hline
\end{tabular}

(1) Inclui apenas as observaçōes para as quais os atributos de interesse estão claramente identificados.

(2) Todos os coeficientes são estatisticamente significativos ao nível de $5 \%$, com exceção dos assinalados por asterisco (que são significativos ao nível de $10 \%$ ) e por ns (que são não-significativos). 
Tabela 68. Números-índices obtidos dos coeficientes das equações de rendimento ajustadas para a PEA ocupada $^{(1)}$, por sexo e classe ocupacional. São Paulo, 1987 . (2) $^{(2)}$

\begin{tabular}{|c|c|c|c|c|c|}
\hline \multirow[t]{2}{*}{ SEXO/FATOR } & \multicolumn{5}{|c|}{ CLASSES } \\
\hline & 1 & 2 & 3 & 4 & 5 \\
\hline \multicolumn{6}{|l|}{ HOMENS } \\
\hline INTERCEPTO & 632.967 & 3289.583 & 1382.289 & 1280.186 & 1429.243 \\
\hline \multicolumn{6}{|l|}{ ESCOLARIDADE } \\
\hline Primário Incompleto & $1.459 \mathrm{~ns}$ & $1.069 \mathrm{~ns}$ & 1.345 & 1.242 & 1.311 \\
\hline Primário Completo & $1.620^{*}$ & $1.169 \mathrm{~ns}$ & 1.555 & 1.706 & 1.546 \\
\hline Ginásio Incompleto & 2.771 & $1.206 \mathrm{~ns}$ & 2.048 & 1.972 & 1.788 \\
\hline Ginásio Completo & 2.481 & $1.839^{*}$ & 2.532 & 2.590 & 2.252 \\
\hline Colegial e Superior & 4.715 & 3.206 & 3.358 & 4.429 & 3.968 \\
\hline \multicolumn{6}{|l|}{ IDADE } \\
\hline 18 a 19 anos & $1.244 \mathrm{~ns}$ & $1.758 \mathrm{~ns}$ & 1.418 & $1.153^{*}$ & 1.462 \\
\hline 20 a 24 anos & 1.690 & $1.495 \mathrm{~ns}$ & 1.779 & 1.484 & 1.680 \\
\hline 25 a 29 anos & 2.453 & $1.789 \mathrm{~ns}$ & 2.416 & 2.041 & 2.226 \\
\hline 30 a 39 anos & 3.875 & 2.219 & 3.282 & 2.616 & 2.905 \\
\hline 40 a 49 anos & 4.153 & 2.804 & 3.547 & 3.045 & 3.336 \\
\hline 50 anos ou mais & 3.785 & 2.652 & 3.080 & 2.785 & 3.271 \\
\hline \multicolumn{6}{|l|}{ SITUAÇÃO } \\
\hline Região Urbana & 1.598 & $1.066 \mathrm{~ns}$ & $1.054 \mathrm{~ns}$ & 1.368 & 1.294 \\
\hline \multicolumn{6}{|l|}{ POSIÇÃO NA OCUPAÇÃO } \\
\hline Autônomos e empregadores & $1.264 \mathrm{~ns}$ & $0.972 \mathrm{~ns}$ & 1.287 & 1.644 & 1.437 \\
\hline \multicolumn{6}{|c|}{ POSSE DE CARTEIRA ASSINADA } \\
\hline Com Carteira Assinada & $1.260^{*}$ & $0.917 \mathrm{~ns}$ & 1.382 & 1.468 & 1.364 \\
\hline \multicolumn{6}{|l|}{ MULHERES } \\
\hline INTERCEPTO & 1334.487 & 2259.383 & 1855.516 & 1170.620 & 2265.260 \\
\hline \multicolumn{6}{|l|}{ ESCOLARIDADE } \\
\hline Primário Incompleto & 1.198 & $1.186 \mathrm{~ns}$ & $1.272 *$ & 1.433 & $1.547 \mathrm{~ns}$ \\
\hline Primário Completo & 1.453 & $1.164 \mathrm{~ns}$ & 1.465 & 1.652 & $1.451 \mathrm{~ns}$ \\
\hline Ginásio Incompleto & 1.702 & 1.489 & 1.934 & 2.064 & $1.544 \mathrm{~ns}$ \\
\hline Ginásio Completo & 2.273 & 1.801 & 2.177 & 2.510 & 2.993 \\
\hline Colegial e Superior & 4.435 & 3.250 & 3.384 & 4.230 & 4.392 \\
\hline \multicolumn{6}{|l|}{ IDADE } \\
\hline 18 a 19 anos & $1.134^{*}$ & $1.088 \mathrm{~ns}$ & $1.096 \mathrm{~ns}$ & $1.201^{*}$ & $0.964 \mathrm{~ns}$ \\
\hline 20 a 24 anos & 1.510 & 1.754 & 1.336 & 1.466 & $1.044 \mathrm{~ns}$ \\
\hline 25 a 29 anos & 1.768 & 2.116 & 1.597 & 1.962 & $1.494 \mathrm{~ns}$ \\
\hline 30 a 39 anos & 2.254 & 2.559 & 2.222 & 2.496 & 2.157 \\
\hline 40 a 49 anos & 2.576 & 2.522 & 2.604 & 2.455 & 2.318 \\
\hline 50 anos ou mais & 2.212 & 2.960 & 1.868 & 2.442 & 2.801 \\
\hline \multicolumn{6}{|l|}{ SITUAÇÃO } \\
\hline Região Urbana & 1.143 & $0.998 \mathrm{~ns}$ & $1.005 \mathrm{~ns}$ & 1.227 & $0.980 \mathrm{~ns}$ \\
\hline \multicolumn{6}{|l|}{ POSIÇÃO NA OCUPAÇÃO } \\
\hline Autônomos e empregadores & 1.130 & $1.018 \mathrm{~ns}$ & 1.358 & 1.820 & $1.310 \mathrm{~ns}$ \\
\hline \multicolumn{6}{|c|}{ POSSE DE CARTEIRA ASSINADA } \\
\hline Com Carteirs Assinada & 1.186 & $0.947 \mathrm{~ns}$ & 1.206 & 1.389 & $1.388^{*}$ \\
\hline
\end{tabular}

(1) Inclui apenas as observações para as quais os atributos de interesse estão claramente identificados.

(2) Todos os coeficientes são estatisticamente significativos ao nível de $5 \%$, com exceção dos assinalados por asterisco (que são significativos ao nível de $10 \%$ ) e por ns (que são não-significativos). 
Tabela G9. Estimativas dos coeficientes das equações de rendimento ajustadas para a PEA ocupada(1), por sexo e classe ocupacional. São Paulo, 1988. (2)

\begin{tabular}{|c|c|c|c|c|c|}
\hline \multirow[t]{2}{*}{ SEXO/FATOR } & \multicolumn{5}{|c|}{ CLASSES } \\
\hline & 1 & 2 & 3 & 4 & 5 \\
\hline \multicolumn{6}{|l|}{ HOMENS } \\
\hline INTERCEPTO & 7.355439 & 8.315223 & 7.255935 & 6.968914 & 7.088568 \\
\hline \multicolumn{6}{|l|}{ ESCOLARIDADE } \\
\hline Primário Incompleto & $-0.16962 \mathrm{~ns}$ & $-0.62835 \mathrm{~ns}$ & $0.21045 \mathrm{~ns}$ & 0.27259 & 0.31898 \\
\hline Primário Completo & 0.39661 & $-0.68857 \mathrm{~ns}$ & 0.26274 & 0.67345 & 0.54744 \\
\hline Ginásio Incompleto & 0.61390 & $-0.38543 \mathrm{~ns}$ & 0.65571 & 0.83368 & 0.66973 \\
\hline Ginásio Completo & $0.52480 *$ & $-0.49574 \mathrm{~ns}$ & 0.72404 & 1.11477 & 0.89419 \\
\hline Colegial e Superior & 1.57454 & $-0.20829 \mathrm{~ns}$ & 1.27669 & 1.76656 & 1.44880 \\
\hline \multicolumn{6}{|l|}{ IDADE } \\
\hline 18 a 19 anos & $0.52580^{*}$ & $0.17704 \mathrm{~ns}$ & 0.40871 & $0.11848 \mathrm{~ns}$ & 0.36773 \\
\hline 20 a 24 anos & $0.38631 \mathrm{~ns}$ & $0.24175 \mathrm{~ns}$ & 0.52861 & 0.25059 & 0.56729 \\
\hline 25 a 29 anos & 0.57863 & $0.23889 \mathrm{~ns}$ & 0.90584 & 0.47431 & 0.86689 \\
\hline 30 a 39 anos & 0.62814 & 0.61647 ns & 1.19323 & 0.88646 & 1.12956 \\
\hline 40 a 49 anos & 1.04894 & 1.30746 & 1.40242 & 1.08852 & 1.27614 \\
\hline 50 anos ou mais & 0.54507 & $0.34481 \mathrm{~ns}$ & 1.16323 & 0.82329 & 1.20816 \\
\hline \multicolumn{6}{|l|}{ SITUAÇÃO } \\
\hline Região Urbana & $0.25560 \mathrm{~ns}$ & $0.40178 \mathrm{~ns}$ & $0.00021 \mathrm{~ns}$ & 0.37188 & 0.25428 \\
\hline \multicolumn{6}{|l|}{ POSIÇÃO NA OCUPAÇÃO } \\
\hline Autônomos e empregadores & 0.52301 & 0.79046 & 0.64939 & 0.45004 & 0.32604 \\
\hline \multicolumn{6}{|c|}{ POSSE DE CARTEIRA ASSINADA } \\
\hline Com Carteira Assinada & $0.18641 \mathrm{~ns}$ & $0.47288^{*}$ & 0.40602 & 0.58419 & 0.37700 \\
\hline \multicolumn{6}{|l|}{ MULHERES } \\
\hline INTERCEPTO & 7.085603 & 7.408395 & 7.297242 & 7.125937 & 6.957482 \\
\hline \multicolumn{6}{|l|}{ ESCOLARIDADE } \\
\hline Primário Incompleto & 0.10442 & $0.00182 \mathrm{~ns}$ & $0.18894 \mathrm{~ns}$ & $0.25545^{*}$ & $0.47855 \mathrm{~ns}$ \\
\hline Primánio Completo & 0.29792 & $0.35189 \mathrm{~ns}$ & 0.43707 & 0.52822 & 1.08261 \\
\hline Ginásio Incompleto & 0.51031 & $0.59183 *$ & 0.58903 & 0.63405 & 1.01878 \\
\hline Ginásio Completo & 0.80661 & $0.63397 *$ & 0.76445 & 1.02633 & 1.12835 \\
\hline Colegial e Superior & 1.49385 & 1.02292 & 1.32444 & 1.61959 & 1.90339 \\
\hline \multicolumn{6}{|l|}{ IDADE } \\
\hline 18 a 19 anos & 0.15781 & $0.28574 \mathrm{~ns}$ & $0.07369 \mathrm{~ns}$ & $0.23061 \mathrm{~ns}$ & $0.14821 \mathrm{~ns}$ \\
\hline 20 a 24 anos & 0.39016 & 0.75204 & 0.19850 & 0.31080 & $0.49049 *$ \\
\hline 25 a 29 anos & 0.63790 & 0.72139 & 0.58488 & 0.42609 & 0.61977 \\
\hline 30 a 39 anos & 0.87767 & 0.66147 & 0.80609 & 0.87166 & 0.91933 \\
\hline 40 a 49 anos & 0.95998 & 0.90278 & 0.83905 & 0.75987 & 1.28594 \\
\hline 50 anos ou mais. & 0.72005 & 0.76518 & 0.77043 & 0.87066 & 0.75916 \\
\hline \multicolumn{6}{|l|}{ SITUAÇÃO } \\
\hline Região Urbana & $0.02197 \mathrm{~ns}$ & $0.19999 \mathrm{~ns}$ & $0.10470 \mathrm{~ns}$ & 0.21201 & $0.27390 \mathrm{~ns}$ \\
\hline \multicolumn{6}{|l|}{ POSIÇÃO NA OCUPAÇÃO } \\
\hline Autônomos e empregadores & 0.19046 & $0.2713 *$ & 0.38122 & 0.37141 & 0.42724 \\
\hline \multicolumn{6}{|c|}{ POSSE DE CARTEIRA ASSINADA } \\
\hline Com Carteira Assinada & 0.35957 & $0.08079 \mathrm{~ns}$ & 0.25389 & 0.39468 & $-0.01313 \mathrm{~ns}$ \\
\hline
\end{tabular}

(1) Inclui apenas as observações para as quais os atributos de interesse estão claramente identificados.

(2) Todos os coeficientes são estatisticamente significativos ao nível de 5\%, com exceção dos assinalados por asterisco (que são significativos ao nivel de $10 \%$ e por ns (que são não-significativos). 
Tabela G10. Números-índices obtidos dos coeficientes das equações de rendimento ajustadas para a PEA ocupada(1), por sexo e classe ocupacional. São Paulo, 1988 . $^{(2)}$

\begin{tabular}{|c|c|c|c|c|c|}
\hline \multirow[t]{2}{*}{ SEXO/FATOR } & \multicolumn{5}{|c|}{ CLASSES } \\
\hline & 1 & 2 & 3 & 4 & 5 \\
\hline \multicolumn{6}{|l|}{ HOMENS } \\
\hline INTERCEPTO & 1564.684 & 4085.596 & 1416.487 & 1063.308 & 1198.191 \\
\hline \multicolumn{6}{|l|}{ ESCOLARIDADE } \\
\hline Primário Incompleto & $0.844 \mathrm{~ns}$ & $0.533 \mathrm{~ns}$ & $1.234 \mathrm{~ns}$ & 1.313 & 1.376 \\
\hline Primário Completo & 1.487 & $0.502 \mathrm{~ns}$ & 1.300 & 1.961 & 1.729 \\
\hline Ginásio Incompleto & 1.848 & $0.680 \mathrm{~ns}$ & 1.927 & 2.302 & 1.954 \\
\hline Ginásio Completo & $1.690^{*}$ & $0.609 \mathrm{~ns}$ & 2.063 & 3.049 & 2.445 \\
\hline Colegial e Superior & 4.829 & $0.812 \mathrm{~ns}$ & 3.585 & 5.851 & 4.258 \\
\hline \multicolumn{6}{|l|}{ IDADE } \\
\hline 18 a 19 anos & $1.692 *$ & $1.194 \mathrm{~ns}$ & 1.505 & $1.126 \mathrm{~ns}$ & 1.444 \\
\hline 20 a 24 anos & $1.472 \mathrm{~ns}$ & $1.273 \mathrm{~ns}$ & 1.697 & 1.285 & 1.763 \\
\hline 25 a 29 anos & 1.784 & $1.270 \mathrm{~ns}$ & 2.474 & 1.607 & 2.379 \\
\hline 30 a 39 anos & 1.874 & $1.852 \mathrm{~ns}$ & 3.298 & 2.427 & 3.094 \\
\hline 40 a 49 anos & 2.855 & 3.697 & 4.065 & 2.970 & 3.583 \\
\hline 50 anos ou mais & 1.725 & $1.412 \mathrm{~ns}$ & 3.200 & 2.278 & 3.347 \\
\hline \multicolumn{6}{|l|}{ SITUAÇÃO } \\
\hline Região Urbana & $1.291 \mathrm{~ns}$ & $1.494 \mathrm{~ns}$ & $1.000 \mathrm{~ns}$ & 1.450 & 1.290 \\
\hline \multicolumn{6}{|l|}{ POSIÇÃO NA OCUPAÇÃO } \\
\hline Autônomos e empregadores & 1.687 & 2.204 & 1.914 & 1.568 & 1.385 \\
\hline \multicolumn{6}{|c|}{ POSSE DE CARTEIRA ASSINADA } \\
\hline Com Carteira Assinada & $1.205 \mathrm{~ns}$ & $1.605 *$ & 1.501 & 1.794 & 1.458 \\
\hline \multicolumn{6}{|l|}{ MULHERES } \\
\hline INTERCEPTO & 1194.643 & 1649.776 & 1476.223 & 1243.813 & 1050.984 \\
\hline \multicolumn{6}{|l|}{ ESCOLARIDADE } \\
\hline Primário Incompleto & 1.110 & $1.002 \mathrm{~ns}$ & $1.208 \mathrm{~ns}$ & $1.291 *$ & $1.614 \mathrm{~ns}$ \\
\hline Primário Completo & 1.347 & $1.422 \mathrm{~ns}$ & 1.548 & 1.696 & 2.952 \\
\hline Ginásio Incompleto & 1.666 & $1.807^{*}$ & 1.802 & 1.885 & 2.770 \\
\hline Ginásio Completo & 2.240 & $1.885^{*}$ & 2.148 & 2.791 & 3.091 \\
\hline Colegial e Superior & 4.454 & 2.781 & 3.760 & 5.051 & 6.709 \\
\hline \multicolumn{6}{|l|}{ IDADE } \\
\hline 18 a 19 anos & 1.171 & $1.331 \mathrm{~ns}$ & $1.076 \mathrm{~ns}$ & $1.259 \mathrm{~ns}$ & $1.160 \mathrm{~ns}$ \\
\hline 20 a 24 anos & 1.477 & 2.121 & 1.220 & 1.365 & $1.633 *$ \\
\hline 25 a 29 anos & 1.893 & 2.057 & 1.795 & 1.531 & 1.858 \\
\hline 30 a 39 anos & 2.405 & 1.938 & 2.239 & 2.391 & 2.508 \\
\hline 40 a 49 anos & 2.612 & 2.466 & 2.314 & 2.138 & 3.618 \\
\hline 50 anos ou mais & 2.055 & 2.149 & 2.161 & 2.388 & 2.136 \\
\hline \multicolumn{6}{|l|}{ SITUAÇÃO } \\
\hline Região Urbana & $1.022 \mathrm{~ns}$ & $1.221 \mathrm{~ns}$ & $1.110 \mathrm{~ns}$ & 1.236 & $1.315 \mathrm{~ns}$ \\
\hline \multicolumn{6}{|l|}{ POSIÇÃO NA OCUPAÇÃO } \\
\hline Autônomos e entpregadores & 1.210 & $1.312 *$ & 1.464 & 1.450 & 1.533 \\
\hline \multicolumn{6}{|c|}{ POSSE DE CARTEIRA ASSINADA } \\
\hline Com Carteira Assinada & 1.433 & $1.084 \mathrm{~ns}$ & 1.289 & 1.484 & $0.987 \mathrm{~ns}$ \\
\hline
\end{tabular}

(1) Inclui apenas as observaçoes para as quais os atributos de interesse estâo claramente identificados.

(2) Todos os coeficientes são estatisticamente significativos ao nivel de 5\%, com exceção dos assinalados por asterisco (que são significativos ao nivel de $10 \%$ ) e por ns (que são não-significativos). 
Tabela G11. Estimativas dos coeficientes das equações de rendimento ajustadas para a PEA ocupada(1), por sexo e classe ocupacional. São Paulo, 1989.(2)

\begin{tabular}{|c|c|c|c|c|c|}
\hline \multirow[t]{2}{*}{ SEXO/FATOR } & \multicolumn{5}{|c|}{ CLASSES } \\
\hline & 1 & 2 & 3 & 4 & 5 \\
\hline \multicolumn{6}{|l|}{ HOMENS } \\
\hline INTERCEPTO & 7.799885 & 7.400582 & 7.897281 & 6.982930 & 7.387132 \\
\hline \multicolumn{6}{|l|}{ ESCOLARIDADE } \\
\hline Primário Incormpleto & $0.12898 \mathrm{~ns}$ & $0.30801 \mathrm{~ns}$ & $-0.03206 \mathrm{~ns}$ & 0.41184 & 0.26602 \\
\hline Primánio Completo & $0.40295^{*}$ & 0.50406 & $-0.04038 \mathrm{~ns}$ & 0.72284 & 0.43766 \\
\hline Ginásio Incompleto & $0.42344 \mathrm{~ns}$ & 0.55232 & $0.25473 *$ & 0.90762 & 0.60149 \\
\hline Ginásio Completo & 1.39421 & 0.93742 & 0.50965 & 1.26982 & 0.81039 \\
\hline Colegial e Superior & 1.18091 & 1.35620 & 0.93522 & 1.77312 & 1.35012 \\
\hline \multicolumn{6}{|l|}{ IDADE } \\
\hline 18 a 19 anos & $-0.14315 \mathrm{~ns}$ & $0.34681 \mathrm{~ns}$ & 0.27701 & $0.21691 *$ & 0.20168 \\
\hline 20 a 24 anos & $-0.12386 \mathrm{~ns}$ & 0.36571 * & 0.45394 & 0.38725 & 0.55357 \\
\hline 25 a 29 anos & $0.44638 \mathrm{~ns}$ & 0.81704 & 0.63028 & 0.68344 & 0.74126 \\
\hline 30 a 39 anos & $0.51617^{*}$ & 0.93205 & 1.07138 & 0.90303 & 1.02252 \\
\hline 40 a 49 anos & $0.41872 \mathrm{~ns}$ & 0.82300 & 1.28093 & 1.11032 & 1.19964 \\
\hline 50 anos ou mais & $0.47132 \mathrm{~ns}$ & 1.07465 & 1.01073 & 1.02424 & 1.15180 \\
\hline \multicolumn{6}{|l|}{ SITUAÇĀO } \\
\hline Região Urbana & 0.39212 & $0.39667^{*}$ & $-0.05118 \mathrm{~ns}$ & 0.44810 & 0.20076 \\
\hline \multicolumn{6}{|l|}{ POSIÇÃO NA OCUPAÇÃO } \\
\hline \multicolumn{5}{|c|}{ POSSE DE CARTEIRA ASSINADA } & 0.44963 \\
\hline Com Carteira Assinada & $-0.01711 \mathrm{~ns}$ & $0.04892 \mathrm{~ns}$ & 0.34388 & 0.44010 & 0.34977 \\
\hline \multicolumn{6}{|l|}{ MULHERES } \\
\hline INTERCEPTO & 7.333844 & 7.736620 & 7.955980 & 6.975201 & 6.063794 \\
\hline \multicolumn{6}{|l|}{ ESCOLARIDADE } \\
\hline Primánio Incompleto & $0.11123 \mathrm{~ns}$ & $0.04513 \mathrm{~ns}$ & $-0.07542 \mathrm{~ns}$ & 0.43319 & $0.38193 \mathrm{~ns}$ \\
\hline Primário Completo & 0.25902 & 0.40791 & $0.09493 \mathrm{~ns}$ & 0.77530 & 0.88178 \\
\hline Ginásio Incompleto & 0.49437 & 0.51502 & $0.22039 *$ & 0.69286 & 1.14378 \\
\hline Ginásio Completo & 0.79506 & 0.74543 & 0.36607 & 1.05117 & 1.43341 \\
\hline Colegial e Superior & 1.46549 & 1.32104 & 0.91192 & 1.77422 & 1.90211 \\
\hline \multicolumn{6}{|l|}{ IDADE } \\
\hline 18 a 19 anos & 0.25252 & $-0.09133 \mathrm{~ns}$ & $0.12405 \mathrm{~ns}$ & $0.12641 \mathrm{~ns}$ & $0.26555 \mathrm{~ns}$ \\
\hline 20 a 24 anos & 0.41913 & $-0.01016 \mathrm{~ns}$ & 0.32928 & $0.23180 \mathrm{~ns}$ & 0.72167 \\
\hline 25 a 29 anos & 0.63686 & 0.32508 & 0.54419 & 0.49155 & 0.79289 \\
\hline 30 a 39 anos & 0.89293 & 0.47522 & 0.81338 & 0.81024 & 0.84747 \\
\hline 40 a 49 anos & 0.99299 & 0.60629 & 0.97947 & 0.94168 & 1.45074 \\
\hline 50 anos ou mais & 0.95683 & 0.57157 & 0.86612 & 1.00752 & 1.53397 \\
\hline \multicolumn{6}{|l|}{ SITUAÇÃo } \\
\hline Região Urbana & $-0.04876 \mathrm{~ns}$ & $0.24395 \mathrm{~ns}$ & $-0.00494 \mathrm{~ns}$ & 0.34250 & 1.30054 \\
\hline \multicolumn{6}{|l|}{ POSIÇÃO NA OCUPAÇÃO } \\
\hline Autônomos e empregadores & 0.17401 & 0.34383 & 0.18621 & 0.49017 & $0.35044 \mathrm{~ns}$ \\
\hline \multicolumn{6}{|c|}{ POSSE DE CARTEIRA ASSINADA } \\
\hline Com Carteira Assinada & 0.28812 & $-0.00626 \mathrm{~ns}$ & 0.13715 & 0.41455 & $-0.14357 \mathrm{~ns}$ \\
\hline
\end{tabular}

(1) Inclui apenas as observações para as quais os atributos de interesse estão claramente identificados.

(2) Todos os coeficientes são estatisticamente significativos ao nível de $5 \%$, com exceção dos assinalados por asterisco (que são significativos ao nível de 10\%) e por ns (que são não-significativos). 
Tabela G12. Números-índices obtidos dos coeficientes das equações de rendimento ajustadas para a PEA ocupada(1), por sexo e classe ocupacional. São Paulo, 1989. (2)

\begin{tabular}{|c|c|c|c|c|c|}
\hline \multirow[t]{2}{*}{ SEXO/FATOR } & \multicolumn{5}{|c|}{ CLASSES } \\
\hline & 1 & $\mathbf{2}$ & 3 & 4 & 5 \\
\hline \multicolumn{6}{|l|}{ HOMENS } \\
\hline INTERCEPTO & 2440.321 & 1636.937 & 2689.958 & 1078.072 & 1615.050 \\
\hline \multicolumn{6}{|l|}{ ESCOLARIDADE } \\
\hline Primáno Incompleto & $1.138 \mathrm{~ns}$ & $1.361 \mathrm{~ns}$ & $0.968 \mathrm{~ns}$ & 1.510 & 1.305 \\
\hline Primário Completo & $1.496^{*}$ & 1.655 & $0.960 \mathrm{~ns}$ & 2.060 & 1.549 \\
\hline Ginásio Incompleto & $1.527 \mathrm{~ns}$ & 1.737 & $1.290^{*}$ & 2.478 & 1.825 \\
\hline Ginásio Completo & 4.032 & 2.553 & 1.665 & 3.560 & 2.249 \\
\hline Colegial e Superior & 3.257 & 3.881 & 2.548 & 5.889 & 3.858 \\
\hline \multicolumn{6}{|l|}{ IDADE } \\
\hline 18 a 19 anos & $0.867 \mathrm{~ns}$ & $1.415 \mathrm{~ns}$ & 1.319 & $1.242^{*}$ & 1.223 \\
\hline 20 a 24 anos & $0.884 \mathrm{~ns}$ & $1.442 *$ & 1.575 & 1.473 & 1.739 \\
\hline 25 a 29 anos & $1.563 \mathrm{~ns}$ & 2.264 & 1.878 & 1.981 & 2.099 \\
\hline 30 a 39 anos & $1.676^{*}$ & 2.540 & 2.919 & 2.467 & 2.780 \\
\hline 40 a 49 anos & $1.520 \mathrm{~ns}$ & 2.277 & 3.600 & 3.035 & 3.319 \\
\hline 50 anos ou mais & $1.602 \mathrm{~ns}$ & 2.929 & 2.748 & 2.785 & 3.164 \\
\hline \multicolumn{6}{|l|}{ SITUAÇÃo } \\
\hline Região Urbana & 1.480 & $1.487^{*}$ & $0.950 \mathrm{~ns}$ & 1.565 & 1.222 \\
\hline \multicolumn{6}{|l|}{ POSIÇÃO NA OCUPAÇĀO } \\
\hline Autônomos e empregadores & $0.888 \mathrm{~ns}$ & 1.830 & 1.497 & 1.764 & 1.568 \\
\hline \multicolumn{6}{|c|}{ POSSE DE CARTEIRA ASSINADA } \\
\hline Com Carteira Assinada & $0.983 \mathrm{~ns}$ & $1.050 \mathrm{~ns}$ & 1.410 & 1.553 & 1.419 \\
\hline \multicolumn{6}{|l|}{ MULHERES } \\
\hline INTERCEPTO & 1531.257 & 2290.717 & 2852.582 & 1069.772 & 430.004 \\
\hline \multicolumn{6}{|l|}{ ESCOLARIDADE } \\
\hline Primário Incompleto & $1.118 \mathrm{~ns}$ & $1.046 \mathrm{~ns}$ & $0.927 \mathrm{~ns}$ & 1.542 & $1.465 \mathrm{~ns}$ \\
\hline Primário Completo & 1.296 & 1.504 & $1.100 \mathrm{~ns}$ & 2.171 & 2.415 \\
\hline Ginásio Incompleto & 1.639 & 1.674 & $1.247^{*}$ & 1.999 & 3.139 \\
\hline Ginásio Completo & 2.215 & 2.107 & 1.442 & 2.861 & 4.193 \\
\hline Colegial e Superior & 4.330 & 3.747 & 2.489 & 5.896 & 6.700 \\
\hline \multicolumn{6}{|l|}{ IDADE } \\
\hline 18 a 19 anos & 1.287 & $0.913 \mathrm{~ns}$ & $1.132 \mathrm{~ns}$ & $1.135 \mathrm{~ns}$ & $1.304 \mathrm{~ns}$ \\
\hline 20 a 24 anos & 1.521 & $0.990 \mathrm{~ns}$ & 1.390 & $1.261 \mathrm{~ns}$ & 2.058 \\
\hline 25 a 29 anos & 1.891 & 1.384 & 1.723 & 1.635 & 2.210 \\
\hline 30 a 39 anos & 2.442 & 1.608 & 2.256 & 2.248 & 2.334 \\
\hline 40 a 49 anos & 2.699 & 1.834 & 2.663 & 2.564 & 4.266 \\
\hline 50 anos ou mais & 2.603 & 1.771 & 2.378 & 2.739 & 4.637 \\
\hline \multicolumn{6}{|l|}{ SITUAÇÃO } \\
\hline Região Urbana & $0.952 \mathrm{~ns}$ & $1.276 \mathrm{~ns}$ & $0.995 \mathrm{~ns}$ & 1.408 & 3.671 \\
\hline \multicolumn{6}{|l|}{ POSIÇÃO NAOCUPAÇÃO } \\
\hline Autônomos e empregadores & 1.190 & 1.410 & 1.205 & 1.633 & $1.420 \mathrm{~ns}$ \\
\hline \multicolumn{6}{|c|}{ POSSE DE CARTEIRA ASSINADA } \\
\hline Com Carteira Assinada & 1.334 & $0.994 \mathrm{~ns}$ & 1.147 & 1.514 & $0.866 \mathrm{~ns}$ \\
\hline
\end{tabular}

(1) Inclui apenas as observações para as quais os atributos de interesse estão claramente identificados.

(2) Todos os coeficientes são estatisticamente significativos ao nível de $5 \%$, com exceção dos assinalados por asterisco (que são significativos ao nível de $10 \%$ ) e por ns (que são não-significativos). 
Tabela G13. Estimativas dos coeficientes das equações de rendimento ajustadas para a PEA ocupada(1), por sexo e classe ocupacional. São Paulo, 1990. (2)

\begin{tabular}{|c|c|c|c|c|c|}
\hline \multirow[t]{2}{*}{ SEXO/FATOR } & \multicolumn{5}{|c|}{ CLASSES } \\
\hline & 1 & 2 & 3 & 4 & 5 \\
\hline \multicolumn{6}{|l|}{ HOMENS } \\
\hline INTERCEPTO & 7.106982 & 8.099449 & 7.601251 & 6.951248 & 7.335136 \\
\hline \multicolumn{6}{|l|}{ ESCOLARDADE } \\
\hline Primário Incompleto & $0.38000^{*}$ & $-0.11623 \mathrm{~ns}$ & $0.13766 \mathrm{~ns}$ & 0.31135 & 0.30063 \\
\hline Primánio Completo & $0.37132 *$ & $0.13072 \mathrm{~ns}$ & 0.33881 & 0.63269 & 0.49098 \\
\hline Ginásio Incompleto & 0.72875 & $0.01000 \mathrm{~ns}$ & 0.52376 & 0.77383 & 0.66541 \\
\hline Ginásio Completo & $0.41091 \mathrm{~ns}$ & $0.36716 \mathrm{~ns}$ & 0.78848 & 1.03678 & 0.78118 \\
\hline Colegial e Superior & 1.48324 & 0.86013 & 1.18528 & 1.59005 & 1.33076 \\
\hline \multicolumn{6}{|l|}{ IDADE } \\
\hline 18 a 19 anos & $-0.09546 \mathrm{~ns}$ & $0.07402 \mathrm{~ns}$ & 0.17852 & 0.21539 & 0.26800 \\
\hline 20 a 24 anos & $0.43971^{*}$ & 0.56953 & 0.49932 & 0.37403 & 0.59581 \\
\hline 25 a 29 anos & $0.23143 \mathrm{~ns}$ & 1.08059 & 0.72680 & 0.51951 & 0.80338 \\
\hline 30 a 39 anos & 0.66796 & 1.05141 & 1.10317 & 0.88393 & 1.04149 \\
\hline 40 a 49 anos & 0.60161 & 1.17642 & 1.27328 & 1.06708 & 1.21452 \\
\hline 50 anos ou mais & 0.81170 & 1.27404 & 1.11223 & 0.93530 & 1.08132 \\
\hline \multicolumn{6}{|l|}{ SITUAÇĀO } \\
\hline Região Urbana & 0.36678 & $0.19306 \mathrm{~ns}$ & $-0.02432 \mathrm{~ns}$ & 0.43417 & 0.21837 \\
\hline \multicolumn{6}{|l|}{ POSIÇÃO NA OCUPAÇÃO } \\
\hline Aưtônomos e empregadores & $0.31348 \mathrm{~ns}$ & $0.02832 \mathrm{~ns}$ & 0.33607 & 0.53920 & 0.30923 \\
\hline \multicolumn{6}{|c|}{ POSSE DE CARTEIRA ASSINADA } \\
\hline Com Carteira Assinada & 0.27862 & -0.37128 & 0.10628 & 0.37541 & 0.17851 \\
\hline \multicolumn{6}{|l|}{ MULHERES } \\
\hline INTERCEPTO & 7.361472 & 8.114535 & 7.871077 & 7.077322 & 6.888510 \\
\hline \multicolumn{6}{|l|}{ ESCOLARIDADE } \\
\hline Primário Incompleto & $0.02336 \mathrm{~ns}$ & $-0.14719 \mathrm{~ns}$ & $-0.19302 \mathrm{~ns}$ & $0.21927 *$ & $0.23893 \mathrm{~ns}$ \\
\hline Primário Completo & 0.28076 & $0.10870 \mathrm{~ns}$ & $0.07394 \mathrm{~ns}$ & 0.52544 & $0.25738 \mathrm{~ns}$ \\
\hline Ginásio Incompleto & 0.45638 & $0.12798 \mathrm{~ns}$ & $0.28600^{*}$ & 0.76131 & $0.71833 *$ \\
\hline Ginásio Completo & 0.67907 & 0.46611 & 0.44125 & 0.98011 & $0.68882 *$ \\
\hline Colegial e Superior & 1.44132 & 1.15972 & 0.91351 & 1.58812 & 1.32790 \\
\hline \multicolumn{6}{|l|}{ IDADE } \\
\hline 18 a 19 anos & 0.14027 & $-0.03193 \mathrm{~ns}$ & $-0.02389 \mathrm{~ns}$ & $0.10951 \mathrm{~ns}$ & $0.23791 \mathrm{~ns}$ \\
\hline 20 a 24 anos & 0.38776 & $0.26658 \mathrm{~ns}$ & 0.26257 & $0.15764 \mathrm{~ns}$ & $0.41254 \mathrm{~ns}$ \\
\hline 25 a 29 anos & 0.69544 & 0.52211 & 0.59067 & 0.42397 & 0.74624 \\
\hline 30 a 39 anos & 0.81087 & 0.63018 & 0.79046 & 0.58594 & 0.94556 \\
\hline 40 a 49 anos & 0.98604 & 0.74786 & 0.90366 & 0.72683 & 0.94529 \\
\hline 50 anos ou mais & 0.87728 & 0.77059 & 0.71744 & 0.51743 & 0.86097 \\
\hline \multicolumn{6}{|l|}{ SITUAÇÃO } \\
\hline Região Urbana & $0.03186 \mathrm{~ns}$ & $0.00785 \mathrm{~ns}$ & $0.05925 \mathrm{~ns}$ & 0.38864 & 0.80269 \\
\hline POSIÇÃO NA OCUPAÇÃO & & & & & . \\
\hline Autônomos e empregadores & 0.15127 & $-0.11524 \mathrm{~ns}$ & 0.32671 & 0.57725 & 0.37161 \\
\hline \multicolumn{6}{|c|}{ POSSE DE CARTEIRA ASSINADA } \\
\hline Com Carteria Assinada & $0.06316^{*}$ & $-0.18650^{*}$ & $-0.02634 \mathrm{~ns}$ & 0.38645 & $-0.07223 \mathrm{~ns}$ \\
\hline
\end{tabular}

(1) Inclui apenas as observações para as quais os atributos de interesse estão claramente identificados.

(2) Todos os coeficientes são estatisticamente significativos ao nível de $5 \%$, com exceção dos assinalados por asterisco (que são significativos ao nível de 10\%) e por ns (que são não-significativos). 
Tabela G14. Números-índices obtidos dos coeficientes das equações de rendimento ajustadas para a PEA ocupada $^{(1)}$, por sexo e classe ocupacional. São Paulo, 1990 . $^{(2)}$

\begin{tabular}{|c|c|c|c|c|c|}
\hline \multirow[t]{2}{*}{ SEXO/FATOR } & \multicolumn{5}{|c|}{ CLASSES } \\
\hline & 1 & 2 & 3 & 4 & 5 \\
\hline \multicolumn{6}{|l|}{ HOMENS } \\
\hline INTERCEPTO & 1220.459 & 3292.653 & 2000.697 & 1044.452 & 1533.236 \\
\hline \multicolumn{6}{|l|}{ ESCOLARIDADE } \\
\hline Primánio Incompleto & $1.462^{*}$ & $0.890 \mathrm{~ns}$ & $1.148 \mathrm{~ns}$ & 1.365 & 1.351 \\
\hline Primário Completo & $1.450^{*}$ & $1.140 \mathrm{~ns}$ & 1.403 & 1.883 & 1.634 \\
\hline Ginásio Incompleto & 2.072 & $1.010 \mathrm{~ns}$ & 1.688 & 2.168 & 1.945 \\
\hline Ginásio Completo & $1.508 \mathrm{~ns}$ & $1.444 \mathrm{~ns}$ & 2.200 & 2.820 & 2.184 \\
\hline Col egiale Superior & 4.407 & 2.363 & 3.272 & 4.904 & 3.784 \\
\hline \multicolumn{6}{|l|}{ IDADE } \\
\hline 18 a 19 anos & $0.909 \mathrm{~ns}$ & $1.077 \mathrm{~ns}$ & 1.195 & 1.240 & 1.307 \\
\hline 20 a 24 anos & $1.552^{*}$ & 1.767 & 1.648 & 1.454 & 1.814 \\
\hline 25 a 29 anos & $1.260 \mathrm{~ns}$ & 2.946 & 2.068 & 1.681 & 2.233 \\
\hline 30 a 39 anos & 1.950 & 2.862 & 3.014 & 2.420 & 2.833 \\
\hline 40 a 49 anos & 1.825 & 3.243 & 3.573 & 2.907 & 3.369 \\
\hline 50 anos ou mais & 2.252 & 3.575 & 3.041 & 2.548 & 2.949 \\
\hline \multicolumn{6}{|l|}{ SITUAÇÃO } \\
\hline Região Urbana & 1.443 & $1.213 \mathrm{~ns}$ & $0.976 \mathrm{~ns}$ & 1.544 & 1.244 \\
\hline \multicolumn{6}{|l|}{ POSIÇÃO NA OCUPAÇĀO } \\
\hline Autônomos e empregador es & $1.368 \mathrm{~ns}$ & $1.029 \mathrm{~ns}$ & 1.399 & 1.715 & 1.362 \\
\hline \multicolumn{6}{|c|}{ POSSE DE CARTEIRA ASSINADA } \\
\hline Com Carteir aAssinada & 1.321 & 0.690 & 1.112 & 1.456 & 1.195 \\
\hline \multicolumn{6}{|l|}{ MULHERES } \\
\hline INTERCEPTO & 1574.152 & 3342.703 & 2620.386 & 1184.791 & 980.939 \\
\hline \multicolumn{6}{|l|}{ ESCOLARIDADE } \\
\hline Primário Incompleto & $1.024 \mathrm{~ns}$ & $0.863 \mathrm{~ns}$ & $0.824 \mathrm{~ns}$ & $1.245^{*}$ & $1.270 \mathrm{~ns}$ \\
\hline Primário Completo & 1.324 & $1.115 \mathrm{~ns}$ & $1.077 \mathrm{~ns}$ & 1.691 & $1.294 \mathrm{~ns}$ \\
\hline Ginásio Incompleto & 1.578 & $1.137 \mathrm{~ns}$ & $1.331 *$ & 2.141 & $2.051^{*}$ \\
\hline Ginásio Completo & 1.972 & 1.594 & 1.555 & 2.665 & $1.991^{*}$ \\
\hline Col egiale Superior & 4.226 & 3.189 & 2.493 & 4.895 & 3.773 \\
\hline \multicolumn{6}{|l|}{ DADE } \\
\hline 18 a 19 anos & 1.151 & $0.969 \mathrm{~ns}$ & $0.976 \mathrm{~ns}$ & $1.116 \mathrm{~ns}$ & $1.269 \mathrm{~ns}$ \\
\hline 20 a 24 anos & 1.474 & $1.305 \mathrm{~ns}$ & 1.300 & $1.171 \mathrm{~ns}$ & $1.511 \mathrm{~ns}$ \\
\hline 25 a 29 an os & 2.005 & 1.686 & 1.805 & 1.528 & 2.109 \\
\hline 30 a 39 anos & 2.250 & 1.878 & 2.204 & 1.797 & 2.574 \\
\hline 40 a 49 anos & 2.681 & 2.112 & 2.469 & 2.069 & 2.574 \\
\hline 50 anos ou mais & 2.404 & 2.161 & 2.049 & 1.678 & 2.365 \\
\hline \multicolumn{6}{|l|}{ SITUAÇÃO } \\
\hline \multirow{2}{*}{\multicolumn{6}{|c|}{ POSIÇÃO NA OCUPAÇÃO }} \\
\hline & & & & & \\
\hline Autônomos e entpregadores & 1.163 & $0.891 \mathrm{~ns}$ & 1.386 & 1.781 & 1.450 \\
\hline \multicolumn{6}{|c|}{ POSSE DE CARTEIRA ASSINADA } \\
\hline Com Carteira Assinada & $1.065^{*}$ & $0.830^{*}$ & $0.974 \mathrm{~ns}$ & 1.472 & $0.930 \mathrm{~ns}$ \\
\hline
\end{tabular}

(1) Inclui apenas as observações para as quais os atributos de interesse estão claramente identificados.

(2) Todos os coeficientes são estatisticamente significativos ao nível de $5 \%$, com exceção dos assinalados por asterisco (que são significativos ao nível de $10 \%$ e por ns (que são não-significativos). 
Tabela G15. Estimativas dos coeficientes das equações de rendimento ajustadas para a PEA ocupada(1), por sexo e classe ocupacional. Pernambuco, 1981. (2)

\begin{tabular}{|c|c|c|c|c|c|}
\hline \multirow[t]{2}{*}{ SEXO/FATOR } & \multicolumn{5}{|c|}{ CLASSES } \\
\hline & 1 & 2 & 3 & 4 & 5 \\
\hline \multicolumn{6}{|l|}{ HOMENS } \\
\hline INTERCEPTO & 7.106982 & 8.099449 & 7.601251 & 6.951248 & 7.335136 \\
\hline \multicolumn{6}{|l|}{ ESCOLARIDADE } \\
\hline Primário Inconpleto & 0.51448 & $0.58081 \mathrm{~ns}$ & 0.53112 & 0.14445 & 0.20761 \\
\hline Primário Completo & 0.60574 & $0.66117 \mathrm{~ns}$ & 0.53057 & 0.31079 & 0.43441 \\
\hline Ginásio Inconpleto & 0.76292 & $0.98138^{*}$ & 0.98333 & 0.49028 & 0.52172 \\
\hline Ginásio Compieto & $0.71267 \mathrm{~ns}$ & 1.20351 & 0.81079 & 0.67018 & 0.79688 \\
\hline Colegial e Superior & 1.34829 & 1.94766 & 1.41206 & 1.28738 & 1.51128 \\
\hline \multicolumn{6}{|l|}{ IDADE } \\
\hline 18 a 19 anos & $0.31150 \mathrm{~ns}$ & $0.90784 \mathrm{~ns}$ & 0.51573 & 0.61901 & 0.15685 \\
\hline 20 a 24 anos & 0.85267 & 1.09956 & 0.70436 & 0.66446 & 0.29137 \\
\hline 25 a 29 anos & 1.05881 & 1.25916 & 1.09556 & 0.97704 & 0.50028 \\
\hline 30 a 39 anos & 1.52148 & 1.23054 & 1.51646 & 1.29691 & 0.60347 \\
\hline 40 a 49 anos & 1.09741 & 1.43798 & 1.77118 & 1.27167 & 0.73784 \\
\hline 50 anos ou mais & 1.01408 & 1.90995 & 1.60643 & 1.10981 & 0.49213 \\
\hline \multicolumn{6}{|l|}{ SITUAÇÃO } \\
\hline Região Urbana & $0.17989 \mathrm{~ns}$ & $-0.07513 \mathrm{~ns}$ & $0.04814 \mathrm{~ns}$ & $0.13207^{*} *$ & 0.22809 \\
\hline \multicolumn{6}{|l|}{ POSIÇÃO NA OCUPAÇÃO } \\
\hline Autônomos e empregadores & $0.56435^{*}$ & $-0.12293 \mathrm{~ns}$ & $-0.09192 \mathrm{~ns}$ & 0.35825 & 0.15685 \\
\hline \multicolumn{6}{|c|}{ POSSE DE CARTEIRA ASSINADA } \\
\hline Com Carteira Assinada & $0.34500^{*}$ & $0.04782 \mathrm{~ns}$ & $0.08672 \mathrm{~ns}$ & 0.18386 & 0.39321 \\
\hline \multicolumn{6}{|l|}{ MULHERES } \\
\hline INTERCEPTO & 7.361472 & 8.114535 & 7.871077 & 7.077322 & 6.888510 \\
\hline \multicolumn{6}{|l|}{ ESCOLARIDADE } \\
\hline Primário Incompleto & 0.14956 & $0.42031 \mathrm{~ns}$ & 0.96256 & $0.19353 \mathrm{~ns}$ & $0.00071 \mathrm{~ns}$ \\
\hline Primário Completo & 0.45470 & 0.62183 & 0.78247 & 0.37304 & $-0.40249^{*}$ \\
\hline Ginásio Incompleto & 0.61780 & $0.37271 \mathrm{~ns}$ & 1.27363 & 0.45894 & $0.15535 \mathrm{~ns}$ \\
\hline Ginásio Completo & 0.73946 & $0.13335 \mathrm{~ns}$ & 1.23822 & 0.63907 & 1.41813 \\
\hline Colegial e Superior & 1.42733 & 1.79492 & 1.80460 & 1.24794 & 1.47888 \\
\hline \multicolumn{6}{|l|}{ IDADE } \\
\hline 18 a 19 anos & $0.01645 \mathrm{~ns}$ & $0.18371 \mathrm{~ns}$ & $0.13890 \mathrm{~ns}$ & $0.08330 \mathrm{~ns}$ & $-0.02921 \mathrm{~ns}$ \\
\hline 20 a 24 anos & 0.40545 & $0.56174 \mathrm{~ns}$ & $0.18711 \mathrm{~ns}$ & 0.42125 & $0.15407 \mathrm{~ns}$ \\
\hline 25 a 29 anos & 0.62431 & 1.30541 & 0.48049 & 0.80315 & $0.21471 \mathrm{~ns}$ \\
\hline 30 a 39 anos & 0.66818 & 1.36014 & 0.77265 & 0.93522 & 0.39830 \\
\hline 40 a 49 anos & 0.83861 & 1.34794 & 1.04813 & 0.99514 & $0.25268 \mathrm{~ns}$ \\
\hline 50 anos ou mais & 0.74917 & 2.12303 & 1.26808 & 0.87526 & $-0.11729 \mathrm{~ns}$ \\
\hline \multicolumn{6}{|l|}{ SITUAÇÃO } \\
\hline Região Urbana & $-0.01871 \mathrm{~ns}$ & $-0.16591 \mathrm{~ns}$ & $0.10942 \mathrm{~ns}$ & $0.10912 \mathrm{~ns}$ & $0.05480 \mathrm{~ns}$ \\
\hline \multicolumn{6}{|l|}{ POSIÇÃO NA OCUPAÇÃO } \\
\hline Autônomos e empregadores & 0.17871 & 0.70673 & $0.76482 *$ & 0.52697 & $-0.02297 \mathrm{~ns}$ \\
\hline \multicolumn{6}{|c|}{ POSSE DE CARTEIRA ASSINADA } \\
\hline Com Carteira Assinada & 0.51904 & 0.47391 & $0.10002 \mathrm{~ns}$ & 0.48347 & 0.61321 \\
\hline
\end{tabular}

(1) Inclui apenas as observações para as quais os atributos de interesse estão claramente identificados.

(2) Todos os coeficientes são estatisticamente significativos ao nível de $5 \%$, com exceção dos assinalados por asterisco (que são significativos ao nível de 10\%) e por ns (que são não-significativos). 
Tabela G16. Números-indices obtidos dos coeficientes das equações de rendimento ajustadas para a PEA ocupada (1), por sexo e classe ocupacional. Pernambuco, 1981.(2)

\begin{tabular}{|c|c|c|c|c|c|}
\hline \multirow[t]{2}{*}{ SEXO/FATOR } & \multicolumn{5}{|c|}{ CLASSES } \\
\hline & 1 & 2 & 3 & 4 & 5 \\
\hline \multicolumn{6}{|l|}{ HOMENS } \\
\hline INTERCEPTO & 552.242 & 759.598 & 927.186 & 1057.488 & 1553.771 \\
\hline \multicolumn{6}{|l|}{ ESCOLARIDADE } \\
\hline Primário Incompleto & 1.673 & $1.787 \mathrm{~ns}$ & 1.701 & 1.155 & 1.231 \\
\hline Primáno Completo & 1.833 & $1.937 \mathrm{~ns}$ & 1.700 & 1.365 & 1.544 \\
\hline Ginásio Incompleto & 2.145 & $2.668 *$ & 2.673 & 1.633 & 1.685 \\
\hline Ginásio Completo & $2.039 \mathrm{~ns}$ & 3.332 & 2.250 & 1.955 & 2.219 \\
\hline Colegial e Superior & 3.851 & 7.012 & 4.104 & 3.623 & 4.533 \\
\hline \multicolumn{6}{|l|}{ IDADE } \\
\hline 18 a 19 anos & $1.365 \mathrm{~ns}$ & $2.479 \mathrm{~ns}$ & 1.675 & 1.857 & 1.170 \\
\hline 20 a 24 anos & 2.346 & 3.003 & 2.023 & 1.943 & 1.338 \\
\hline 25 a 29 anos & 2.883 & 3.522 & 2.991 & 2.657 & 1.649 \\
\hline 30 a 39 anos & 4.579 & 3.423 & 4.556 & 3.658 & 1.828 \\
\hline 40 a 49 anos & 2.996 & 4.212 & 5.878 & 3.567 & 2.091 \\
\hline 50 anos ou mais & 2.757 & 6.753 & 4.985 & 3.034 & 1.636 \\
\hline \multicolumn{6}{|l|}{ SITUAÇÃO } \\
\hline Região Urbana & $1.197 \mathrm{~ns}$ & $0.928 \mathrm{~ns}$ & $1.049 \mathrm{~ns}$ & $1.141^{*}$ & 1.256 \\
\hline \multicolumn{6}{|l|}{ POSIÇÃO NA OCUPAÇÃO } \\
\hline Autônomos e empregadores & $1.758^{*}$ & $0.884 \mathrm{~ns}$ & $0.912 \mathrm{~ns}$ & 1.431 & 1.170 \\
\hline \multicolumn{6}{|c|}{ POSSE DE CARTEIRA ASSINADA } \\
\hline Com Carteira Assinada & $1.412 *$ & $1.049 \mathrm{~ns}$ & $1.091 \mathrm{~ns}$ & 1.202 & 1.482 \\
\hline \multicolumn{6}{|l|}{ MULHERES } \\
\hline INTERCEPTO & 703.800 & 511.725 & 745.257 & 758.618 & 1781.639 \\
\hline \multicolumn{6}{|l|}{ ESCOLARIDADE } \\
\hline Primário Incompleto & 1.161 & $1.522 \mathrm{~ns}$ & 2.618 & $1.214 \mathrm{~ns}$ & $1.001 \mathrm{~ns}$ \\
\hline Primáno Completo & 1.576 & 1.862 & 2.187 & 1.452 & $0.669 *$ \\
\hline Ginásio Incompleto & 1.855 & $1.452 \mathrm{~ns}$ & 3.574 & 1.582 & $1.168 \mathrm{~ns}$ \\
\hline Ginásio Completo & 2.095 & $1.143 \mathrm{~ns}$ & 3.449 & 1.895 & 4.129 \\
\hline Colegial e Superior & 4.168 & 6.019 & 6.078 & 3.483 & 4.388 \\
\hline \multicolumn{6}{|l|}{ IDADE } \\
\hline 18 a 19 anos & 1.017 ns & $1.202 \mathrm{~ns}$ & $1.149 \mathrm{~ns}$ & $1.087 \mathrm{~ns}$ & $0.971 \mathrm{~ns}$ \\
\hline 20 a 24 anos & 1.500 & $1.754 \mathrm{~ns}$ & $1.206 \mathrm{~ns}$ & 1.524 & $1.167 \mathrm{~ns}$ \\
\hline 25 a 29 anos & 1.867 & 3.689 & 1.617 & 2.233 & $1.239 \mathrm{~ns}$ \\
\hline 30 a 39 anos & 1.951 & 3.897 & 2.166 & 2.548 & 1.489 \\
\hline 40 a 49 anos & 2.313 & 3.849 & 2.852 & 2.705 & $1.287 \mathrm{~ns}$ \\
\hline 50 anos ou mais & 2.115 & 8.356 & 3.554 & 2.399 & $0.889 \mathrm{~ns}$ \\
\hline \multicolumn{6}{|l|}{ SITUAÇÃO } \\
\hline Região Urbana & $0.981 \mathrm{~ns}$ & $0.847 \mathrm{~ns}$ & $1.116 \mathrm{~ns}$ & $1.115 \mathrm{~ns}$ & $1.056 \mathrm{~ns}$ \\
\hline \multicolumn{6}{|l|}{ POSIÇÃO NA OCUPAÇÃO } \\
\hline \multicolumn{6}{|c|}{ POSSE DE CARTEIRA ASSINADA } \\
\hline Com Carteira Assinada & 1.680 & 1.606 & $1.105 \mathrm{~ns}$ & 1.622 & 1.846 \\
\hline
\end{tabular}

(1) Inclui apenas as observaçōes para as quais os atributos de interesse estão claramente identificados.

(2) Todos os coeficientes são estatisticamente significativos ao nível de $5 \%$, com exceção dos assinalados por asterisco (que são significativos ao nivel de $10 \%$ ) e por ns (que são não-significativos). 
Tabela G17. Estimativas dos coeficientes das equações de rendimento ajustadas para a PEA ocupada(1), por sexo e classe ocupacional. Pernambuco, 1983. (2)

\begin{tabular}{|c|c|c|c|c|c|}
\hline \multirow[t]{2}{*}{ SEXO/FATOR } & \multicolumn{5}{|c|}{ CLASSES } \\
\hline & 1 & 2 & 3 & 4 & 5 \\
\hline \multicolumn{6}{|l|}{ HOMENS } \\
\hline INTERCEPTO & 6.313986 & 6.632789 & 6.832154 & 6.963652 & 7.348440 \\
\hline \multicolumn{6}{|l|}{ ESCOLARIDADE } \\
\hline Primário Incompleto & $0.11239 \mathrm{~ns}$ & $0.98717 \mathrm{~ns}$ & $0.13497 \mathrm{~ns}$ & 0.22975 & 0.18918 \\
\hline Primário Completo & 0.69315 & $0.35179 \mathrm{~ns}$ & $0.27498^{*}$ & 0.37576 & 0.39700 \\
\hline Ginásio Incompleto & $0.28315 \mathrm{~ns}$ & $0.37901 \mathrm{~ns}$ & 0.57363 & 0.57453 & 0.44511 \\
\hline Ginásio Completo & 0.67883 & $0.90686 \mathrm{~ns}$ & 0.71391 & 0.90087 & 0.74280 \\
\hline Colegial e Superior & 1.26715 & 2.08340 & 1.46604 & 1.41939 & 1.43732 \\
\hline \multicolumn{6}{|l|}{ IDADE } \\
\hline \multicolumn{6}{|l|}{18 a 19 anos } \\
\hline 20 a 24 anos & 0.45094 & $0.30050 \mathrm{~ns}$ & $0.16311 \mathrm{~ns}$ & 0.37660 & 0.24767 \\
\hline 25 a 29 anos & $0.39212 \mathrm{~ns}$ & $-0.19305 \mathrm{~ns}$ & 0.58100 & 0.79213 & 0.41382 \\
\hline 30 a 39 anos & 0.58864 & $0.64545 \mathrm{~ns}$ & 0.95414 & 1.07541 & 0.61465 \\
\hline 40 a 49 anos & 0.84789 & $1.09175 \mathrm{~ns}$ & 1.06558 & 1.13742 & 0.71553 \\
\hline 50 anos ou mais & 0.65770 & $0.58913 \mathrm{~ns}$ & 1.24083 & 1.05353 & 0.46906 \\
\hline \multicolumn{6}{|l|}{ SITUAÇÃO } \\
\hline Região Urbana & $-0.07622 \mathrm{~ns}$ & $-0.16816 \mathrm{~ns}$ & $0.01470 \cdot \mathrm{ns}$ & $-0.00454 \mathrm{~ns}$ & 0.09943 \\
\hline \multicolumn{6}{|l|}{ POSIÇÃO NA OCUPAÇÃO } \\
\hline Autônomos e empregadores & 0.42421 & $-0.43123 \mathrm{~ns}$ & 0.34456 & 0.44091 & 0.15578 \\
\hline \multicolumn{6}{|c|}{ POSSE DE CARTEIRA ASSINADA } \\
\hline Com Carteira Assinada & 0.50000 & $-0.53148 \mathrm{~ns}$ & 0.36365 & 0.35329 & 0.33752 \\
\hline \multicolumn{6}{|l|}{ MULHERES } \\
\hline INTERCEPTO & 6.556494 & 6.237788 & 6.613729 & 6.631499 & 7.485289 \\
\hline \multicolumn{6}{|l|}{ ESCOLARIDADE } \\
\hline Primário Incompleto & 0.12047 & 1.25277 & $0.19429 \mathrm{~ns}$ & $0.14644 \mathrm{~ns}$ & $-0.06604 \mathrm{~ns}$ \\
\hline Primário Completo & 0.31999 & 1.56119 & 0.67467 & $0.18678 \mathrm{~ns}$ & 0.48834 \\
\hline Ginásio Incompleto & 0.51035 & 1.68036 & 0.38174 & 0.41268 & 0.73647 \\
\hline Ginásio Completo & 0.84035 & 1.47484 & 0.87290 & 0.57970 & 1.52573 \\
\hline Colegial e Superior & 1.47204 & 2.50250 & 1.48387 & 1.37737 & 1.78713 \\
\hline \multicolumn{6}{|l|}{ IDADE } \\
\hline \multicolumn{6}{|l|}{18 a 19 anos } \\
\hline 20 a 24 anos & 0.30123 & $0.09291 \mathrm{~ns}$ & 0.40945 & $-0.13760 \mathrm{~ns}$ & $0.32708 *$ \\
\hline 25 a 29 anos & 0.51488 & $0.41660 \mathrm{~ns}$ & 0.75975 & 0.37785 & 0.61624 \\
\hline 30 a 39 anos & 0.62248 & $0.45258 \mathrm{~ns}$ & 0.91601 & 0.48323 & 0.48518 \\
\hline 40 a 49 anos & 0.77040 & $0.60560 *$ & 1.04021 & 0.67656 & 0.49793 \\
\hline 50 anos ou mais & 0.80310 & 0.94465 & 0.90558 & 0.67398 & 0.39609 \\
\hline \multicolumn{6}{|l|}{ SITUAÇÃO } \\
\hline Região Urbana & $-0.07035 \mathrm{~ns}$ & $0.03617 \mathrm{~ns}$ & $0.08425 \mathrm{~ns}$ & $0.25647 *$ & $0.09662 \mathrm{~ns}$ \\
\hline \multicolumn{6}{|l|}{ POSIÇÃO NA OCUPAÇÃO } \\
\hline Autônomos e empregadores & 0.18586 & $0.30634 \mathrm{~ns}$ & 0.26593 & 0.45717 & -0.33882 \\
\hline \multicolumn{6}{|c|}{ POSSE DE CARTEIRA ASSINADA } \\
\hline Com Carteira Assinada & 0.51912 & 0.48592 & 0.44420 & 0.60537 & $0.30876 *$ \\
\hline
\end{tabular}

(1) Inclui apenas as observações para as quais os atributos de interesse estão claramente identificados.

(2) Todos os coeficientes são estatisticamente significativos ao nível de 5\%, com exceção dos assinalados por asterisco (que são significativos ao nível de 10\%) e por ns (que são não-significativos). 

Tabela G18. Números-indices obtidos dos coeficientes das equações de rendimento ajustadas para a PEA ocupada (1), por sexo e classe ocupacional. Pernambuco, 1983.(2)

\begin{tabular}{|c|c|c|c|c|c|}
\hline \multirow[t]{2}{*}{ SEXO/FATOR } & \multicolumn{5}{|c|}{ CLASSES } \\
\hline & 1 & 2 & 3 & 4 & 5 \\
\hline \multicolumn{6}{|l|}{ HOMENS } \\
\hline INTERCEPTO & 1030.587 & 2724.865 & 1135.749 & 1068.100 & 1582.136 \\
\hline \multicolumn{6}{|l|}{ ESCOLARIDADE } \\
\hline Primári olncompleto & $1.119 \mathrm{~ns}$ & $2.684 \mathrm{~ns}$ & $1.145 \mathrm{~ns}$ & 1.258 & 1.208 \\
\hline Primánio Compl to & 2.000 & $1.422 \mathrm{~ns}$ & $1.317^{*}$ & 1.456 & 1.487 \\
\hline Ginási olncompleto & $1.327 \mathrm{~ns}$ & $1.461 \mathrm{~ns}$ & 1.775 & 1.776 & 1.561 \\
\hline Ginási oCompl to & 1.972 & $2.477 \mathrm{~ns}$ & 2.042 & 2.462 & 2.102 \\
\hline Colegial e Superior & 3.551 & 8.032 & 4.332 & 4.135 & 4.209 \\
\hline \multicolumn{6}{|l|}{ IDADE } \\
\hline \multicolumn{6}{|l|}{18 a 19 anos } \\
\hline 20 a 24 anos & 1.570 & $1.351 \mathrm{~ns}$ & $1.177 \mathrm{~ns}$ & 1.457 & 1.281 \\
\hline 25 a 29 anos & $1.480 \mathrm{~ns}$ & $0.824 \mathrm{~ns}$ & 1.788 & 2.208 & 1.513 \\
\hline 30 a 39 anos & 1.802 & $1.907 \mathrm{~ns}$ & 2.596 & 2.931 & 1.849 \\
\hline 40 a 49 anos & 2.335 & $2.979 \mathrm{~ns}$ & 2.903 & 3.119 & 2.045 \\
\hline 50 anos ou mais & 1.930 & $1.802 \mathrm{~ns}$ & 3.458 & 2.868 & 1.598 \\
\hline \multicolumn{6}{|l|}{ SITUAÇÃO } \\
\hline Região Urbana & $0.927 \mathrm{~ns}$ & $0.845 \mathrm{~ns}$ & $1.015 \mathrm{~ns}$ & $0.995 \mathrm{~ns}$ & 1.105 \\
\hline \multicolumn{6}{|l|}{ POSIÇÃO NA OCUPAÇÃO } \\
\hline Autônomos e empregadores & 1.528 & $0.650 \mathrm{~ns}$ & 1.411 & 1.554 & 1.169 \\
\hline \multicolumn{6}{|c|}{ POSSE DE CARTERA ASSINADA } \\
\hline Com Carteira Assinada & 1.649 & $0.588 \mathrm{~ns}$ & 1.439 & 1.424 & 1.401 \\
\hline \multicolumn{6}{|l|}{ MULHERES } \\
\hline INTERCEPTO & 695.444 & 384.531 & 639.055 & 836.884 & 1140.982 \\
\hline \multicolumn{6}{|l|}{ ESCOLARIDADE } \\
\hline Primário Incompleto & 1.128 & 3.500 & $1.214 \mathrm{~ns}$ & $1.158 \mathrm{~ns}$ & $0.936 \mathrm{~ns}$ \\
\hline Primário Compl ato & 1.377 & 4.764 & 1.963 & $1.205 \mathrm{~ns}$ & 1.630 \\
\hline Ginási oIncompleto & 1.666 & 5.367 & 1.465 & 1.511 & 2.089 \\
\hline Ginásio Compl eto & 2.317 & 4.370 & 2.394 & 1.785 & 4.598 \\
\hline Colegial e Superi or & 4.358 & 12.213 & 4.410 & 3.964 & 5.972 \\
\hline \multicolumn{6}{|l|}{ IDADE } \\
\hline \multicolumn{6}{|l|}{18 a 19 anos } \\
\hline 20 a 24 anos & 1.352 & $1.097 \mathrm{~ns}$ & 1.506 & $0.871 \mathrm{~ns}$ & $1.387^{*}$ \\
\hline 25 a 29 anos & 1.673 & $1.517 \mathrm{~ns}$ & 2.138 & 1.459 & 1.852 \\
\hline 30 a 39 anos & 1.864 & $1.572 \mathrm{~ns}$ & 2.499 & 1.621 & 1.624 \\
\hline 40 a 49 anos & 2.161 & $1.832 *$ & 2.830 & 1.967 & 1.645 \\
\hline 50 anos ou mais & 2.232 & 2.572 & 2.473 & 1.962 & 1.486 \\
\hline \multicolumn{6}{|l|}{ SITUAÇÃo } \\
\hline Região Urbana & $0.932 \mathrm{~ns}$ & $1.037 \mathrm{~ns}$ & $1.088 \mathrm{~ns}$ & $1.292 *$ & $1.101 \mathrm{~ns}$ \\
\hline \multicolumn{6}{|l|}{ POSIÇÃO NA OCUPAÇÃO } \\
\hline Autônomos e empregadores & 1.204 & $1.358 \mathrm{~ns}$ & 1.305 & 1.580 & 0.713 \\
\hline \multicolumn{6}{|c|}{ POSSE DE CARTEIRA ASSINADA } \\
\hline Com Carteira Assinada & 1.681 & 1.626 & 1.559 & 1.832 & $1.362 *$ \\
\hline
\end{tabular}

(1) Inclui apenas as observaçōes para as quais os atributos de interesse estão claramente identificados.

(2) Todos os coeficientes são estatisticamente significativos ao nível de $5 \%$, com exceção dos assinalados por asterisco (que são significativos ao nivel de 10\%) e por ns (que são não-significativos). 
Tabela G19. Estimativas dos coeficientes das equações de rendimento ajustadas para a PEA ocupada(1), por sexo e classe ocupacional. Pernambuco, 1985. (2)

\begin{tabular}{|c|c|c|c|c|c|}
\hline \multirow[t]{2}{*}{ SEXO/FATOR } & \multicolumn{5}{|c|}{ CLASSES } \\
\hline & 1 & 2 & 3 & 4 & 5 \\
\hline \multicolumn{6}{|l|}{ HOMENS } \\
\hline INTERCEPTO & 7.207804 & 6.822013 & 6.872952 & 6.973381 & 7.166951 \\
\hline \multicolumn{6}{|l|}{ ESCOLARIDADE } \\
\hline Primário Incompleto & 0.48984 & $0.72629 \mathrm{~ns}$ & $0.12020 \mathrm{~ns}$ & 0.25975 & 0.18679 \\
\hline Primário Completo & $0.31156 \mathrm{~ns}$ & $0.34760 \mathrm{~ns}$ & 0.31261 & 0.45357 & 0.40288 \\
\hline Ginásio Incompleto & 0.55854 & $0.27253 \mathrm{~ns}$ & 0.45955 & 0.44217 & 0.50032 \\
\hline Ginásio Completo & 0.90117 & $-0.02457 \mathrm{~ns}$ & 0.82058 & 0.75168 & 0.76836 \\
\hline Colegial e Superior & 1.21934 & 1.51058 & 1.26454 & 1.54461 & 1.41997 \\
\hline \multicolumn{6}{|l|}{ IDADE } \\
\hline 18 a 19 anos & $0.43708 \mathrm{~ns}$ & $0.59961 \mathrm{~ns}$ & $0.32462 *$ & 0.30163 & 0.17462 \\
\hline 20 a 24 anos & $0.46216^{*}$ & $0.41305 \mathrm{~ns}$ & 0.44288 & 0.58070 & 0.29860 \\
\hline 25 a 29 anos & 0.78997 & $0.46065 \mathrm{~ns}$ & 0.76789 & 0.82222 & 0.47356 \\
\hline 30 a 39 anos & 0.56867 & $1.03956 \mathrm{~ns}$ & 0.85995 & 1.27736 & 0.68006 \\
\hline 40 a 49 anos & 0.78819 & $1.05125 \mathrm{~ns}$ & 1.37343 & 1.37860 & 0.77435 \\
\hline 50 anos ou mais & $0.35055 \mathrm{~ns}$ & $0.82902 \mathrm{~ns}$ & 1.42121 & 1.09338 & 0.61213 \\
\hline \multicolumn{6}{|l|}{ SITUAÇĀO } \\
\hline Região Urbana & $-0.22327 \mathrm{~ns}$ & $0.45648 \mathrm{~ns}$ & $0.20073 \mathrm{~ns}$ & $-0.02366 \mathrm{~ns}$ & 0.19356 \\
\hline \multicolumn{6}{|l|}{ POSIÇÃO NA OCUPAÇÃO } \\
\hline Autônomos e empregadores & 0.52746 & $0.29829 \mathrm{~ns}$ & 0.11401 ns & 0.28260 & 0.14637 \\
\hline \multicolumn{6}{|c|}{ POSSE DE CARTEIRA ASSINADA } \\
\hline Com Carteira Assinada & 0.41363 & $0.32367 \mathrm{~ns}$ & 0.38394 & 0.37823 & 0.47202 \\
\hline \multicolumn{6}{|l|}{ MULHERES } \\
\hline INTERCEPTO & 6.407233 & 6.904873 & 6.465508 & 6.053608 & 6.978912 \\
\hline \multicolumn{6}{|l|}{ ESCOLARIDADE } \\
\hline Primário Incompleto & 0.25195 & $0.14822 \mathrm{~ns}$ & $0.16520 \mathrm{~ns}$ & 0.57278 & $0.03505 \mathrm{~ns}$ \\
\hline Primário Completo & 0.38507 & 0.64135 & $0.02826 \mathrm{~ns}$ & 0.61783 & $0.10323 \mathrm{~ns}$ \\
\hline Ginásio Incompleto & 0.54594 & $0.44684^{*}$ & 0.68714 & 1.02302 & 0.52310 \\
\hline Ginásio Conpleto & 0.86244 & 1.12900 & 0.69666 & 1.15292 & 1.47572 \\
\hline Colegial e Superior & 1.49763 & 2.00527 & 1.30467 & 1.80311 & 1.40757 \\
\hline \multicolumn{6}{|l|}{ IDADE } \\
\hline 18 a 19 anos & $0.08016 \mathrm{~ns}$ & $-0.14938 \mathrm{~ns}$ & $0: 09425 \mathrm{~ns}$ & $0.51914^{*}$ & $-0.12243 \mathrm{~ns}$ \\
\hline 20 a 24 anos & 0.39512 & $-0.20490 \mathrm{~ns}$ & $0.14865 \mathrm{~ns}$ & $0.30827 \mathrm{~ns}$ & $0.20106 \mathrm{~ns}$ \\
\hline 25 a 29 anos & 0.62097 & $-0.20091 \mathrm{~ns}$ & $0.37885^{*}$ & $0.50334^{*}$ & $0.22825 \mathrm{~ns}$ \\
\hline 30 a 39 anos & 0.83093 & $0.44852 \mathrm{~ns}$ & 0.70002 & 0.69915 & 0.49811 \\
\hline 40 a 49 anos & 0.84691 & $0.43129 \mathrm{~ns}$ & 0.98471 & 1.23168 & 0.34743 \\
\hline 50 anos ou mais & 0.84793 & $0.57191 \mathrm{~ns}$ & 1.61406 & 0.86233 & $0.21226 \mathrm{~ns}$ \\
\hline \multicolumn{6}{|l|}{ SITUAÇÃO } \\
\hline Região Urbana & -0.22842 & $0.28714^{*}$ & 0.26297 & $0.06517 \mathrm{~ns}$ & 0.18826 \\
\hline \multicolumn{6}{|l|}{ POSIÇÃO NA OCUPAÇÃO } \\
\hline Autônomos e empregedores & $0.09163^{*}$ & $0.21781 \mathrm{~ns}$ & $0: 27441$ & $0.27097 \mathrm{~ns}$ & $-0.07016 \mathrm{~ns}$ \\
\hline \multicolumn{6}{|c|}{ POSSE DE CARTEIRA ASSINADA } \\
\hline Com Carteira Assinada & 0.74178 & $0.21195^{*}$ & 0.66741 & 0.53968 & 0.74156 \\
\hline
\end{tabular}

(1) Inclui apenas as observações para as quais os atributos de interesse estão claramente identificados.

(2) Todos os coeficientes são estatisticamente significativos ao nível de $5 \%$, com exceção dos assinalados por asterisco (que são significativos ao nível de 10\%) e por ns (que são não-significativos). 

Tabela G20. Números-indices obtidos dos coeficientes das equações de rendimento ajustadas para a PEA ocupada(1), por sexo e classe ocupacional. Pernambuco, 1985. (2)

\begin{tabular}{|c|c|c|c|c|c|}
\hline \multirow[t]{2}{*}{ SEXO/FATOR } & \multicolumn{5}{|c|}{ CLASSES } \\
\hline & 1 & 2 & 3 & 4 & 5 \\
\hline \multicolumn{6}{|l|}{ HOMENS } \\
\hline INTERCEPTO & 1675.354 & 2226.756 & 3208.051 & 2789.953 & 3706.669 \\
\hline \multicolumn{6}{|l|}{ ESCOLARIDADE } \\
\hline Primário Incompleto & 1.632 & $2.067 \mathrm{~ns}$ & $1.128 \mathrm{~ns}$ & 1.297 & 1.205 \\
\hline Primário Completo & $1.366 \mathrm{~ns}$ & $1.416 \mathrm{~ns}$ & 1.367 & 1.574 & 1.496 \\
\hline Ginásio Incompleto & 1.748 & $1.313 \mathrm{~ns}$ & 1.583 & 1.556 & 1.649 \\
\hline Ginásio Completo & 2.462 & $0.976 \mathrm{~ns}$ & 2.272 & 2.121 & 2.156 \\
\hline Colegial e Superior & 3.385 & 4.529 & 3.541 & 4.686 & 4.137 \\
\hline \multicolumn{6}{|l|}{ IDADE } \\
\hline 18 a 19 anos & $1.548 \mathrm{~ns}$ & $1.821 \mathrm{~ns}$ & 1.384 * & 1.352 & 1.191 \\
\hline 20 a 24 anos & $1.587^{*}$ & $1.511 \mathrm{~ns}$ & 1.557 & 1.787 & 1.348 \\
\hline 25 a 29 anos & 2.203 & $1.585 \mathrm{~ns}$ & 2.155 & 2.276 & 1.606 \\
\hline 30 a 39 anos & 1.766 & $2.828 \mathrm{~ns}$ & 2.363 & 3.587 & 1.974 \\
\hline 40 a 49 anos & 2.199 & $2.861 \mathrm{~ns}$ & 3.949 & 3.969 & 2.169 \\
\hline 50 anos ou mais & $1.420 \mathrm{~ns}$ & $2.291 \mathrm{~ns}$ & 4.142 & 2.984 & 1.844 \\
\hline \multicolumn{6}{|l|}{ SITUAÇÃO } \\
\hline Região Urbana & $0.800 \mathrm{~ns}$ & $1.579 \mathrm{~ns}$ & $1.222 \mathrm{~ns}$ & $0.977 \mathrm{~ns}$ & 1.214 \\
\hline \multicolumn{6}{|l|}{ POSIÇÃO NA OCUPAÇÃO } \\
\hline Autônomos e enpregadores & 1.695 & $1.348 \mathrm{~ns}$ & $1.121 \mathrm{~ns}$ & 1.327 & 1.158 \\
\hline \multicolumn{6}{|c|}{ POSSE DE CARTEIRA ASSINADA } \\
\hline Com Carteira Assinada & 1.512 & $1.382 \mathrm{~ns}$ & 1.468 & 1.460 & 1.603 \\
\hline \multicolumn{6}{|l|}{ MULHERES } \\
\hline INTERCEPTO & 1683.296 & 8280.826 & 3693.102 & 3198.800 & 3171.396 \\
\hline \multicolumn{6}{|l|}{ ESCOLARIDADE } \\
\hline Primário Incompleto & 1.287 & $1.160 \mathrm{~ns}$ & $1.180 \mathrm{~ns}$ & 1.773 & $1.036 \mathrm{~ns}$ \\
\hline Primáno Completo & 1.470 & 1.899 & $1.029 \mathrm{~ns}$ & 1.855 & $1.109 \mathrm{~ns}$ \\
\hline Ginásio Incompleto & 1.726 & $1.563^{*}$ & 1.988 & 2.782 & 1.687 \\
\hline Ginásio Completo & 2.369 & 3.093 & 2.007 & 3.167 & 4.374 \\
\hline Colegial e Superior & 4.471 & 7.428 & 3.686 & 6.068 & 4.086 \\
\hline \multicolumn{6}{|l|}{ IDADE } \\
\hline 18 a 19 anos & $1.083 \mathrm{~ns}$ & $0.861 \mathrm{~ns}$ & $1.099 \mathrm{~ns}$ & $1.681^{*}$ & $0.885 \mathrm{~ns}$ \\
\hline 20 a 24 anos & 1.485 & $0.815 \mathrm{~ns}$ & $1.160 \mathrm{~ns}$ & $1.361 \mathrm{~ns}$ & $1.223 \mathrm{~ns}$ \\
\hline 25 a 29 anos & 1.861 & $0.818 \mathrm{~ns}$ & $1.461 *$ & $1.654^{*}$ & $1.256 \mathrm{~ns}$ \\
\hline 30 a 39 anos & 2.295 & $1.566 \mathrm{~ns}$ & 2.014 & 2.012 & 1.646 \\
\hline 40 a 49 anos & 2.332 & $1.539 \mathrm{~ns}$ & 2.677 & 3.427 & 1.415 \\
\hline 50 anos ou mais & 2.335 & $1.772 \mathrm{~ns}$ & 5.023 & 2.369 & $1.236 \mathrm{~ns}$ \\
\hline \multicolumn{6}{|l|}{ SITUAÇÃO } \\
\hline Região Urbana & 0.796 & $1.333 *$ & 1.301 & $1.067 \mathrm{~ns}$ & 1.207 \\
\hline \multicolumn{6}{|l|}{ POSIÇÃO NA OCUPAÇÃO } \\
\hline Autônomos e empregadores & $1.096^{*}$ & $1.243 \mathrm{~ns}$ & 1.316 & $1.311 \mathrm{~ns}$ & $0.932 \mathrm{~ns}$ \\
\hline \multicolumn{6}{|c|}{ POSSE DE CARTEIRA ASSINADA } \\
\hline Com Carteira Assinada & 2.100 & $1.236 *$ & 1.949 & 1.715 & 2.099 \\
\hline
\end{tabular}

(1) Inclui apenas as observações para as quais os atributos de interesse estão claramente identificados.

(2) Todos os coeficientes são estatisticamente significativos ao nível de $5 \%$, com exceção dos assinalados por asterisco (que são significativos ao nível de $10 \%$ ) e por ns (que são não-significativos). 
Tabela G21. Estimativas dos coeficientes das equações de rendimento ajustadas para a PEA ocupada(1), por sexo e classe ocupacional. Pernambuco, 1987. (2)

\begin{tabular}{|c|c|c|c|c|c|}
\hline \multirow[t]{2}{*}{ SEXO/FATOR } & \multicolumn{5}{|c|}{ CLASSES } \\
\hline & 1 & 2 & 3 & 4 & 5 \\
\hline \multicolumn{6}{|l|}{ HOMENS } \\
\hline INTERCEPTO & 5.796377 & 7.036866 & 6.902125 & 7.210361 & 7.194951 \\
\hline \multicolumn{6}{|l|}{ ESCOLARIDADE } \\
\hline \multicolumn{6}{|l|}{ Primário Incompleto } \\
\hline Primário Completo & $0.59632 *$ & $-0.52952 \mathrm{~ns}$ & $0.29017 \mathrm{~ns}$ & 0.28841 & 0.24269 \\
\hline Ginásio Incompleto & 0.62396 & $0.33135 \mathrm{~ns}$ & 0.51985 & 0.30608 & 0.33021 \\
\hline Ginásio Completo & $0.70560^{*}$ & $0.40509 \mathrm{~ns}$ & 0.93034 & 0.51167 & 0.46150 \\
\hline Colegial e Superior & 1.24949 & 0.84381 & 1.54644 & 1.44197 & 1.36214 \\
\hline \multicolumn{6}{|l|}{ IDADE } \\
\hline 18 a 19 anos & 1.96150 & $0.03176 \mathrm{~ns}$ & $0.54026 \mathrm{~ns}$ & $0.19082 \mathrm{~ns}$ & 0.16738 \\
\hline 20 a 24 anos & 1.49338 & $0.28683 \mathrm{~ns}$ & $0.38869 *$ & 0.29650 & 0.38506 \\
\hline 25 a 29 anos & 2.22949 & $0.62891 \mathrm{~ns}$ & 0.71995 & 0.65634 & 0.49667 \\
\hline 30 a 39 anos & 1.94417 & 0.98136 & 0.90887 & 0.88320 & 0.61660 \\
\hline 40 a 49 anos & 2.00879 & 1.57410 & 1.15788 & 1.01973 & 0.76063 \\
\hline 50 anos ou mais & 1.64024 & 1.56650 & 0.81724 & 0.79516 & 0.48266 \\
\hline \multicolumn{6}{|l|}{ SITUAÇÃO } \\
\hline Região Urbana & $-0.04636 \mathrm{~ns}$ & $0.43430 *$ & $0.28645 \mathrm{~ns}$ & $-0.00019 \mathrm{~ns}$ & 0.36922 \\
\hline \multicolumn{6}{|l|}{ POSIÇÃO NA OCUPAÇÃO } \\
\hline Autônomos e empregadores & 0.89499 & $-0.11070 \mathrm{~ns}$ & $0.19181 \mathrm{~ns}$ & 0.62804 & 0.27313 \\
\hline \multicolumn{6}{|c|}{ POSSE DE CARTEIRA ASSINADA } \\
\hline Com Carteira Assinada & $0.32736 \mathrm{~ns}$ & $0.19967 \mathrm{~ns}$ & $0.06319 \mathrm{~ns}$ & 0.34667 & 0.38388 \\
\hline \multicolumn{6}{|l|}{ MULHERES } \\
\hline INTERCEPTO & 6.598506 & 6.536666 & 6.017734 & 6.962963 & 6.855615 \\
\hline \multicolumn{6}{|l|}{$\begin{array}{l}\text { ESCOLARIDADE } \\
\text { Primário Incompleto }\end{array}$} \\
\hline Primáno Completo & 0.18350 & $-0.10241 \mathrm{~ns}$ & 0.81326 & $0.27443 *$ & $0.13383 \mathrm{~ns}$ \\
\hline Ginásio Incompleto & 0.30936 & $0.19685 \mathrm{~ns}$ & 1.49935 & 0.58390 & $0.47905 \mathrm{~ns}$ \\
\hline Ginásio Completo & 0.34924 & $0.39153 \mathrm{~ns}$ & 1.37822 & 0.75982 & $0.58817 \mathrm{~ns}$ \\
\hline Colegial e Superior & 1.23060 & 1.08547 & 1.80053 & 1.25754 & 2.12020 \\
\hline \multicolumn{6}{|l|}{ IDADE } \\
\hline 18 a 19 anos & $-0.06580 \mathrm{~ns}$ & $0.28685 \mathrm{~ns}$ & $0.09006 \mathrm{~ns}$ & $0.15694 \mathrm{~ns}$ & $0.36994 \mathrm{~ns}$ \\
\hline 20 a 24 anos & 0.29537 & $0.92188 \mathrm{~ns}$ & $0.32344 \mathrm{~ns}$ & $0.28869 \mathrm{~ns}$ & $0.39931 \mathrm{~ns}$ \\
\hline 25 a 29 anos & 0.32546 & 1.27138 & $0.58890 \mathrm{~ns}$ & 0.58419 & 0.71824 \\
\hline 30 a 39 anos & 0.54568 & 1.59825 & $0.86906^{*}$ & 0.62568 & 0.69455 \\
\hline 40 a 49 anos & 0.60391 & 1.73655 & 1.48267 & 0.83632 & 0.62091 \\
\hline 50 anos ou mais & 0.44769 & 1.62548 & 1.65610 & 0.88672 & 0.59436 \\
\hline \multicolumn{6}{|l|}{ SITUAÇĀO } \\
\hline Região Urbana & 0.20198 & $0.05330 \mathrm{~ns}$ & $0.21059 \mathrm{~ns}$ & $-0.20157 \mathrm{~ns}$ & $0.09577 \mathrm{~ns}$ \\
\hline \multicolumn{6}{|l|}{ POSIÇÃO NA OCUPAÇÃO } \\
\hline Autônomos e empregegdores & 0.40655 & $0.06132 \mathrm{~ns}$ & $0.35167 \mathrm{~ns}$ & 0.64556 & $0.24952 *$ \\
\hline \multicolumn{6}{|c|}{ POSSE DE CARTEIRA ASSINADA } \\
\hline Com Carteira Assinada & 0.69030 & $0.08799 \mathrm{~ns}$ & $0.23829 \mathrm{~ns}$ & 0.53749 & 0.53061 \\
\hline
\end{tabular}

(1) Inclui apenas as observaç̃̃es para as quais os atributos de interesse estão claramente identificados.

(2) Todos os coeficientes são estatisticamente significativos ao nível de 5\%, com exceção dos assinalados por asterisco (que são significativos ao nível de $10 \%$ ) e por ns (que são não-significativos). 

Tabela G22. Números-índices obtidos dos coeficientes das equações de rendimento ajustadas para a PEA ocupada(1), por sexo e classe ocupacional. Pernambuco, 1987.(2)

\begin{tabular}{|c|c|c|c|c|c|}
\hline \multirow[t]{2}{*}{ SEXO/FATOR } & \multicolumn{5}{|c|}{ Classes } \\
\hline & 1 & 2 & 3 & 4 & 5 \\
\hline \multicolumn{6}{|l|}{ HOMENS } \\
\hline INTERCEPTO & 329.105 & 1137.816 & 1353.381 & 1332.685 & 733.998 \\
\hline \multicolumn{6}{|l|}{ ESCOLARIDADE } \\
\hline \multicolumn{6}{|l|}{ Primário Incompleto } \\
\hline Primário Completo & $1.815^{*}$ & $0.589 \mathrm{~ns}$ & $1.337 \mathrm{~ns}$ & 1.334 & 1.275 \\
\hline Ginásio Incompleto & 1.866 & $1.393 \mathrm{~ns}$ & 1.682 & 1.358 & 1.391 \\
\hline Ginásio Completo & $2.025 *$ & $1.499 \mathrm{~ns}$ & 2.535 & 1.668 & 1.586 \\
\hline Colegial e Superior & 3.489 & 2.325 & 4.695 & 4.229 & 3.905 \\
\hline \multicolumn{6}{|l|}{ IDADE } \\
\hline 18 a 19 anos & 7.110 & $1.032 \mathrm{~ns}$ & $1.716 \mathrm{~ns}$ & $1.210 \mathrm{~ns}$ & 1.182 \\
\hline 20 a 24 anos & 4.452 & 1.332 ns & $1.475^{*}$ & 1.345 & 1.470 \\
\hline 25 a 29 anos & 9.295 & $1.876 \mathrm{~ns}$ & 2.054 & 1.928 & 1.643 \\
\hline 30 a 39 anos & 6.988 & 2.668 & 2.482 & 2.419 & 1.853 \\
\hline 40 a 49 anos & 7.454 & 4.826 & 3.183 & 2.772 & 2.140 \\
\hline 50 anos ou mais & 5.156 & 4.790 & 2.264 & 2.215 & 1.620 \\
\hline \multicolumn{6}{|l|}{ SITUAÇÃO } \\
\hline Região Urbana & $0.955 \mathrm{~ns}$ & $1.544^{*}$ & $1.332 \mathrm{~ns}$ & $1.000 \mathrm{~ns}$ & 1.447 \\
\hline \multicolumn{6}{|l|}{ POSIÇÃO NA OCUPAÇÃO } \\
\hline Autônomos e empregadores & 2.447 & $0.895 \mathrm{~ns}$ & $1.211 \mathrm{~ns}$ & 1.874 & 1.314 \\
\hline \multicolumn{6}{|c|}{ POSSE DE CARTEIRA ASSINADA } \\
\hline Com Carteira Assinada & $1.387 \mathrm{~ns}$ & $1.221 \mathrm{~ns}$ & $1.065 \mathrm{~ns}$ & 1.414 & 1.468 \\
\hline \multicolumn{6}{|l|}{ MULHERES } \\
\hline INTERCEPTO & 733.998 & 689.982 & 410.647 & 1056.760 & 949.196 \\
\hline \multicolumn{6}{|l|}{ ESCOLARIDADE } \\
\hline \multicolumn{6}{|l|}{ Primário Incompleto } \\
\hline Primário Completo & 1.201 & $0.903 \mathrm{~ns}$ & 2.255 & $1.316^{*}$ & $1.143 \mathrm{~ns}$ \\
\hline Ginásio Incompleto & 1.363 & $1.218 \mathrm{~ns}$ & 4.479 & 1.793 & $1.615 \mathrm{~ns}$ \\
\hline Ginásio Completo & 1.418 & $1.479 \mathrm{~ns}$ & 3.968 & 2.138 & $1.801 \mathrm{~ns}$ \\
\hline Colegial e Superior & 3.423 & 2.961 & 6.053 & 3.517 & 8.333 \\
\hline \multicolumn{6}{|l|}{ IDADE } \\
\hline 18 a 19 anos & $0.936 \mathrm{~ns}$ & $1.332 \mathrm{~ns}$ & $1.094 \mathrm{~ns}$ & $1.170 \mathrm{~ns}$ & $1.448 \mathrm{~ns}$ \\
\hline 20 a 24 anos & 1.344 & $2.514 \mathrm{~ns}$ & $1.382 \mathrm{~ns}$ & $1.335 \mathrm{~ns}$ & $1.491 \mathrm{~ns}$ \\
\hline 25 a 29 anos & 1.385 & 3.566 & $1.802 \mathrm{~ns}$ & 1.794 & 2.051 \\
\hline 30 a 39 anos & 1.726 & 4.944 & $2.385^{*}$ & 1.870 & 2.003 \\
\hline 40 a 49 anos & 1.829 & 5.678 & 4.405 & 2.308 & 1.861 \\
\hline 50 anos ou mais & 1.565 & 5.081 & 5.239 & 2.427 & 1.812 \\
\hline \multicolumn{6}{|l|}{ SITUAÇÃO } \\
\hline Região Urbana & 1.224 & $1.055 \mathrm{~ns}$ & $1.234 \mathrm{~ns}$ & $0.817 \mathrm{~ns}$ & $1.101 \mathrm{~ns}$ \\
\hline \multicolumn{6}{|l|}{ POSIÇÃO NA OCUPAÇÃO } \\
\hline Autônomos e empregadores & 1.502 & $1.063 \mathrm{~ns}$ & $1.421 \mathrm{~ns}$ & 1.907 & $1.283^{*}$ \\
\hline \multicolumn{6}{|c|}{ POSSE DE CARTEIRA ASSINADA } \\
\hline Com Carteira Assinada & 1.994 & $1.092 \mathrm{~ns}$ & $1.269 \mathrm{~ns}$ & 1.712 & 1.700 \\
\hline
\end{tabular}

(1) Inclui apenas as observações para as quais os atributos de interesse estão claramente identificados.

(2) Todos os coeficientes são estatisticamente significativos ao nível de $5 \%$, com exceção dos assinalados por asterisco (que são significativos ao nível de 10\%) e por ns (que são não-significativos). 
Tabela G23. Estimativas dos coeficientes das equações de rendimento ajustadas para a PEA ocupada(1), por sexo e classe ocupacional. Pernambuco, 1988. (2)

\begin{tabular}{|c|c|c|c|c|c|}
\hline \multirow[t]{2}{*}{ SEXO/FATOR } & \multicolumn{5}{|c|}{ CLASSES } \\
\hline & 1 & 2 & 3 & 4 & 5 \\
\hline \multicolumn{6}{|l|}{ HOMENS } \\
\hline INTERCEPTO & 6.785493 & 6.829642 & 6.822160 & 6.979135 & 6.807259 \\
\hline \multicolumn{6}{|l|}{ ESCOLARIDADE } \\
\hline Primário Incompleto & $0.30500 \mathrm{~ns}$ & $0.07063 \mathrm{~ns}$ & 0.73518 & $0.20438 \mathrm{~ns}$ & 0.32998 \\
\hline Primário Completo & $0.50201 \mathrm{~ns}$ & $-0.14478 \mathrm{~ns}$ & 0.88514 & 0.31923 & 0.47038 \\
\hline Ginásio Incompleto & $0.52084 \mathrm{~ns}$ & $0.39240 \mathrm{~ns}$ & 0.95955 & 0.71421 & 0.65682 \\
\hline Ginásio Completo & $0.05743 \mathrm{~ns}$ & $0.82933^{*}$ & 1.16401 & 0.89958 & 0.78823 \\
\hline Colegial e Superior & 1.02487 & 1.10475 & 1.88582 & 1.44906 & 1.55279 \\
\hline \multicolumn{6}{|l|}{ IDADE } \\
\hline 18 a 19 anos & $-0.01904 \mathrm{~ns}$ & $-0.39034 \mathrm{~ns}$ & $-0.26612 \mathrm{~ns}$ & $0.04450 \mathrm{~ns}$ & 0.20494 \\
\hline 20 a 24 anos & $0.69324^{*}$ & $0.71418 \mathrm{~ns}$ & $0.18174 \mathrm{~ns}$ & $0.24816 \mathrm{~ns}$ & 0.49639 \\
\hline 25 a 29 anos & 0.89405 & $0.83830 \mathrm{~ns}$ & 0.84357 & 0.54729 & 0.65988 \\
\hline 30 a 39 anos & 0.98731 & 1.61400 & 1.17185 & 0.91896 & 0.81215 \\
\hline 40 a 49 anos & 1.17674 & 2.04326 & 1.21348 & 1.18119 & 0.95036 \\
\hline 50 anos ou mais & 1.02485 & 1.57989 & 1.41030 & 0.73415 & 0.79781 \\
\hline \multicolumn{6}{|l|}{ SITUAÇÃO } \\
\hline Região Urbana & $0.23004 \mathrm{~ns}$ & $-0.29599 \mathrm{~ns}$ & $-0.14696 \mathrm{~ns}$ & $-0.11049 \mathrm{~ns}$ & 0.16113 \\
\hline \multicolumn{6}{|l|}{ POSIÇÃO NA OCUPAÇÃO } \\
\hline Autônomos e empregadores & $-0.22190 \mathrm{~ns}$ & 1.22368 & $0.20020 \mathrm{~ns}$ & 0.53659 & 0.28436 \\
\hline \multicolumn{6}{|c|}{ POSSE DE CARTEIRA ASSINADA } \\
\hline Com Carteira Assinada & $0.21861 \mathrm{~ns}$ & 0.69814 & 0.34743 & 0.60139 & 0.46823 \\
\hline \multicolumn{6}{|l|}{ MULHERES } \\
\hline INTERCEPTO & 6.152634 & 6.979135 & 6.030393 & 6.509369 & 7.134819 \\
\hline \multicolumn{6}{|l|}{ ESCOLARIDADE } \\
\hline Primário Incompleto & 0.32146 & $-0.07904 \mathrm{~ns}$ & 0.69993 & $0.11159 \mathrm{~ns}$ & $0.08816 \mathrm{~ns}$ \\
\hline Primánio Complato & 0.51706 & $0.19288 \mathrm{~ns}$ & 1.43686 & 0.48226 & $0.47813^{*}$ \\
\hline Ginásio Incompleto & 0.61328 & $0.26316 \mathrm{~ns}$ & 1.25041 & 0.63349 & $0.45118 \mathrm{~ns}$ \\
\hline Ginásio Completo & 0.64049 & $0.27015 \mathrm{~ns}$ & 1.44478 & 0.84517 & $0.15331 \mathrm{~ns}$ \\
\hline Colegial e Superior & 1.53658 & 1.35560 & 2.02233 & 1.19057 & 1.93626 \\
\hline \multicolumn{6}{|l|}{ IDADE } \\
\hline 18 a 19 anos & $0.18065 \mathrm{~ns}$ & $0.25240 \mathrm{~ns}$ & $0.31558 \mathrm{~ns}$ & $0.06618 \mathrm{~ns}$ & $-0.00913 \mathrm{~ns}$ \\
\hline 20 a 24 anos & 0.44960 & $0.38037 \mathrm{~ns}$ & $0.66094 \mathrm{~ns}$ & $0.06423 \mathrm{~ns}$ & $0.00922 \mathrm{~ns}$ \\
\hline 25 a 29 anos & 0.57232 & 0.73349 & 1.25099 & $0.55506 \mathrm{~ns}$ & $0.05937 \mathrm{~ns}$ \\
\hline 30 a 39 anos & 0.90978 & 0.67987 & 1.48649 & 0.84959 & $-0.00404 \mathrm{~ns}$ \\
\hline 40 a 49 anos & 1.03880 & 0.91387 & 1.53335 & 1.23188 & $-0.02640 \mathrm{~ns}$ \\
\hline 50 anos ou mais & 0.83017 & 1.03570 & 1.70554 & 0.96720 & $-0.09327 \mathrm{~ns}$ \\
\hline \multicolumn{6}{|l|}{ SITUAÇÃO } \\
\hline Região Urbana & $-0.09248 \mathrm{~ns}$ & $-0.25275 \mathrm{~ns}$ & $-0.18784 \mathrm{~ns}$ & $0.20880 \mathrm{~ns}$ & 0.29974 \\
\hline \multicolumn{6}{|l|}{ POSIÇÃO NA OCUPAÇÃO } \\
\hline Autônomos e empregadores & 0.23580 & 0.81777 & $-0.17996 \mathrm{~ns}$ & $0.16697 \mathrm{~ns}$ & 0.44435 \\
\hline \multicolumn{6}{|c|}{ POSSE DE CARTEIRA ASSINADA } \\
\hline Com Carteira Assinada & 0.75793 & 0.56316 & $0.17584 \mathrm{~ns}$ & 0.47921 & 0.61947 \\
\hline
\end{tabular}

((1) Inclui apenas as observaçỏes para as quais os atributos de interesse estảo claramente identificados.

(2) Todos os coeficientes são estatisticamente significativos ao nível de $5 \%$, com exceção dos assinalados por asterisco (que são significativos ao nível de 10\%) e por ns (que são não-significativos). 
Tabela G24. Números-indices obtidos dos coeficientes das equações de rendimento ajustadas para a PEA ocupada(1), por sexo e classe ocupacional. Pernambuco, 1988. (2)

\begin{tabular}{|c|c|c|c|c|c|}
\hline \multirow[t]{2}{*}{ SEXO/FATOR } & \multicolumn{5}{|c|}{ CLASSES } \\
\hline & 1 & 2 & 3 & 4 & 5 \\
\hline \multicolumn{6}{|l|}{ HOMENS } \\
\hline INTERCEPTO & 884.916 & 924.860 & 917.966 & 1073.989 & 904.388 \\
\hline \multicolumn{6}{|l|}{ ESCOLARIDADE } \\
\hline Primário Incompleto & $1.357 \mathrm{~ns}$ & $1.073 \mathrm{~ns}$ & 2.086 & $1.227 \mathrm{~ns}$ & 1.391 \\
\hline Primário Completo & $1.652 \mathrm{~ns}$ & $0.865 \mathrm{~ns}$ & 2.423 & 1.376 & 1.601 \\
\hline Ginásio Incompleto & $1.683 \mathrm{~ns}$ & $1.481 \mathrm{~ns}$ & 2.611 & 2.043 & 1.929 \\
\hline Ginásio Completo & $1.059 \mathrm{~ns}$ & $2.292 *$ & 3.203 & 2.459 & 2.199 \\
\hline Colegial e Superior & 2.787 & 3.018 & 6.592 & 4.259 & 4.725 \\
\hline IDADE & & . & & & \\
\hline 18 a 19 anos & $0.981 \mathrm{~ns}$ & $0.677 \mathrm{~ns}$ & $0.766 \mathrm{~ns}$ & $1.046 \mathrm{~ns}$ & 1.227 \\
\hline 20 a 24 anos & $2.000^{*}$ & $2.043 \mathrm{~ns}$ & $1.199 \mathrm{~ns}$ & $1.282 \mathrm{~ns}$ & 1.643 \\
\hline 25 a 29 anos & 2.445 & $2.312 \mathrm{~ns}$ & 2.325 & 1.729 & 1.935 \\
\hline 30 a 39 anos & 2.684 & 5.023 & 3.228 & 2.507 & 2.253 \\
\hline 40 a 49 anos & 3.244 & 7.716 & 3.365 & 3.258 & 2.587 \\
\hline 50 anos ou mais & 2.787 & 4.854 & 4.097 & 2.084 & 2.221 \\
\hline \multicolumn{6}{|l|}{ SITUAÇĀO } \\
\hline Região Urbana & $1.259 \mathrm{~ns}$ & $0.744 \mathrm{~ns}$ & $0.863 \mathrm{~ns}$ & $0.895 \mathrm{~ns}$ & 1.175 \\
\hline \multicolumn{6}{|l|}{ POSIÇÃO NA OCUPAÇÃO } \\
\hline Autônomos e empregadores & $0.801 \mathrm{~ns}$ & 3.400 & $1.222 \mathrm{~ns}$ & 1.710 & $\cdot 1.329$ \\
\hline \multicolumn{6}{|c|}{ POSSE DE CARTEIRA ASSINADA } \\
\hline Com Carteira Assinada & $1.244 \mathrm{~ns}$ & 2.010 & 1.415 & 1.825 & 1.597 \\
\hline \multicolumn{6}{|l|}{ MULHERES } \\
\hline INTERCEPTO & 469.954 & 1068.848 & 415.878 & 671.403 & 1254.910 \\
\hline \multicolumn{6}{|l|}{ ESCOLARIDADE } \\
\hline Primário Incompleto & 1.379 & $0.924 \mathrm{~ns}$ & 2.014 & $1.118 \mathrm{~ns}$ & $1.092 \mathrm{~ns}$ \\
\hline Primário Completo & 1.677 & $1.213 \mathrm{~ns}$ & 4.207 & 1.620 & $1.613^{*}$ \\
\hline Ginásio Incompleto & 1.846 & $1.301 \mathrm{~ns}$ & 3.492 & 1.884 & $1.570 \mathrm{~ns}$ \\
\hline Ginásio Completo & 1.897 & $1.310 \mathrm{~ns}$ & 4.241 & 2.328 & $1.166 \mathrm{~ns}$ \\
\hline Colegial e Superior & 4.649 & 3.879 & 7.556 & 3.289 & 6.933 \\
\hline \multicolumn{6}{|l|}{ IDADE } \\
\hline 18 a 19 anos & $1.198 \mathrm{~ns}$ & $1.287 \mathrm{~ns}$ & $1.371 \mathrm{~ns}$ & $1.068 \mathrm{~ns}$ & $0.991 \mathrm{~ns}$ \\
\hline 20 a 24 anos & 1.568 & $1.463 \mathrm{~ns}$ & $1.937 \mathrm{~ns}$ & $1.066 \mathrm{~ns}$ & $1.009 \mathrm{~ns}$ \\
\hline 25 a 29 anos & 1.772 & 2.082 & 3.494 & $1.742 \mathrm{~ns}$ & $1.061 \mathrm{~ns}$ \\
\hline 30 a 39 anos & 2.484 & 1.974 & 4.422 & 2.339 & $0.996 \mathrm{~ns}$ \\
\hline 40 a 49 anos & 2.826 & 2.494 & 4.634 & 3.428 & $0.974 \mathrm{~ns}$ \\
\hline 50 anos ou mais & 2.294 & 2.817 & 5.504 & 2.631 & $0.911 \mathrm{~ns}$ \\
\hline \multicolumn{6}{|l|}{ SITUAÇÃo } \\
\hline Regiảo Urbana & $0.912 \mathrm{~ns}$ & $0.777 \mathrm{~ns}$ & $0.829 \mathrm{~ns}$ & $1.232 \mathrm{~ns}$ & 1.350 \\
\hline \multicolumn{6}{|l|}{ POSIÇÃO NA OCUPAÇÃO } \\
\hline Autônomos e entpregadores & 1.266 & 2.265 & $0.835 \mathrm{~ns}$ & $1.182 \mathrm{~ns}$ & 1.559 \\
\hline \multicolumn{6}{|c|}{ POSSE DE CARTEIRA ASSINADA } \\
\hline Com Carteira Assinada & 2.134 & 1.756 & $1.192 \mathrm{~ns}$ & 1.615 & 1.858 \\
\hline
\end{tabular}

(1) Inclui apenas as observaçōes para as quais os atributos de interesse estão claramente identificados.

(2) Todos os coeficientes são estatisticamente significativos ao nível de $5 \%$, com exceção dos assinalados por asterisco (que são significativos ao nível de $10 \%$ ) e por ns (que são não-significativos). 
Tabela G25. Estimativas dos coeficientes das equações de rendimento ajustadas para a PEA ocupada(1), por sexo e classe ocupacional. Pernambuco, 1989. (2)

\begin{tabular}{|c|c|c|c|c|c|}
\hline \multirow[t]{2}{*}{ SEXO/FATOR } & \multicolumn{5}{|c|}{ CLASSES } \\
\hline & 1 & 2 & 3 & 4 & 5 \\
\hline \multicolumn{6}{|l|}{ HOMENS } \\
\hline INTERCEPTO & 7.046727 & 6.827232 & 6.808162 & 6.942015 & 7.119232 \\
\hline \multicolumn{6}{|l|}{ ESCOLARIDADE } \\
\hline Primário Incompleto & 0.46004 ns & $0.48754 \mathrm{~ns}$ & $0.04670 \mathrm{~ns}$ & $0.16879 \mathrm{~ns}$ & 0.21064 \\
\hline Primáno Completo & $0.93558 *$ & $0.59129 \mathrm{~ns}$ & $-0.07885 \mathrm{~ns}$ & 0.39142 & 0.43253 \\
\hline Ginásio Incompleto & $0.72349 \mathrm{~ns}$ & 0.83577 & 0.51148 & 0.41186 & 0.56026 \\
\hline Ginásio Completo & 1.20911 & $0.81377 *$ & 0.79327 & 0.58251 & 0.92587 \\
\hline Colegial e Superior & 1.76255 & 1.63824 & 1.34723 & 1.33580 & 1.53779 \\
\hline \multicolumn{6}{|l|}{ IDADE } \\
\hline 18 a 19 anos & $-0.88131 \mathrm{~ns}$ & $0.15102 \mathrm{~ns}$ & $0.09153 \mathrm{~ns}$ & $0.18982 \mathrm{~ns}$ & 0.23494 \\
\hline 20 a 24 anos & $-0.26648 \mathrm{~ns}$ & $-0.01410 \mathrm{~ns}$ & $0.21585 \mathrm{~ns}$ & 0.50605 & 0.30531 \\
\hline 25 a 29 anos & $0.14408 \mathrm{~ns}$ & $0.17473 \mathrm{~ns}$ & 0.56934 & 0.80446 & 0.56119 \\
\hline 30 a 39 anos & $0.65690 \mathrm{~ns}$ & $0.56004 \mathrm{~ns}$ & 0.99257 & 1.05032 & 0.71257 \\
\hline 40 a 49 anos & $1.01354 \mathrm{~ns}$ & 1.23044 & 1.18483 & 1.44249 & 0.81506 \\
\hline 50 anos ou mais & $0.35609 \mathrm{~ns}$ & 1.42334 & 1.14663 & 1.04212 & 0.70391 \\
\hline \multicolumn{6}{|l|}{ SITUAÇĀO } \\
\hline $\begin{array}{l}\text { Região Urbana } \\
\text { POSIÇÃO NA OCUPAÇÃO }\end{array}$ & $-0.26288 \mathrm{~ns}$ & $0.08437 \mathrm{~ns}$ & 0.40980 & $0.15230 \mathrm{~ns}$ & 0.20361 \\
\hline \multicolumn{5}{|c|}{ POSSE DE CARTEIRA ASSINADA } & 0.37609 \\
\hline Com Carteira Assinada & $0.39166 \mathrm{~ns}$ & $0.34432 \mathrm{~ns}$ & $0.22443 \mathrm{~ns}$ & 0.29676 & 0.32360 \\
\hline \multicolumn{6}{|l|}{ MULHERES } \\
\hline INTERCEPTO & 6.472411 & 6.776410 & 7.473114 & 5.881240 & 7.432385 \\
\hline \multicolumn{6}{|l|}{ ESCOLARIDADE } \\
\hline Primário Incompleto & 0.27328 & $-0.08753 \mathrm{~ns}$ & $-0.03385 \mathrm{~ns}$ & 0.45942 & $0.04857 \mathrm{~ns}$ \\
\hline Primário Completo & 0.22126 & $0.32187 \mathrm{~ns}$ & $0.21364 \mathrm{~ns}$ & 1.08308 & $0.07134 \mathrm{~ns}$ \\
\hline Ginásio Incompleto & 0.46197 & 0.63323 & $0.14120 \mathrm{~ns}$ & 0.94166 & $0.30539 \mathrm{~ns}$ \\
\hline Ginásio Completo & 0.72471 & 0.87585 & $0.49335 \mathrm{~ns}$ & 1.00221 & 0.70902 \\
\hline Colegial e Superior & 1.30765 & 1.50005 & 1.10717 & 1.65601 & 1.43293 \\
\hline \multicolumn{6}{|l|}{ IDADE } \\
\hline 18 a 19 anos & 0.62998 & $0.44635 \mathrm{~ns}$ & $-0.27639 \mathrm{~ns}$ & $0.23459 \mathrm{~ns}$ & $-0.15640 \mathrm{~ns}$ \\
\hline 20 a 24 anos & 0.61956 & $-0.03279 \mathrm{~ns}$ & $-0.08206 \mathrm{~ns}$ & 0.70491 & $-0.14277 \mathrm{~ns}$ \\
\hline 25 a 29 anos & 0.82045 & $0.06309 \mathrm{~ns}$ & $0.14267 \mathrm{~ns}$ & 0.90719 & $0.17324 \mathrm{~ns}$ \\
\hline 30 a 39 anos & 0.87400 & $0.35423 \mathrm{~ns}$ & 0.72698 & 1.16257 & $0.22749 \mathrm{~ns}$ \\
\hline 40 a 49 anos & 1.07280 & $0.73850 *$ & 0.64722 & 1.42984 & $0.07168 \mathrm{~ns}$ \\
\hline 50 anos ou mais & 0.93595 & $0.61094 \mathrm{~ns}$ & 1.08681 & 1.13635 & $0.24747 \mathrm{~ns}$ \\
\hline \multicolumn{6}{|l|}{ SITUAÇĀO } \\
\hline \multicolumn{5}{|l|}{ POSIÇÃO NA OCUPAÇÃO } & $0.14177 \mathrm{~ns}$ \\
\hline $\begin{array}{l}\text { Autônomos e empregadores } \\
\text { POSSE DE CARTEIRA ASSI }\end{array}$ & 0.35029 & 1.58717 & $0.09024 \mathrm{~ns}$ & 0.66888 & $0.21756 \mathrm{~ns}$ \\
\hline Com Carteira Assinada & 0.43542 & 0.39885 & 0.32887 & 0.51859 & 0.39264 \\
\hline
\end{tabular}

(1) Inclui apenas as observaçōes para as quais os atributos de interesse estão claramente identificados.

(2) Todos os coeficientes são estatisticamente significativos ao nível de $5 \%$, com exceção dos assinalados por asterisco (que são significativos ao nível de 10\%) e por ns (que são não-significativos). 
Tabela G26. Números-indices obtidos dos coeficientes das equações de rendimento ajustadas para a PEA ocupada (1), por sexo e classe ocupacional. Pernambuco, 1989. (2)

\begin{tabular}{|c|c|c|c|c|c|}
\hline \multirow[t]{2}{*}{ SEXO/FATOR } & \multicolumn{5}{|c|}{ CLASSES } \\
\hline & 1 & 2 & 3 & 4 & 5 \\
\hline \multicolumn{6}{|l|}{ HOMENS } \\
\hline INTERCEPTO & 1149.092 & 922.633 & 905.206 & 1034.853 & 1235.501 \\
\hline \multicolumn{6}{|l|}{ ESCOLARIDADE } \\
\hline Primáno Incompleto & $1.584 \mathrm{~ns}$ & $1.628 \mathrm{~ns}$ & $1.048 \mathrm{~ns}$ & $1.184 \mathrm{~ns}$ & 1.234 \\
\hline Primário Completo & $2.549^{*}$ & $1.806 \mathrm{~ns}$ & $0.924 \mathrm{~ns}$ & 1.479 & 1.541 \\
\hline Ginásio Incompleto & $2.062 \mathrm{~ns}$ & 2.307 & 1.668 & 1.510 & 1.751 \\
\hline Ginásio Completo & 3.351 & $2.256^{*}$ & 2.211 & 1.791 & 2.524 \\
\hline Colegial e Superior & 5.827 & 5.146 & 3.847 & 3.803 & 4.654 \\
\hline \multicolumn{6}{|l|}{ IDADE } \\
\hline 18 a 19 anos & $0.414 \mathrm{~ns}$ & $1.163 \mathrm{~ns}$ & $1.096 \mathrm{~ns}$ & $1.209 \mathrm{~ns}$ & 1.265 \\
\hline 20 a 24 anos & $0.766 \mathrm{~ns}$ & $0.986 \mathrm{~ns}$ & $1.241 \mathrm{~ns}$ & 1.659 & 1.357 \\
\hline 25 a 29 anos & $1.155 \mathrm{~ns}$ & $1.191 \mathrm{~ns}$ & 1.767 & 2.235 & 1.753 \\
\hline 30 a 39 anos & $1.929 \mathrm{~ns}$ & $1.751 \mathrm{~ns}$ & 2.698 & 2.859 & 2.039 \\
\hline 40 a 49 anos & $2.755 \mathrm{~ns}$ & 3.423 & 3.270 & 4.231 & 2.259 \\
\hline 50 anos ou mais & $1.428 \mathrm{~ns}$ & 4.151 & 3.148 & 2.835 & 2.022 \\
\hline \multicolumn{6}{|l|}{ SITUAÇÃO } \\
\hline Região Urbana & $0.769 \mathrm{~ns}$ & $1.088 \mathrm{~ns}$ & 1.507 & $1.165 \mathrm{~ns}$ & 1.226 \\
\hline \multicolumn{6}{|l|}{ POSIÇÃO NA OCUPAÇÃO } \\
\hline Autônomos e empregadores & 2.523 & $3.150 \mathrm{~ns}$ & 1.679 & 1.977 & 1.457 \\
\hline \multicolumn{6}{|c|}{ POSSE DE CARTEIRA ASSINADA } \\
\hline Com Carteira Assinada & $1.479 \mathrm{~ns}$ & $1.411 \mathrm{~ns}$ & $1.252 \mathrm{~ns}$ & 1.345 & 1.382 \\
\hline \multicolumn{6}{|l|}{ MULHERES } \\
\hline INTERCEPTO & 647.042 & 876.915 & 1760.079 & 358.253 & 1689.833 \\
\hline \multicolumn{6}{|l|}{ ESCOLARIDADE } \\
\hline Prinnário Incompleto & 1.314 & $0.916 \mathrm{~ns}$ & $0.967 \mathrm{~ns}$ & 1.583 & $1.050 \mathrm{~ns}$ \\
\hline Primário Completo & 1.248 & $1.380 \mathrm{~ns}$ & $1.238 \mathrm{~ns}$ & 2.954 & $1.074 \mathrm{~ns}$ \\
\hline Ginásio Incompleto & 1.587 & 1.884 & $1.152 \mathrm{~ns}$ & 2.564 & $1.357 \mathrm{~ns}$ \\
\hline Ginásio Completo & 2.064 & 2.401 & $1.638 \mathrm{~ns}$ & 2.724 & 2.032 \\
\hline Colegial e Superior & 3.697 & 4.482 & 3.026 & 5.238 & 4.191 \\
\hline \multicolumn{6}{|l|}{ IDADE } \\
\hline 18 a 19 anos & 1.878 & $1.563 \mathrm{~ns}$ & $0.759 \mathrm{~ns}$ & $1.264 \mathrm{~ns}$ & $0.855 \mathrm{~ns}$ \\
\hline 20 a 24 anos & 1.858 & $0.968 \mathrm{~ns}$ & $0.921 \mathrm{~ns}$ & 2.024 & $0.867 \mathrm{~ns}$ \\
\hline 25 a 29 anos & 2.272 & $1.065 \mathrm{~ns}$ & $1.153 \mathrm{~ns}$ & 2.477 & $1.189 \mathrm{~ns}$ \\
\hline 30 a 39 anos & 2.396 & $1.425 \mathrm{~ns}$ & 2.069 & 3.198 & $1.255 \mathrm{~ns}$ \\
\hline 40 a 49 anos & 2.924 & $2.093 *$ & 1.910 & 4.178 & $1.074 \mathrm{~ns}$ \\
\hline 50 anos ou mais & 2.550 & $1.842 \mathrm{~ns}$ & 2.965 & 3.115 & $1.281 \mathrm{~ns}$ \\
\hline \multicolumn{6}{|l|}{ SITUAÇÃO } \\
\hline Região Urbana & $0.92 \operatorname{lns}$ & $1.195 \mathrm{~ns}$ & $1.029 \mathrm{~ns}$ & $1.077 \mathrm{~ns}$ & $1.152 \mathrm{~ns}$ \\
\hline \multicolumn{6}{|l|}{ POSIÇÃO NA OCUPAÇÃO } \\
\hline Autônomos e empregadores & 1.419 & 4.890 & $1.094 \mathrm{~ns}$ & 1.952 & $1.243 \mathrm{~ns}$ \\
\hline \multicolumn{6}{|c|}{ POSSE DE CARTEIRA ASSINADA } \\
\hline Com Carteira Assinada & 1.546 & 1.490 & 1.389 & 1.680 & 1.481 \\
\hline
\end{tabular}

(1) Inclui apenas as observaçőes para as quais os atributos de interesse estão claramente identificados.

(2) Todos os coeficientes são estatisticamente significativos ao nivel de $5 \%$, com exceção dos assinalados por asterisco (que são significativos ao nivel de $10 \%$ ) e por ns (que são não-significativos). 
Tabela G27. Estimativas dos coeficientes das equações de rendimento ajustadas para a PEA ocupada(1), por sexo e classe ocupacional. Pernambuco, 1990.(2)

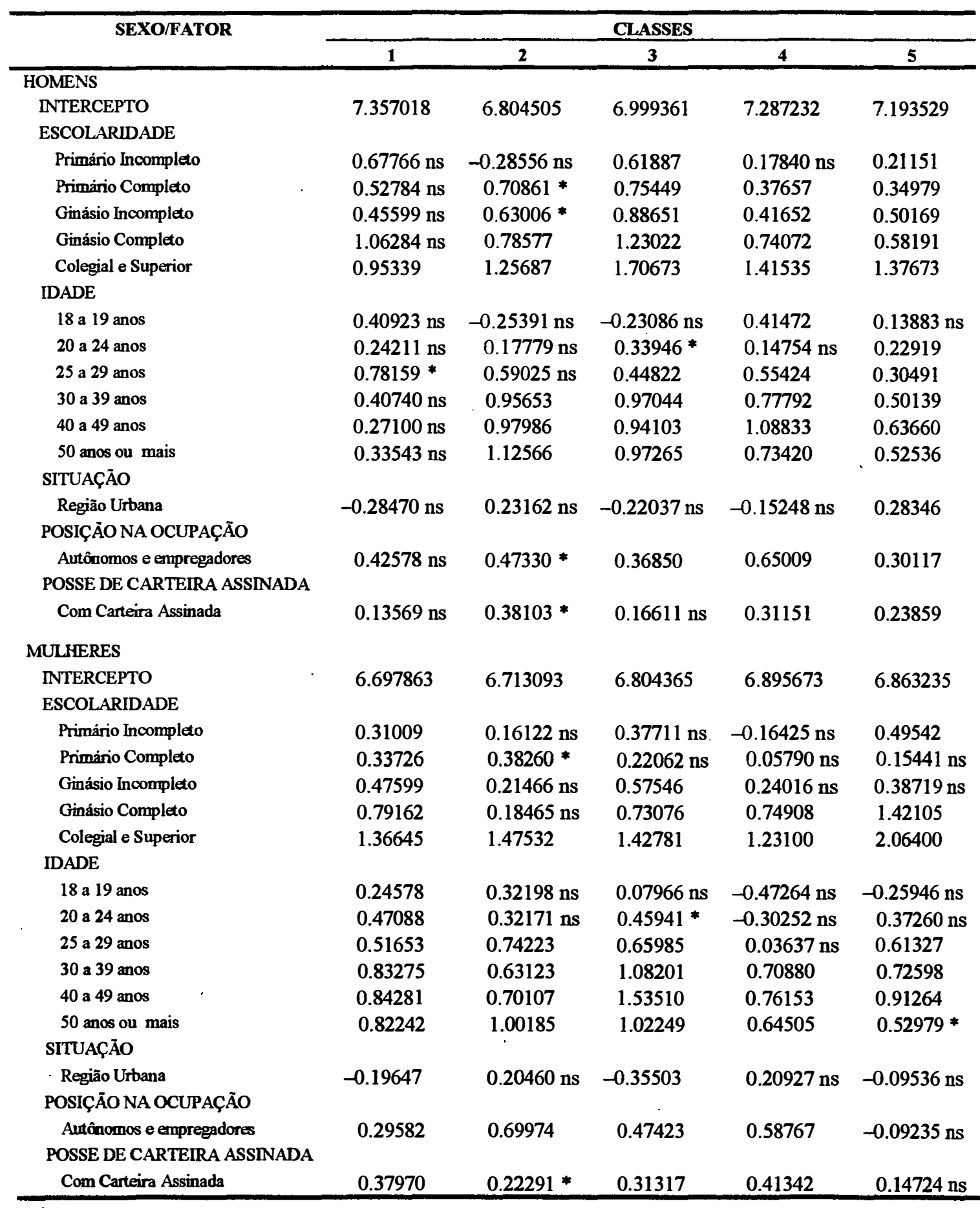

(1) Inclui apenas as observações para as quais os atributos de interesse estão claramente identificados.

(2) Todos os coeficientes são estatisticamente significativos ao nível de 5\%, com exceção dos assinalados por asterisco (que são significativos ao nível de 10\%) e por ns (que são não-significativos). 


\begin{abstract}
Tabela G28. Números-índices obtidos dos coeficientes das equações de rendimento ajustadas para a PEA ocupada (1), por sexo e classe ocupacional. Pernambuco, 1990.(2)
\end{abstract}

\begin{tabular}{|c|c|c|c|c|c|}
\hline \multirow[t]{2}{*}{ SEXO/FATOR } & \multicolumn{5}{|c|}{ CLASSES } \\
\hline & 1 & 2 & 3 & 4 & 5 \\
\hline \multicolumn{6}{|l|}{ HOMENS } \\
\hline INTERCEPTO & 1567.156 & 901.901 & 1095.933 & 1461.520 & 1330.791 \\
\hline \multicolumn{6}{|l|}{ ESCOLARIDADE } \\
\hline Primário Incompleto & $1.969 \mathrm{~ns}$ & $0.752 \mathrm{~ns}$ & 1.857 & $1.195 \mathrm{~ns}$ & 1.236 \\
\hline Primário Conmpleto & $1.695 \mathrm{~ns}$ & $2.031 *$ & 2.127 & 1.457 & 1.419 \\
\hline Ginásio Incompleto & $1.578 \mathrm{~ns}$ & $1.878 *$ & 2.427 & 1.517 & 1.652 \\
\hline Ginásio Completo & $2.895 \mathrm{~ns}$ & 2.194 & 3.422 & 2.097 & 1.789 \\
\hline Colegial e Superior & 2.594 & 3.514 & 5.511 & 4.118 & 3.962 \\
\hline \multicolumn{6}{|l|}{ IDADE } \\
\hline 18 a 19 anos & $1.506 \mathrm{~ns}$ & $0.776 \mathrm{~ns}$ & $0.794 \mathrm{~ns}$ & 1.514 & $1.149 \mathrm{~ns}$ \\
\hline 20 a 24 anos & $1.274 \mathrm{~ns}$ & $1.195 \mathrm{~ns}$ & $1.404^{*}$ & $1.159 \mathrm{~ns}$ & 1.258 \\
\hline 25 a 29 anos & $2.185^{*}$ & $1.804 \mathrm{~ns}$ & 1.566 & 1.741 & 1.356 \\
\hline 30 a 39 anos & $1.503 \mathrm{~ns}$ & 2.603 & 2.639 & 2.177 & 1.651 \\
\hline 40 a 49 anos & $1.311 \mathrm{~ns}$ & 2.664 & 2.563 & 2.969 & 1.890 \\
\hline 50 anos ou mais & $1.399 \mathrm{~ns}$ & 3.082 & 2.645 & 2.084 & 1.691 \\
\hline \multicolumn{6}{|l|}{ SITUAÇÃO } \\
\hline Região Urbana & $0.752 \mathrm{~ns}$ & $1.261 \mathrm{~ns}$ & $0.802 \mathrm{~ns}$ & $0.859 \mathrm{~ns}$ & 1.328 \\
\hline \multicolumn{6}{|l|}{ POSIÇÃO NA OCUPAÇÃO } \\
\hline Autônomos e empregadores & $1.531 \mathrm{~ns}$ & $1.605^{*}$ & 1.446 & 1.916 & 1.351 \\
\hline \multicolumn{6}{|c|}{ POSSE DE CARTEIRA ASSINADA } \\
\hline Com Carteira Assinada & $1.145 \mathrm{~ns}$ & $1.464^{*}$ & $1.181 \mathrm{~ns}$ & 1.365 & 1.269 \\
\hline \multicolumn{6}{|l|}{ MULHERES } \\
\hline INTERCEPTO & 810.672 & 923.113 & 901.775 & 987.990 & 956.456 \\
\hline \multicolumn{6}{|l|}{ ESCOLARIDADE } \\
\hline Primánio Incompleto & 1.364 & $1.175 \mathrm{~ns}$ & $1.458 \mathrm{~ns}$ & $0.849 \mathrm{~ns}$ & 1.641 \\
\hline Primário Completo & 1.401 & $1.466^{*}$ & $1.247 \mathrm{~ns}$ & $1.060 \mathrm{~ns}$ & $1.167 \mathrm{~ns}$ \\
\hline Ginásio Incompleto & 1.610 & $1.239 \mathrm{~ns}$ & 1.778 & $1.271 \mathrm{~ns}$ & $1.473 \mathrm{~ns}$ \\
\hline Ginásio Completo & 2.207 & $1.203 \mathrm{~ns}$ & 2.077 & 2.115 & 4.141 \\
\hline Colegial e Superior & 3.921 & 4.372 & 4.170 & 3.425 & 7.877 \\
\hline \multicolumn{6}{|l|}{ IDADE } \\
\hline 18 a 19 anos & 1.279 & $1.380 \mathrm{~ns}$ & $1.083 \mathrm{~ns}$ & $0.623 \mathrm{~ns}$ & $0.771 \mathrm{~ns}$ \\
\hline 20 a 24 anos & 1.601 & $1.379 \mathrm{~ns}$ & $1.583 *$ & $0.739 \mathrm{~ns}$ & $1.452 \mathrm{~ns}$ \\
\hline 25 a 29 anos & 1.676 & 2.101 & 1.934 & $1.037 \mathrm{~ns}$ & 1.846 \\
\hline 30 a 39 anos & 2.300 & 1.880 & 2.951 & 2.032 & 2.067 \\
\hline 40 a 49 anos & 2.323 & 2.016 & 4.642 & 2.142 & 2.491 \\
\hline 50 anos ou mais & 2.276 & 2.723 & 2.780 & 1.906 & $1.699 *$ \\
\hline SITUAÇĀO & & & & & \\
\hline Região Urbana & 0.822 & $1.227 \mathrm{~ns}$ & 0.701 & $1.233 \mathrm{~ns}$ & $0.909 \mathrm{~ns}$ \\
\hline \multicolumn{6}{|l|}{ POSIÇÃO NA OCUPAÇÃO } \\
\hline Autônomos e empregadores & 1.344 & 2.013 & 1.607 & 1.800 & $0.912 \mathrm{~ns}$ \\
\hline \multicolumn{6}{|c|}{ POSSE DE CARTEIRA ASSINADA } \\
\hline Com Carteira Assinada & 1.462 & $1.250^{*}$ & 1.368 & 1.512 & $1.159 \mathrm{~ns}$ \\
\hline
\end{tabular}

(1) Inclui apenas as observações para as quais os atributos de interesse estão claramente identificados.

(2) Todos os coeficientes são estatisticamente significativos ao nível de $5 \%$, com exceção dos assinalados por asterisco (que são significativos ao nível de 10\%) e por ns (que são não-significativos). 


\section{APÊNDICE H}

Tabela Hl. Distribuição percentual de homens e mulheres da PEA ocupada, por variável e classe ocupacional. São Paulo, 1981.

Tabela H2. Distribuição percentual de homens e mulheres da PEA ocupada, por variável e classe ocupacional. São Paulo, 1983.

Tabela H3. Distribuição percentual de homens e mulheres da PEA ocupada, por variável e classe ocupacional. São Paulo, 1984..

Tabela H4. Distribuição percentual de homens e mulheres da PEA ocupada, por variável e classe ocupacional. São Paulo, 1985.

Tabela 5. Distribuição percentual de homens e mulheres da PEA ocupada, por variável e classe ocupacional. São Paulo, 1987.

Tabela H6. Distribuição percentual de homens e mulheres da PEA ocupada, por variável e classe ocupacional. São Paulo, 1988.

Tabela H7. Distribuição percentual de homens e mulheres da PEA ocupada, por variável e classe ocupacional. São Paulo, 1989.

Tabela H8. Distribuição percentual de homens e mulheres da PEA ocupada, por variável e classe ocupacional. São Paulo, 1990.

Tabela H9. Distribuição percentual de homens e mulheres da PEA ocupada, por variável e classe ocupacional. Pernambuco, 1981.

Tabela H10. Distribuição percentual de homens e mulheres da PEA ocupada, por variável e classe ocupacional. Pernambuco, 1983.

Tabela H11. Distribuição percentual de homens e mulheres da PEA ocupada, por variável e classe ocupacional. Pernambuco, 1984.

Tabela H12. Distribuição percentual de homens e mulheres da PEA ocupada, por variável e classe ocupacional. Pernambuco, 1985.

Tabela H13. Distribuição percentual de homens e mulheres da PEA ocupada, por variável e classe ocupacional. Pernambuco, 1987.

Tabela H14. Distribuição percentual de homens e mulheres da PEA ocupada, por variável e classe ocupacional. Pernambuco, 1988.

Tabela H15. Distribuição percentual de homens e mulheres da PEA ocupada, por variável e classe ocupacional. Pernambuco, 1989.

Tabela H16. Distribuição percentual de homens e mulheres da PEA ocupada, por variável e classe ocupacional. Pernambuco, 1990. 
Tabela H1. Distribuição percentual de homens e mulheres da PGA ocupada, por variável e classe ocupacional. são Paulo, 1981. (1)

\begin{tabular}{|c|c|c|c|c|c|}
\hline \multirow[t]{2}{*}{ SEXO/FATOR } & \multicolumn{5}{|c|}{ CLASSES } \\
\hline & 1 & 2 & 3 & 4 & 5 \\
\hline \multicolumn{6}{|l|}{ HOMENS } \\
\hline \multicolumn{6}{|l|}{ ESCOLARIDADE } \\
\hline Primário Incompleto & 16.95 & 19.79 & 10.27 & 24.56 & 21.39 \\
\hline Primánio Completo & 26.14 & 26.38 & 20.28 & 24.97 & 29.71 \\
\hline Ginásio Incompleto & 12.82 & 14.81 & 17.67 & 11.81 & 11.84 \\
\hline Ginásio Completo & 7.20 & 10.44 & 11.36 & 6.04 & 8.69 \\
\hline Colegial e Superior & 24.12 & 24.72 & 37.46 & 16.89 & 19.79 \\
\hline IDADE & & & & & . \\
\hline 18 a 19 anos & 4.13 & 6.57 & 10.20 & 6.66 & 3.64 \\
\hline 20 a 24 anos & 9.20 & 18.06 & 25.13 & 14.36 & 13.27 \\
\hline 25 a 29 anos & 10.80 & 17.06 & 16.58 & 13.05 & 16.89 \\
\hline 30 a 39 anos & 23.06 & 28.60 & 15.86 & 20.25 & 27.75 \\
\hline 40 a 49 anos & 20.51 & 17.066 & 10.95 & 15.42 & 18.97 \\
\hline 50 anos ou mais & 25.61 & 8.79 & 8.41 & 14.47 & 14.75 \\
\hline SITUAÇÃO & & & & & \\
\hline Região Urbana & 87.75 & 98.35 & 97.45 & 79.57 & 92.35 \\
\hline \multicolumn{6}{|l|}{ POSIÇÃO NA OCUPAÇÃO } \\
\hline Autônomos e empregadores & 14.36 & 0.55 & 10.07 & 16.45 & 30.09 \\
\hline \multicolumn{6}{|l|}{ POSSE DE CARTEIRA ASSINADA } \\
\hline Com Carteira Assinada & 45.15 & 78.59 & 75.51 & 43.14 & 58.21 \\
\hline \multicolumn{6}{|l|}{ MULHERES } \\
\hline \multicolumn{6}{|l|}{ ESCOLARIDADE } \\
\hline Primário Incompleto & 19.80 & 10.53 & 8.93 & 19.02 & 10.15 \\
\hline Primário Completo & 24.50 & 28.16 & 17.10 & 21.49 & 23.46 \\
\hline Ginásio Incompleto & 13.06 & 13.99 & 11.42 & 13.33 & 13.52 \\
\hline Ginásio Completo & 6.26 & 10.72 & 11.49 & 9.40 & 10.54 \\
\hline Colegial e Superior & 24.08 & 31.81 & 48.19 & 23.30 & 38.16 \\
\hline \multicolumn{6}{|l|}{ DADE } \\
\hline 18 a 19 anos & 6.71 & 6.71 & 10.75 & 9.41 & 5.17 \\
\hline 20 a 24 anos & 15.09 & 19.35 & 29.19 & 19.38 & 20.67 \\
\hline 25 a 29 anos & 14.68 & 14.75 & 18.23 & 14.68 & 18.69 \\
\hline 30 a 39 anos & 23.35 & 26.43 & 17.54 & 18.52 & 27.03 \\
\hline 40 a 49 anos & 15.10 & 17.04 & 7.87 & 11.04 & 13.52 \\
\hline 50 anos ou mais & 10.30 & 8.81 & 4.99 & 6.34 & 9.75 \\
\hline \multicolumn{6}{|l|}{ SITUAÇÃO } \\
\hline Região Urbana & 95.74 & 97.89 & 97.28 & 85.10 & 95.62 \\
\hline \multicolumn{6}{|l|}{ POSIÇÃO NA OCUPAÇÃO } \\
\hline Autônomos e empregadores & 24.15 & 0.96 & 9.45 & 13.04 & 25.86 \\
\hline \multicolumn{6}{|c|}{ POSSE DE CARTEIRA ASSINADA } \\
\hline Com Carteira Assinada & 33.66 & 75.48 & 75.80 & 46.71 & 65.39 \\
\hline
\end{tabular}

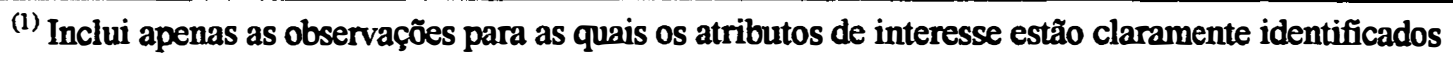


Tabela H2. Distribuição percentual de homens e mulheres da PEA ocupada, por variável e classe ocupacional. São Paulo, 1983. (1)

\begin{tabular}{|c|c|c|c|c|c|}
\hline \multirow[t]{2}{*}{ SEXO/FATOR } & \multicolumn{5}{|c|}{ CLASSES } \\
\hline & 1 & 2 & 3 & 4 & 5 \\
\hline \multicolumn{6}{|l|}{ HOMENS } \\
\hline \multicolumn{6}{|l|}{ ESCOLARIDADE } \\
\hline Primário Incompleto & 18.28 & 17.61 & 8.19 & 21.70 & 20.25 \\
\hline Primário Completo & 23.60 & 18.92 & 16.22 & 23.00 & 31.20 \\
\hline Ginásio Incompleto & 12.76 & 12.82 & 16.44 & 10.76 & 12.30 \\
\hline Ginásio Completo & 8.06 & 6.63 & 13.29 & 7.57 & 8.63 \\
\hline Colegial e Superior & 23.45 & 37.36 & 44.30 & 23.89 & 19.24 \\
\hline \multicolumn{6}{|l|}{ IDADE } \\
\hline 18 a 19 anos & 5.57 & 4.24 & 10.68 & 6.07 & 3.1969 \\
\hline 20 a 24 anos & 11.48 & 20.30 & 27.33 & 15.54 & 12.74 \\
\hline 25 a 29 anos & 10.79 & 19.48 & 17.01 & $15: 57$ & 16.02 \\
\hline 30 a 39 anos & 22.46 & 22.36 & 17.80 & 22.23 & 30.08 \\
\hline 40 a 49 anos & 19.13 & 17.53 & 8.22 & 13.85 & 18.75 \\
\hline 50 anos ou mais & 25.38 & 10.89 & 5.40 & 14.90 & 15.71 \\
\hline \multicolumn{6}{|l|}{ SITUAÇÃO } \\
\hline Região Urbana & 83.40 & 94.28 & 97.00 & 82.32 & 91.78 \\
\hline \multicolumn{6}{|l|}{ POSIÇÃO NA OCUPAÇÃO } \\
\hline Autônomos e empregadores & 16.84 & 4.71 & 7.56 & 15.21 & 32.85 \\
\hline \multicolumn{6}{|l|}{ POSSE DE CARTEIRA ASSINADA } \\
\hline Com Carteira Assinada & 42.56 & 66.56 & 76.39 & 46.65 & 53.84 \\
\hline \multicolumn{6}{|l|}{ MULHERES } \\
\hline \multicolumn{6}{|l|}{ ESCOLARIDADE } \\
\hline Primário Incompleto & 21.53 & 12.37 & 6.74 & 16.65 & 8.75 \\
\hline Primário Completo & 26.04 & 17.52 & 15.24 & 20.28 & 24.30 \\
\hline Ginásio Incompleto & 12.77 & 10.58 & 13.63 & 14.59 & 12.57 \\
\hline Ginásio Completo & 7.27 & 9.09 & 12.82 & 9.09 & 13.31 \\
\hline Colegial e Superior & 22.25 & 43.83 & 49.09 & 27.42 & 35.66 \\
\hline \multicolumn{6}{|l|}{ IDADE } \\
\hline 18 a 19 anos & 6.57 & 6.74 & 12.30 & 8.57 & 5.51 \\
\hline 20 a 24 anos & 14.76 & 16.69 & 28.76 & 19.65 & 17.04 \\
\hline 25 a 29 anos & 14.41 & 15.06 & 17.95 & 15.26 & 19.85 \\
\hline 30 a 39 anos & 25.40 & 29.18 & 17.83 & 22.04 & 28.15 \\
\hline 40 a 49 anos & 15.92 & 16.54 & 8.97 & 11.36 & 13.28 \\
\hline 50 anos ou mais & 9.65 & 10.20 & 4.74 & 8.20 & 11.95 \\
\hline \multicolumn{6}{|l|}{ STTUAÇÃO } \\
\hline Região Urbana & 94.87 & 95.70 & 96.84 & 86.72 & 93.83 \\
\hline \multicolumn{6}{|l|}{ POSIÇÃO NA OCUPAÇÃO } \\
\hline Autônomos e empregadores & 22.75 & 4.91 & 8.42 & 12.84 & 38.91 \\
\hline \multicolumn{6}{|l|}{ POSSE DE CARTEIRA ASSINADA } \\
\hline Com Carteira Assinada & 31.07 & 57.65 & 75.56 & 48.99 & 52.56 \\
\hline
\end{tabular}

(1) Inclui apenas as observaçőes para as quais os atributos de interesse estão claramente identificados. 
Tabela H3. Distribuição percentual de homens e mulheres da PEA ocupada, por variável e classe ocupacional. são Paulo, 1984. (1)

\begin{tabular}{|c|c|c|c|c|c|}
\hline \multirow[t]{2}{*}{ SEXO/FATOR } & \multicolumn{5}{|c|}{ CLASSES } \\
\hline & 1 & 2 & 3 & 4 & 5 \\
\hline \multicolumn{6}{|l|}{ HOMENS } \\
\hline \multicolumn{6}{|l|}{ ESCOI_ARIDADE } \\
\hline Primário Incompleto & 19.69 & 11.25 & 10.01 & 21.90 & 18.26 \\
\hline Primário Completo & 20.11 & 26.26 & 16.55 & 21.27 & 29.87 \\
\hline Ginásio Incompleto & 15.15 & 16.39 & 18.22 & 8.99 & 13.43 \\
\hline Ginásio Completo & 7.24 & 9.23 & 15.13 & 7.79 & 9.84 \\
\hline Colegial e Superior & 23.06 & 33.10 & 35.79 & 26.31 & 20.72 \\
\hline \multicolumn{6}{|l|}{ IDADE } \\
\hline 18 a 19 anos & 5.69 & 6.85 & 11.99 & 4.94 & 3.29 \\
\hline 20 a 24 anos & 12.49 & 16.39 & 28.79 & 14.24 & 12.38 \\
\hline 25 a 29 anos & 12.14 & 20.16 & 17.08 & 15.87 & 16.83 \\
\hline 30 a 39 anos & 18.91 & 31.04 & 16.10 & 23.01 & - 30.46 \\
\hline 40 a 49 anos & 18.54 & 12.63 & 8.11 & 17.58 & 18.75 \\
\hline 50 anos ou mais & 23.49 & 10.22 & 5.31 & 15.46 & 14.32 \\
\hline \multicolumn{6}{|l|}{ SITUAÇÃO } \\
\hline Região Urbana & 81.56 & 93.85 & 96.62 & 80.36 & 92.43 \\
\hline \multicolumn{6}{|l|}{ POSIÇÃO NA OCUPAÇÃO } \\
\hline Autônomos e empregadores & 10.65 & 10.26 & 8.72 & 18.64 & 30.37 \\
\hline \multicolumn{6}{|l|}{ POSSE DE CARTEIRA ASSINADA } \\
\hline Com Carteira Assinada & 46.65 & 66.15 & 72.71 & 44.72 & 55.87 \\
\hline \multicolumn{6}{|l|}{ MULHERES } \\
\hline \multicolumn{6}{|l|}{ ESCOLARIDADE } \\
\hline Primário Incompleto & 19.98 & 11.69 & 7.93 & 20.50 & 9.98 \\
\hline Primánio Completo & 23.59 & 23.30 & 16.20 & 21.24 & 20.93 \\
\hline Ginásio Incompleto & 13.65 & 10.49 & 16.83 & 8.98 & 12.66 \\
\hline Ginásio Completo & 7.85 & 11.33 & 13.21 & 5.51 & 9.38 \\
\hline Colegial e Superior & 22.92 & 40.31 & 43.12 & 33.04 & 42.38 \\
\hline \multicolumn{6}{|l|}{ IDADE } \\
\hline 18 a 19 anos & 7.51 & 2.21 & 11.51 & 4.79 & 5.98 \\
\hline 20 a 24 anos & 16.77 & 12.66 & 27.48 & 16.86 & 15.40 \\
\hline 25 a 29 anos & 13.47 & 14.73 & 18.78 & 18.01 & 22.06 \\
\hline 30 a 39 anos & 23.81 & 33.07 & 18.62 & 26.09 & 25.42 \\
\hline 40 a 49 anos & 15.47 & 21.93 & 7.41 & 14.24 & 15.83 \\
\hline 50 anos ou mais & 9.55 & 11.83 & 4.44 & 8.33 & 11.08 \\
\hline \multicolumn{6}{|l|}{ SITUAÇÃO } \\
\hline Região Urbana & 94.67 & 95.47 & 97.56 & 85.27 & 97.46 \\
\hline \multicolumn{6}{|l|}{ POSIÇÃO NA OCUPAÇÃO } \\
\hline Autônomos e empregadores & 21.08 & 14.75 & 10.77 & 16.23 & 39.26 \\
\hline \multicolumn{6}{|c|}{ POSSE DE CARTEIRA ASSINADA } \\
\hline Com Carteira Assinada & 30.31 & 54.98 & 73.87 & 48.63 & 50.29 \\
\hline
\end{tabular}

(1) Inclui apenas as observações para as quais os atributos de interesse estão claramente identificados. 
Tabela H4. Distribuição percentual de homens e mulheres da PEA ocupada, por variável e classe ocupacional. São Paulo, 1985. (1)

\begin{tabular}{|c|c|c|c|c|c|}
\hline \multirow[t]{2}{*}{ SEXO/FATOR } & \multicolumn{5}{|c|}{ CLASSES } \\
\hline & 1 & 2 & 3 & 4 & 5 \\
\hline \multicolumn{6}{|l|}{ HOMENS } \\
\hline \multicolumn{6}{|l|}{ ESCOLARIDADE } \\
\hline Primário Incompleto & 17.08 & 17.51 & 8.93 & 11.56 & 19.98 \\
\hline Primário Completo & 19.38 & 26.63 & 14.67 & 22.49 & 29.17 \\
\hline Ginásio Incompleto & 16.48 & 11.75 & 14.58 & 16.51 & 12.90 \\
\hline Ginásio Completo & 10.58 & 10.85 & 12.60 & 11.85 & 8.82 \\
\hline Colegial e Superior & 27.80 & 28.80 & 46.10 & 33.55 & 19.32 \\
\hline \multicolumn{6}{|l|}{ DADE } \\
\hline 18 a 19 anos & 5.29 & 4.04 & 9.82 & 5.76 & 4.29 \\
\hline 20 a 24 anos & 17.47 & 19.62 & 25.57 & 15.91 & 12.91 \\
\hline 25 a 29 anos & 12.80 & 18.55 & 17.79 & 15.06 & 15.41 \\
\hline 30 a 39 anos & 21.45 & 27.51 & 18.08 & 26.62 & 28.71 \\
\hline 40 a 49 anos & 13.63 & 15.37 & 9.29 & 16.44 & 17.84 \\
\hline 50 anos ou mais & 19.37 & 11.68 & 6.74 & 11.72 & 14.56 \\
\hline \multicolumn{6}{|l|}{ SITUAÇÃO } \\
\hline Região Urbana & 84.22 & 98.78 & 97.64 & 97.30 & 88.19 \\
\hline \multicolumn{6}{|l|}{ POSIÇÃO NA OCUPAÇÃO } \\
\hline Autônomos e empregadores & 12.26 & 8.80 & 12.07 & 29.07 & 23.99 \\
\hline \multicolumn{6}{|l|}{ POSSE DE CARTEIRA ASSINADA } \\
\hline Com Carteira Assinada & 45.60 & 70.30 & 72.06 & 55.82 & 57.46 \\
\hline \multicolumn{6}{|l|}{ MULHERES } \\
\hline \multicolumn{6}{|l|}{ ESCOLARIDADE } \\
\hline Primánio Incompleto & 18.13 & 12.23 & 6.56 & 8.84 & 18.71 \\
\hline Primánio Completo & 24.13 & 24.38 & 14.44 & 20.04 & 21.89 \\
\hline Ginásio Incompleto & 13.57 & 13.96 & 12.13 & 19.20 & 10.27 \\
\hline Ginásio Completo & 7.01 & 11.40 & 11.91 & 14.42 & 9.14 \\
\hline Colegial e Superior & 26.18 & 32.52 & 52.10 & 35.00 & 29.68 \\
\hline \multicolumn{6}{|l|}{ IDADE } \\
\hline 18 a 19 anos & 5.99 & 5.84 & 10.96 & 8.41 & 6.03 \\
\hline 20 a 24 anos & 15.61 & 15.89 & 25.10 & 22.21 & 16.42 \\
\hline 25 a 29 anos & 14.49 & 14.69 & 19.44 & 16.90 & 17.33 \\
\hline 30 a 39 anos & 25.98 & 30.77 & 21.26 & 22.94 & 26.52 \\
\hline 40 a 49 anos & 15.58 & 18.85 & 9.08 & 10.65 & 13.18 \\
\hline 50 anos ou mais & 9.62 & 6.78 & 3.93 & 6.55 & 10.16 \\
\hline \multicolumn{6}{|l|}{ SITUAÇÃO } \\
\hline Região Urbana & 94.46 & 95.89 & 97.63 & 96.16 & 85.64 \\
\hline \multicolumn{6}{|l|}{ POSIÇÃO NA OCUPAÇÃO } \\
\hline Autônomos e empregadores & 19.11 & 9.78 & 11.39 & 23.23 & 19.79 \\
\hline \multicolumn{6}{|c|}{ POSSE DE CARTEIRA ASSINADA } \\
\hline Com Carteira Assinada & 31.79 & 62.02 & 72.42 & 57.70 & 52.52 \\
\hline
\end{tabular}

(1) Inclui apenas as observaç̃̃es para as quais os atributos de interesse estão claramente identificados. 
Tabela 5. Distribuição percentual de homens e mulheres da PEA ocupada, por variável e classe ocupacional. são Paulo, 1987. (1)

\begin{tabular}{|c|c|c|c|c|c|}
\hline \multirow[t]{2}{*}{ SEXO/FATOR } & \multicolumn{5}{|c|}{ CLASSES } \\
\hline & 1 & 2 & 3 & 4 & 5 \\
\hline \multicolumn{6}{|l|}{ HOMENS } \\
\hline \multicolumn{6}{|l|}{ ESCOLARIDADE } \\
\hline Primário Incompleto & 15.73 & 11.41 & 10.68 & 15.97 & 18.32 \\
\hline Primánio Completo & 20.04 & 25.23 & 15.10 & 20.05 & 29.73 \\
\hline Ginásio Incompleto & 15.17 & 11.33 & 16.97 & 13.27 & 14.48 \\
\hline Ginásio Completo & 11.37 & 10.92 & 14.66 & 9.27 & 10.40 \\
\hline Colegial e Superior & 30.32 & 36.80 & 39.37 & 32.80 & 20.44 \\
\hline \multicolumn{6}{|l|}{ DADE } \\
\hline 18 a 19 anos & 3.49 & 2.73 & 9.81 & 4.63 & 3.79 \\
\hline 20 a 24 anos & 22.55 & 23.08 & 23.79 & 13.67 & 12.51 \\
\hline 25 a 29 anos & 14.44 & 17.46 & 14.71 & 14.59 & 15.84 \\
\hline 30 a 39 anos & 22.40 & 27.54 & 17.32 & 24.69 & 30.06 \\
\hline 40 a 49 anos & 11.18 & 14.80 & 9.95 & 17.42 & 18.86 \\
\hline 50 anos ou mais & 19.057 & 11.50 & 9.91 & 15.16 & 14.15 \\
\hline \multicolumn{6}{|l|}{ SITUAÇÃO } \\
\hline Região Urbana & 87.53 & 97.85 & 96.65 & 85.62 & 91.56 \\
\hline \multicolumn{6}{|l|}{ POSIÇÃO NA OCUPAÇÃO } \\
\hline Autônomos e empregadores & 5.43 & 12.57 & 8.42 & 24.81 & 27.53 \\
\hline \multicolumn{6}{|l|}{ POSSE DE CARTEIRA ASSINADA } \\
\hline Com Carteira Assinada & 58.71 & 61.88 & 76.96 & 53.37 & 59.37 \\
\hline \multicolumn{6}{|l|}{ MULHERES } \\
\hline \multicolumn{6}{|l|}{ ESCOLARIDADE } \\
\hline Primánio Incompleto & 17.22 & 12.55 & 6.61 & 11.35 & 11.37 \\
\hline Primário Completo & 22.00 & 20.79 & 12.76 & 18.32 & 20.87 \\
\hline Ginásio Incompleto & 14.77 & 10.94 & 17.23 & 17.86 & 16.39 \\
\hline Ginásio Completo & 8.02 & 11.81 & 12.81 & 12.72 & 6.15 \\
\hline Colegial e Superior & 28.73 & 36.29 & 48.13 & 33.37 & 42.51 \\
\hline \multicolumn{6}{|l|}{ DADE } \\
\hline 18 a 19 anos & 5.89 & 1.6106 & 10.69 & 7.14 & 9.56 \\
\hline 20 a 24 anos & 15.45 & 14.20 & 24.95 & 18.98 & 18.31 \\
\hline 25 a 29 anos & 14.71 & 16.29 & 17.79 & 15.72 & 16.07 \\
\hline 30 a 39 anos & 26.84 & 31.83 & 21.47 & 25.04 & 28.57 \\
\hline 40 a 49 anos & 15.59 & 20.30 & 8.94 & 12.33 & 14.31 \\
\hline 50 anos ou mais & 11.00 & 10.90 & 4.04 & 7.65 & 7.21 \\
\hline \multicolumn{6}{|l|}{ SITUAÇÃO } \\
\hline Região Urbana & 94.11 & 95.40 & 96.35 & 89.55 & 93.81 \\
\hline \multicolumn{6}{|l|}{ POSIÇÃO NA OCUPAÇÃO } \\
\hline Autônomos e empregadores & 16.98 & 15.24 & 8.56 & 20.73 & 25.83 \\
\hline \multicolumn{6}{|c|}{ POSSE DE CARTEIRA ASSINADA } \\
\hline Com Carteira Assinada & 38.98 & 54.40 & 74.93 & 56.39 & 64.02 \\
\hline
\end{tabular}

(1) Inclui apenas as observações para as quais os atributos de interesse estão claramente identificados. 
Tabela H6. Distribuição percentual de homens e mulheres da PEA ocupada, por variável e classe ocupacional. São Paulo, 1988. (1)

\begin{tabular}{|c|c|c|c|c|c|}
\hline \multirow[t]{2}{*}{ SEXO/FATOR } & \multicolumn{5}{|c|}{ CLASSES } \\
\hline & 1 & 2 & 3 & 4 & 5 \\
\hline \multicolumn{6}{|l|}{ HOMENS } \\
\hline \multicolumn{6}{|l|}{ ESCOLARIDADE } \\
\hline Primário Incompleto & 12.23 & 10.14 & 9.81 & 17.71 & 18.65 \\
\hline Primário Completo & 19.11 & 27.74 & 15.85 & 19.44 & 28.67 \\
\hline Ginásio Incompleto & 15.80 & 19.19 & 19.49 & 10.23 & 16.40 \\
\hline Ginásio Completo & 5.53 & 6.93 & 12.17 & 8.70 & 11.05 \\
\hline Colegial e Superior & 32.77 & 34.14 & 39.86 & 36.11 & 18.56 \\
\hline \multicolumn{6}{|l|}{ IDADE } \\
\hline 18 a 19 anos & 4.95 & 6.93 & 9.60 & 4.29 & 4.26 \\
\hline 20 a 24 anos & 13.47 & 13.86 & 21.35 & 11.62 & 12.77 \\
\hline 25 a 29 anos & 10.48 & 13.61 & 14.49 & 14.40 & 13.88 \\
\hline 30 a 39 anos & 23.78 & 23.75 & 21.06 & 28.96 & 29.29 \\
\hline 40 a 49 anos & 15.71 & 20.28 & 11.39 & 17.79 & 18.34 \\
\hline 50 anos ou mais & 23.57 & 14.38 & 7.94 & 15.68 & 15.86 \\
\hline \multicolumn{6}{|l|}{ SITUAÇÃO } \\
\hline Região Urbana & 83.88 & 94.67 & 96.19 & 83.17 & 90.74 \\
\hline \multicolumn{6}{|l|}{ POSIÇÃO NA OCUPAÇÃO } \\
\hline Aut ônomose empregadores & 8.24 & 20.80 & 7.53 & 27.84 & 28.02 \\
\hline \multicolumn{6}{|l|}{ POSSE DE CARTEIRA ASSINADA } \\
\hline Com Carteira Assinada & 57.32 & 57.32 & 75.26 & 53.55 & 56.86 \\
\hline \multicolumn{6}{|l|}{ MULHERES } \\
\hline \multicolumn{6}{|l|}{ ESCOLARIDADE } \\
\hline Primário Incompl eto & 16.06 & 5.42 & 7.84 & 14.21 & 12.43 \\
\hline Primário Completo & 20.95 & 14.56 & 13.38 & 18.84 & 20.94 \\
\hline Ginásio Incompleto & 15.23 & 20.55 & 17.00 & 12.03 & 14.99 \\
\hline Ginásio Completo & 9.15 & 16.52 & 11.53 & 8.20 & 13.71 \\
\hline Col egial e Superior & 30.53 & 40.06 & 47.23 & 39.80 & 35.85 \\
\hline \multicolumn{6}{|l|}{$\mathrm{IDADE}$} \\
\hline 18 a 19 anos & 6.07 & 3.55 & 10.33 & 4.01 & 4.17 \\
\hline 20 a 24 anos & 16.23 & 12.23 & 23.90 & 13.95 & 16.03 \\
\hline 25 a 29 anos & 14.31 & 16.63 & 16.74 & 16.86 & 17.00 \\
\hline 30 a 39 anos & 25.75 & 30.80 & 23.03 & 32.46 & 38.49 \\
\hline 40 a 49 anos & 17.75 & 21.76 & 10.33 & 17.71 & 12.59 \\
\hline 50 anos ou mais & 11.23 & 8.41 & 4.75 & 7.50 & 8.19 \\
\hline \multicolumn{6}{|l|}{ SITUAÇÃO } \\
\hline Região Urbana & 93.71 & 97.39 & 95.63 & 88.66 & 96.06 \\
\hline \multicolumn{6}{|l|}{ POSIÇÃO NA OCUPAÇÃO } \\
\hline Autônomos e empregadores & 19.09 & 31.02 & 8.58 & 29.35 & 26.81 \\
\hline \multicolumn{6}{|l|}{ POSSE DE CARTEIRA ASSINADA } \\
\hline Com Carteira Assinada & 39.67 & 43.49 & 72.48 & 52.19 & 59.64 \\
\hline
\end{tabular}

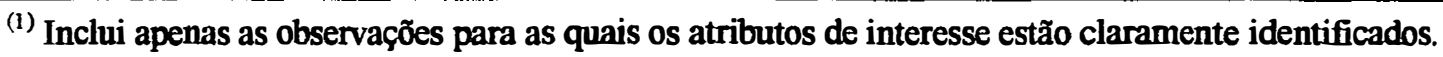


Tabela H7. Distribuição percentual de homens e mulheres da PEA ocupada, por variável e classe ocupacional. são Paulo, 1989. (1)

\begin{tabular}{|c|c|c|c|c|c|}
\hline \multirow[t]{2}{*}{ SEXO/FATOR } & \multicolumn{5}{|c|}{ CLASSES } \\
\hline & 1 & 2 & 3 & 4 & 5 \\
\hline \multicolumn{6}{|l|}{ HOMENS } \\
\hline \multicolumn{6}{|l|}{ ESCOLARIDADE } \\
\hline Primánio Incompl eb & 16.08 & 12.11 & 8.19 & 14.07 & 18.02 \\
\hline Primánio Completo & 22.09 & 19.71 & 14.29 & 21.23 & 28.12 \\
\hline Ginásio Incompleto & 9.82 & 23.49 & 21.42 & 10.34 & 18.18 \\
\hline Ginásio Completo & 5.20 & 7.37 & 13.76 & 9.84 & 10.67 \\
\hline Colegiale Superior & 36.99 & 33.21 & 39.99 & 36.48 & 17.64 \\
\hline \multicolumn{6}{|l|}{ IDADE } \\
\hline 18 a 19 anos & 4.51 & 6.84 & 10.80 & 4.07 & 4.30 \\
\hline 20 a 24 anos & 10.75 & 17.69 & 21.58 & 11.03 & 12.98 \\
\hline 25 a 29 anos & 10.87 & 16.44 & 16.51 & 13.28 & 13.55 \\
\hline 30 a 39 anos & 26.70 & 23.71 & 18.79 & 28.98 & 30.12 \\
\hline 40 a 49 anos & 16.98 & 18.02 & 10.42 & 20.45 & 19.17 \\
\hline 50 anos ou mais & 24.40 & 10.13 & 6.22 & 16.59 & 14.38 \\
\hline \multicolumn{6}{|l|}{ SITUAÇÃO } \\
\hline Região Urbana & 85.53 & 95.36 & 95.76 & 85.08 & 90.54 \\
\hline \multicolumn{6}{|l|}{ POSIÇÃO NA OCUPAÇÃO } \\
\hline Autônomos e empregadores & 19.64 & 4.32 & 5.39 & 34.65 & 26.52 \\
\hline \multicolumn{6}{|l|}{ POSSE DE CARTEIRA ASSINADA } \\
\hline Com Carteira Assinada & 47.52 & 63.12 & 75.74 & 45.64 & 59.36 \\
\hline \multicolumn{6}{|l|}{ MULHERES } \\
\hline \multicolumn{6}{|l|}{ ESCOLARIDADE } \\
\hline Primário Incompleto & 17.49 & 12.54 & 6.12 & 13.62 & 7.30 \\
\hline Primánio Completo & 21.82 & 19.69 & 13.21 & 18.67 & 19.56 \\
\hline Ginásio Incompleto & 14.06 & 20.41 & 16.39 & 11.31 & 15.91 \\
\hline Ginásio Completo & 7.27 & 12.19 & 14.51 & 8.52 & 15.19 \\
\hline Colegial e Superior & 30.50 & 30.72 & 46.31 & 38.97 & 39.21 \\
\hline \multicolumn{6}{|l|}{ IDADE } \\
\hline 18 a 19 anos & 5.28 & 4.15 & 10.69 & 4.73 & 10.03 \\
\hline 20 a 24 anos & 15.52 & 15.84 & 20.67 & 11.77 & 14.99 \\
\hline 25 a 29 anos & 13.10 & 15.22 & 19.37 & 16.54 & 17.12 \\
\hline 30 a 39 anos & 26.84 & 27.00 & 20.87 & 29.43 & 31.09 \\
\hline 40 a 49 anos & 17.79 & 19.01 & 9.17 & 16.75 & 13.07 \\
\hline 50 anos ou mais & 11.46 & 10.31 & 5.75 & 11.05 & 7.10 \\
\hline \multicolumn{6}{|l|}{ SITUAÇÃO } \\
\hline Região Urbana & 92.92 & 95.97 & 95.54 & 88.16 & 92.69 \\
\hline \multicolumn{6}{|l|}{ POSIÇÃO NA OCUPAÇÃO } \\
\hline Autônomos e empregadores & 16.20 & 10.57 & 8.34 & 31.37 & 29.60 \\
\hline \multicolumn{6}{|l|}{ POSSE DE CARTEIRA ASSINADA } \\
\hline Com Carteira Assinada & 37.93 & 63.67 & 74.71 & 46.88 & 57.33 \\
\hline
\end{tabular}

(1) Inclui apenas as observações para as quais os atributos de interesse estão claramente identificados. 
Tabela H8. Distribuição percentual de homens e mulheres da PEA ocupada, por variável e classe ocupacional. são Paulo, 1990. (1)

\begin{tabular}{|c|c|c|c|c|c|}
\hline \multirow[t]{2}{*}{ SEXO/FATOR } & \multicolumn{5}{|c|}{ CLASSES } \\
\hline & 1 & 2 & 3 & 4 & 5 \\
\hline \multicolumn{6}{|l|}{ HOMENS } \\
\hline \multicolumn{6}{|l|}{ ESCOLARIDADE } \\
\hline Primário Incompleto & 17.25 & 10.26 & 8.35 & 14.95 & 17.48 \\
\hline Primário Completo & 19.44 & 11.33 & · 15.36 & 17.57 & 27.60 \\
\hline Ginásio Incompleto & 13.91 & 18.40 & 21.30 & 11.47 & 17.14 \\
\hline Ginásio Completo & 10.28 & 10.80 & 12.03 & 8.79 & 10.54 \\
\hline Colegial e Superior & 25.68 & 46.02 & 40.54 & 38.64 & 20.97 \\
\hline \multicolumn{6}{|l|}{ IDADE } \\
\hline 18 a 19 anos & 2.91 & 3.73 & 8.79 & 3.20 & 3.77 \\
\hline 20 a 24 anos & 10.39 & 22.43 & 20.82 & 10.89 & 12.58 \\
\hline 25 a 29 anos & 11.89 & 14.67 & 15.69 & 13.65 & 13.52 \\
\hline 30 a 39 anos & 25.99 & 22.67 & 19.81 & 29.67 & 30.11 \\
\hline 40 a 49 anos & 12.61 & 18.55 & 11.47 & 19.33 & 20.02 \\
\hline 50 anos ou mais & 27.59 & 10.35 & 7.78 & 15.87 & 15.29 \\
\hline \multicolumn{6}{|l|}{ SITUAÇÃO } \\
\hline Região Urbana & 76.62 & 95.20 & 94.92 & 84.11 & 90.10 \\
\hline \multicolumn{6}{|l|}{ POSIÇÃO NA OCUPAÇÃO } \\
\hline Autônomos e empregadores & 10.58 & 13.15 & 8.21 & 33.81 & 28.69 \\
\hline \multicolumn{6}{|l|}{ POSSE DE CARTEIRA ASSINADA } \\
\hline Com Carteira Assinada & 58.92 & 60.06 & 70.95 & 48.58 & 57.64 \\
\hline \multicolumn{6}{|l|}{ MULHERES } \\
\hline \multicolumn{6}{|l|}{ ESCOLARIDADE } \\
\hline Primário Incompleto & 15.08 & 11.80 & 6.18 & 14.28 & 7.73 \\
\hline Primánio Completo & 21.03 & 18.14 & 13.94 & 14.19 & 17.13 \\
\hline Ginásio Incompleto & 15.98 & 11.22 & 18.20 & 9.67 & 16.18 \\
\hline Ginásio Completo & 9.78 & 11.13 & 13.42 & 8.50 & 9.80 \\
\hline Colegial e Superior & 30.62 & 42.38 & 46.35 & 45.64 & 47.20 \\
\hline \multicolumn{6}{|l|}{ IDADE } \\
\hline 18 a 19 anos & 5.77 & 3.86 & 11.19 & 4.37 & 3.57 \\
\hline 20 a 24 anos & 14.05 & 13.91 & 23.36 & 15.91 & 15.74 \\
\hline 25 a 29 anos & 15.55 & 15.71 & 15.56 & 18.98 & 17.06 \\
\hline 30 a 39 anos & 26.31 & 31.08 & 24.45 & 31.70 & 34.41 \\
\hline 40 a 49 anos & 16.69 & 22.75 & 7.96 & 15.33 & 18.53 \\
\hline 50 anos ou mais & 11.55 & 9.52 & 4.91 & 8.43 & 5.4508 \\
\hline \multicolumn{6}{|l|}{ SITUAÇÃO } \\
\hline Região Urbana & 92.94 & 94.85 & 95.79 & 85.78 & 93.54 \\
\hline \multicolumn{6}{|l|}{ POSIÇÃO NA OCUPAÇÃO } \\
\hline Autônomos e empregadores & 19.63 & 12.87 & 11.12 & .32 .87 & 34.11 \\
\hline \multicolumn{6}{|c|}{ POSSE DE CARTEIRA ASSINADA } \\
\hline Com Carteira Assinada & 39.46 & 62.56 & 70.81 & 48.35 & 52.83 \\
\hline
\end{tabular}

${ }^{(1)}$ Inclui apenas as observações para as quais os atributos de interesse estão claramente identificados. 
Tabela H9. Distribuição percentual de homens e mulheres da PEA ocupada, por variável e classe ocupacional. Pernambuco, 1981. (1)

\begin{tabular}{|c|c|c|c|c|c|}
\hline \multirow[t]{2}{*}{ SEXO/FATOR } & \multicolumn{5}{|c|}{ CLASSES } \\
\hline & 1 & 2 & 3 & 4 & 5 \\
\hline \multicolumn{6}{|l|}{ HOMENS } \\
\hline \multicolumn{6}{|l|}{ ESCOLARIDADE } \\
\hline Phimánio Incompl eto & 19.58 & 12.08 & 9.45 & 23.54 & 24.89 \\
\hline Primário Compl eto & 12.22 & 12.06 & 10.40 & 13.76 & 11.94 \\
\hline Ginásio Incompl eto & 9.43 & 3.91 & 13.45 & 12.57 & 6.77 \\
\hline Ginásio Completo & 2.76 & 9.13 & 10.61 & 6.13 & 2.95 \\
\hline Colegial e Superior & 24.66 & 44.95 & 50.64 & 18.37 & 6.20 \\
\hline \multicolumn{6}{|l|}{ IDADE } \\
\hline 18 a 19 anos & 5.75 & 1.30 & 4.13 & 4.61 & 5.31 \\
\hline 20 a 24 anos & 16.13 & 17.25 & 27.84 & 12.85 & 12.44 \\
\hline 25 a 29 anos & 6.47 & 16.95 & 22.45 & 12.58 & 10.77 \\
\hline 30 a 39 anos & 12.22 & 19.91 & 18.45 & 21.80 & 23.14 \\
\hline 40 a 49 anos & 20.93 & 11.75 & 9.95 & 15.87 & 16.81 \\
\hline 50 anos ou mais & 23.32 & 23.09 & 11.02 & 21.16 & 20.89 \\
\hline \multicolumn{6}{|l|}{ SITUAÇÃO } \\
\hline Região Urbana & 85.52 & 94.46 & 91.01 & 88.74 & 52.02 \\
\hline \multicolumn{6}{|l|}{ POSIÇÃO NA OCUPAÇÃO } \\
\hline Autônomos e empregadores & 8.30 & 15.97 & 2.61 & 58.01 & 34.08 \\
\hline \multicolumn{6}{|l|}{ POSSE DE CARTEIRA ASSINADA } \\
\hline Com Carteira Assinada & 43.12 & 59.64 & 74.51 & 24.43 & 30.74 \\
\hline \multicolumn{6}{|l|}{ MULHERES } \\
\hline \multicolumn{6}{|l|}{ ESCOLARIDADE } \\
\hline Primánio Incompl eto & 20.70 & 16.92 & 4.94 & 18.53 & 17.29 \\
\hline Primário Compl eto & 14.75 & 12.50 & 7.26 & 16.56 & 5.80 \\
\hline Ginásio Incompl eto & 12.78 & 6.98 & 9.60 & 14.02 & 1.63 \\
\hline Ginásio Completo & 5.58 & 0.52 & 7.39 & 9.94 & 1.40 \\
\hline Colegial e Superior & 23.71 & 45.15 & 66.25 & 19.14 & 4.93 \\
\hline \multicolumn{6}{|l|}{ IDADE } \\
\hline 18 a 19 anos & 5.95 & 3.86 & 4.80 & 7.53 & 4.88 \\
\hline 20 a 24 anos & 15.85 & 13.82 & 19.97 & 12.73 & 6.96 \\
\hline 25 a 29 anos & 13.89 & 12.92 & 27.55 & 11.70 & 9.79 \\
\hline 30 a 39 anos & 24.62 & 29.99 & 24.16 & 25.66 & 20.54 \\
\hline 40 a 49 anos & 14.57 & 21.84 & 15.56 & 16.89 & 24.36 \\
\hline 50 anos ou mais & 12.74 & 10.85 & 3.72 & 15.51 & 16.82 \\
\hline \multicolumn{6}{|l|}{ SITUAÇÃO } \\
\hline Região Urbana & 85.67 & 93.43 & 93.43 & 90.96 & 35.59 \\
\hline \multicolumn{6}{|l|}{ POSIÇÃO NA OCUPAÇÃO } \\
\hline Autônomos e empregadores & 37.68 & 14.60 & 0.65 & 55.56 & 26.68 \\
\hline \multicolumn{6}{|c|}{ POSSE DE CARTEIRA ASSINADA } \\
\hline Com Carteira Assinada & 28.20 & 40.86 & 80.90 & 26.59 & 20.97 \\
\hline
\end{tabular}

${ }^{(1)}$ Inclui apenas as observações para as quais os atributos de interesse estão claramente identificados. 
Tabela H10. Distribuição percentual de homens e mulheres da PEA ocupada, por variável e classe ocupacional. Pernambuco, 1983. (1)

\begin{tabular}{|c|c|c|c|c|c|}
\hline \multirow[t]{2}{*}{ SEXO/FATOR } & \multicolumn{5}{|c|}{ CLASSES } \\
\hline & 1 & $\mathbf{2}$ & 3 & 4 & $\mathbf{5}$ \\
\hline \multicolumn{6}{|l|}{ HOMENS } \\
\hline \multicolumn{6}{|l|}{ ESCOLARIDADE } \\
\hline Primário Incompleto & 18.24 & 1.56 & 12.31 & 21.14 & 23.96 \\
\hline Primário Completo & 14.23 & 6.31 & 12.87 & 15.21 & 14.47 \\
\hline Ginásio Incompleto & 14.09 & 19.85 & 13.87 & 13.55 & 9.25 \\
\hline Gi nśi oCompleto & 12.15 & 6.31 & 8.85 & 6.88 & 3.27 \\
\hline Colegial e Superior & 16.41 & 52.75 & 43.10 & 21.31 & 7.00 \\
\hline \multicolumn{6}{|l|}{ DADE } \\
\hline 18 a 19 anos & 4.91 & 4.42 & 5.39 & 5.31 & 5.46 \\
\hline 20 a 24 anos & 21.01 & 21.40 & 19.86 & 12.00 & 12.95 \\
\hline 25 a 29 anos & 6.55 & 18.41 & 17.92 & 12.95 & 12.28 \\
\hline 30 a 39 anos & 18.59 & 35.62 & 20.55 & 22.23 & 21.96 \\
\hline 40 a 49 anos & 17.20 & 10.68 & 15.14 & 18.06 & 16.60 \\
\hline 50 anos ou mai s & 18.24 & 9.48 & 12.46 & 19.72 & 19.85 \\
\hline \multicolumn{6}{|l|}{ SITUAÇÃO } \\
\hline Regi ãoUrbana & 88.98 & 86.45 & 90.08 & 89.97 & 56.87 \\
\hline \multicolumn{6}{|l|}{ POSIÇÃO NA OCUPAÇÃO } \\
\hline Autônomos e empregadores & 18.29 & 23.98 & 17.57 & 54.91 & 29.64 \\
\hline POSSE DE CARTEIRA ASSINADA & & & . & & \\
\hline Com Carteira Assinada & 41.58 & 62.14 & 57.98 & 25.62 & 24.95 \\
\hline \multicolumn{6}{|l|}{ MULHERES } \\
\hline \multicolumn{6}{|l|}{ ESCOLARIDADE } \\
\hline Primário Incompleto & 20.60 & 10.90 & 8.00 & 14.25 & 21.61 \\
\hline Primário Completo & 17.72 & 14.35 & 9.95 & 18.46 & 5.29 \\
\hline Ginási oIncompleto & 11.31 & 8.96 & 11.87 & 15.21 & 2.36 \\
\hline Ginásio Completo & 5.79 & 4.72 & 8.22 & 5.65 & 1.10 \\
\hline Colegial e Superior & 21.58 & 51.79 & 56.99 & 24.13 & 5.74 \\
\hline \multicolumn{6}{|l|}{$\mathrm{DADE}$} \\
\hline 18 a 19 anos & 5.62 & 4.71 & 5.15 & 5.29 & 1.97 \\
\hline 20 a 24 anos & 14.97 & 7.35 & 20.12 & 15.07 & 12.07 \\
\hline 25 a 29 anos & 13.61 & 20.88 & 21.79 & 13.17 & 11.62 \\
\hline 30 a 39 anos & 24.12 & 27.63 & 25.66 & 22.99 & 25.38 \\
\hline 40 a 49 anos & 18.80 & 15.32 & 18.47 & 19.69 & 20.19 \\
\hline 50 anos ou mais & 11.43 & 15.65 & 5.42 & 17.22 & 18.04 \\
\hline \multicolumn{6}{|l|}{ SITUAÇÃO } \\
\hline Região Urbana & 82.59 & 85.35 & 91.89 & 91.73 & 28.18 \\
\hline \multicolumn{6}{|l|}{ POSIÇÃO NA OCUPAÇÃO } \\
\hline Autônomos e empregadores & 33.80 & 30.44 & 15.85 & 54.39 & 23.64 \\
\hline \multicolumn{6}{|l|}{ POSSE DE CARTEIRA ASSINADA } \\
\hline Com Carteira Assinada & 29.04 & 53.59 & 63.77 & 24.93 & 10.47 \\
\hline
\end{tabular}

(1) Inclui apenas as observações para as quais os atributos de interesse estão claramente identificados. 
Tabela H11. Distribuição percentual de homens e mulheres da PEA ocupada, por variável e classe ocupacional. Pernambuco, 1984: (1)

\begin{tabular}{|c|c|c|c|c|c|}
\hline \multirow[t]{2}{*}{ SEXO/FATOR } & \multicolumn{5}{|c|}{ CLASSES } \\
\hline & 1 & 2 & 3 & 4 & 5 \\
\hline \multicolumn{6}{|l|}{ HOMENS } \\
\hline \multicolumn{6}{|l|}{ ESCOLARIDADE } \\
\hline Primário Incompleto & 23.14 & 9.60 & 10.93 & 21.73 & 23.90 \\
\hline Pnimário Completo & 6.95 & 11.07 & 12.51 & 16.46 & 12.43 \\
\hline Ginásio Incompleto & 13.67 & 10.00 & 14.35 & 14.24 & 7.85 \\
\hline Ginásio Completo & 9.11 & 0.00 & 9.12 & 5.26 & 3.05 \\
\hline Colegial e Superior & 14.46 & 61.89 & 46.30 & 20.13 & 6.96 \\
\hline \multicolumn{6}{|l|}{ IDADE } \\
\hline 18 a 19 anos & 3.75 & 1.48 & 4.98 & 4.24 & 5.17 \\
\hline 20 a 24 anos & 9.91 & 17.43 & 20.25 & 12.50 & 12.74 \\
\hline 25 a 29 anos & 13.67 & 18.91 & 18.79 & 11.77 & 12.75 \\
\hline 30 a 39 anos & 22.57 & 32.17 & 21.93 & 23.30 & 22.15 \\
\hline 40 a 49 anos & 16.84 & 12.99 & 12.38 & 21.78 & 16.56 \\
\hline 50 anos ou mais & 15.27 & 7.43 & 11.46 & 19.38 & 19.15 \\
\hline \multicolumn{6}{|l|}{ SITUAÇÃO } \\
\hline Região Urbana & 78.02 & 89.61 & 93.15 & 86.51 & 53.04 \\
\hline \multicolumn{6}{|l|}{ POSIÇÃO NA OCUPAÇÃO } \\
\hline Autônomos e empregadores & 22.69 & 27.01 & 22.71 & 56.79 & 35.38 \\
\hline \multicolumn{6}{|l|}{ POSSE DE CARTEIRA ASSINADA } \\
\hline Com Carteira Assinada & 36.88 & 57.05 & 56.53 & 27.04 & 22.85 \\
\hline \multicolumn{6}{|l|}{ MULHERES } \\
\hline \multicolumn{6}{|l|}{ ESCOLARIDADE } \\
\hline Primáno Incompleto & 22.22 & 5.35 & 6.44 & 17.50 & 18.40 \\
\hline Primário Completo & 15.27 & 5.64 & 7.42 & 13.01 & 5.83 \\
\hline Ginásio Incompleto & 13.74 & 10.84 & 11.61 & 16.39 & 1.79 \\
\hline GinásioCompleto & 4.31 & 2.89 & 9.44 & 8.41 & 1.79 \\
\hline Colegial e Superior & 20.67 & 71.38 & 60.54 & 26.80 & 6.46 \\
\hline \multicolumn{6}{|l|}{ IDADE } \\
\hline 18 a 19 anos & 4.73 & 8.24 & 4.98 & 3.58 & 2.99 \\
\hline 20 a 24 anos & 16.40 & 16.89 & 20.60 & 12.24 & 9.35 \\
\hline 25 a 29 anos & 13.76 & 13.73 & 20.04 & 14.71 & 10.42 \\
\hline 30 a 39 anos & 24.92 & 30.90 & 28.17 & 25.39 & 25.79 \\
\hline 40 a 49 anos & 17.65 & 23.59 & 15.09 & 20.42 & 17.79 \\
\hline 50 anos ou mais & 11.04 & 4.48 & 8.69 & 17.07 & 24.73 \\
\hline \multicolumn{6}{|l|}{ SITUAÇÃO } \\
\hline Região Urbana & 83.11 & 87.84 & 91.26 & 88.06 & 30.24 \\
\hline \multicolumn{6}{|l|}{ POSIÇÃO NA OCUPAÇÃO } \\
\hline Autônomos e empregadores & 38.00 & 18.34 & 19.50 & 59.08 & 34.43 \\
\hline \multicolumn{6}{|c|}{ POSSE DE CARTEIRA ASSINADA } \\
\hline Com Carteira Assinada & 25.04 & 54.77 & 63.20 & 26.13 & 15.40 \\
\hline
\end{tabular}

(1) Inclui apenas as observações para as quais os atributos de interesse estão claramente identificados. 
Tabela H12. Distribuição percentual de homens e mulheres da PEA ocupada, por variável e classe ocupacional. Pernambuco, 1985. (1)

\begin{tabular}{|c|c|c|c|c|c|}
\hline \multirow[t]{2}{*}{ SEXO/FATOR } & \multicolumn{5}{|c|}{ CLASSES } \\
\hline & 1 & 2 & 3 & 4 & 5 \\
\hline \multicolumn{6}{|l|}{ HOMENS } \\
\hline \multicolumn{6}{|l|}{ ESCOLARIDADE } \\
\hline Primánio Incompleto & 19.94 & 6.07 & 11.67 & 23.74 & 22.75 \\
\hline Primário Completo & 14.53 & 11.89 & 14.07 & 16.15 & 13.12 \\
\hline Ginásio Incompleto & 13.81 & 15.79 & 13.24 & 14.75 & 9.70 \\
\hline Ginásio Completo & 4.20 & 7.58 & 10.22 & 6.16 & 3.18 \\
\hline Colegial e Superior & 21.46 & 52.61 & 42.62 & 17.67 & 5.96 \\
\hline \multicolumn{6}{|l|}{ IDADE } \\
\hline 18 a 19 anos & 4.92 & 3.91 & 5.36 & 5.02 & 5.28 \\
\hline 20 a 24 anos & 20.53 & 17.55 & 19.35 & 12.56 & 13.59 \\
\hline 25 a 29 anos & 12.47 & 22.29 & 14.37 & 12.84 & 12.63 \\
\hline 30 a 39 anos & 14.89 & 19.02 & 22.09 & 21.88 & 20.71 \\
\hline 40 a 49 anos & 12.84 & 15.81 & 13.65 & 17.41 & 16.75 \\
\hline 50 anos ou mais & 16.58 & 18.19 & 16.82 & 20.30 & 20.08 \\
\hline \multicolumn{6}{|l|}{ SITUAÇÃO } \\
\hline Região Urbana & 81.04 & 95.69 & 95.46 & 86.39 & 52.21 \\
\hline \multicolumn{6}{|l|}{ POSIÇÃO NA OCUPAÇÃO } \\
\hline Autônomos e empregadores & 15.74 & 15.16 & 18.98 & 61.49 & 32.50 \\
\hline \multicolumn{6}{|l|}{ POSSE DE CARTEIRA ASSINADA } \\
\hline Com Carteira Assinada & 33.71 & 64.90 & 61.70 & 17.42 & 27.82 \\
\hline \multicolumn{6}{|l|}{ MULHERES } \\
\hline \multicolumn{6}{|l|}{ ESCOLARIDADE } \\
\hline Primário Incompleto & 20.31 & 13.24 & 8.58 & 15.45 & 21.56 \\
\hline Primário Completo & 16.81 & 8.69 & 9.73 & 14.02 & 7.24 \\
\hline Ginásio Incompleto & 15.51 & 8.24 & 10.83 & 18.88 & 3.31 \\
\hline Ginási o Completo & 5.10 & 2.65 & 8.95 & 8.60 & 0.92 \\
\hline Colegial e Superior & 22.68 & 54.37 & 54.87 & 23.89 & 3.91 \\
\hline \multicolumn{6}{|l|}{ IDADE } \\
\hline 18 a 19 anos & 7.39 & 0.44 & 7.10 & 6.41 & 2.97 \\
\hline 20 a 24 anos & 17.62 & 12.07 & 20.13 & 13.65 & 10.20 \\
\hline 25 a 29 anos & 13.36 & 14.95 & 19.14 & 12.47 & 8.27 \\
\hline 30 a 39 anos & 23.32 & 36.41 & 25.94 & 25.32 & 23.31 \\
\hline 40 a 49 anos & 15.96 & 23.66 & 15.23 & 19.70 & 21.49 \\
\hline 50 anos ou mais & 10.62 & 10.46 & 7.45 & 17.02 & 19.60 \\
\hline \multicolumn{6}{|l|}{ SITUAÇÃO } \\
\hline Região Urbana & 83.45 & 81.60 & 91.40 & 93.12 & 24.82 \\
\hline \multicolumn{6}{|l|}{ POSIÇÃO NA OCUPAÇÃO } \\
\hline Autônomos e empregadores & 30.84 & 5.34 & 18.69 & 61.55 & 25.06 \\
\hline \multicolumn{6}{|l|}{ POSSE DE CARTEIRA ASSINADA } \\
\hline Com Carteira Assinada & 23.00 & 61.70 & 57.97 & 24.03 & 17.66 \\
\hline
\end{tabular}


Tabela H13. Distribuição percentual de homens e mulheres da PEA ocupada, por variável e classe ocupacional. Pernambuco, $1987 .(1)$

\begin{tabular}{|c|c|c|c|c|c|}
\hline \multirow[t]{2}{*}{ SEXO/FATOR } & \multicolumn{5}{|c|}{ CLASSES } \\
\hline & 1 & 2 & $\mathbf{3}$ & 4 & 5 \\
\hline \multicolumn{6}{|l|}{ HOMENS } \\
\hline \multicolumn{6}{|l|}{ ESCOLARIDADE } \\
\hline Primário Incompleto & 20.31 & 12.12 & 10.55 & 20.46 & 26.92 \\
\hline Primário Completo & 12.96 & 9.35 & 13.65 & 13.91 & 12.53 \\
\hline Ginásio Incompleto & 17.20 & 7.97 & 16.74 & 19.42 & 9.45 \\
\hline Ginásio Completo & 5.62 & 5.52 & 8.12 & 5.94 & 3.92 \\
\hline Colegial e Superior & 24.46 & 61.22 & 43.47 & 22.27 & 7.77 \\
\hline \multicolumn{6}{|l|}{ IDADE } \\
\hline 18 a 19 anos & 4.24 & 2.76 & 3.55 & 5.39 & 5.37 \\
\hline 20 a 24 anos & 13.23 & 15.94 & 20.04 & 14.06 & 14.10 \\
\hline 25 a 29 anos & 21.95 & 8.28 & 17.51 & 12.85 & 12.88 \\
\hline 30 a 39 anos & 21.71 & 32.84 & 23.46 & 19.68 & 23.27 \\
\hline 40 a 49 anos & 11.83 & 20.08 & 11.32 & 17.23 & 16.71 \\
\hline 50 anos ou mais & 24.80 & 14.89 & 9.40 & 18.15 & 18.44 \\
\hline \multicolumn{6}{|l|}{ SITUAÇÃO } \\
\hline Região Urbana & 83.05 & 87.57 & 87.62 & 87.21 & 54.26 \\
\hline \multicolumn{6}{|l|}{ POSIÇÃO NA OCUPAÇÃO } \\
\hline Autônomos e empregadores & 11.85 & 4.14 & 13.41 & 50.03 & 32.05 \\
\hline \multicolumn{6}{|l|}{ POSSE DE CARTEIRA ASSINADA } \\
\hline Com Carteira Assinada & 54.62 & 70.57 & 68.34 & 24.87 & 29.87 \\
\hline \multicolumn{6}{|l|}{ MULHERES } \\
\hline \multicolumn{6}{|l|}{ ESCOLARIDADE } \\
\hline Primánio Incompleto & 21.80 & 7.33 & 2.57 & 14.39 & 21.01 \\
\hline Primário Completo & 15.41 & 8.60 & 6.58 & 14.69 & 5.46 \\
\hline Ginásio Incompleto & 13.82 & 8.11 & 8.70 & 15.14 & 2.76 \\
\hline Ginásio Completo & 4.19 & 9.73 & 11.17 & 10.12 & 1.91 \\
\hline Colegial e Superior & 25.10 & 66.23 & 61.34 & 30.39 & 5.44 \\
\hline \multicolumn{6}{|l|}{ IDADE } \\
\hline 18 a 19 anos & 5.62 & 1.76 & 4.25 & 2.75 & 2.70 \\
\hline 20 a 24 anos & 14.66 & 10.51 & 21.12 & 18.76 & 6.97 \\
\hline 25 a 29 anos & 15.94 & 16.57 & 19.33 & 11.93 & 10.47 \\
\hline 30 a 39 anos & 24.85 & 32.50 & 29.28 & 27.92 & 20.22 \\
\hline 40 a 49 anos & 16.13 & 23.84 & 13.06 & 18.96 & 22.52 \\
\hline 50 anos ou mai s & 12.42 & 12.42 & 10.39 & 12.92 & 28.44 \\
\hline \multicolumn{6}{|l|}{ SITUAÇÃO } \\
\hline Região Urbana & 83.02 & 89.49 & 87.84 & 89.48 & 24.62 \\
\hline \multicolumn{6}{|l|}{ POSIÇÃO NA OCUPAÇÃO } \\
\hline Autônomos e empregadores & 32.40 & 10.01 & 13.89 & 55.51 & 24.71 \\
\hline \multicolumn{6}{|c|}{ POSSE DE CARTEIRA ASSINADA } \\
\hline Com Carteira Assinada & 26.43 & 67.98 & 66.98 & 23.16 & 19.53 \\
\hline
\end{tabular}

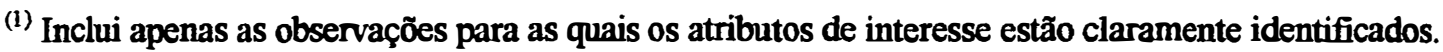


Tabela H14. Distribuição percentual de homens e mulheres da PEA ocupada, por variável e classe ocupacional. Pernambuco, 1988. (1)

\begin{tabular}{|c|c|c|c|c|c|}
\hline \multirow[t]{2}{*}{ SEXO/FATOR } & \multicolumn{5}{|c|}{ CLASSES } \\
\hline & 1 & 2 & 3 & 4 & 5 \\
\hline \multicolumn{6}{|l|}{ HOMENS } \\
\hline \multicolumn{6}{|l|}{ ESCOLARDADE } \\
\hline Primário Incompleto & 20.52 & 10.91 & 11.49 & 16.85 & 25.45 \\
\hline Primário Compl eto & 20.06 & 15.43 & 9.06 & 11.41 & 12.89 \\
\hline Ginásio Incomplet o & 8.47 & 14.07 & 14.86 & 17.33 & 9.57 \\
\hline Ginásio Completo & 2.97 & 8.36 & 5.79 & 7.98 & 3.71 \\
\hline Colegial e Superior & 31.97 & 42.87 & 49.96 & 29.56 & 7.53 \\
\hline \multicolumn{6}{|l|}{ IDADE } \\
\hline 18 a 19 anos & 1.99 & 11.60 & 5.00 & 6.62 & 4.41 \\
\hline 20 a 24 anos & 18.53 & 20.46 & 21.23 & 12.93 & 12.22 \\
\hline 25 a 29 anos & 18.00 & 19.86 & .17 .84 & 16.69 & 14.37 \\
\hline 30 a 39 anos & 16.02 & 21.73 & 20.26 & 22.60 & 21.65 \\
\hline 40 a 49 anos & 6.48 & 12.19 & 18.52 & 15.54 & 16.43 \\
\hline 50 anos ou mais & 21.44 & 10.92 & 12.01 & 18.22 & 20.46 \\
\hline \multicolumn{6}{|l|}{ SITUAÇÃO } \\
\hline Região Urbana & 82.00 & 96.17 & 92.58 & 85.91 & 56.78 \\
\hline \multicolumn{6}{|l|}{ POSIÇÃO NA OCUPAÇÃO } \\
\hline Autônomos e empregadores & 5.96 & $\cdot 13.47$ & 20.45 & 49.51 & 36.35 \\
\hline \multicolumn{6}{|l|}{ POSSE DE CARTEIRA ASSINADA } \\
\hline Com Carteira Assinada & 33.87 & 68.54 & 60.30 & 34.87 & 26.56 \\
\hline \multicolumn{6}{|l|}{ MULHERES } \\
\hline \multicolumn{6}{|l|}{ ESCOLARIDADE } \\
\hline Primánio Incompleto & 21.25 & 15.18 & 10.53 & 13.99 & 19.97 \\
\hline Primánio Completo & 14.02 & 14.88 & 7.09 & 13.59 & 6.33 \\
\hline Ginásio Incompleto & 14.53 & 13.86 & 14.08 & 15.95 & 3.15 \\
\hline Ginásio Completo & 4.41 & 7.42 & 7.10 & 11.46 & 2.91 \\
\hline Colegial e Superior & 25.33 & 39.46 & 57.04 & 32.38 & 6.02 \\
\hline \multicolumn{6}{|l|}{ IDADE } \\
\hline 18 a 19 anos & 5.80 & 2.46 & 6.55 & 6.26 & 5.13 \\
\hline 20 a 24 anos & 16.99 & 10.87 & 17.01 & 14.76 & 8.90 \\
\hline 25 a 29 anos & 13.49 & 16.10 & 16.12 & 13.67 & 7.66 \\
\hline 30 a 39 anos & 23.95 & 30.67 & 31.76 & 23.65 & 19.82 \\
\hline 40 a 49 anos & 18.15 & 24.23 & 17.00 & 20.88 & 17.76 \\
\hline 50 anos ou mais & 11.52 & 5.94 & 9.48 & 17.06 & 23.64 \\
\hline \multicolumn{6}{|l|}{ SITUAÇÃO } \\
\hline Região Urbana & 82.20 & 89.32 & 93.06 & 91.06 & 34.44 \\
\hline \multicolumn{6}{|l|}{ POSIÇÃO NA OCUPAÇÃO } \\
\hline Autônomos e empregadores & 28.44 & 13.82 & 21.46 & 49.66 & 29.14 \\
\hline \multicolumn{6}{|l|}{ POSSE DE CARTEIRA ASSINADA } \\
\hline Com Carteira Assinada & 25.80 & 50.60 & 56.11 & 30.62 & 18.49 \\
\hline
\end{tabular}

${ }^{(1)}$ Inclui apenas as observagões para as quais os atributos de interesse estão claramente identificados. 
Tabela H15. Distribuição percentual de homens e mulheres da PEA ocupada, por variável e classe ocupacional. Pernambuco, 1989. (1)

\begin{tabular}{|c|c|c|c|c|c|}
\hline \multirow[t]{2}{*}{ SEXO/FATOR } & \multicolumn{5}{|c|}{ Classes } \\
\hline & 1 & 2 & 3 & 4 & 5 \\
\hline \multicolumn{6}{|l|}{ HOMENS } \\
\hline \multicolumn{6}{|l|}{ ESCOLARIDADE } \\
\hline Primário Incompleto & 9.35 & 6.39 & 10.18 & 18.97 & 25.30 \\
\hline Primánio Completo & 21.58 & 10.35 & 7.12 & 15.50 & 12.58 \\
\hline Ginásio Incompleto & 7.79 & 29.58 & 14.21 & 18.27 & 11.98 \\
\hline Ginásio Completo & 15.47 & 6.92 & 10.82 & 6.98 & 3.80 \\
\hline Colegial e Superior & 24.10 & 30.57 & 49.36 & 22.12 & 8.34 \\
\hline \multicolumn{6}{|l|}{ IDADE } \\
\hline 18 a 19 anos & 10.79 & 6.92 & 7.24 & 4.37 & 5.71 \\
\hline 20 a 24 anos & 21.70 & 28.00 & 19.01 & 16.23 & 12.52 \\
\hline 25 a 29 anos & 13.91 & 14.29 & 9.77 & 12.49 & 13.39 \\
\hline 30 a 39 anos & 22.54 & 8.90 & 28.89 & 21.76 & 21.83 \\
\hline 40 a 49 anos & 6.23 & 15.81 & 17.15 & 17.05 & 16.61 \\
\hline 50 anos ou mais & 17.03 & 14.75 & 11.46 & 18.55 & 18.71 \\
\hline \multicolumn{6}{|l|}{ SITUAÇÃO } \\
\hline Região Urbana & 84.53 & 85.77 & 89.66 & 86.83 & 57.18 \\
\hline \multicolumn{6}{|l|}{ POSIÇÃO NA OCUPAÇÃO } \\
\hline Autônomos e empregadores & 10.79 & 1.98 & 18.37 & 54.56 & 34.76 \\
\hline \multicolumn{6}{|l|}{ POSSE DE CARTEIRA ASSINADA } \\
\hline Com Carteira Assinada & 47.36 & 61.14 & 64.24 & 26.06 & 29.67 \\
\hline \multicolumn{6}{|l|}{ MULHERES } \\
\hline \multicolumn{6}{|l|}{ ESCOLARTDADE } \\
\hline Primário Incompleto & 20.77 & 15.58 & 2.99 & 14.15 & 20.51 \\
\hline Primário Completo & 14.99 & 8.07 & 7.53 & 12.73 & 10.25 \\
\hline Ginásio Incompleto & 17.50 & 16.10 & 16.43 & 19.36 & 5.27 \\
\hline Ginásio Completo & 5.61 & 7.61 & 6.00 & 7.21 & 2.30 \\
\hline Colegial e Superior & 23.82 & 39.28 & 61.90 & 29.92 & 8.06 \\
\hline \multicolumn{6}{|l|}{ IDADE } \\
\hline 18 a 19 anos & 5.79 & 3.36 & 5.01 & 5.10 & 5.02 \\
\hline 20 a 24 anos & 15.60 & 12.11 & 16.64 & 17.66 & 10.29 \\
\hline 25 a 29 anos & 15.50 & 18.56 & 23.23 & 11.33 & 8.63 \\
\hline 30 a 39 anos & 22.79 & 30.22 & 27.14 & 27.80 & 19.43 \\
\hline 40 a 49 anos & 16.67 & 22.37 & 14.80 & 19.03 & 17.13 \\
\hline 50 anos ou mais & 10.13 & 10.49 & 7.87 & 12.02 & 26.96 \\
\hline \multicolumn{6}{|l|}{ SITUAÇÃO } \\
\hline Região Urbana & 81.82 & 86.85 & 93.88 & 83.91 & 37.90 \\
\hline \multicolumn{6}{|l|}{ POSIÇÃO NA OCUPAÇÃO } \\
\hline Autônomos e empregadores & 28.09 & 4.26 & 20.60 & 48.42 & 30.25 \\
\hline \multicolumn{6}{|l|}{ POSSE DE CARTEIRA ASSINADA } \\
\hline Com Carteira Assinada & 23.59 & 50.04 & 50.14 & 35.36 & 16.55 \\
\hline
\end{tabular}

${ }^{(1)}$ Inclui apenas as observações para as quais os atributos de interesse estão claramente identificados. 
Tabela H16. Distribuição percentual de homens e mulheres da PEA ocupada, por variável e classe ocupacional. Pernambuco, 1990.(1)

\begin{tabular}{|c|c|c|c|c|c|}
\hline \multirow[t]{2}{*}{ SEXO/FATOR } & \multicolumn{5}{|c|}{ CLASSES } \\
\hline & 1 & 2 & 3 & 4 & 5 \\
\hline \multicolumn{6}{|l|}{ HOMENS } \\
\hline \multicolumn{6}{|l|}{ ESCOLARDADE } \\
\hline Primário Incompleto & 14.71 & 13.17 & 14.04 & 17.39 & 24.56 \\
\hline Primário Completo & 24.45 & 6.36 & 9.40 & 14.09 & 12.88 \\
\hline Ginásio Incompleto & 16.87 & 15.14 & 19.66 & 16.96 & 13.05 \\
\hline Ginásio Completo & 3.26 & 10.33 & 9.83 & 8.81 & 3.45 \\
\hline Colegial e Superior & 22.25 & 41.79 & 41.86 & 27.07 & 8.35 \\
\hline \multicolumn{6}{|l|}{ IDADE } \\
\hline 18 a 19 anos & 9.24 & 1.59 & 8.50 & 4.66 & 4.62 \\
\hline 20 a 24 anos & 17.96 & 15.90 & 18.94 & 12.44 & 13.70 \\
\hline 25 a 29 anos & 11.41 & 13.55 & 18.18 & 12.80 & 11.92 \\
\hline 30 a 39 anos & 17.34 & 34.67 & 21.45 & 21.47 & 22.71 \\
\hline 40 a 49 anos & 13.57 & 11.96 & 10.87 & 16.88 & 16.72 \\
\hline 50 anos ou mais & 14.14 & 17.94 & 10.57 & 20.31 & 19.57 \\
\hline \multicolumn{6}{|l|}{ SITUAÇÃO } \\
\hline Região Urbana & 80.45 & 90.84 & 91.21 & 86.95 & 59.50 \\
\hline \multicolumn{6}{|l|}{ POSIÇÃO NA OCUPAÇÃO } \\
\hline Autônomos e empregadores & 14.14 & 15.59 & 25.04 & 58.23 & 31.22 \\
\hline \multicolumn{6}{|l|}{ POSSE DE CARTEIRA ASSINADA } \\
\hline Com Carteira Assinada & 36.39 & 58.07 & 57.20 & 26.66 & 30.56 \\
\hline \multicolumn{6}{|l|}{ MULHERES } \\
\hline \multicolumn{6}{|l|}{ ESCOLARIDADE } \\
\hline Primánio Incompleto & 19.18 & 13.95 & 5.46 & 15.62 & 23.29 \\
\hline Primánio Completo & 14.93 & 12.56 & 8.20 & 12.33 & 11.01 \\
\hline Ginásio Incompleto & 14.35 & 11.86 & 18.39 & 13.31 & 4.25 \\
\hline Ginásio Completo & 4.08 & 4.63 & 8.78 & 7.13 & 1.76 \\
\hline Colegial e Superior & 29.27 & 44.09 & 53.69 & 42.07 & 11.31 \\
\hline \multicolumn{6}{|l|}{ IDADE } \\
\hline 18 a 19 anos & 6.60 & 3.62 & 9.28 & 3.97 & 1.95 \\
\hline 20 a 24 anos & 15.32 & 9.46 & 16.52 & 12.72 & 9.22 \\
\hline 25 a 29 anos & 15.87 & 17.88 & 19.27 & 14.48 & 13.48 \\
\hline 30 a 39 anos & 24.79 & 37.12 & 27.90 & 27.29 & 24.50 \\
\hline 40 a 49 anos & 15.33 & 17.48 & 11.68 & 21.56 & 23.12 \\
\hline 50 anos ou mais & 11.06 & 11.16 & 8.50 & 14.01 & 19.91 \\
\hline \multicolumn{6}{|l|}{ SITUAÇÃO } \\
\hline Região Urbana & 80.85 & 80.89 & 89.22 & 88.07 & 37.76 \\
\hline \multicolumn{6}{|l|}{ POSIÇÃO NA OCUPAÇÃO } \\
\hline Autônomos e empregadores & 26.00 & 19.07 & 27.94 & 58.02 & 34.28 \\
\hline \multicolumn{6}{|l|}{$\begin{array}{l}\text { POSSE DE CARTEIRA } \\
\text { ASSINADA }\end{array}$} \\
\hline Com Carteira Assinada & 29.40 & 38.42 & 53.66 & 28.06 & 30.15 \\
\hline
\end{tabular}

${ }^{(1)}$ Inclui apenas as observações para as quais os atributos de interesse estão claramente identificados. 


\section{APÊNDICE I}

Tabela Il. Capacidade de previsão da distribuição da PEA masculina ocupada(1) por classe nos modelos logitos multinomiais estimados. São Paulo e Pernambuco, 1981 a 1990 (8 de acertos).

\begin{tabular}{crrrrr}
\hline & \multicolumn{5}{c}{ CLASSES OCUPACIONAIS } \\
\cline { 2 - 5 } ANO & 1 & 2 & 3 & \multicolumn{1}{c}{4} & 5 \\
\hline São Paulo & & & & & \\
81 & 0,00 & 0,00 & 4,16 & 16,54 & 97,14 \\
83 & 0,00 & 0,00 & 22,52 & 19,84 & 93,21 \\
84 & 0,00 & 0,00 & 20,75 & 13,76 & 95,54 \\
85 & 0,00 & 0,00 & 6,28 & 1,26 & 99,16 \\
87 & 0,00 & 0,00 & 7,44 & 8,92 & 95,91 \\
88 & 0,00 & 0,00 & 14,95 & 6,03 & 94,89 \\
89 & 0,00 & 0,00 & 21,40 & 18,55 & 87,63 \\
90 & 0,00 & 0,00 & 20,22 & 8,62 & 92,31 \\
Pernambuco & & & & & \\
81 & 0,00 & 0,00 & 1,67 & 9,17 & 96,82 \\
83 & 0,00 & 0,00 & 0,97 & 12,62 & 95,30 \\
84 & 0,00 & 0,00 & 0,22 & 6,34 & 97,17 \\
85 & 0,00 & 0,00 & 12,67 & 13,19 & 94,92 \\
87 & 0,00 & 0,00 & 3,30 & 14,92 & 93,57 \\
88 & 0,00 & 0,00 & 9,09 & 8,73 & 94,81 \\
89 & 0,00 & 0,00 & 4,85 & 11,06 & 94,79 \\
90 & 0,00 & 0,00 & 1,09 & 20,73 & 94,42 \\
\hline (1) Inclui apenas as pessoas para as & quais & os & atributos & de & interesse \\
estão claramente identificados. & & &
\end{tabular}

